
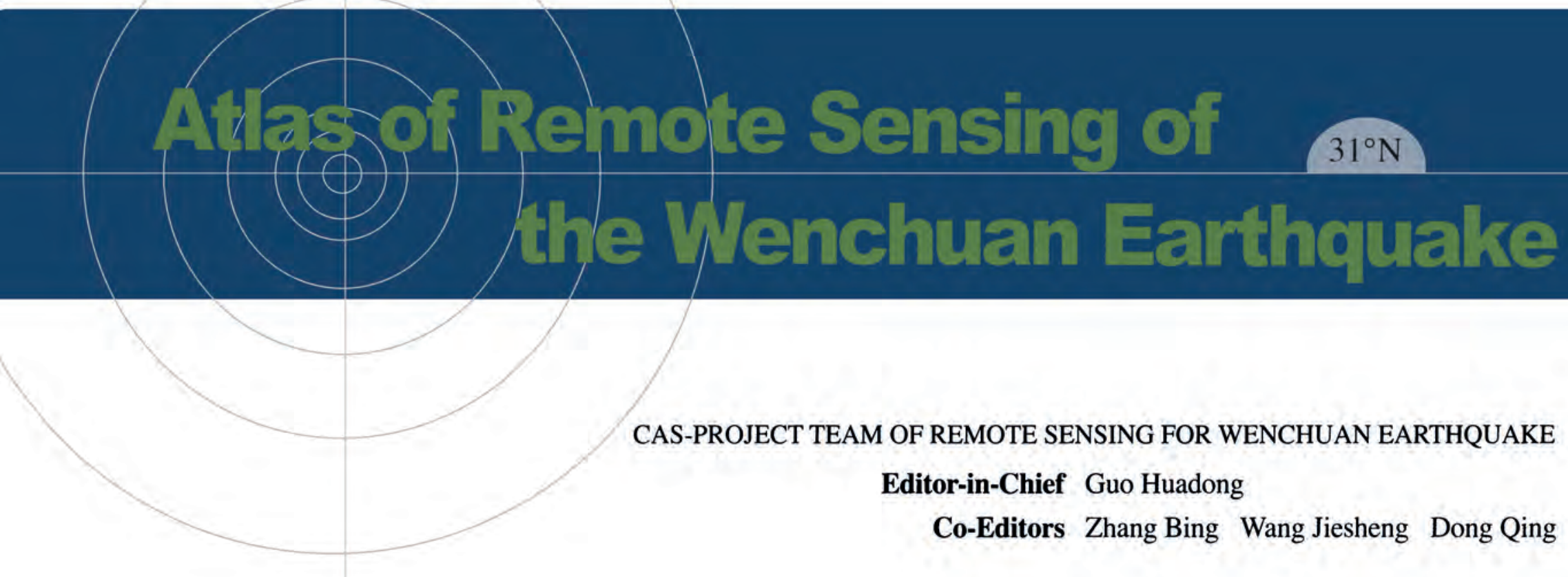

CAS-PROJECT TEAM OF REMOTE SENSING FOR WENCHUAN EARTHQUAKE

Editor-in-Chief Guo Huadong

Co-Editors Zhang Bing Wang Jiesheng Dong Qing

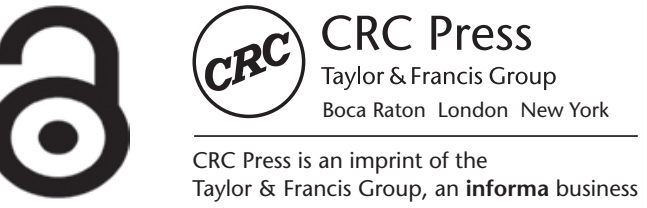




\section{CRC Press}

Taylor \& Francis Group

6000 Broken Sound Parkway NW, Suite 300

Boca Raton, FL 33487-2742

(c) 2010 by Taylor and Francis Group, LLC

CRC Press is an imprint of Taylor \& Francis Group, an Informa business

No claim to original U.S. Government works

ISBN-13: 978-1-138-11217-9 (pbk)

ISBN-13: 978-1-4398-1674-5 (hbk)

This book contains information obtained from authentic and highly regarded sources. Reasonable efforts have been made to publish reliable data and information, but the author and publisher cannot assume responsibility for the validity of all materials or the consequences of their use. The authors and publishers have attempted to trace the copyright holders of all material reproduced in this publication and apologize to copyright holders if permission to publish in this form has not been obtained. If any copyright material has not been acknowledged please write and let us know so we may rectify in any future reprint.

The Open Access version of this book, available at www.taylorfrancis.com, has been made available under a Creative Commons Attribution-Non Commercial-No Derivatives 4.0 license.

For permission to photocopy or use material electronically from this work, please access www.copyright.com (http://www.copyright.com/) or contact the Copyright Clearance Center, Inc. (CCC), 222 Rosewood Drive, Danvers, MA 01923, 978-750-8400. CCC is a not-for-profit organization that provides licenses and registration for a variety of users. For organizations that have been granted a photocopy license by the CCC, a separate system of payment has been arranged.

Trademark Notice: Product or corporate names may be trademarks or registered trademarks, and are used only for identification and explanation without intent to infringe.

Library of Congress Cataloging-in-Publication Data

Atlas of remote sensing of the Wenchuan earthquake / Huadong Guo. p. $\mathrm{cm}$.

ISBN 978-1-4398-1674-5 (hardcover : alk. paper)

1. Earthquakes--China--Wenchuan Xian (Sichuan Sheng)--Remote-sensing maps. 2. Wenchuan Xian (Sichuan Sheng, China)--Maps. 3. China--Remote-sensing maps. I. Guo, Huadong. II. Title.

Visit the Taylor \& Francis Web site at

http://www.taylorandfrancis.com

and the CRC Press Web site at

http://www.crcpress.com 


\section{Advisory Committee}

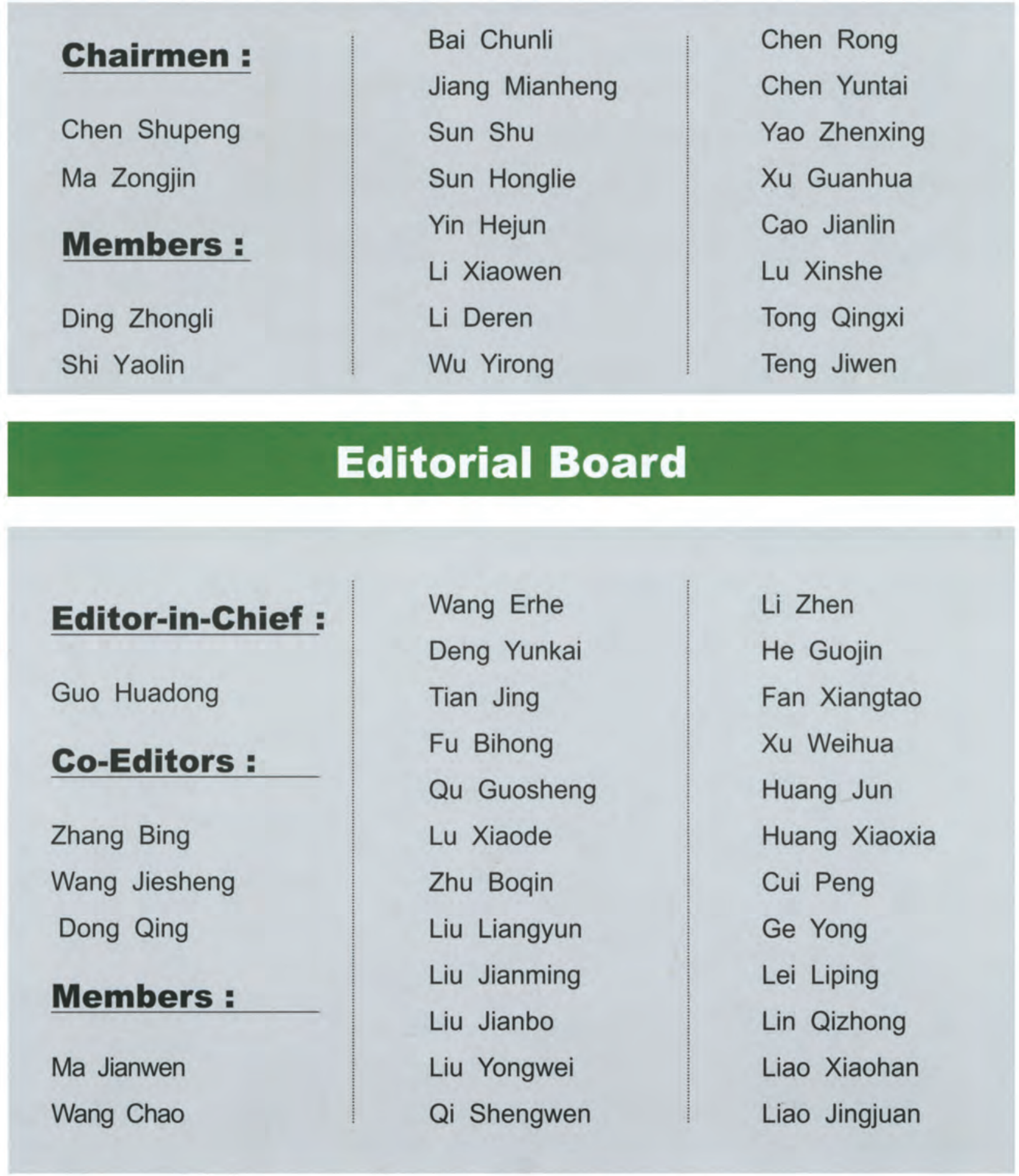




\section{PROJECT TEAM OF REMOTE SENSING FOR WENCHUAN EARTHQUAKE CHINESE ACADEMY OF SCIENCES}

- Center for Earth Observation and Digital Earth, CAS

- Institute of Electronics, CAS

- Institute of Remote Sensing Applications, CAS

- Institute of Geographic Sciences and Natural Resources

Research, CAS

- Institute of Geology and Geophysics, CAS

- Institute of Mountain Hazards and Environment, CAS

- Research Center for Eco-Environmental Sciences, CAS 
On 12 May 2008, Wenchuan County in Sichuan experienced a severe earthquake of magnitude 8.0 on the Richter scale, causing heavy losses in human life and property. Gaining immediate information from the disaster area and obtaining first-hand data was exceedingly difficult when the tremor first hit, since the roads were blocked, communications went down, many secondary disasters occurred, and weather conditions were very bad. The lack of information was a serious problem for disaster rescue decision-making since urgent monitoring and disaster assessment were vital if scientific support was to be provided for the search and rescue operations.

The Chinese Academy of Sciences (CAS) gave full attention to its comprehensive remote sensing techniques and talented scientists by immediately establishing the Emergency Headquarter of Remote Sensing for Earthquake Resistance and Disaster Relief. The Project Team of Remote Sensing Monitoring and Assessment of the Wenchuan Earthquake was set up by experts from seven CAS institutes, including Center for Earth Observation and Digital Earth, Institute of Electronics, Institute of Remote Sensing Applications, Institute of Geographic Sciences and Natural Resources Research, Institute of Geology and Geophysics, Chengdu Institute of Mountain Hazards and Environment, and Research Center for Eco-Environmental Sciences. Thus, remote sensing of the quake disaster was extended on all fronts. A program was immediately initiated to acquire data from earth observation satellites and two high-altitude airplanes deployed for obtaining high-resolution optical and radar data. On-the-spot investigations in the impacted area were carried out promptly. Therefore, a unified, all-weather day and night monitoring grid was formed with space, air and in-situ observing capacities. Disaster analyzing personnel did not spare any efforts day-in and day-out, collecting, transferring, processing, interpreting remote sensing data and images, and promptly completing series analysis reports. Those reports were immediately submitted to the Headquarters for Earthquake Resistance and Disaster Relief of governments at national, ministerial and provincial levels. The dedicated work provided convincing evidence for decision-making.

Accumulated knowledge in science and technology is a treasured fundamental resource for future progress, and summarizing knowledge scientifically is an important part in scientific and technological activities. Based on the accumulated data and images collected by the Project Team during quake relief, and requested by international readers, Taylor \& Francis Group published Atlas of Remote Sensing for the Wenchuan Earthquake. Throughout the Atlas, the original appearances of quake-hit areas have been reconstructed thanks to the robust 
information and the in-depth analysis of researchers. The Atlas exhibits the disaster from six aspects, including geological disasters, barrier lakes, collapsed buildings, damaged roads, destroyed farmland and forests, and demolished infrastructure. The Atlas also demonstrates that the Dujiangyan Irrigation Project, which has been standing for 2000 years, remains fully functioning and keeps the Chengdu Plain operating optimally even after encountering an 8.0 magnitude earthquake. I believe that the publication will be welcomed by all circles, and play an important role in Wenchuan re-construction and regional development. I hope the Atlas can also serve as an informative reference for earthquake research.

The Wenchuan earthquake has warned us that natural disasters pose great challenges that humankind must face together. Natural disasters have occurred frequently in recent years. Earthquakes, tsunamis, floods and hurricanes have claimed tens of thousands of lives and caused heavy economic losses, bringing great trauma to human society. Effectively preventing natural disasters and reducing losses to a minimum have become real and pressingly important issues. Scientific and technological innovations should provide powerful support for disaster prevention and reduction. Different types of natural disasters require different solutions, thus development of new technical approaches, methods, and facilities are in great demand. A comprehensive earth observation system has to be established to capture abnormal phenomena in real time and near real time. We must monitor closely the occurrence and development of potential disasters and improve disaster warning ability. We should pay much attention to meteorological, geological, and seismological disasters that could cause serious damage to society. We will develop scientific models and carry out research on disaster simulation to increase our disaster warning ability and make contributions to global disaster research.

President $\mathrm{Hu}$ Jintao has recently set tasks for the scientific community on disaster prevention and mitigation. He has pledged to accelerate the applications of remote sensing, geographic information systems, global positioning systems and information communication technology, and urged speeding up the transfer and integration of high technologies for disaster prevention and mitigation. He has also called for setting up a national platform to share information on disaster mitigation and risk management, and to improve disaster monitoring, warning, assessment, and emergency rescue systems at both national and local levels.

It is my sincere hope that scientists and engineers in fields of remote sensing and geosciences courageously and enthusiastically assume these important tasks, and carry out the glorious mission that our country has bestowed upon us. I recommend that professionals 1) focus on disaster mitigation issues, 2) actively explore and recognize disaster mechanism, 3) develop key technologies for disaster monitoring, warning and prevention, 4) offer effective solutions, 5) provide strong scientific support that will safeguard human life and property, and 6) make contributions worthy of our time and abilities.

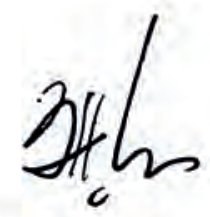

\section{Lu Yongxiang}

Vice Chairman, Standing Committee of National People's Congress, China

President, Chinese Academy of Sciences

June, 2009 
Earth Observation has played an increasingly important role in natural disaster mitigation with the rapid development of multi-platform, multi-frequency, multi-mode, high-spatial, ultra-spectral and high-temporal resolution technological capabilities. In recent years, reduction and prevention of disaster has been identified as the highest priority among nine societal benefits outlined by Global Earth Observation System of Systems (GEOSS), participated in by more than 70 countries and over 40 international organizations. In addition, the International Charter on Disaster Reduction and Cooperation was set up by multi-nation space organizations to provide a unified system of space data acquisition and delivery when confronting major natural disasters. China has also attached great importance to the application of space technology for natural disaster relief.

Immediately after the Wenchuan earthquake on May 12, 2008, the Chinese Academy of Sciences (CAS) deployed its earthquake remote sensing resources, setting up the CAS Emergency Headquarter of Remote Sensing for Earthquake Resistance and Disaster Relief. The CAS Project Team of Remote Sensing Monitoring and Assessment of the Wenchuan Earthquake was established by researchers from seven CAS institutes. Afterwards, remote sensing on quake-hit areas was fully extended. Within a month, the Project Team had taken advantage of two mega-science facilities of the remote sensing satellite ground station and the high-altitude remote sensing airplanes to give full play to the strengths and abilities at their command. The Project Team provided large amounts of data, information and suggestions for decision-makers at central and local government level, following the procedure of dataacquiring, information processing, disaster analysis and assessment, and report submission. At the same time, coorganized by the Ministry of Science and Technology (MOST) and Chinese Academy of Sciences, a data sharing mechanism was formed at a meeting attended by representatives from 13 ministries, and consultation meetings hosted by the Center for Earth Observation and Digital Earth (CEODE) were organized.

Remote sensing technology has played an active role in the Wenchuan earthquake monitoring and assessment. Remote sensing data recorded lasting and irreplaceable instantaneous pre- and post-quake landscapes. The purpose of the Atlas of Remote Sensing for the Wenchuan Earthquake is to systematically summarize the scientific results, promote academic exchange, and popularize remote sensing knowledge for disaster monitoring as well as to realize data sharing in a larger scope.

The Atlas consists of eight chapters. The first chapter, "Remote Sensing Data" introduces optical and radar data 
on quake-hit areas acquired through airborne and spaceborne remote sensing. The second chapter, "Geological Disasters" describes disasters caused by landslides, avalanches, detritus flows and fractures. The third chapter, "Barrier Lakes" narrates the distribution and dangers of the barrier lakes, one of the most serious secondary disasters caused by the earthquake. The fourth chapter, "Collapsed Buildings" analyzes spatial distribution and degree of damage of crushed buildings in urban and rural areas. The fifth chapter, "Damaged Roads" illustrates the five-level damage classification for national and provincial highways, county roads, and rural paths. The sixth chapter, "Destroyed Farmlands and Forests" assesses damaged conditions of forest vegetation and farmland resulting from the secondary geological disasters caused by the earthquake. The seventh chapter, "Demolished Infrastructure" shows the damage to hydrological engineering systems, mining area constructions and power transmission projects. The eighth chapter, "Civilization Perseveres" depicts a two-thousand-year old Dujiangyan Irrigation Project, which has been functioning even after encountering an 8.0 magnitude earthquake.

After the earthquake, we carried out field investigations in quake-hit areas including Dujiangyan, Wenchuan, Beichuan, Mianyang, and Mianzhu to validate remote sensing results. Our experience has made us reflect deeply on disaster relief work. Firstly, an emergency disaster monitoring system with advanced, practical, fast and reliable technical ability should be further established. Secondly, in an emergency, an authoritative institution should be guaranteed with a "scientific dispatching system" so that it could effectively coordinate key space infrastructures to achieve a high degree of data sharing among different agencies. Thirdly, the Earth has existed for 4.5 billion years, and some natural events, regarded as disasters by human beings, were merely natural phenomena in the Earth's long-term evolutionary process. Therefore the existence of humankind is always in concomitance with natural calamities; we must wage our struggles with natural disasters in accordance with the idea that humankind should coexist harmoniously with nature.

During the earthquake resistance and disaster relief period, Ms. Liu Yandong, State Councilor; Prof, Lu Yongxiang, Vice Chairman of the Standing Committee of the National People's Congress and CAS President; Prof. Bai Chunli, CAS Executive Vice-President, and CAS Vice-Presidents Jiang Mianheng, Ding Zhongli,Yin Hejun and other CAS senior administrators as well as Deputy Minister Cao Jianlin of MOST came to the CAS Project Team to coordinate work and approve the Project. Our team colleagues worked shoulder by shoulder, day in and day out. During the period of compiling the Atlas, advisory committee of the Atlas headed by Prof. Chen Shupeng and Prof. Ma Zongjin offered scientific directions in various ways, and colleagues of the editorial board worked meticulously and conscientiously. On behalf of the Project Team and editorial board, I sincerely express my heartfelt thanks and extend my highest respects to everybody. The assistance of CRC Press, esppecially of Irma Shagla, Rob Loftis, Suzanne Lassandro, and who converted a draft English manuscript of the Atlas into finished publication, are gratefuly acknowledged. It is also with thanks to Anthony J. Lewis and Barbara A. Lewis, of Louisiana State University, who reviewed the manuscript in response to appeals for assistance in English editing. A number of associates assisted in this Atlas, and special thanks go to Gao Wei, Wang Changlin, Liu Jie, Ling Thompson, and Liu Chuansheng.

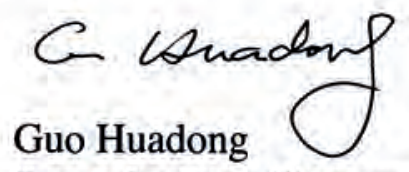

Center for Earth Observation and Digital Earth, Chinese Academy of Sciences

June, 2009 


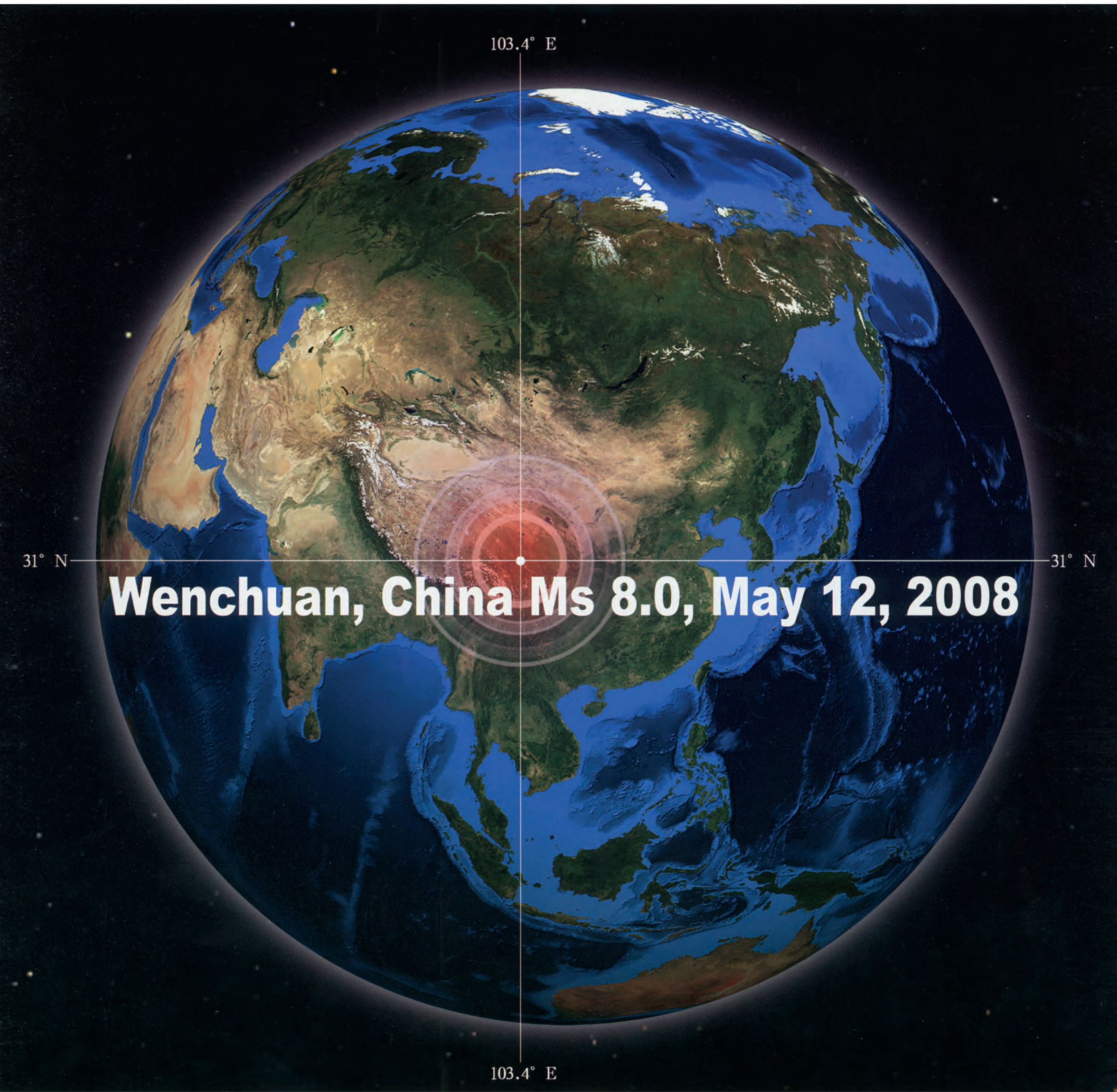




\section{Distribution of Earthquakes over Ms 6 in the World}

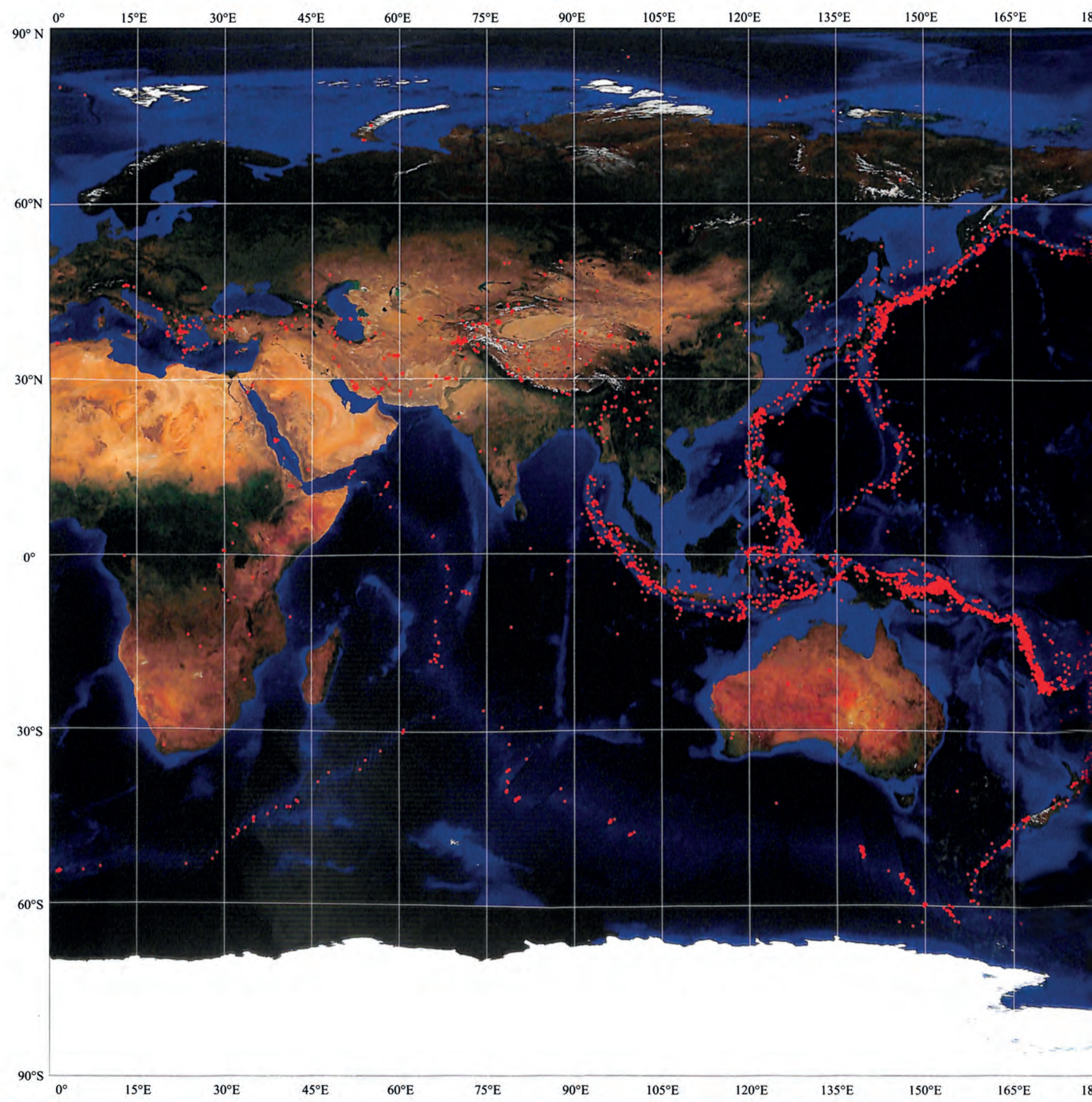




\section{(From January I, 1958 to May 31, 2008)}

$60^{\circ} \mathrm{W}$

$45^{\circ} \mathrm{W}$

$30^{\circ} \mathrm{W}$

$15^{\circ} \mathrm{W}$ $90^{\circ} \mathrm{N}$

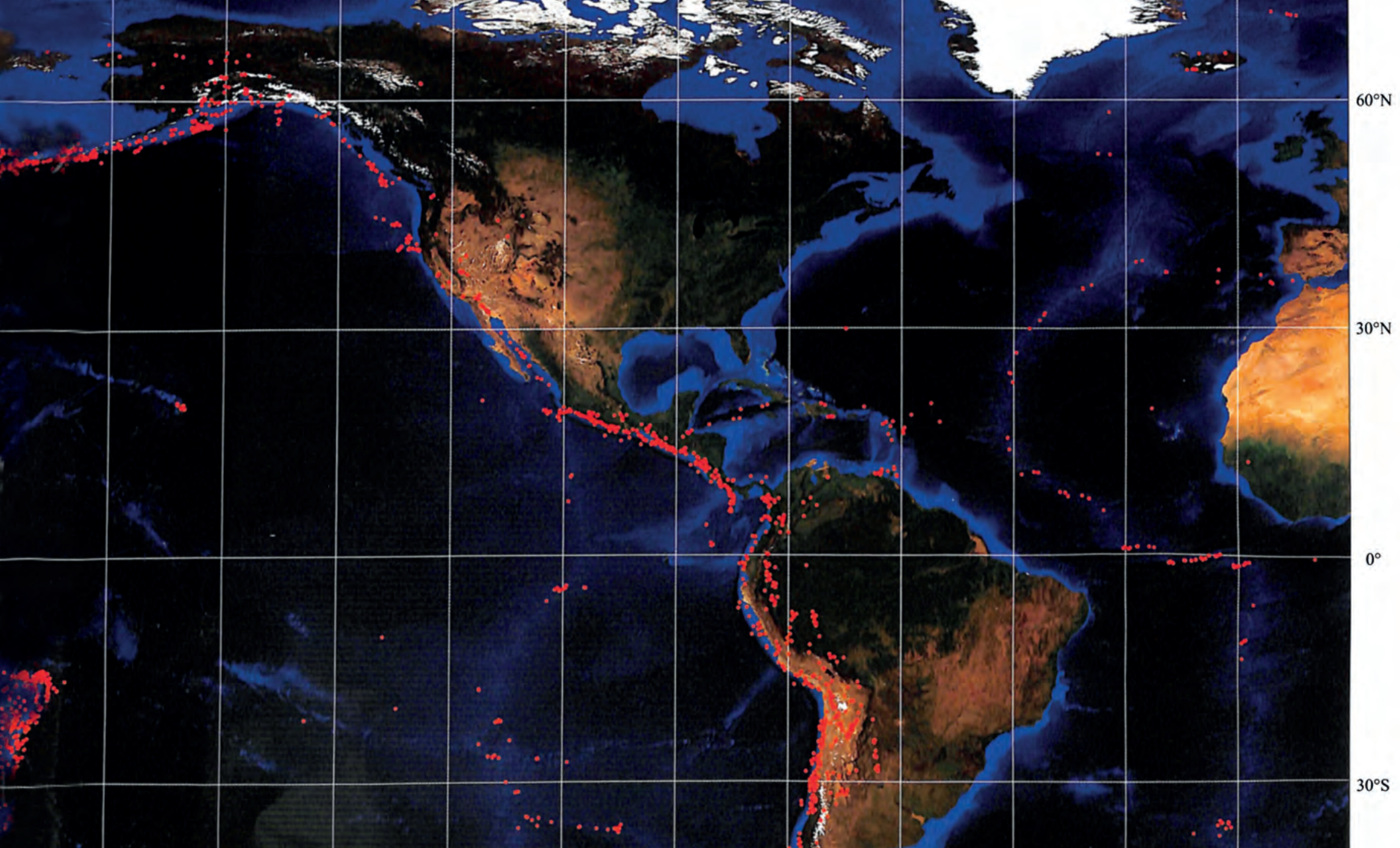

$0^{\circ} \mathrm{E}$

$165^{\circ} \mathrm{W}$

$150^{\circ} \mathrm{W}$

$135^{\circ} \mathrm{W}$

$120^{\circ} \mathrm{W}$

$105^{\circ} \mathrm{W}$

$90^{\circ} \mathrm{W}$

$75^{\circ} \mathrm{W}$

$60^{\circ} \mathrm{W}$

$45^{\circ} \mathrm{W}$

$30^{\circ} \mathrm{W}$

$15^{\circ} \mathrm{W}$ 
SATELLITE IMAGE OF THE PEOPLE'S REPUB

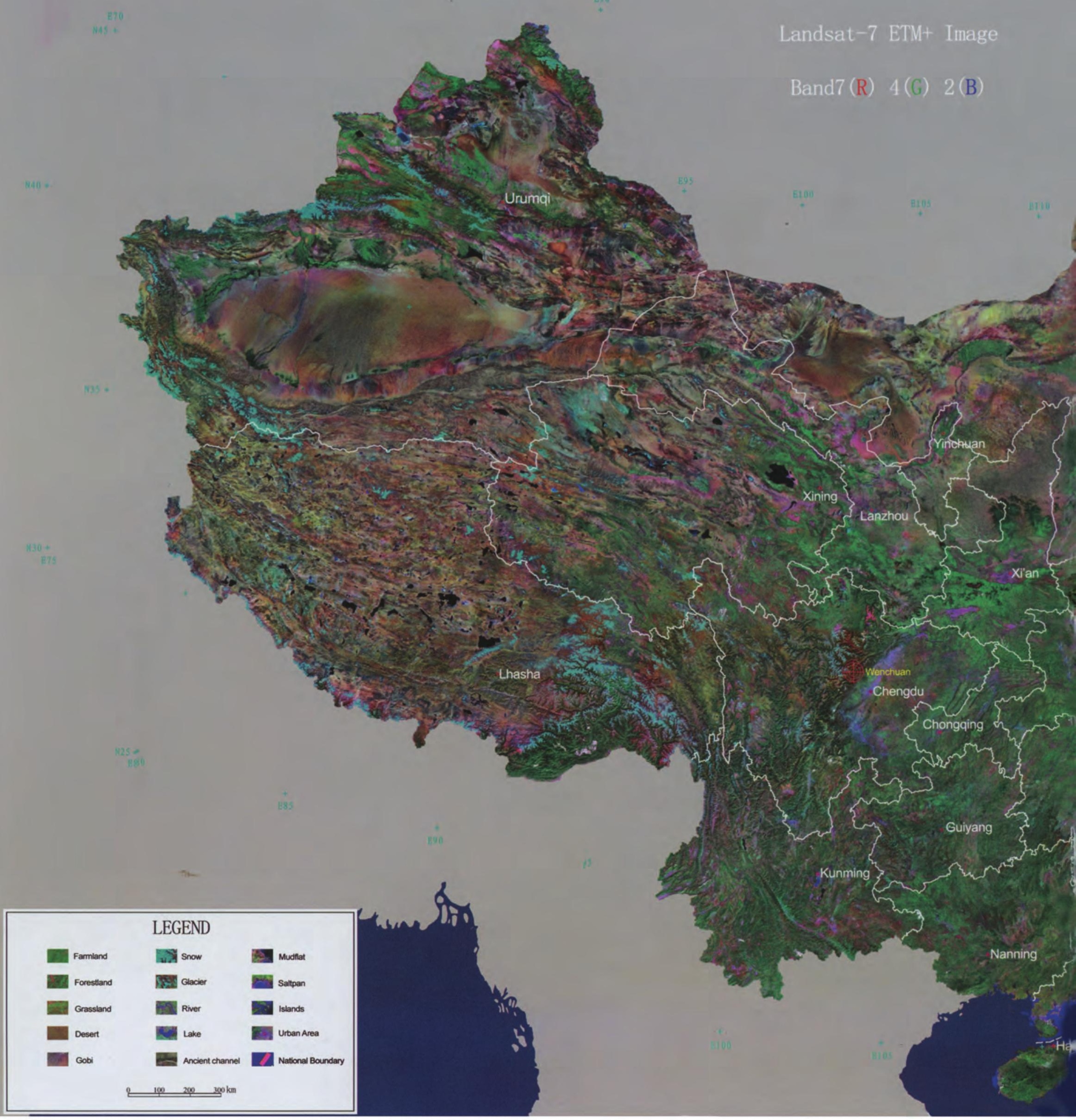




\section{Landsat image at the earthquake affected area}

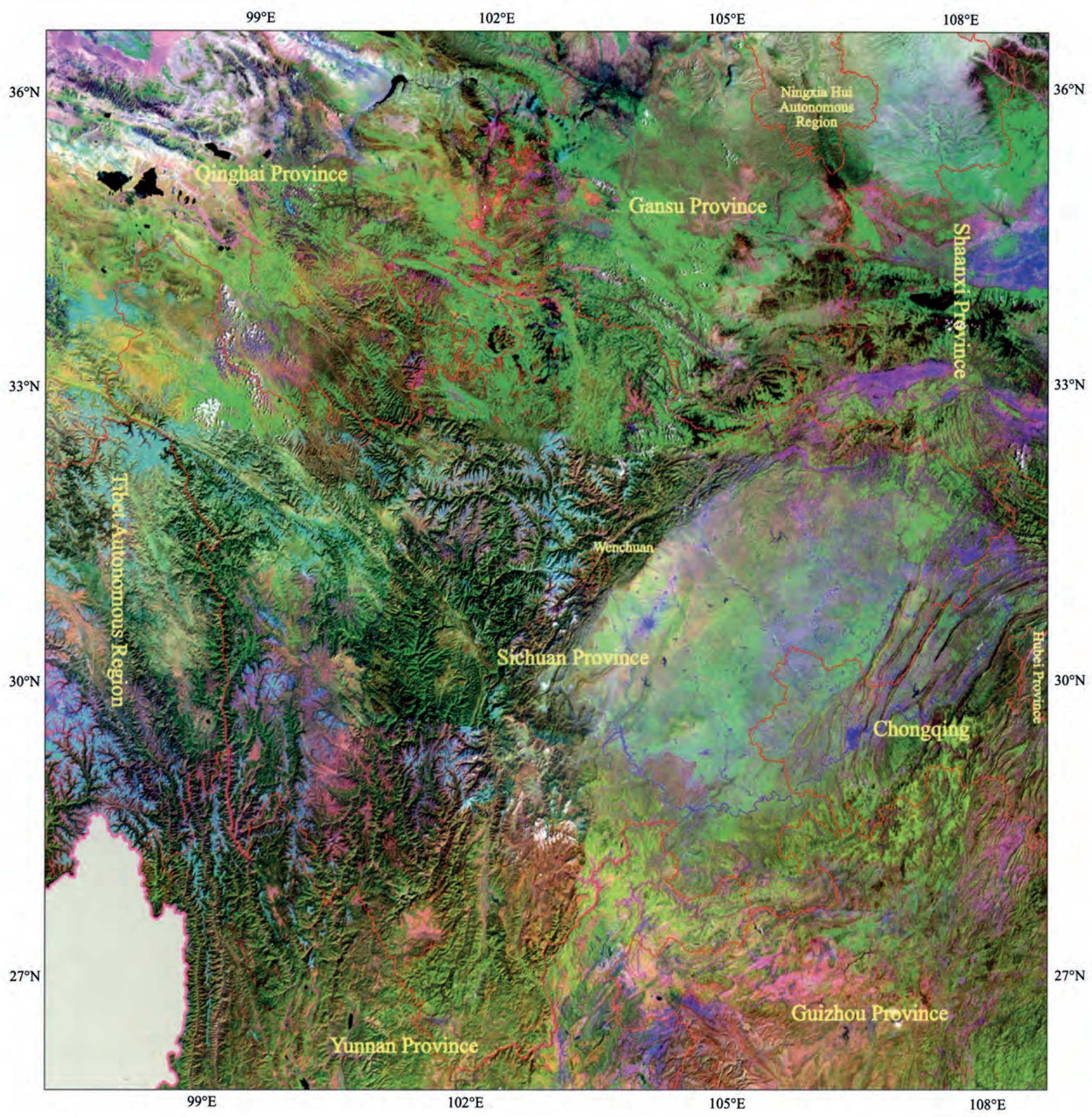

Bands: 5 (R) 4 (G) 3 (B) 


\section{Map of Wenchuan earthquake area}

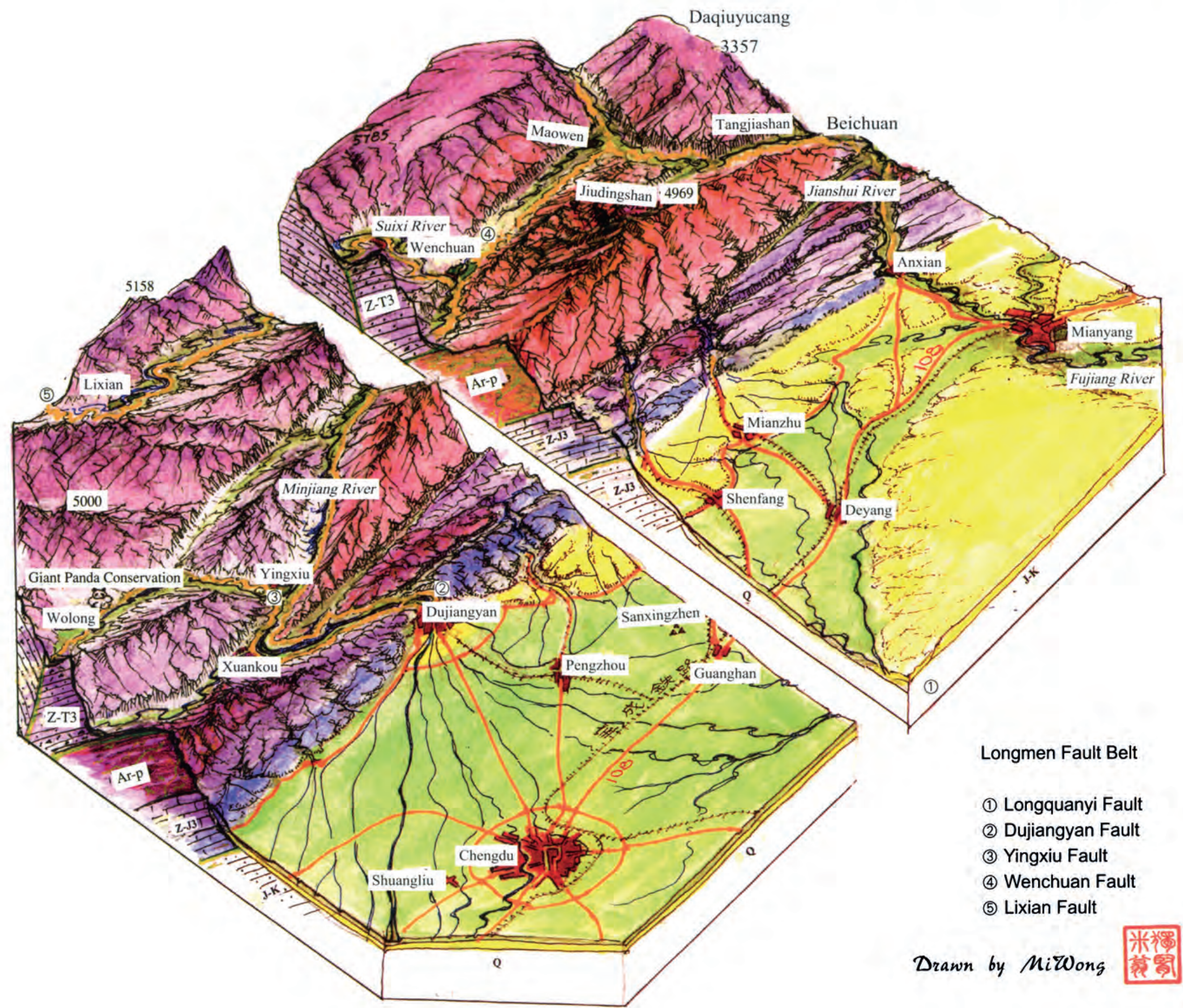




\section{Three-dimensional image at the earthquake affected area}

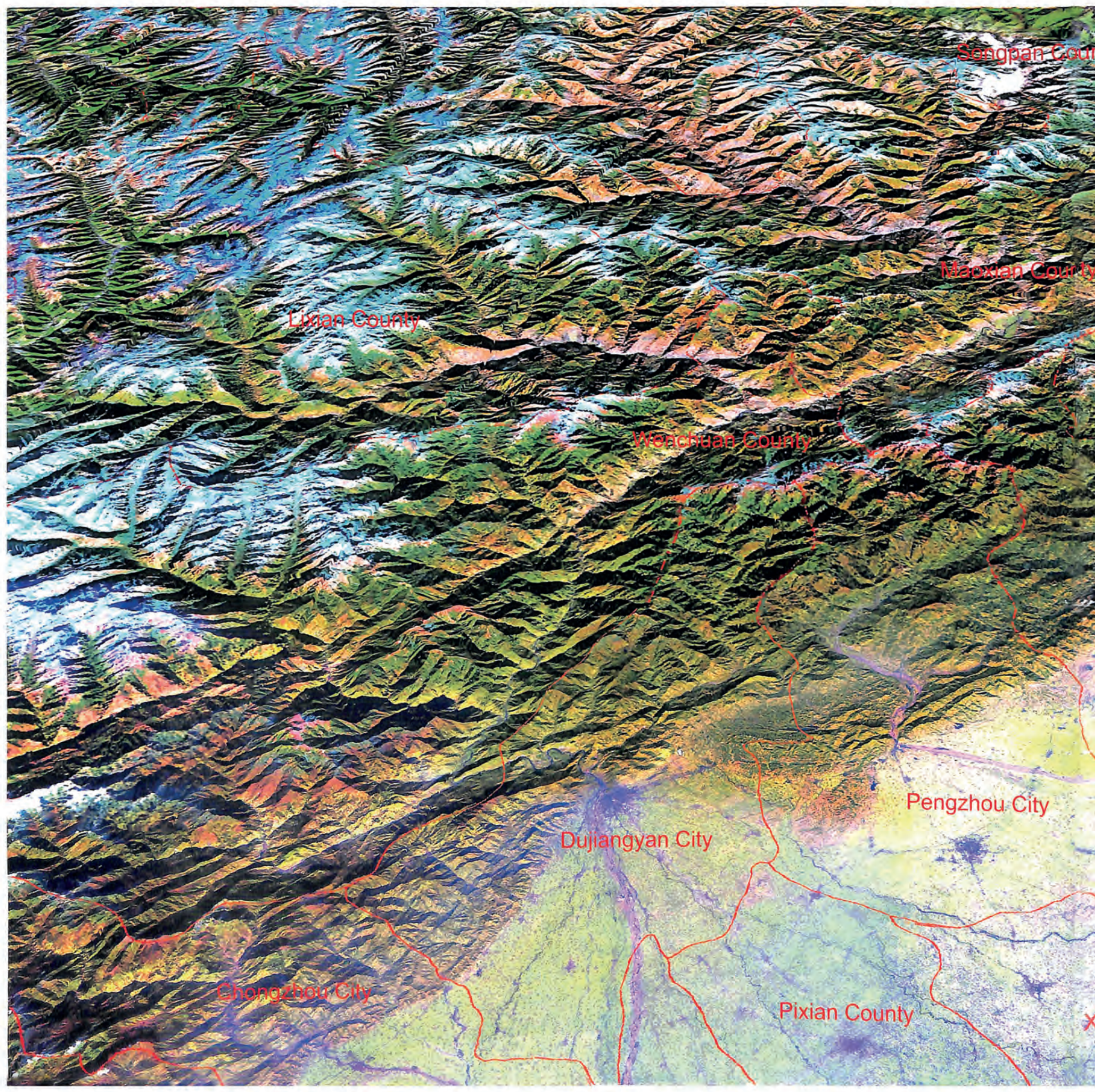




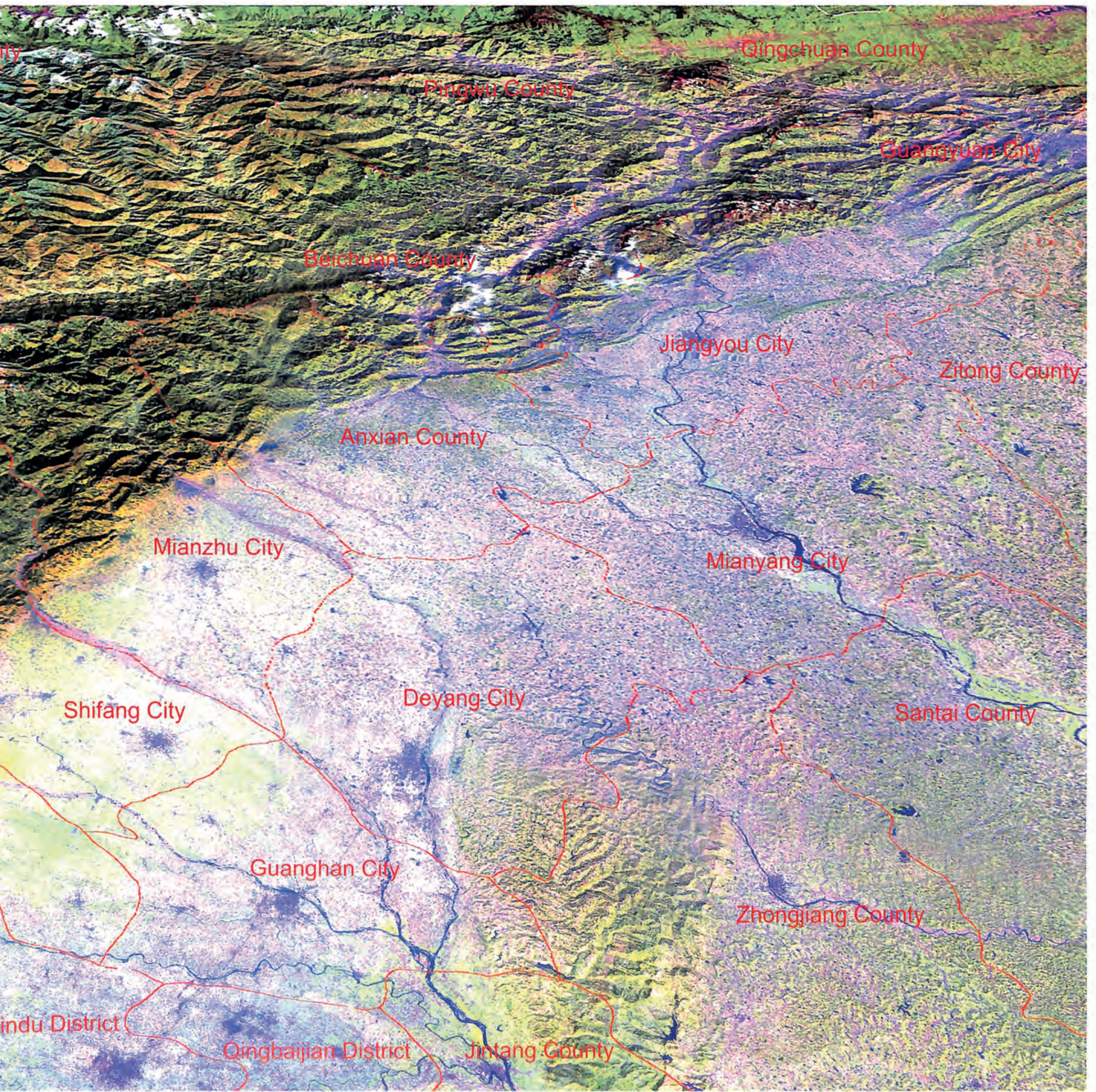




\section{Atlas of Remote Sensing of the Wenchuan Earthquake}

\section{CONTENTS}

\section{Preface}

Foreword

Distribution of Earthquakes over Ms 6 in the world

Satellite image of the Pepole's Republic of China

Landsat image at the earthquake affected area

Map of Wenchuan earthquake area

Three-dimensional image at the earthquake affected area

\section{$i$ \\ iii \\ vi \\ viii \\ $x$ \\ $x i$ \\ $x i i$}

Chapter 1 Remote Sensing Data

Satellite remote sensing data 2

Airborne remote sensing data

13

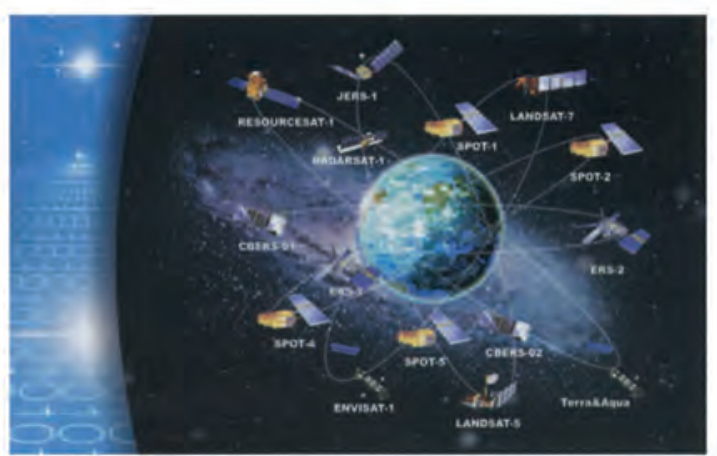

Chapter 2 Geological Disaster

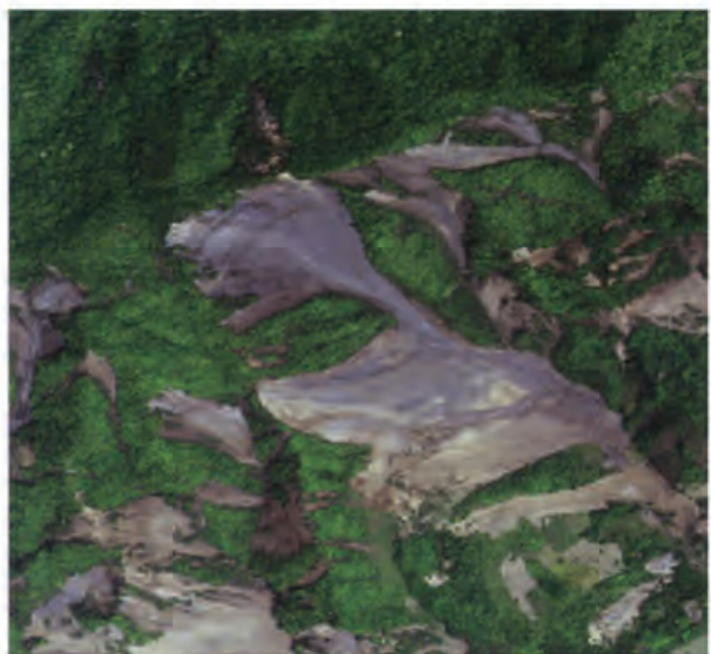

Regional geology background map of the Wenchuan earthquake area

Geology disaster distribution map of the Jianjiang River

Geology disaster distribution map of the Minjiang River

Aerial remote sensing image showing the earthquake fault around the town of Yingxiu, in Wenchuan County

Aerial remote sensing image showing the earthquake fault around the town of Qushan, in Beichuan County

Airborne remote sensing image showing the earthquake fault around the town of Pingtong, in Pingwu County

Airborne remote sensing image showing the earthquake fault around the town of Shikanzi, in Pingwu County 
Airborne optical image of Lamamiao in Pingwu County

Airborne optical image of the town of Nanxin, in Maoxian County

Airborne optical image of Matou, in Wenchuan County

Airborne optical image of Younian, in Wenchuan County

Airborne optical image of Jinhe phosphorite mine in the city of Mianzhu

Airborne optical remote sensing image of Chenjiaba Township, Beichuan County

Airborne optical remote sensing image of Guandili Township, Pingwu County

Airborne optical remote sensing image of Daojiaoli, Pingwu County

IKONOS optical remote sensing image near Wenchuan County

Airborne optical remote sensing image of Shibangou, Hongguang

Township, Qingchuan County

Airborne optical remote sensing image of Dongjienao, Wenchuan County

Airborne optical remote sensing image of Ganxipu, Yingxiu Township,

Wenchuan County

False-color composite of the IKONOS satellite image near the town of Yingxiu, in Wenchuan County

Airborne optical image for the town of Jintiaogou, in Maoxian County

Airborne optical image of the village of Shaba, in Beichuan County

Airborne optical image of the village of Bayi, in the town of Shiba,

in Qingchuan County

Airborne optical image of the village of Xiaomaoping, in Wenchuan County

Airborne optical remote sensing image of Xindian, in Wenchuan County

Airborne optical remote sensing image of the village of Banzigou,

in Wenchuan County

Airborne optical remote sensing image of Zesang, in Wenchuan County

Airborne optical remote sensing image of Maliuwan, in Wenchuan County

Airborne optical remote sensing image of the village of Yangdian,

in Wenchuan County

Airborne optical remote sensing image of the village of Gujing,

in Qingchuan County

$A L O S$ satellite imagery of Gaochuan Township, in Anxian County

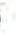

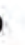
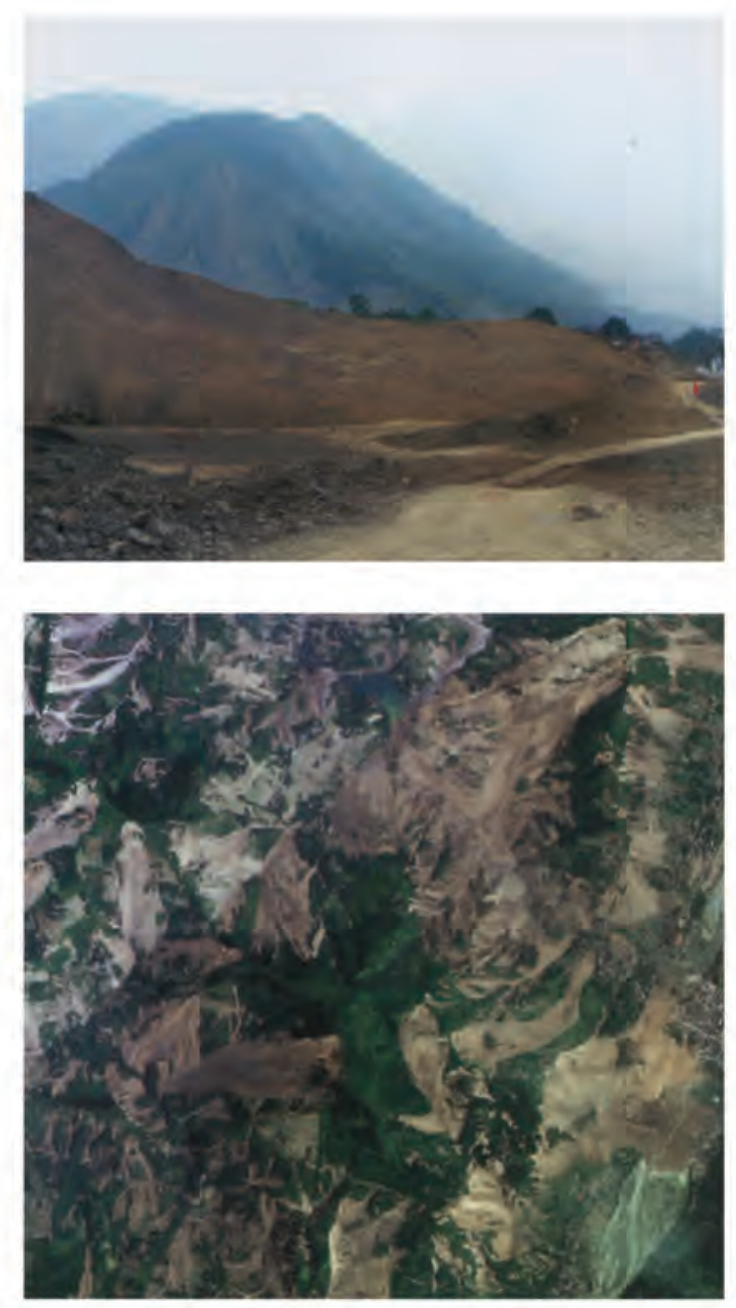

\section{Chapter 3 Barrier Lakes}

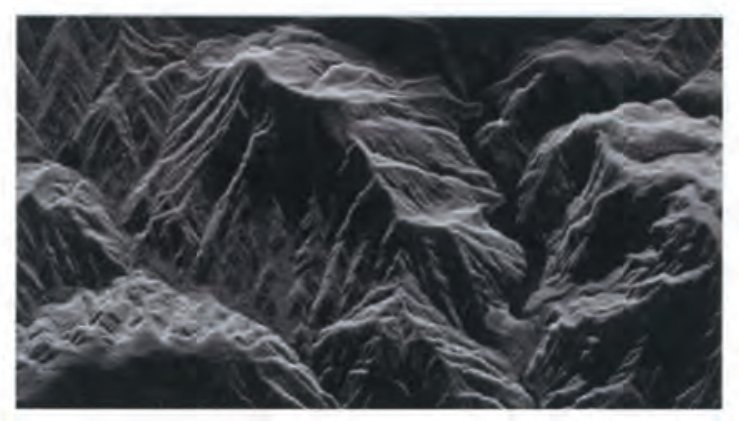

Full view of Tangjiashan barrier lake in Beichuan County (May 19, 2008) 


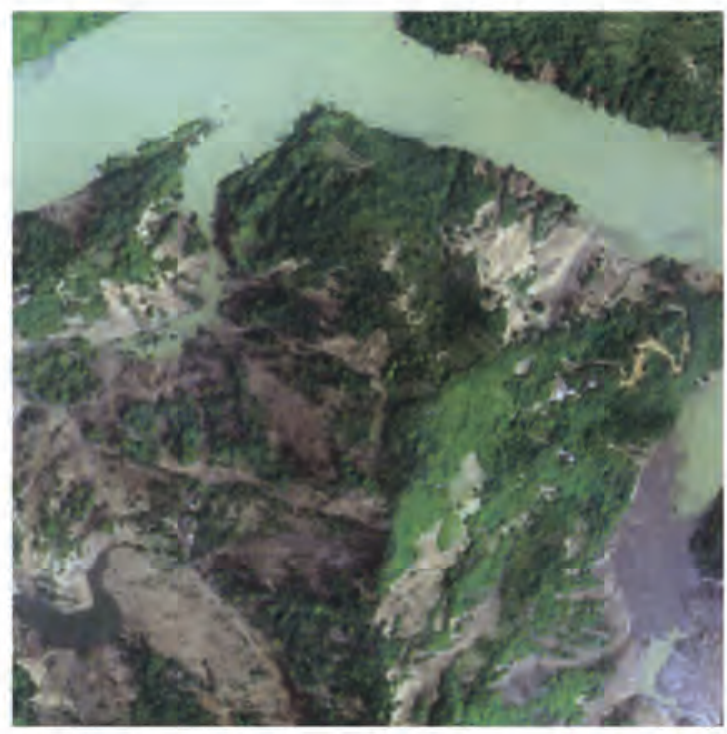

Airborne optical image of a barrier lake in Xiaojiaqiao $\quad 74$

Airborne optical image of the barrier lake in Donghekou, in Qingchuan County $\quad 74$

Airborne optical image of the barrier lake in Kuzhuba, in Beichuan County $\quad 77$

Airborne optical image of barrier lake in Shibangou, in Qingchuan County $\quad 77$

$\begin{array}{ll}\text { Airborne optical image of the barrier lake of Yanyangtan, in Beichuan County } & 78\end{array}$

Airborne optical image of the barrier lake in Guanzipu, in Qingchuan County $\quad 78$

$\begin{array}{ll}\text { TerraSAR-X satellite-based radar image of Jianjiang and Tongkou River Basin } & 81\end{array}$

Airborne SAR image of Tianchi Village in the town of North Hanwang 82

Airborne optical image of the barrier lake of Changheba in the city of Mianzhu $\quad 83$

Airborne SAR image of Ganhekou and Machaotan in the city of Shifang $\quad 84$

Airborne optical image around the barrier lake in Nanba of Pingwu County $\quad 85$

Airborne optical image at Wenjiaba in Pingwu County 86

Satellite radar image based COSMO-SkyMed in Tongkou River of

Beichuan County

87

Satellite based IKONOS image around the barrier lake in

the town of North Yingxiu

89

\section{Chapter 4 Collapsed Buildings}

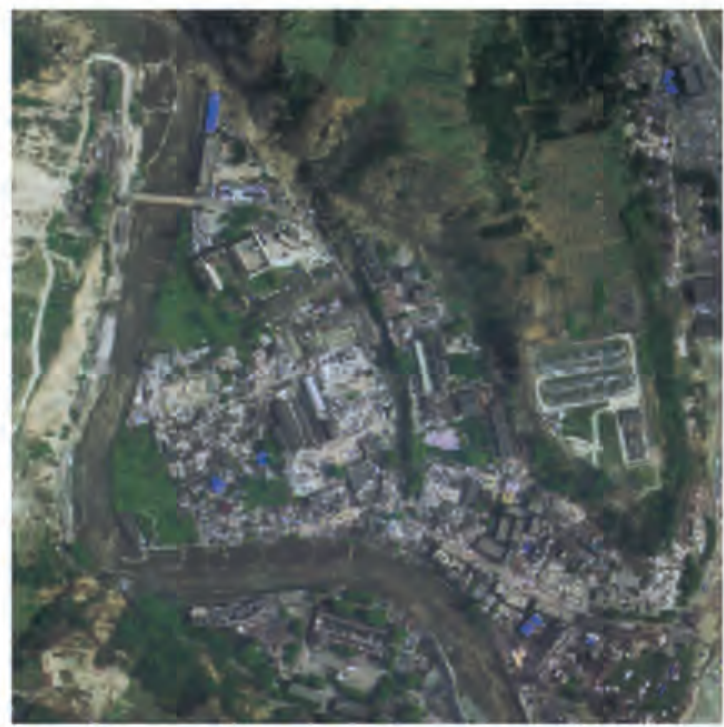

Houses collapsed in main quake-stricken region

93

Distribution of collapsed houses in urban area of Wenchuan County 94

Airborne optical images of the town of Yingxiu, in Wenchuan County 97

Disaster assessment on houses collapse in the city of Dujiangyan 99

The map of house collapse in the city of Dujiangyan $\quad 100$

Airborne optical image of the town of Juyuan, in the city of Dujiangyan $\quad 101$

Airborne optical images of the town of Zhongxing, in the city of Dujiangyan $\quad 103$

Distribution of the collapsed houses in Maoxian County 104

The IKONOS image of Maoxian County 105

Airborne SAR images of Maoxian County $\quad 106$

The Pre-earthquake SPOT 5 image of Maoxian County ( November 1, 2005) 107

Distribution of the collapsed houses in the town of Zagunao, in Lixian County $\quad 108$

Airborne optical image of the town of Shigu, in Maoxian County 109

Airborne optical image of the town of Longfeng, in the city of Pengzhou $\quad 110$

Airborne optical image of the town of Dabao, in the city of Pengzhou 111

Airborne optical image of the town of Hongbai, in the city of Shifang 112

Airborne optical image of the village of Xiaojiaping, in the town of

Longmenshan, in the city of Pengzhou $\quad 112$

Airborne optical image of the town of Yinghua, in the city of Shifang $\quad 114$

Airborne optical image of the town of Yunxi, in the city of Shifang 115

Distribution of the collapsed house in the city of Mianzhu 116

The Radar image in the town of Hanwang, in the city of Mianzhu 117

Airborne optical image of the town of Hanwang, in the city of Mianzhu 119

.xvi . 
Airborne optical images of the town of Zundao, in the city of Mianzhu Airborne optical images of the town of Guangii, in the city of Mianzhu Distribution of collapsed houses in Anxian County

Distribution of the destroyed houses in the town of Anchang, in Anxian County Airborne optical images of the town of Xiushui, in Anxian County Airborne optical images of the town of Xiaoba, Anxian County Airborne optical images of the town of Chaping, Anxian County Distribution of the destroyed houses in the city of Mianyang Airborne SAR image of the city of Mianyang

Post-earthquake and pre-earthquake Radarsat images of the city of Mianyang Airborne optical image of the town of Xinzao, in the city of Mianyang Airborne optical image in the town of Qingyi, in the city of Mianyang WorldView image of the town of Wujia, in the city of Mianyang Airborne optical images of the town of Caopo, in Wenchuan County Distribution of the collapsed houses in the city of Jiangyou Post-earthquake and Pre-earthquake Radarsat images of urban area of the city of Jiangyou

Airborne optical image of the town of Xiping, in the city of Jiangyou

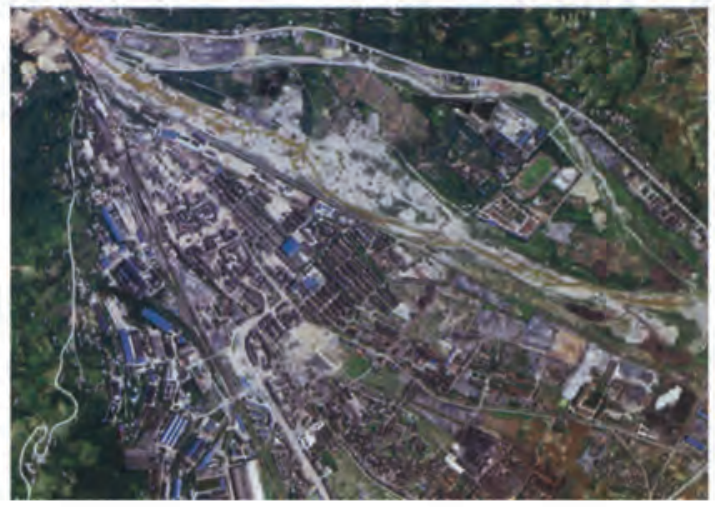

120

120

122

123

125

125

127

128

129

130

132

132

135

135

136

137

138
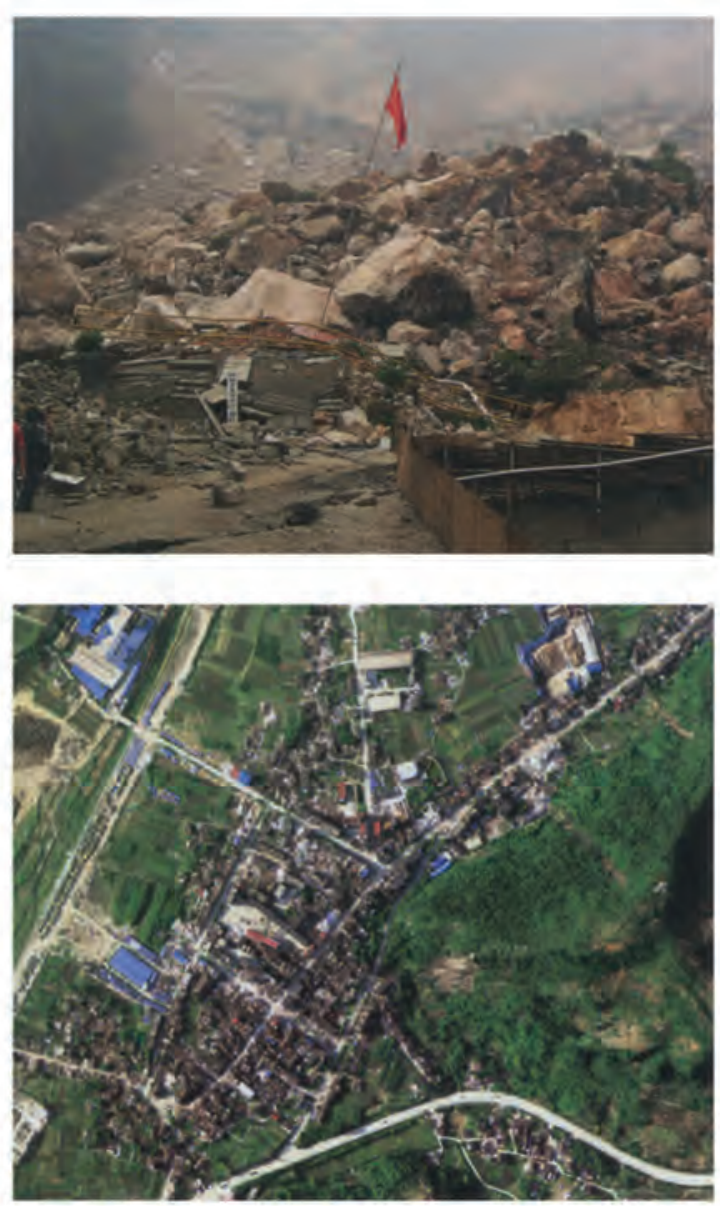

Airborne optical image of the town of Sandui, in the city of Guangyuan 138

Airborne optical image of the town of Muyu, in Qingchuan County 141

Airborne optical image of the town of Qingxi, Qingchuan County 143

Airborne optical image of the town of Guanzhuang, in Qingchuan County 143

Airborne optical image of the town of Long ' an, in Pingwu County 144

Airborne optical images of the town of Nanba, Pingwu County 145

Airborne optical image of the town of Chenjiaba, Beichuan County 146

IKONOS image of the town of Yuli, Beichuan County 146

Post-earthquake and pre-earthquake Radarsat images of urban area of Deyang $\quad 148$

Airborne optical images of the town of Yuli, Beichuan County 150

Airborne optical images of the town of Yuli, Beichuan County 151

Airborne optical image of the town of Leigu, Beichuan County 152

Airborne optical image of the town of Leigu, Beichuan County 153

Three-dimensional airborne remote sensing image of Beichuan County 155

The Airborne optical image of Beichuan County

The Airborne remote sensing classification image for

collapsed houses in old urban district of Beichuan County

Three dimensional airborne image of urban area of

Beichuan County (partial) (May 27, 2008)

Three dimensional airborne image of old urban district of

Beichuan County ( May 27, 2008 )

The old urban in Beichuan after the Earthquake

161

Three dimensional airborne image of new urban district of

Beichuan County ( May 27, 2008) 


\section{Chapter 5 Damaged Roads}

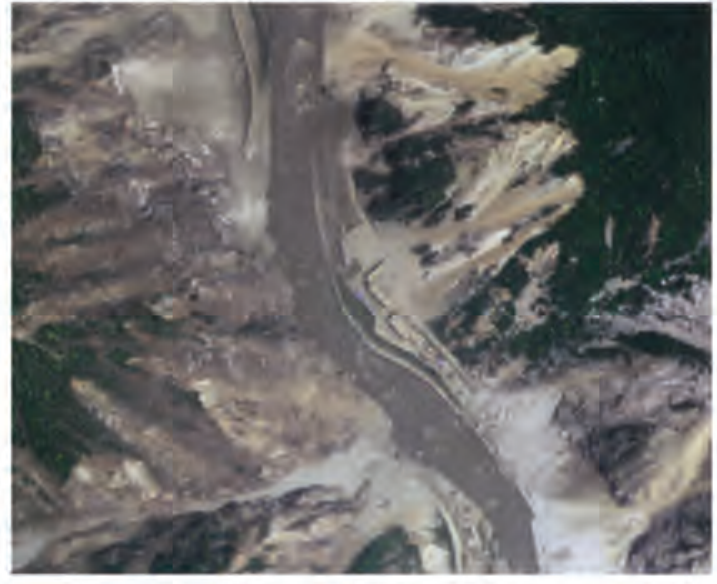

Airborne ADS40 image of the village of Xiejunmen, Tianchi in Mianyang

Airborne ADS40 image of Zhicheng, Yuli in Beichuan, May 16, 2008

Airborne ADS40 image of Zhicheng, Yuli in Beichuan, May 27, 2008

Airborne ADS40 image of Zhangjiaba, Xuanping, Beichuan

Airborne ADS40 image of Guozhupu, Wenchuan

Airborne ADS40 image of the town of Caopo, in Wenchuan County

Airborne ADS40 image of Zaojiaotuo, Yinxing in Wenchuan

Airborne ADS40 image of Taipingyi Reservoir, in Wenchuan

Airborne ADS40 image of the village of Fotangbagou, in the town of Yingxing, in Wenchuan County

Airborne ADS40 image of the village of Taoguangou, in the town of Yingxing, in Wenchuan County

Airborne ADS40 image of Moutuo, Nanxinzhen in Maoxian County

Airborne ADS40 image of the village of Yan 'erya, in the town of

Fengyi, in Maoxian County

Airborne ADS40 image of Jiyu, in the town of Fengyi, in Maoxian County

Airborne ADS40 image of Xiaojiaqiao, Qianfo, in Anxian County

Airborne ADS40 image of Shangheba, Yingxing, in Wenchuan County

Airborne ADS40 image of the town of Hanwang, in the city of Mianzhu

Airborne radar image over the village of Laochang, in the town

of Chenjiaba, in Beichuan County ( May 25, 2008 )

Airborne radar image over the town of Nanba, in Pingwu County (May 26, 2008 )

The post-earthquake Xiaoyudong Bridge

Airborne radar image over the town of Xiaoyudong, Pengzhou (May 17, 2008 )

Airborne radar image over Wenchuan County (May 15, 2008 )

Airborne radar image over the Zipingpu Reservoir (May 17, 2008)

IKONOS image over urban district of Wenchuan County ( May 18, 2008 )

Road damage in the city of Jiangyou

Road damage in Qingchuan County

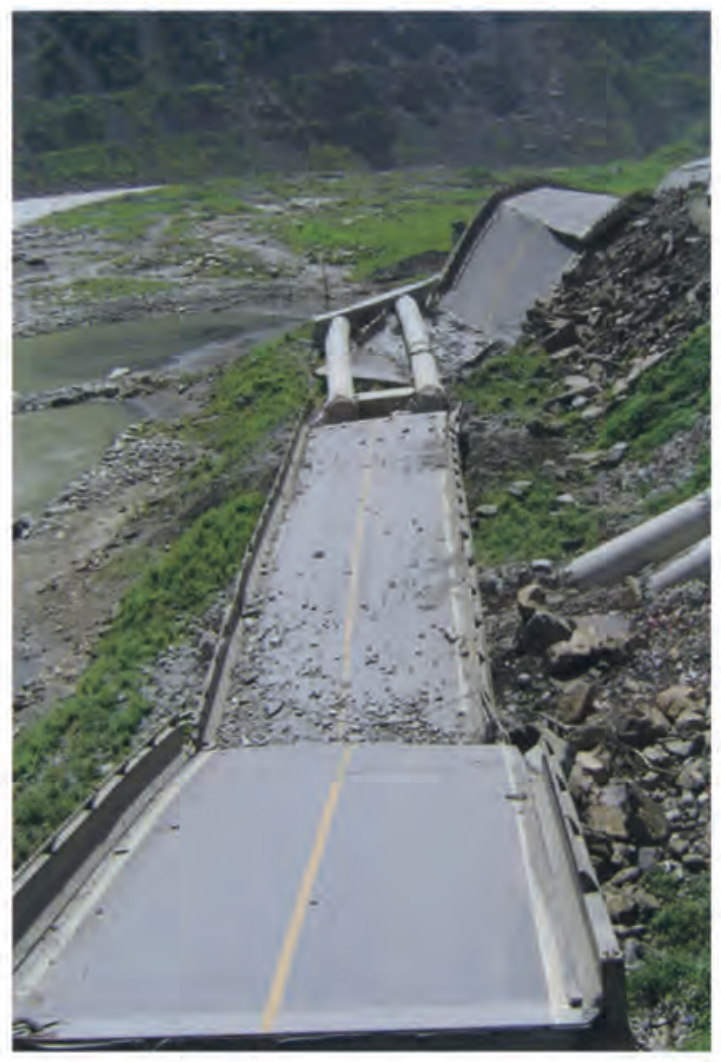




\section{Chapter 6 Destroyed Farmlands and Forests}

The beautiful terraces in Sichuan Province

Distribution of destroyed farmlands in the hit counties of

Wenchuan earthquake

Terraces before and after the earthquake

Airborne optical remote sensing image for Xupingba

SPOT 5 image from the town of Nanba to the town of Shuiguan,

in Pingwu County

Airborne optical remote sensing image acquired on May 28,

2008 around Tangjiaba

Airborne optical remote sensing image acquired on May 28, 2008 for Liangjiasan

Airborne optical remote sensisng image acquired on May 28 ,

2008 around the village of Leidashu

The inundated farmlands of Beichuan County

Destroyed landscape in the valley of Minjiang River

Destroyed landscape caused by secondary geological disasters

Secondary geological disasters around Wenchuan County

Wenchuan earthquake's influence on giant panda habitats and their natural reservations
198

199

200

201

203

203

204

205

206

207

208

209

211

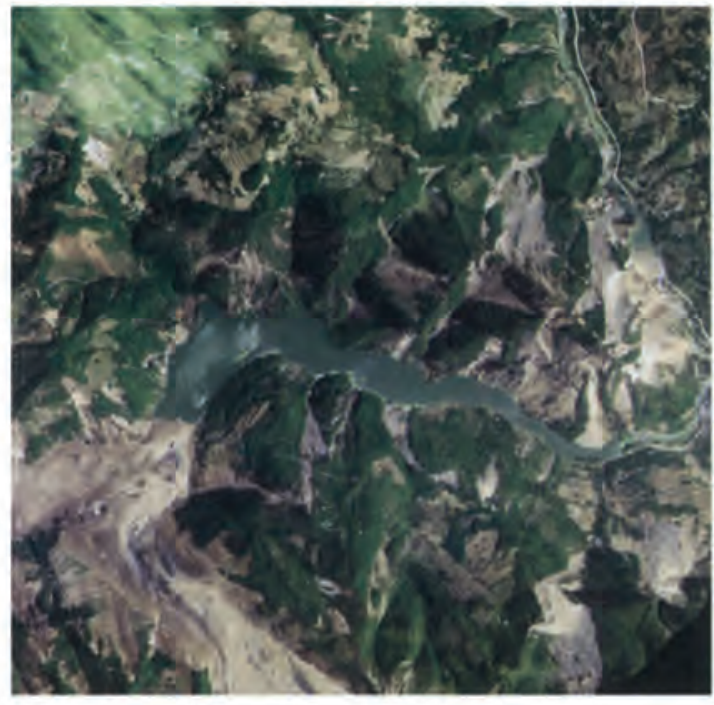

Chapter 7 Demolished Infrastructure

Airborne optical remote sensing image of the Taipingyi power station in the town of Yinxing, in Wenchuan County

SPOT 5 remote sensing image of the Taipingyi power station

in the town of Yinxing, in Wenchuan County

Airborne optical remote sensing image of the Kuzhuba power station

in the town of Qushan, in Beichuan County

Airborne optical remote sensing image of the power station

in the town of Nanxin, in Maowen County

Airborne optical remote sensing image of the Banpocun power station

in the town of Miansi, in Wenchuan County

Airborne optical remote sensing image of Futangba power station

in the town of Miansi, in Wenchuan County

Airborne radar remote sensing image of Xiazhuang Village in Wenchuan County

Airborne optical remote sensing image of Shapai power station in the town of

Caopo, in Wenchuan County 
Airborne optical remote sensing image of Jinhe Phosphate Mine

in the town of Hongbai, in the city of Shifang

Airborne radar remote sensing image of Zipingpu Reservoir in the city of

Dujiangyan (1)

Airborne radar remote sensing image of Zipingpu Reservoir in the city of

\section{Chapter 8 Civilization Perseveres}

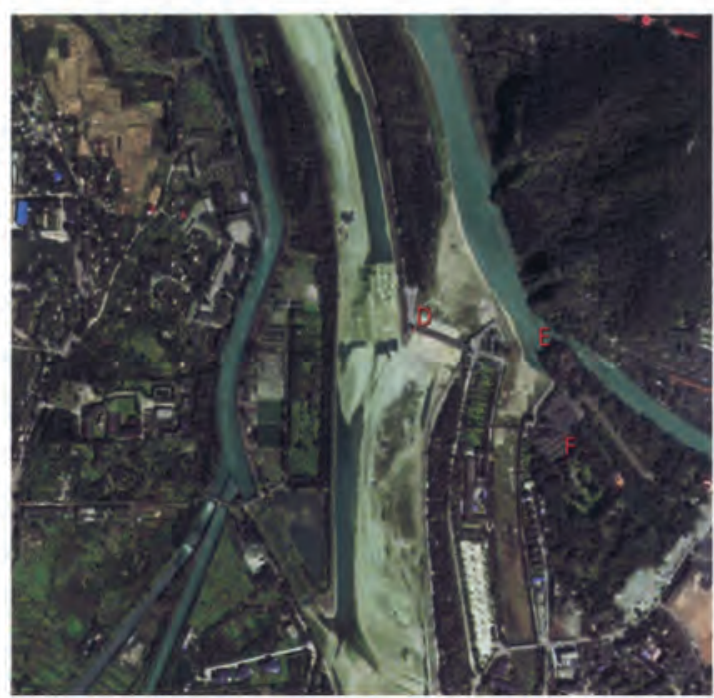

Landsat S-TM image of the city of Dujiangyan acquired on June 26, 1994

A distribution map of the main parts of Dujiangyan irrigation project and other important scenic spots

Erwang temple built in memory of $\mathrm{Li}$ Bing and his son for their great contribution to lead the construction of the Dujiangyan irrigation system

\section{Index}




\section{Remote Sensing Data}

Remote sensing instruments can measure the characteristics of objects without contacting with them. Based on the principle that different objects have different responses to electromagnetic waves, remote sensing instruments collect data on the ground, detect the nature of surface objects, and identify various types of ground objects by sensors boarded on different platforms (tower, balloon, aircraft, rocket, manmade Earth satellite, spacecraft, space shuttle, etc.) above the ground. Remote sensing is the systematic integration of technologies for detecting and monitoring the Earth' $s$ resources and environment, including the process of detecting electromagnetic waves (radiation and scattering) on the Earth's surface, transmitting information, processing, and interpretation. After decades of development, remote sensing technology has been widely used in resource management, environmental studies, hydrology, meteorology, geology, urban studies, agriculture, forestry, surveying and mapping, disaster analysis, and other fields.

At present, the most commonly used remote sensing data acquisition platforms are satellites and aircraft. The United States' launch of the first Earth-observation satellite in 1972 marked the beginning of the era of space remote sensing. Since then, humankind has rediscovered the Earth from the perspective of space. Subsequently, the major powers developed a variety of photoelectric technologies; microwave technology and computer technology developed; and remote sensing technology entered a new phase when multi-resolution, multi-band, multi-polarization, multitemporal massive Earth-observation data could be provided in real time. Satellite remote sensing has many benefits, such as wide coverage, repeated observation, and no restrictions from space. 
Aerial remote sensing has matured as a technology since its beginnings in aerial photography reconnaissance. It has the advantages of allowing large-scale imaging, achieving high resolution, mapping across a wide terrain, and investigating detailed areas. However, there are limitations in flight altitude, endurance, attitude control, all-weather performance ability, and the range of dynamic monitoring. Aerial and satellite remote sensing could be used in conjunction, each performing applications to which it is suited.

Visible light, infrared light, and microwave are the bands usually used in remote sensing. Visible light works as camera. Infrared sensors are generally larger, are more complex in structure, and possess a more sophisticated system that can perceive the infrared band outside of visible light. The imaging mechanism of microwave remote sensing is different from that of the optical sensor, and synthetic aperture radar (SAR) is a common technology in microwave remote sensing. SAR emits electromagnetic wave energy, records backscattered signal strength from the ground, and displays an image after processing. Microwave is sensitive to dielectric constant and roughness of ground objects and is widely used in estimation of crop yield, forest surveys, disaster monitoring, marine applications, geological exploration, and military reconnaissance. Microwave technology does not rely on sunlight and has the ability to acquire images under all weather conditions and at all times, as well as having particular penetration capabilities. Microwave remote sensing data and optical data are highly complementary.

The satellite remote sensing data used in this Atlas are partly from the Center for Earth Observation and Digital Earth (CEODE) of the Chinese Academy of Sciences, others are provided by international organizations and companies. Aerial remote sensing images are obtained with two of CEODE's aerial remote sensing aircraft.

\section{Satellite Remote Sensing Data}

After the Wenchuan earthquake occurred, on the same day, CEODE immediately began to receive remote sensing data and access to foreign satellite data through international cooperation. Table 2.1 lists parameters about related satellite data used in this Atlas. 
Table. 2.1. Remote Sensing Satellite Parameters

\begin{tabular}{|c|c|c|c|c|c|c|c|c|c|c|c|}
\hline Satellite & Landsat-5 & SPOT $2 / 4$ & SPOT 5 & Resouresat & Envisat & Radarsat-1 & ALOS & IKONOS & QuickBird & TerraSAR-X & EROS-B \\
\hline $\begin{array}{c}\text { Nation/ } \\
\text { Institution }\end{array}$ & USA & France & France & India & ESA & Canada & Japan & USA & USA & German & Israel \\
\hline Launch Time & 1984 & $1990 / 1998$ & 2002 & 2003 & 2002 & 1995 & 2006 & 1999 & 2001 & 2007 & 2006 \\
\hline Sensor Type & Optical & Optical & Optical & Optical & Radar & Radar & $\begin{array}{l}\text { Optical } \\
\text { /Radar }\end{array}$ & Optical & Optical & Radar & Optical \\
\hline Sensor Name & TM & HRV & $\begin{array}{l}\text { HRG } \\
\text { /HRS }\end{array}$ & $\begin{array}{l}\text { LISS3 } \\
\text { /LISS4 } \\
\text { IAwiFS }\end{array}$ & ASAR SAR & $\begin{array}{l}\text { PRISM } \\
\text { IAvnir-2 } \\
\text { IPALSAR }\end{array}$ & & & & & \\
\hline Orbital Type & $\begin{array}{l}\text { Sun-syn- } \\
\text { chronous }\end{array}$ & $\begin{array}{l}\text { Sun-syn- } \\
\text { chronous }\end{array}$ & $\begin{array}{l}\text { Sun-syn- } \\
\text { chronous }\end{array}$ & $\begin{array}{l}\text { Sun-syn- } \\
\text { chronous }\end{array}$ & $\begin{array}{l}\text { Sun-syn- } \\
\text { chronous }\end{array}$ & $\begin{array}{l}\text { Helio-syn- } \\
\text { chronous }\end{array}$ & $\begin{array}{l}\text { Helio-syn- } \\
\text { chronous }\end{array}$ & $\begin{array}{l}\text { Helio-syn- } \\
\text { chronous }\end{array}$ & $\begin{array}{l}\text { Helio-syn- } \\
\text { chronous }\end{array}$ & $\begin{array}{l}\text { Helio-syn- } \\
\text { chronous }\end{array}$ & $\begin{array}{l}\text { Helio-syn- } \\
\text { chronous }\end{array}$ \\
\hline $\begin{array}{c}\text { Orbital } \\
\text { Altitude/ } / \mathrm{km}\end{array}$ & 705 & 832 & 832 & 778 & 800 & 798 & 691 & 681 & 450 & 514 & 510 \\
\hline $\begin{array}{c}\text { Orbit } \\
\text { Inclination } /\left({ }^{\circ}\right)\end{array}$ & 98.22 & 98.721 & 98.721 & 98.731 & 98.0 & 98.6 & 98.16 & 98.1 & 97.2 & 97.44 & 97.2 \\
\hline $\begin{array}{c}\text { Orbital } \\
\text { period/min }\end{array}$ & 98.9 & 101.4 & 101.4 & 101.35 & 101 & 100.7 & 93.4 & 98.33 & 93.5 & 94.85 & 93.4 \\
\hline $\begin{array}{l}\text { Imaging } \\
\text { Method }\end{array}$ & $\begin{array}{l}\text { Optical- } \\
\text { mechanical } \\
\text { scan }\end{array}$ & Push-broom & Push-broom & Push-broom & $\begin{array}{l}\text { Synthetic } \\
\text { aperture }\end{array}$ & $\begin{array}{l}\text { Synthetic } \\
\text { aperture }\end{array}$ & $\begin{array}{c}\text { Synthetic } \\
\text { aperture/ } \\
\text { optical- } \\
\text { mechanical } \\
\text { scan }\end{array}$ & Push-broom & Push-broom & $\begin{array}{l}\text { Synthetic } \\
\text { aperture }\end{array}$ & Push-broom \\
\hline $\begin{array}{l}\text { Stereo- } \\
\text { Imaging }\end{array}$ & $=$ & Across-track & $\begin{array}{c}\text { Along- } \\
\text { track(HRS)/ } \\
\text { across-track }\end{array}$ & Across-track & $\begin{array}{c}\text { Across-track } \\
\text { (Interferom- } \\
\text { etry ) }\end{array}$ & $\begin{array}{l}\text { Across- } \\
\text { track(Inte- } \\
\text { rerometry) }\end{array}$ & Along-track & $\begin{array}{l}\text { Along-track/ } \\
\text { across-track }\end{array}$ & $\begin{array}{l}\text { Along-track/ } \\
\text { across-track }\end{array}$ & $\begin{array}{l}\text { Across- } \\
\text { track(Inter- } \\
\text { ferometry) }\end{array}$ & $\begin{array}{l}\text { Along-track/ } \\
\text { across-track }\end{array}$ \\
\hline $\begin{array}{c}\text { Maximum } \\
\text { Oblique } \\
\text { viewing angle }\end{array}$ & 27 & 27 & 26 & $15-45$ & $10-49$ & 44 & 60 & 30 & $20-55$ & 45 & \\
\hline Swath (km) & 185 & 60 & 60 & $\begin{array}{l}23.9 \\
170 \\
1141 \\
1737\end{array}$ & $100 / 400$ & $\begin{array}{c}50 \\
175 \\
1100 \\
1150 \\
/ 170 \\
1300 \\
1500\end{array}$ & $\begin{array}{c}\text { PRISM: } \\
35 / 70 \\
\text { Avnir-2: } \\
70 \\
\text { PALSAR: } \\
20-350\end{array}$ & 11 & 16.5 & $10 / 30 / 100$ & 7 \\
\hline $\begin{array}{c}\text { Spatial } \\
\text { Resolution (m) }\end{array}$ & 30 & $\begin{array}{c}10 \text { (Pan) } 20 \\
\text { (Multisp- } \\
\text { ectral) }\end{array}$ & $\begin{array}{c}2.5 \text { (Sper- } \\
\text { mode) } \\
/ 5(\text { pan }) / 10 \\
\text { (Multispec- } \\
\text { tral) }\end{array}$ & $\begin{array}{l}\text { LISS4: } 5.8 \\
\text { LISS3:23.5 } \\
\text { AWiFS: } 56\end{array}$ & $25-100$ & $10-100$ & $\begin{array}{c}\text { PRISM:2.5 } \\
\text { Avnir-2:10 } \\
\text { PAL- } \\
\text { SAR:7-100 }\end{array}$ & $\begin{array}{c}0.82 \\
\text { (Pan) } 3.2 \\
\text { (Multis- } \\
\text { pectral) }\end{array}$ & $\begin{array}{l}0.61 \text { (Pan) } \\
2.44 \text { (Mul- } \\
\text { tispectral) }\end{array}$ & $\begin{array}{c}\text { Spotlight:1 } \\
\text { Stripmap:3 } \\
\text { Scan- } \\
\text { SAR:16 }\end{array}$ & 0.7 (Pan) \\
\hline
\end{tabular}




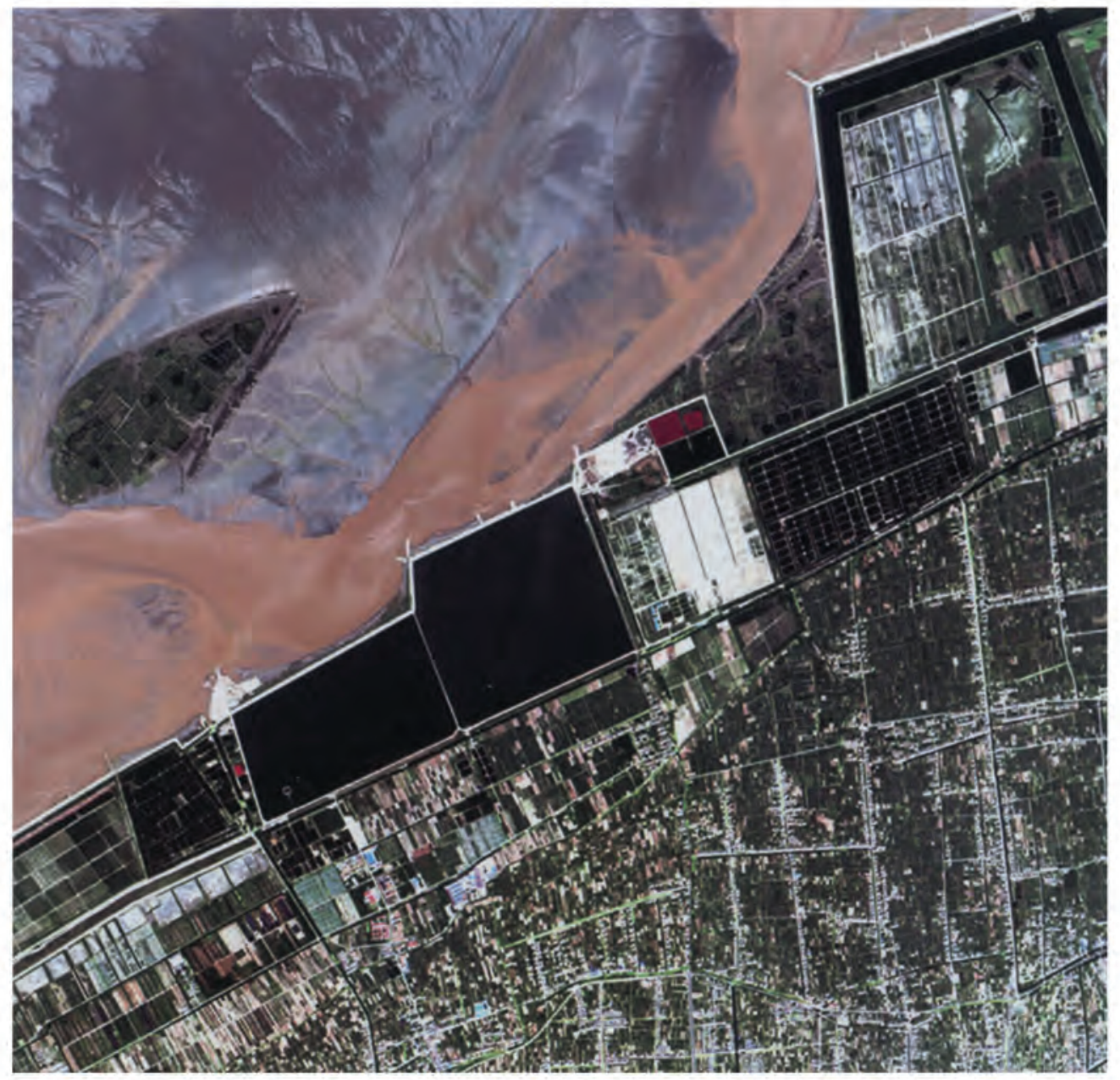

A Sample image of QuickBird Satellite,Chengdu
The QuickBird optical satellite, which was launched in 2001 by Digital Globe, offered the most highly accurate and highest resolution imagery among the commercial satellites at that time. QuickBird's global collection of panchromatic (resolution $0.61 \mathrm{~m}$ ) and multispectral (resolution $2.44 \mathrm{~m}$ ) imagery and color imagery, which is fused by the panchromatic and multispectral imagery, is designed to support applications such as map publishing, surveying, city design, agriculture and forest monitoring, digital information extraction, target recognition, and global information systems. During the Wenchuan earthquake, the QuickBird satellite data were used to determine appropriate methods and responses to dealing with different situations.

Table 2.2. QuickBird Primary Information

\begin{tabular}{|c|c|}
\hline Launch date & October 18, 2001 \\
\hline Orbital altitude $(\mathrm{km})$ & 450 \\
\hline Revisit period (days) & $1-3.5$ \\
\hline Swath $(\mathrm{km})$ & 16.5 \\
\hline Resolution & 0.61 m(panchromatic), 2.44(multispectral) \\
\hline
\end{tabular}

Table 2.3. Technical Specification of Sensors in QuickBird Satellite

\begin{tabular}{c|c}
\hline \multirow{4}{*}{$\begin{array}{c}\text { Resolution and } \\
\text { Spectral Band }\end{array}$} & $\begin{array}{c}\text { Panchromatic Ground sample } \\
\text { distance (GSD) at nadir } 0.61 \mathrm{~m}\end{array}$ \\
\cline { 2 - 2 } & $\begin{array}{c}\text { Black and White:0.445-0.990 } \mu \mathrm{m} \\
\text { distance (GSD) at nadir:2.44m }\end{array}$ \\
\cline { 2 - 2 } Blue:0.45-0.520 $\mu \mathrm{m}$
\end{tabular}

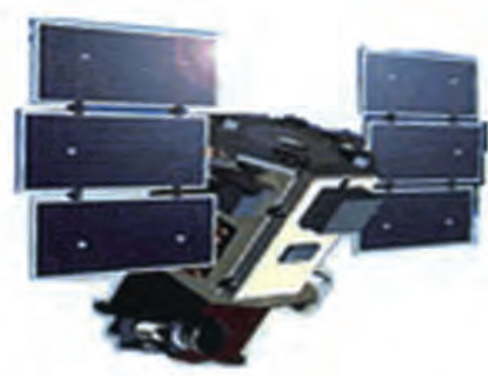




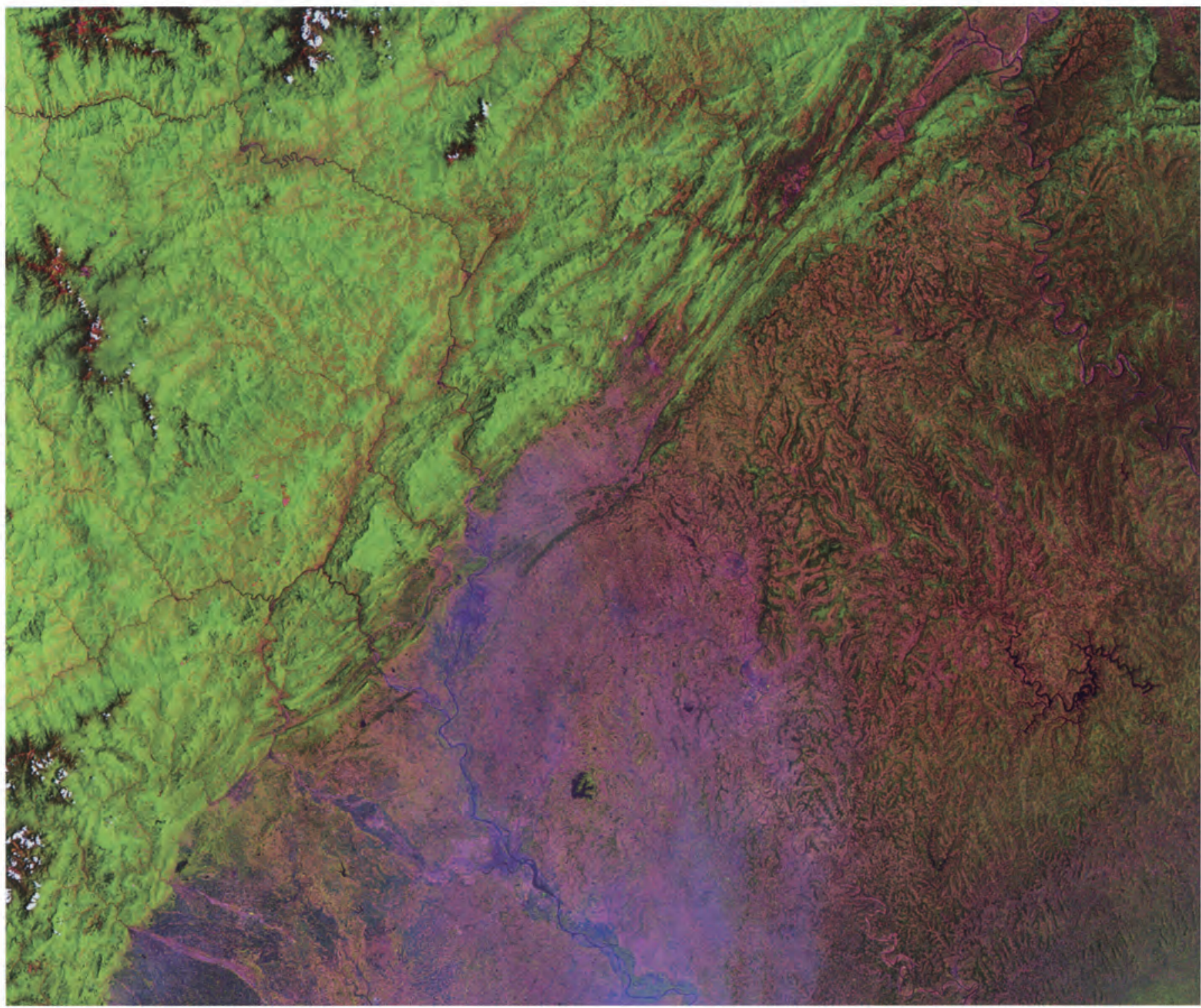

Sample image of Landsat 5 Satellite, Mianyang (May 19, 2006)

In the 1970s, America launched the first generation land resource satellite. In the 1980s, the second generation satellites (Landsat 4, 5) were in orbit too. There was a big breakthrough in this generation; and in the $1990 \mathrm{~s}$, the third generation satellites (Landsat 6, 7) were launched. Recently, Landsat 5, 7 have been widely used over China.

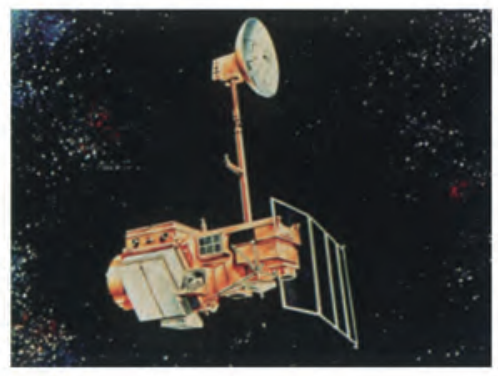

Table 2.4. Technical Specifications of TM

\begin{tabular}{ccc}
\hline Band & Spectral range $(\mu \mathrm{m})$ & Ground resolution $(\mathrm{m})$ \\
\hline B1 (Blue-Green) & $0.45-0.52$ & 30 \\
\hline B2 (Green) & $0.52-0.60$ & 30 \\
\hline B3 (Red) & $0.63-0.69$ & 30 \\
\hline B4 (Near IR) & $0.76-0.90$ & 30 \\
\hline B5 (SWIR) & $1.55-1.75$ & 30 \\
\hline B6 (LWIR) & $10.40-12.5$ & 120 \\
\hline B7 (SWIR) & $2.08-2.35$ & 30 \\
\hline
\end{tabular}




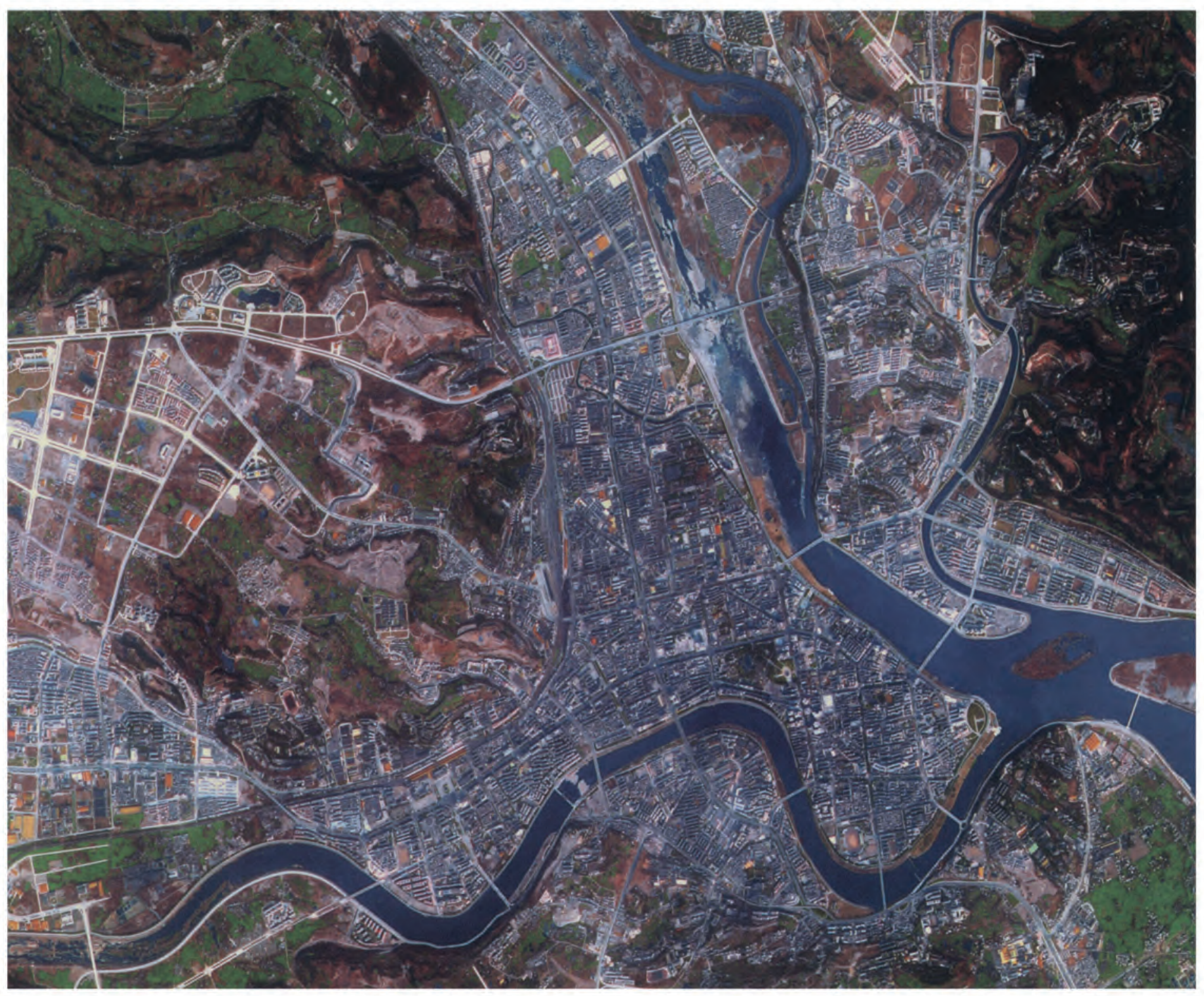

$\Delta$ Sample image of SPOT 5 Satellite (Mianyang, February 10, 2005)

The SPOT 5 Satellite is representative of France's space remote sensing program. SPOT 5 has higher resolution. It is the highest level of the SPOT satellites. It is used widely in agriculture, forest management, geology, urban planning, natural disaster management, and mapping.

Table 2.5. Specifications of SPOT 5

\begin{tabular}{c|c}
\hline Launch Date & May 4,2002 \\
\hline $\begin{array}{c}\text { Orbital } \\
\text { altitude }(\mathrm{km})\end{array}$ & 832 \\
\hline $\begin{array}{c}\text { Repeat } \\
\text { cycle (days) }\end{array}$ & 26 \\
\hline Swath (km) & 60 \\
\hline Sensors & HRG/HRS \\
\hline
\end{tabular}

Table 2.6. HRG Spectral Bands of SPOT 5

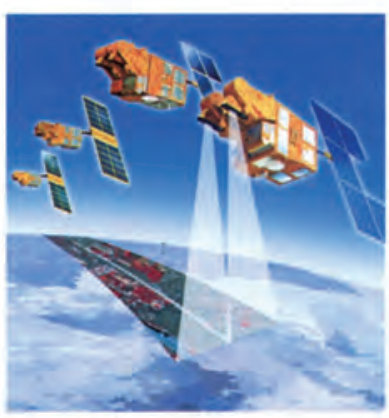

\begin{tabular}{ccc}
\hline Band & $\begin{array}{c}\text { Spectral } \\
\text { Range }(\mu \mathrm{m})\end{array}$ & Resolution $(\mathrm{m})$ \\
\hline PAN & $0.49-0.69$ & $2.5 / 5$ \\
\hline B1 & $0.459-0.61$ & 10 \\
\hline B2 & $0.61-0.68$ & 10 \\
\hline B3 & $0.78-0.89$ & 10 \\
\hline SWIR & $1.58-1.79$ & 20 \\
\hline
\end{tabular}


Resourcesat-1 (IRS-PO), launched in 2003 by India, operates three sensors: multi-spectral sensors LISS-4, LISS-3, and advanced wide-field scanner AWiFS. The highest resolution sensor is $5.8 \mathrm{~m}$. The observed data are widely used in precision agriculture, forestry, environment, geological exploration, infrastructure planning, mapping, and national defense. The majority of the data applied to the May 12 Wenchuan earthquake relief were provided by LISS-4.

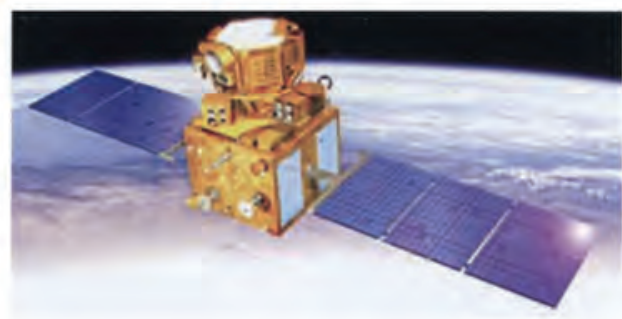

Table 2.7. Specifications of Indian IRS-P6

\begin{tabular}{c|c}
\hline Date of Launch & October17, 2003 \\
\hline Mission lifetime (years) & 5 \\
\hline Design Altitude(km) & 817 \\
\hline Repeat cycle(LISS-III) (days) & 24 \\
\hline Revisit period (LISS-IV) (days) & 5 \\
\hline Repeat cycle(AWiFS) (days) & 5 \\
\hline
\end{tabular}

Table 2.8. Major Specifications of LISS-III

\begin{tabular}{c|c}
\hline Items & Specifications \\
\hline pixel number of CCD & 6000 \\
\hline \multirow{4}{*}{$\begin{array}{c}\text { Band Range } \\
(\mu \mathrm{m})\end{array}$} & B3(green): $0.52-0.59$ \\
\cline { 2 - 2 } & B4(near infrared): 0.62-0.68 \\
\cline { 2 - 2 } & $\begin{array}{c}\text { B5(near infrared of short wave) } \\
1.55-1.70\end{array}$ \\
\hline Swath $(\mathrm{km})$ & 141 \\
\hline Resolution(m) & 23 \\
\hline $\begin{array}{c}\text { Band registration ac- } \\
\text { curacy }\end{array}$ & $<0.25$ pixel \\
\hline
\end{tabular}

Resoucesat-1(IRS-P6 LISS-3) sample image (SanXia area, March 8, 2008)
Table 2.9. Major Specifications of LISS-IV

\begin{tabular}{|c|c|}
\hline Items & Specifications \\
\hline pixel number of $C C D$ & 12,000 \\
\hline \multirow{3}{*}{$\begin{array}{l}\text { Band Range } \\
\qquad(\mu \mathrm{m})\end{array}$} & B2(green): 0.52-0.59 \\
\hline & B3(red): $0.62-0.68$ \\
\hline & B4(near infrared): $0.77-0.86$ \\
\hline Swath(multispectral mode) $(\mathrm{km})$ & 23.9 \\
\hline Swath(Mono mode) (km) & 70 \\
\hline Ground sampling distance $(\mathrm{m})$ & 5.8 (nadir) \\
\hline Side looking angle range & $\begin{array}{c} \pm 26^{\circ} \text { (amount to } \pm 398 \mathrm{~km} \text { on } \\
\text { ground) }\end{array}$ \\
\hline Band registration accuracy & $<0.25$ pixel \\
\hline
\end{tabular}

Table 2.10. Major Specifications of AWiFS Sensor

\begin{tabular}{c|c}
\hline Items & Specifications \\
\hline pixel number of CCD & 6000 \\
\hline \multirow{3}{*}{$\begin{array}{c}\text { Band Range } \\
(\mu \mathrm{m})\end{array}$} & B2(green): $0.52-0.59$ \\
\cline { 2 - 2 } & B3(red): 0.62-0.68 \\
\cline { 2 - 2 } & $\begin{array}{c}\text { B5(near infrared): } 0.77-0.86 \\
\text { Swath }(\mathrm{km})\end{array}$ \\
\hline Resolution $(\mathrm{m})$ & $\mathbf{1 . 5 5 - 1 . 7 0}$ \\
\hline Band registration accuracy & 740 \\
\hline
\end{tabular}

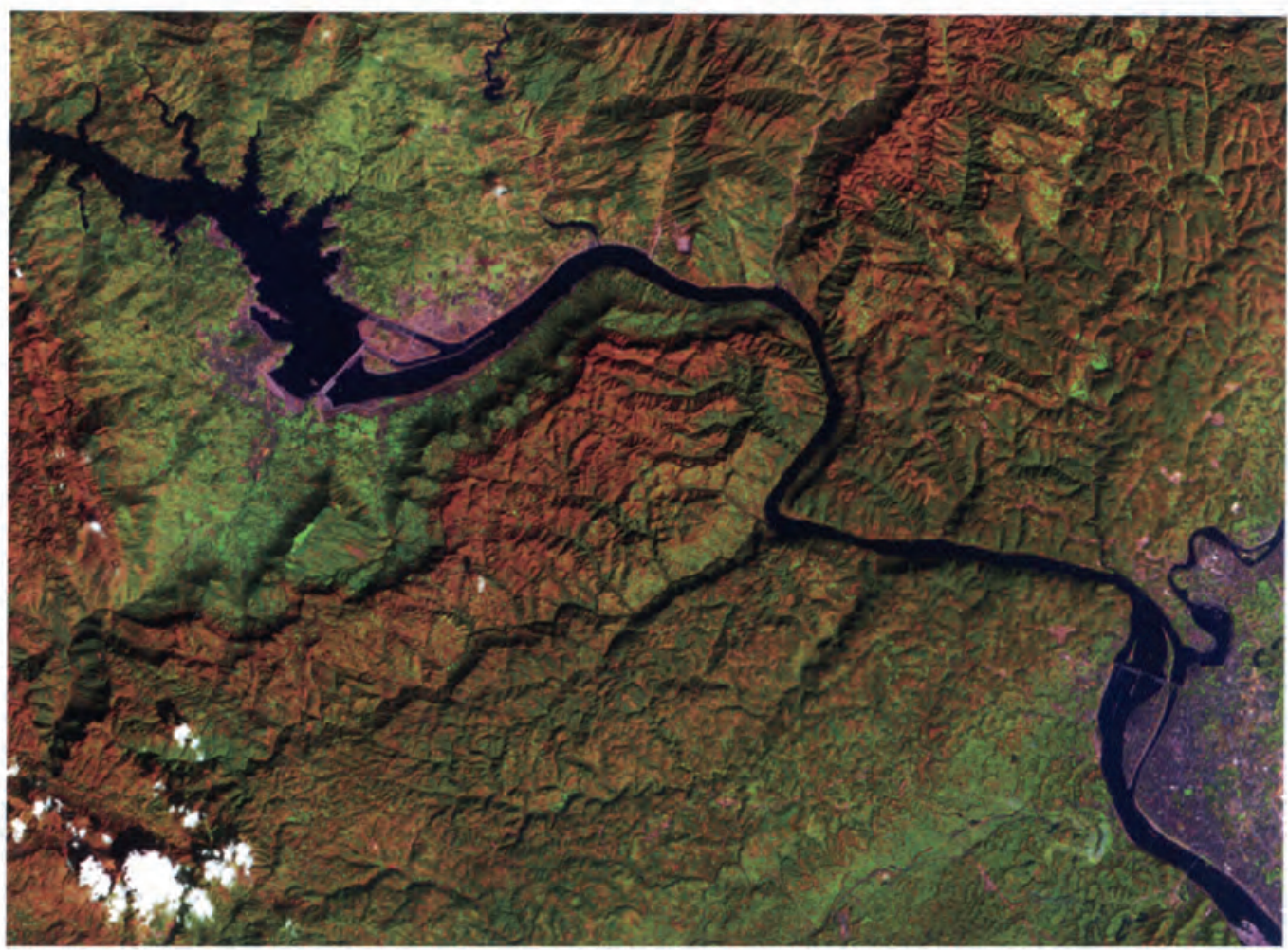

Remote Sensing Data । 7 
Launched in 1999 by a U.S. company, Space Imaging, IKONOS is the world's first commercial high-resolution satellite designed by Lockheed Martin. The spatial resolution is $0.8 \mathrm{~m}$ in panchromatic images and 4-m in multispectral mode. Panchromatic and multi-spectral images can be fused into the 1-m-resolution true-color mode. It opens up a faster and more economical way to obtain the latest Earth information and can partially replace aerial remote sensing. IKONOS is widely used in cities, ports, land, forest, environment, disaster investigation, and military monitoring. During May 12 Wenchuan earthquake relief efforts, the IKONOS images were applied for precise identification and interpretation of the disaster area.

Table 2.11. Primary Information of American IKONOS

\begin{tabular}{c|c}
\hline $\begin{array}{c}\text { Date of } \\
\text { Launch }\end{array}$ & September 24, 1999 \\
\hline $\begin{array}{c}\text { Size of } \\
\text { satellite }\end{array}$ & $\begin{array}{c}\text { Height, 1.8m; Diameter, } \\
1.6 \mathrm{~m}\end{array}$ \\
\hline $\begin{array}{c}\text { Orbit } \\
\text { altitude }(\mathrm{km})\end{array}$ & 681 \\
\hline $\begin{array}{c}\text { Revisit } \\
\text { period }\end{array}$ & $\begin{array}{c}1 \mathrm{~m}, 2.9 \text { days; } 1.5 \mathrm{~m}, \\
1.5 \text { days }\end{array}$ \\
\hline Orbit type & Sun-synchronous \\
\hline Weight $(\mathrm{kg})$ & 817 (1600 pounds) \\
\hline
\end{tabular}

Table 2.12. Major Specifications of Sensor

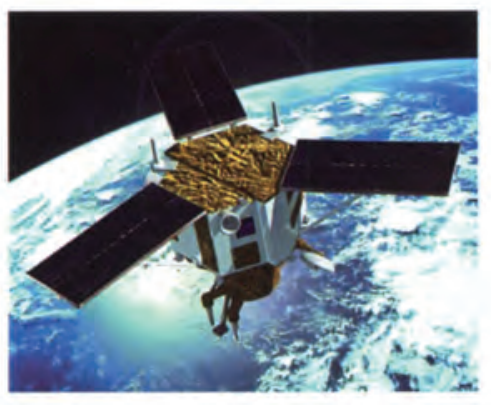

\begin{tabular}{c|l}
\hline \multirow{4}{*}{$\begin{array}{c}\text { Band Range } \\
(\mu \mathrm{m})\end{array}$} & Panchromatic: $0.45-0.90$ \\
\cline { 2 - 2 } & Muctispectral: \\
\cline { 2 - 2 } & B1(blue): 0.45-0.53 \\
\cline { 2 - 2 } & B2(green): 0.52-0.61 \\
\cline { 2 - 2 } & B3(red): 0.64-0.72 \\
\hline \multirow{2}{*}{ Swath $(\mathrm{km})$} & 11 (near infrared): 0.77-0.88 \\
\hline Resolution & $\begin{array}{c}0.82 \text { (panchromatic) } \\
4 \text { (muctispectral) }\end{array}$ \\
\hline
\end{tabular}

IKONOS sample image (Wenchuan, May 23, 2008)

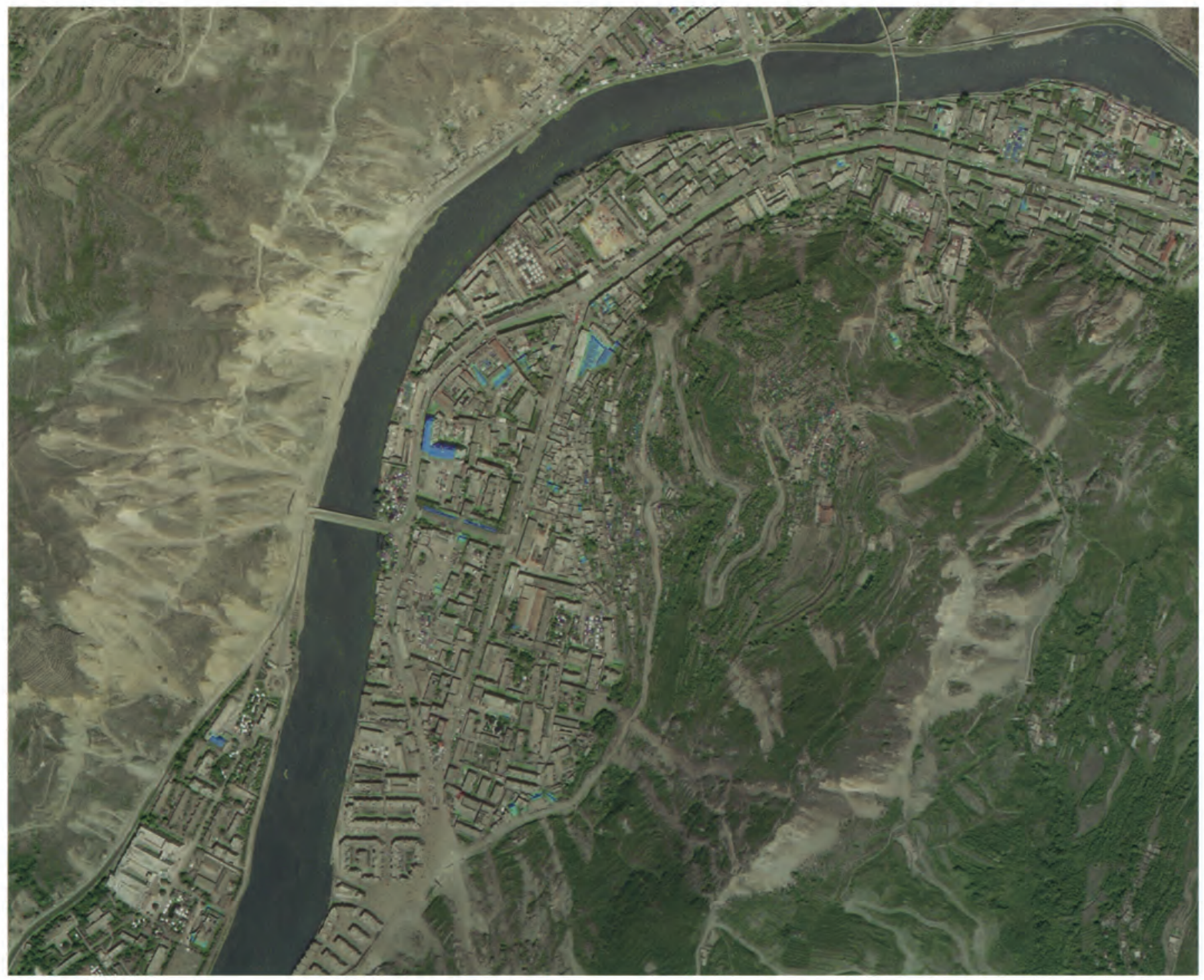

8 I Atlas of Remote Sensing of the Wenchuan Earthquake 


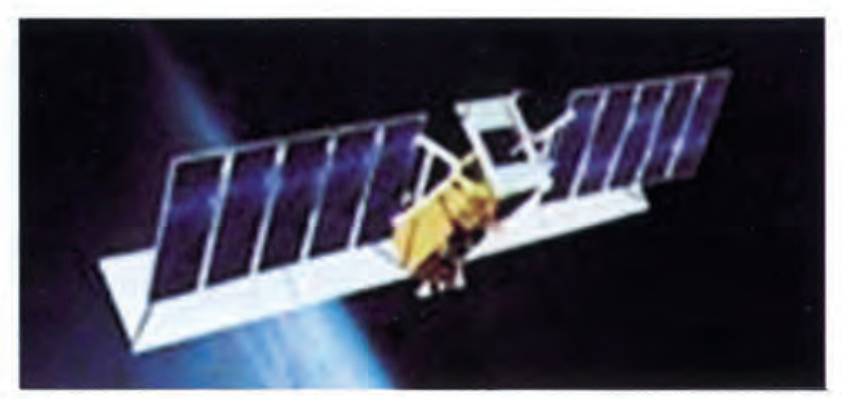

Launched in 1995 by Canada, Radarsat-1 can work under all weather conditions. Its highest resolution is up to $10 \mathrm{~m}$. Radarsat-1 is used for both land and sea. Additionally, it was the first satellite to provide high-resolution data covering the whole Antarctic continent. With seven kinds of modes, 25 sorts of beams, and different angles of incidence, it provides images with 10-100 m multi-resolution and different swaths. Radarsat -1 is widely used to monitor sea ice, analyze flooding, investigate oil pollution, and estimate agricultural yields.

Table 2.13. Major Specifications of Canadian Radarsat-1

\begin{tabular}{c|c}
\hline Items & Specifications \\
\hline Date of Launch & November 4,1995 \\
\hline $\begin{array}{c}\text { Design } \\
\text { lifetime (years) }\end{array}$ & 5 \\
\hline Orbit type & Sun-synchronous \\
\hline Orbit altitude (km) & 798 \\
\hline Revisit period(days) & 24 \\
\hline
\end{tabular}

Table 2.14. Technical Specifications of Canadian Radarsat-1

\begin{tabular}{|c|c|c|c|c|c|c|}
\hline Instrument & Mode & $\begin{array}{c}\text { Nomind } \\
\text { Resolution }(\mathrm{m})\end{array}$ & Swath $(\mathrm{km})$ & $\begin{array}{l}\text { Incident } \\
\text { Angle }\end{array}$ & $\begin{array}{c}\text { Revisit } \\
\text { Period (days) }\end{array}$ & $\begin{array}{l}\text { Download } \\
\text { Speed }\end{array}$ \\
\hline \multirow{7}{*}{$\begin{array}{c}\text { SAR } \\
\text { (Band C) }\end{array}$} & Fine & 10 & 50 & $37^{\circ}-48^{\circ}$ & $2-10$ & \multirow{7}{*}{$\begin{array}{c}105 \\
\text { Mbps }\end{array}$} \\
\hline & Standard & 30 & 100 & $20^{\circ}-49^{\circ}$ & $1-5$ & \\
\hline & Wide & 30 & $130-1652$ & $0^{\circ}-45^{\circ}$ & $1-5$ & \\
\hline & ScanSAR narrow & 50 & 300 & $20^{\circ}-46^{\circ}$ & $1-5$ & \\
\hline & ScanSAR Wide & 100 & 500 & $20^{\circ}-49^{\circ}$ & $1-5$ & \\
\hline & Extended high & 25 & 75 & $49^{\circ}-59^{\circ}$ & $2-10$ & \\
\hline & Extended low & 35 & 170 & $10^{\circ}-23^{\circ}$ & $1-5$ & \\
\hline
\end{tabular}

- Radarsat-1 sample image (Dujiangyan, May 15, 2008)

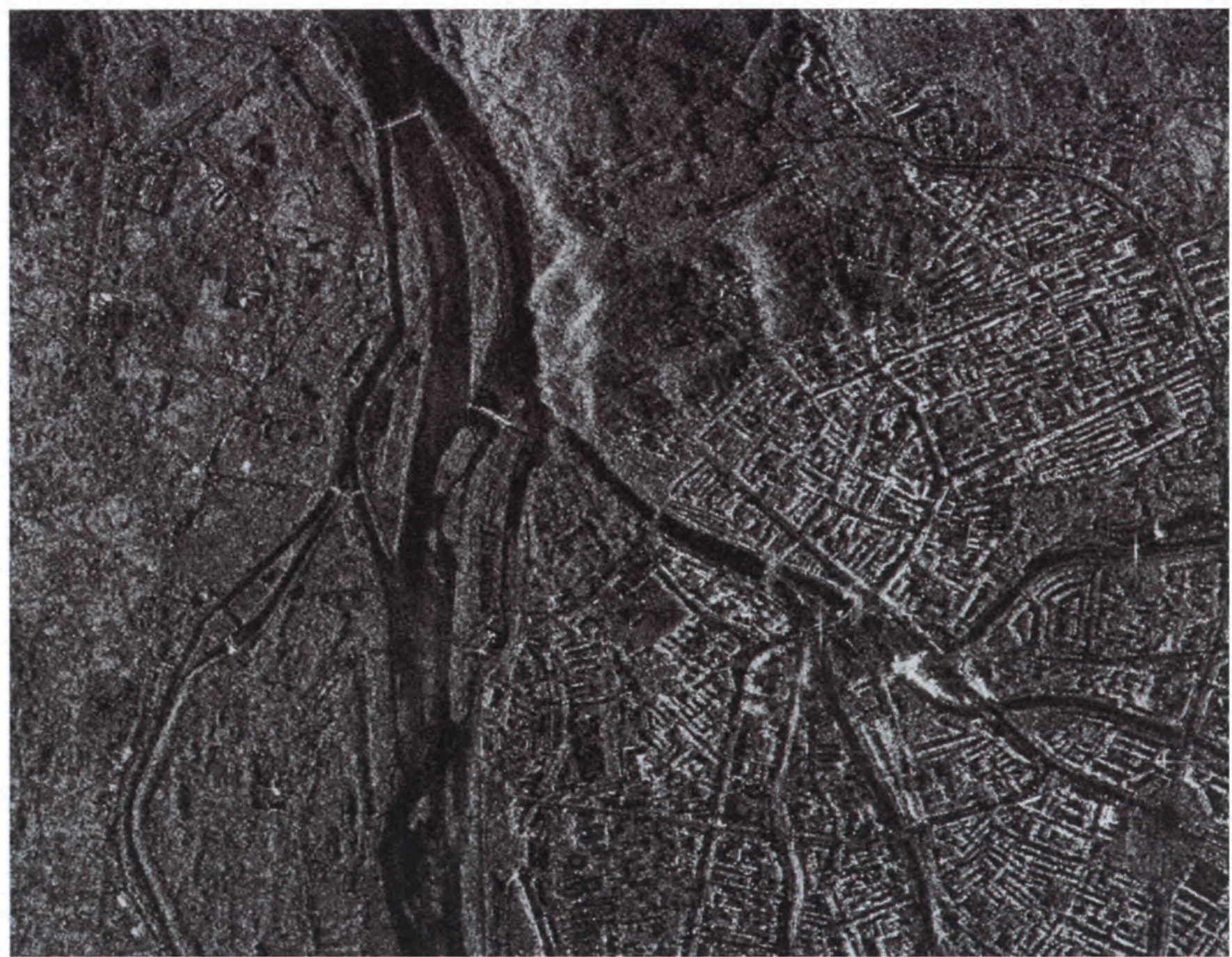


TerraSAR- $X$, a high-resolution radar satellite, was launched in 2007 by Germany. The satellite data spatial resolution is up to $1 \mathrm{~m}$. It works under all weather conditions. It can penetrate vegetation to a certain extent, and can also obtain data similar to airborne images, and its polarization imaging mode can improve its object recognition ability. The data provided by TerraSAR- $X$ are widely applied in national defense security, a variety of terrain thematic mapping, precision agriculture, urban and regional planning, environmental protection, coastal zone management and monitoring of ships, geology, disaster management, and other fields. The satellite data applied in the May 12 Wenchuan earthquake relief is mainly for precise interpretation of disaster areas.

\section{Table 2.18. Specifications of German TerraSAR-X}

\begin{tabular}{c|c}
\hline Date of Launch & June 15,2007 \\
\hline Orbit type & Sun-synchronous \\
\hline Orbit Altitude $(\mathrm{km})$ & $505-533$ \\
\hline Repeat cycle (days) & 11 \\
\hline
\end{tabular}

\section{Table 2.19. Major Specifications of the SAR}

\begin{tabular}{c|c|c|c}
\hline $\begin{array}{c}\text { Working modes } \\
\text { Wavelength }\end{array}$ & SpotLight & \multicolumn{3}{|c|}{ X-band $(3.11 \mathrm{~cm})$} & ScanSAR \\
\hline $\begin{array}{c}\text { Polarization } \\
\text { mode }\end{array}$ & $\begin{array}{c}\mathrm{V} / \mathrm{HH} \\
\mathrm{VV} \text { and } \mathrm{HH}\end{array}$ & $\begin{array}{c}\mathrm{V} / \mathrm{H}+\mathrm{HH} / \mathrm{HH}+\mathrm{HV} / \mathrm{VV}+\mathrm{VH} \\
\mathrm{V}, \mathrm{HH}, \mathrm{HV}, \mathrm{VH}\end{array}$ & $\mathrm{VV/HH}$ \\
\hline $\begin{array}{c}\text { Spatial Resolu- } \\
\text { tion }(\mathrm{m})\end{array}$ & $\leq 1$ & $\leq 3$ & $\leq 16$ \\
\hline Swath $(\mathrm{km})$ & 10 & 30 & 100 \\
\hline \begin{tabular}{c} 
Imaging direction \\
\hline Incident angle
\end{tabular} & $20^{\circ}-55^{\circ}$ & Right side of flying track \\
\hline
\end{tabular}

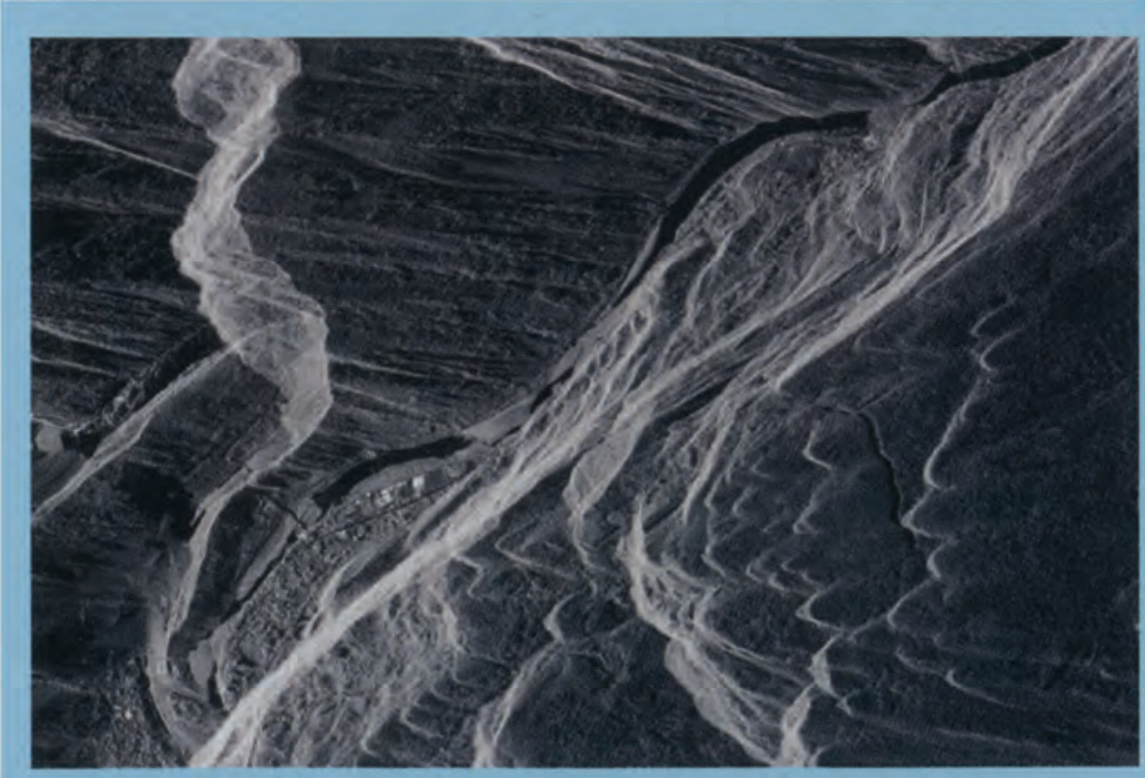

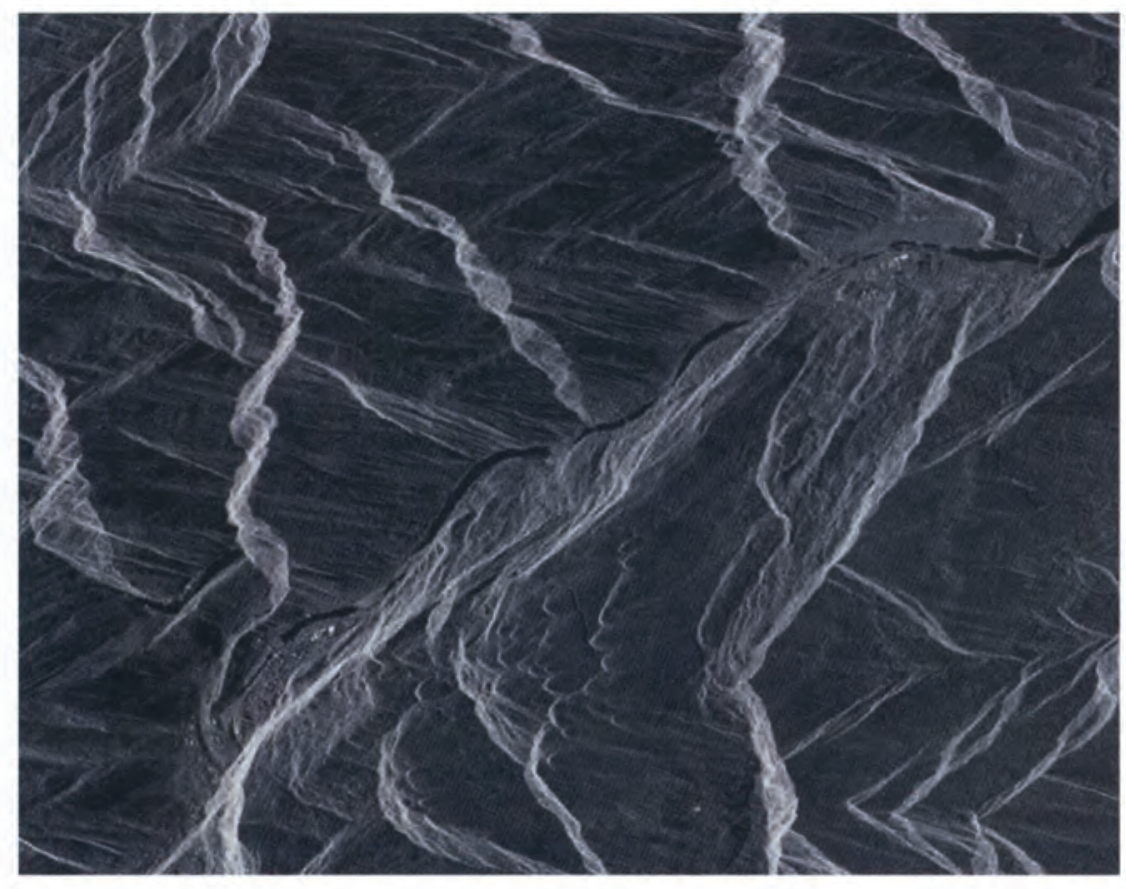

COSMO-SkyMed, a high-resolution radar satellite project, is the satellite jointly developed by the Italian Space Agency and the Italian Ministry of Defense. The satellite was launched in 2007 for the first time. The project consists of four X-band SAR satellites, the satellite data resolution is up to $1 \mathrm{~m}$. The launch of the COSMO-SkyMed satellite constellation team will be completed in 2009. The main purpose of the project is to deal with dangerous situations, to monitor coastal zones, and to improve marine pollution in the Mediterranean surrounding areas. It is used for both military and civil purposes.

Table 2.20. COSMO-SkyMed Specifications

\begin{tabular}{|c|c}
\hline Items & Specifications \\
\hline Polarization mode & $\mathrm{HH}, \mathrm{HV}, \mathrm{HV}, \mathrm{VH}$ \\
\hline Download channel & X-band \\
\hline Compress ratio & $6: 3$ \\
\hline $\begin{array}{c}\text { Pulse repeat fre- } \\
\text { quency }(\mathrm{Hz})\end{array}$ & 3000 \\
\hline Bandwidth $(\mathrm{MHz})$ & 300 \\
\hline Swath $(\mathrm{km})$ & 30 (narrow band); 400 (wide band) \\
\hline Range resolution $(\mathrm{m})$ & 3 (narrow band); 100 (wide band) \\
\hline Azimuth resolution $(\mathrm{m})$ & 3 (narrow band); 100 (wide band) \\
\hline
\end{tabular}

COSMO-SkyMed sample image (Beichuan, May 14, 2008) 
Envisat, launched in 2002, is an important milestone in the Earth-observation satellite series developed by the European Space Agency. The satellite is the largest environmental satellite developed in Europe. It carries many sensors, which implement land observation, sea observation, and air observation. The most important of these sensors is an advanced synthetic aperture radar (ASAR). Envisat was applied to research of land, oceans, atmosphere, and so on, through continuous observation of cartography, to explore resources and to analyze global weather changes and natural disasters.

Table 2.21. Specifications of ESA Envisat

\begin{tabular}{|c|c|}
\hline Date of Launch & October 17, 2003 \\
\hline Weight (kg) & 8200 \\
\hline $\begin{array}{c}\text { Designed lifetime } \\
\text { (years) }\end{array}$ & $5-10$ \\
\hline Orbit Type & Sun- synchronous \\
\hline Orbit Altitude (km) & 800 \\
\hline Repeat cycle (days) & 35 \\
\hline
\end{tabular}

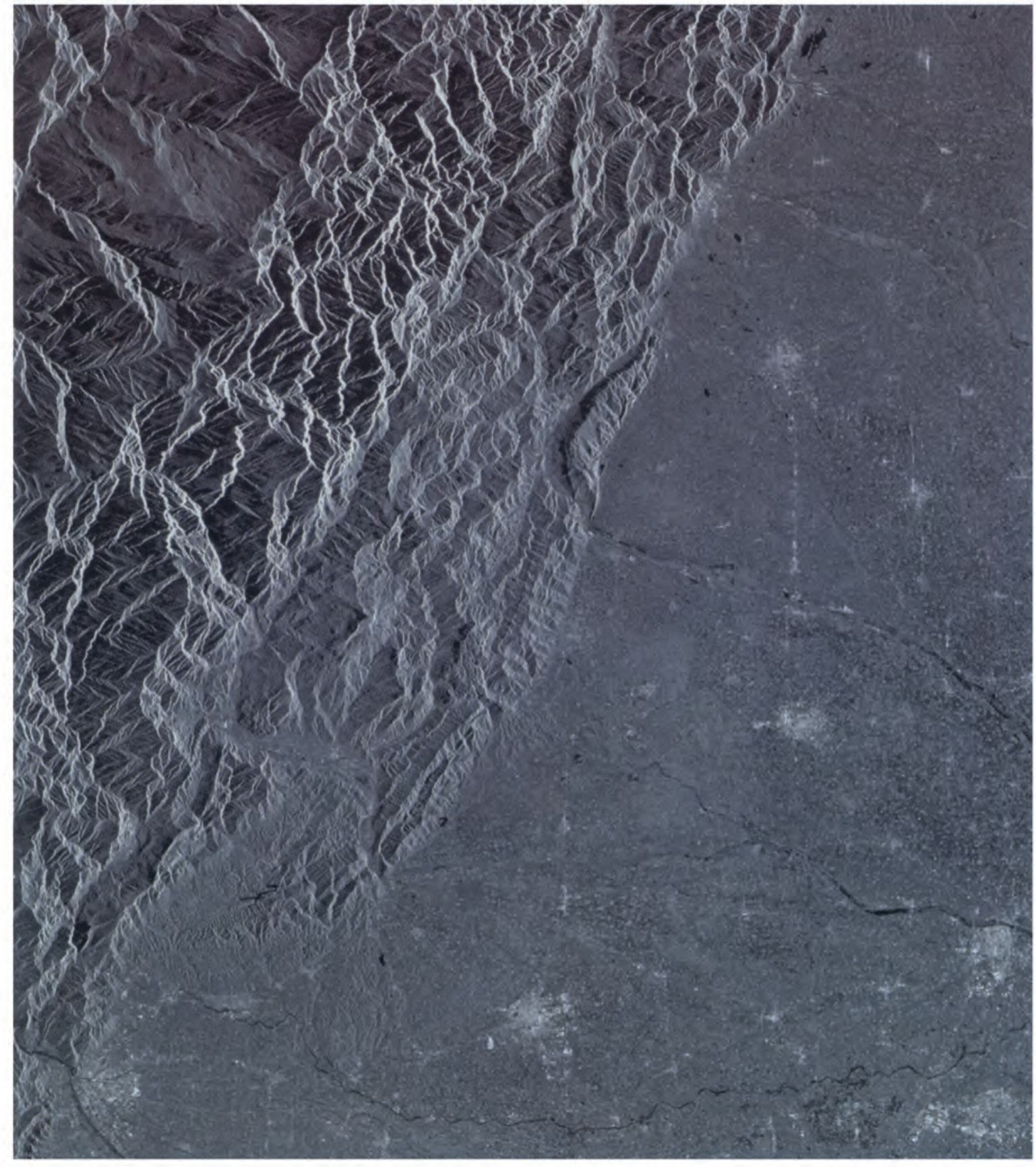

A Envisat sample image (Fujian, October 16, 2004)

Table 2.22. Major Specifications of ASAR

\begin{tabular}{|c|c|c|c|c|c|}
\hline Working Frequency & & & $\mathrm{C} / 5.3 \mathrm{G}$ & & \\
\hline Mode & image & $\begin{array}{l}\text { alternating } \\
\text { polarization }\end{array}$ & $\begin{array}{l}\text { wide } \\
\text { swath }\end{array}$ & $\begin{array}{l}\text { global } \\
\text { monitoring }\end{array}$ & wave \\
\hline Spatial Resolution (m) & 30 & 30 & 150 & 1000 & 10 \\
\hline swath (km) & $\leq 100$ & $\leq 100$ & About 400 & About 400 & 5 \\
\hline $\begin{array}{c}\text { Download } \\
\text { speed(Mbps) }\end{array}$ & 100 & 100 & 100 & 0.9 & 0.9 \\
\hline Polarization mode & $\mathrm{VV}$ or $\mathrm{HH}$ & VVNH or HH/HV & $\mathrm{W}$ or $\mathrm{HH}$ & $\mathrm{WV}$ or $\mathrm{HH}$ & $\mathrm{W}$ or $\mathrm{HH}$ \\
\hline
\end{tabular}




\section{Airborne Remote Sensing Data}

After the Wenchuan earthquake, the Center for Earth Observation and Digital Earth (CEODE), of the Chinese Academy of Sciences (CAS), sent two remote sensing aircraft into the disaster areas. From May 14, 2008 to June 8, 2008, the two remote sensing aircraft spent 227 hours in all to collect 23.7 terabytes (TB) data that include 18.5 TB radar data (X-band) of Institute of Electronics, CAS and 5.3 TB optical data (ADS40), which has created many records in the past 22 years.

The two remote sensing aircrafts in the service of CEODE

Table 2.23. Technical Specifications of ADS40

\begin{tabular}{c|l}
\hline \multirow{4}{*}{ Bands $(\mu \mathrm{m})$} & Panchromatic: $0.465-0.68$ \\
\cline { 2 - 2 } & Multispectral: \\
\cline { 2 - 2 } & B1 (Blue) : 0.43-0.49 \\
\cline { 2 - 2 } & B2 (Green) : 0.535-0.585 \\
\cline { 2 - 2 } & B3 (Red) : 0.61-0.66 \\
\cline { 2 - 2 } & B4 (Near infrared) :0.835-0.885 \\
\hline
\end{tabular}

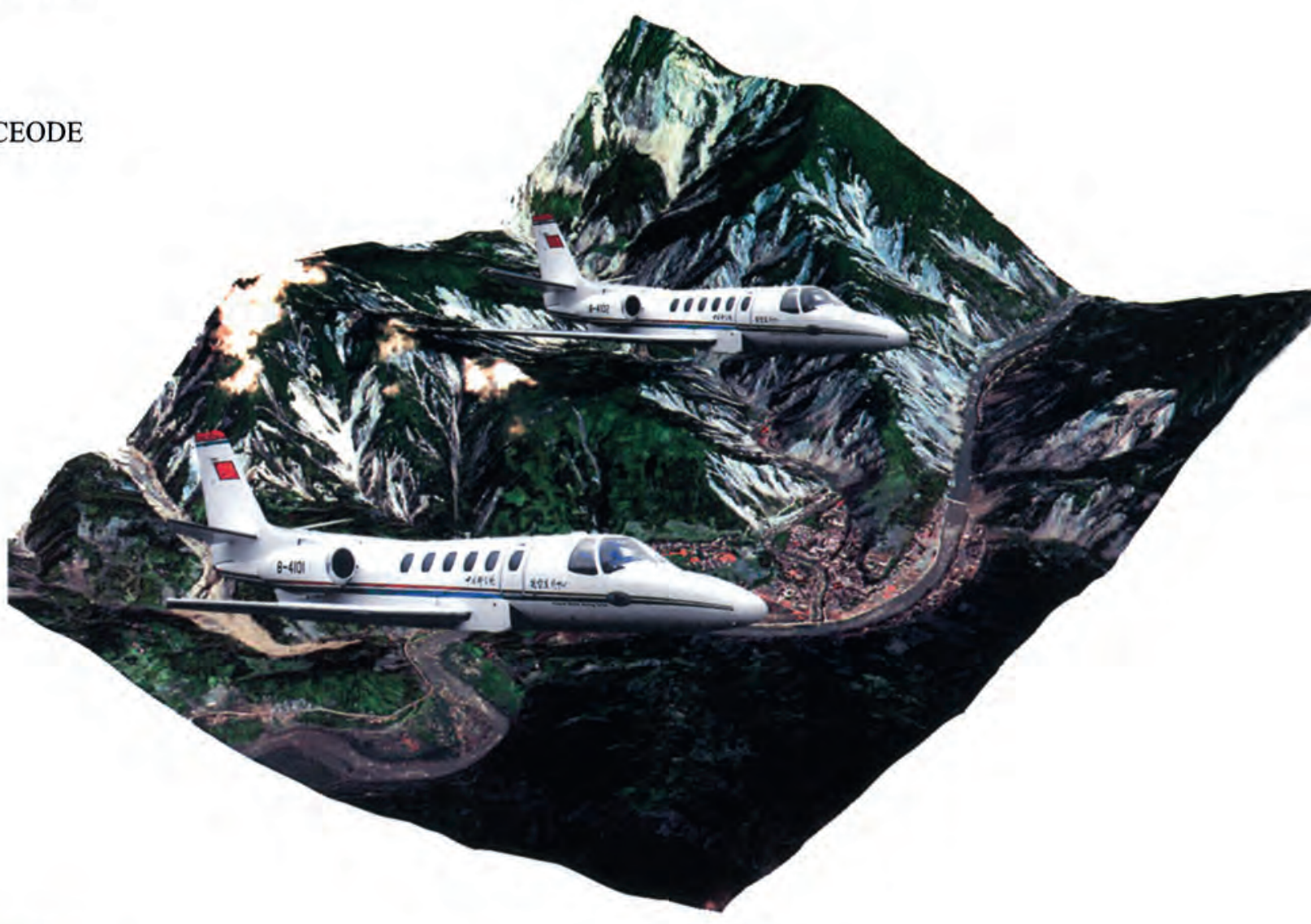

Table 2.24. The Main Technical Specifications of Airborne X-band SAR

\begin{tabular}{c|c}
\hline Working frequency $(\mathrm{GHz})$ & $\mathrm{X} / 9.6$ \\
\hline Working bandwidth $(\mathrm{MHz})$ & 360 \\
\hline Zation polari mode & $\mathrm{VV} / \mathrm{HH} / \mathrm{VH} / \mathrm{HV}$ \\
\hline Mode & Strip imaging \\
\hline Incident Angles & $20^{\circ}-70^{\circ}$ \\
\hline Beamuidth & $2.3^{\circ}$ (Azimuth), $12^{\circ}$ (Range) \\
\hline Resolution & $0.5 \mathrm{~m} \times 0.5 \mathrm{~m}$ \\
\hline
\end{tabular}




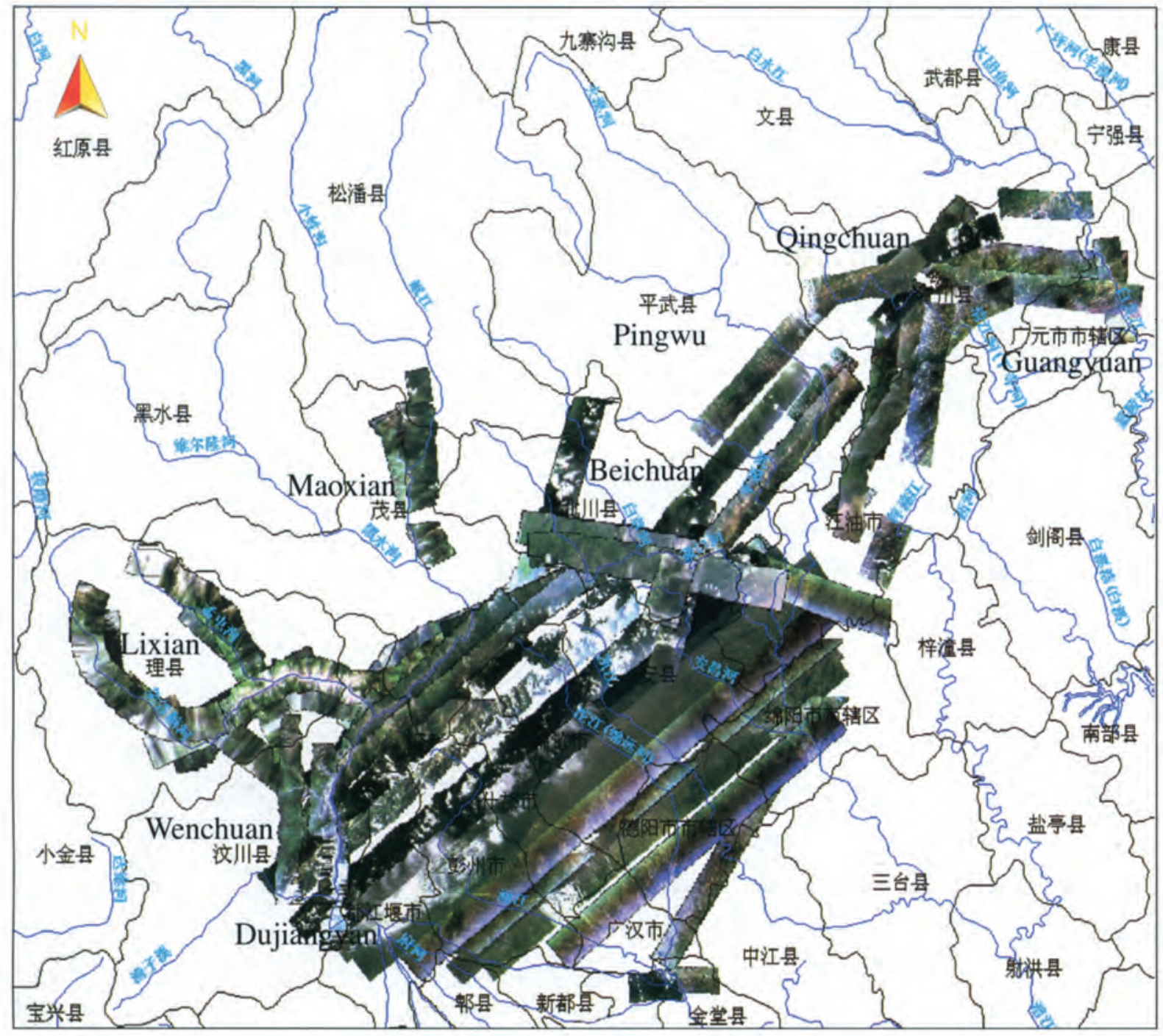

4 Airborne optical data coverage of the Wenchuan earthquake area

$\nabla$ Airborne SAR data coverage of the Wenchuan earthquake area

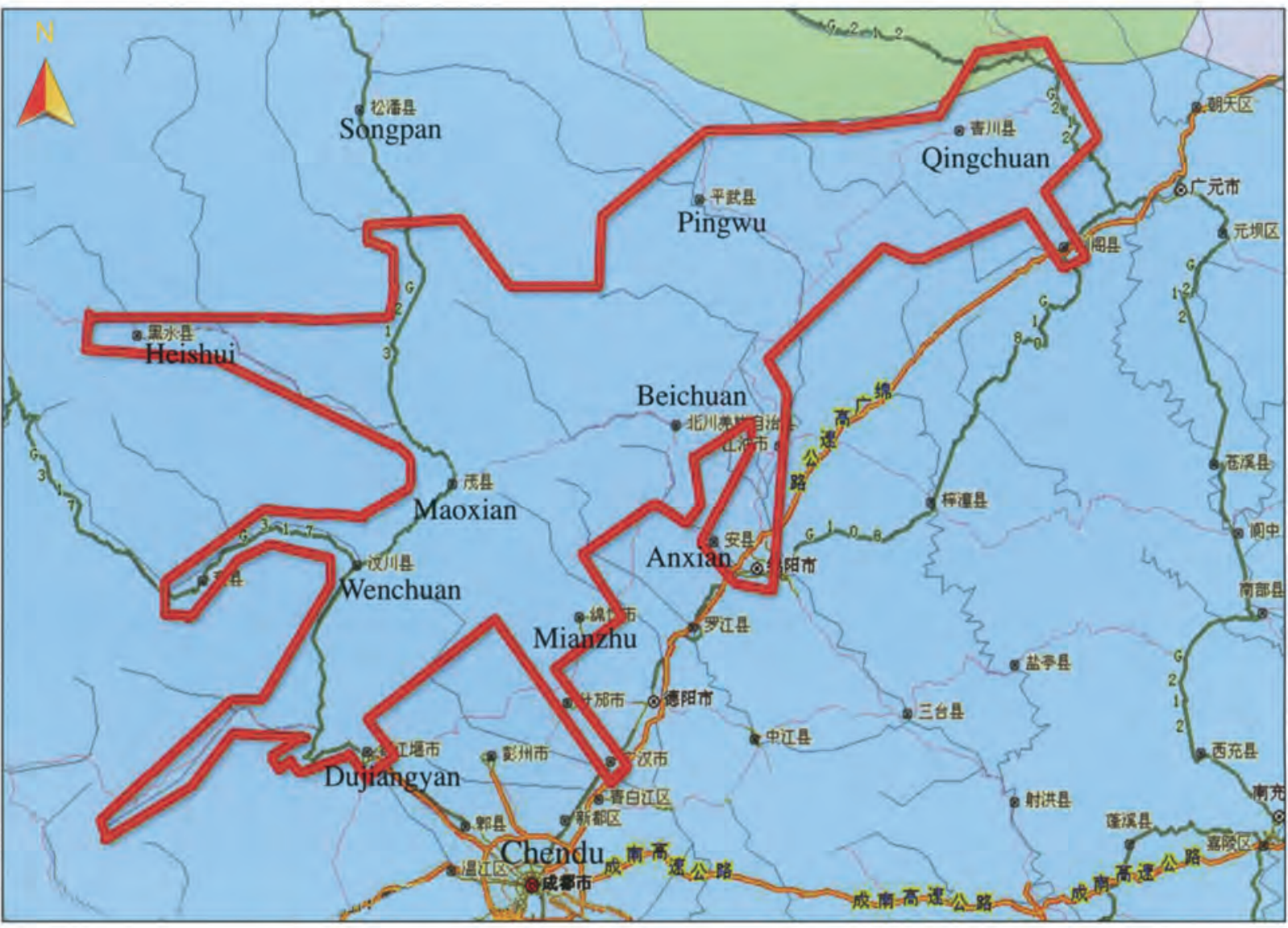

14 I Atlas of Remote Sensing of the Wenchuan Earthquake 

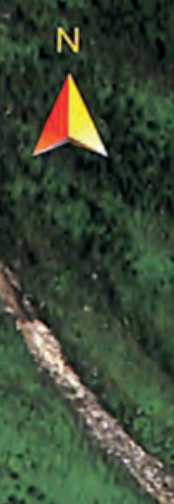

4. (5)

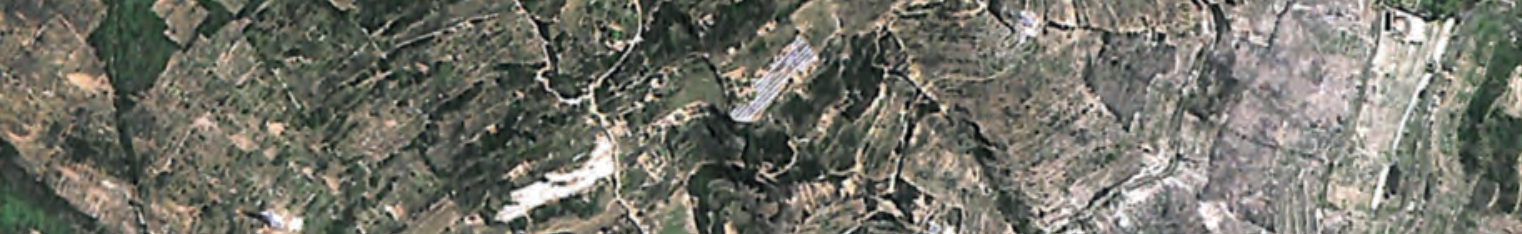

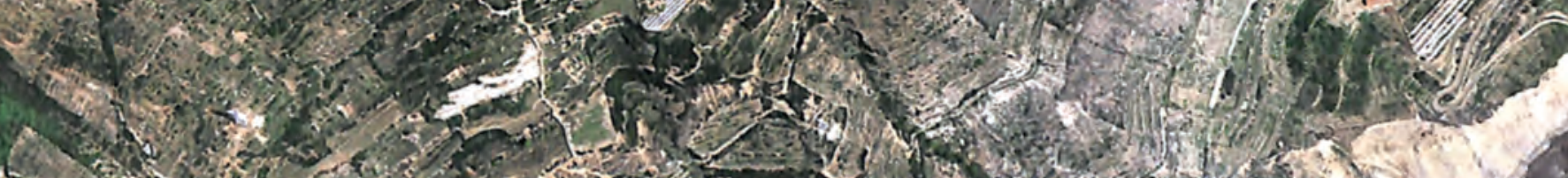

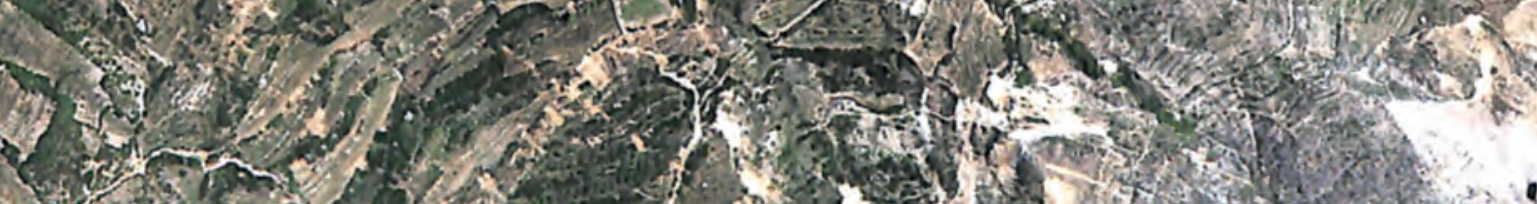

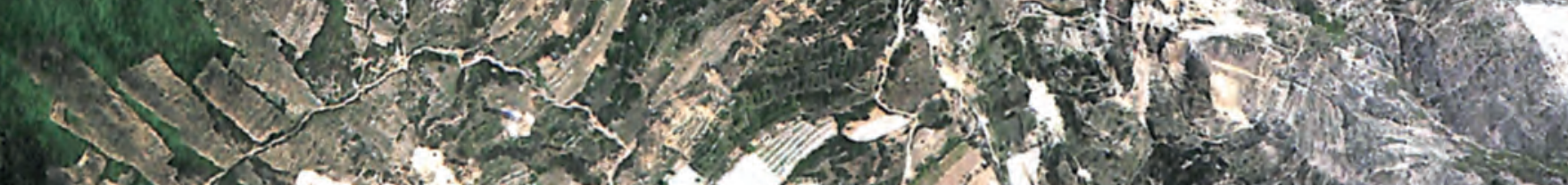




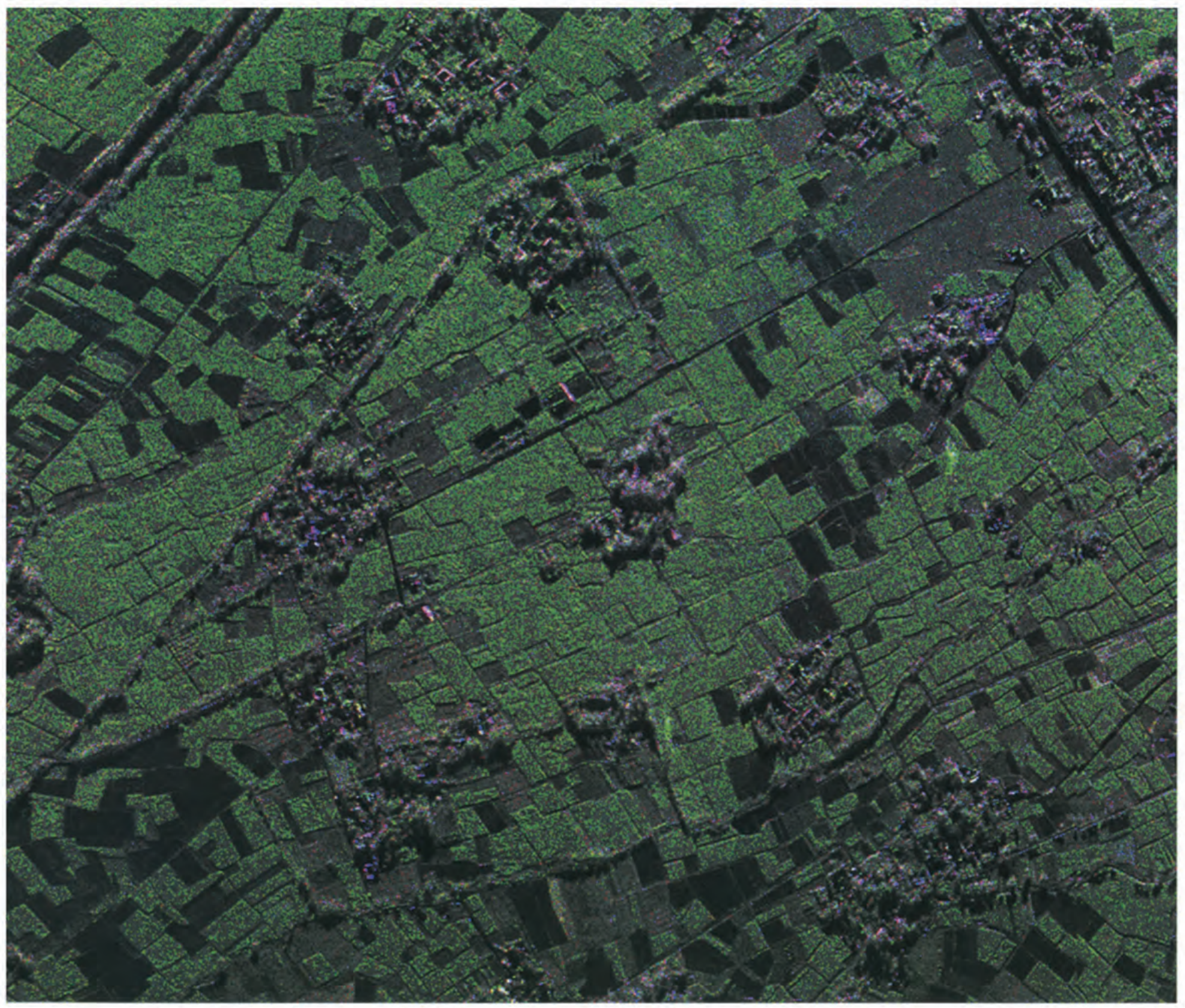

A Airborne X-band multi-polarization image in the suburban Dujiangyan, May 25, 2008

16 I Atlas of Remote Sensing of the Wenchuan Earthquake 
$\nabla$ CEODE has three ground stations locating in Miyun, Kashi, and Sanya, respectively. CEODE has the ability to receive and process remote sensing data in multi-station, multisatellite, multiresolution, all-weather, all time, and quasi-real time conditions.

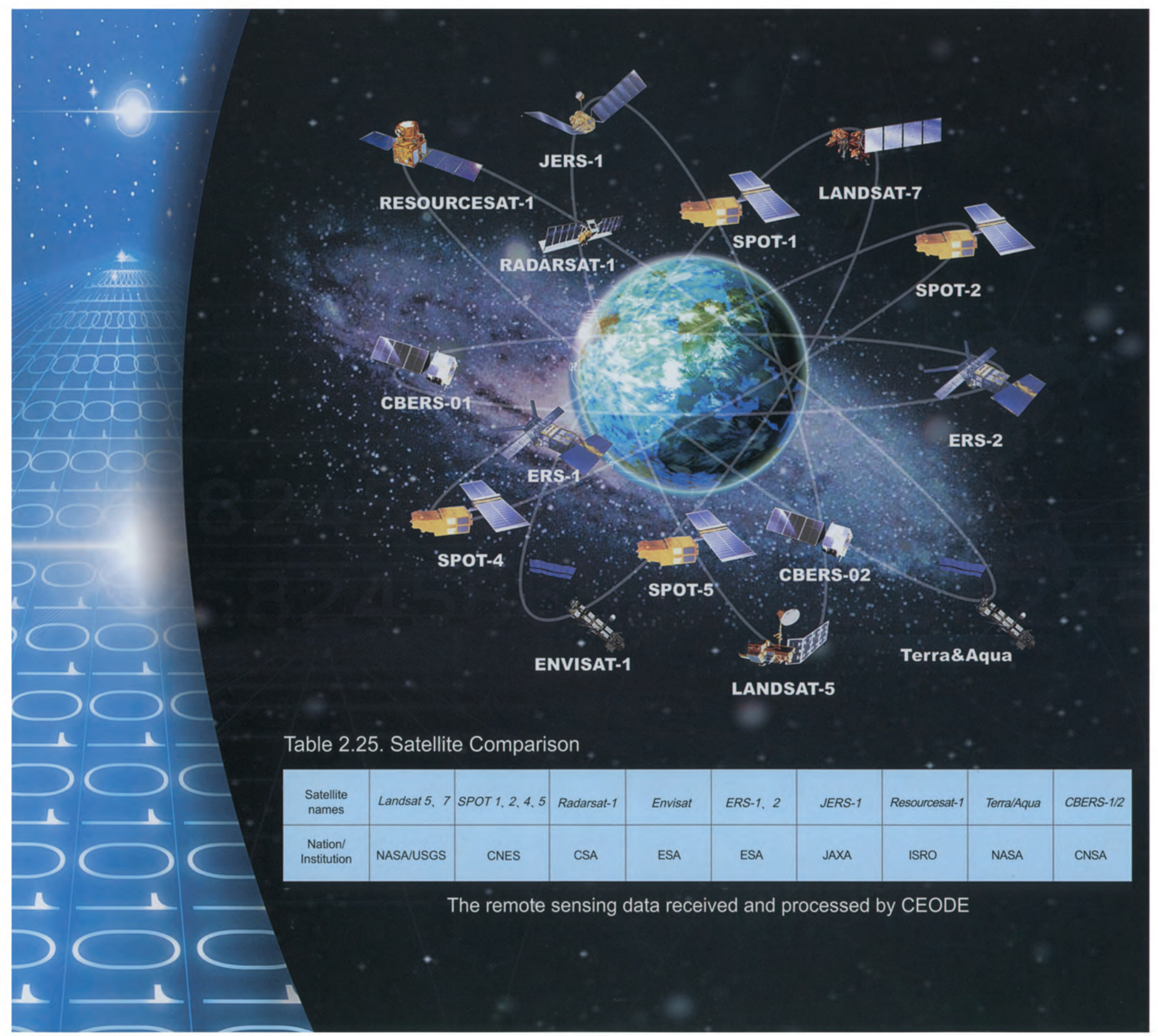




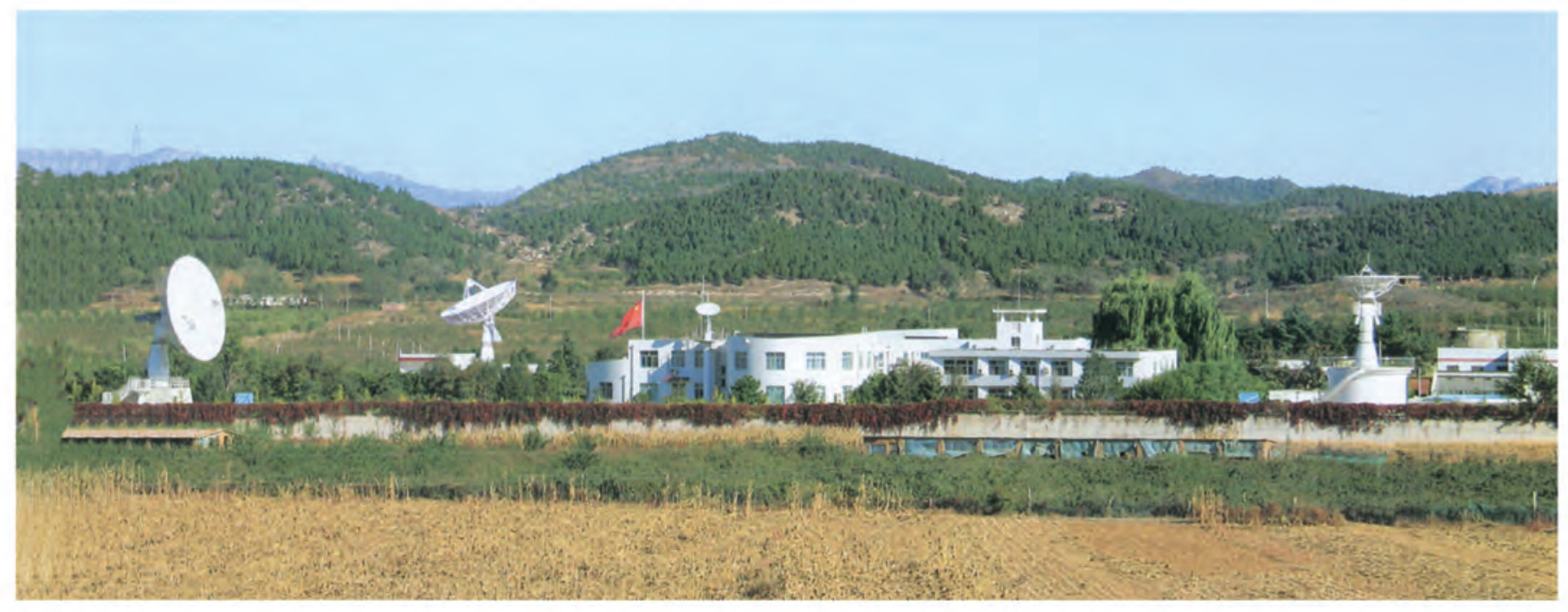

4 The Miyun satellite ground station in suburban of Beijing

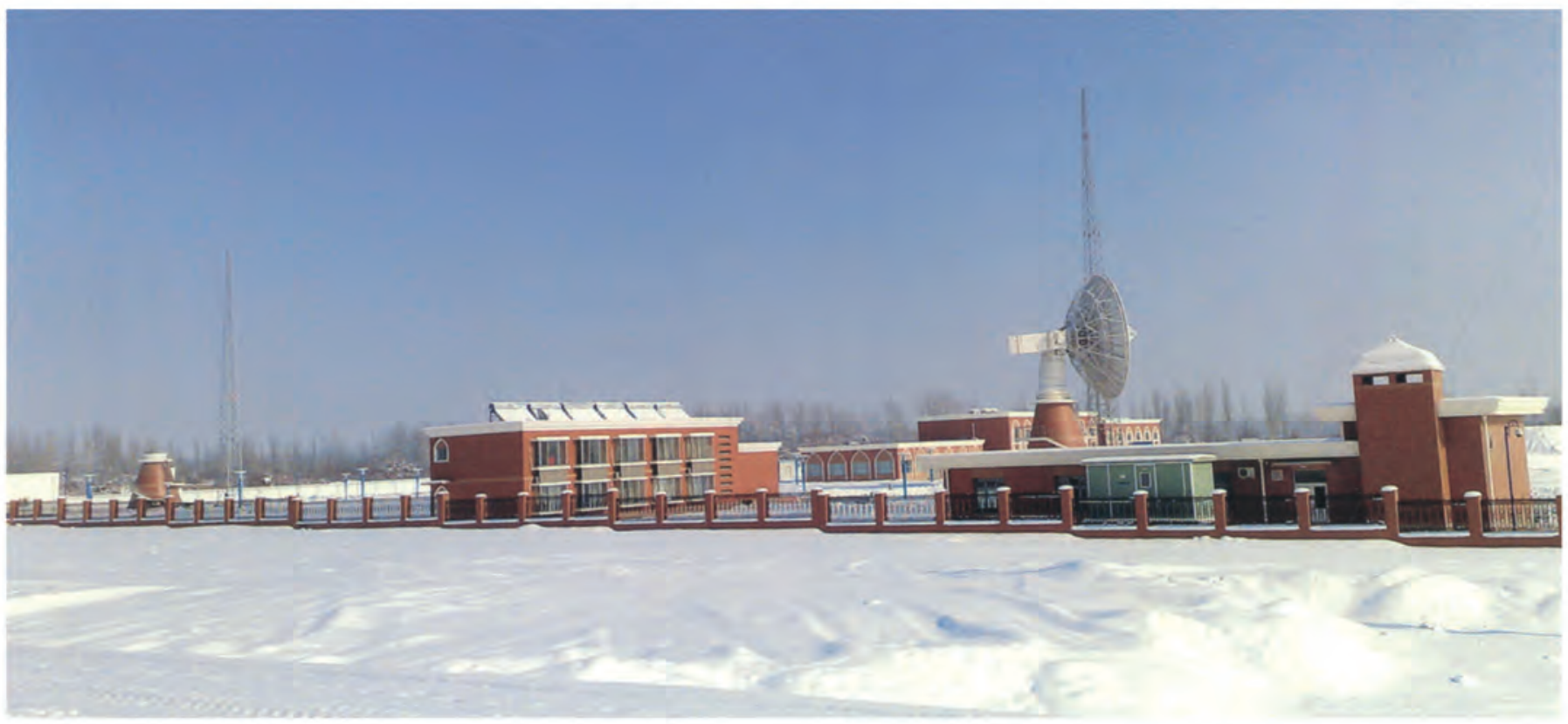

$\Delta$ The Kashi satellite ground station in Xinjiang Uygur Autonomous Region

- The design scheme for the Sanya satellite ground station in Hainan Province

18 I Atlas of Remote Sensing of the Wenchuan Earthquake

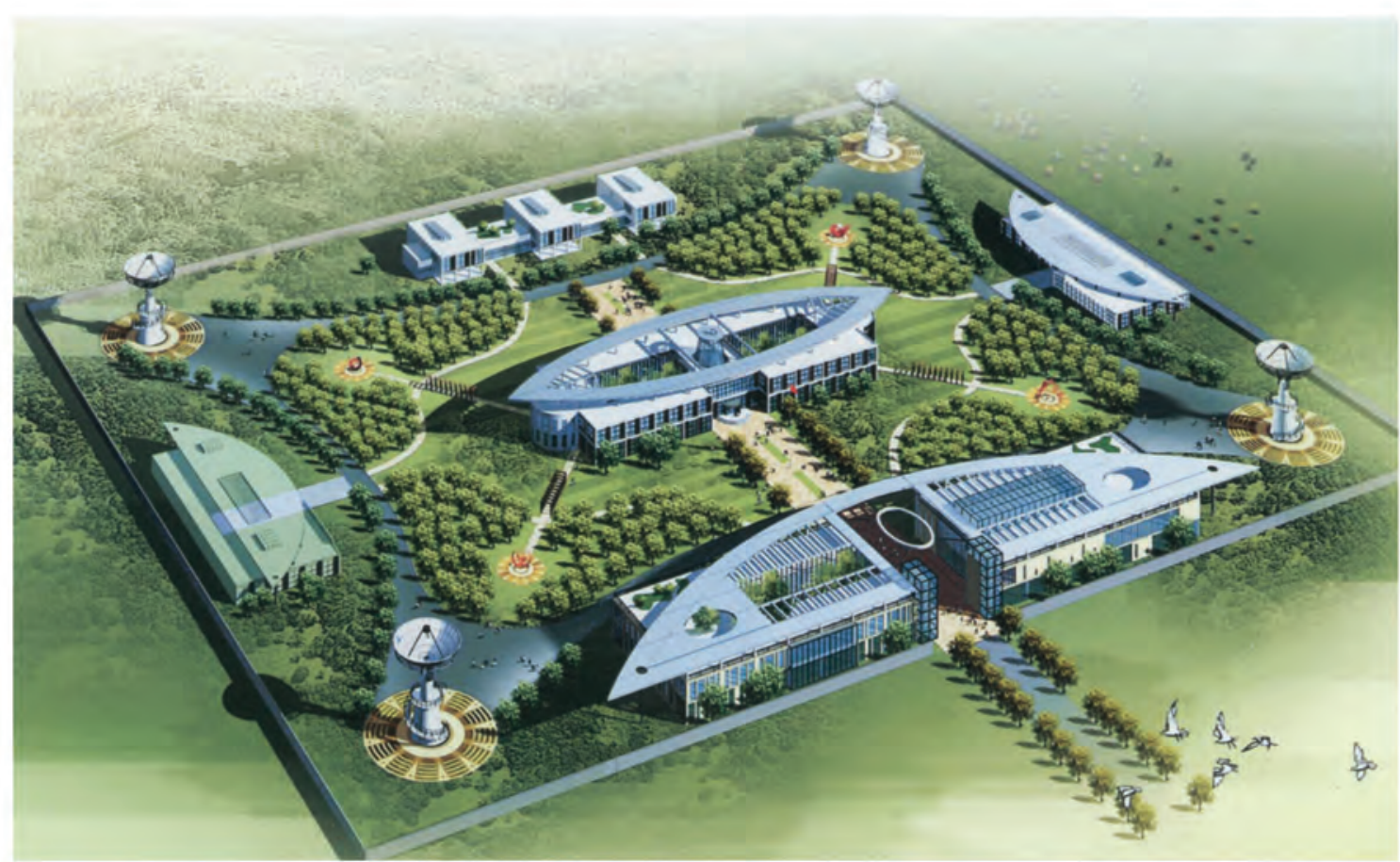




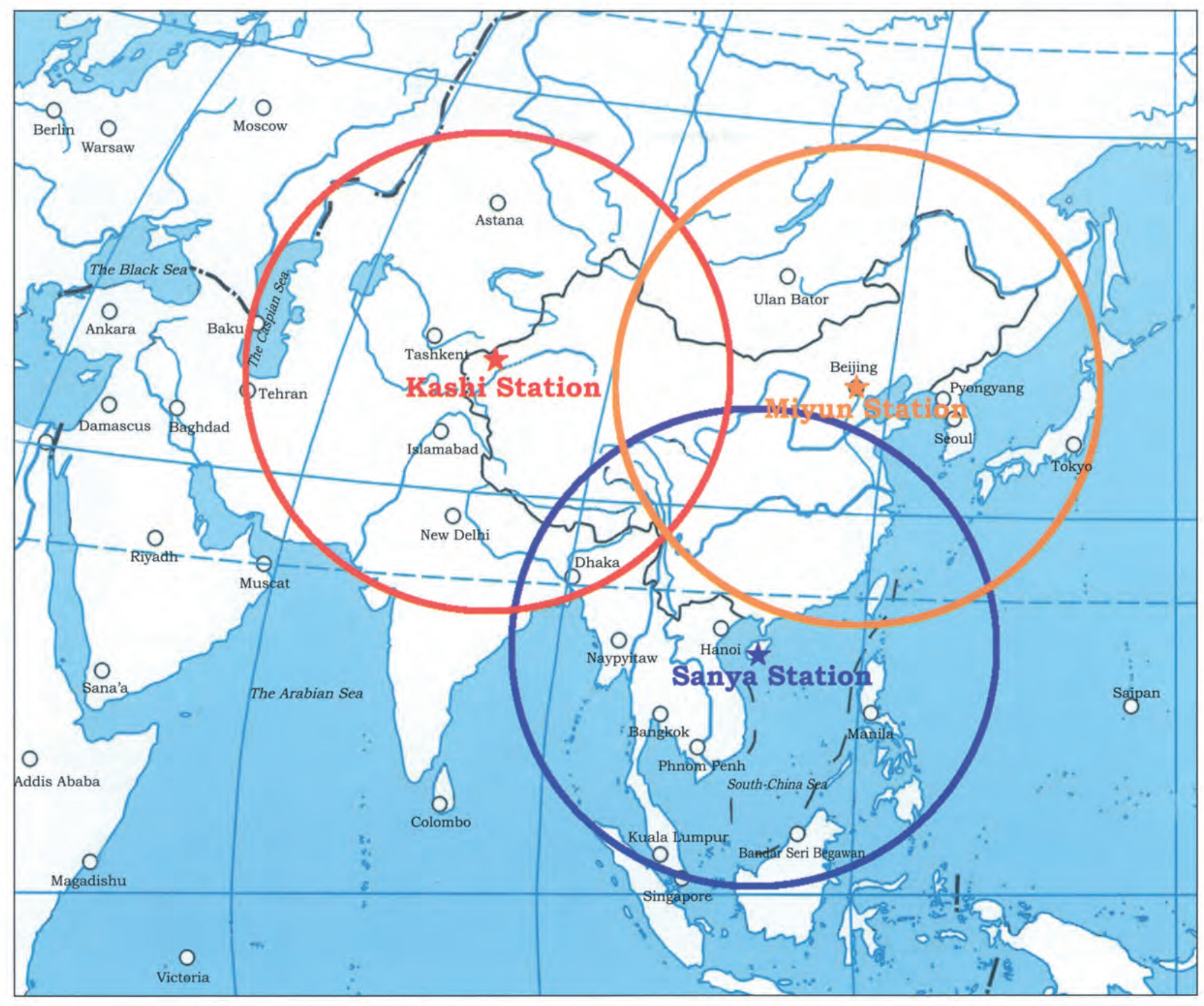

A The Miyun, Kashi, and Sanya ground stations can receive satellite remote sensing data covering $70 \%$ of Asian areas 


\section{Chapter}

\section{Geological Disaster}

Because of the geological and geographic conditions in Wenchuan, the Wenchuan earthquake triggered several secondary geological disasters, such as landslides, landslips, and debris flows, which not only led to heavy casualties and financial losses, but also severely damaged the roads, rivers, engineering projects. farmlands, and forests. The earthquake and the accompanying destruction of vegetation, landforms, rocks, soil, and other natural elements are the major causes of the change in the color and texture shown in the remote sensing images. The earthquake ruptured an approximately $29,000 \mathrm{~km}^{2}$ area. The geological disaster covers an area of $2250 \mathrm{~km}^{2}$, which is $7.8 \%$ of the total area.

The distribution of landslides, landslips, and debris flows can be described as strips along the river incision valleys and the areas with major engineering projects, which are mainly located in the valleys of the Minjiang River. the Jianjiang River. and their tributaries. The vertical elevation is from $800 \mathrm{~m}$ to $1500 \mathrm{~m}$.

The quake affected area has been severely uplifted by tectonic movements and deep incised valleys formed. which have the characteristics of deep slopes, large catchments areas of valley, and wide distribution of quaternary stratum. The bulk of the geologic disasters occurred on slopes (mainly convex slopes) greater than 20 degrees. especially on slopes that are flat in the upper part and steep in the lower part and are close to the river and road. The phyllite and slate are both easily air-slaked. The hard terrain that causes the growth of crannies forms big rocks. The hard layers alternate with soft ones. which are more easily destroyed, and form loose materials consisting of not only big rocks but also debris. Because of gravity, all of the materials of air-slaked base rock accumulate at the slope, forming the origin materials of landslide and debris flow. Hard or half-hard layers, such as quartz sandstone and limestone, which are well fissured, tend to form landslips in the steep valley as a result of unloading. Potential landslide bodies bordered both sides of the valley. When the landslip rocks covered these potential landslides during the earthquake, the landslides lost balance and formed large landslip bodies. Because of the severity of the earthquake, the unstable slopes and potential landslide bodies formed landslides. In the Wenchuan earthquake, there were few single landslides. Because the rainstorm did not occur during the earthquake, there was no large mudslide, but more debris flow. 

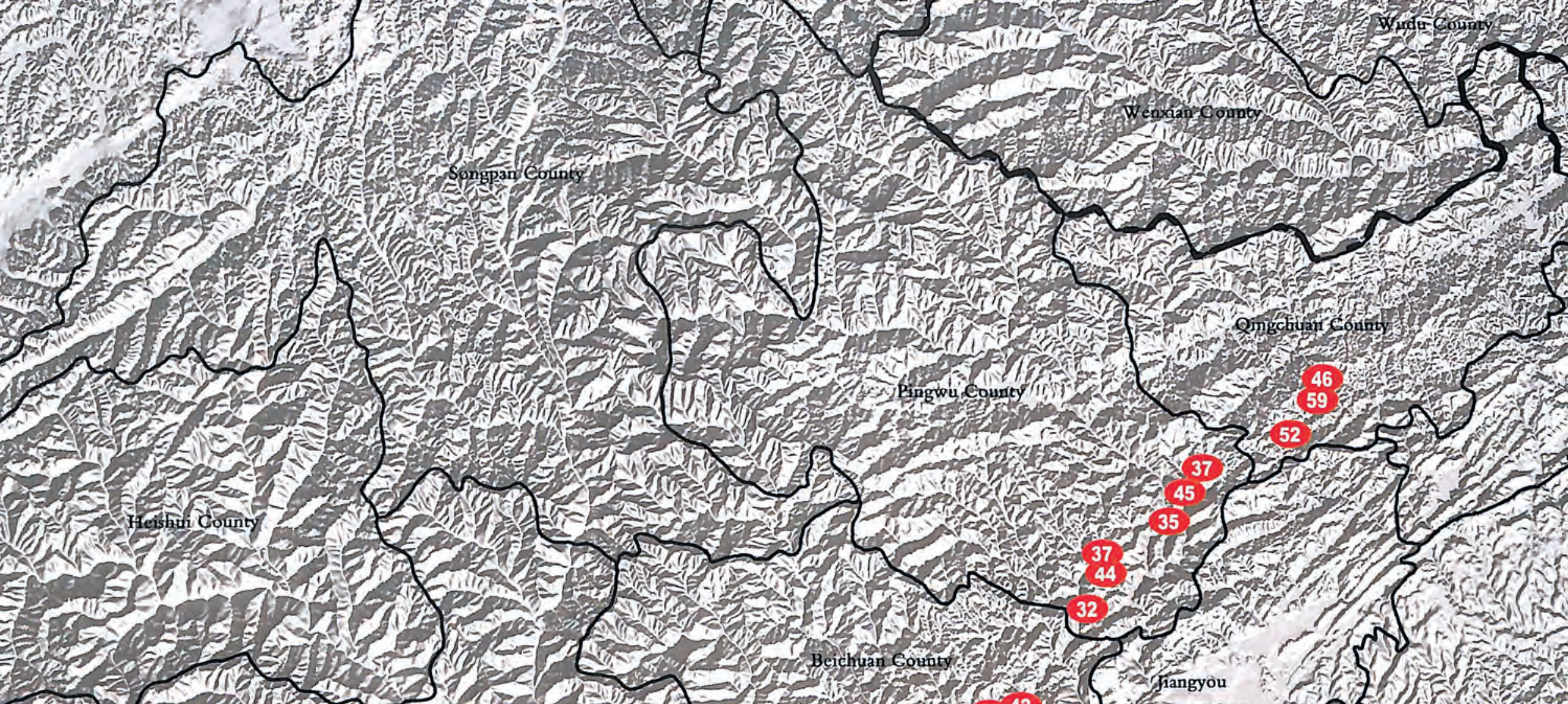

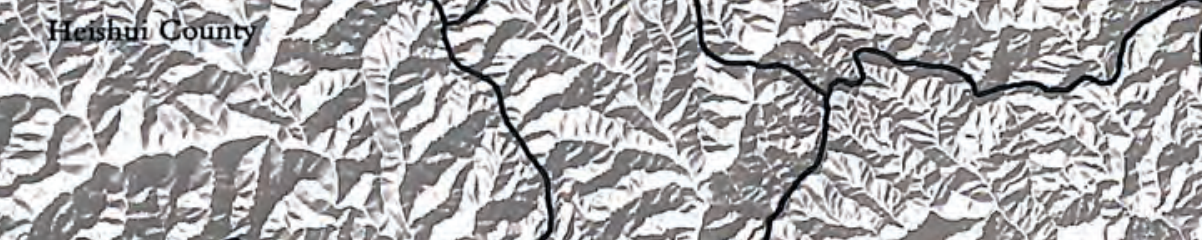

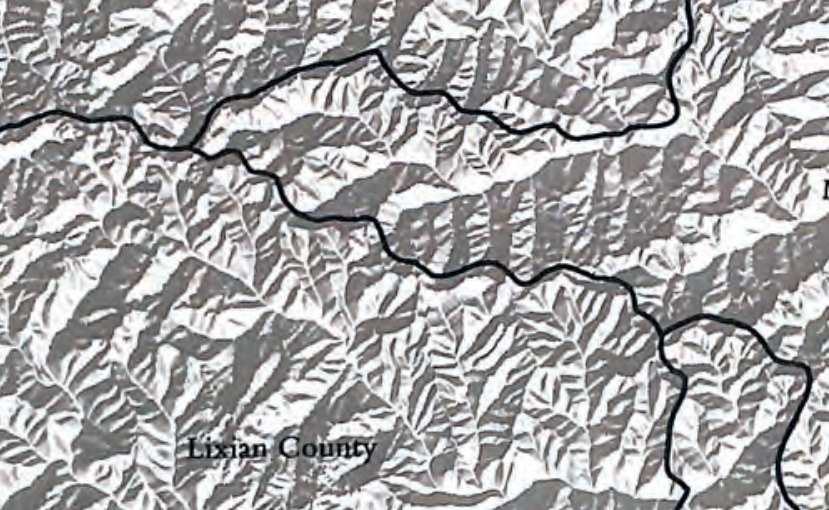

1.
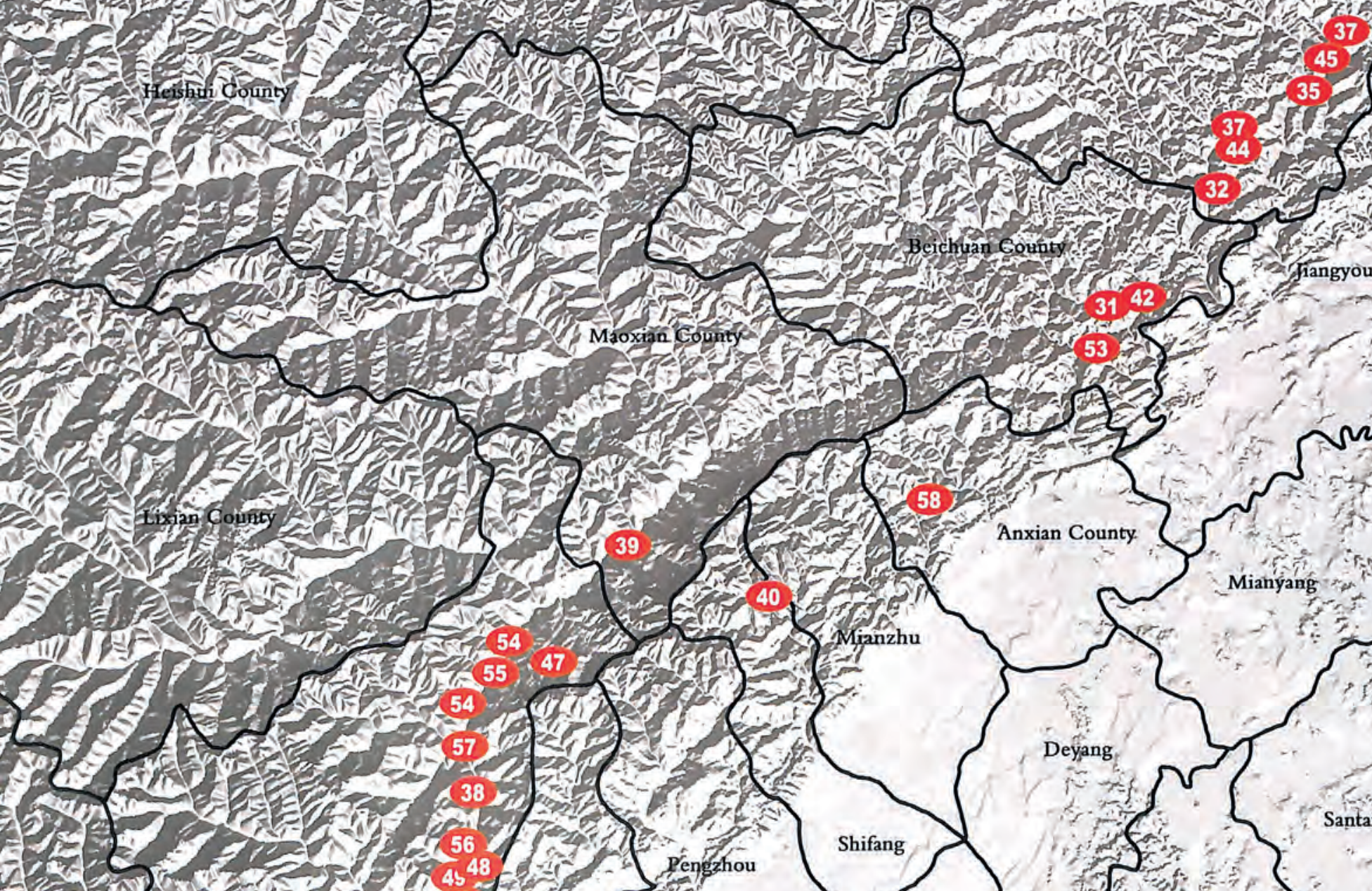

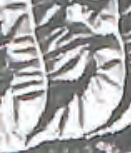

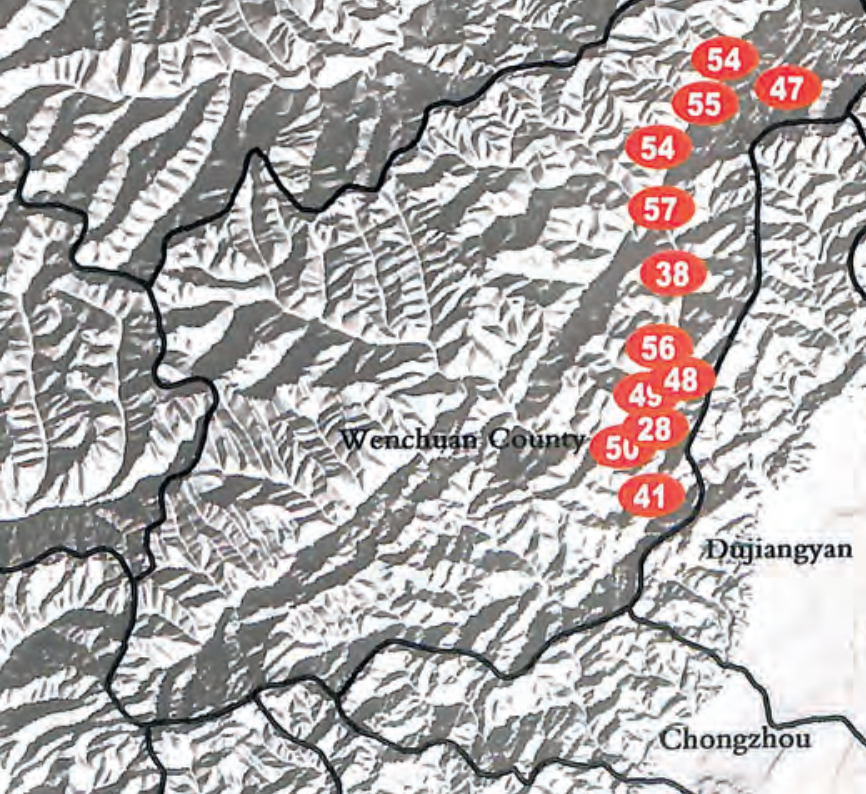

2)

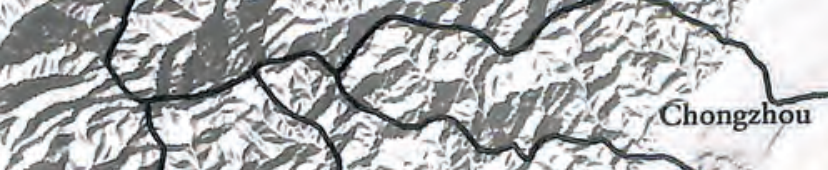

$\frac{5}{2}$

.

(x)

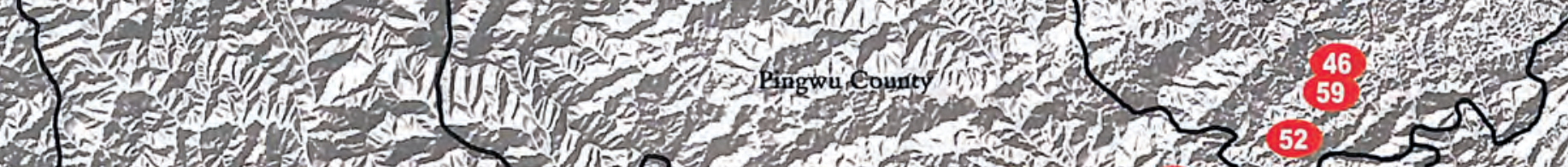

.

11.
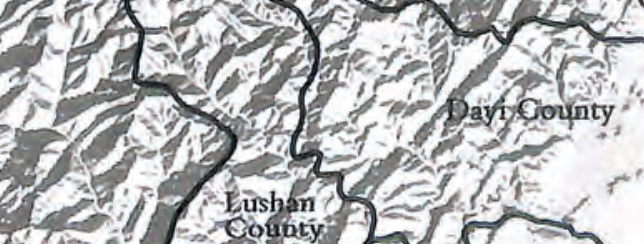

4
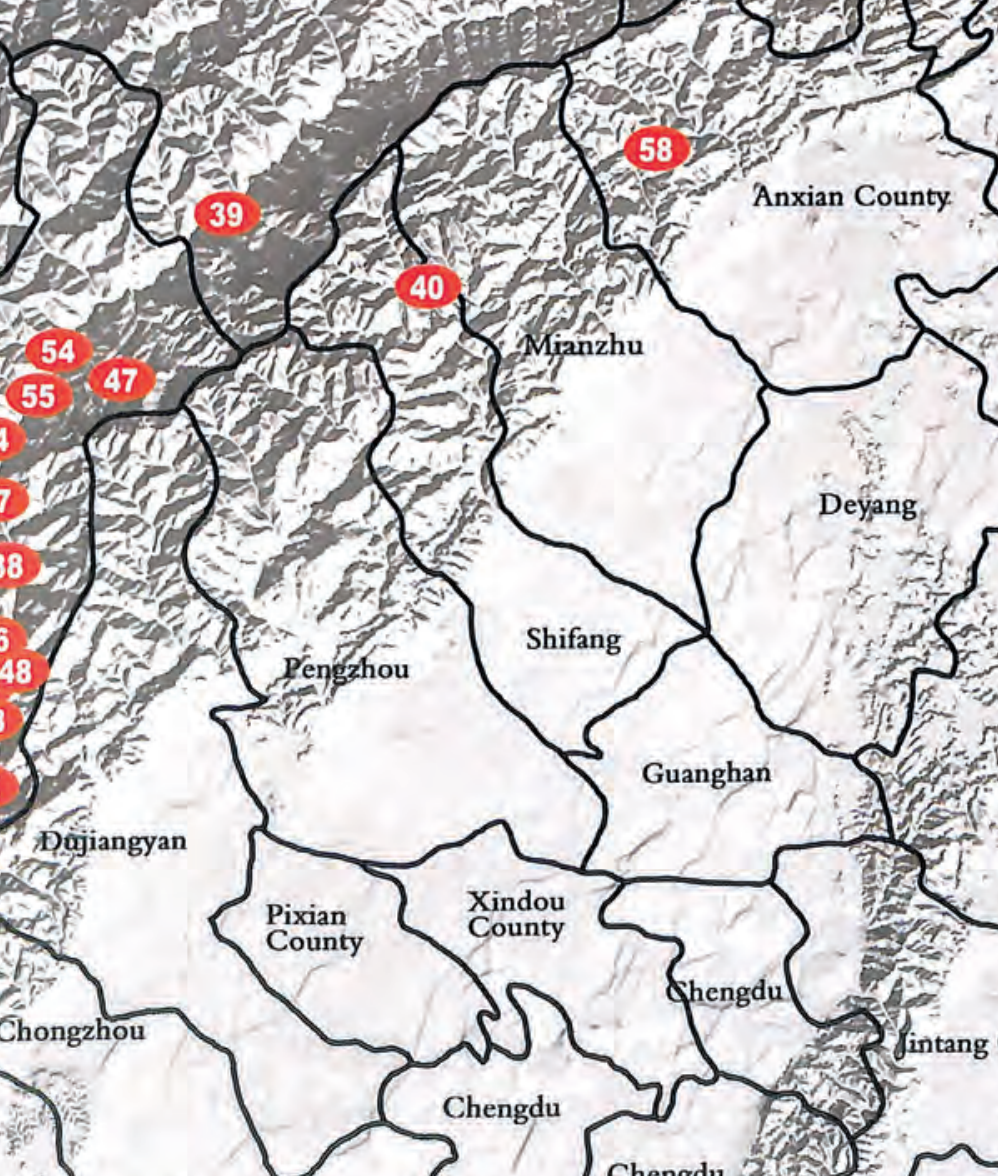


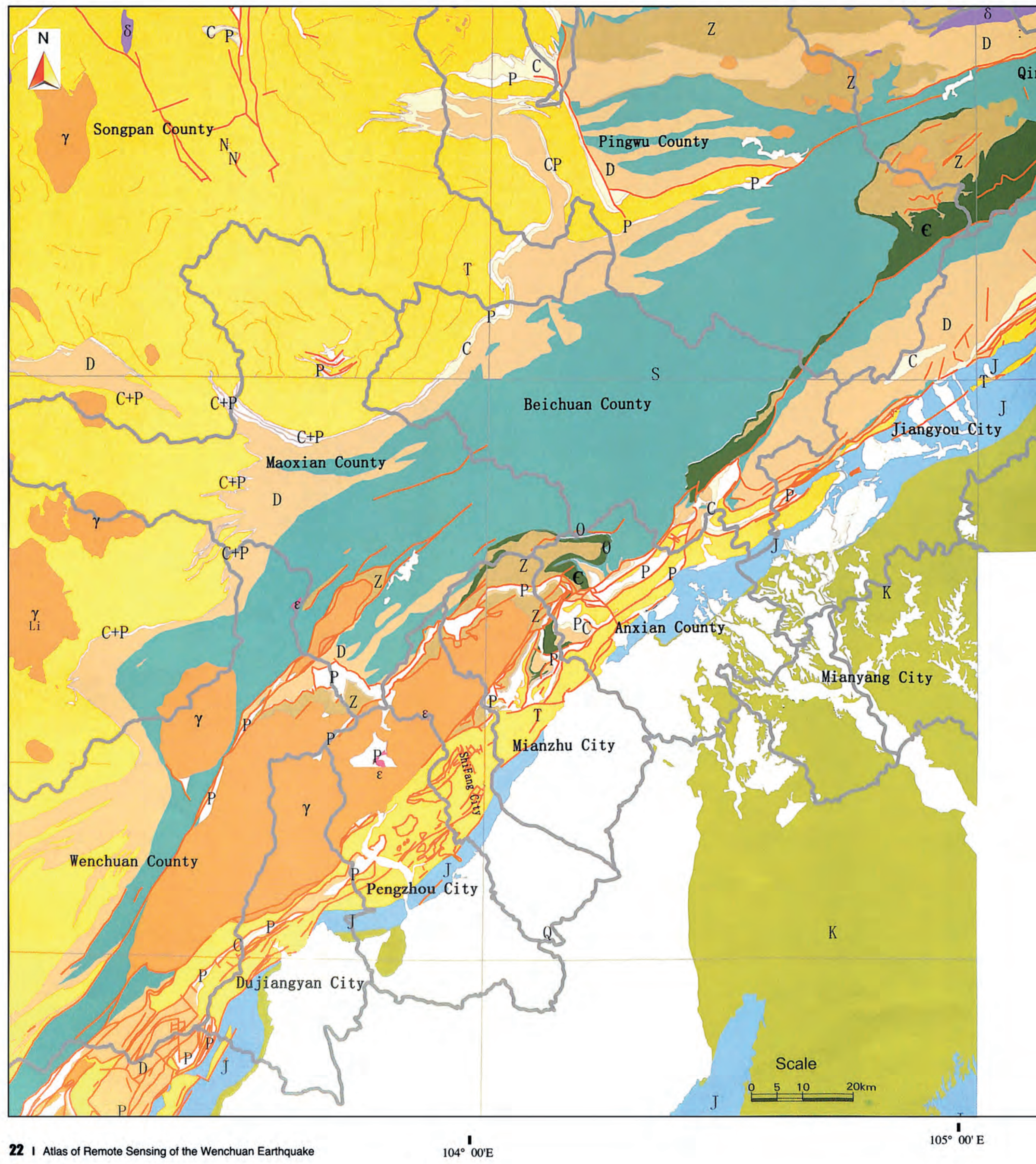




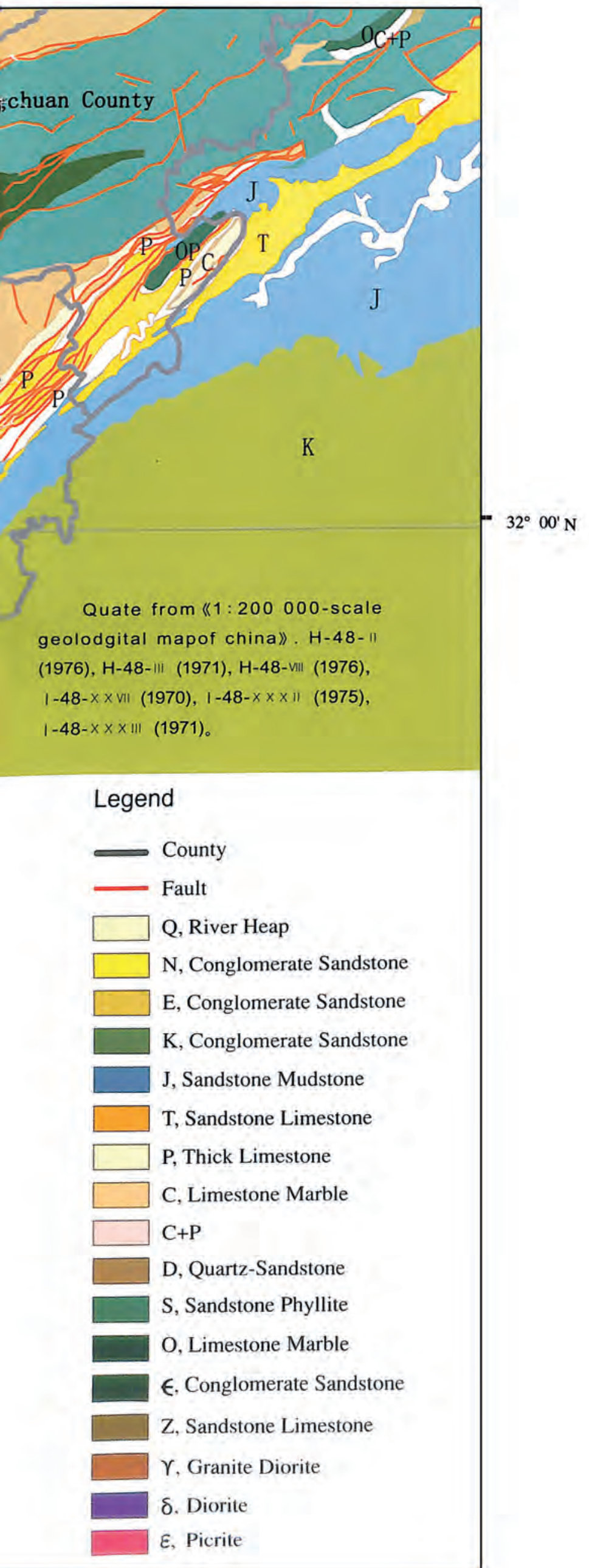

\section{Regional Geological Map of Wenchuan Earthquake Area}

The map shows structural limestone to the northeast. From southeast to northwest is the platform-edge sunken-break belt of Longmen Mountain, the Jia Lidong fold belt, and the Yansan fold belt. The folds are mainly closed line in shape and are often compound folds. The fault structures are often antifaults and anti-cover faults, which are always several kilometers to several hundred kilometers long. The Longmen Mountain break belt is mainly composed of the Guanxian-Jiangyou Fault (front range fault), the Yingxiu-Beichuan Fault (back range fault), the Wenchuan-Maoxian Fault (back range fault), and other relevant folds. The layers of fault zones are broken, and their occurrence is unpatterned; some are even backward. The break belt is accompanied by the base rock inversion. The break belts are several meters wide and have repetitious revival features. There are extrusion joints, mylonitize, and mylonite along the break belts. 


\section{Geology disaster distribution map of the Minjiang River}

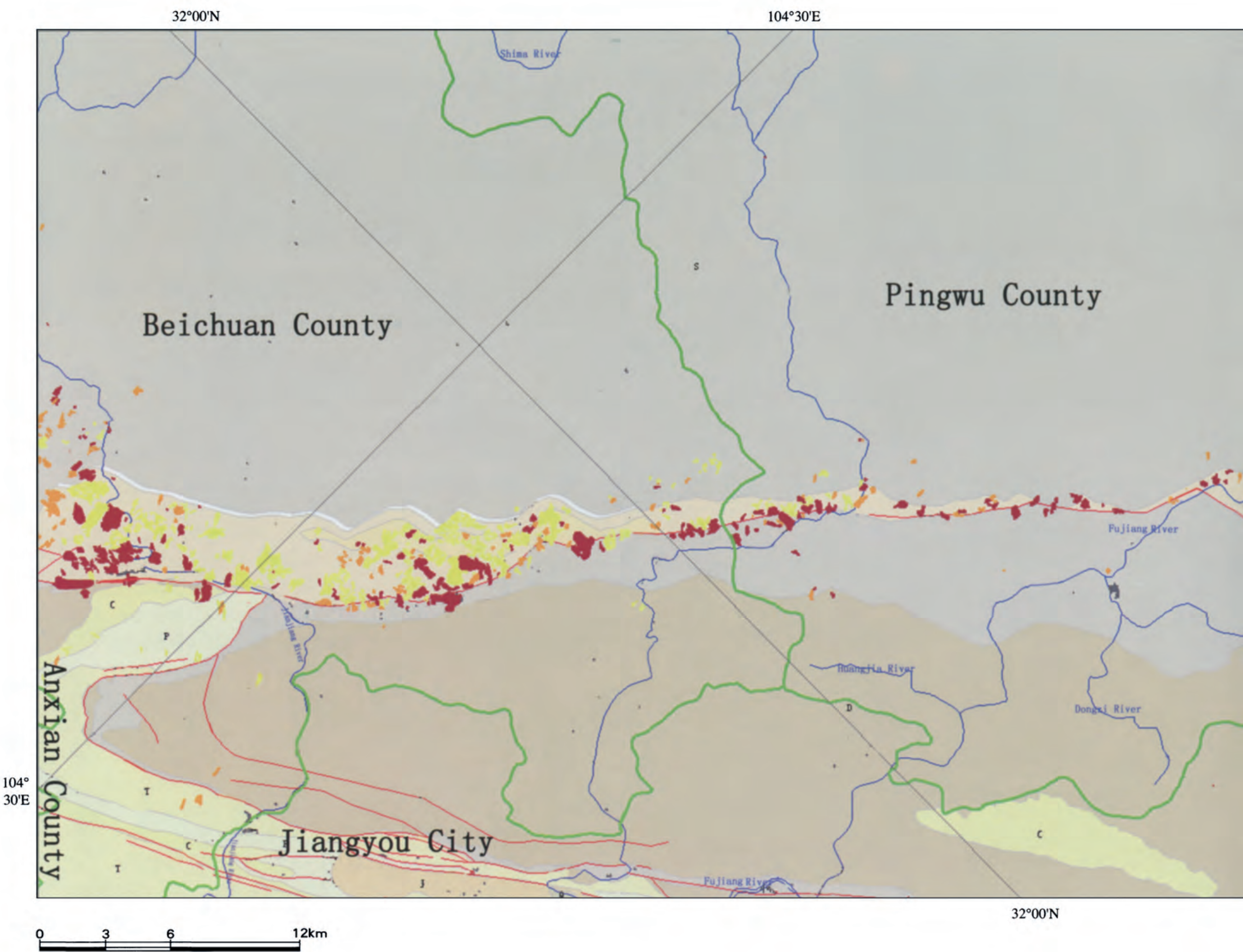




\section{Geology disaster distribution map of the Minjiang River}
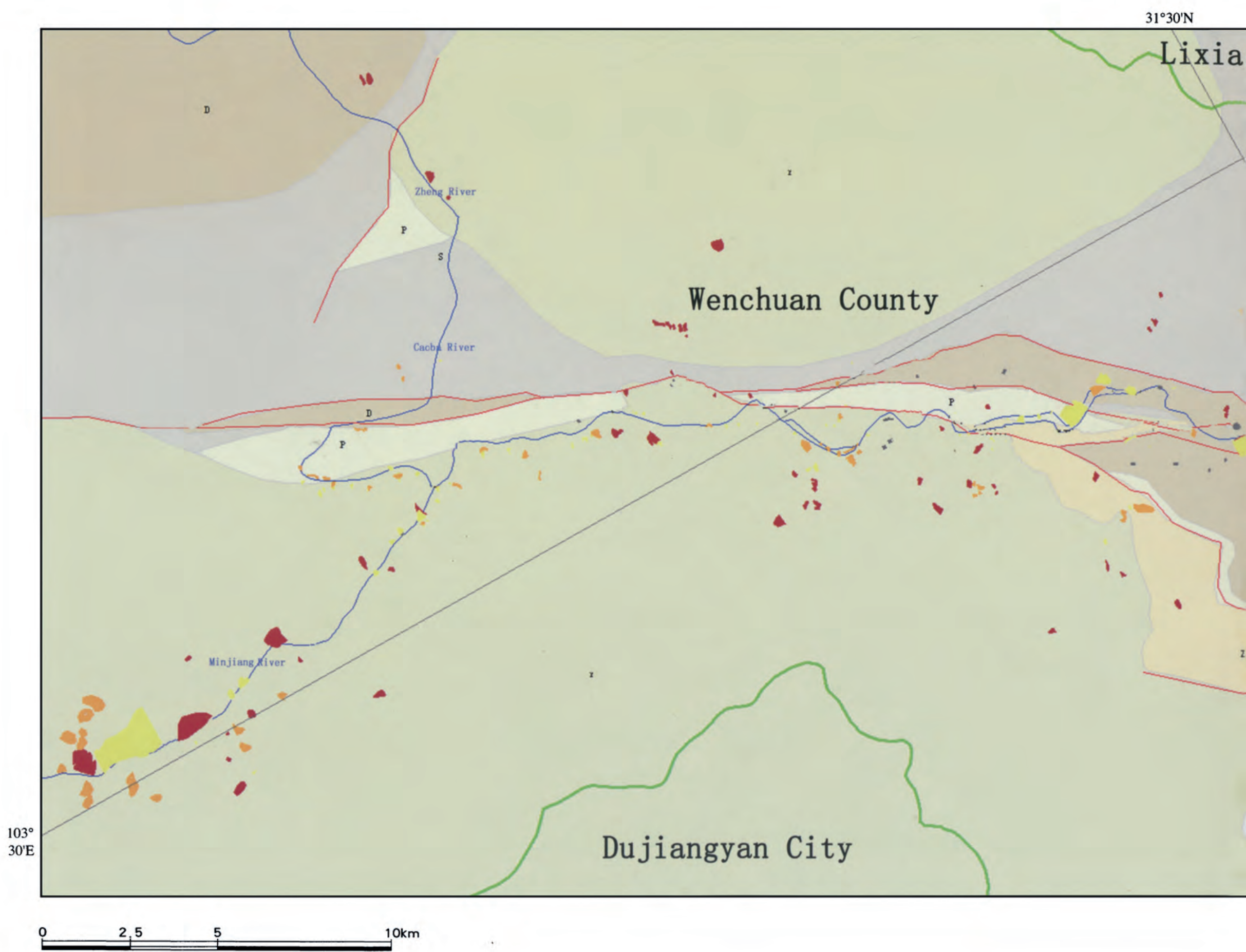


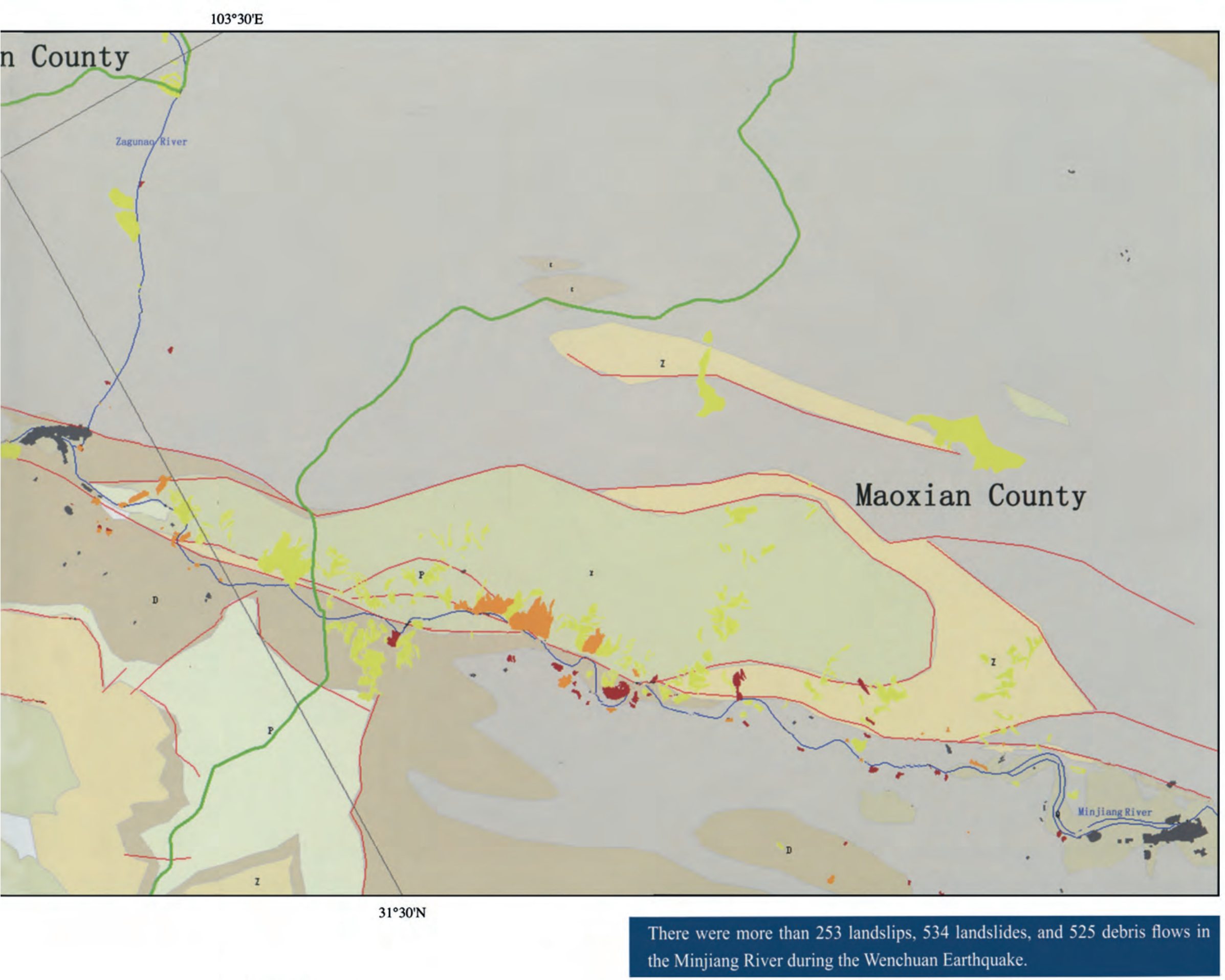

Legend

$\longrightarrow$ County line - River—— Fault $\square$ Residential area $\square$ Landslide $\square$ Landslip Debris flow 


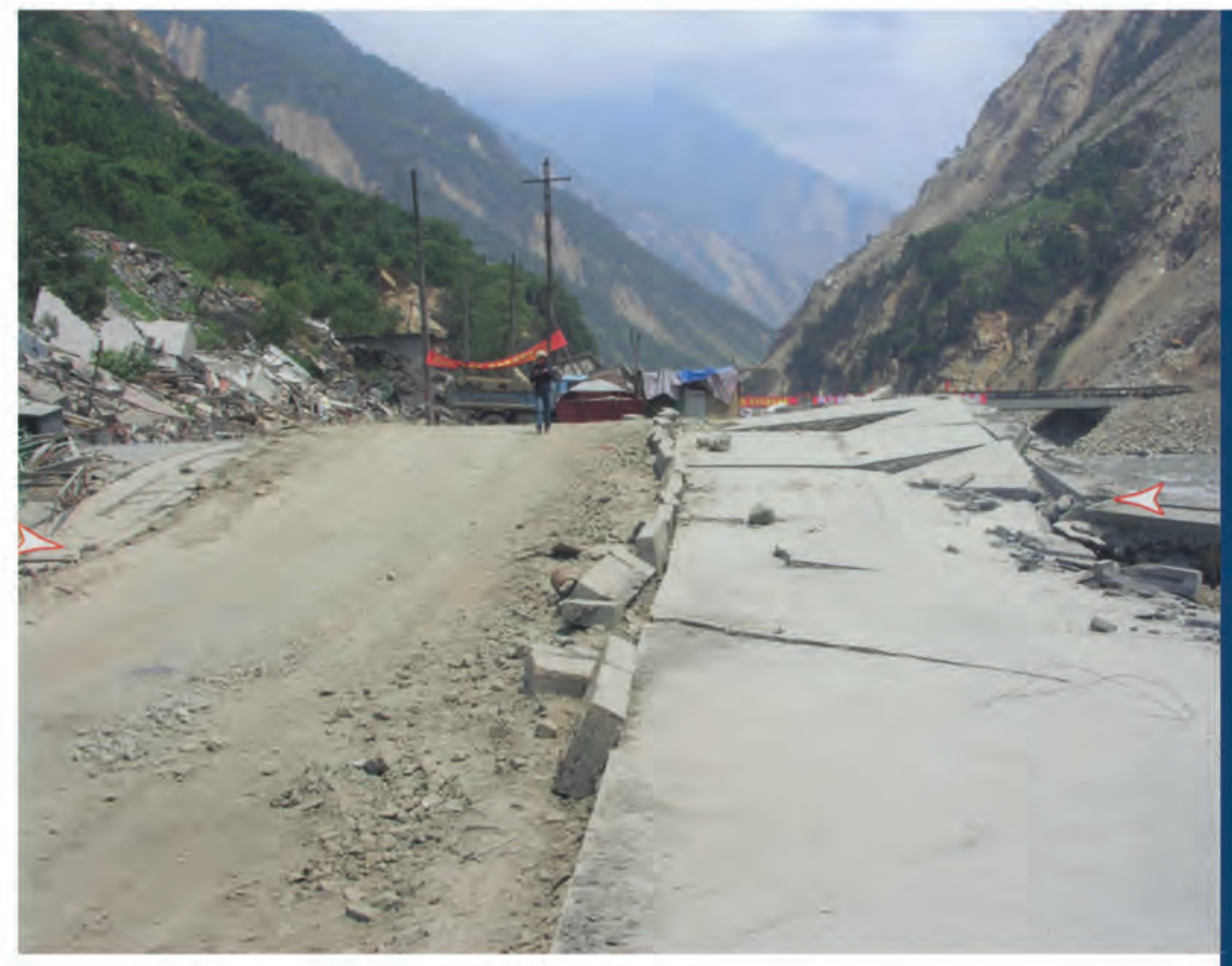

\section{Earthquake Fault}

The surface rupture zones with a certain size and spatially continuous distribution produced by a large earthquake (about magnitude 6.5 and greater) are called earthquake faults. The surface rupture can reach and displace the ground surface, forming a fault scarp (steep break in slope). The resulting fault scarp may be several centimeters to $10 \mathrm{~m}$ in height, and up to about $430 \mathrm{~km}$ in length, depending on the size of the earthquake. The earthquake faults occurred along pre-existing active faults. Its distribution, occurrence, and characteristics of displacement are consistent with the active faults, and therefore become the indication of the active faults. Usually earthquakes above Ms 6.8 are associated with significant earthquake faults in China. Besides magnitude, the length and displacement (horizontal and vertical offset) of the earthquake faults are also closely related to the focal depth, the scale of the active faults, and the regional tectonic setting. The earthquake faults are characterized by the linear features displacing the hill ridge, streams, gullies, terraces, flood plains, and other landscape units on the ground surface in remote sensing imagery.

The image shows irregular linear features of the earthquake faults that occurred on the second and the third terrace on the northwest bank of Minjiang River. Northwest of the town of Yingxiu, the earthquake faults appear as linear shallow tones (marked by arrows in the image) because of collapsed buildings along the fault zone. The earthquake fault traveled along National Highway 213 and the Minjiang River northeast of the town of Yingxiu. During uplift along the northwest wall of the fault (hanging wall), a swift current developed $200 \mathrm{~m}$ southeast of the Minjiang Bridge. On the northeast bank of the Minjiang River, the earthquake faults distributed along the east-northeast striking narrow valley. 


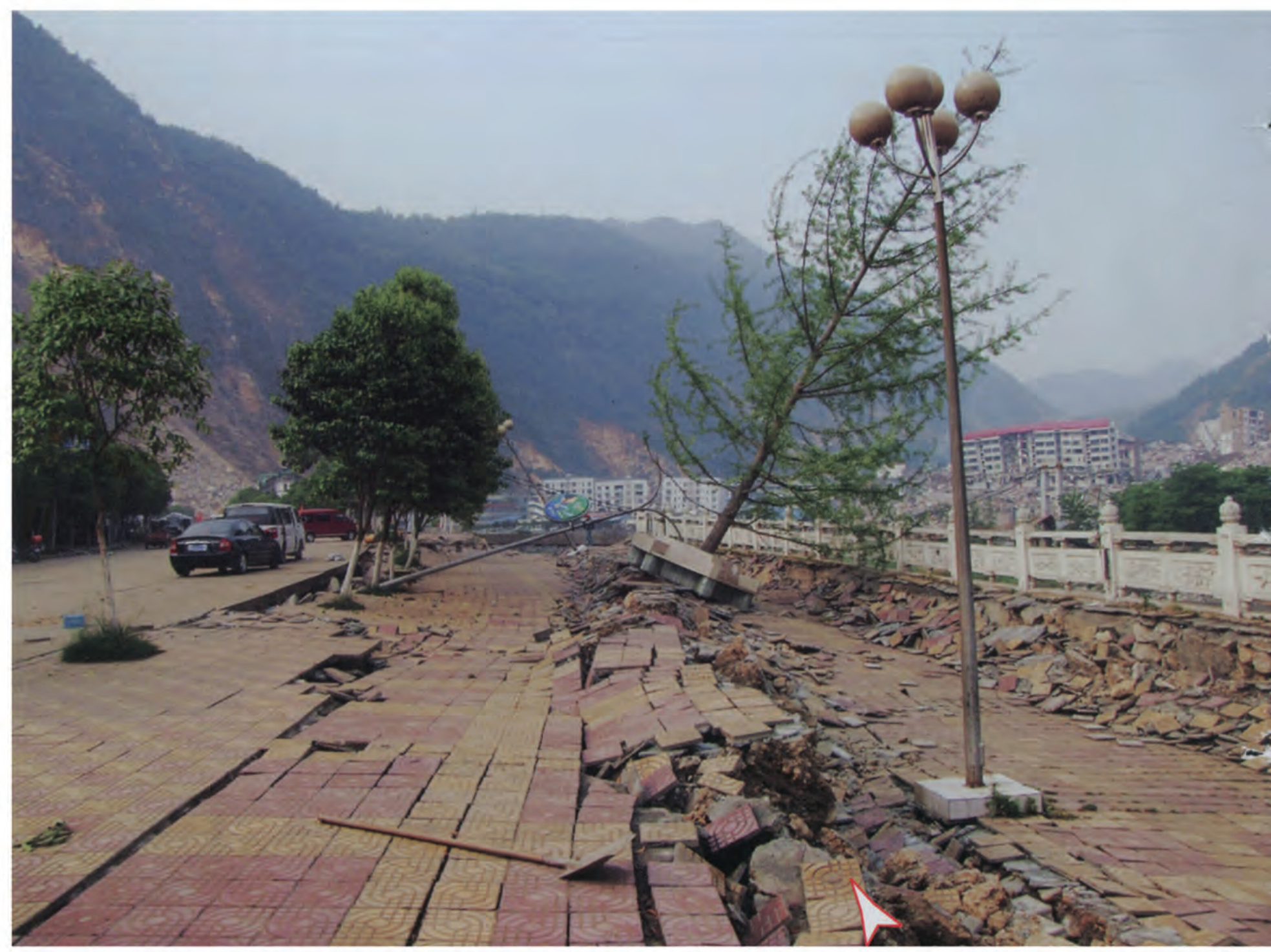

$\Delta$ The photo shows an earthquake fault along the new dike of the Jianjiang River around the town of Qushan, in Beichuan County, and a surface-rupture zone with a width of $15 \mathrm{~m}$ formed along the surface-rupture zone (south-facing view)

\section{- Aerial remote sensing image showing the earthquake fault around Qushan Town of Beichuan County}

The northeast-striking earthquake fault passed through the town of Qushan, in Beichuan County, from the lower right side of the image. The fault's southwest section shows a light-yellow linear feature (indicated by the arrows in image) because of collapsed buildings along the earthquake fault. In addition, owing to the long-term effect of active faults, a landscape typical of meandering river features formed around the town of Qushan. 


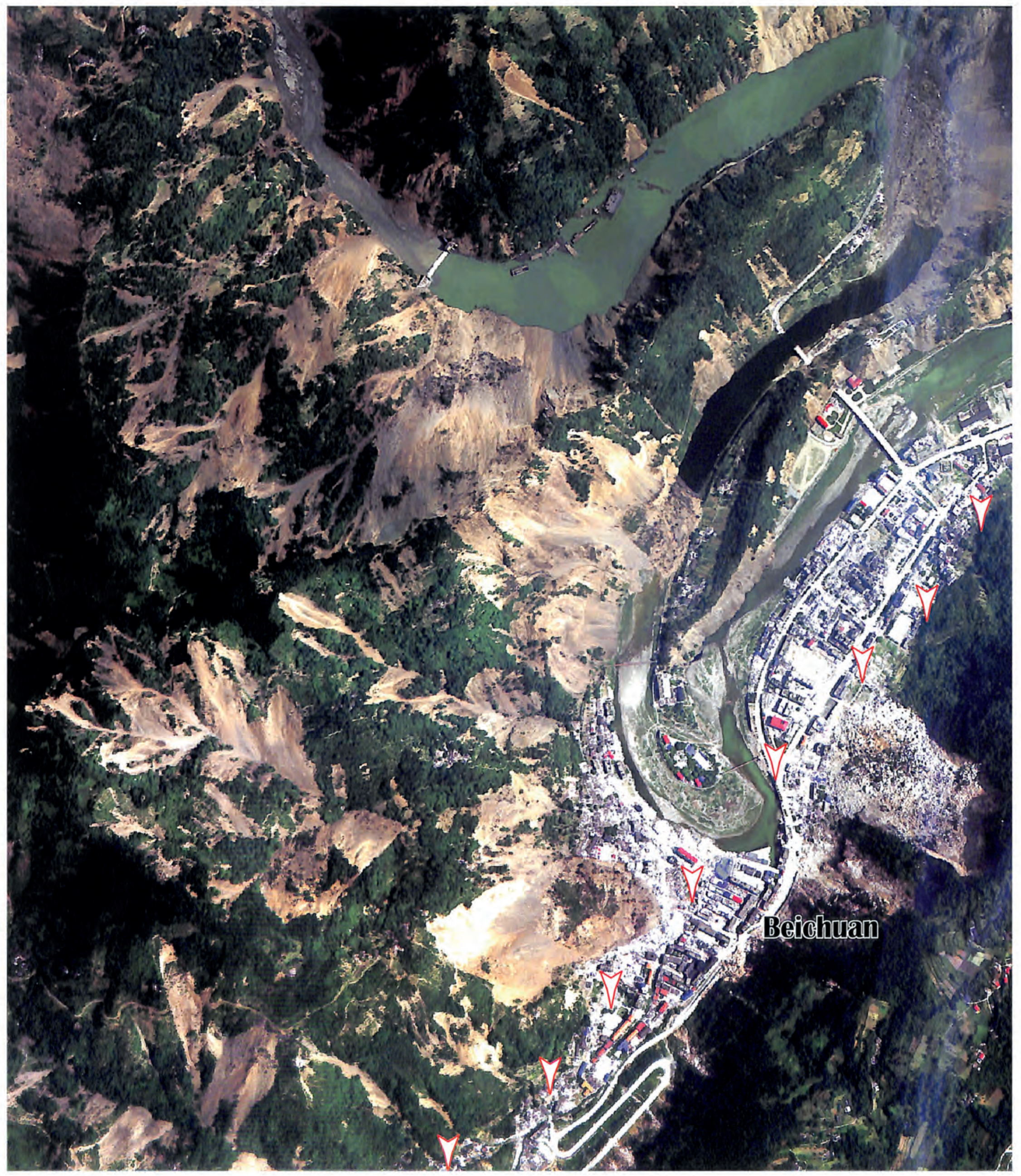




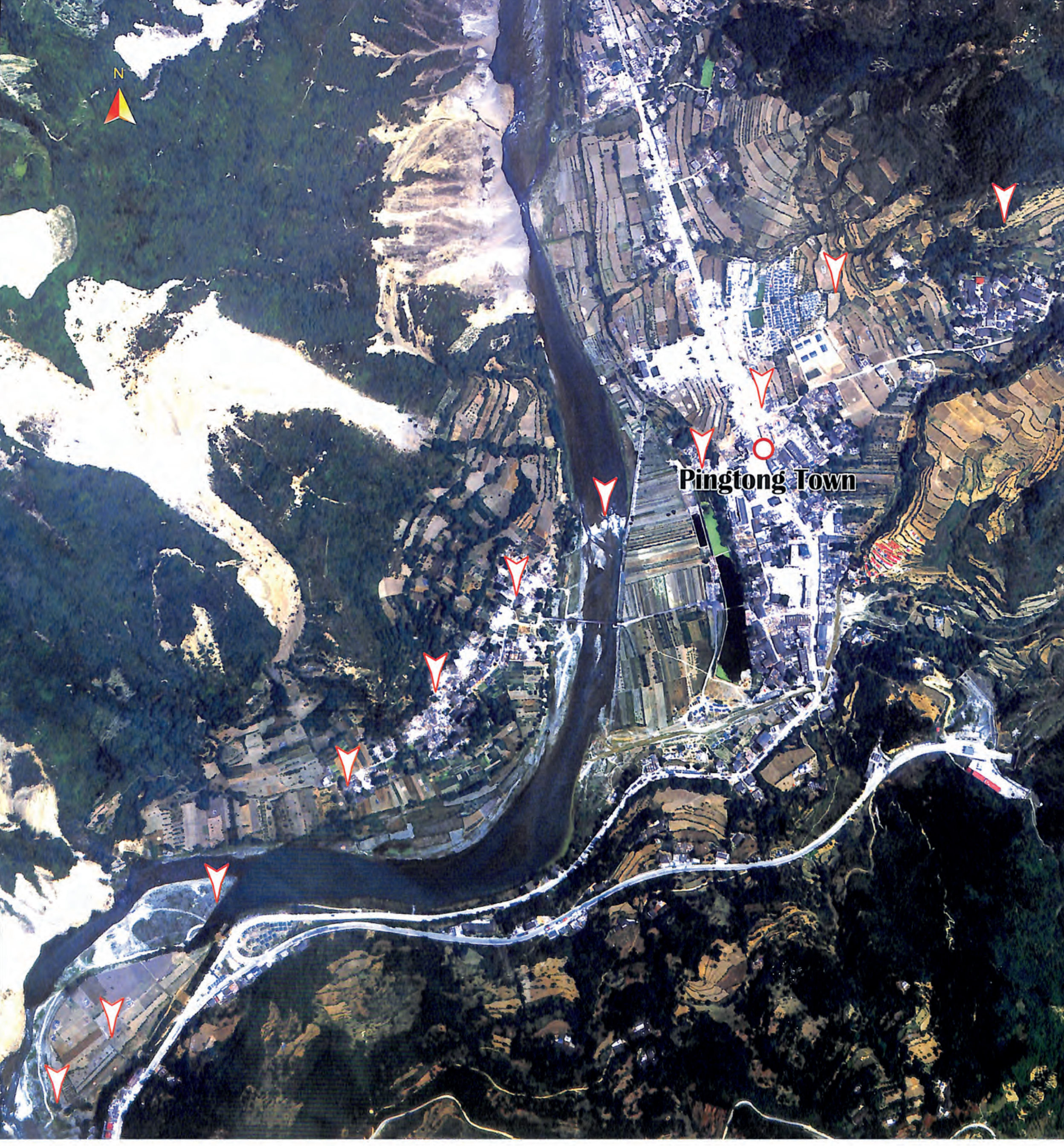

32 I Atlas of Remote Sensing of the Wenchuan Earthquake 


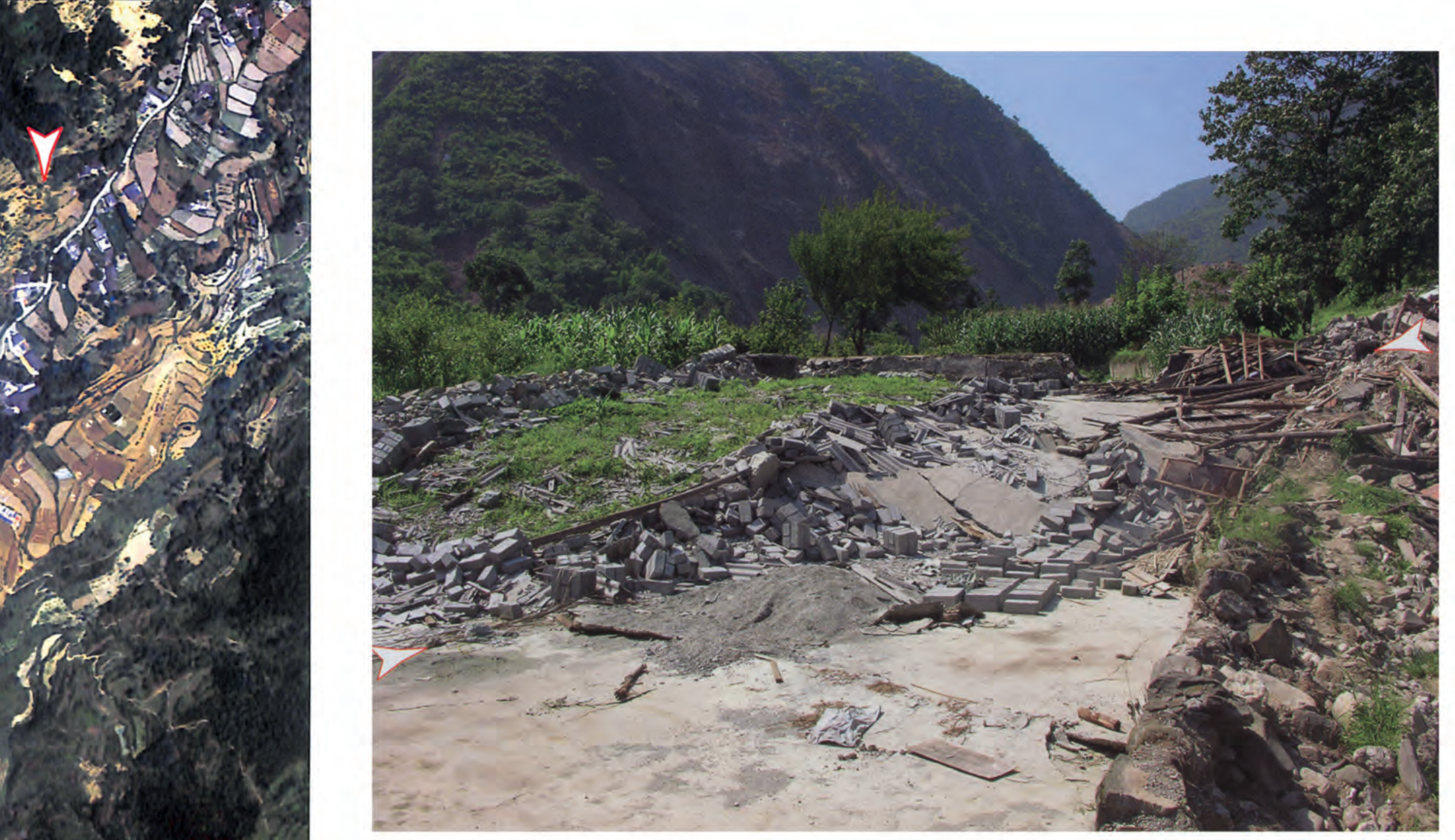

$\Delta$ The earthquake fault deformed a water pool and formed a coseismic fault scarp with a height of ca. $2.5 \mathrm{~m}$, and the surface rupture zone is $15 \mathrm{~m}$ wide, observed from the river terrace west of the town of Pingtong (north-facing view)

\section{Airborne remote sensing images showing the earthquake fault around the town of Pingtong, in Pingwu County}

In the lower left part of the image, the earthquake fault cut the river terrace and flood plain and created a fault scarp. Northeastward to the village of Lijiayuan, the earthquake fault destroyed most of the buildings, and it exhibited light-white linear features in the image. A waterfall formed along the southward flowing river (indicated by an arrow in the image) because of the uplift of the northwest wall of the earthquake fault. The surface-rupture zone appears as a linear image feature in the farmland on the east bank of the river. The earthquake fault passed through the streets of the town and extended toward the northeast. 


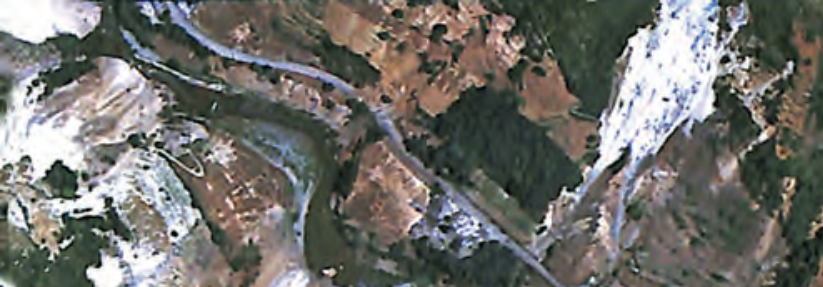

\section{)

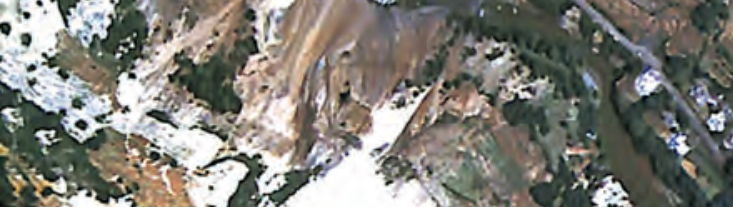

$32-2$ a 10 -

(1)

a

$7 \mathrm{e}$

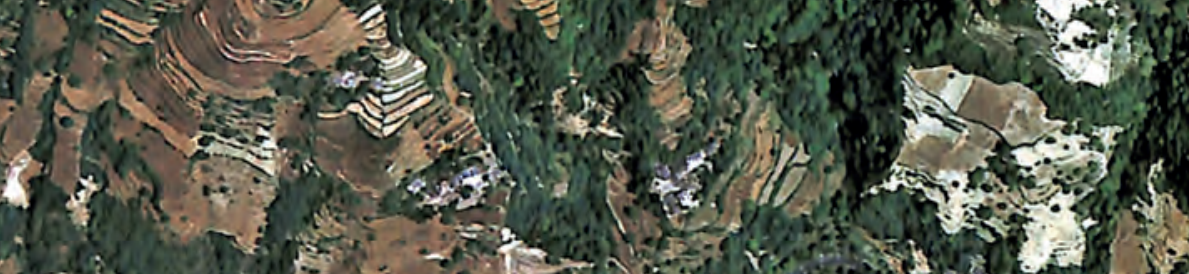

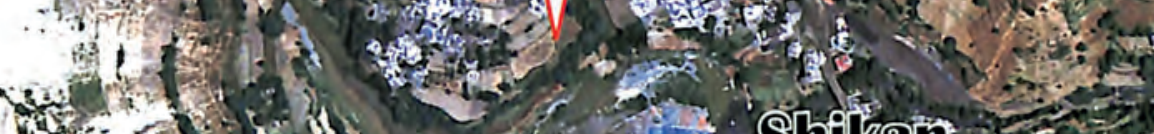

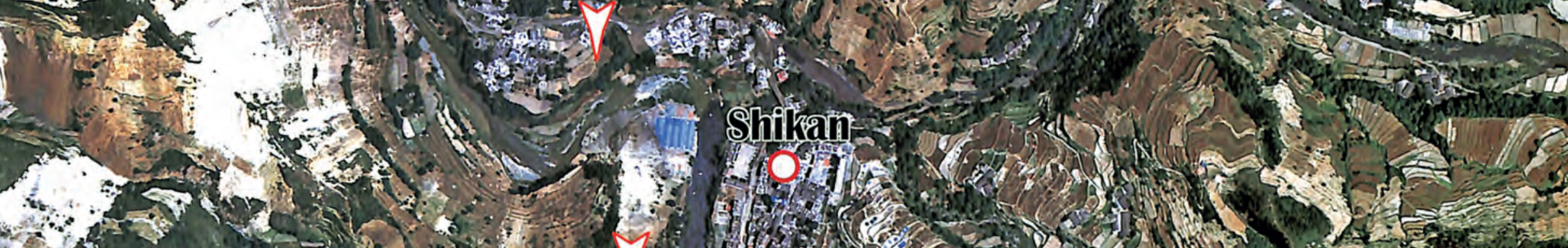

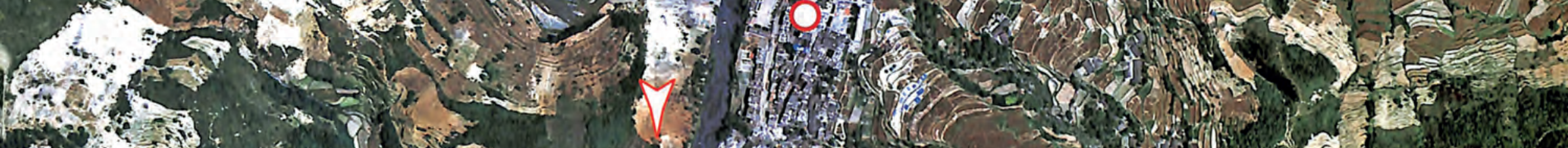
15.

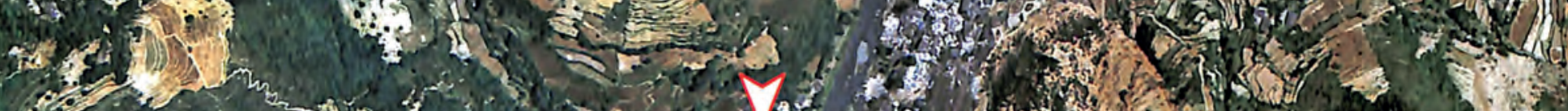

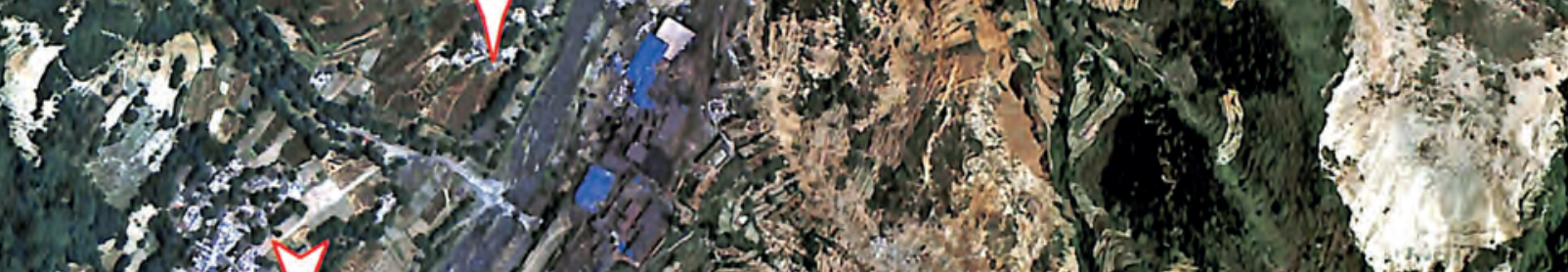

x) 3 and

A

(5)

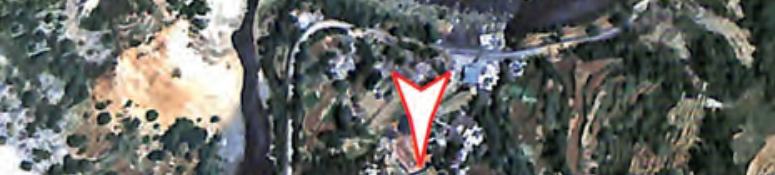

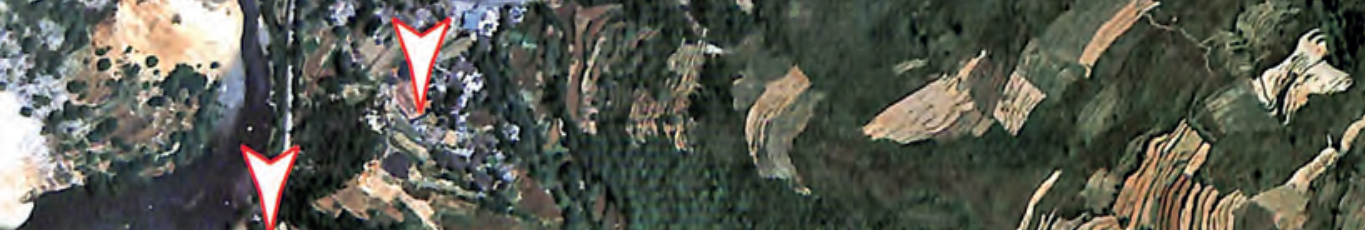

$(3)-1)=$

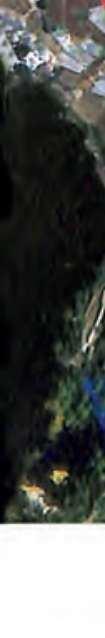

ix.

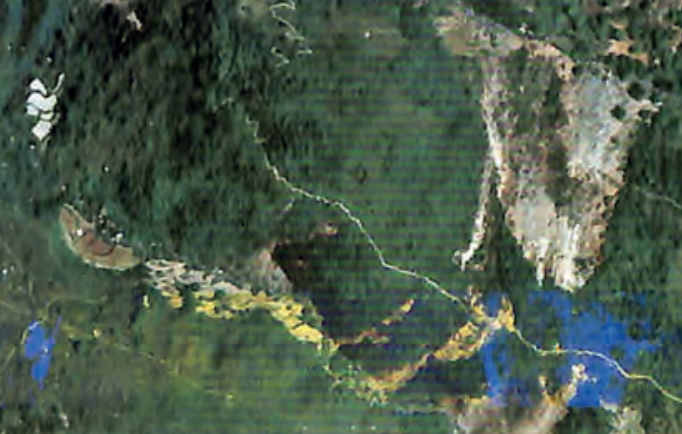

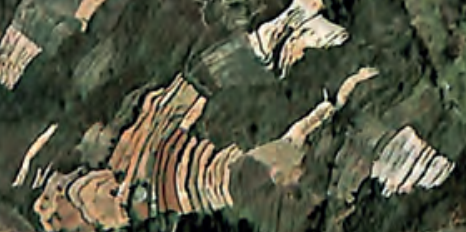

t. 


\section{- Interferogram of PALSAR}

Interferogram of SAR images obtained on February 17, 2008 and May 19, 2008. A large deformation along the center of the Longmen Mountain Fault (Yingxiu-Beichuan Fault) caused decorrelation of the interferogram. This deformation, together with the information of fault distribution from the ground survey, showed that most of the area had subsidence. The scale was approximately centimeters to meters, and there were two deformation centers within Beichuan County and the city of Mianzhu, the LOS deformation beyond $1 \mathrm{~m}$. Since the rock area was stable with respect to the south plain area, the edges were relatively continuous, but the mountain area was located to the north of the fault. The edges were fractal because of the extrusion of the Tibetan Plateau.

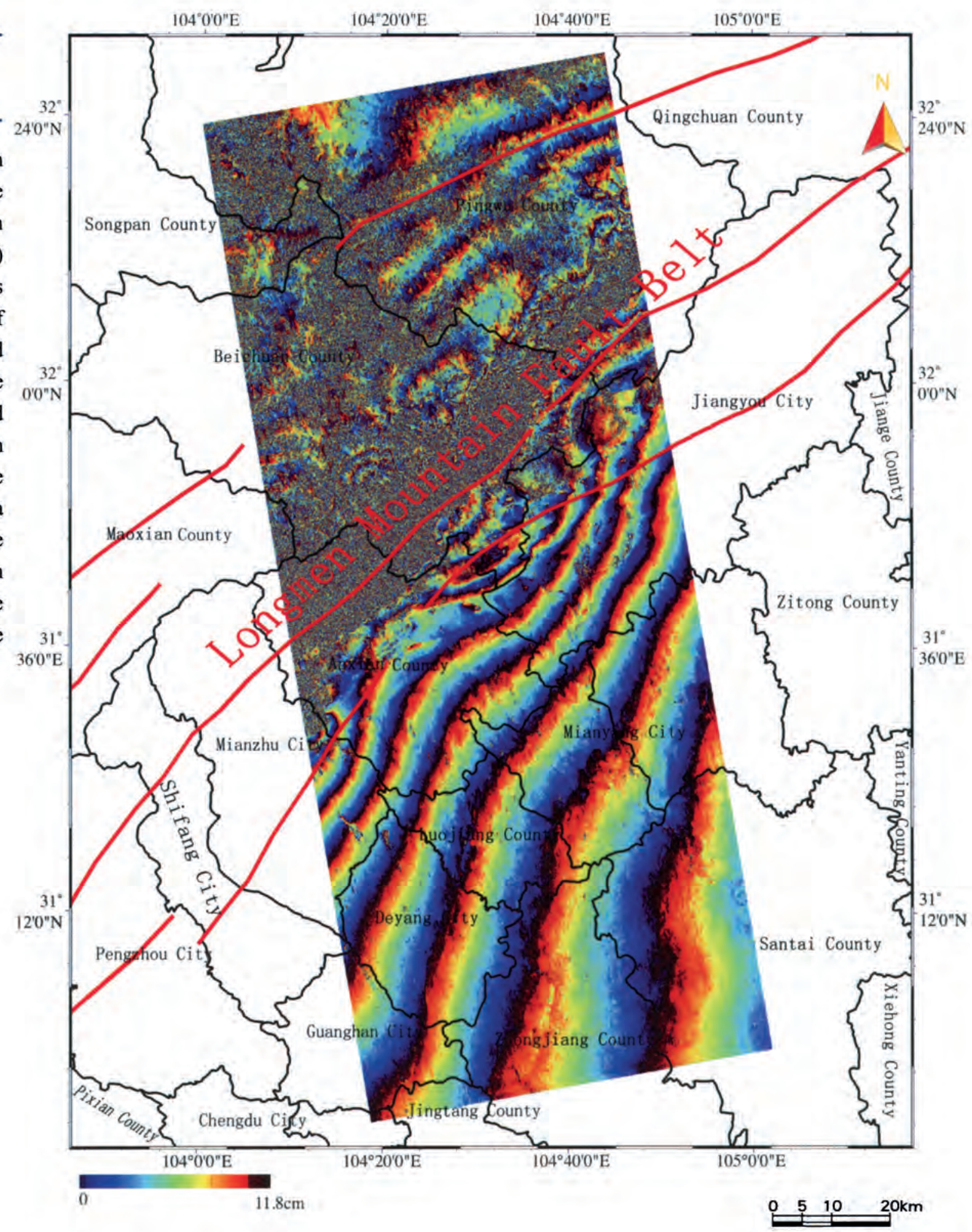

36 I Atlas of Remote Sensing of the Wenchuan Earthquake 


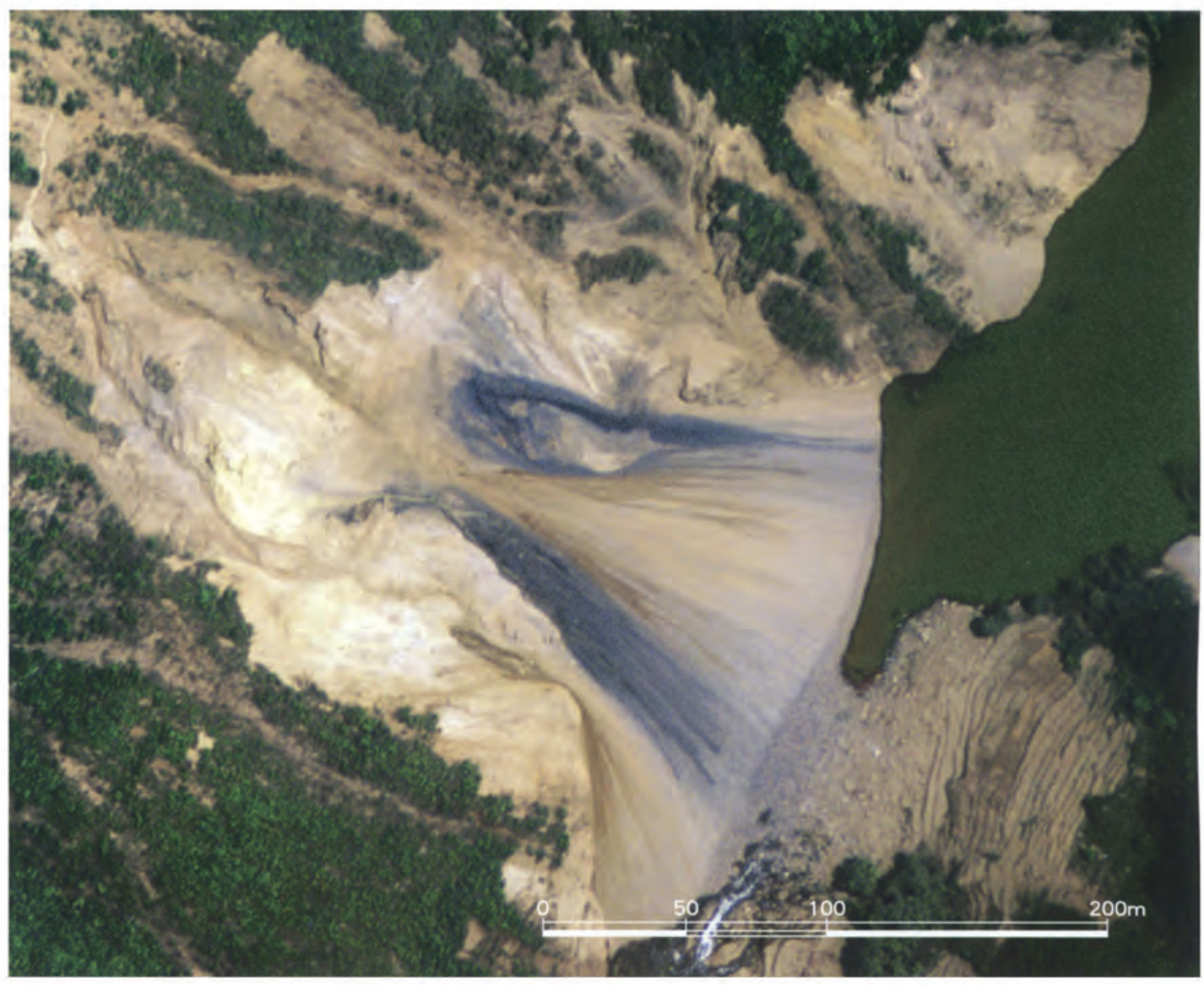

- Airborne optical image of Nanxin Town in Maoxian County

This image, obtained on May 28, 2008, shows large landslips near the LiangJiashan hill area, which caused damage to the vegetation and the side hill, where some parts of the land slid into the water. These events caused channel filling.

- Airborne optical images of Lamamiao in Pingwu County

This image, obtained on May 28, 2008, shows large landslips in the Lamamiao area; the slides dropped from above and piled up at the bottom of the area; the farmland and the trees were covered.

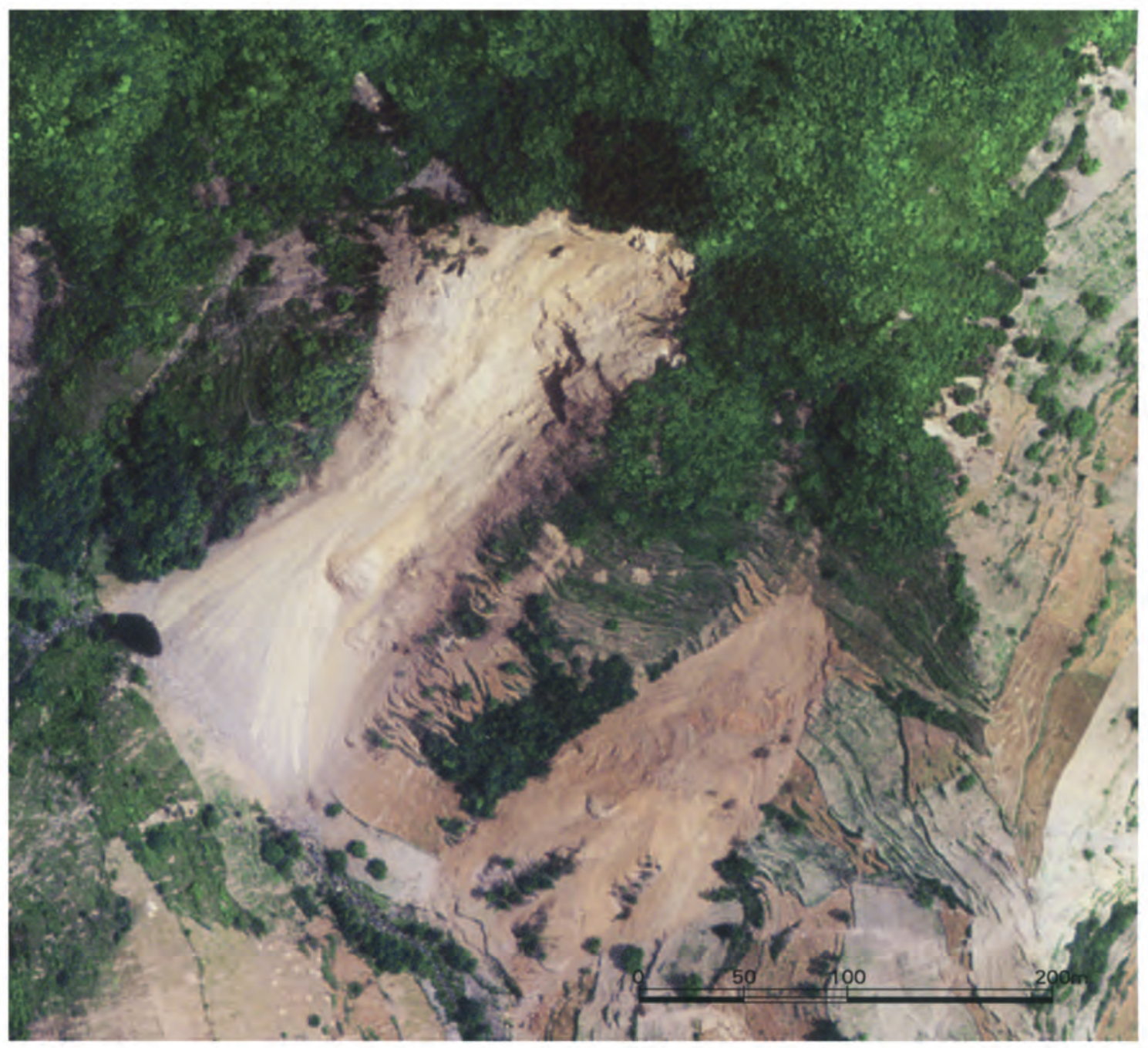


This image, obtained on May 23, 2008, shows large landslips near the town of NanXin. The slides followed along Minjiang River for about $4000 \mathrm{~m}$ and caused channel filling in some places along of the river. This endangered the road along the river, as well as water mains and electric lines.

\section{$\checkmark$ Airborne optical images of Matou in Wenchuan County}

This image, obtained on May 16, 2008, shows three main landslips. The slide marked A is about $0.04 \mathrm{~km}^{2}$ and may cause channel fill in the Minjiang River; the slide marked B is about $0.06 \mathrm{~km}^{2}$ and has caused channel fill in the Minjiang River; the slide marked $\mathrm{C}$ is about $0.15 \mathrm{~km}^{2}$. They are linearly distributed along the mountain slope and cause large areas of sloping and damaged the vegetation on the hill. This can evolve into mud-rock flow and cause new geologic hazards if there are aftershocks or heavy rains.

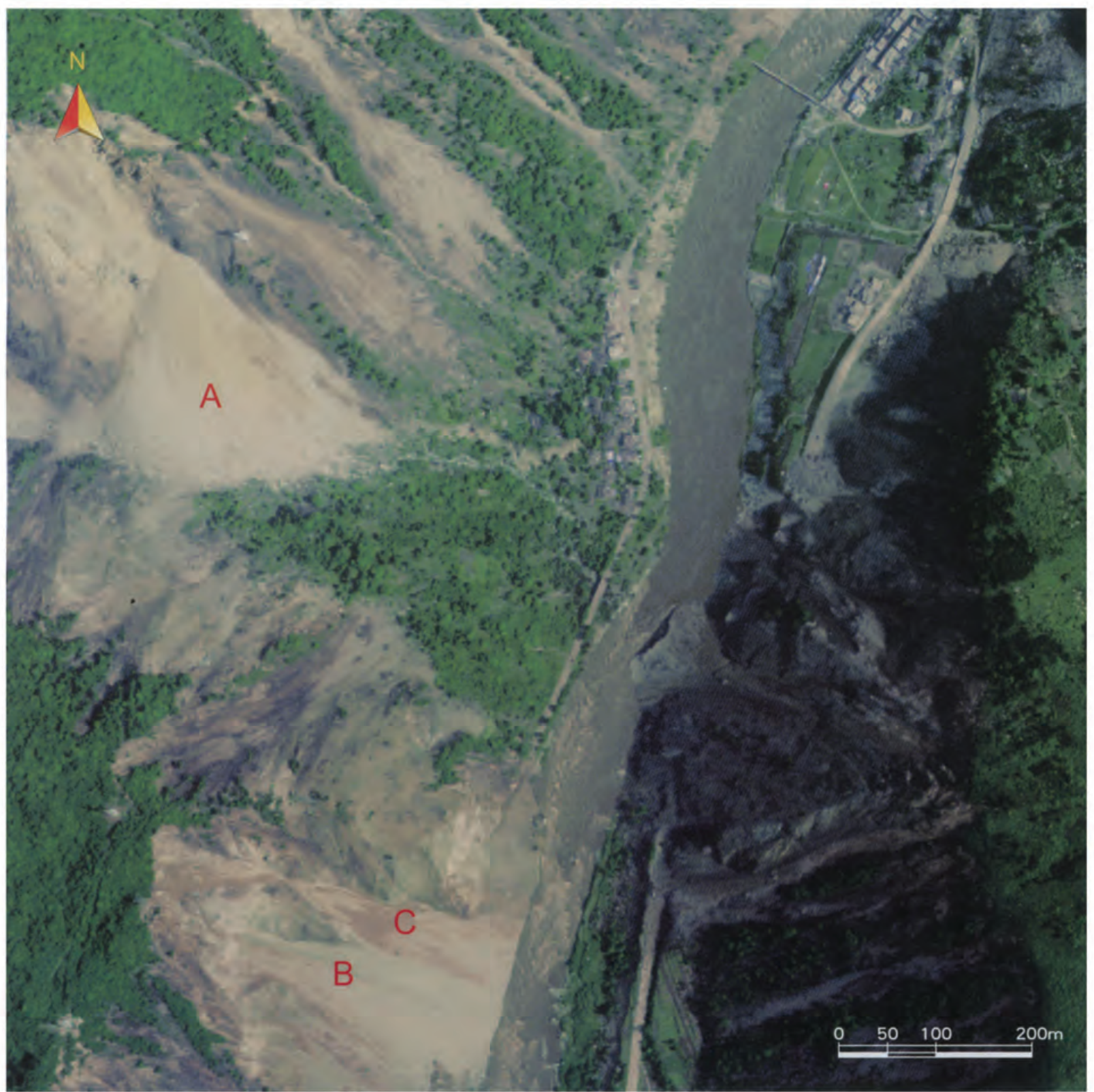

38 I Atlas of Remote Sensing of the Wenchuan Earthquake 

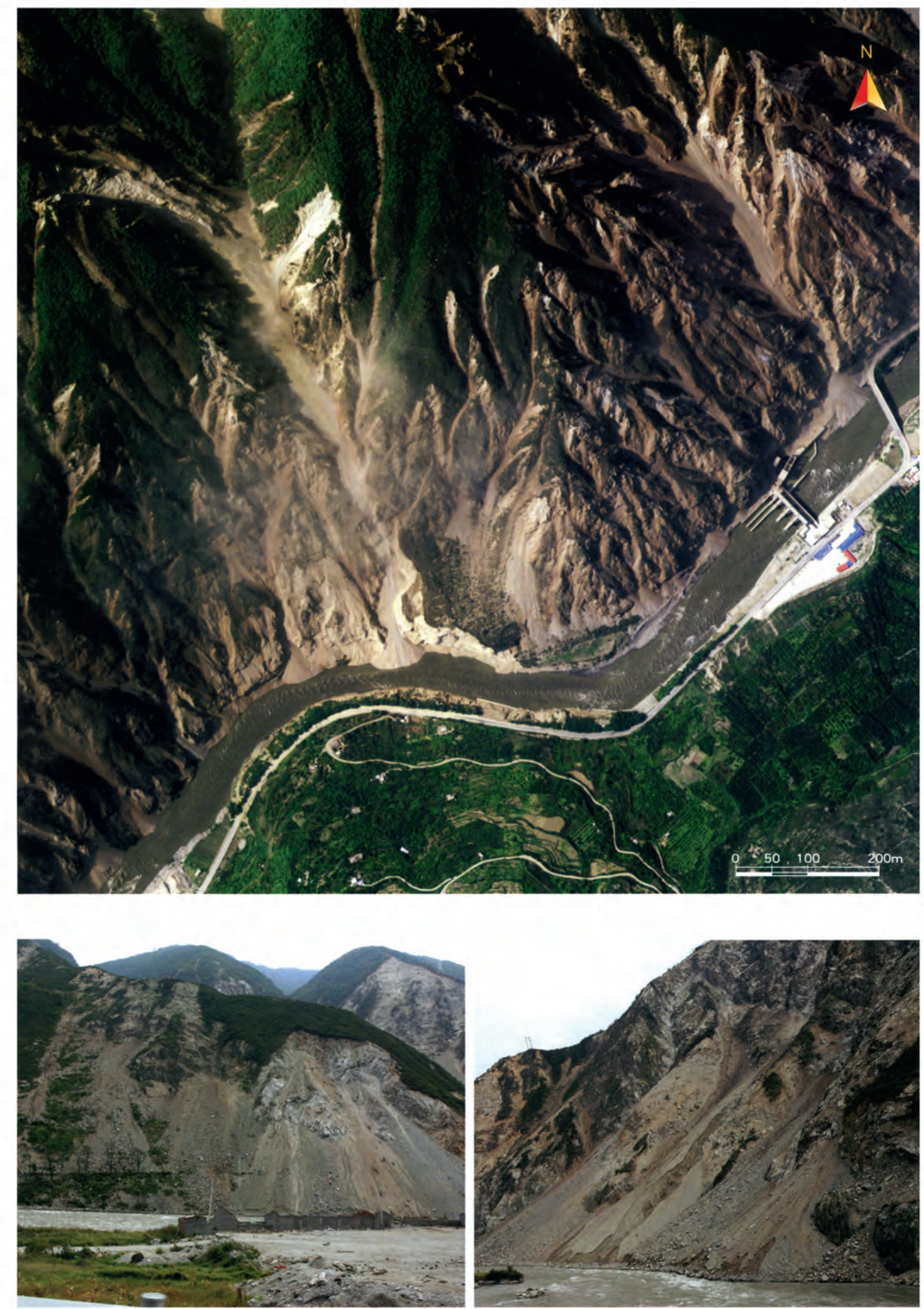

An image of debris flows caused by the earthquake in Minjiang River Basin 
This image, obtained on May 16, 2008, shows large landslips close to the entrance of the Guxi Brook. The slide marked A has caused large areas of sloping on the hill and damaged the vegetation and farm field. Part of the road and house are destroyed. The slide marked B has caused vegetation damage and farm field damage.

V Airborne optical image of Jinhe phosphorite mine in the city of Mianzhu

This image, obtained on May 23, 2008, shows large landslips on the slope of the hill close to the Jinhe phosphorite mine. The slide is about $0.4 \mathrm{~km}^{2}$. It caused channel filling and formed quake lake. Meanwhile, the mine was destroyed, the road was damaged, and the buildings collapsed.

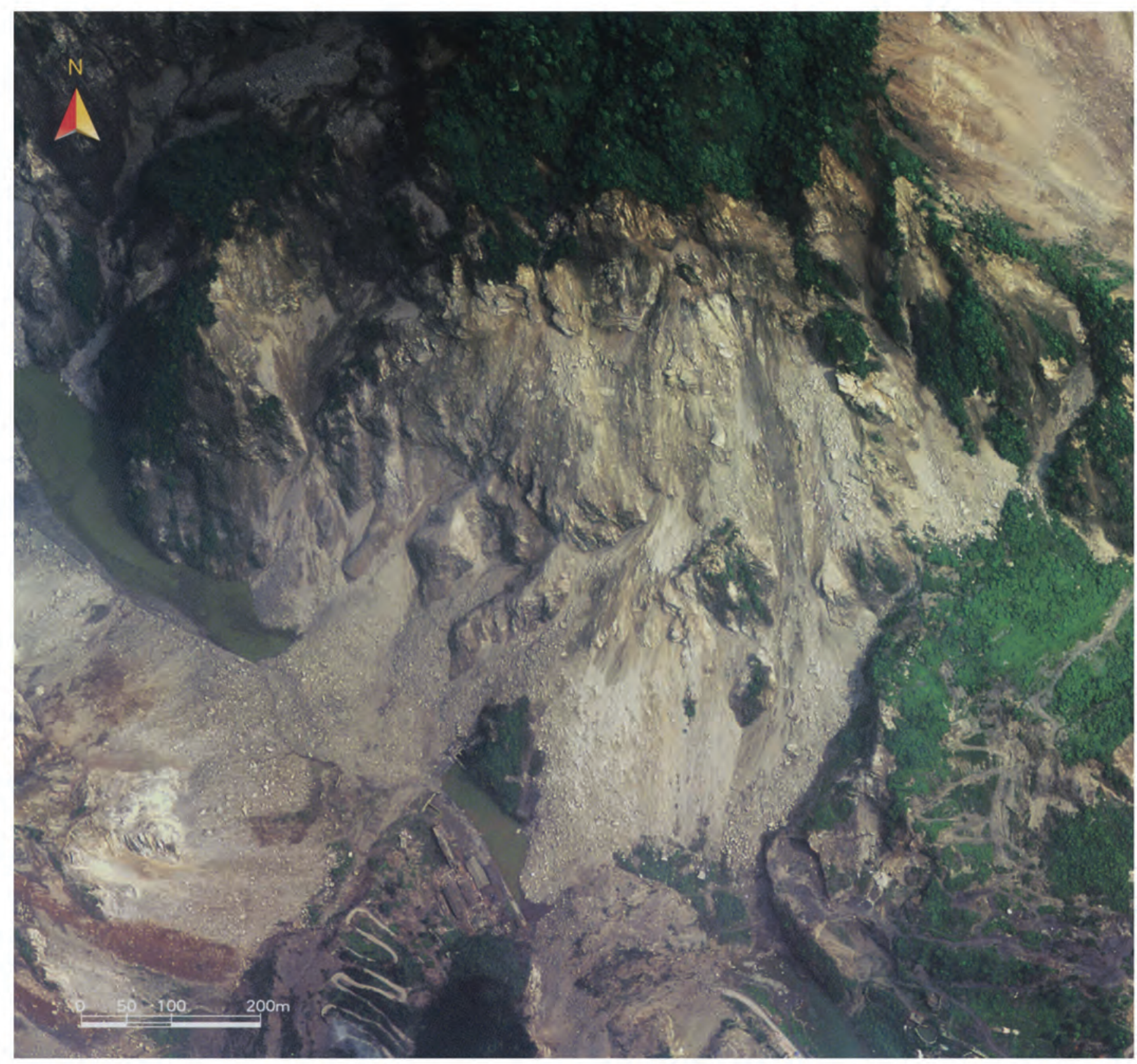

40 I Atlas of Remote Sensing of the Wenchuan Earthquake 


\section{$z$ \\ 0 \\ ari}

stome $\left./ 3^{3}\right)^{3}$

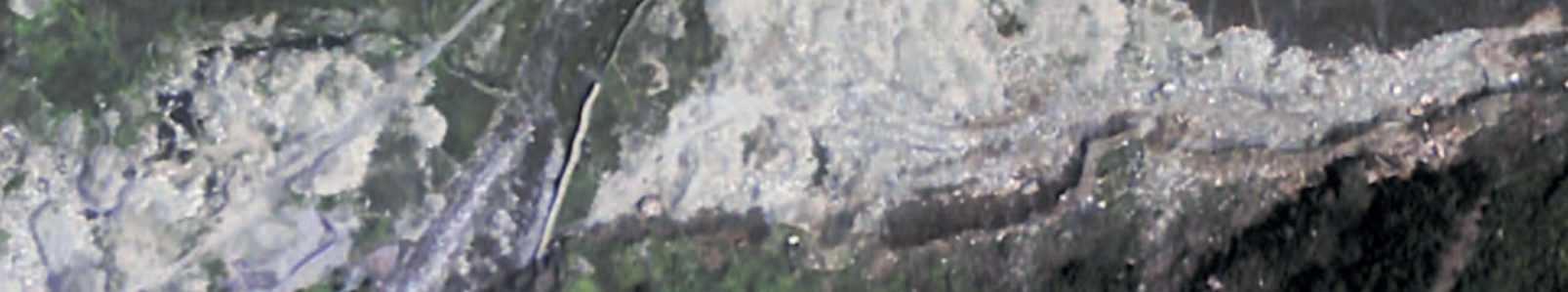

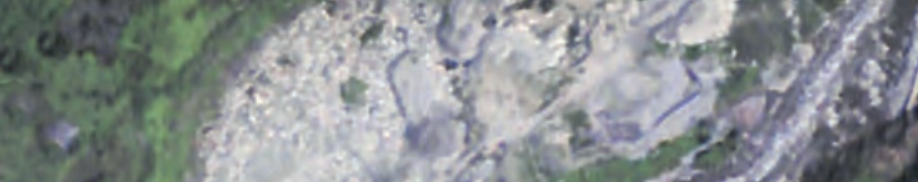

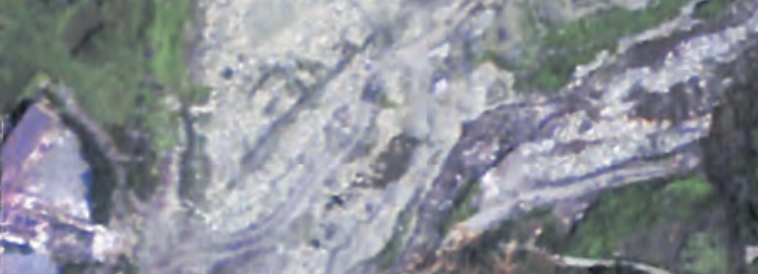

$x$ 
$\operatorname{lot}_{1}(1)=$

nit 69

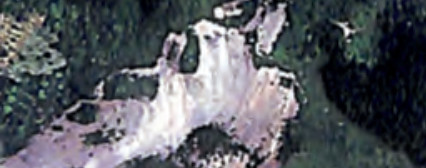

a.

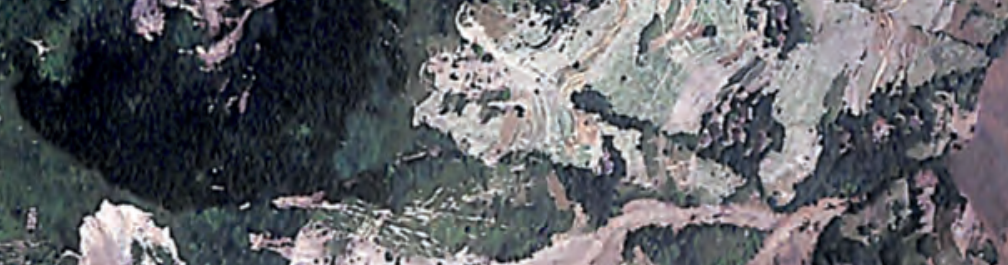

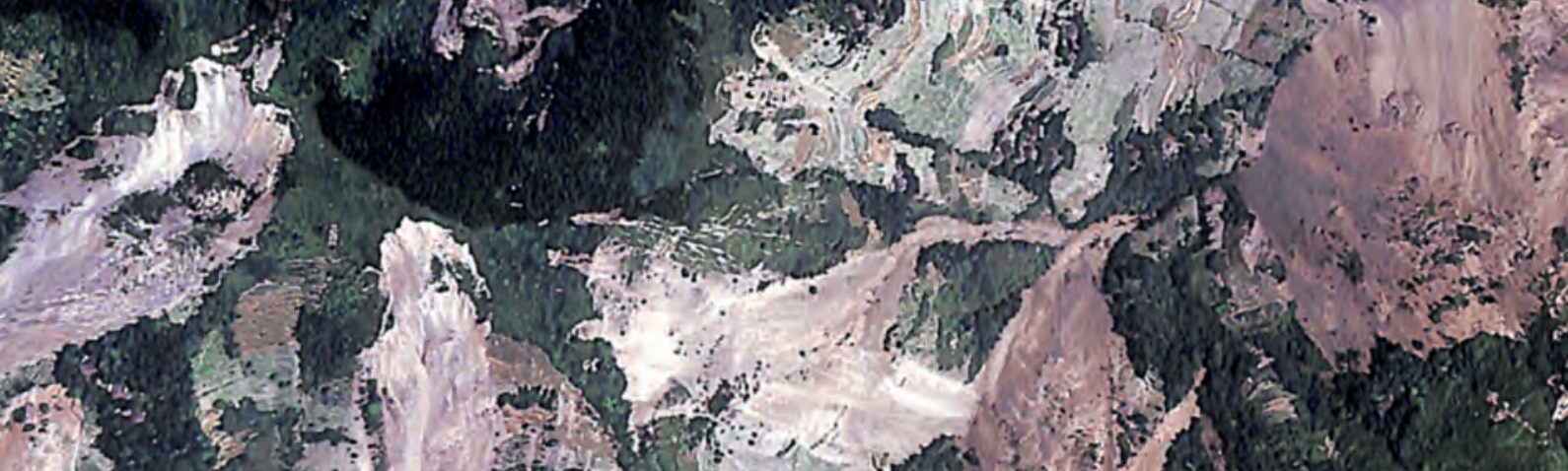

$2 y^{2}+1, y, y^{2}$

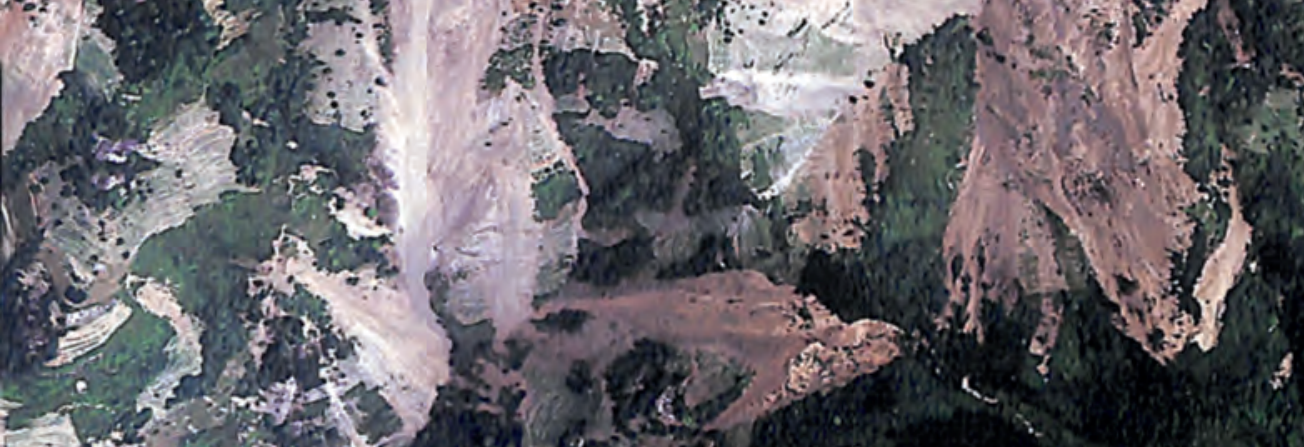

- 201109

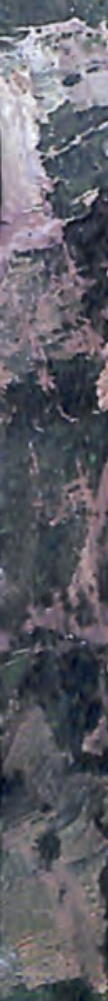

el

3.19
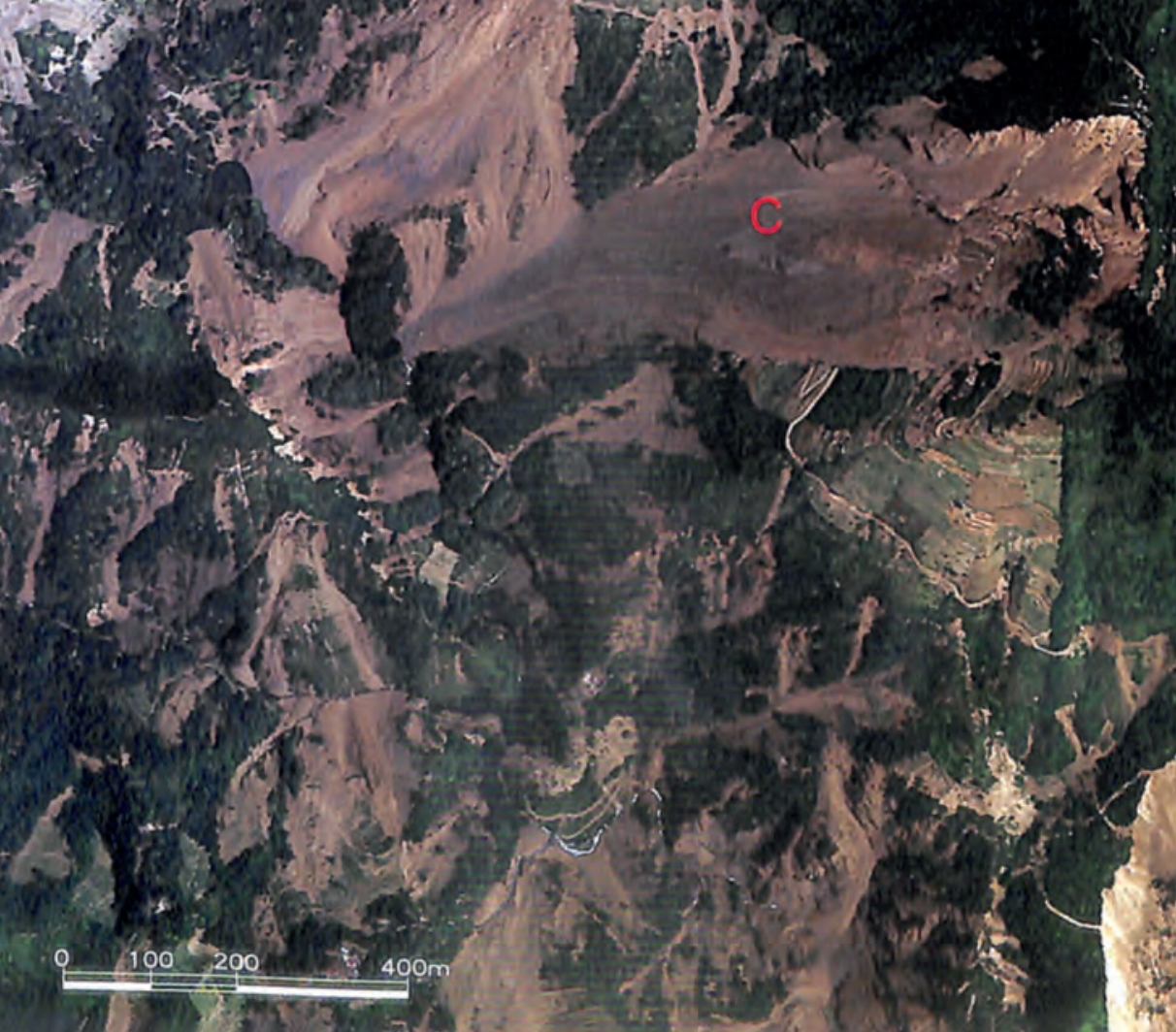

dether

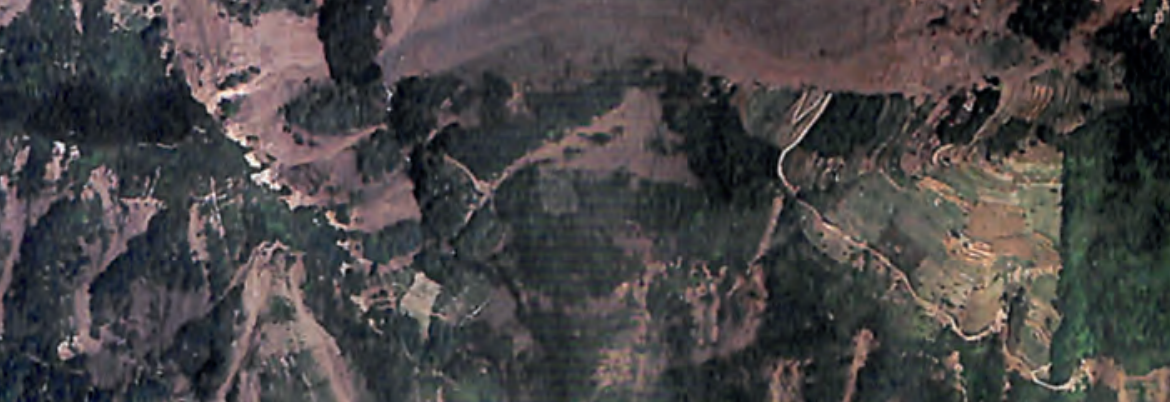

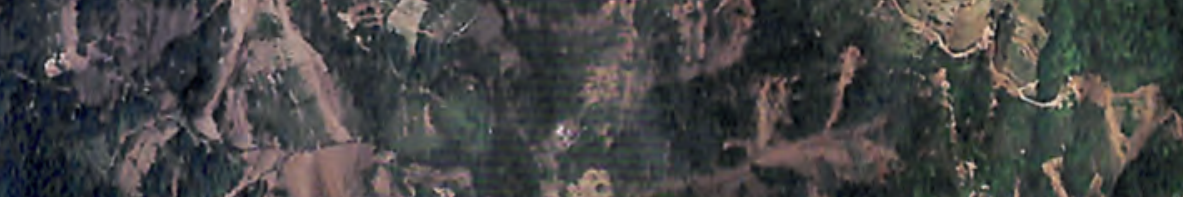

4.

3.) 9

42 I Atlas of Remote Sensing of the Wenchuan Earthquake 

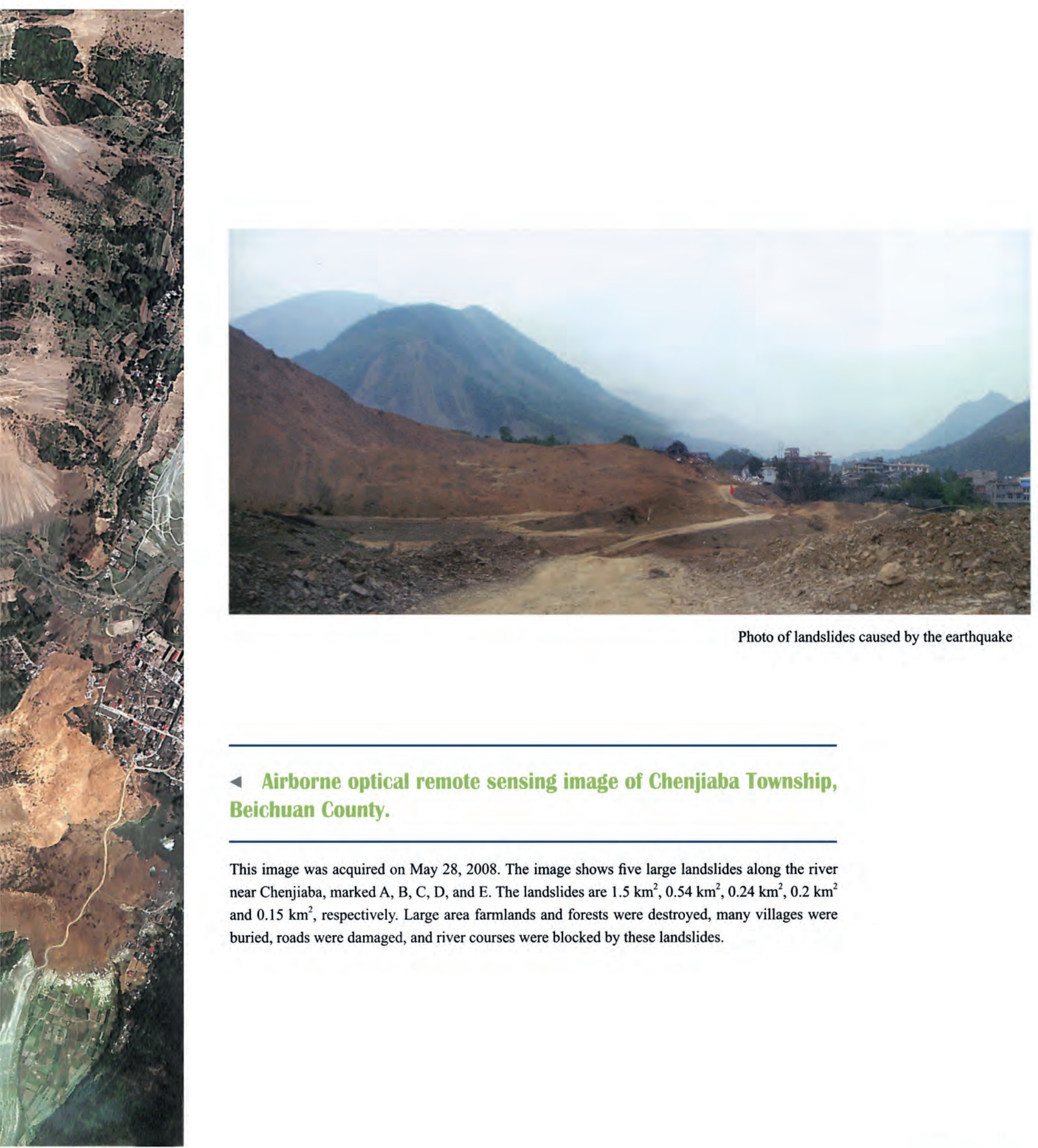

Photo of landslides caused by the earthquake

\section{Airborne optical remote sensing image of Chenjialoa Township, Beichuan County.}

This image was acquired on May 28, 2008. The image shows five large landslides along the river near Chenjiaba, marked A, B, C, D, and E. The landslides are $1.5 \mathrm{~km}^{2}, 0.54 \mathrm{~km}^{2}, 0.24 \mathrm{~km}^{2}, 0.2 \mathrm{~km}^{2}$ and $0.15 \mathrm{~km}^{2}$, respectively. Large area farmlands and forests were destroyed, many villages were buried, roads were damaged, and river courses were blocked by these landslides. 


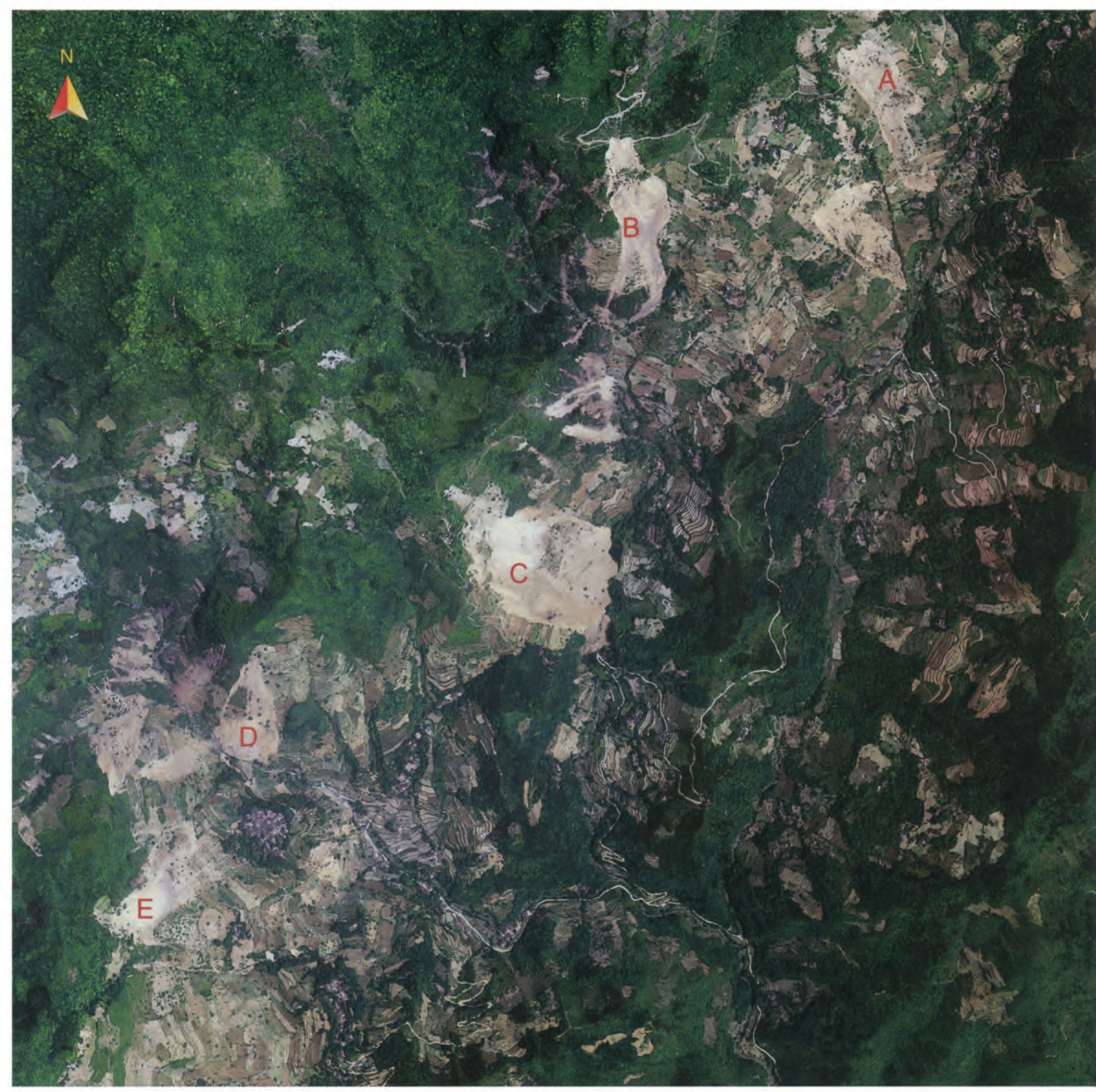

A Airborne optical remote sensing image of Guandili Township, Pingwu County.

This image was acquired on May 28,2008 . The image shows five landslides (marked A, B, C, D, and E) on the hillside near Guandili, which destroyed many farmlands. Landslide areas are $0.07 \mathrm{~km}^{2}, 0.98 \mathrm{~km}^{2}, 0.16 \mathrm{~km}^{2}, 0.05 \mathrm{~km}^{2}$, and 0.06 $\mathrm{km}^{2}$, respectively.

44 I Atlas of Remote Sensing of the Wenchuan Earthquake 
จ Airborne optical remote sensing image of Daojiaoli, Pingwu County.

This image was acquired on May 28, 2008. A $0.3 \mathrm{~km}^{2}$ landslide along the left bank near Daojiaoli destroyed farmlands.

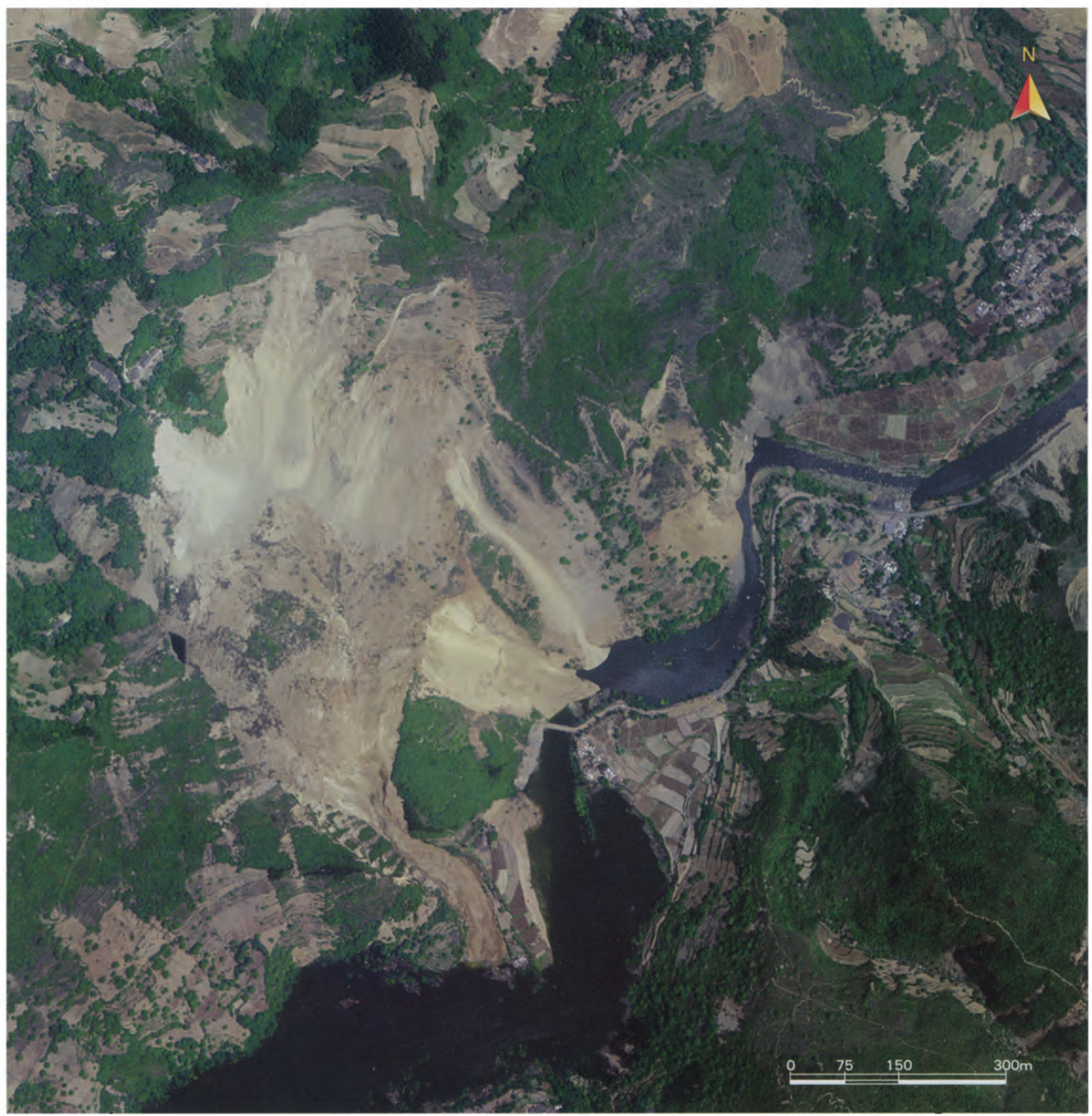




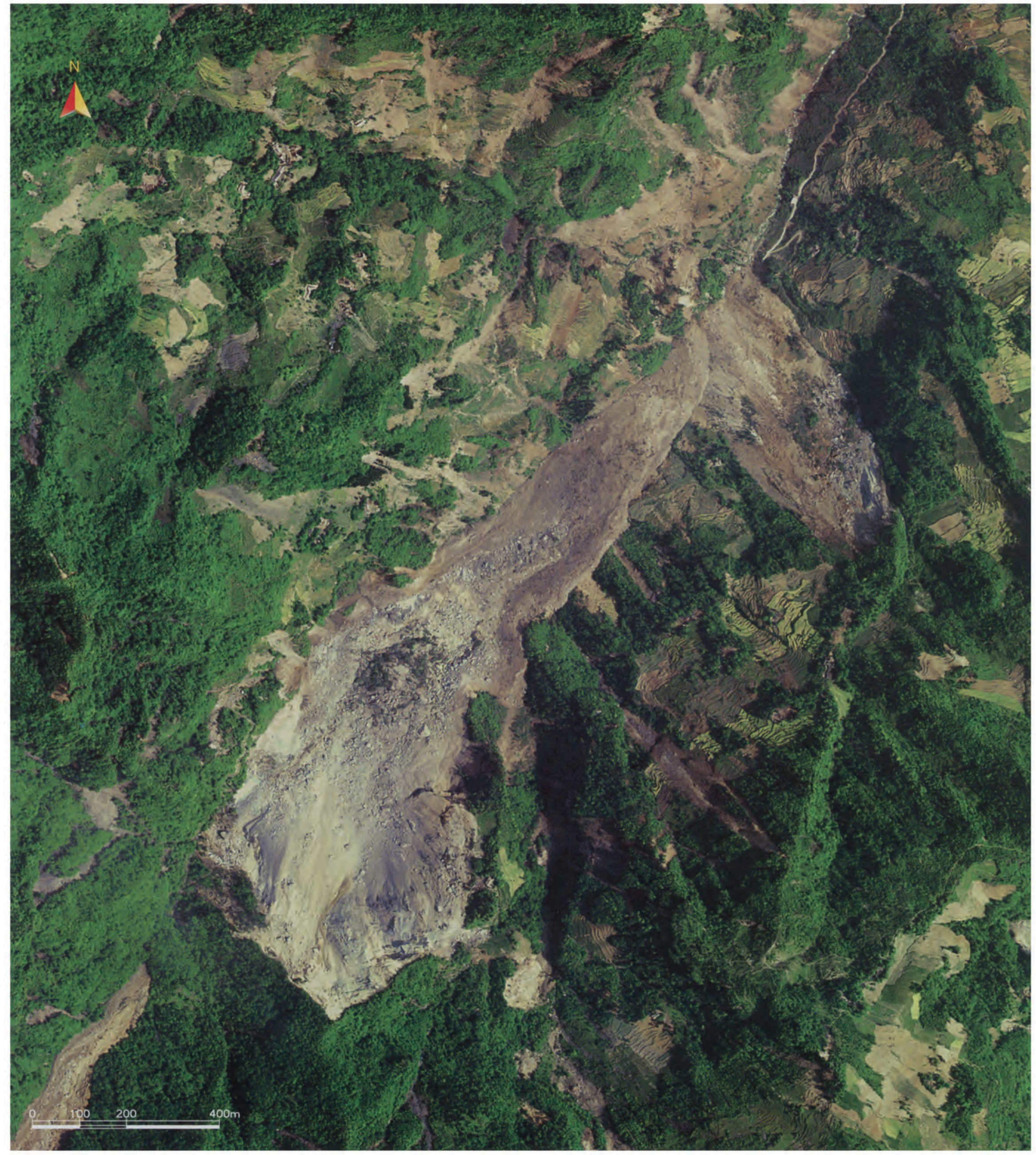




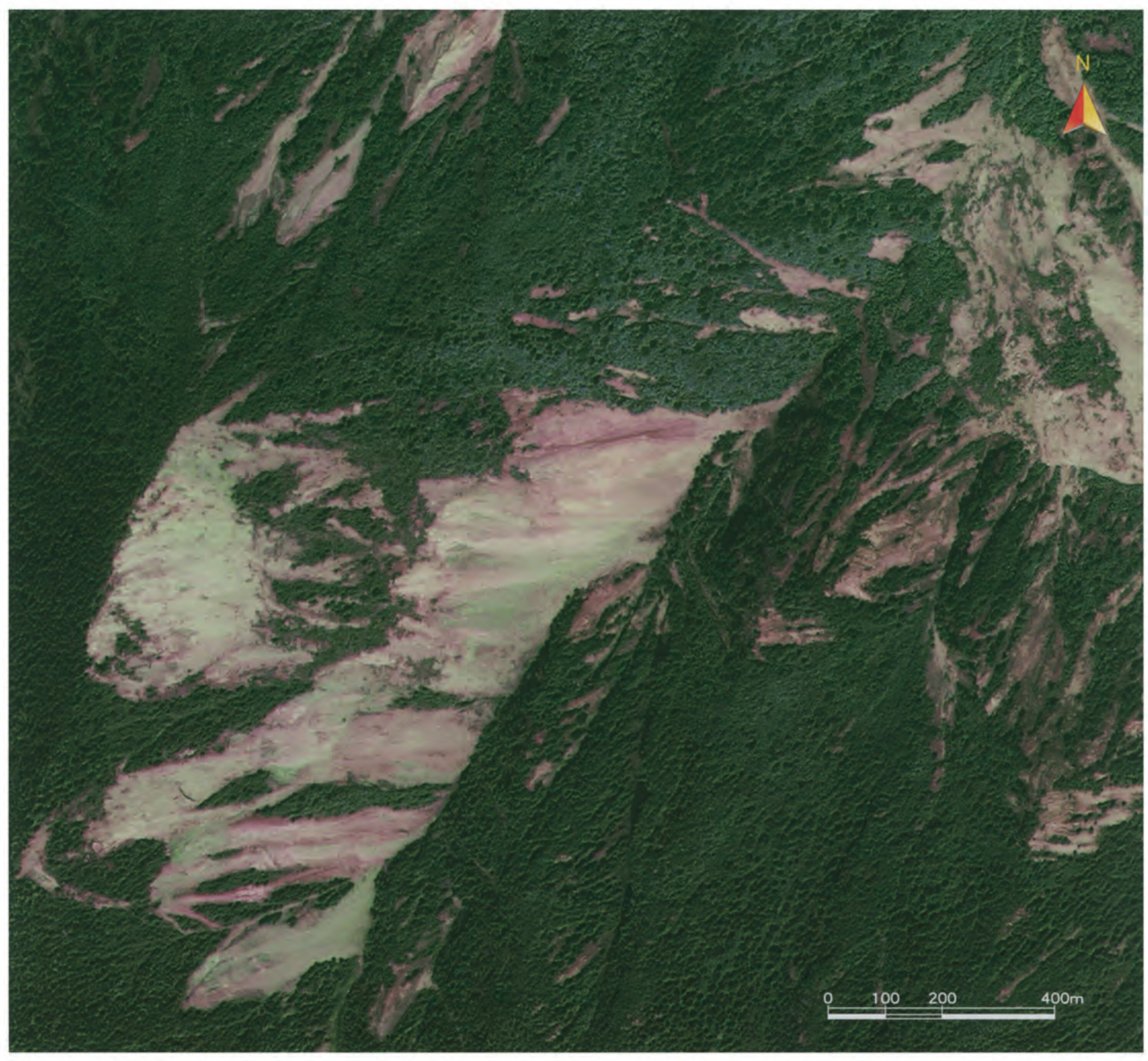

\section{- IKONOS optical remote sensing image near Wenchuan County}

This image was acquired on May 23, 2008. The earthquake caused the massive collapse of the mountains near Wenchuan County. One of the largest collapse areas was $1 \mathrm{~km}^{2}$ in the middle of the image. Vegetation on the mountain was destroyed.

\section{Airborne optical remote sensing image of Shibangou, Hongguang Township, Qingchuan County}

This image was acquired on May 18, 2008. The hillside generated massive landslides near Shibangou, Hongguang Township. These landslides destroyed vegetation and brought clasts, which are very harmful. Under the action of rain erosion, clasts can collect into debris floods. 


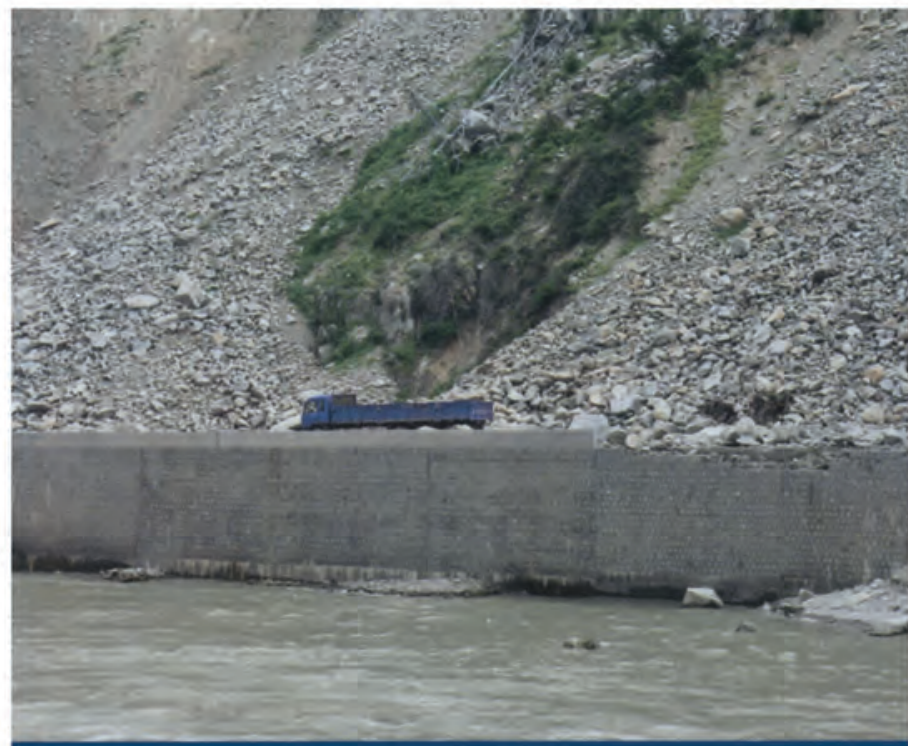

Photograph of earthquake debris flood.

- Airborne optical remote sensing image of Dongfienao, Wenchuan County.

This image, acquired on May 16, 2008, shows a high terrain slope location. Many landslides and collapses were generated in the earthquake. Collapse A destroyed the road. Collapse B destroyed a building. Landslide C

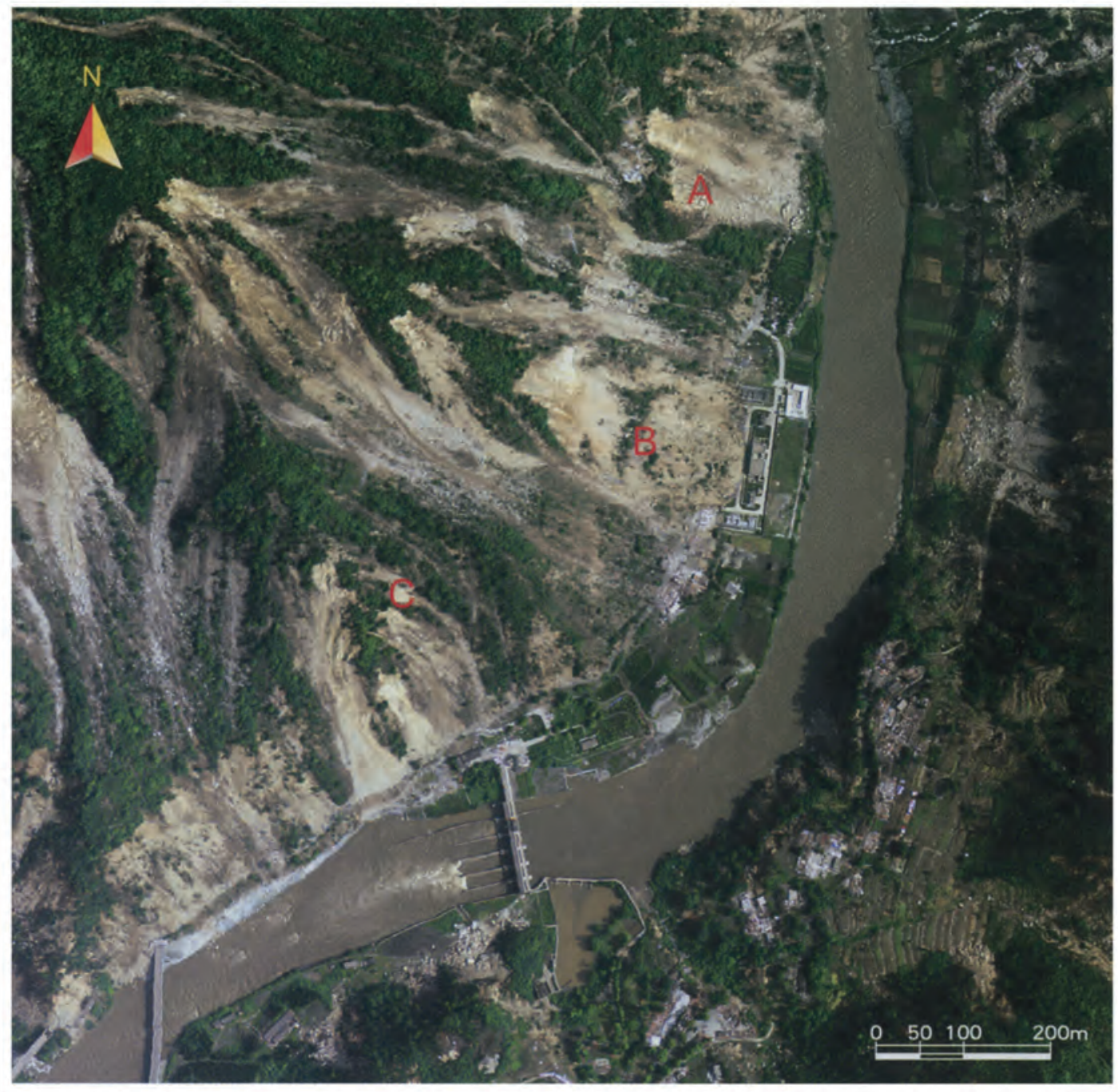
threatened roads and the power station.

- Airborne optical remote sensing image of Ganxipu, Vingxiu Township, Wenchuan County.

This image was acquired on May 16, 2008. The upper right landslide, which is $0.2 \mathrm{~km}^{2}$, formed a scarp that was about $20-\mathrm{m}$ high. This landslide broke vegetation, damaged Minjiang River and roads, and even formed a debris-flow gully.

48 I Atlas of Remote Sensing of the Wenchuan Earthquake 


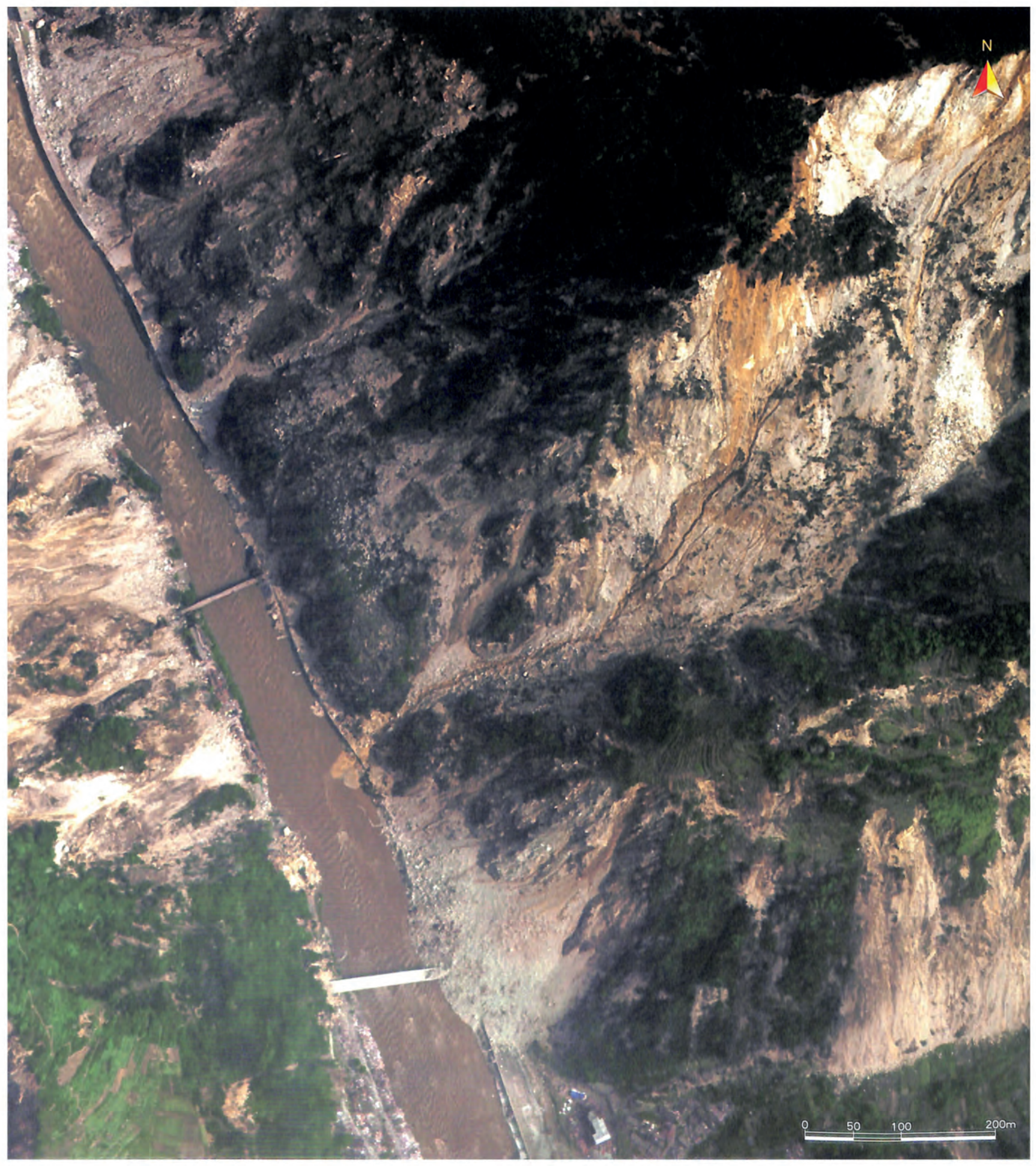




\section{- False-color composite of the IKONOS satellite image near the town of Vingxiu, Wenchuan County}

This image was acquired on May 23, 2008. The red color in the image indicates vegetation. A largearea landslide and collapse occurred in the mountain area of the riverbank of the Minjiang River near the town of Yingxiu. These geological disasters further induced mud-rock flow and debris flow. Vegetation was severely damaged. The road was broken into pieces in many places. Cropland and houses were also destroyed by the earthquake.

\section{Airborne optical image for the town of Jintiaggou, Maoxian County}

This image, acquired on May 15, 2008, shows a large-area landslide and collapse over the mountain slope area on both sides of the major river courses, and it shows debris that flowed into the river valley. The landslide then formed a destructive mud-rock flow and debris flow as a result of rainfall in the river valley and in the tributaries of the major rivers. Crops and forests were extensively damaged. Parts of the houses collapsed. Roads were broken, and rivers were blocked.

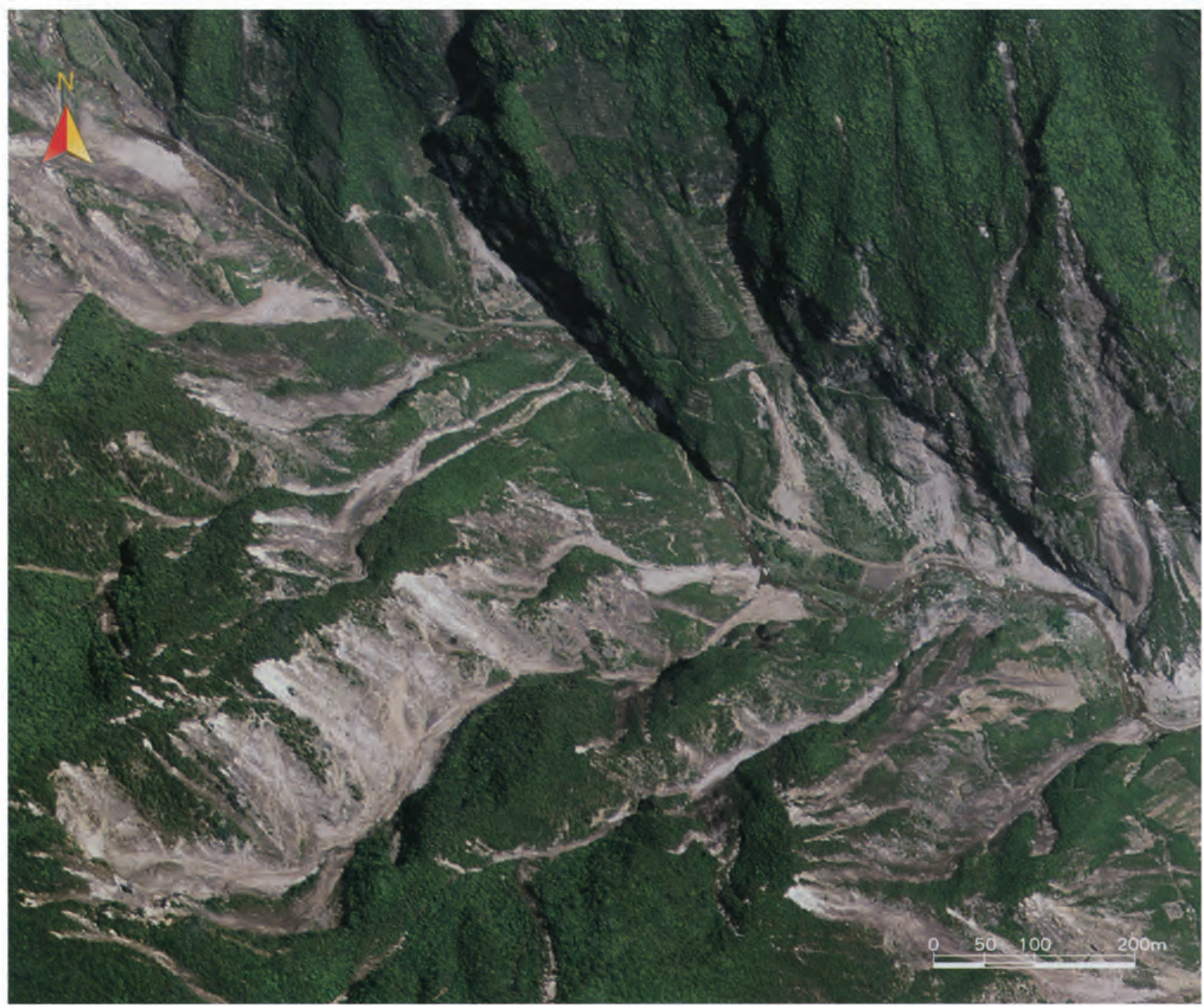

50 I Atlas of Remote Sensing of the Wenchuan Earthquake 

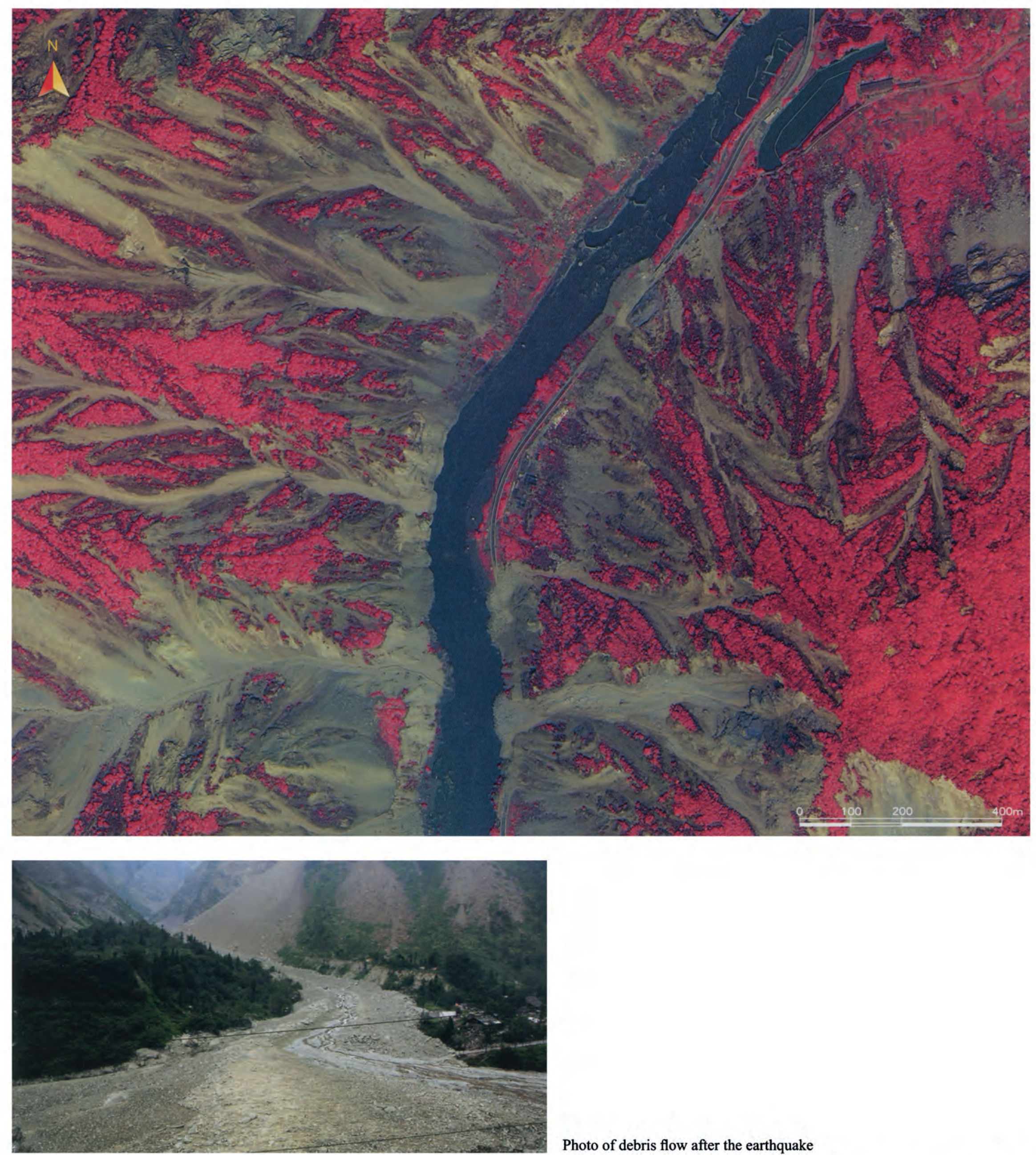

Photo of debris flow after the earthquake 
6. (1)

ext $5=2+3$

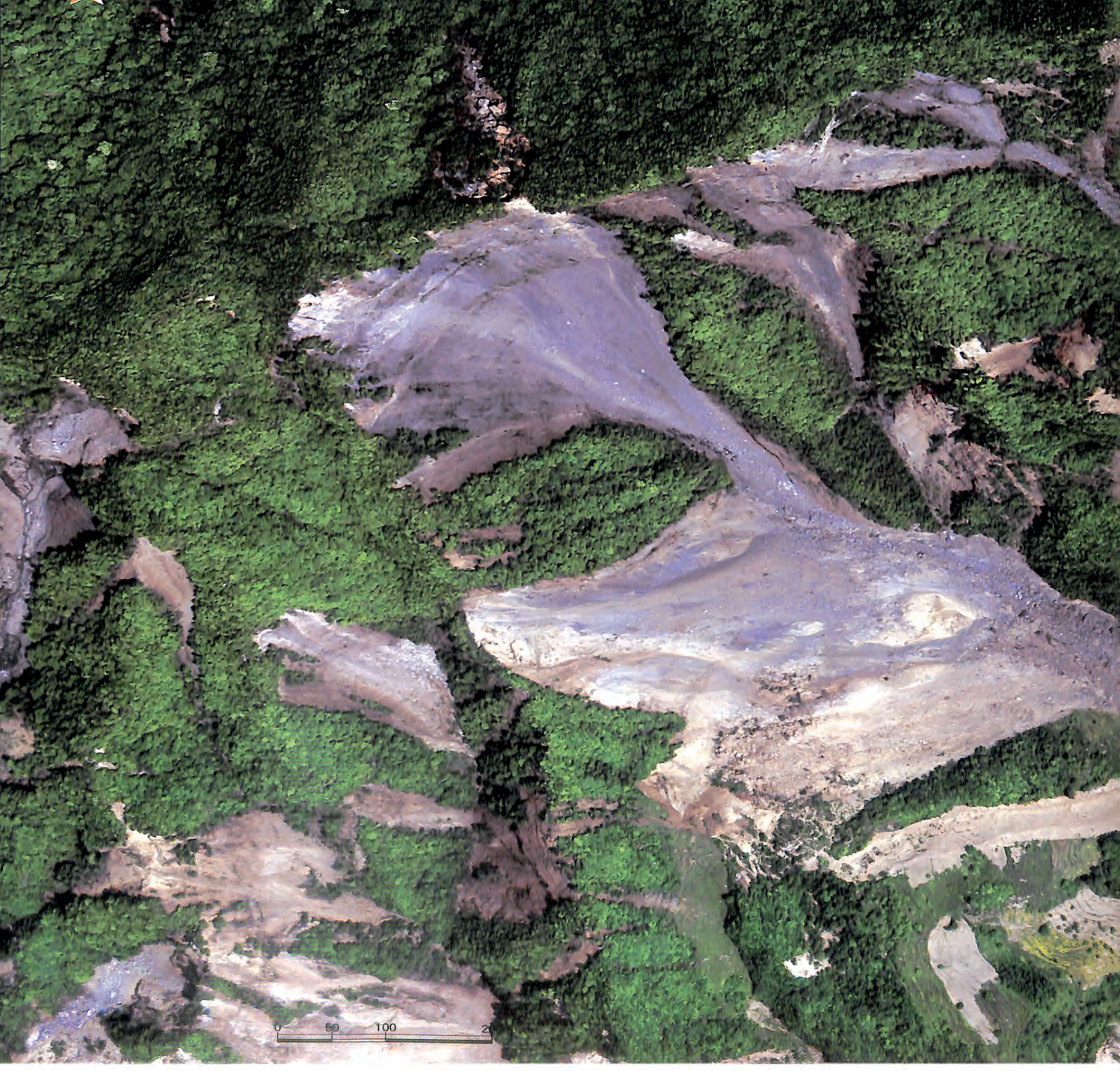

52 I Atlas of Remote Sensing of the Wenchuan Earthquake 

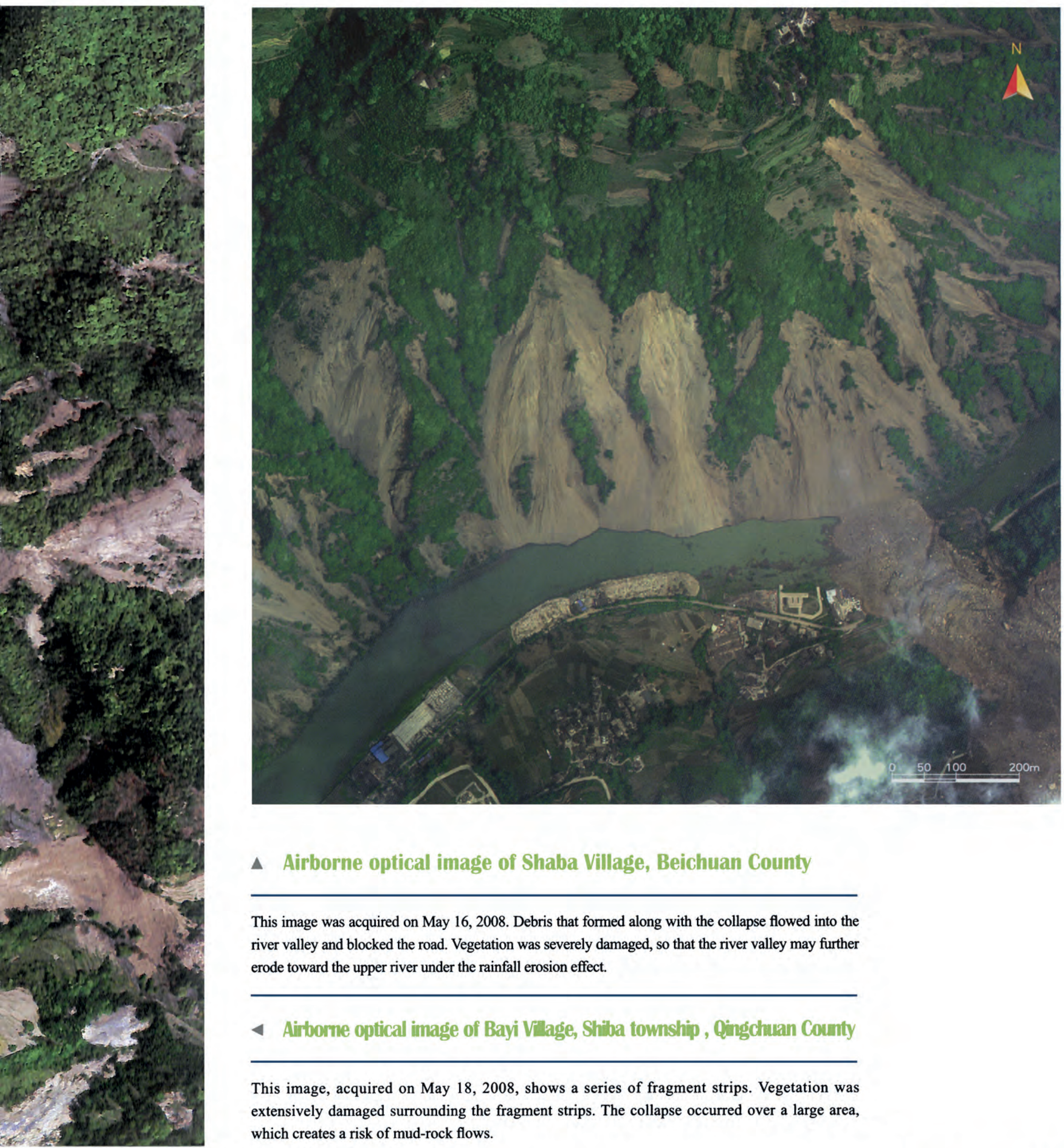

\section{\ Airborne optical image of Shaba Village, Beichuan County}

This image was acquired on May 16, 2008. Debris that formed along with the collapse flowed into the river valley and blocked the road. Vegetation was severely damaged, so that the river valley may further erode toward the upper river under the rainfall erosion effect.

\section{Airbome optical image of Bayi V'llage, Shiba township, Qingchuan County}

This image, acquired on May 18, 2008, shows a series of fragment strips. Vegetation was extensively damaged surrounding the fragment strips. The collapse occurred over a large area, which creates a risk of mud-rock flows. 

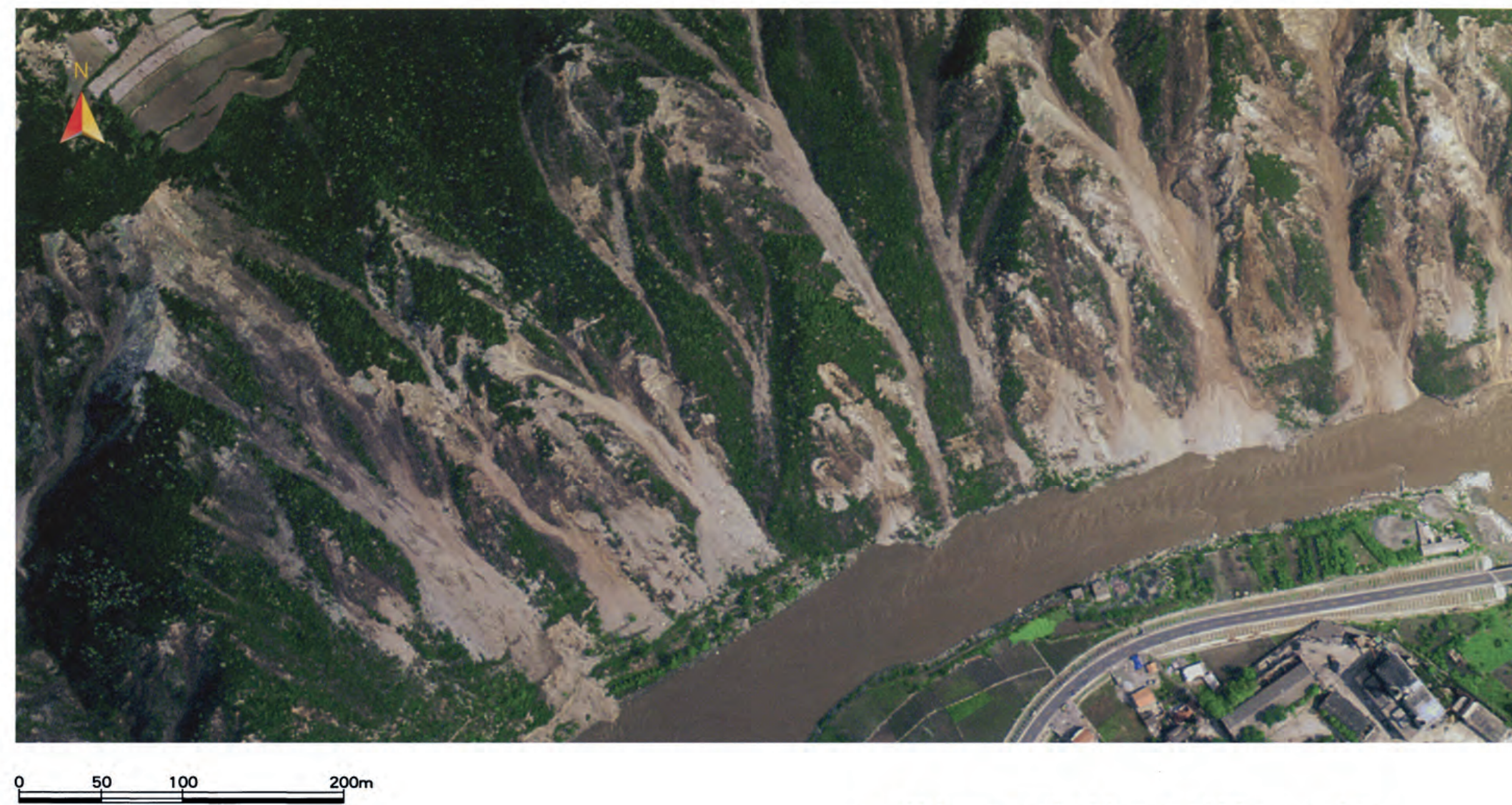

\section{A Airborne optical image of Xiaomaoping Village, Wenchuan County}

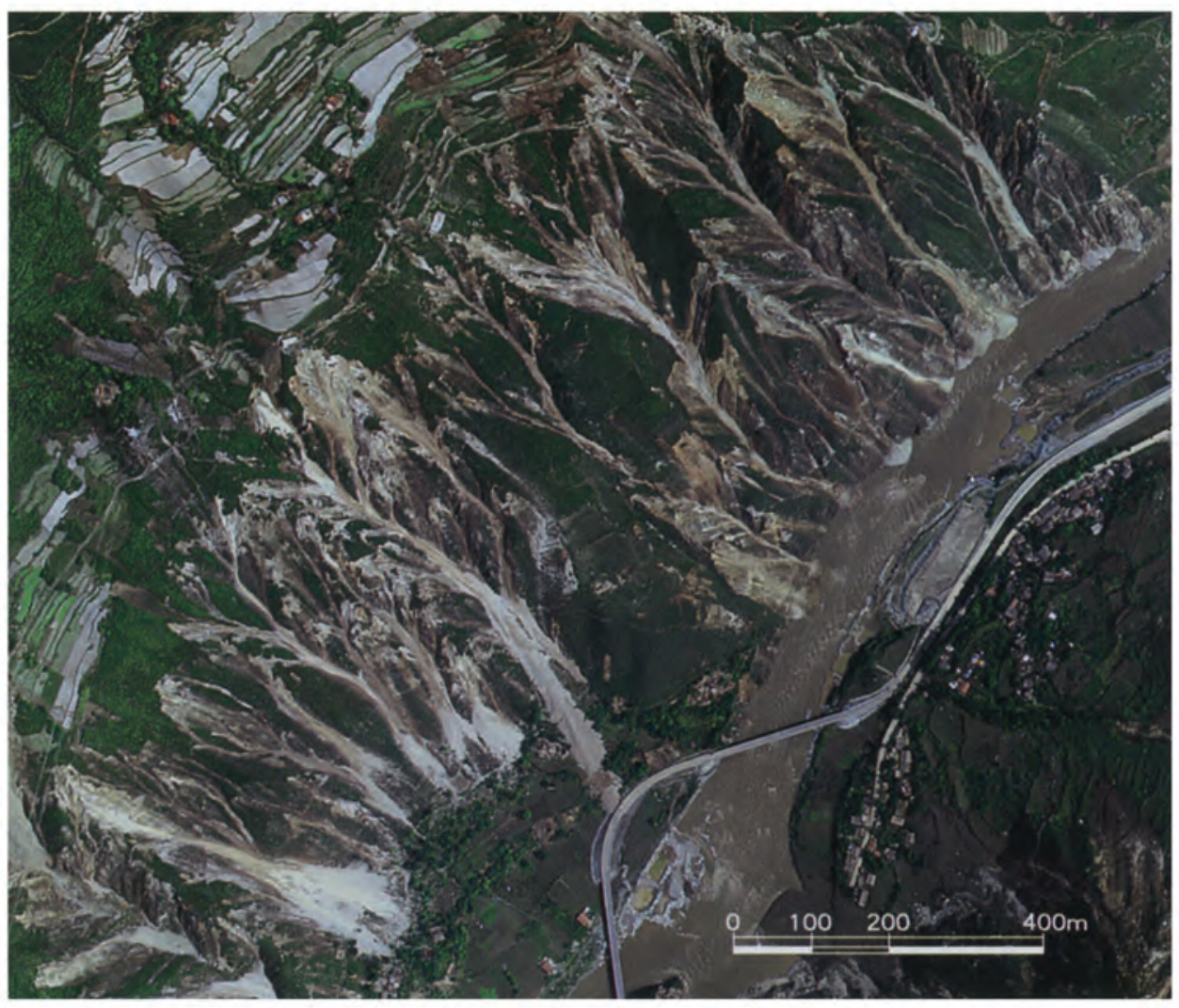

The image was acquired on May 15, 2008. The image depicts the steep slope in the mountain area on the side of the Minjiang River. The Wenchuan Earthquake include mud-rock flows in the river valleys, which blocked the river and threatened the roads and the residential life.

\section{The airborne remote sensing optical imagery of Xindian, in Wenchuan County}

From this image, captured on May 15,2008, we can see that a large clastic flow gully was formed less than $50 \mathrm{~m}$ away from the northwest bank of the Minjiang River.

54 I Atlas of Remote Sensing of the Wenchuan Earthquake 


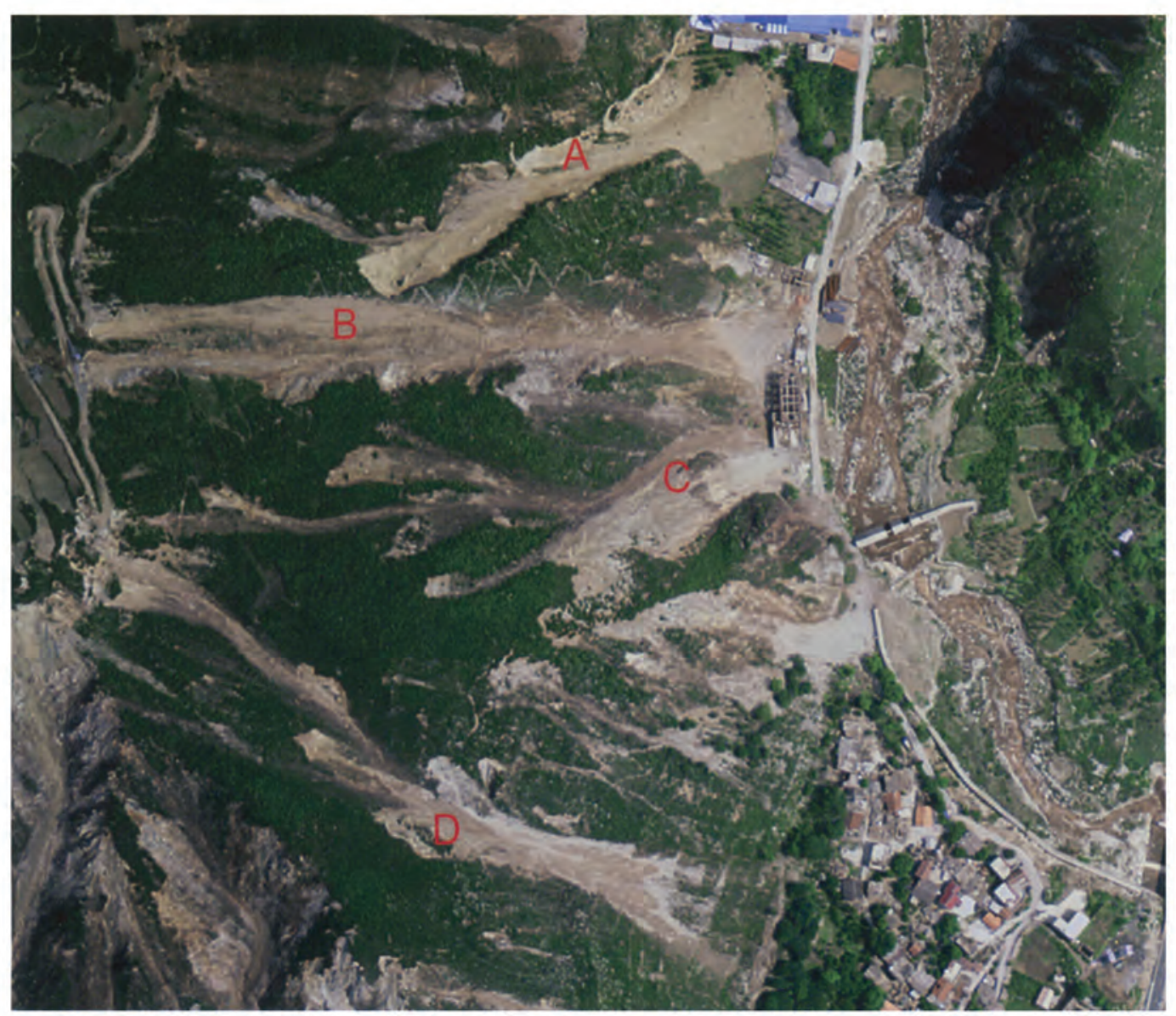

$0 \quad 50 \quad 100$ $200 \mathrm{~m}$

4 Airborne remote sensing optical imagery of Banzigou Village in Wenchuan County

This image was captured on May 15, 2008. There are four clastic flows marked A, B, C, and D. Areas of flows are $0.01,0.015,0.02$ and 0.014 $\mathrm{km}^{2}$, respectively. They washed off the road and destroyed the vegetation.

\section{v Airborne remote sensing optical imagery of Zesang in Wenchuan County}

This image was captured on May 15, 2008. Debris flows and clastic flows were formed on the west bank of the Minjiang River under the action of this earthquake. The vegetation was destroyed on both sides of the gully. The rainwater poses a particular threat in this landscape, and heavy rains threaten the road and riverway in the lower reaches of the river.

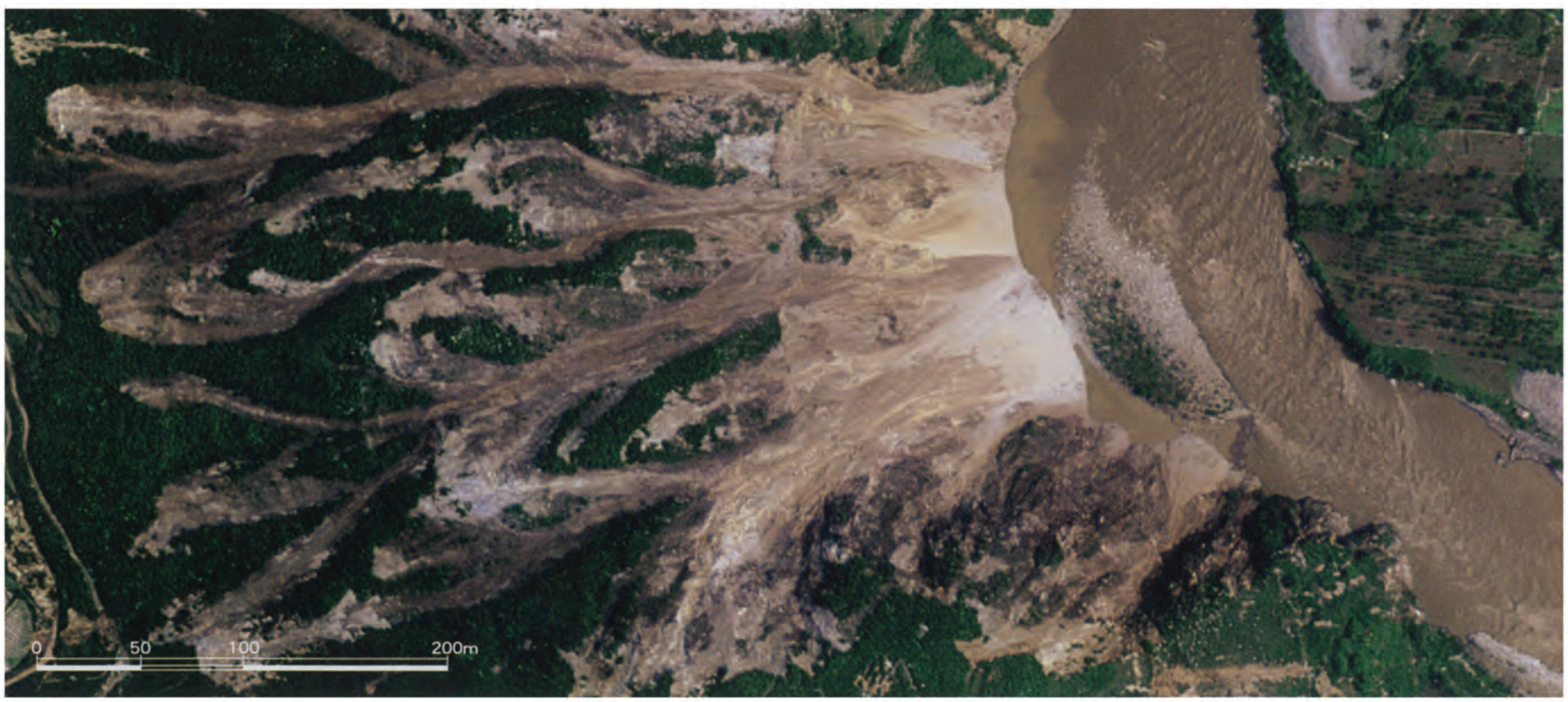




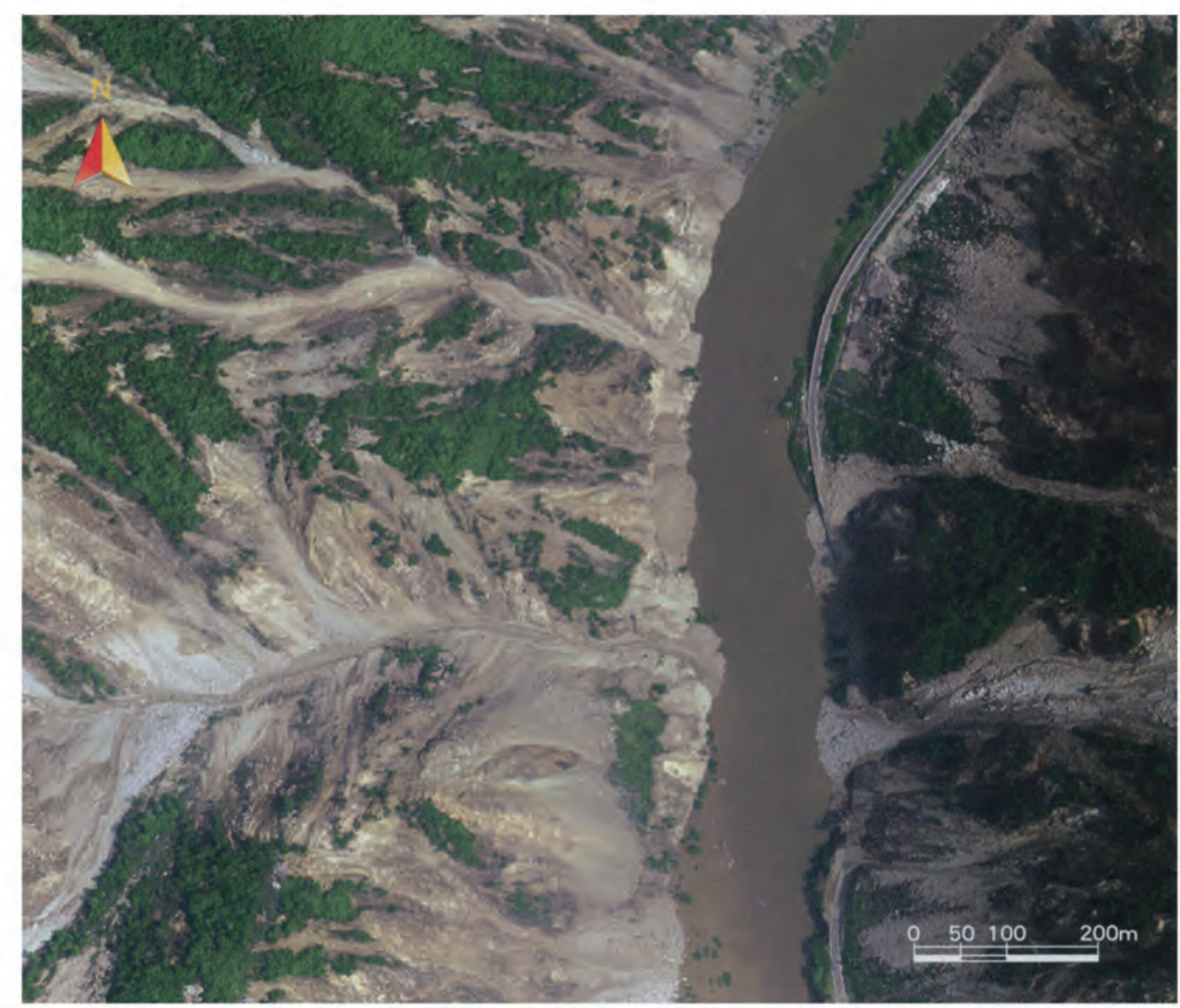

A Airborne remote sensing optical imagery of Maliuwan in Wenchuan County

This image was captured on May 15, 2008. The large clastic flow gully was formed less than every $500 \mathrm{~m}$ on both banks of the Minjiang River, and vegetation was destroyed on both sides of the gully. The alluvial materials at the front of the gully blocked the riverway.
Photo of debris flow after the earthquake

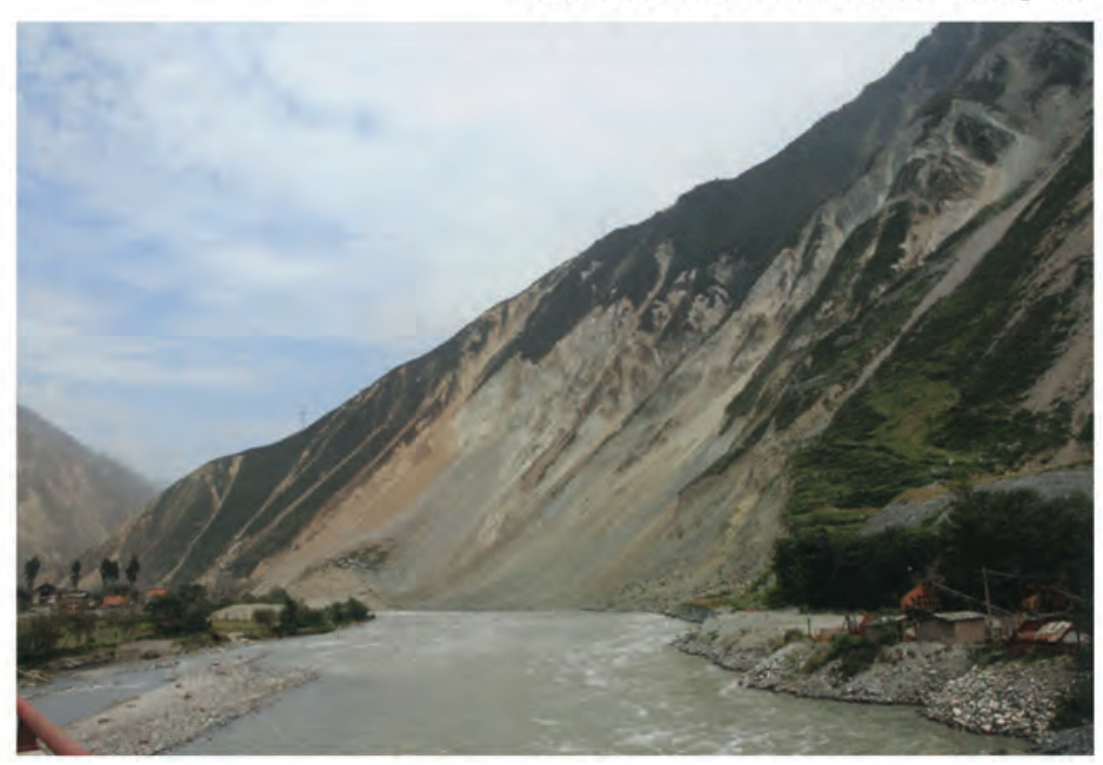

- Airborne remote sensing optical imagery of Yangdian Village in Wenchuan County

This image was captured on May 16, 2008. From the image we can see that the vegetation was destroyed on both banks of the Minjiang River and its branch, and the group clastic flows that formed along the side slope threaten the safety of the Minjiang River, the roads, and buildings. Many buildings were destroyed, and the roads were washed out. The riverways were narrowed by alluvial materials.

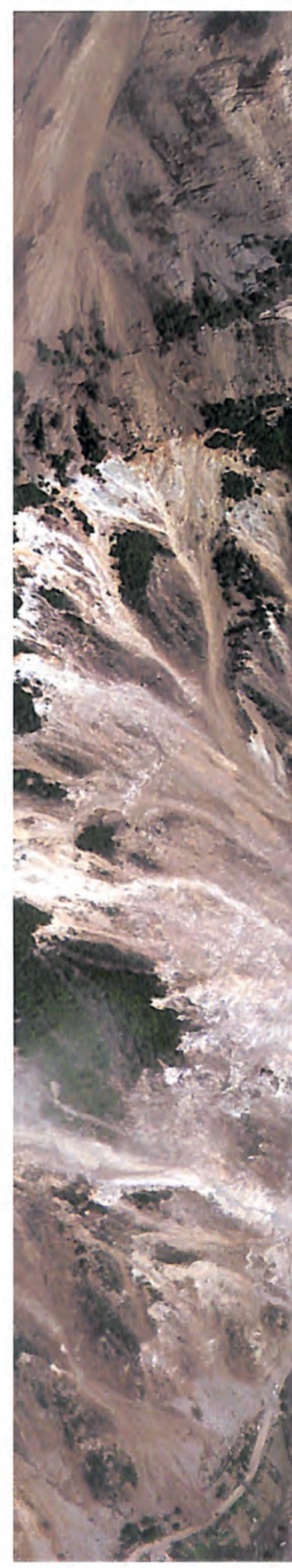

56 I Atlas of Remote Sensing of the Wenchuan Earthquake 
Dor

W.

20

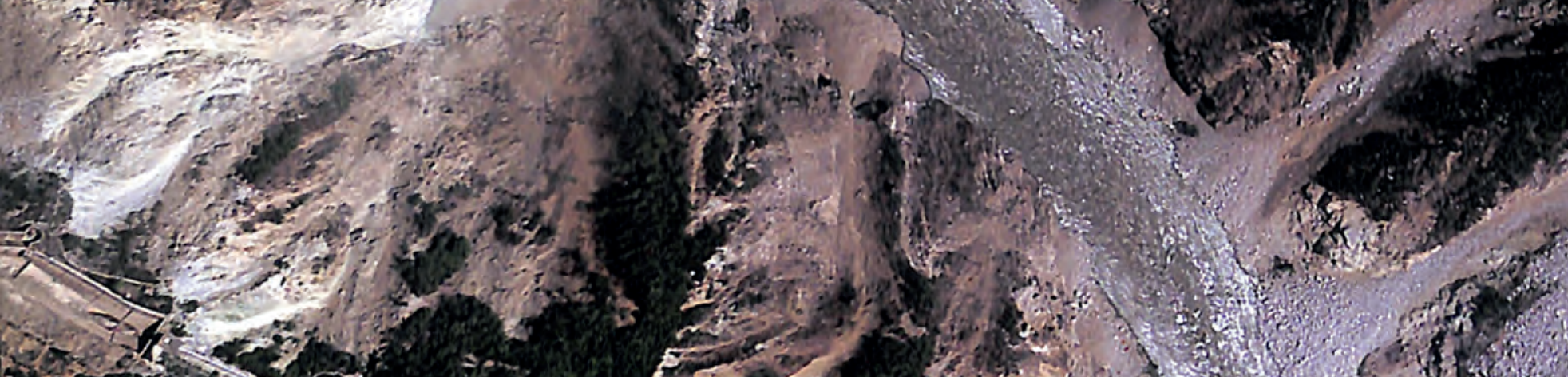

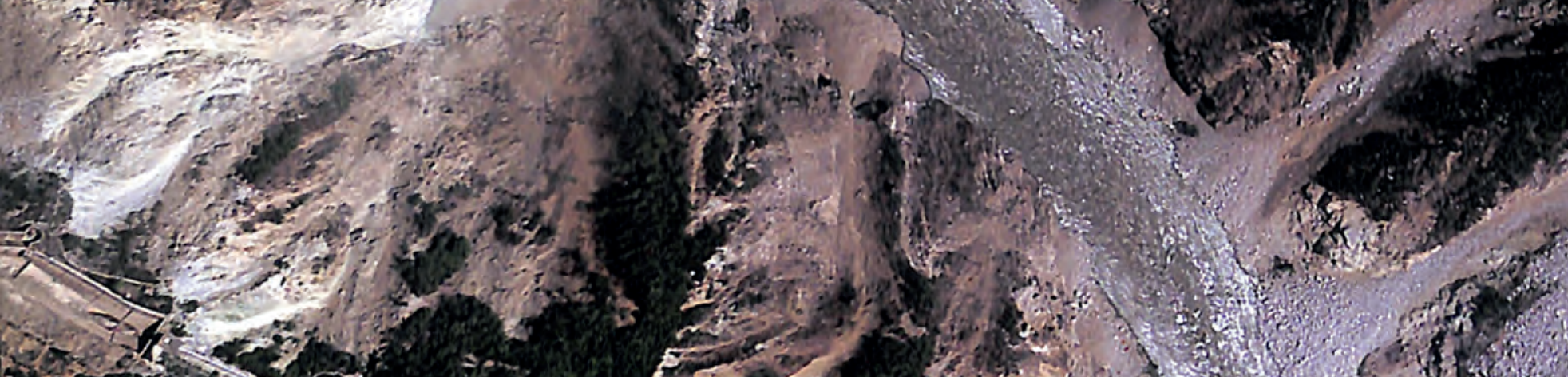

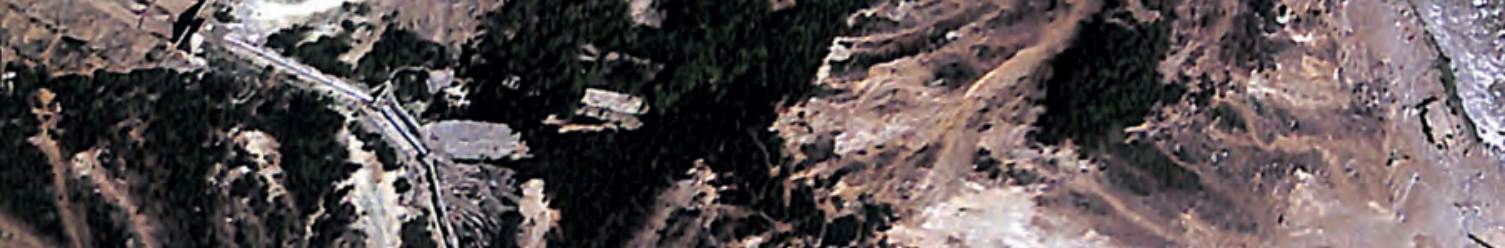

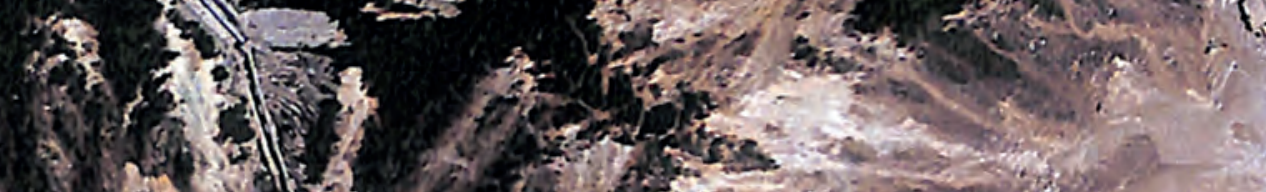
12

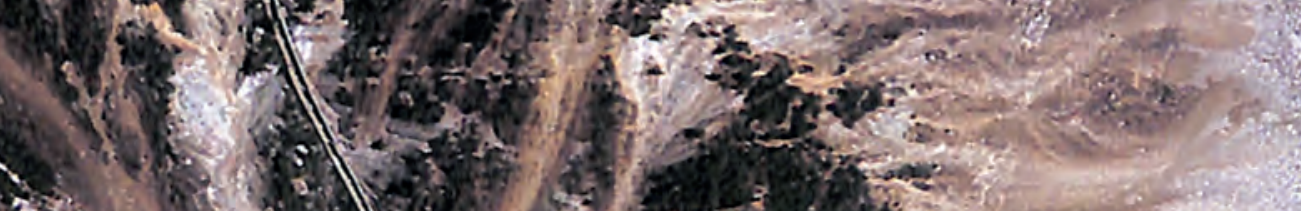

in

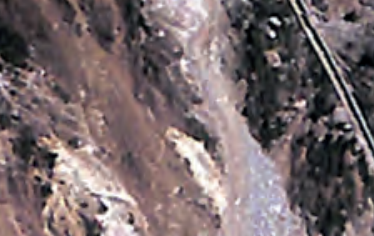

1 1
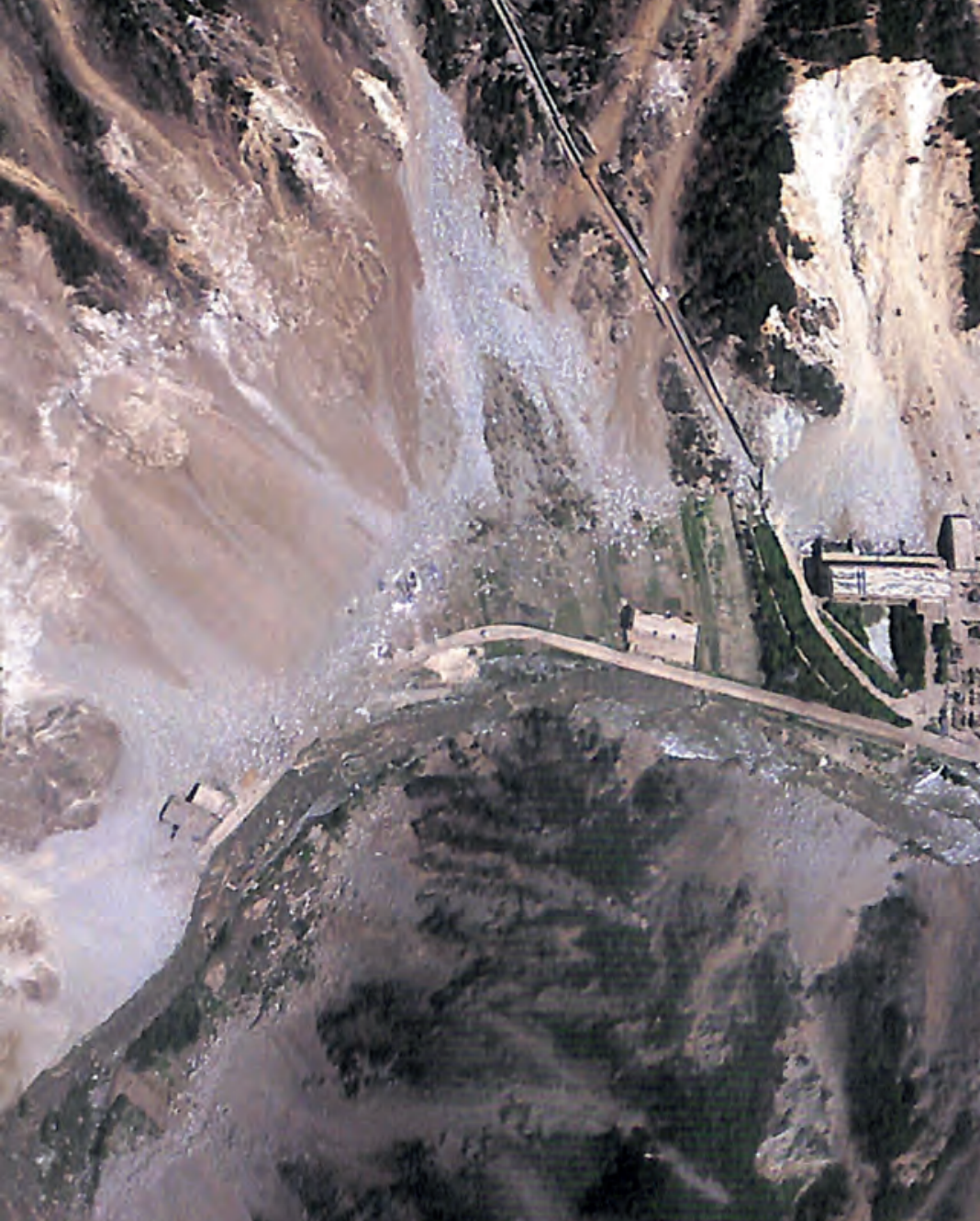
N

atsmyos

$\operatorname{lin} x$

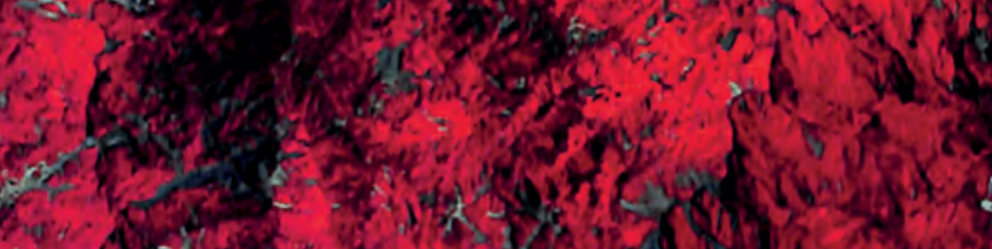

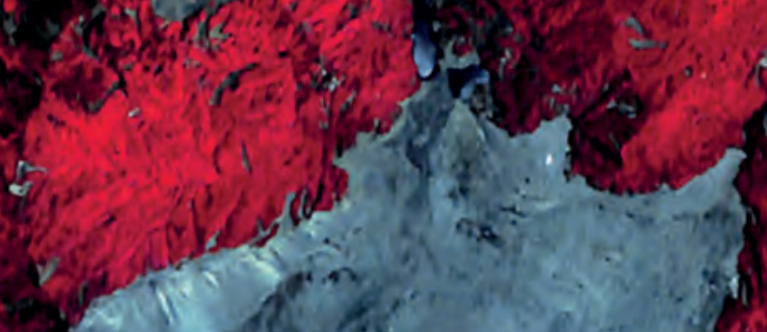

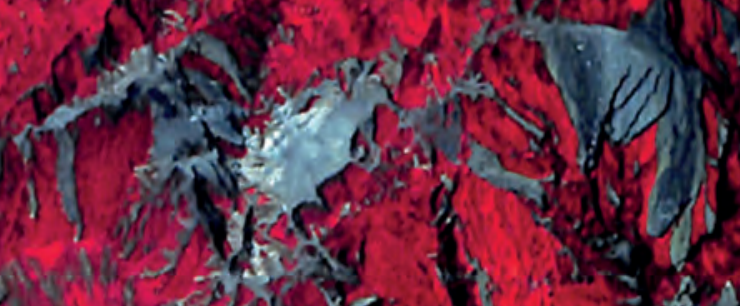

of 13

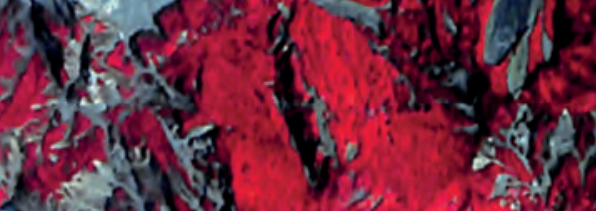

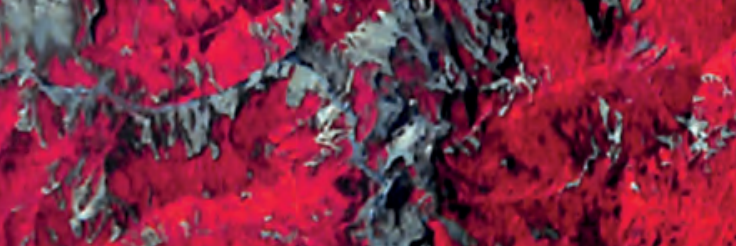

$e^{2}$

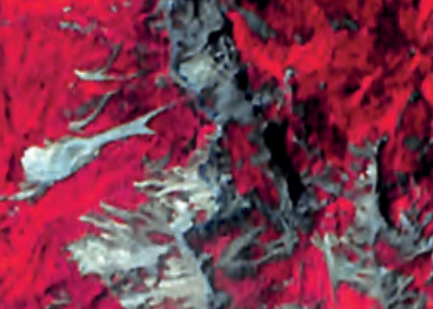

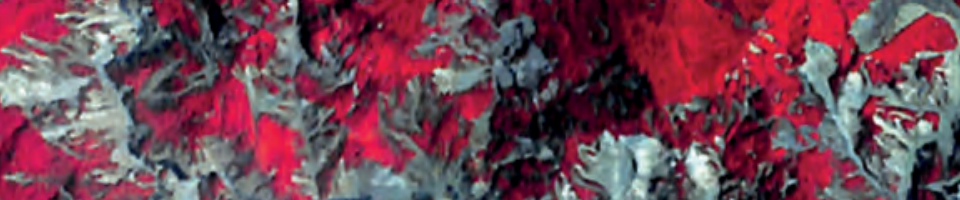

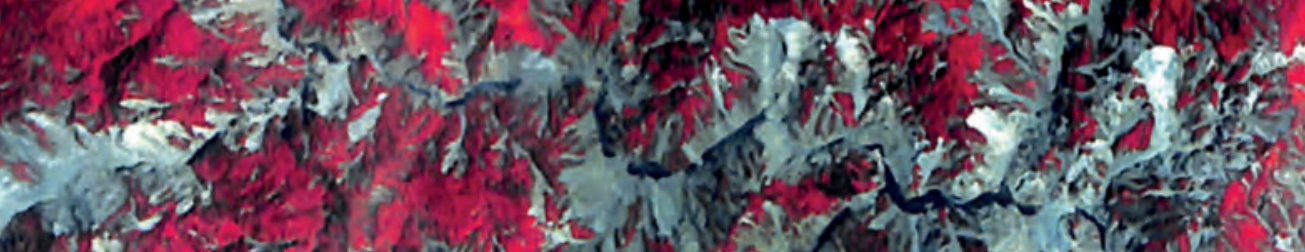

(1)

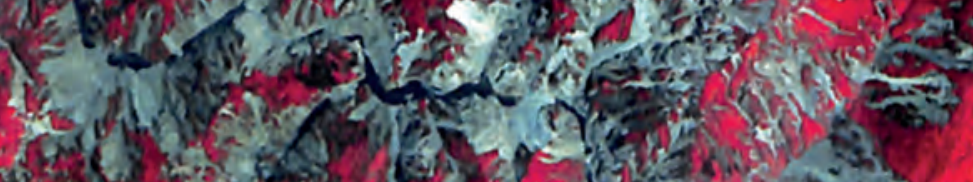

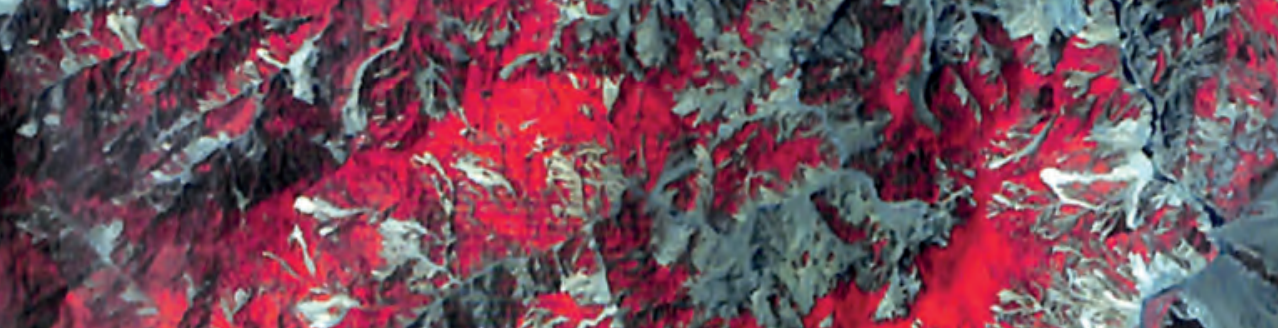

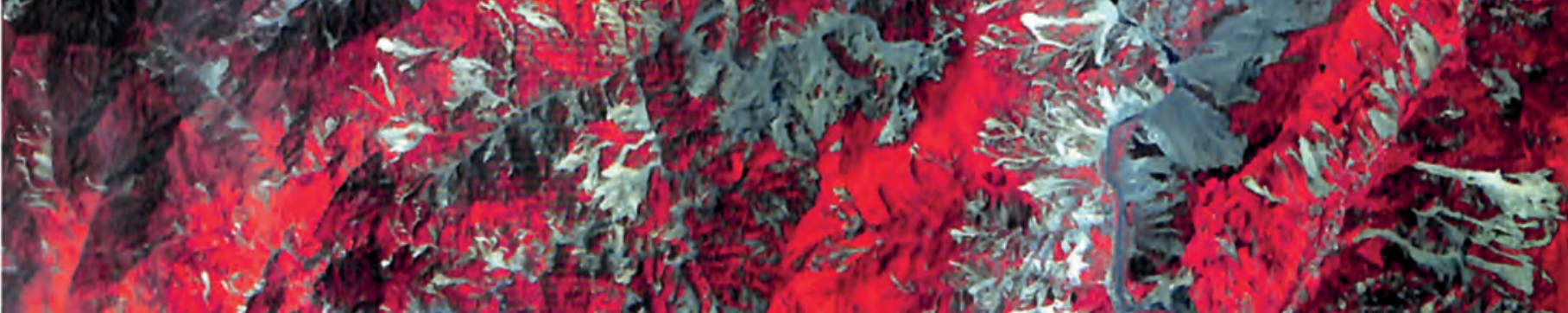

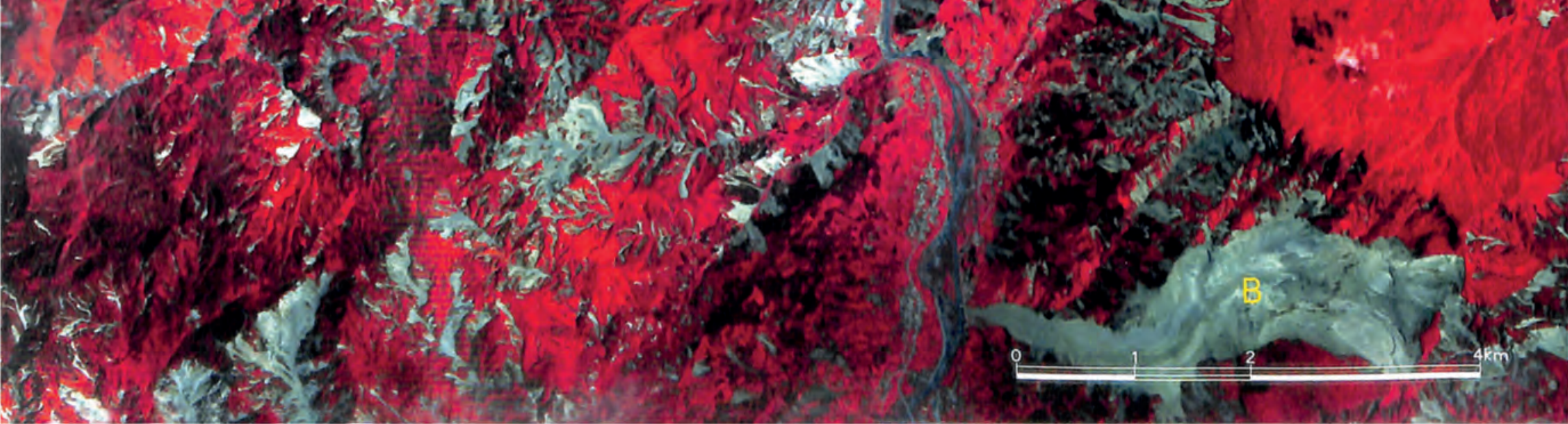

58 I Atlas of Remote Sensing of the Wenchuan Earthquake 


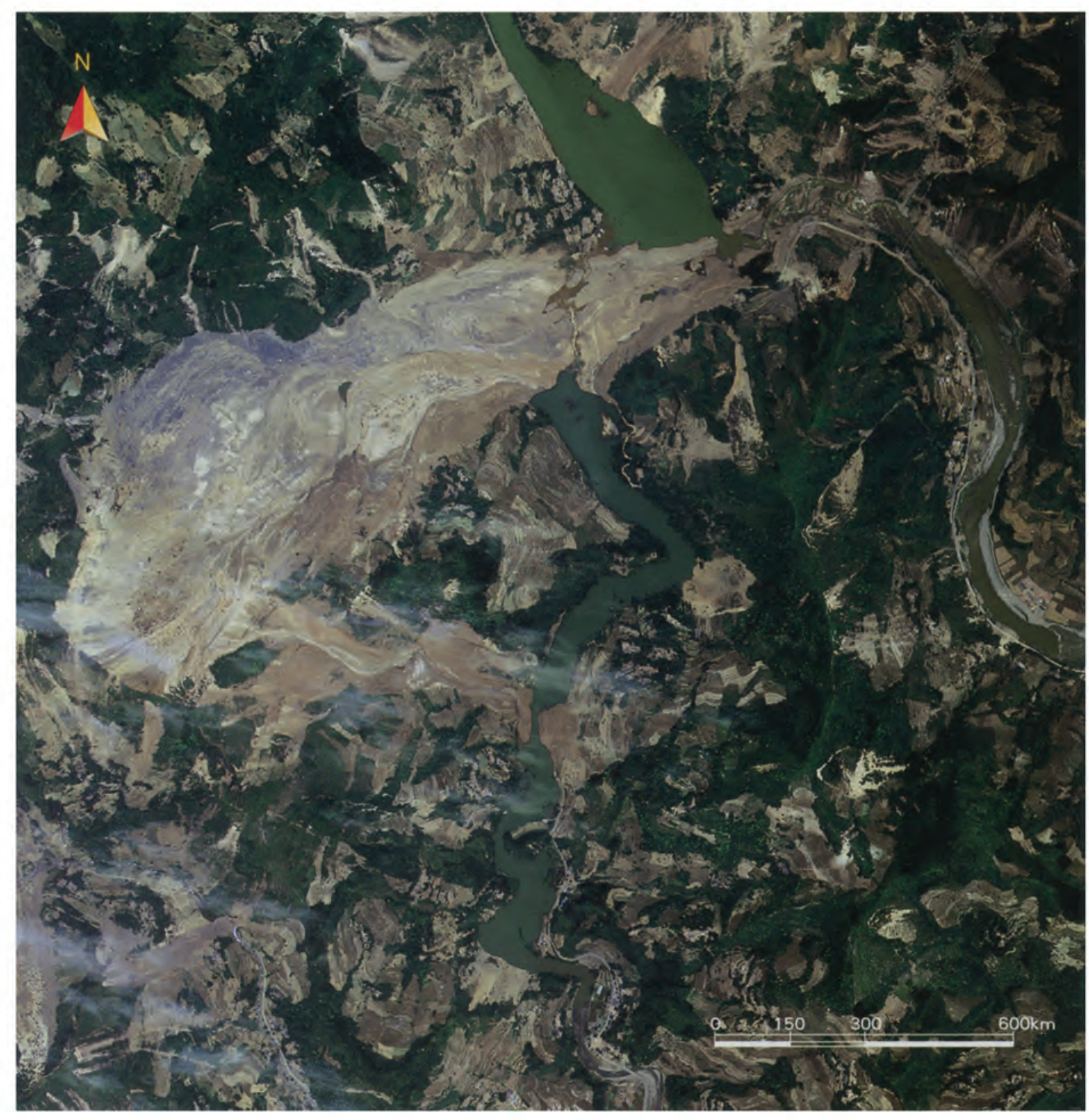

A Airborne remote sensing optical imagery of Gujing Village, in Qingchuan County

This image was captured on May 28, 2008. The large-area landslides were found near Gujing Village. Its area is $1.1 \mathrm{~km}^{2}$. Large areas of farmlands were destroyed, the roads were buried, and the riverways were blocked by slump deposits. Then the barrier lake was formed.

\section{ALOS satellite imagery of Gaochuan Township in Anxian County}

This image was captured on May 16, 2008. From the image we can see that the landslides were found near Gaochuan Township at the junction of Anxian County and Mianzhu City. The sliding mass marked A is located at $104^{\circ} 7^{\prime} 20^{\prime \prime} \mathrm{E}, 31^{\circ} 38^{\prime} 37^{\prime \prime} \mathrm{N}$, its length is $4.89 \mathrm{~km}$, and its area is 8.79 $\mathrm{km}^{2}$. The sliding mass noted by B is located at $104^{\circ} 8^{\prime} 19^{\prime \prime} \mathrm{E}, 31^{\circ} 33^{\prime} 10^{\prime \prime} \mathrm{N}$, and its length is $4.12 \mathrm{~km}$, and its area is $4.78 \mathrm{~km}^{2}$. 


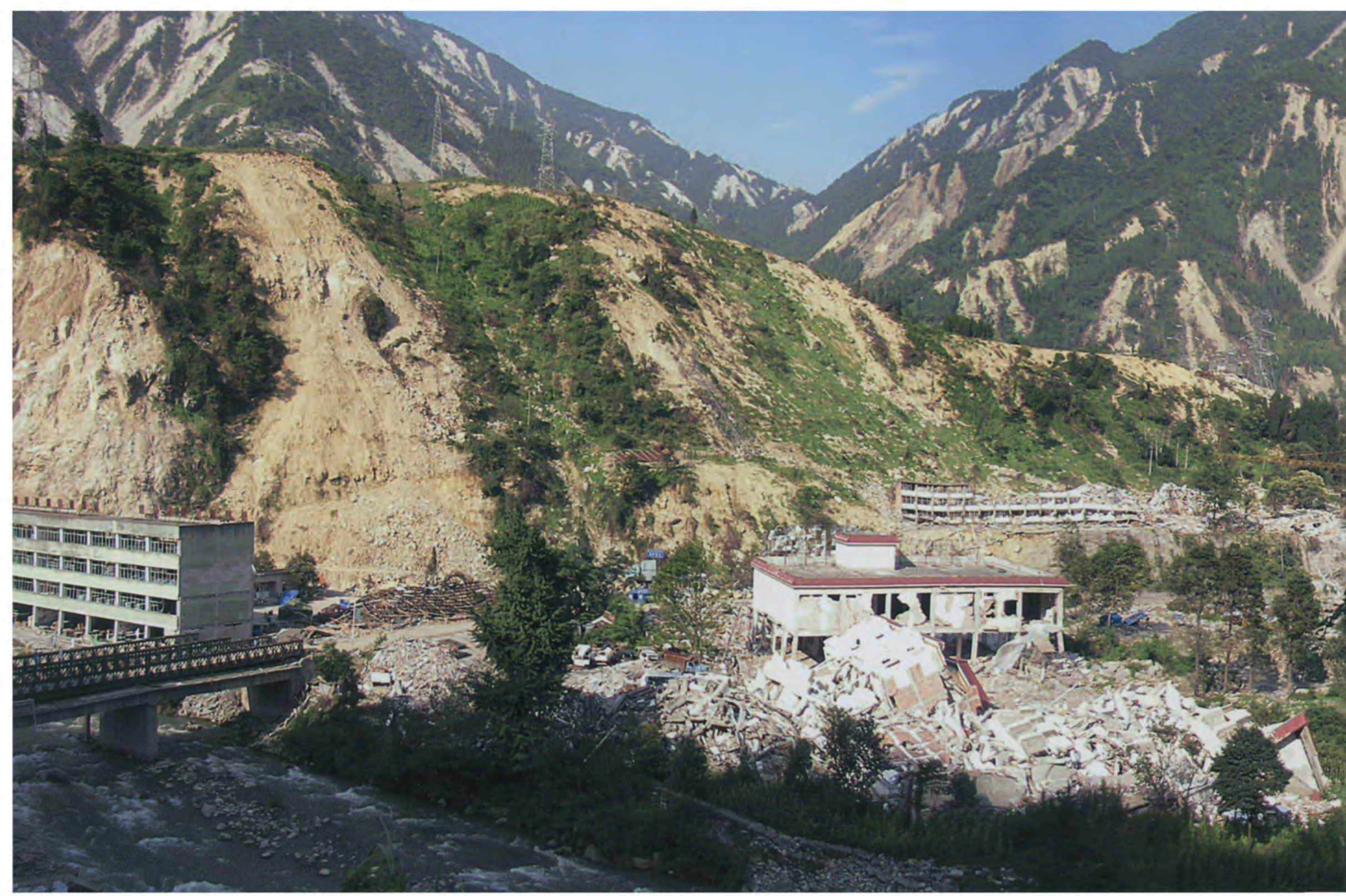

A photo of the town of Yingxiu after the earthquake

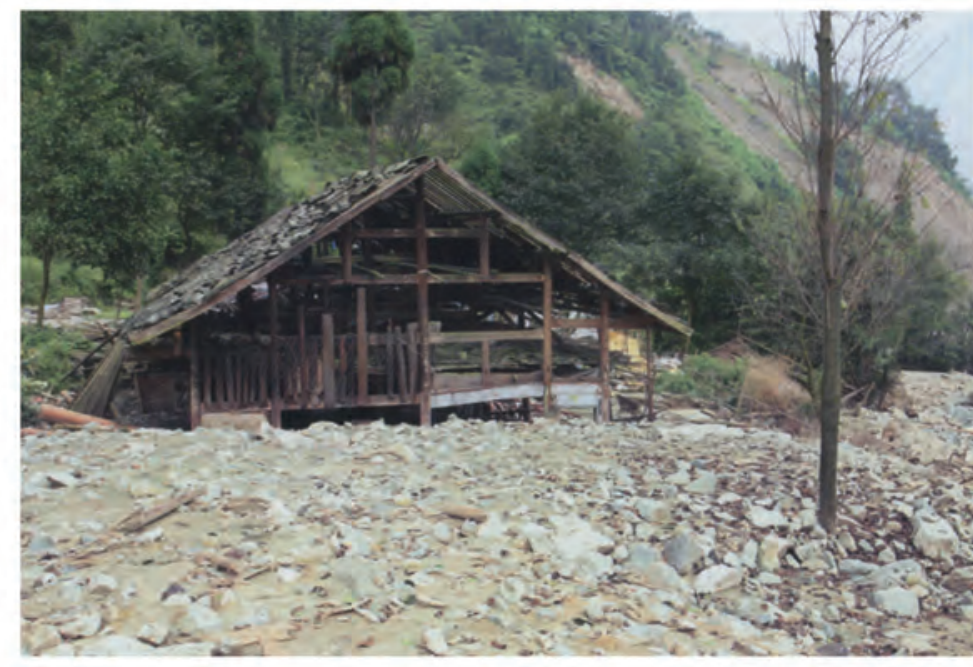

A building destroyed by debris flow

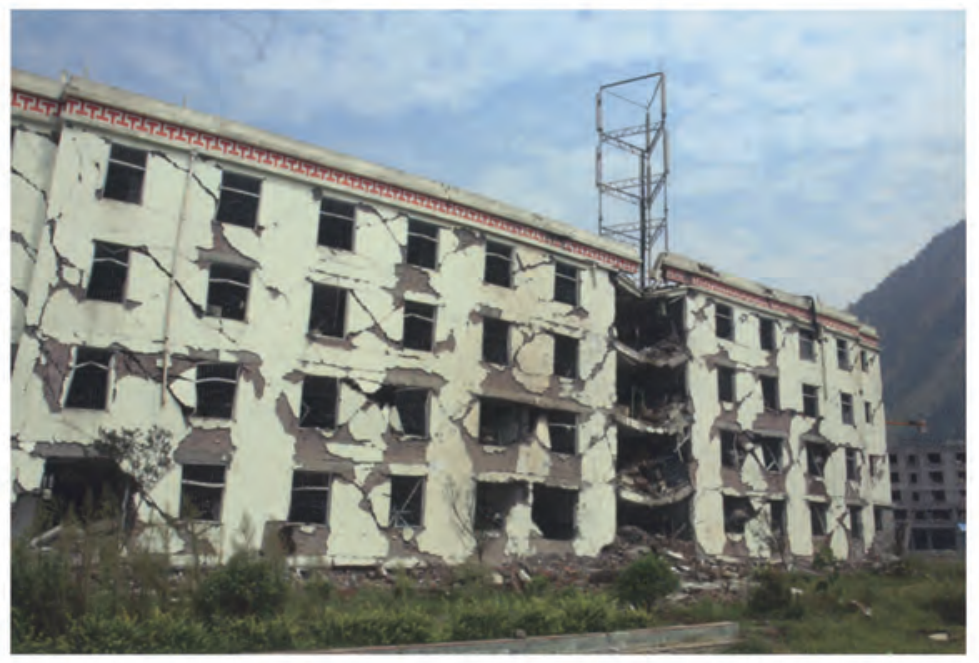

A building destroyed by the earthquake

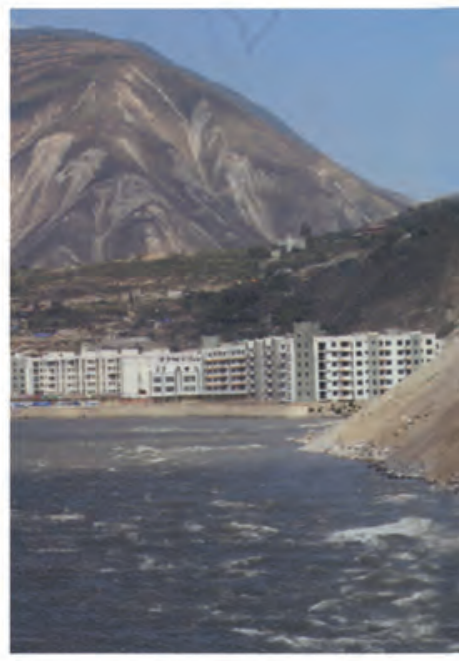

60 I Atlas of Remote Sensing of the Wenchuan Earthquake 


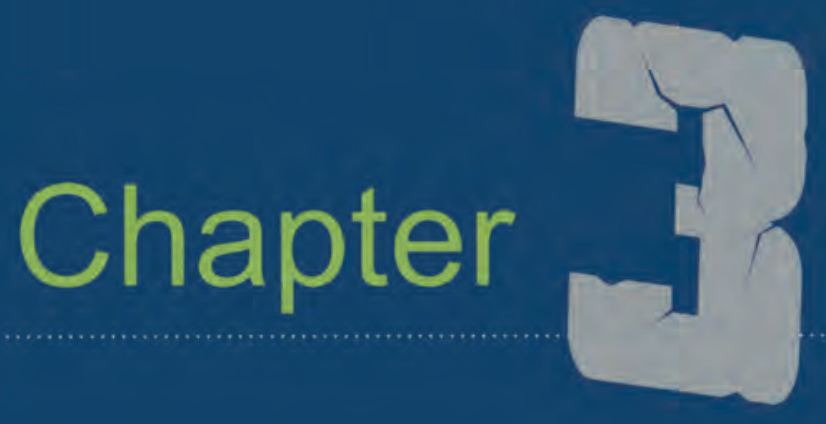

\section{BARRIER LAKES}

Barrier lakes are formed by water accumulation that occurs while a river valley or river bed is blocked by large-scale landslides. Barrier lakes are held in place by unstable dams, which could wash out, corrode, dissolve, or dissipate. The water level of a barrier lake can increase quickly, bringing more potential risks in the event of secondary disasters such as aftershocks and landslides. Barrier lakes can cause large-scale floods when dams collapse.

Many barrier lakes were formed by the Wenchuan earthquake. bringing huge risks to the areas downstream of the barrier lakes. Through analysis and evaluation of remotely sensed images, scientists can determine methods of harnessing barrier lakes. Optical images are intuitive and easy to understand, while radar images can be taken and viewed in all weather conditions. We have examined 46 barrier lakes in the disaster area. In this section we provide high-quality spaceborne and airborne remote sensing images of barrier lakes, including optical images with various resolutions and radar images with various resolutions and polarization conditions, such as spaceborne TerraSAR-X. Radarsat-I and -2. COSMO-SkyMed. IKONOS. SPOT 5, etc., and airborne multi-polarization SAR and optical images with a spatial resolution of $0.5 \mathrm{~m}$. 


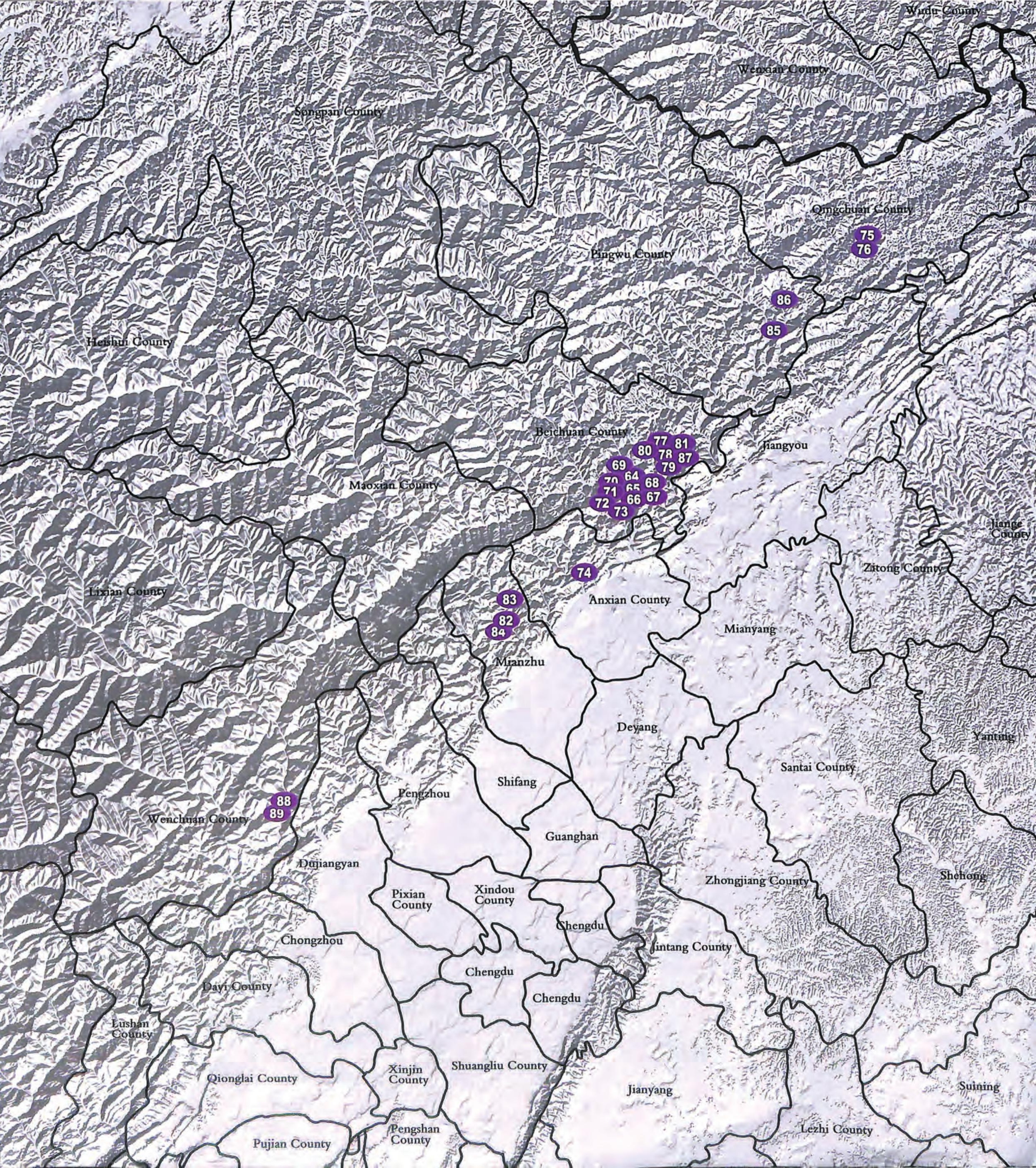


A full view of Tangfiashan Barrier Lake in Beichuan County (acquired on May 19,2008 , from the Cofierdam to Yuli Village)

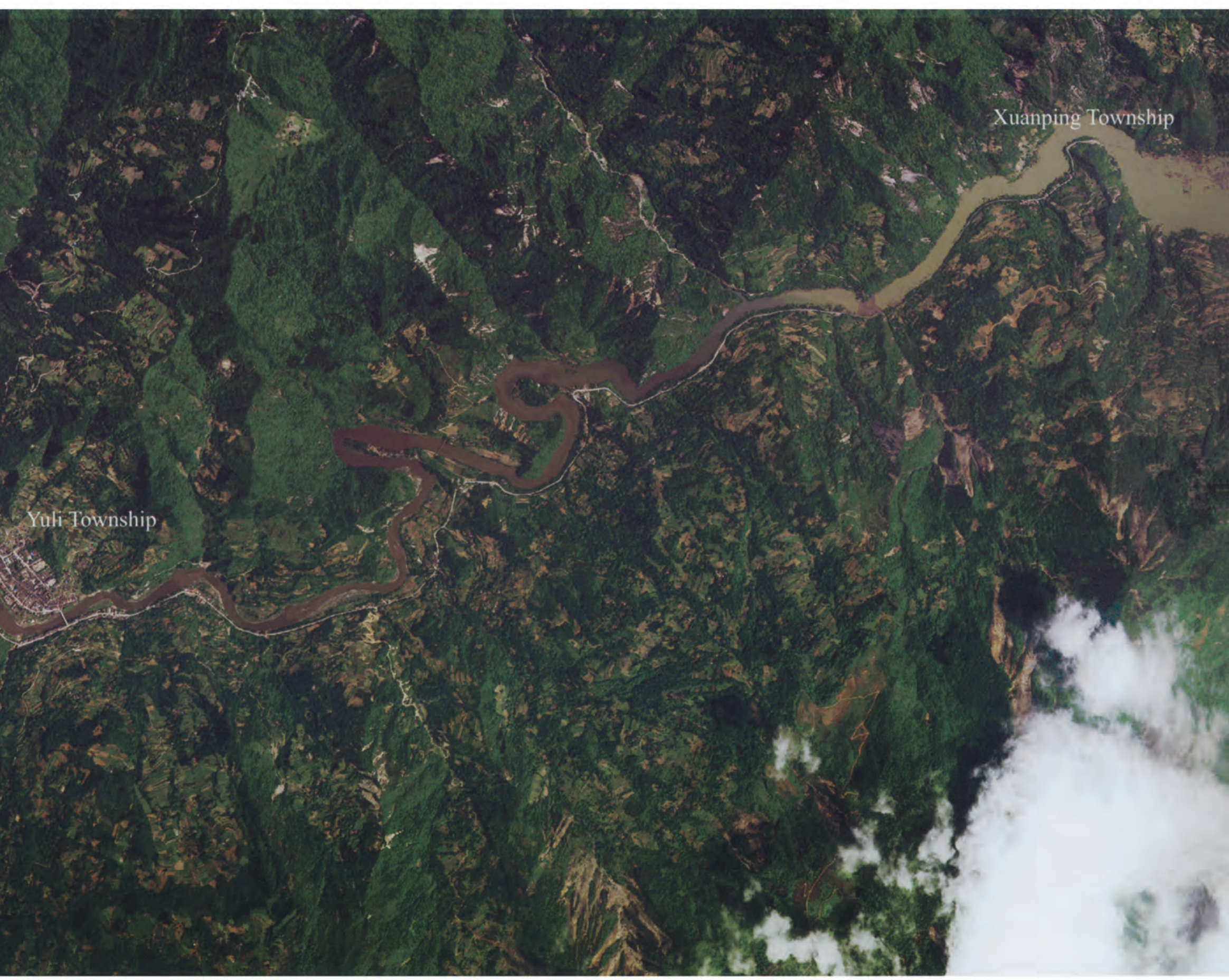

64 I Atlas of Remote Sensing of the Wenchuan Earthquake 


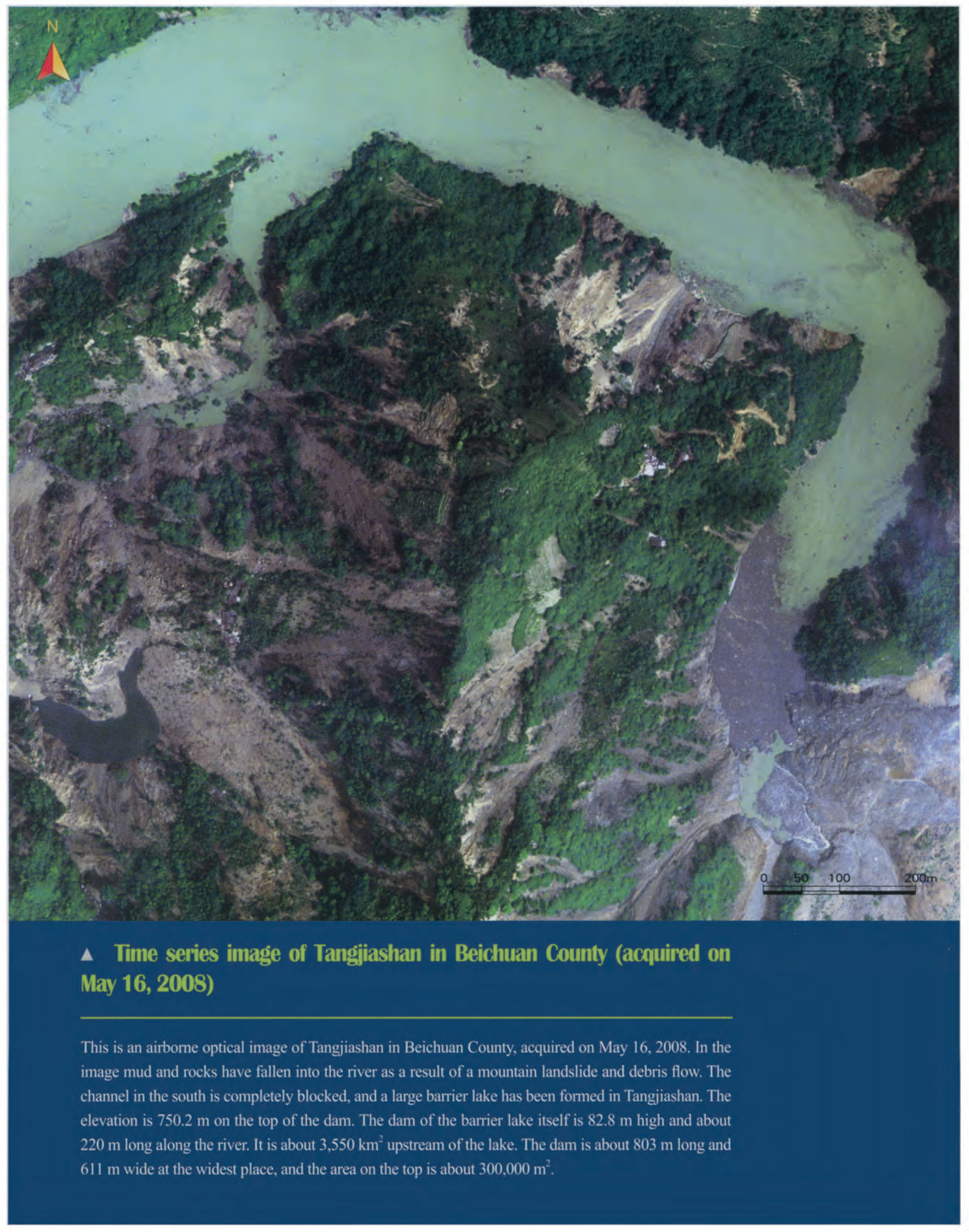

66 I Atlas of Remote Sensing of the Wenchuan Earthquake 
v Time series image of Tangjiashan in Beichuan County (acquired on May 19, 2008)

This is an airborne optical image of Tangjiashan in Beichuan County, acquired on May 19, 2008. The water level is increasing because of the river supply. Until May 19, the water storage of Tangjiashan Barrier Lake was about 30 million $\mathrm{m}^{3}$.

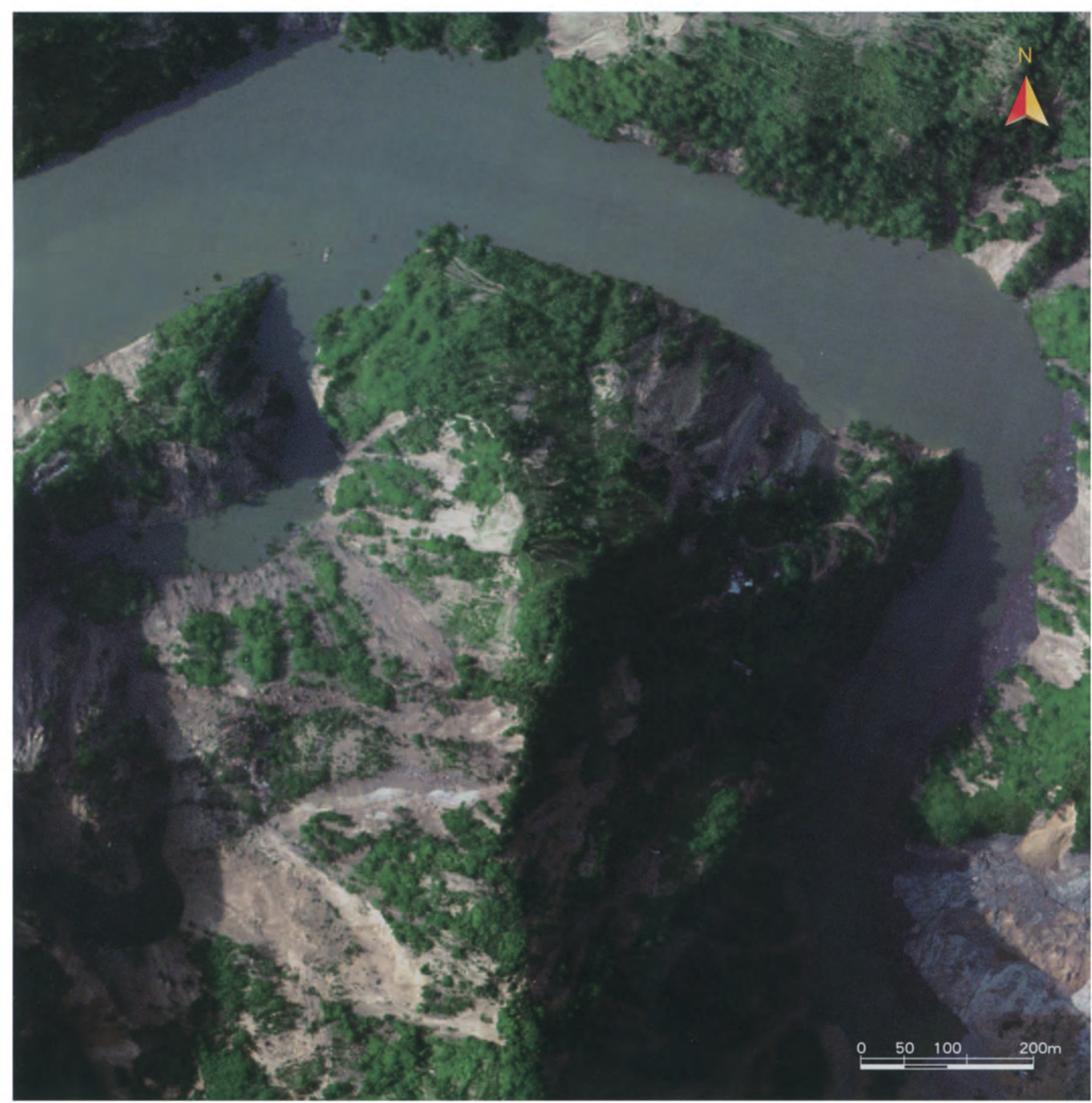




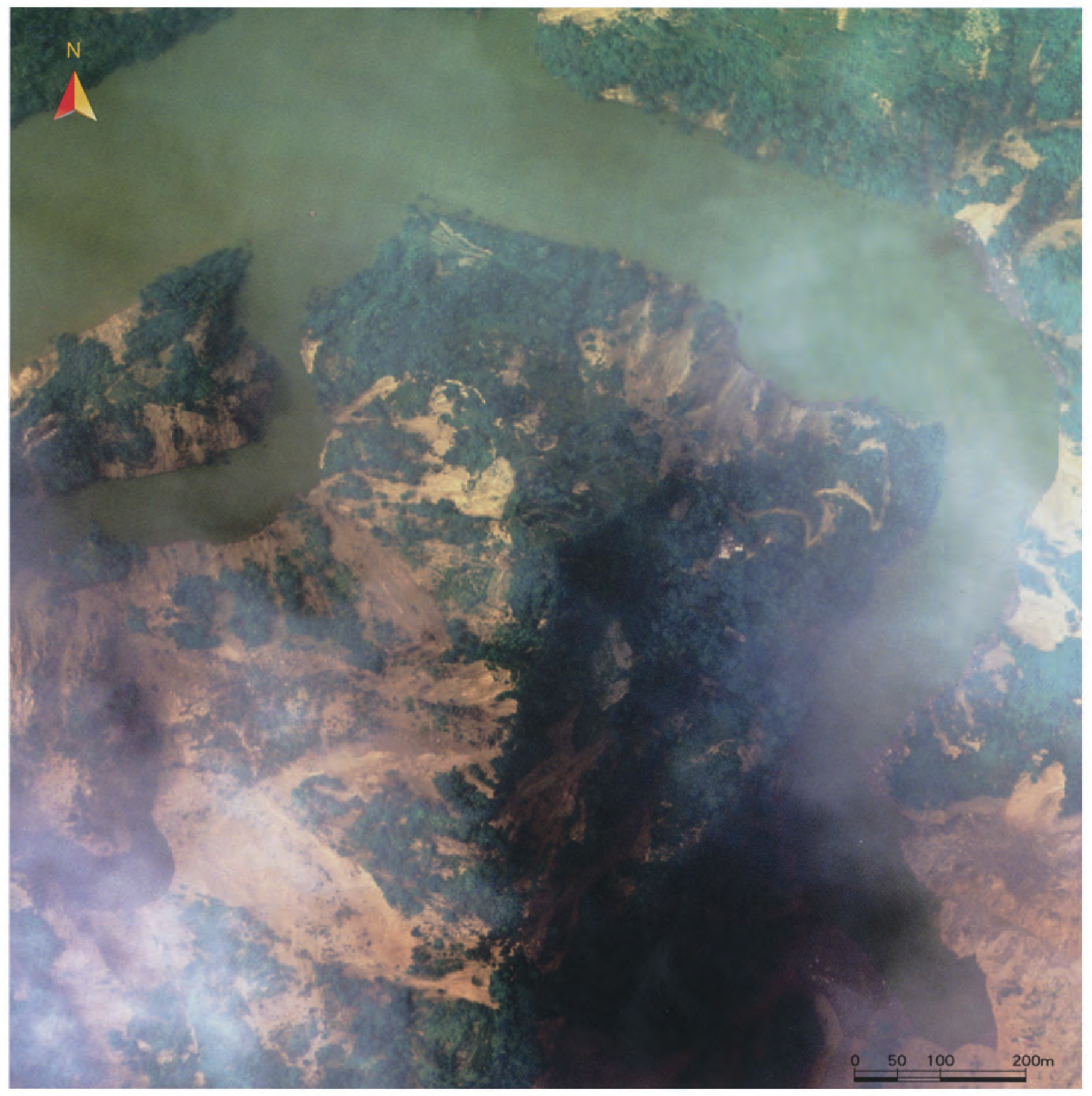

\ Time series image of Tangiiashan in Beichuan County (acquired on May 23, 2008)

This is an airborne optical image of Tangiiashan in Beichuan County, acquired on May 23, 2008. River input caused the water levels to increase constantly. As of 23 May, the water storage of Tangjiashan Barrier Lake was about 100 million $\mathrm{m}^{3}$. The water level increased $2.6 \mathrm{~m}$ compared to the day before. 


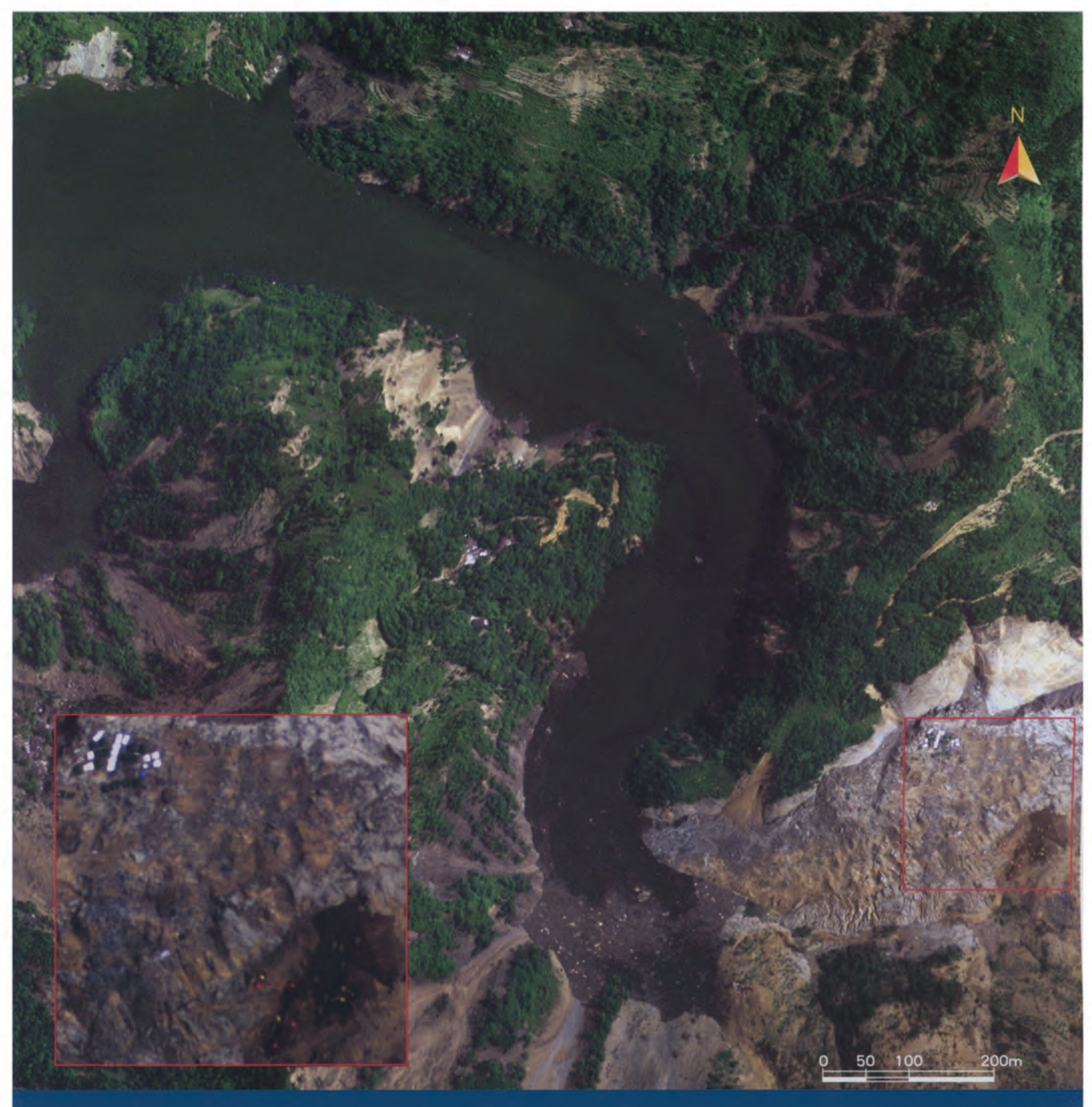

$\Delta$ Time series image of Tangfiashan in Beichuan County (acquired on May 27, 2008)

This is an airborne optical image of Tangiiashan in Beichuan County acquired on May 27, 2008. River input caused the water levels to increase constantly. At 8 am on May 27,the elevation of the water level in Tangjiashan Barrier Lake was $727.02 \mathrm{~m}$, an increase of $1.82 \mathrm{~m}$ compared to the water level at 8 am on May 26, 2008. It was $23.18 \mathrm{~m}$ from the water surface to the top of the dam of the barrier lake. The water depth near the dam is $60.37 \mathrm{~m}$. In the image, disaster-relief tents are clear to the north of the dam. Large equipment is seen working in the diversion channel excavating the field. The diversion channel was excavated $180 \mathrm{~m}$ at that time. 

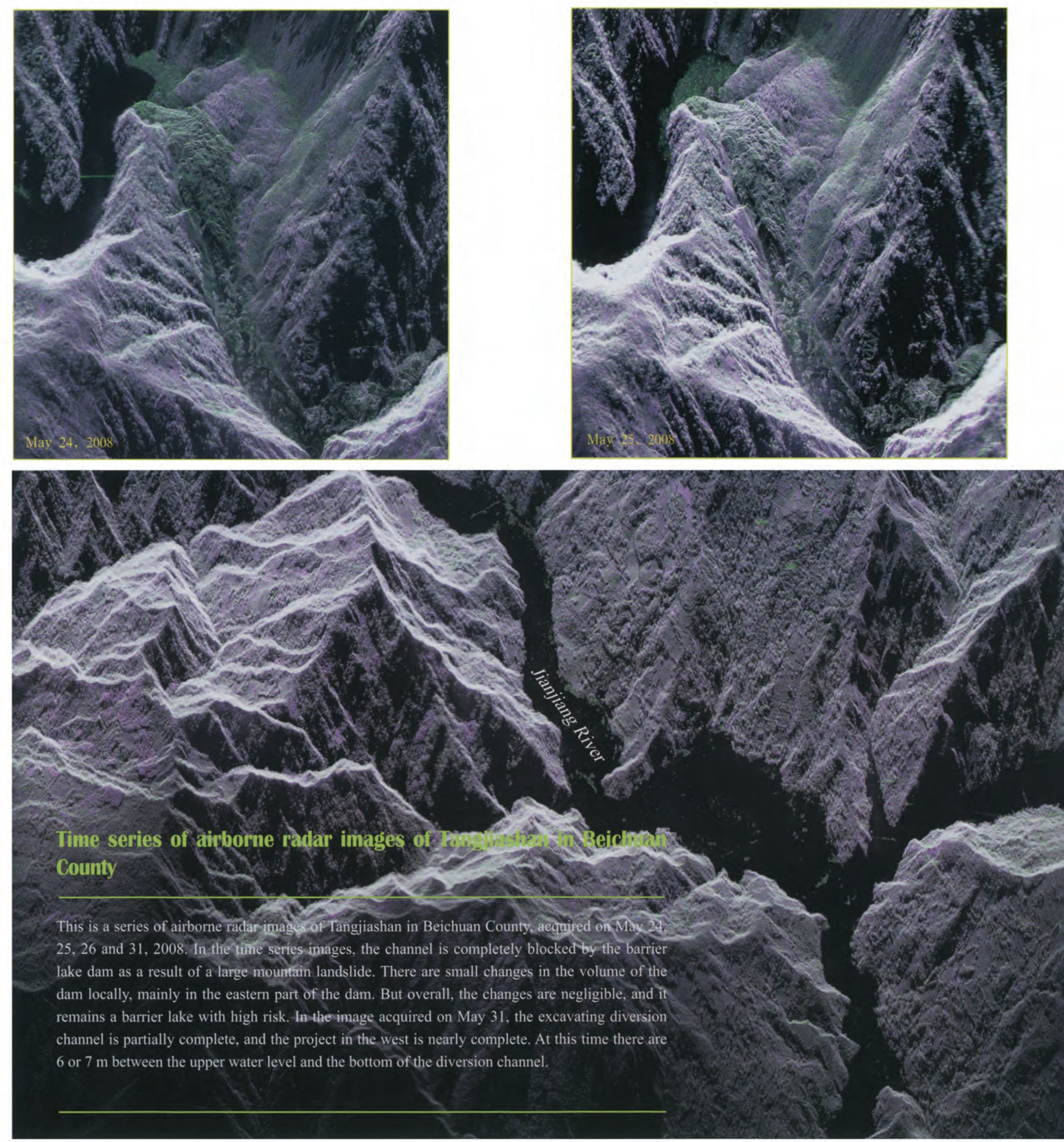

70 I Atlas of Remote Sensing of the Wenchuan Earthquake 


\section{v Comparison of Radarsat images of Tangjiashan in Beichuan County before and after the earthquake}

Above is a Radarsat-1 image acquired on December 19, 2007 (before the earthquake) around the Tangjiashan Barrier Lake in Beichuan County. Below is a Radarsat-1 image acquired on May 14, 2008 (after the earthquake) around the Tangjiashan Barrier Lake in Beichuan County. The changes are clear from the comparison of the two images: barrier lakes and cofferdams are formed, blocking the river channels in Jianjiang Basin because of landslides, debris flow, and some other factors.

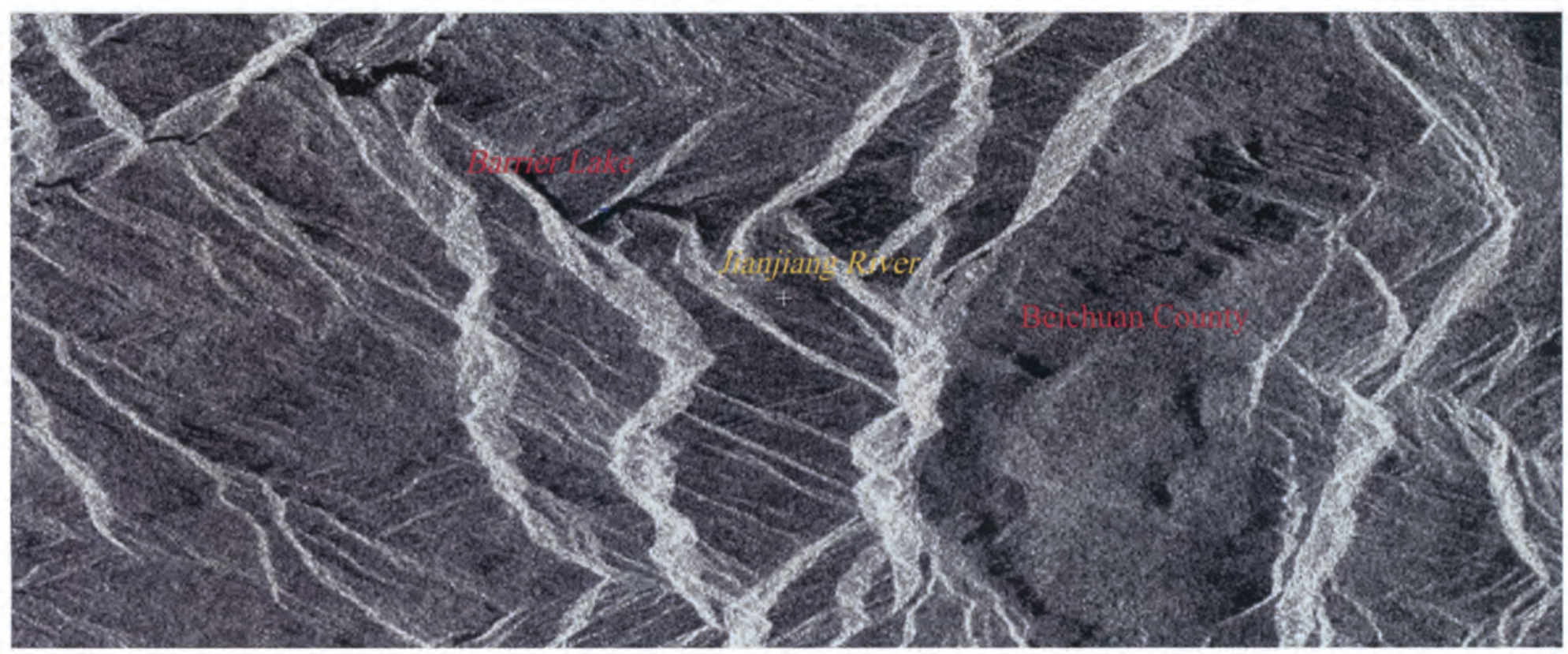

Radarsat-I image acquired on May 14, 2008

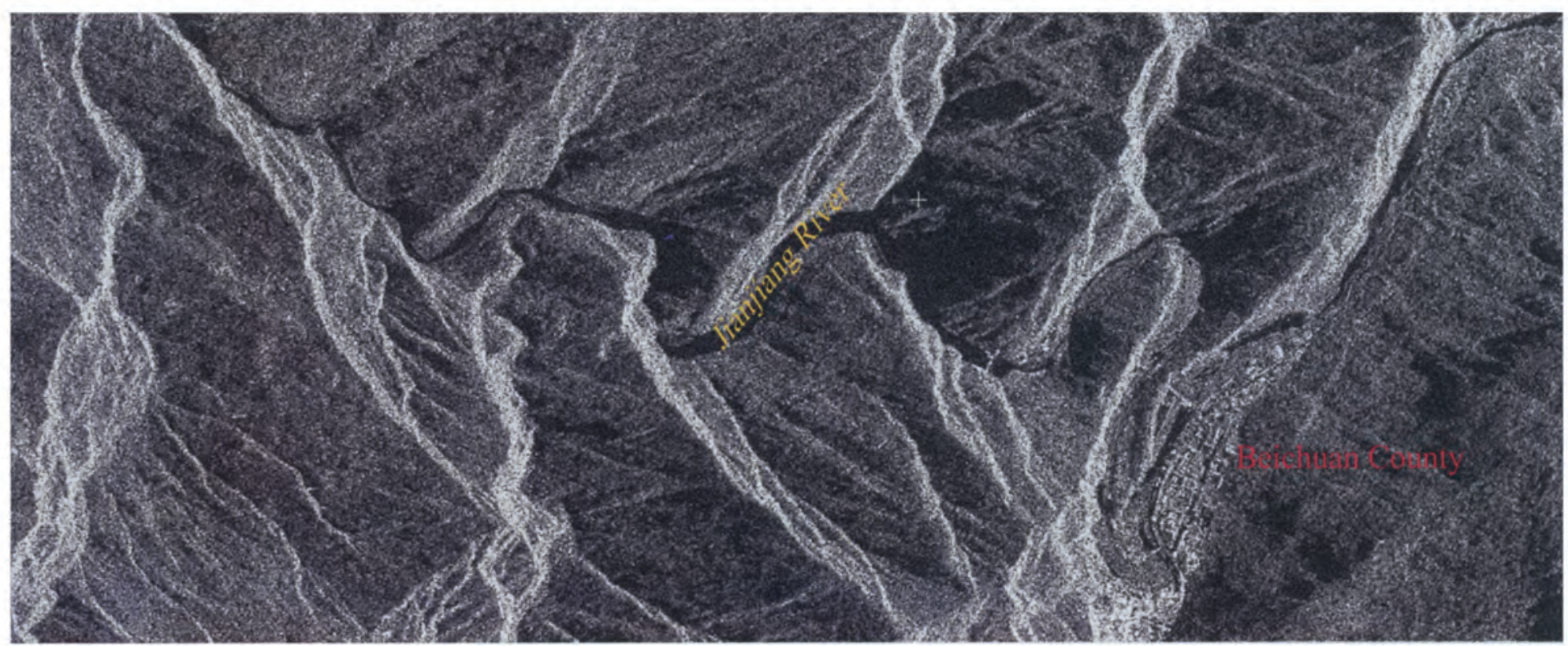

Radarsat- 1 image acquired on December 19, 2007

72 I Atlas of Remote Sensing of the Wenchuan Earthquake 


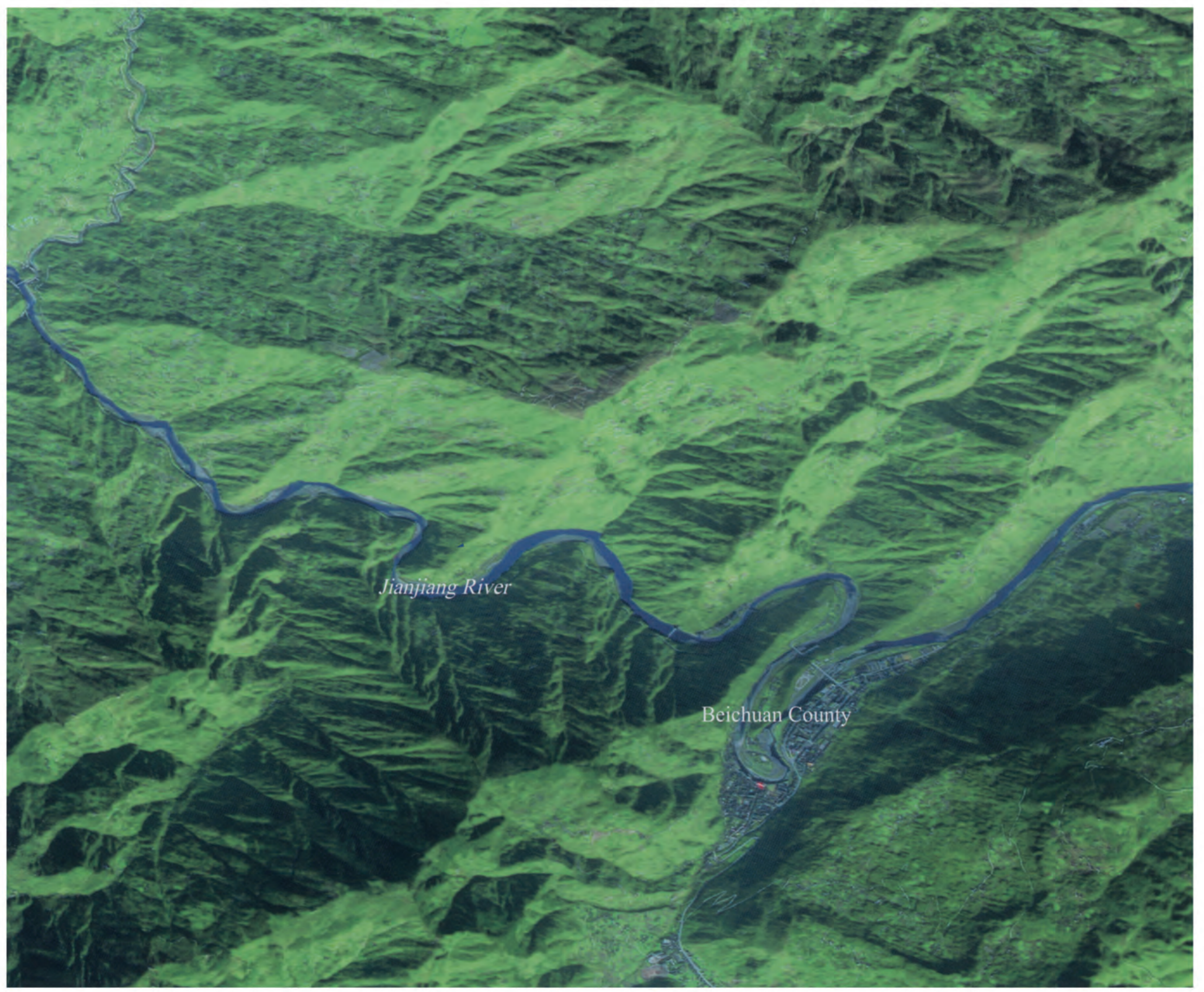

SPOT 5 image acquired on November 10, 2006 


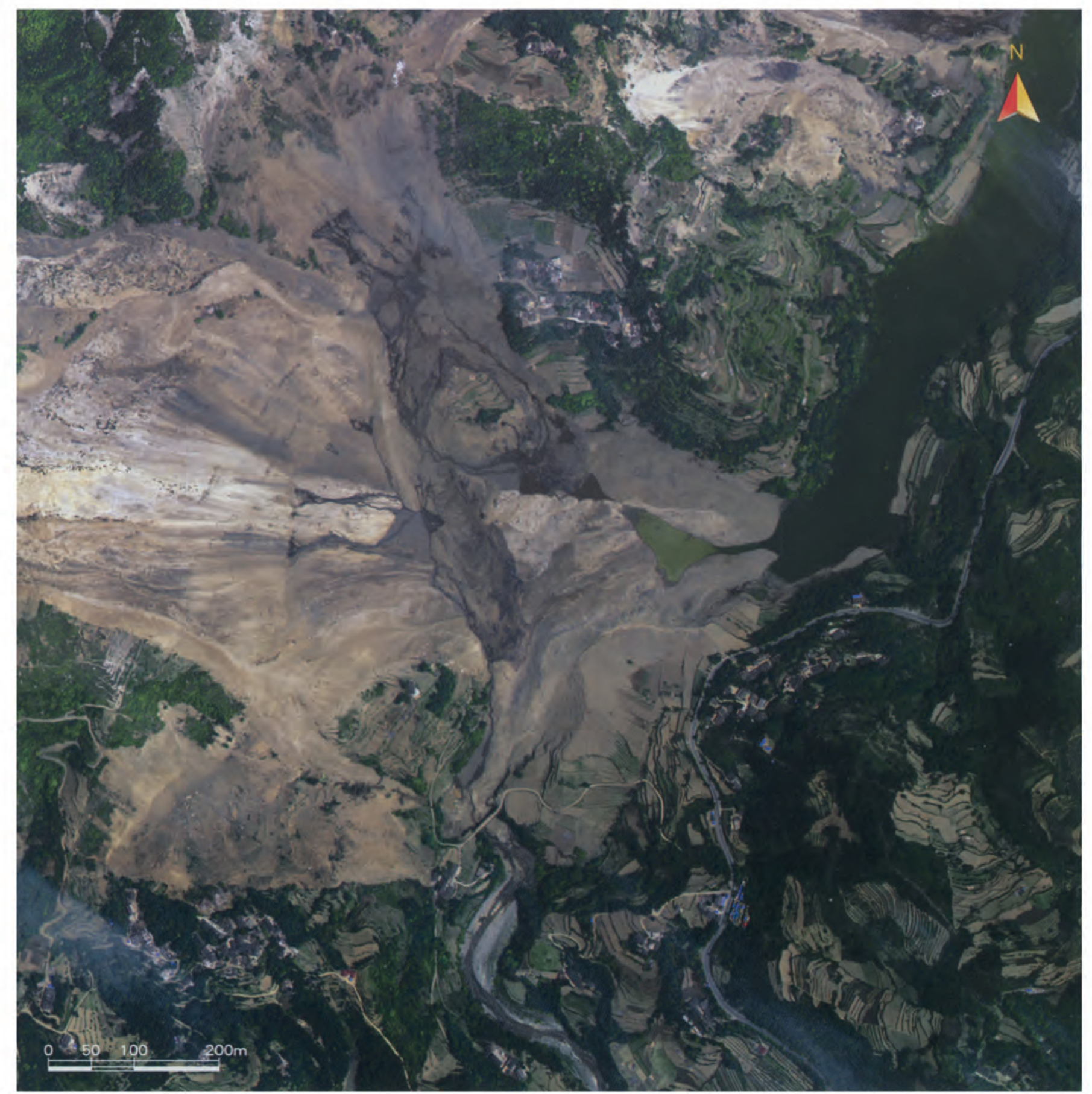

\section{A Airborne optical image of a barrier lake in Xiaojiaqiao}

This is an airborne optical image of Xiaojiaqiao, acquired on May 19, 2008. Large barrier lakes formed in Xiaojiaqiao because of landslides during the earthquake. The river channel was completely blocked by the dam, and this barrier lake is one of the most dangerous lakes. The water volume of the lake is more than 10 million $\mathrm{m}^{3}$, and the water level near the dam is more than $50 \mathrm{~m}$. The dam formed by mountain landslides is $198 \mathrm{~m}$ wide and 200 $\mathrm{m}$ long.

\section{- Airborne optical image of the barrier lake in Donghekou, in Qingchuan County}

This is an airborne optical image of Donghekou in Qingchuan County, acquired on May 28, 2008. The image shows that many mountain landslides occurred in the area of Donghekou, in Hongguang Village, in Qingchuan County as a result of the earthquake, and the landslide volume reached more than 20 million $\mathrm{m}^{3}$. Channels are blocked, and three barrier lakes, Donghekou, Hongshi River, and Shibangou, with a total volume of 12 million $\mathrm{m}^{3}$, were formed in the Qingzhu and Hongshi Rivers. Although the Donghekou Barrier Lake is not too large, the river is completely blocked.

74 I Atlas of Remote Sensing of the Wenchuan Earthquake 

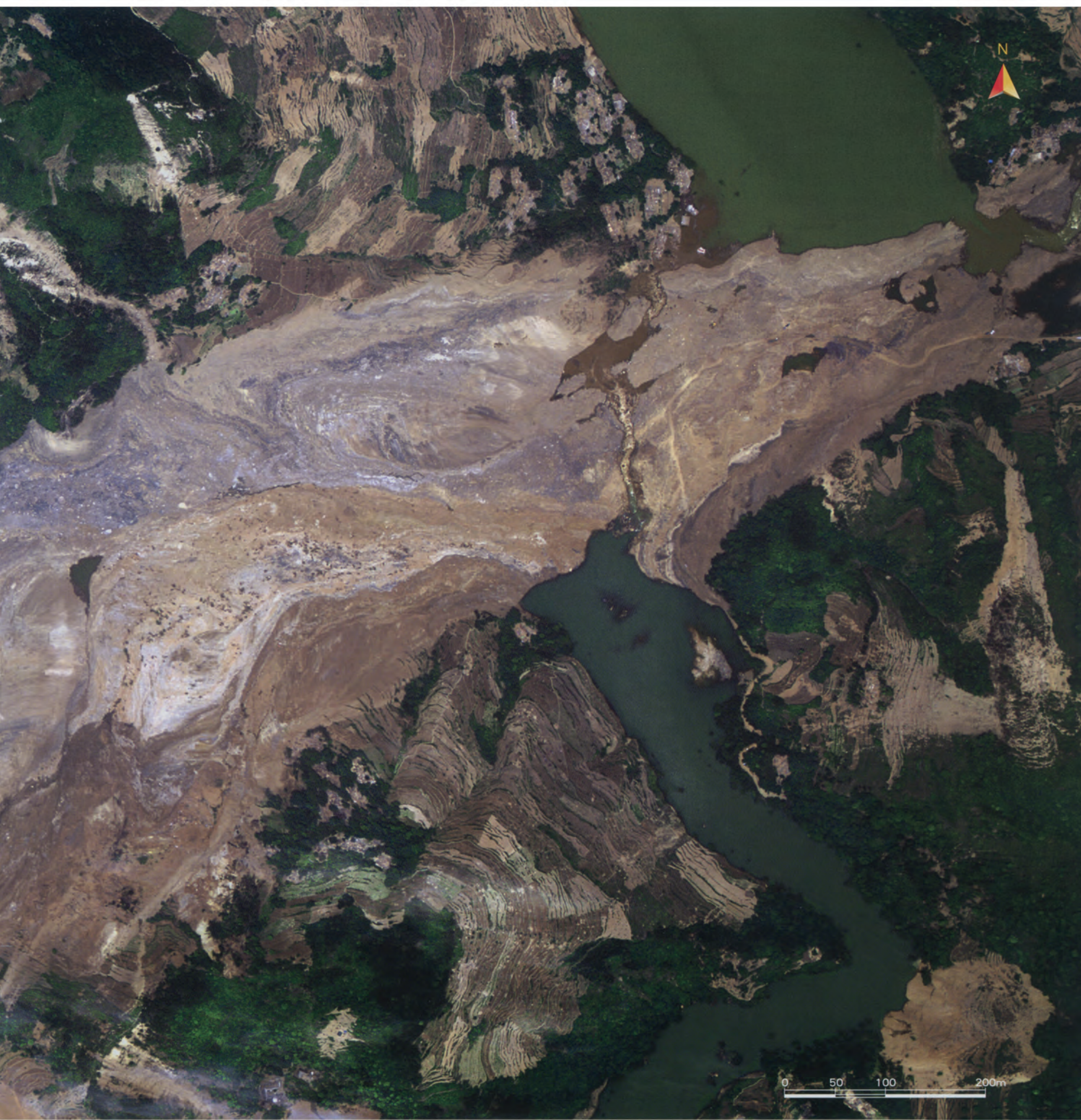

Barrier Lakes । 75 


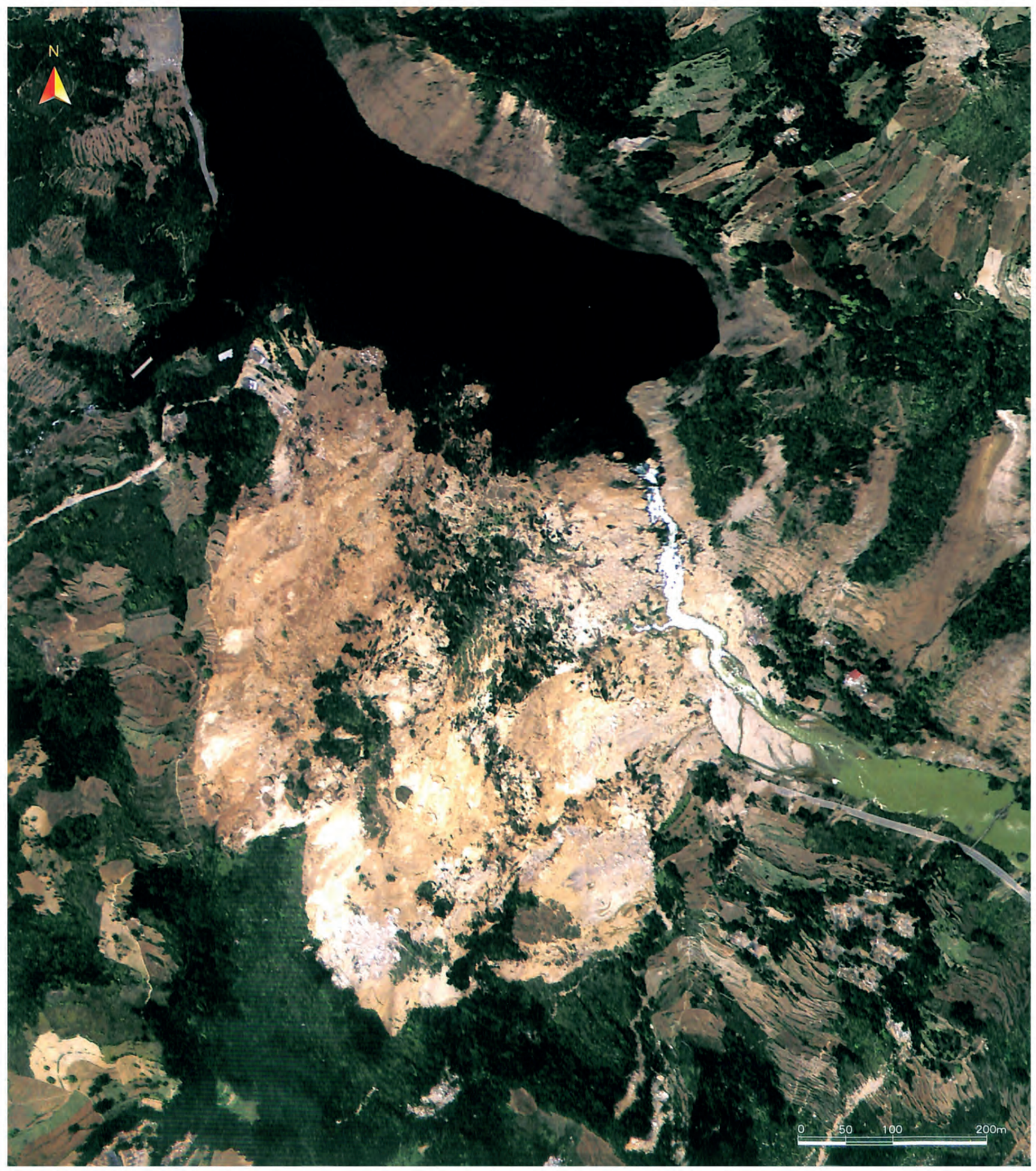

76 I Atlas of Remote Sensing of the Wenchuan Earthquake 


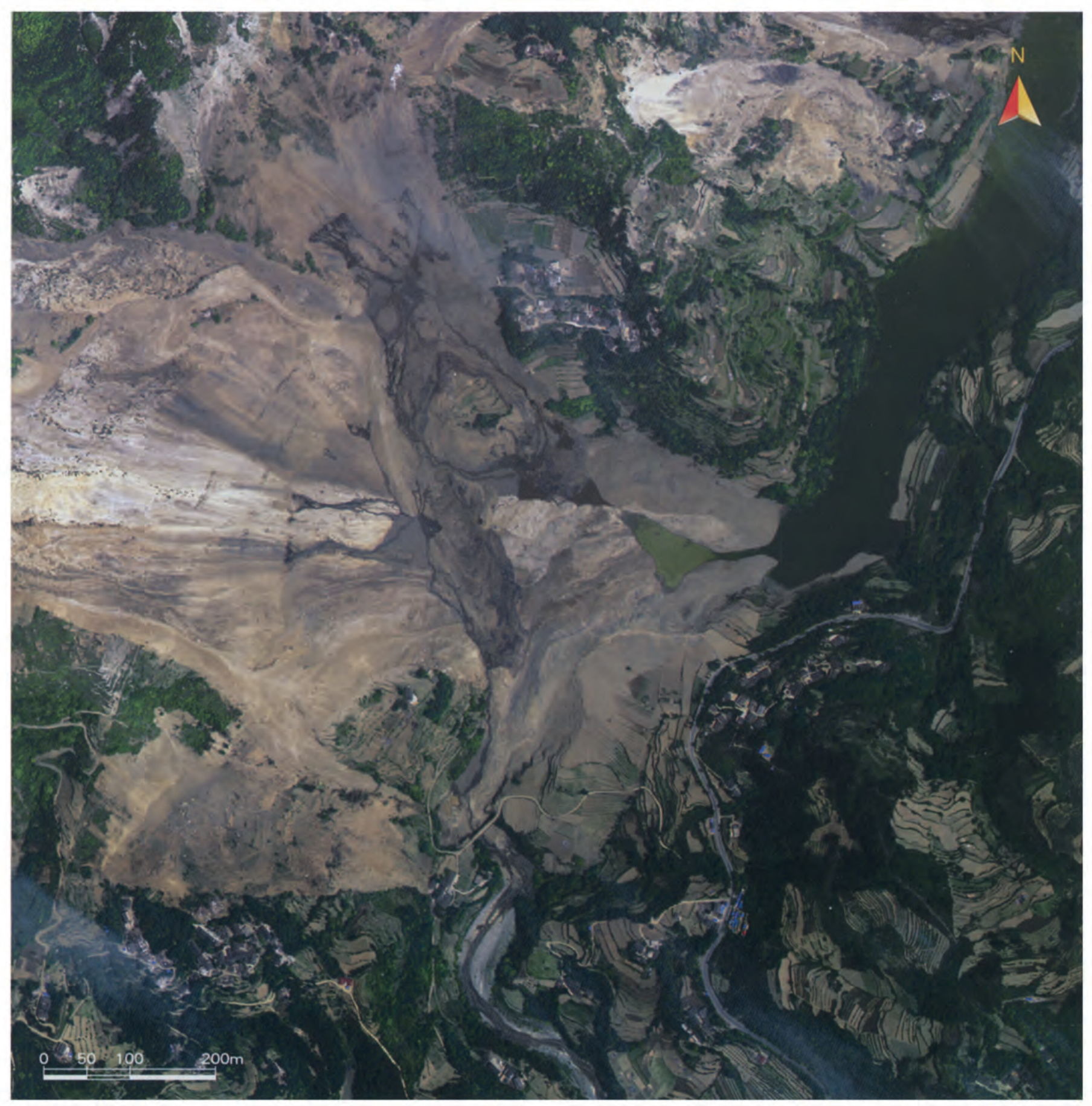

\section{$\checkmark$ Airborne optical image of the barrier lake in Kuzhuba, in Beichuan County}

This is an airborne optical image downstream of Kuzhuba in Beichuan County. Barrier lakes formed because of large mountain landslides blocking the river channel. The massive barrier body is heaped south of the channel and completely blocks the channel. The dam is stable because it is formed of hard stones, so dredging the river channel is very difficult.

\section{Airborne optical image of a barrier lake in Shibangou, in Qingchuan County}

This is an airborne optical image of Shibangou in Qingchuan County and Hongshi River, acquired on May 28, 2008. The large barrier lake is formed because of a large mountain landslide blocking the river channels. The lake lies $3 \mathrm{~km}$ away from Donghekou Barrier Lake upstream of Qingiiang River with a volume of 8 million $\mathrm{m}^{3}$, and it is formed by 10 million $\mathrm{m}^{3}$ of mountain landslide in both sides. The dam is $75 \mathrm{~m}$ high, $450 \mathrm{~m}$ wide, with a drop of $60 \mathrm{~m}$. 


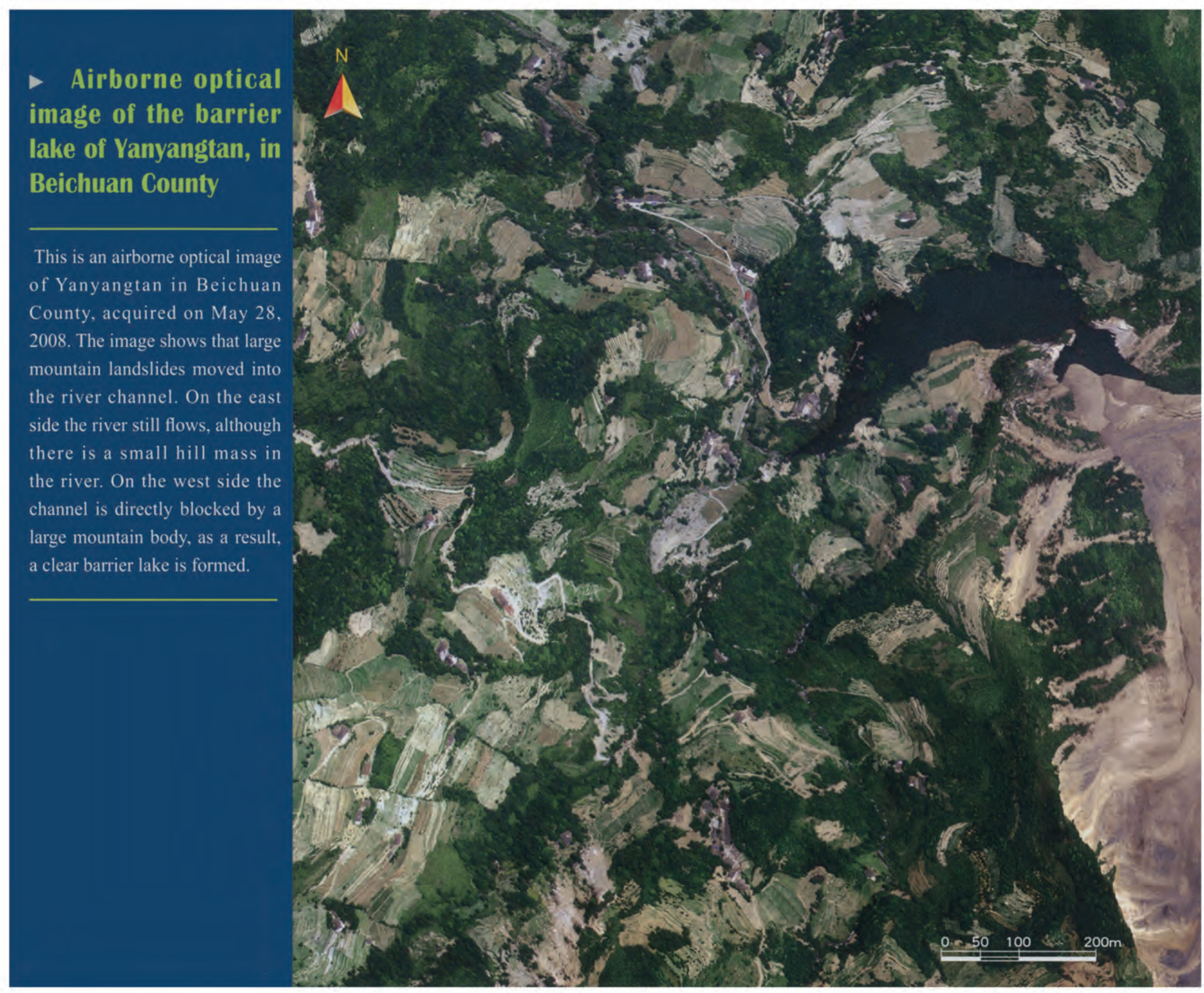

- Airborne optical image of the barrier lake in Guanzipu, in Qingchuan County

This is an airborne optical image of Guanzipu in Beichuan County, acquired on May 28, 2008. The barrier lake is formed south of the river as a result of large mountain landslides, debris flow, and other geological disasters that blocked the river channel. The volume of this lake is relatively small, and its water continues to flow in some places. The part of the river channel that is completely blocked is small.

78 I Atlas of Remote Sensing of the Wenchuan Earthquake 


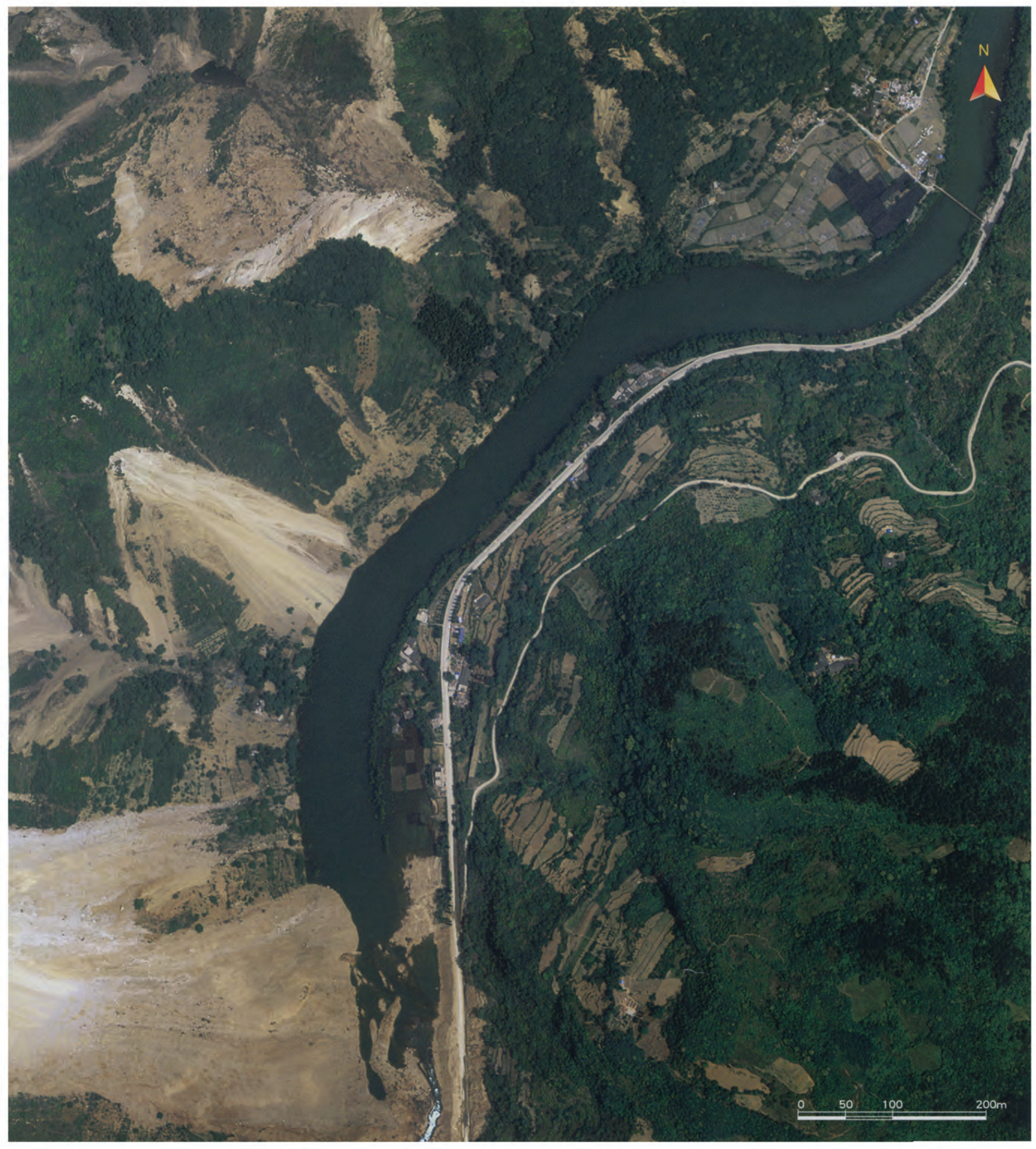



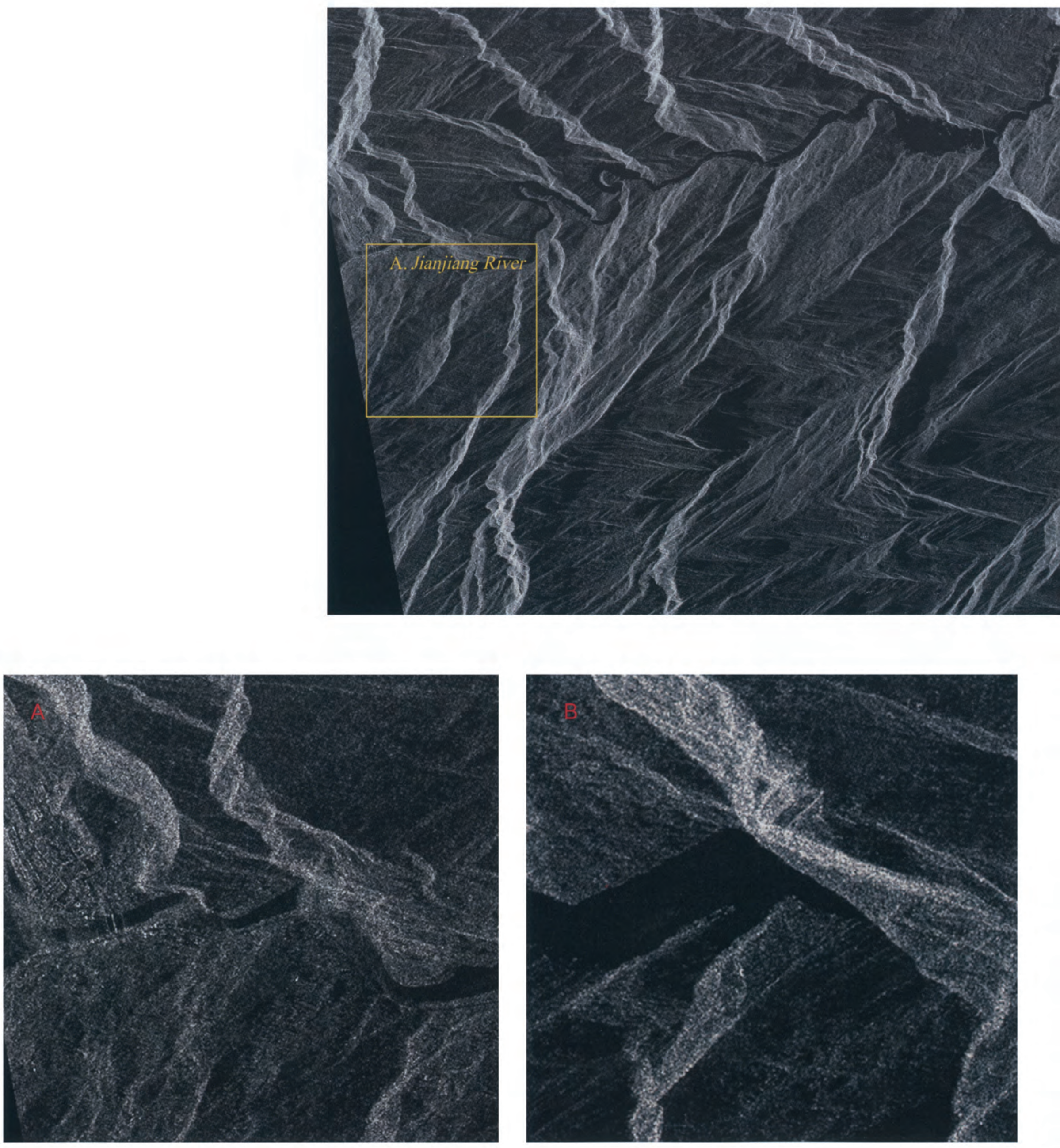

80 I Atlas of Remote Sensing of the Wenchuan Earthquake 


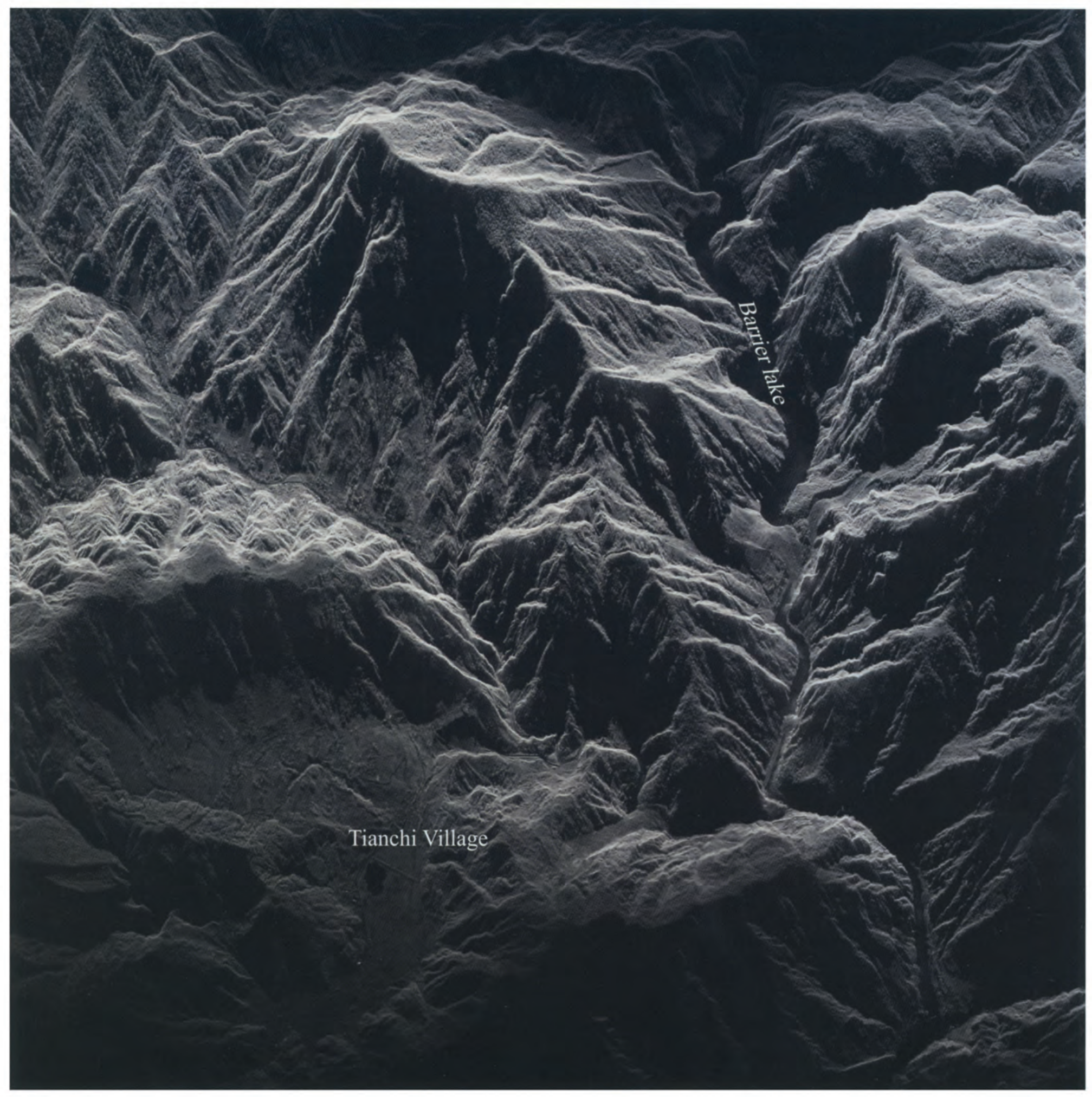

$\Delta$ Airborne SAR image of the village of Tianchi, in the town of North Hanwang

This is an airborne SAR image of the village of Tianchi, in the town of Hanwang, in the city of Mianzhu, acquired on May 24, 2008. The image shows several barrier lakes that formed along the Jinyuan River as a result of mountain landslides blocking the river channel. More than $20 \mathrm{~km}$ away from Hanwang Town in the north, two mountains shut off the river and a 5-km-long barrier lake formed.

82 I Atlas of Remote Sensing of the Wenchuan Earthquake 
$\checkmark$ Airborne optical image of the barrier lake of Changheba in the city of Mianzhu

This is an airborne optical image of Changheba in Mianzhu City acquired on May 23, 2008. In the image, a barrier lake that formed as a result of large mountain landslides blocking the river channel is shown. The river channel is completely blocked. It is clear that the barrier lake formed in the east part of the river in the image.

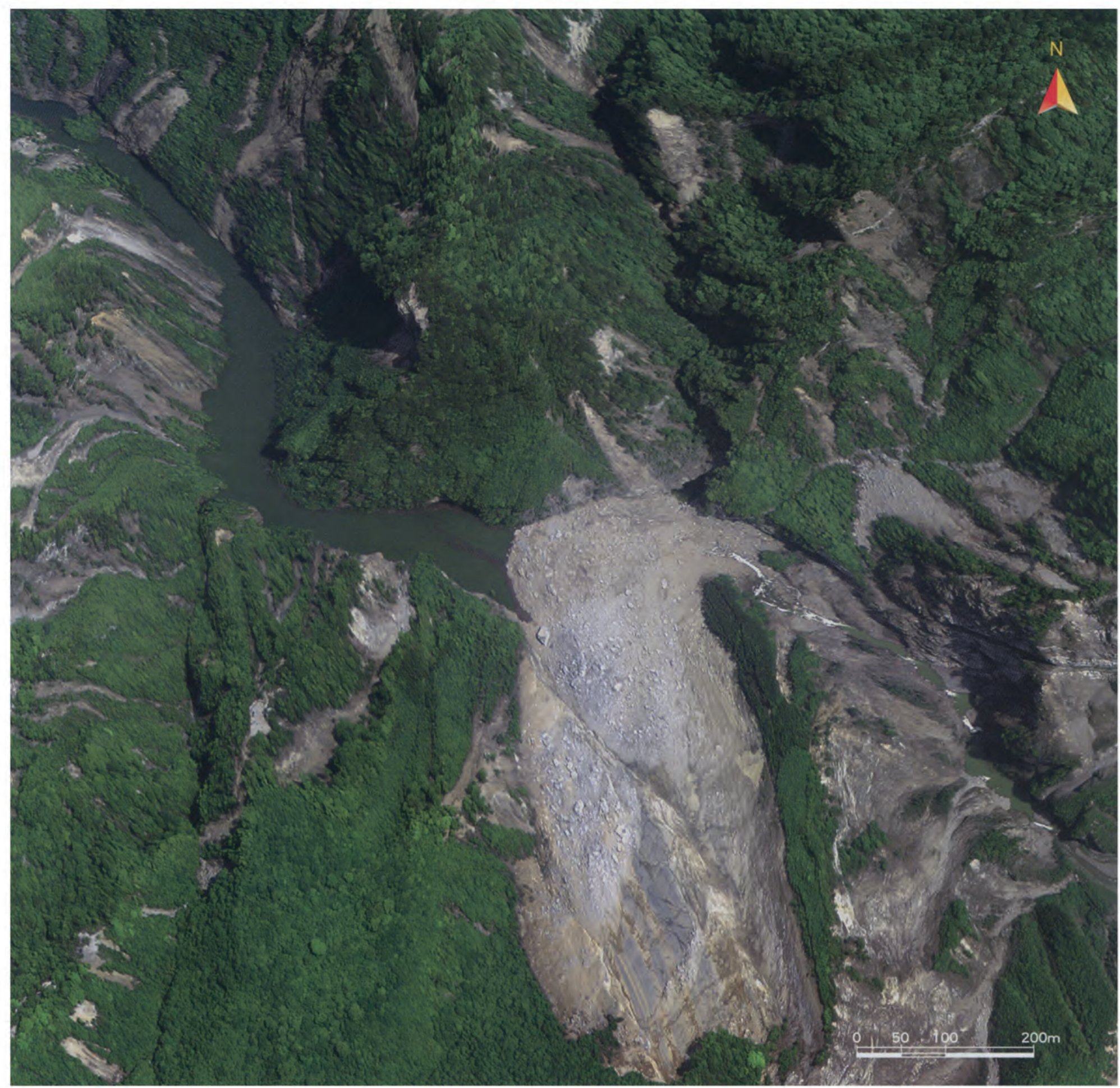

Barrier Lakes I 83 

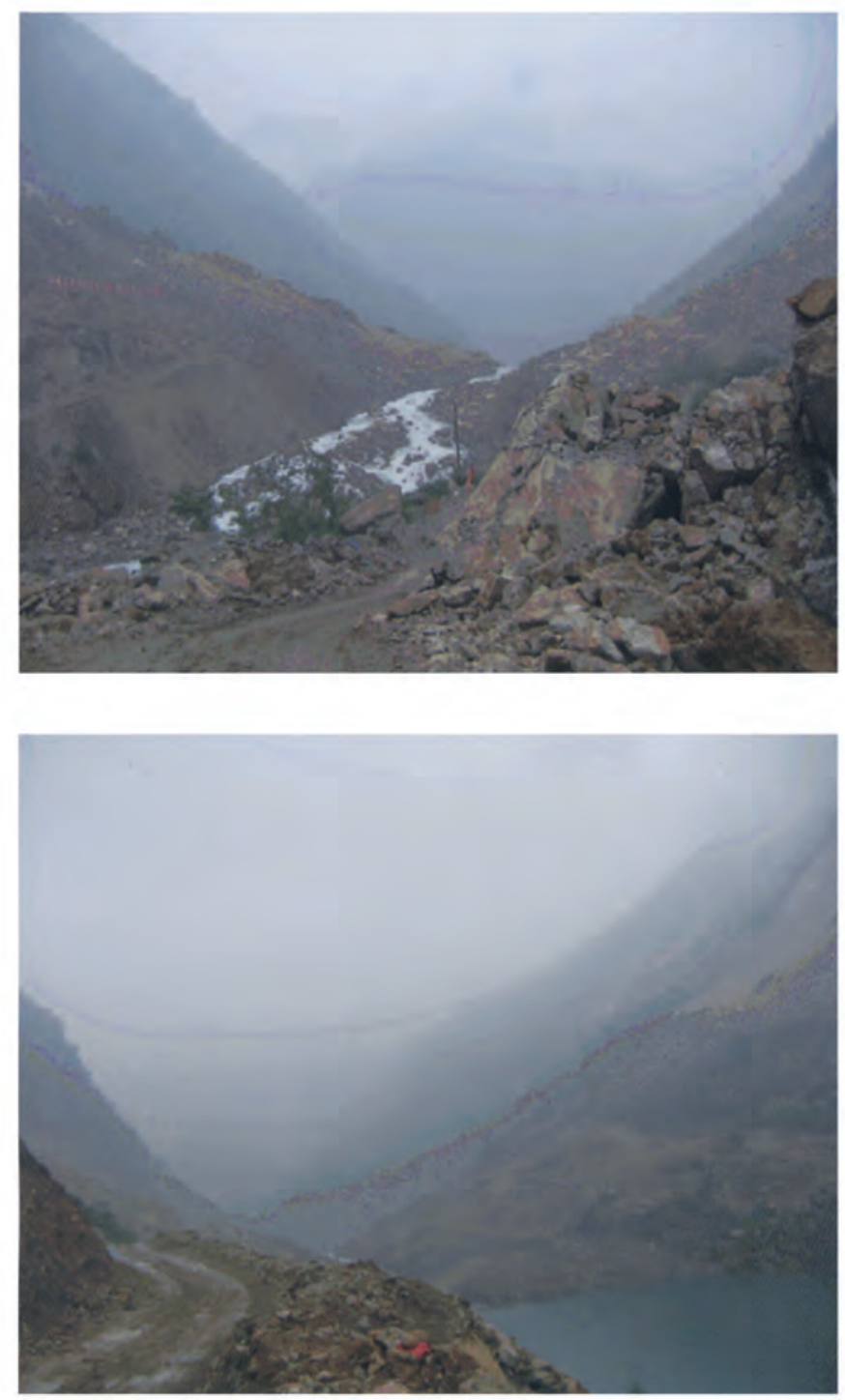

- Airborne SAR image of Ganhekou and Machaotan in Shifang City

This is an airborne SAR image of Ganhekou and Macaotan in the city of Shifang acquired on May 12,2008 . In the image, several collapses occurred on both sides of the upper Shiting River. Four barrier lakes, marked A, B, C, and D, formed in Shihekou and Macao Beach. The two channels in $\mathrm{C}$ and $\mathrm{D}$ have been completely blocked, while channels in A and B become noticeably narrow as a result of the blocking barrier body.

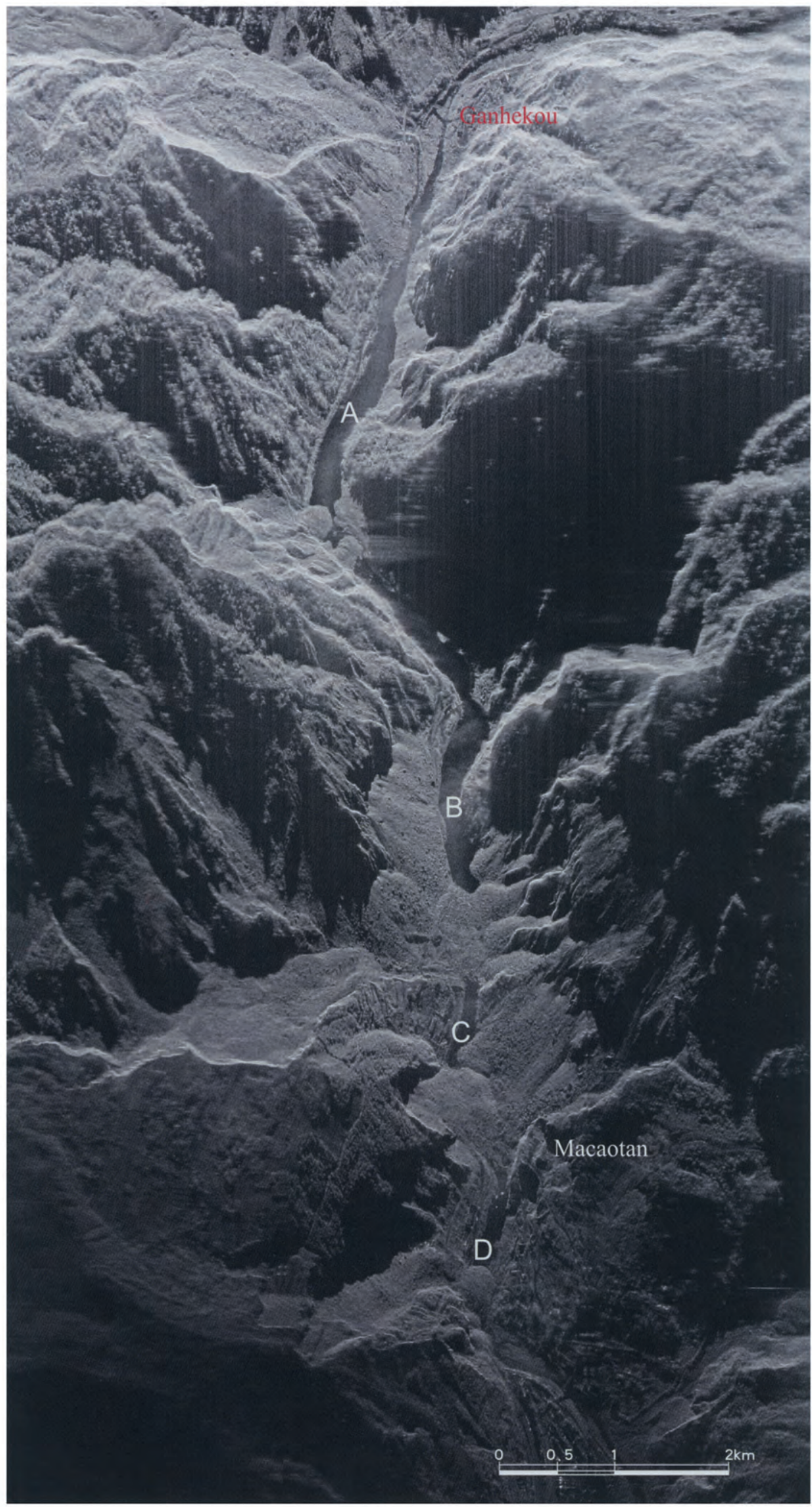

84 I Atlas of Remote Sensing of the Wenchuan Earthquake 


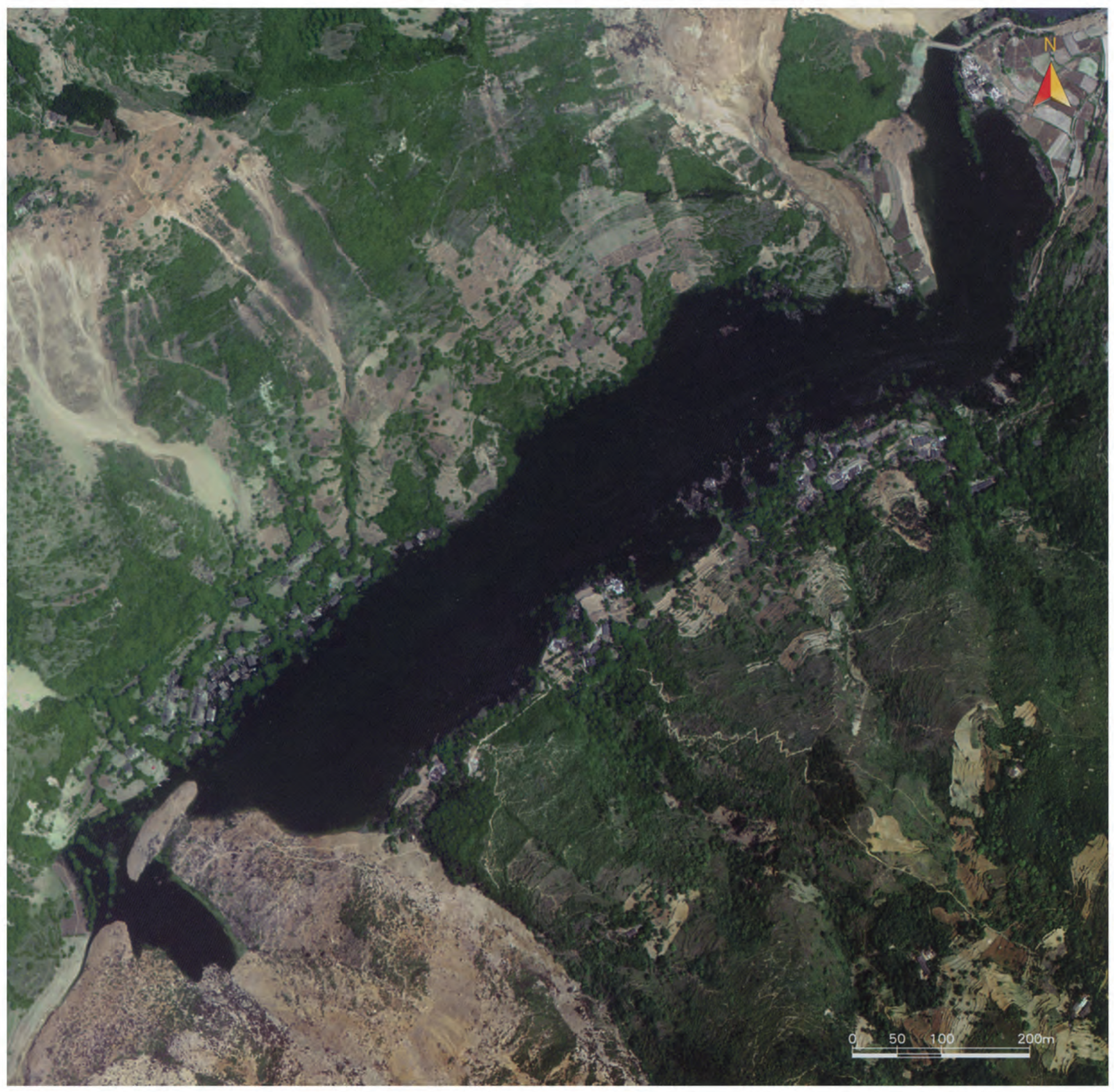

\ Airborne optical image of the barrier lake in Wenjiaba, in Pingwu County

This is an airborne optical image in Pingwu County acquired on May 28, 2008. In the image, several mountain landslides and debris flows occured in Wenjiaba, Pingwu County, in Sichuan province, blocking the river channel, and then a barrier lake formed. The river in the northeast still flows, although a relatively small hill mass lies there. The channel in the southwest is completely blocked by the landslide body. 


\section{v Airborne optical image at Wenjiaba in Pingwu County}

This is an airborne optical image at Wenjiaba in Pingwu County acquired on May 28, 2008. In the image, Wenjiaba lies in the branch of Fujiang, Pingwu County, and the river channel is blocked by mountain landslides as a result of the earthquake, so a large barrier lake formed. Before flood discharge, the lake was $100 \mathrm{~m}$ wide.

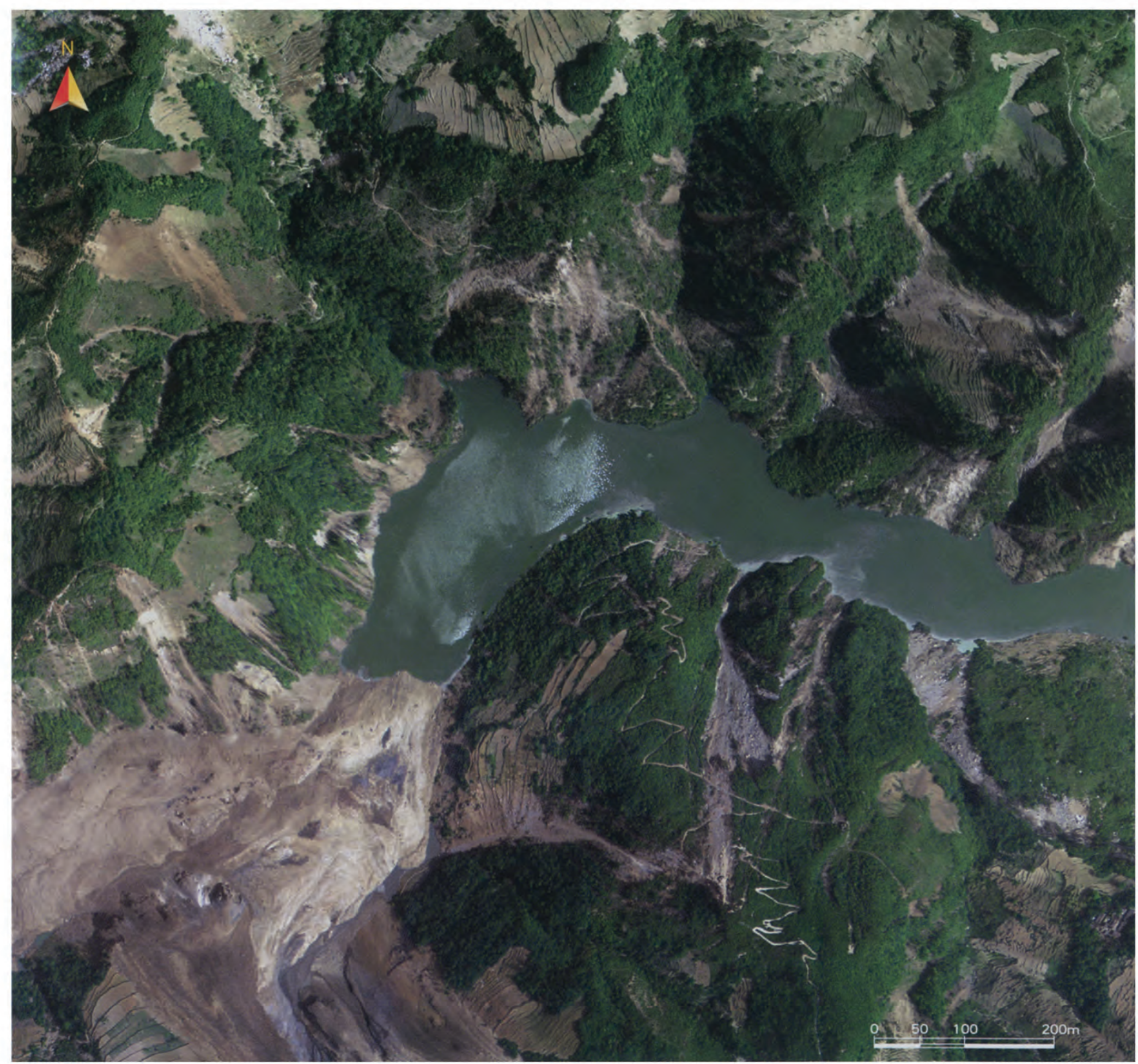

86 I Atlas of Remote Sensing of the Wenchuan Earthquake 


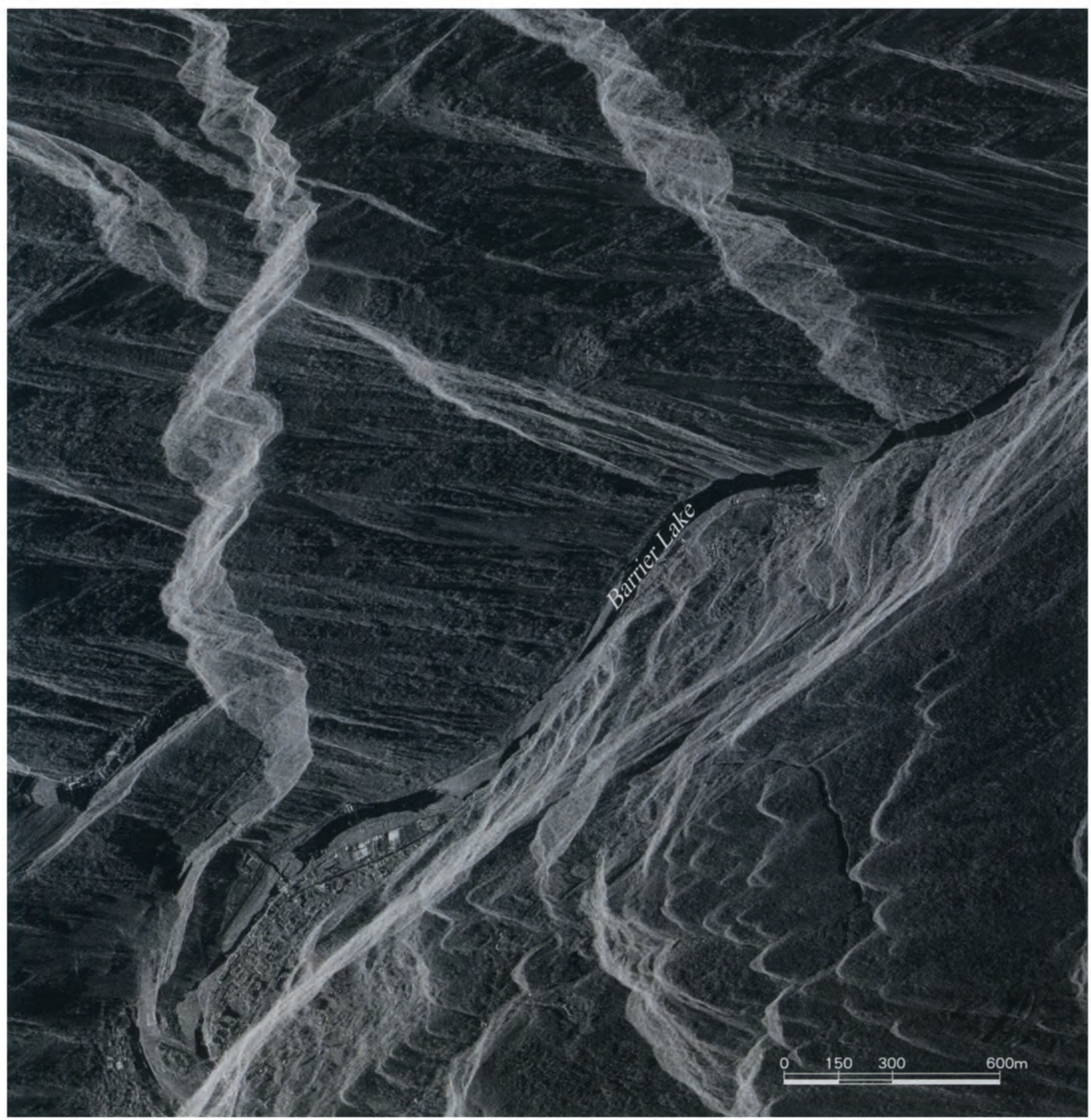

\ Satellite radar image COSMO-SkyMed in Tongkou River of Beichuan County

This radar image is from an Italian satellite, COSMO-SkyMed, with $\mathrm{X}$ band and $\mathrm{HH}$ polarization in the Tongkou River Basin, acquired on May 14, 2008. The image shows several barrier lakes that formed as a result of large landslides blocking the river channel, in which the one besides Beichuan County is the largest and most seriously blocked. 


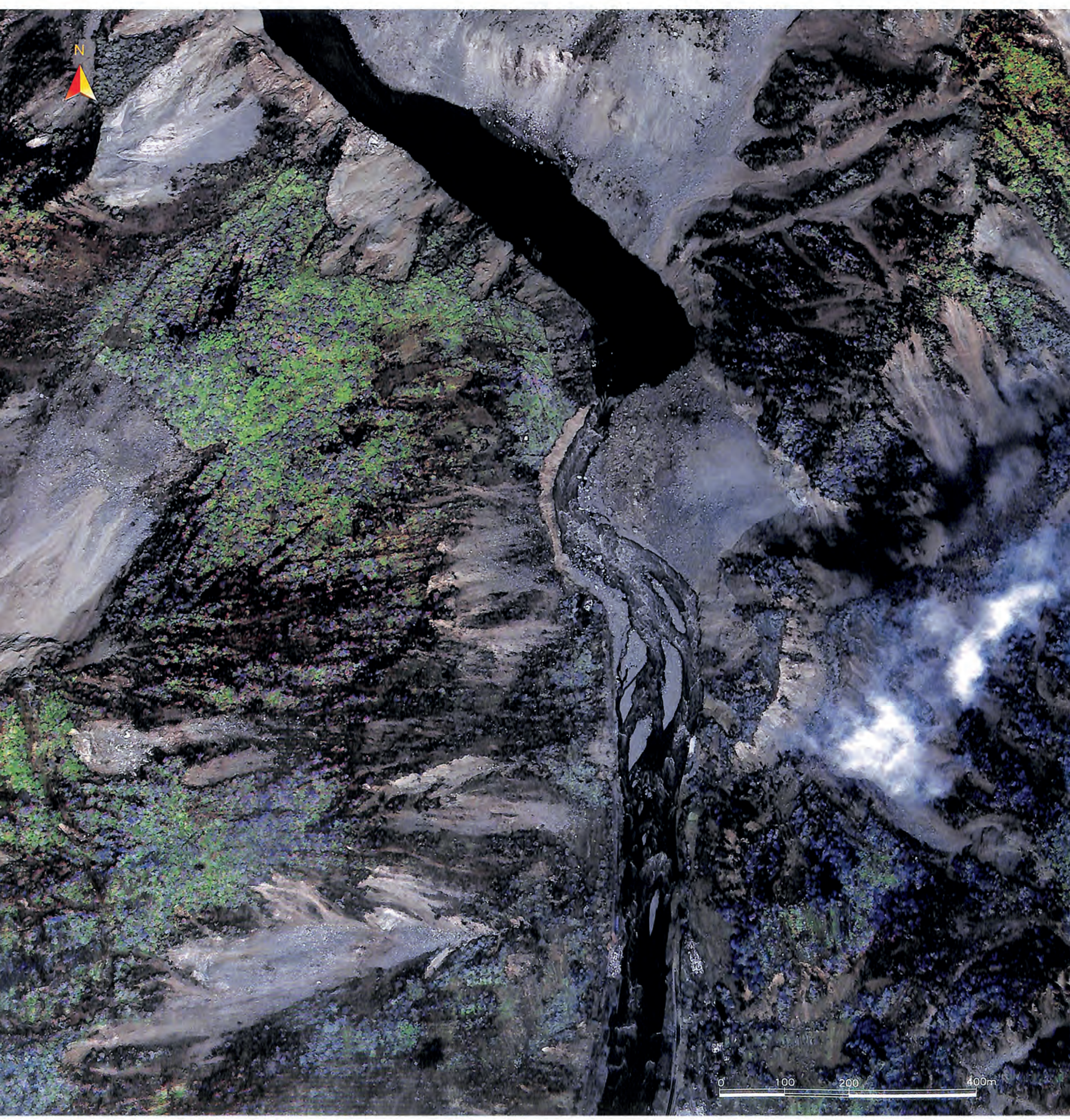



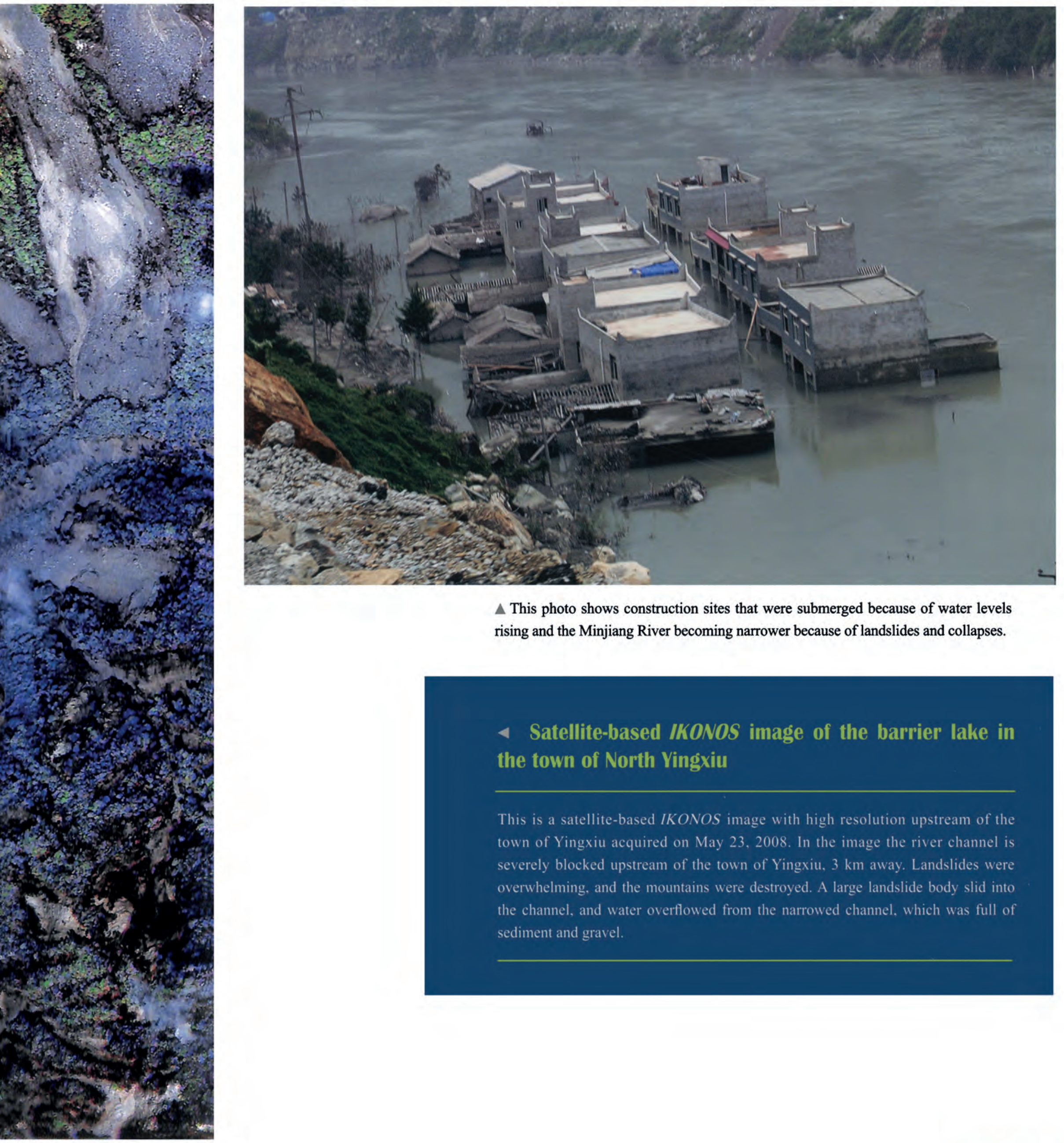

$\Delta$ This photo shows construction sites that were submerged because of water levels rising and the Minjiang River becoming narrower because of landslides and collapses.

4 Satellite-based IKONOS image of the barrier lake in the town of North Yingxiu

This is a satellite-based IKONOS image with high resolution upstream of the town of Yingxiu acquired on May 23, 2008. In the image the river channel is severely blocked upstream of the town of Yingxiu, $3 \mathrm{~km}$ away. Landslides were overwhelming, and the mountains were destroyed. A large landslide body slid into the channel, and water overflowed from the narrowed channel, which was full of sediment and gravel 


\section{Chapter}

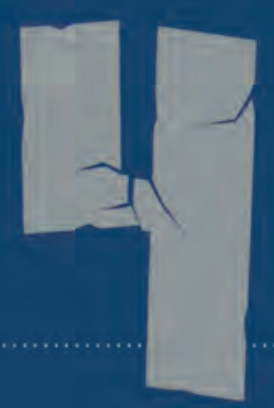

\section{COLAAPSED BUILINGS}

The Wenchuan earthquake and the secondary disasters induced by the earthquake caused massive collapses of buildings, enormous losses of property, and tens of thousands of casualties. This chapter looks at collapsed houses and buildings based on airborne optical images. Airborne radar and optical remote sensing images of the region most severely affected by the earthquake were acquired during May 15-May 28. These images cover 14 counties, including Wenchuan, Beichuan, Mianyang, Shifang, Qingchuan, Maoxian, Anxian, Dujiangyan, Pingwu, Pengzhou, Lixian, Jiangyou, and Guangyuan. To estimate the rates of building collapse, high-spatial satellite data from sources such as IKONOS, QuickBird, WorldView, and SPOT 5 before and after the earthquake were studied, and high-spatial airborne SAR images were used for interpretation.

Using high-resolution airborne images, we studied collapsed buildings in 102 villages and towns in 14 counties and acquired the collapse ratio contour maps of the 14 counties. We compiled these data with the earthquake fault zone data of Longmen Mountain to determine the typical patterns of building collapse. The house collapse ratio in the disaster region was monitored and assessed visually. 


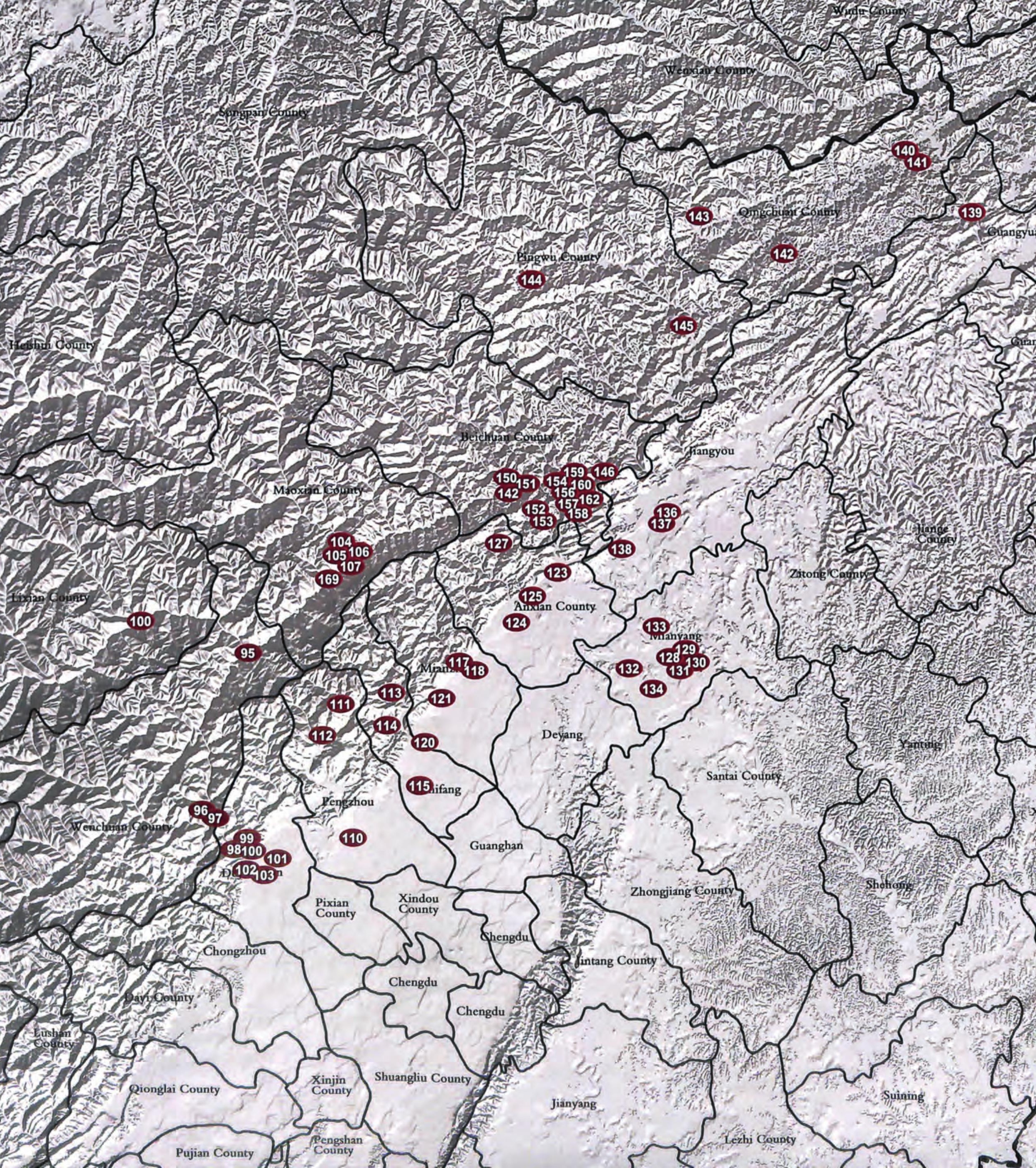


Hongyuan

Sonpan

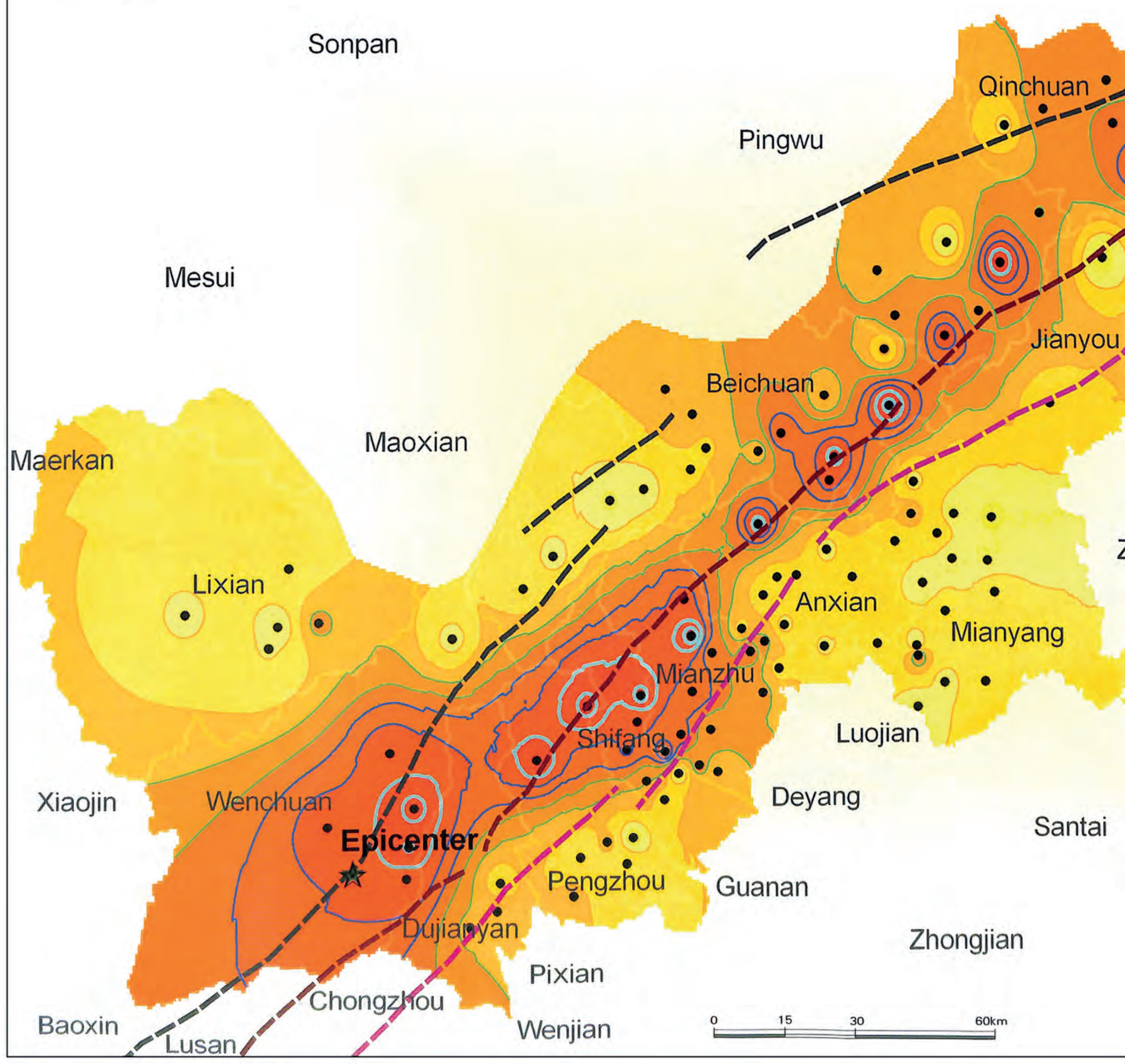




\section{Collapsed houses in the main quake-stricken region}

Using high-resolution airborne images, we studied collapsed buildings in 102 villages and towns in 14 counties and cities and created a contour map showing the collapse ratio in those counties and cities. From this contour map, together with the Longmenshan Fault data, we can clearly see the collapse pattern for houses and buildings.

(1) The most seriously hit villages and towns are located in the Longmenshan Fault, and they are distributed along the hill-front fault (Anxian-Guanxian Fault) and hill-back fault (Wenchuan-Maoxian Fault) within the fault zone.

(2) On the whole, the most seriously affected villages and towns are distributed along the central fault of the Longmenshan Fault, namely, the Beichuan-Yingxiu Fault.

(3) A small quantity of villages and towns suffering severe building collapses are located on the northwest side of the Longmenshan Main Fault, while the majority of them are on the southeast side of the main fault.

(4) In Pingwu County, the city of Guangyuan, and Qingchuan County, areas of severely damaged houses shifted from the Yingxiu-Beichuan Fault to the Wenchuan-Maoxian Fault. On the same cross-section, the amount of destruction is much worse in the town of Shazhou, in Qingchuan County (located on the Wenchuan-Maoxian Fault) than that in the town of Shadui (located on the Yingxiu-Beichuan Fault). 


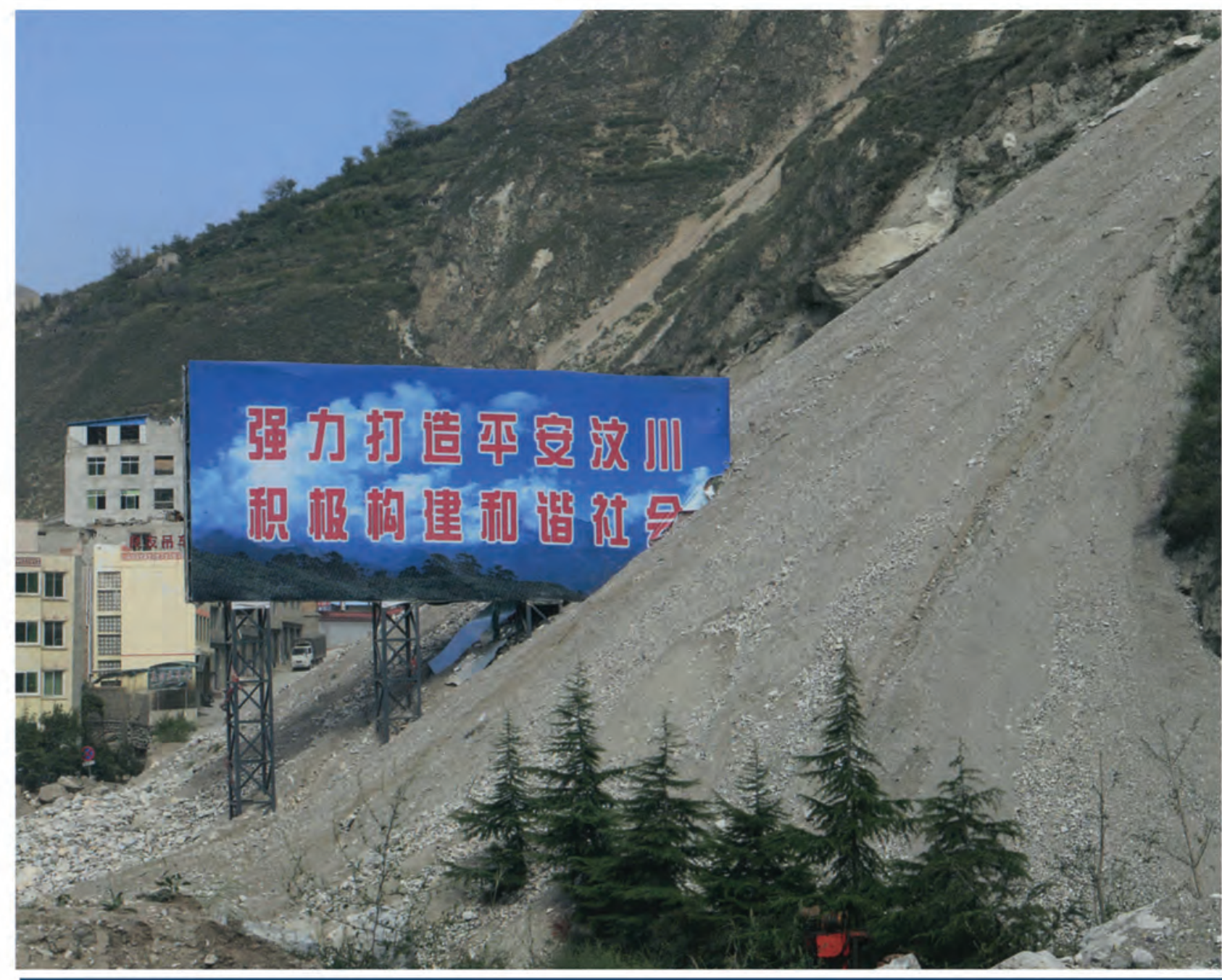

$\Delta$ Earthquake-induced clastic flow

- Distribution of collapsed houses in an urban part of Wenchuan County

Wenchuan County is not only the home of the Qiang people, well known for their traditional needlework, but also the home of the giant panda, which is considered to be a living fossil. Wolong, the most prestigious research center for giant pandas in the world, is located in the southwestern part of Wenchuan County.

Only $46 \mathrm{~km}$ away from the town of Yingxiu, which was the epicenter of the Wenchuan earthquake and located on the Yingxiu-Maoxian Fault, Wenchuan County was seriously damaged in the earthquake. Approximately one-sixth of all the houses in urban areas of the county were ruined.

94 I Atlas of Remote Sensing of the Wenchuan Earthquake 


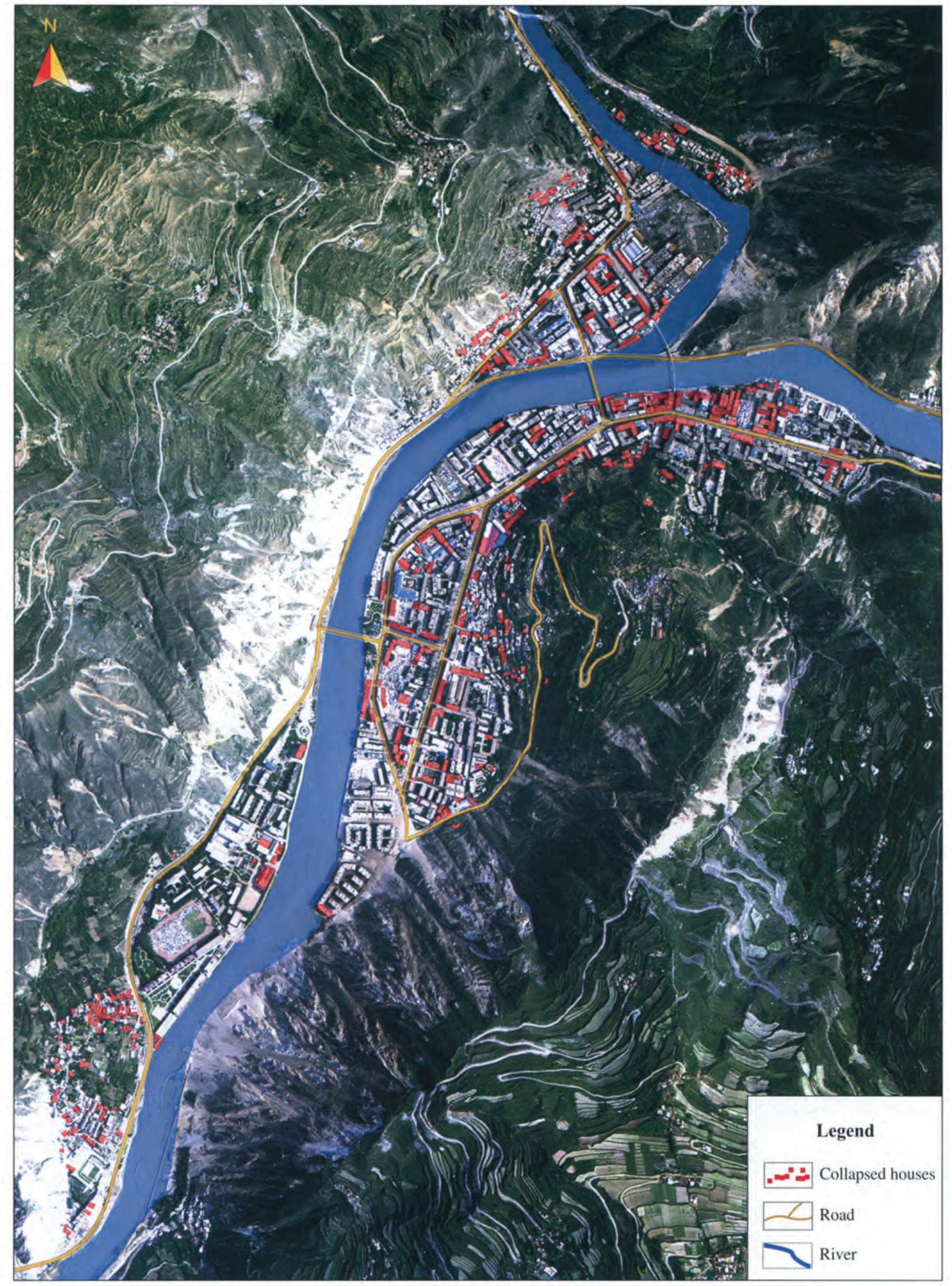




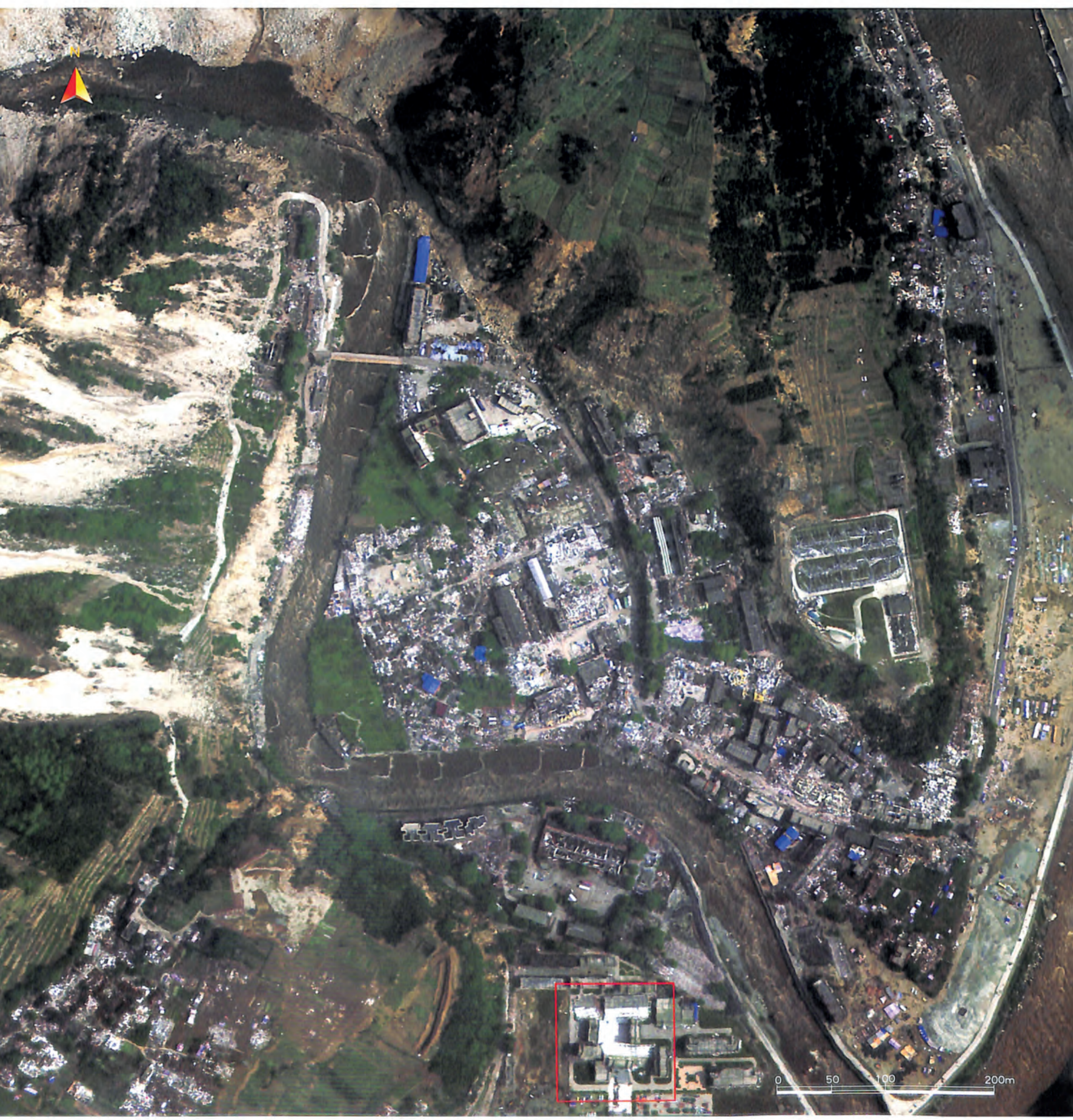

96 I Atlas of Remote Sensing of the Wenchuan Earthquake 

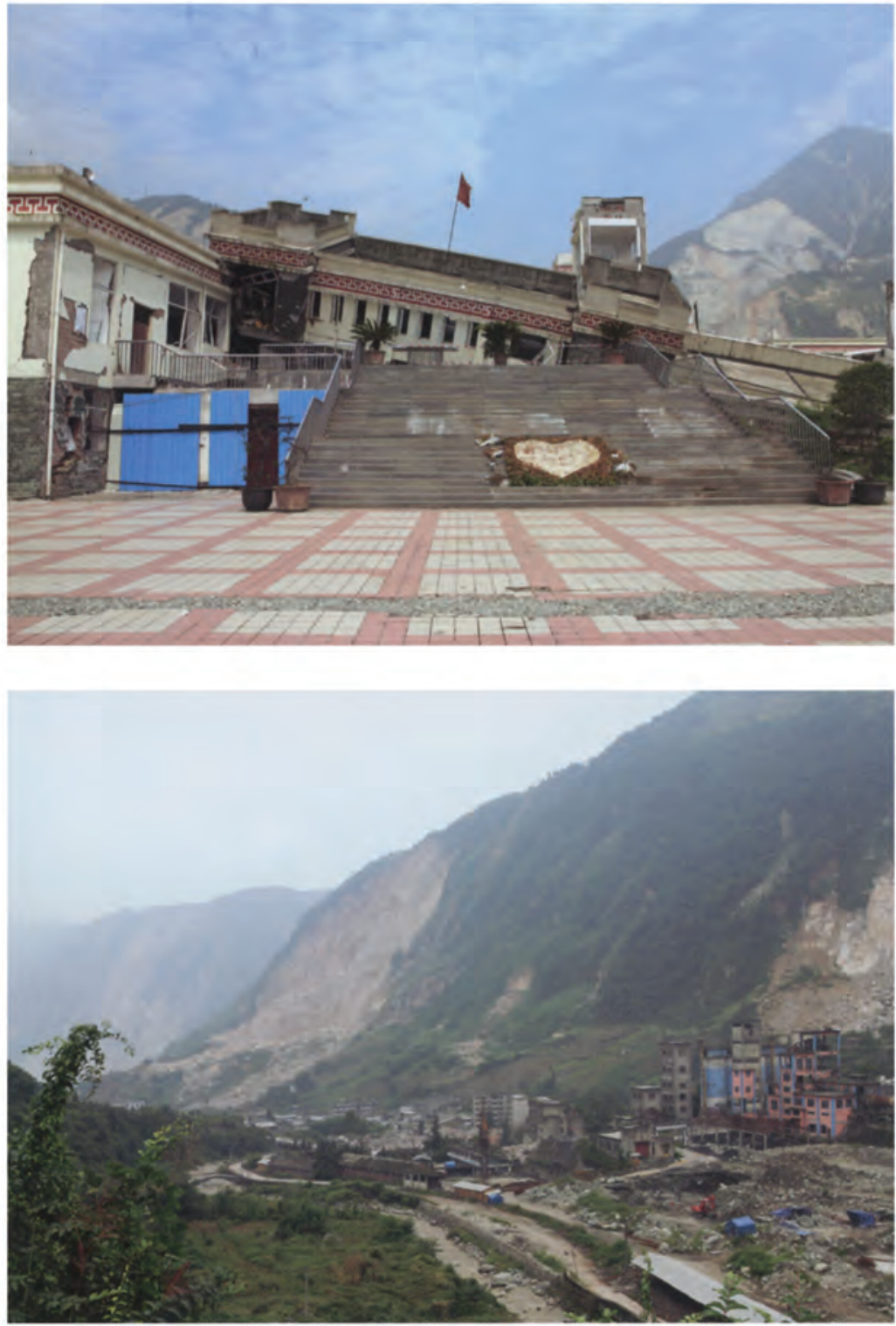

4 Airborne optical images of the town of Yingxiu, Wenchuan County

Acquired May 16, 2008. Located in the Yingxiu-Maoxian Fault, the town of Yingxiu was the epicenter of the Wenchuan earthquake. It was seriously damaged in the earthquake, over $90 \%$ of the houses in the town of Yingxiu collapsed. The red-frame in the image marks the severe damaged Xuankou High School.
4 Xuankou High School after the earthquake

The town of Xuankou after the earthquake 


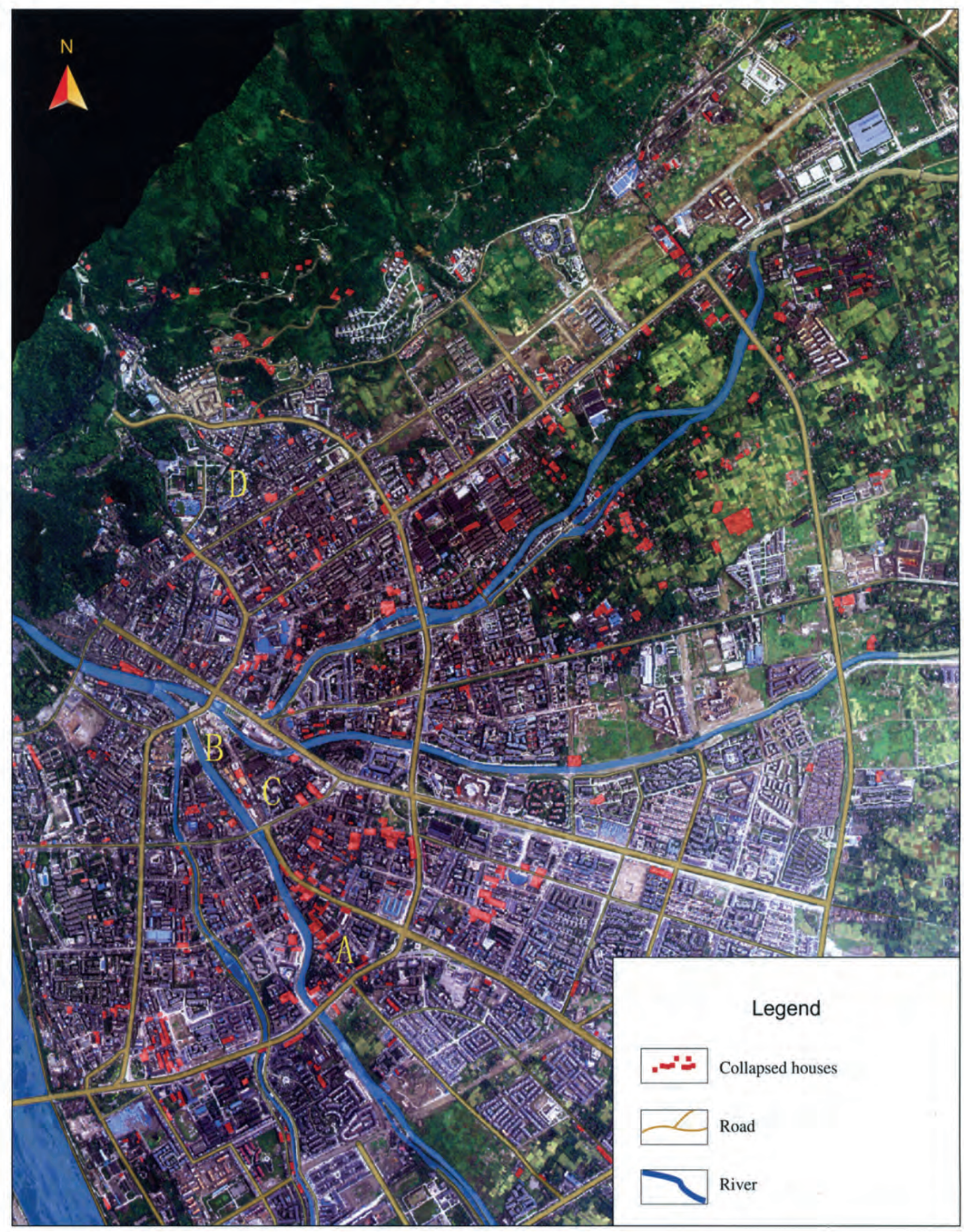

$300 \quad 600$ $1200 \mathrm{~m}$

98 I Atlas of Remote Sensing of the Wenchuan Earthquake 

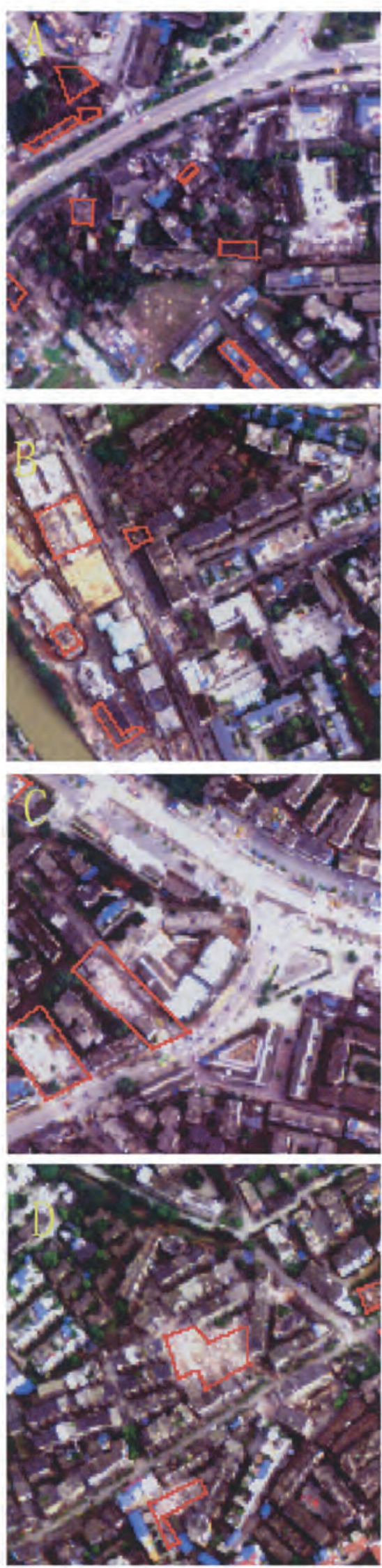

Post-earthquake
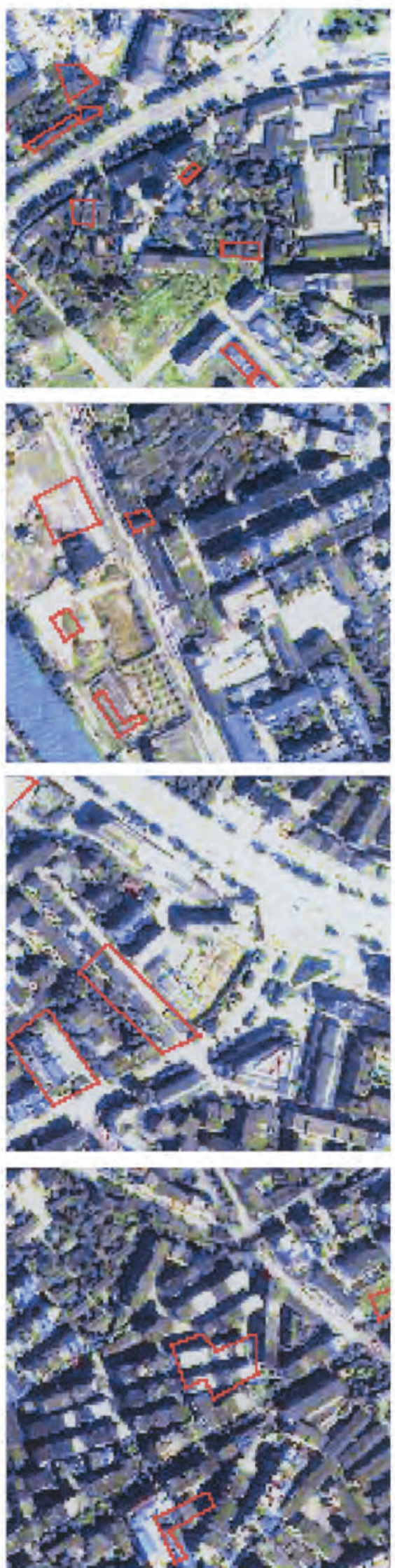

Pre-earthquake

\section{Disaster assessment on building collapse in the city of Dujiangivan}

The city of Dujiangyan lies on the northwest edge of the Chengdu Plain. It is $\mathbf{4 8} \mathbf{~ k m}$ away from the center of the city of Chengdu, and about $20 \mathrm{~km}$ away from the epicenter the town of Yingxiu. Pre-disaster QuickBird satellite images and post-disaster airborne images showed serious earthquake damage. About $\mathbf{1 0} \%$ of the houses in downtown Dujiangyan collapsed. 


\section{Map of collapsed buildings in the city of Dujiangyan}

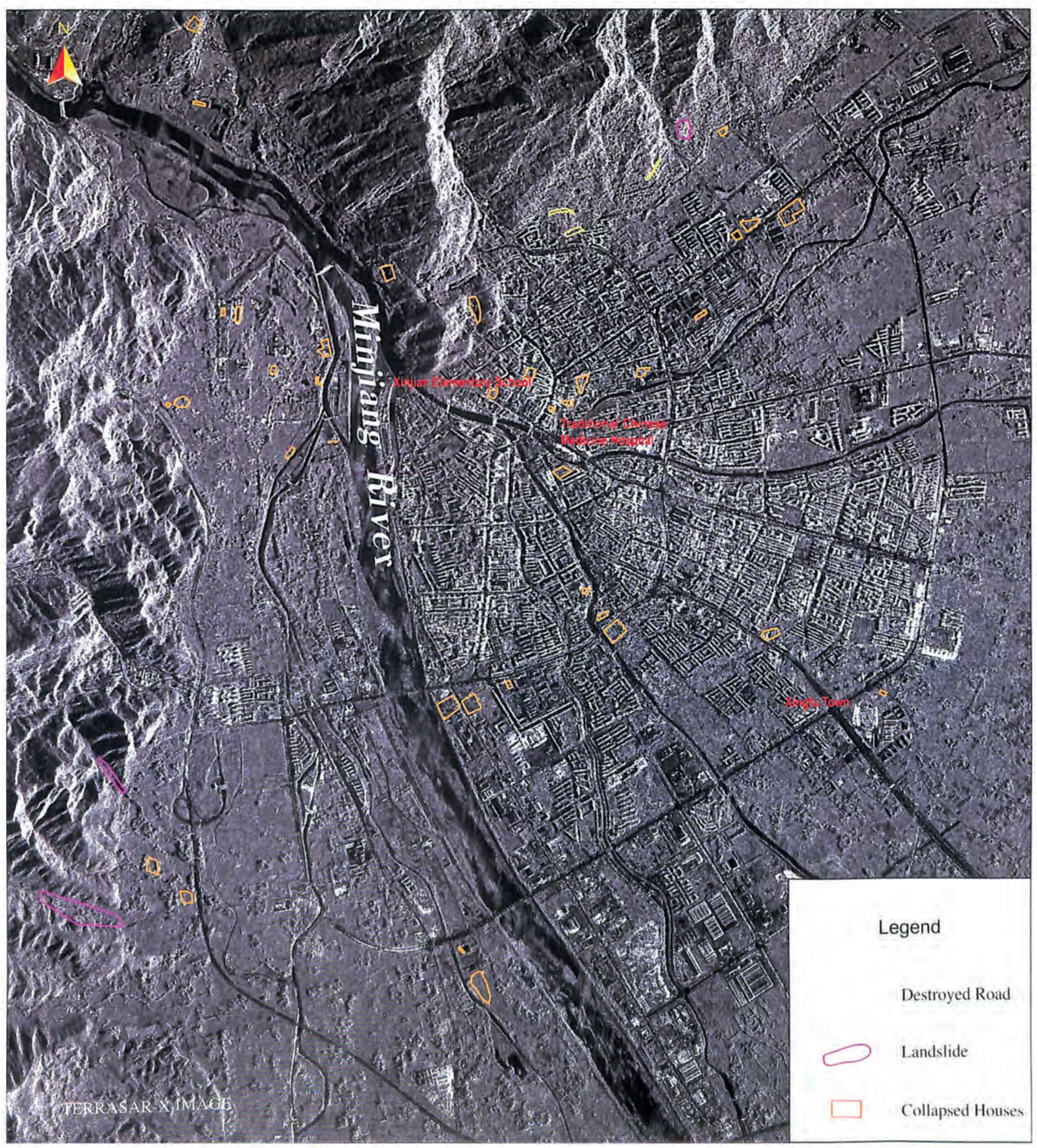

100 I Atlas of Remote Sensing of the Wenchuan Earthquake 


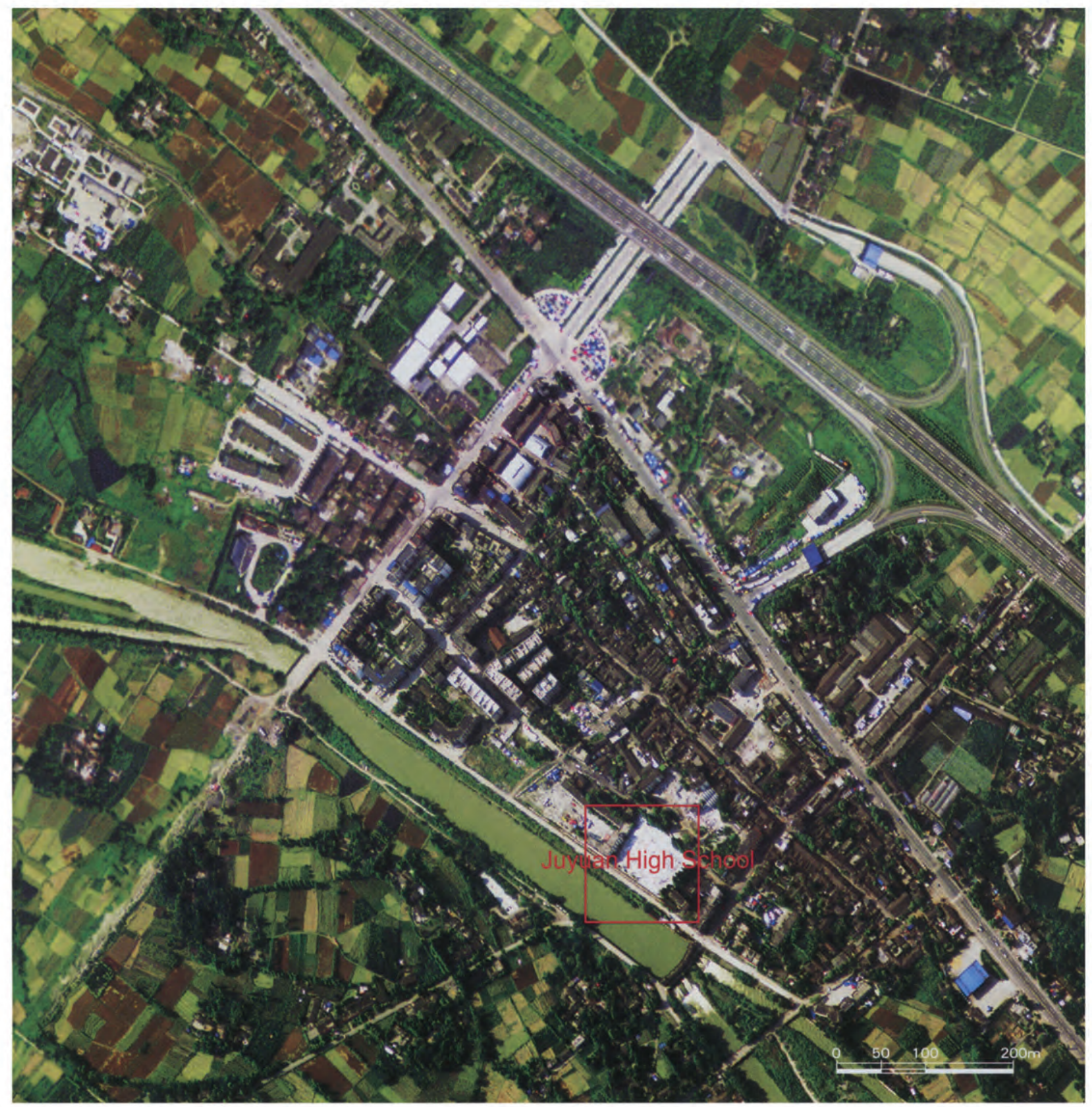

$\Delta$ Airborne optical image of the town of Juyuan, in the city of Dujiangyan

Acquired May 18, 2008. The town of Juyuan is no more than $25 \mathrm{~km}$ away from the town of Yingxiu. The houses in the town of Juyuan were also seriously damaged, and over one-fifth of them collapsed. The red frame inside the image marks Juyuan High School, where heavy casualties occurred.

4 SAR image on May 15, 2008 also shows collapsed houses and buildings in the city of Dujiangyan. Examples include Xinjian Elementary School and the Traditional Chinese Medicine Hospital of the city of Dujiangyan. 


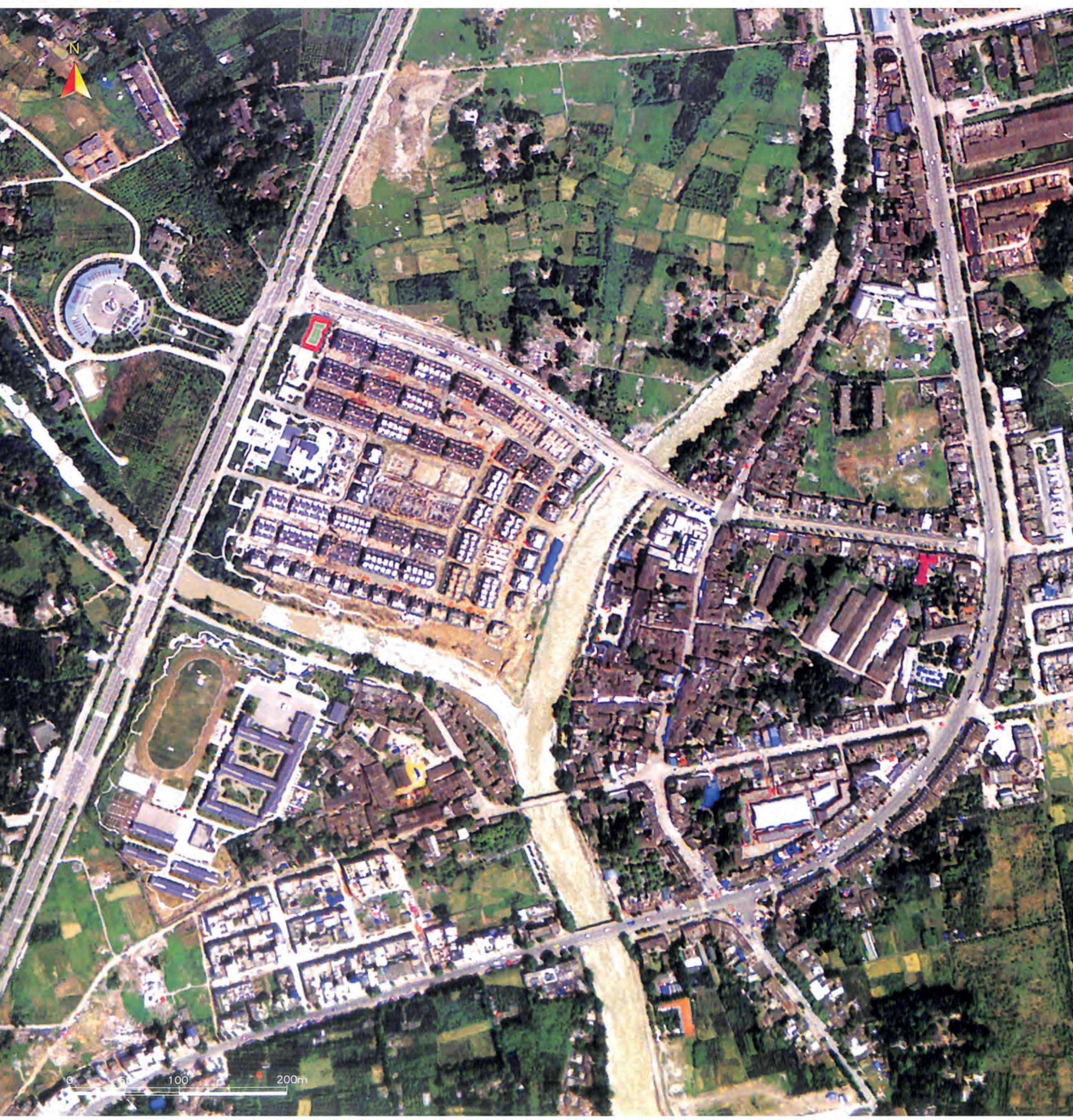

102 I Atlas of Remote Sensing of the Wenchuan Earthquake 

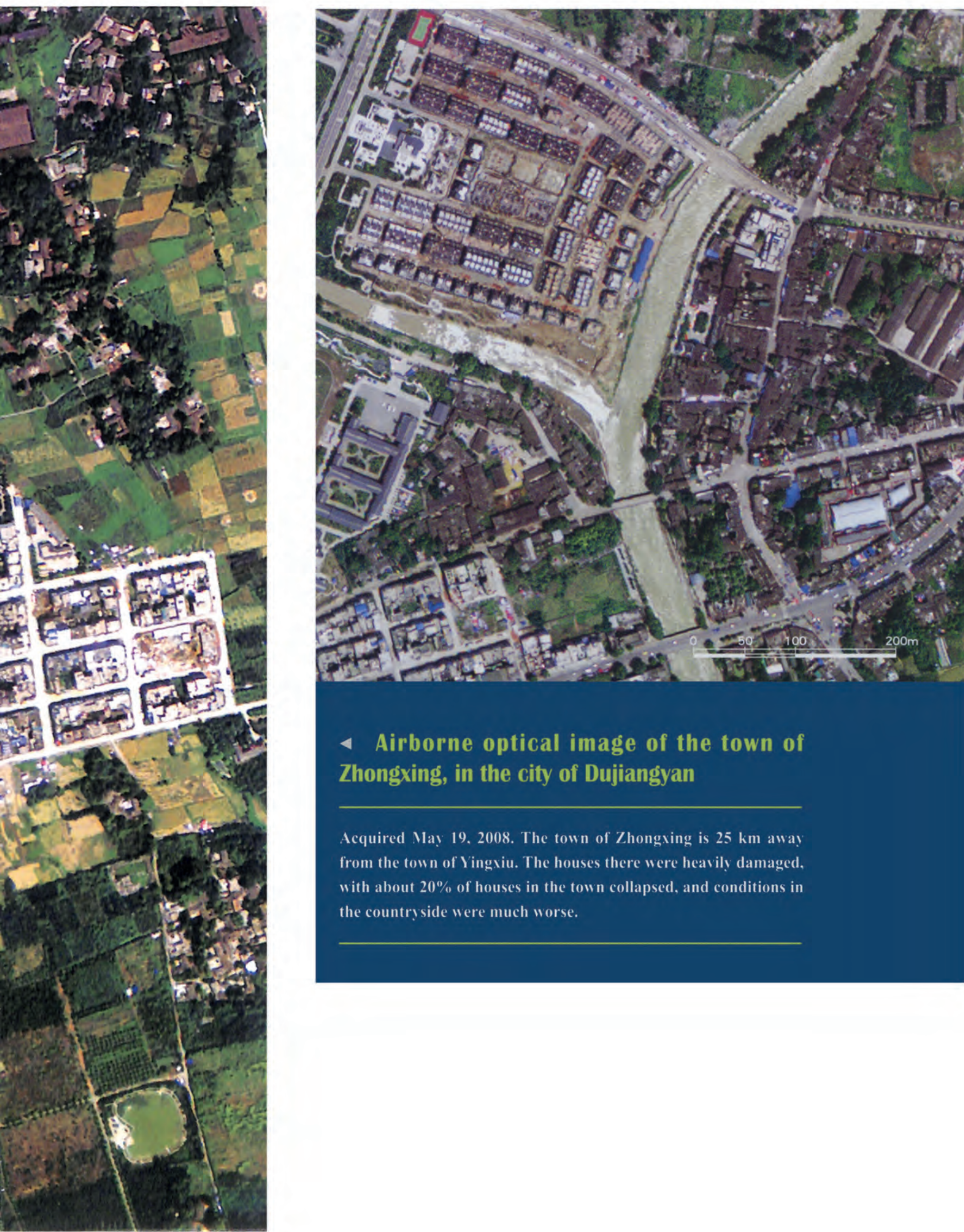

4 Airborne optical image of the town of Zhongxing, in the city of Dujiangyan

Acquired May 19, 2008. The town of Zhongxing is $25 \mathrm{~km}$ away from the town of Yingxiu. The houses there were heavily damaged, with about $20 \%$ of houses in the town collapsed, and conditions in the countryside were much worse. 


\section{Distribution of the collapsed buildings in Maoxian County}

Maoxian County is located in the southeast section of $\mathrm{Aba}$ Tibet and Qiang Autonomous Prefecture, which is the transitional zone from the Qinghai-Tibet Plateau to the Sichuan Plain, and is the main residential area of the Qiang people. Maoxian County lies along the Wenchuan-Maoxian seismic belt, and nearly $20 \%$ of the houses were either severely damaged or collapsed in the urban area of the Maoxian County.

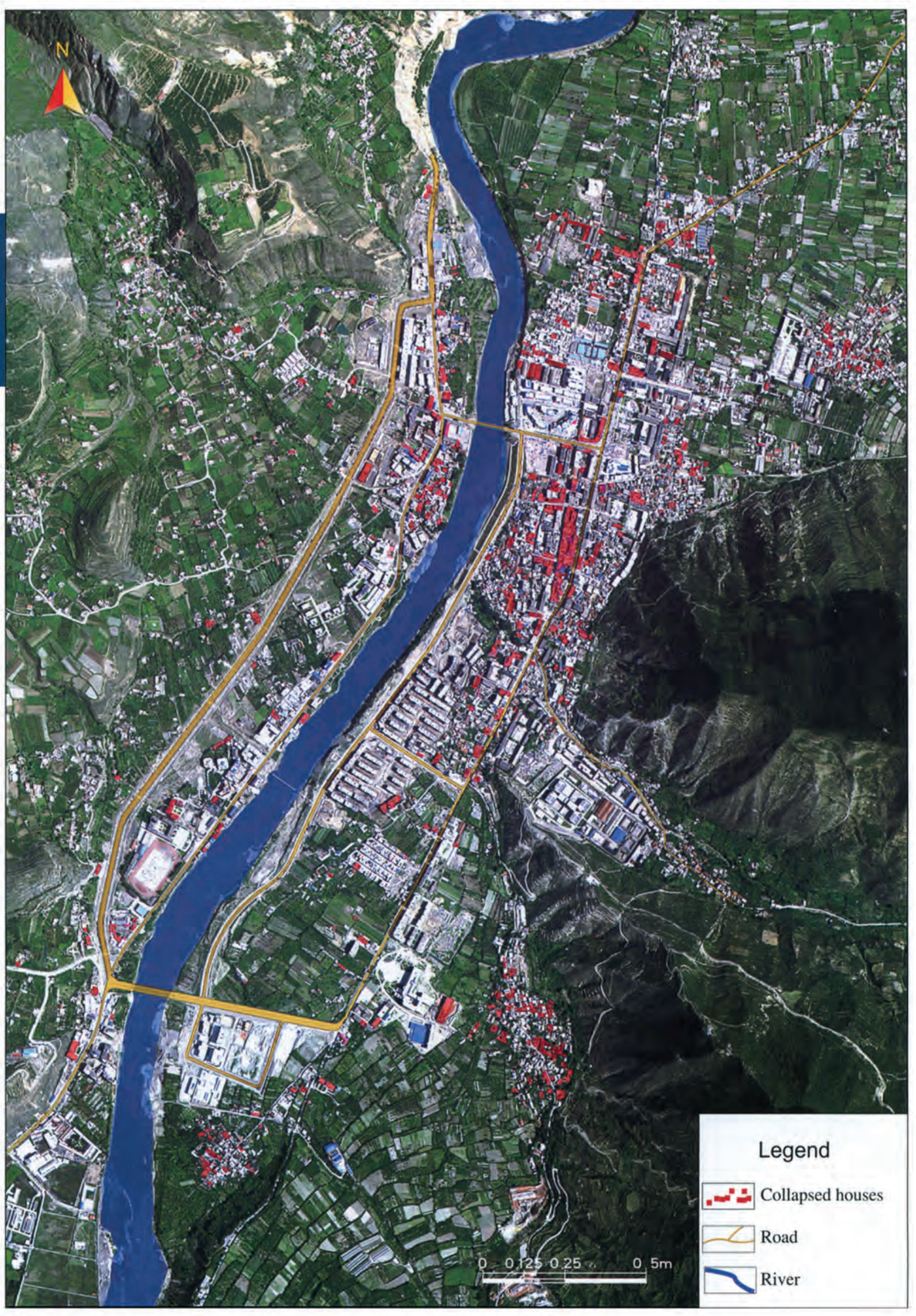

104 I Atlas of Remote Sensing of the Wenchuan Earthquake 
Acquired May 23, 2008. Maoxian County lies on the Wenchuan-Maoxian Fault. In the urban area of the county, about $20 \%$ of the buildings were either collapsed or severely damaged, and these collapsed buildings can be seen clearly on the IKONOS image. The red frame in the image represents the most severe damage.

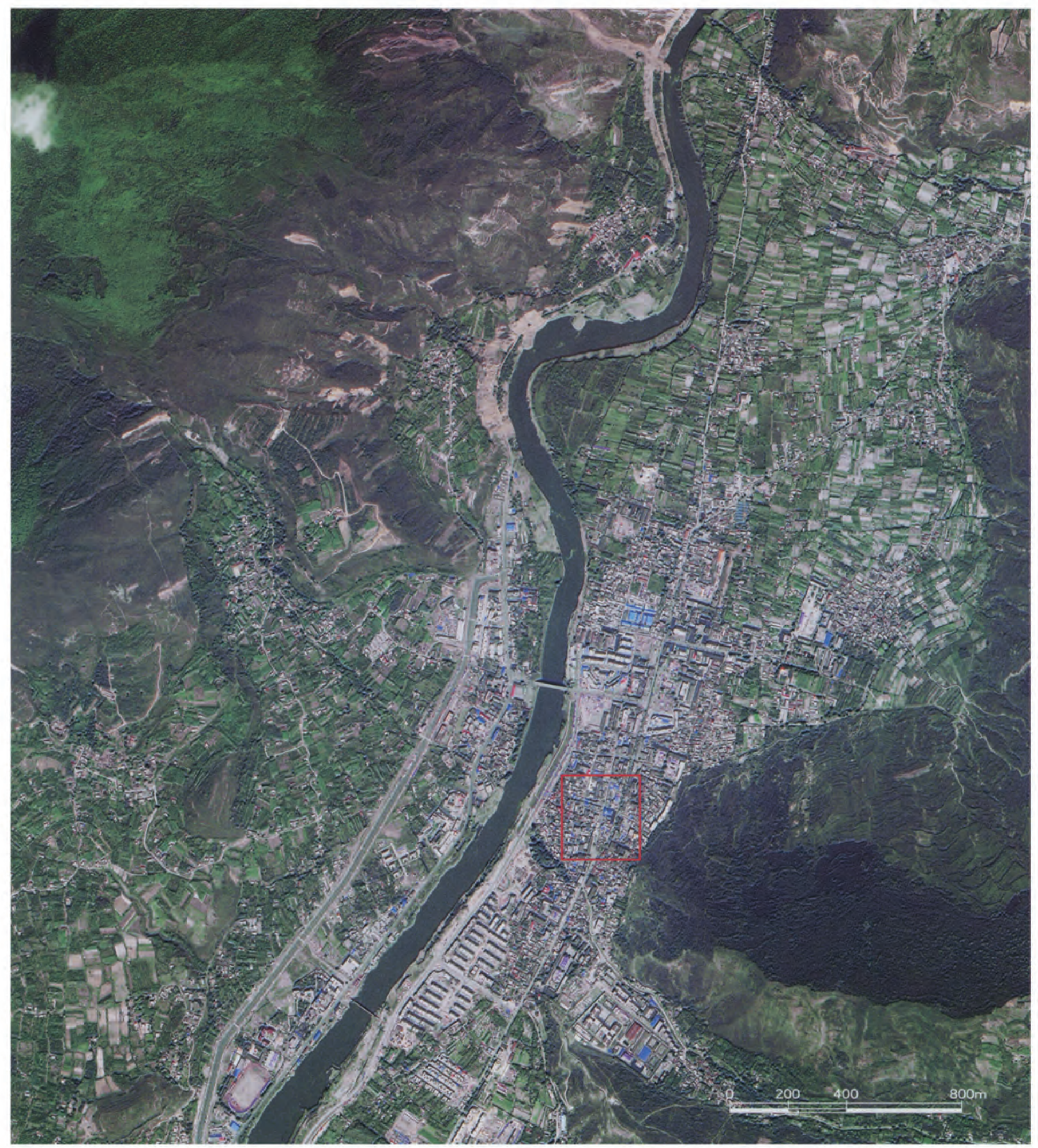


Comparing post-quake X-band high resolution SAR image (acquired May 14, 2008) with prequake 2.5-m resolution SPOT image (acquired November 11, 2005), some collapsed houses in both rural and urban areas were found.

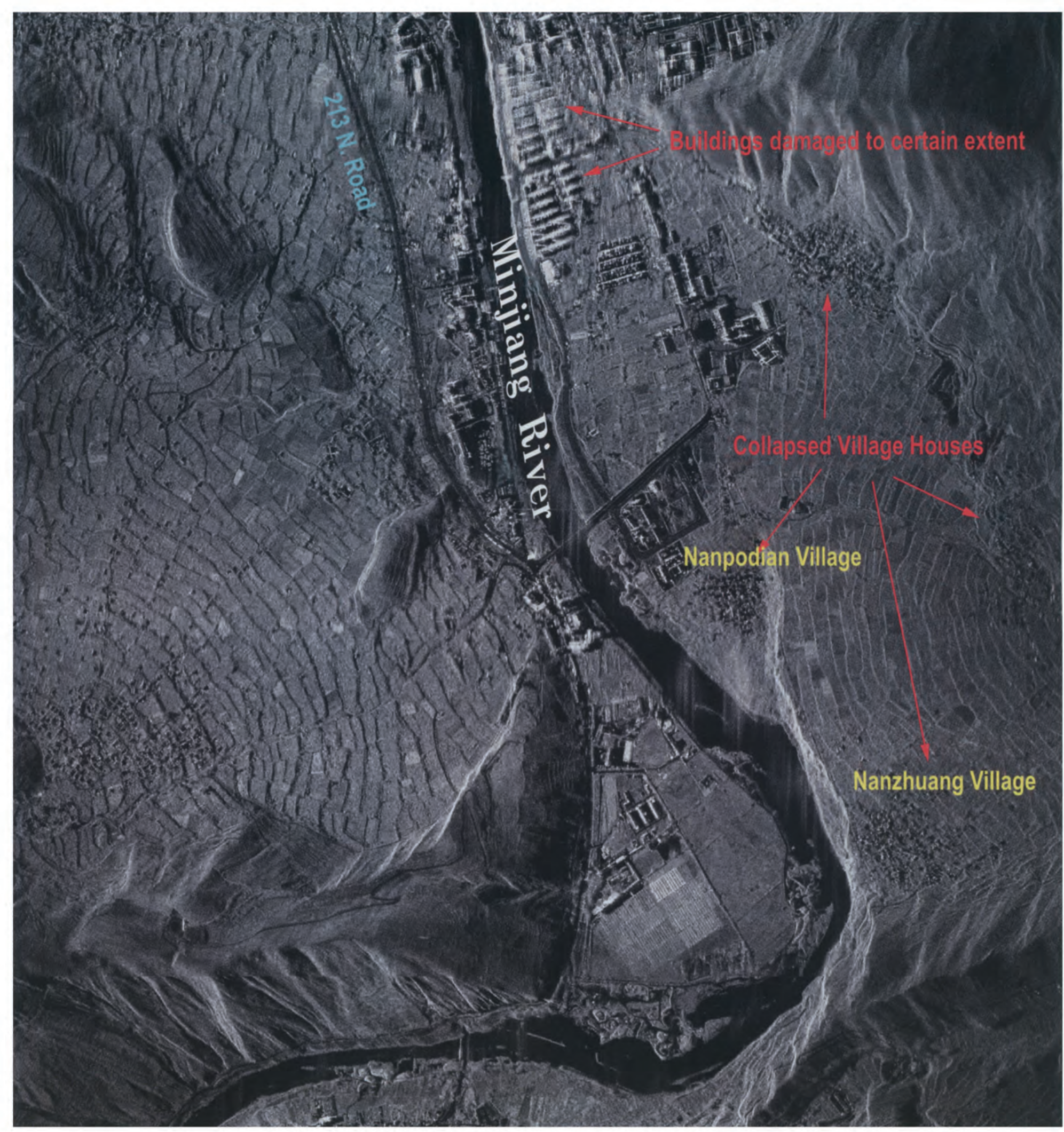

106 I Atlas of Remote Sensing of the Wenchuan Earthquake 
V Pre-earthquake SPOT 5 image of Maoxian County (acquired November 1, 2005)

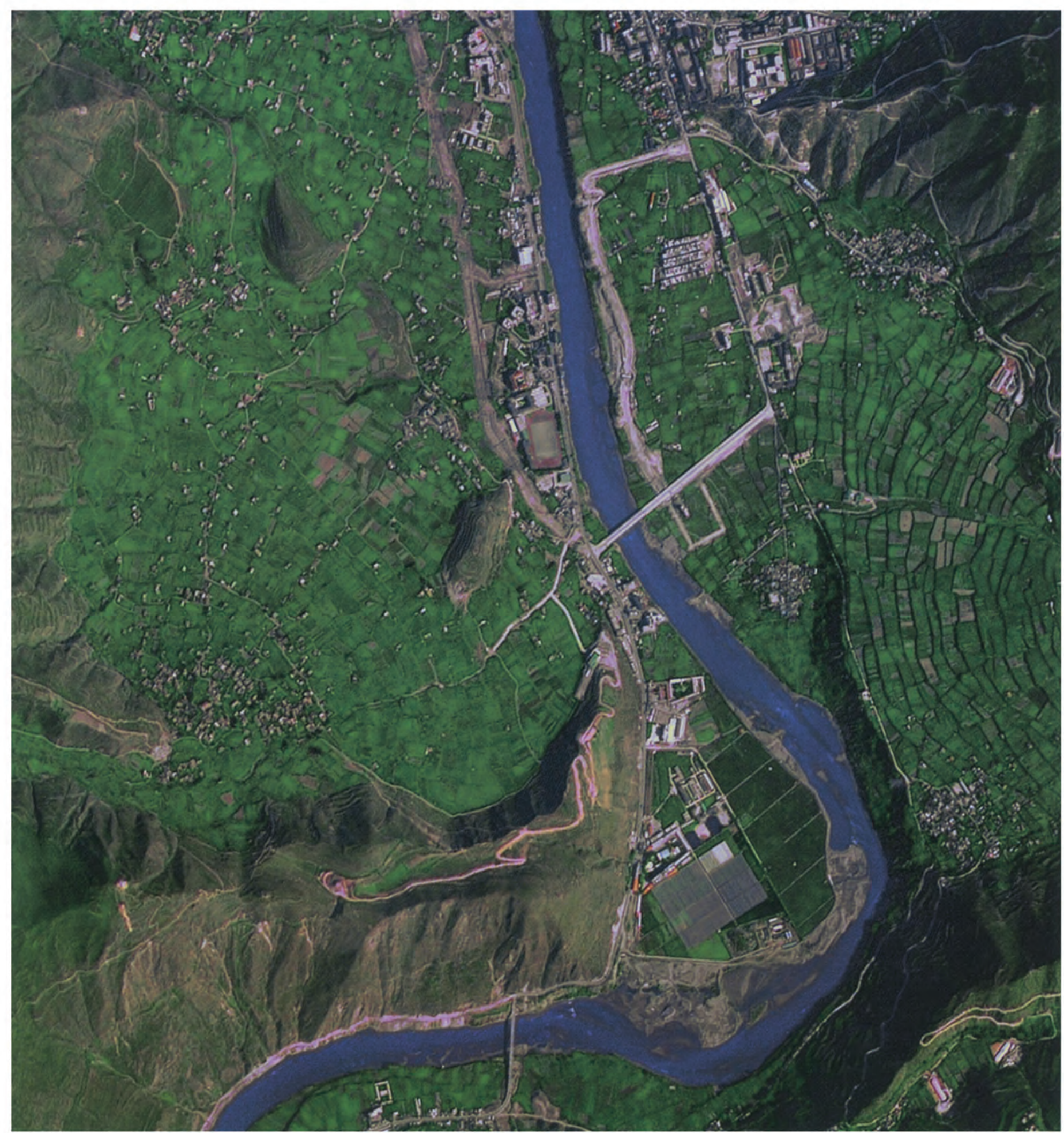




\section{Distribution of the collapsed houses in the town of Zagunao, in Lixian County}

Lixian County, situated in western Sichuan Province, has a population of more than 40,000 people, most of whom are Tibetan or Qiang. The town of Zagunao, which means "lucky place" in Tibetan, is in the urban district of Lixian County, located in mountain valleys about $54 \mathrm{~km}$ away from the epicenter town, Yingxiu. More than $20 \%$ of houses in Zagunao were either collapsed or seriously damaged by the earthquake.

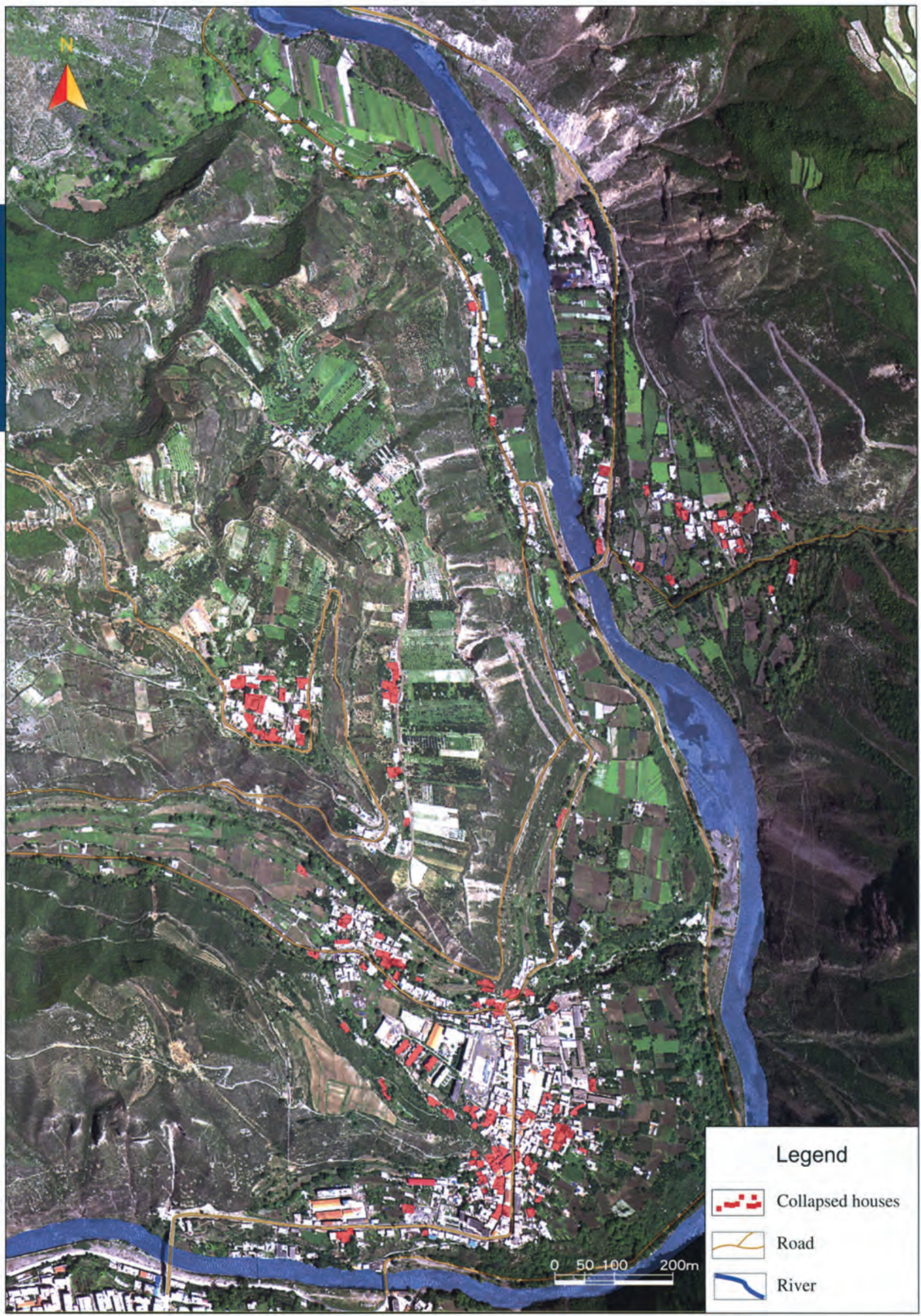

108 I Atlas of Remote Sensing of the Wenchuan Earthquake 


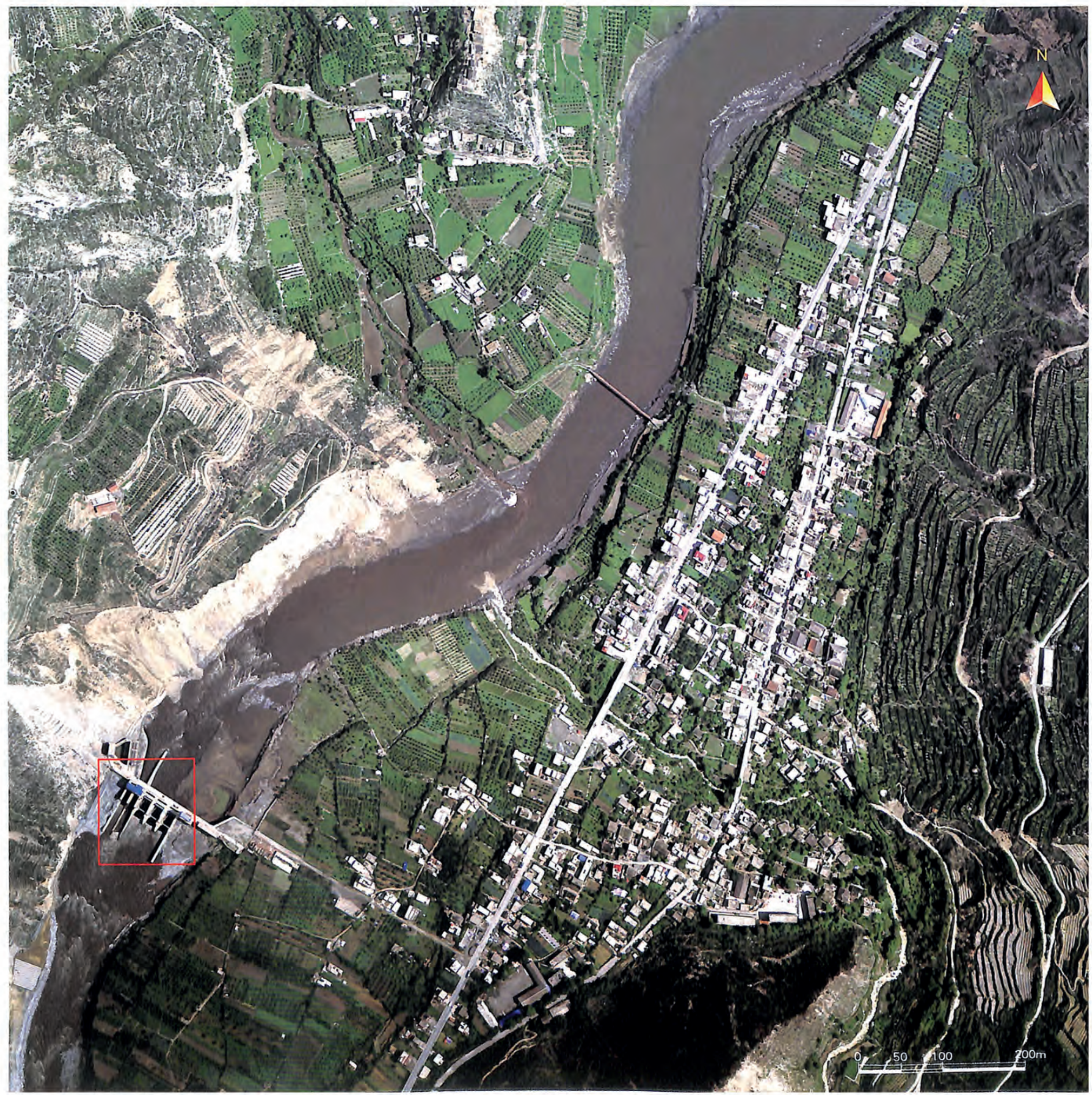

\section{A Airtome optical images of the town of Shigu, Maoxian County}

Acquired May 15, 2008. The town of Shigu is located on the east side of the Minjiang River. The houses and the buildings of the town of Shigu were relatively slightly damaged by the earthquake, and fewer than $20 \%$ of them collapsed. The red frame within the image shows the location of the Jiyu power station of the Baoshan Group, which was at high risk due to the earthquake and the earthquake-induced landslides. 


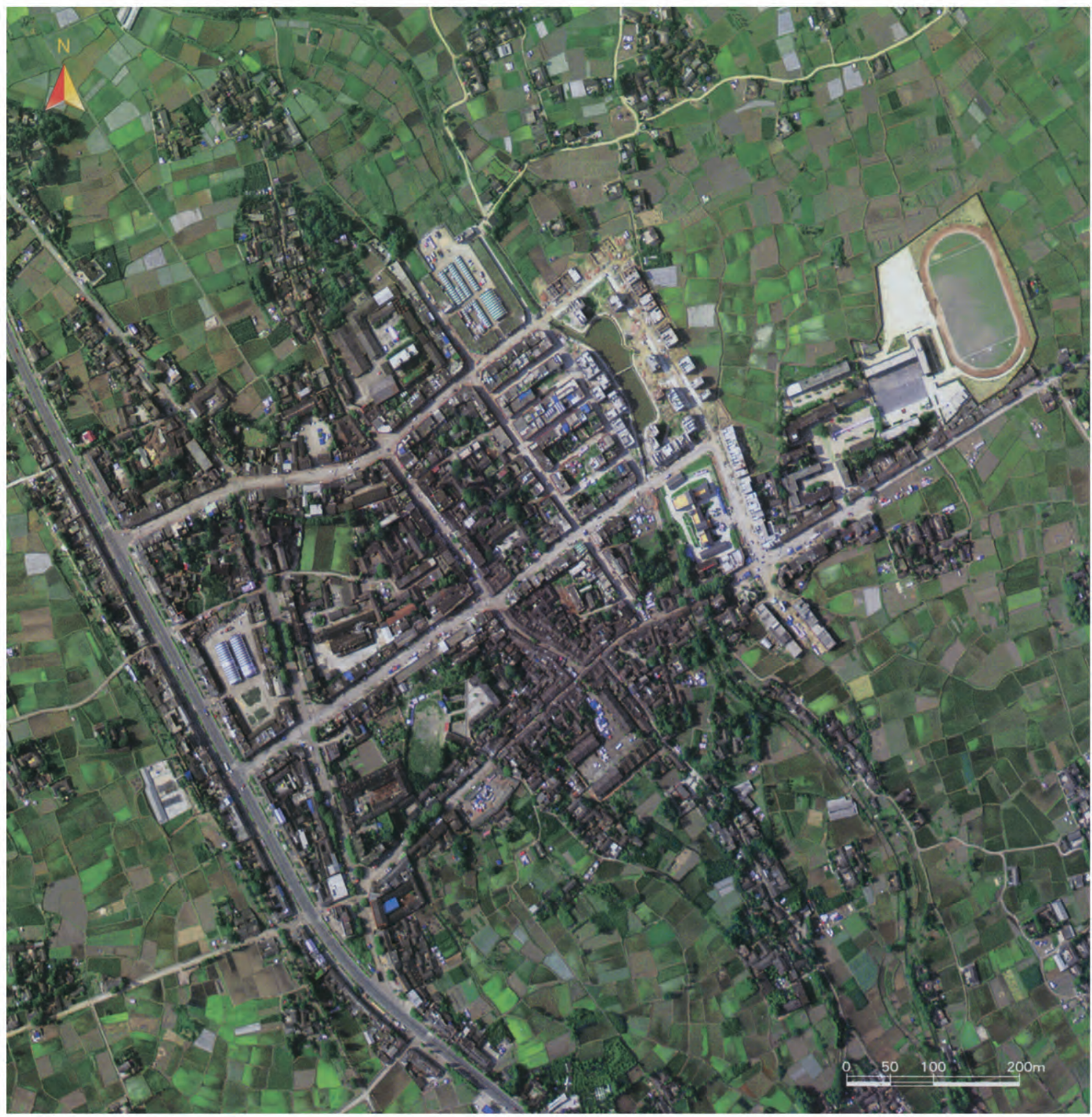

$\Delta$ Airborne optical image of the town of Longfeng, in the city of Pengzhou

Acquired May 19, 2008. The town of Longfeng, located in the piedmont plain of Longmen Mountain, is famous for producing garlic. It is $6 \mathbf{~ k m}$ away from the Anxian-Guanxian Fault and $19 \mathrm{~km}$ away from the Yingxiu-Beichuan Fault. About $20 \%$ of the houses in the town of Longfeng collapsed.

110 I Atlas of Remote Sensing of the Wenchuan Earthquake 
Acquired May 16, 2008. The town of Dabao is located in the mountainous area of the city of Pengzhou. Since the Yingxiu-Beichuan Fault passes through the town of Dabao, its collapse rate was higher than $\mathbf{9 0 \%}$. No effective disaster-relief could access this area because of a traffic block caused by earthquake-induced landslides. The red frame within the image shows the collapsed houses.

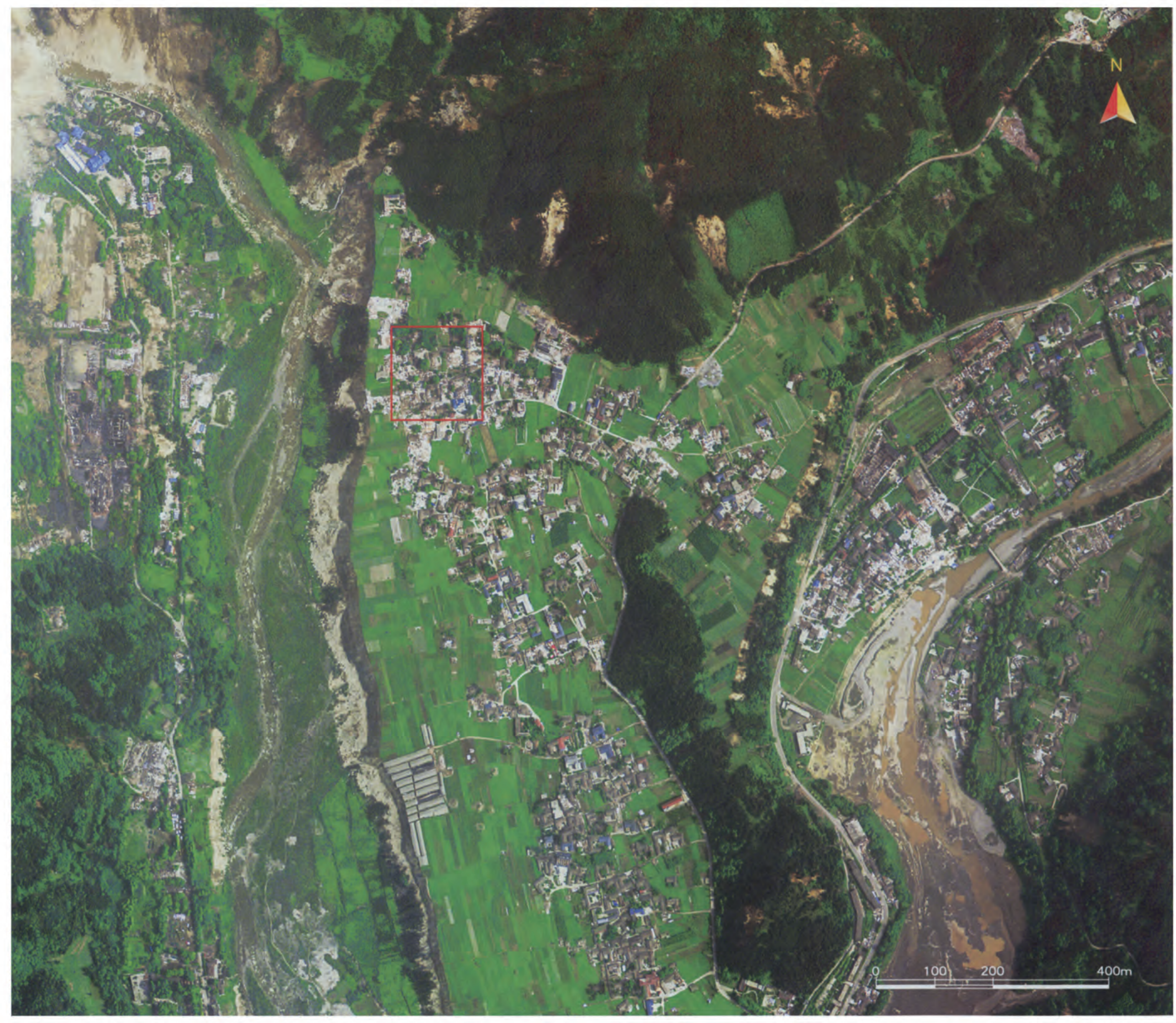


Acquired May 19, 2008. The town of Hongbai lies right above the Yingxiu-Beichuan Fault, so its collapse rate was higher than $\mathbf{9 0} \%$. The red frame shows collapsed houses and disasterrelief tents.

$\checkmark$ Airborne optical image of the village of Xiaojiaping, in the town of Longmenshan, in the city of Pengzhou

Acquired May 23, 2008. The village of Xiaojiaping is located in the town of Longmenshan, in the city of Pengzhou. The Yingxiu-Beichuan Fault passes through the town of Longmenshan. Therefore, the house collapse rate was higher than $\mathbf{9 0 \%}$.

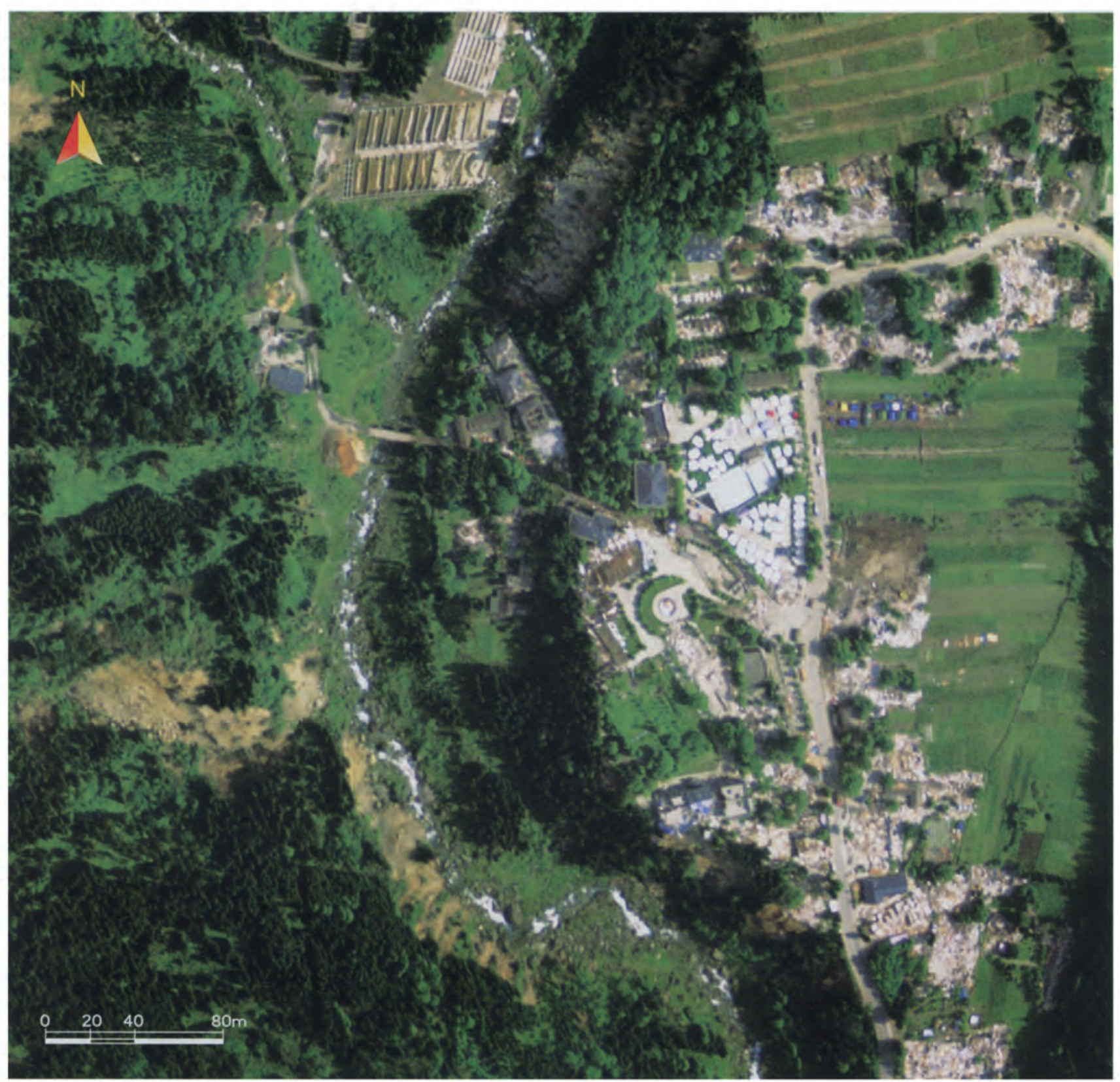

112 I Atlas of Remote Sensing of the Wenchuan Earthquake 


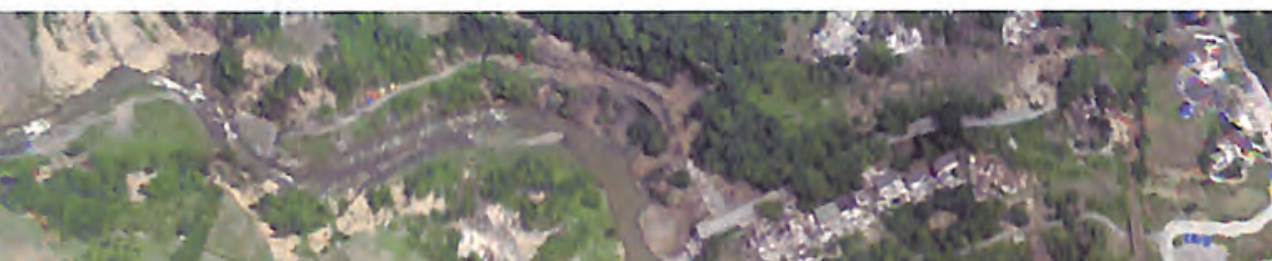

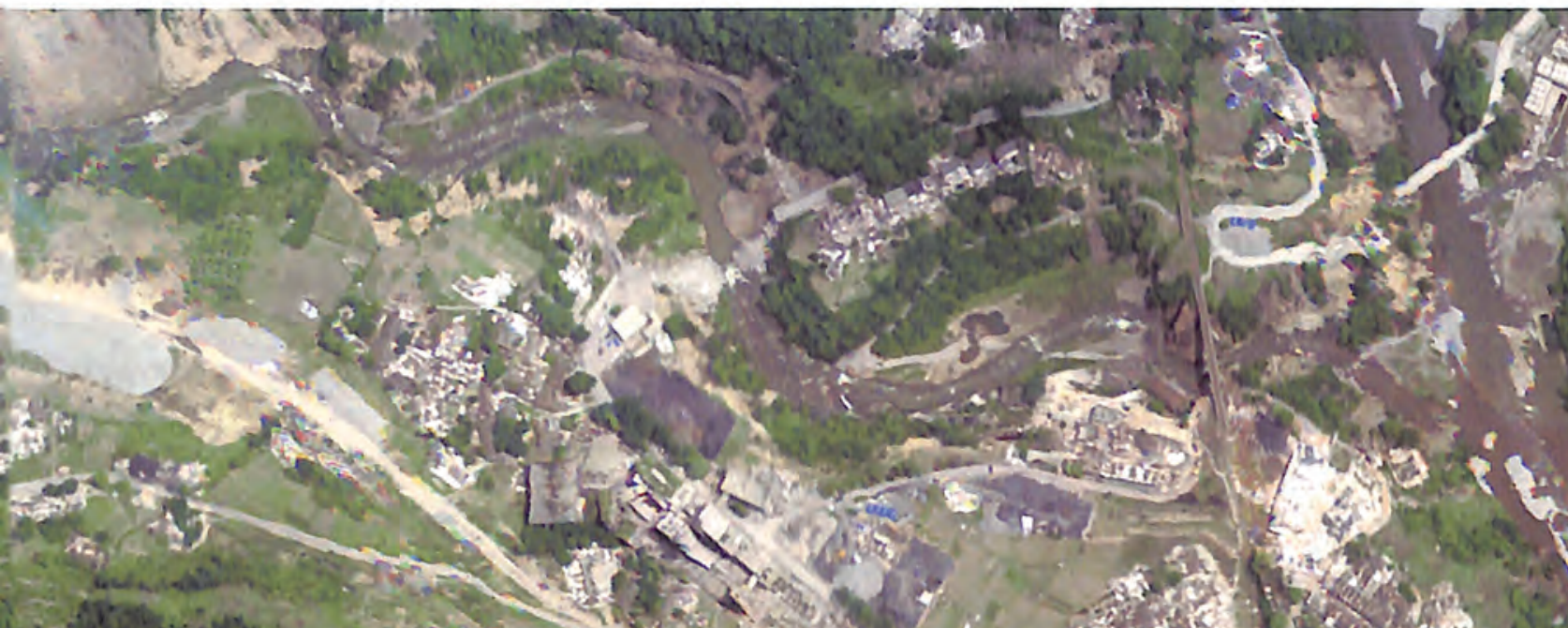

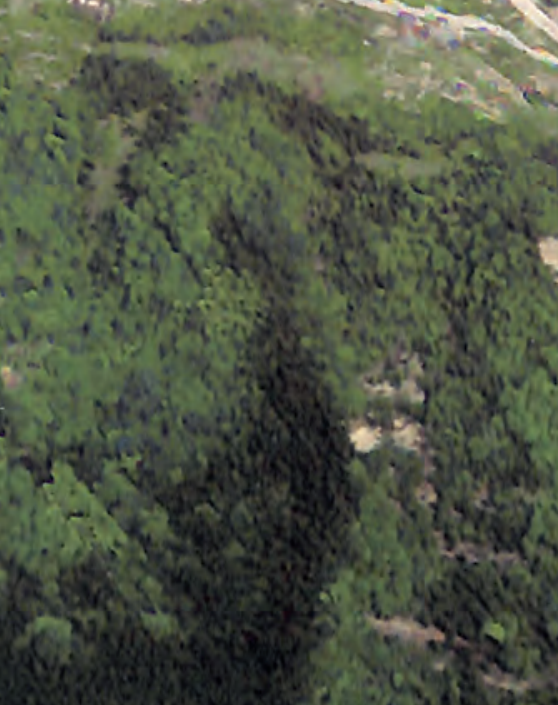

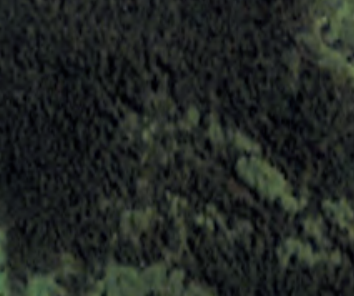

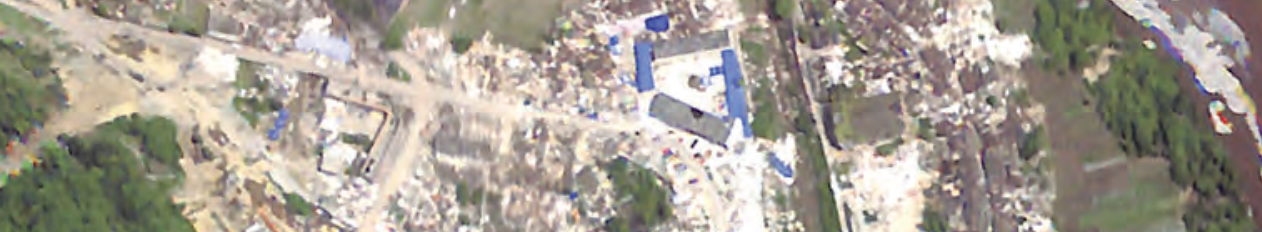
$5 \times 17)^{3}$

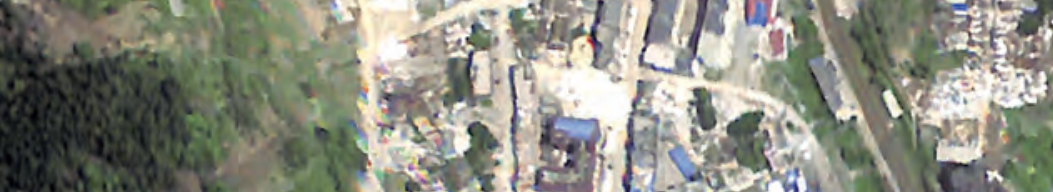
$x-13 y^{2}+2$

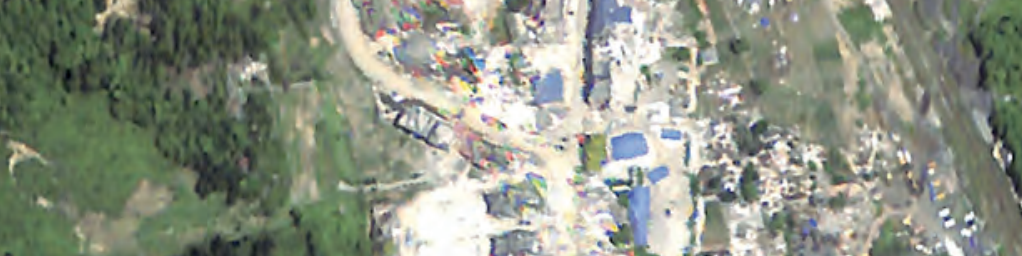

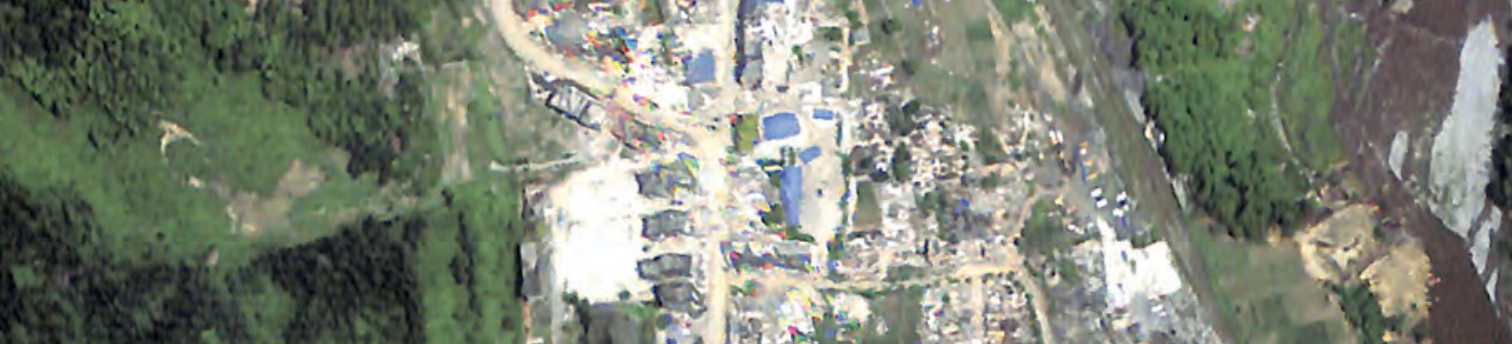
Mind 4 t igi

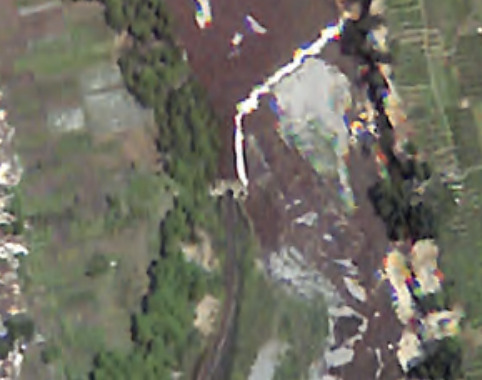

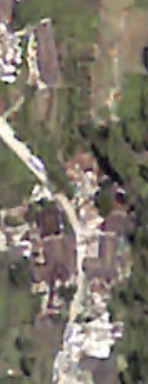

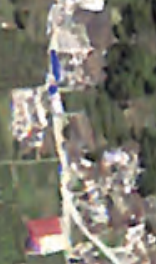
$2=$ 
v Airborne optical image of the town of Yunxi, in the city of Shifang

Acquired May 23, 2008. The town of Yunxi is $\mathbf{4} \mathrm{km}$ away from the Anxian-Guanxian Fault, and had a collapse rate of about $20 \%$. The red frame in the image shows collapsed and damaged houses.

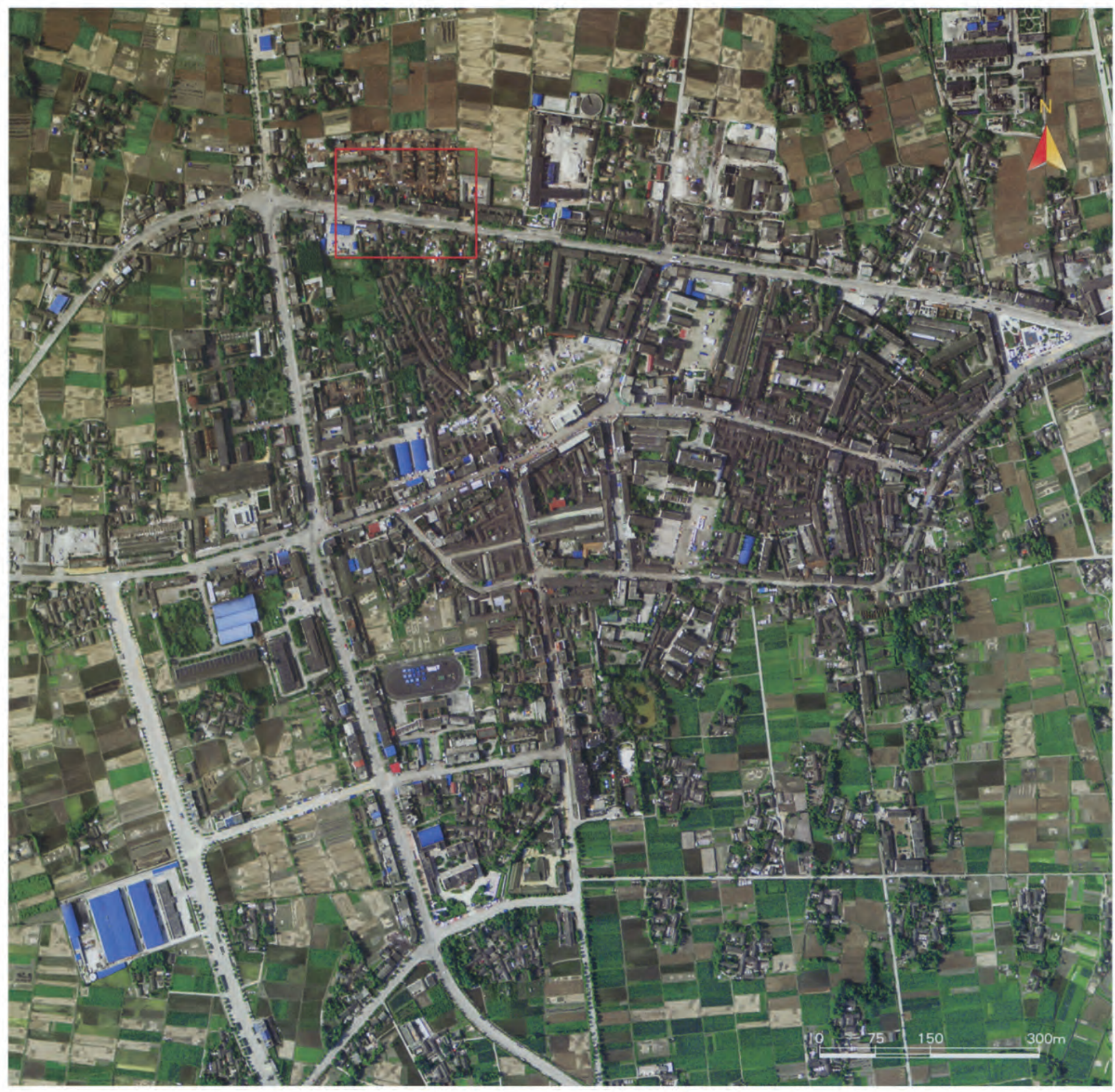




\section{Distribution of col- lapsed houses in the city of Mianzhu}

The city of Mianzhu is located in the northwest part of the Sichuan Basin, and has an area of $1,245 \mathrm{~km}^{2}$, and ranges in altitude from $504 \mathrm{~m}$ to 4,406 $\mathrm{m}$. This city is typically characterized as "Six parts hill land, three parts farm land, and one part water." The YingxiuBeichuan Fault and the AnxianGuanxian Fault pass through this city, so damage was serious and collapse rates were around $40 \%$. The collapse rate increased from the southeast to the northwest, and the collapsed houses were mainly distributed in the nine towns between the town of Guangii and the town of Gongxing. The damage in rural regions was more serious than that in urban areas. The collapse rate in urban regions was less than $\mathbf{1 0 \%}$ on the earthquake fault from the town of Guangji to the town of Gongxing. The collapse rate increased to $25 \%$ in villages and towns, while exceeding $50 \%$ in rural regions.

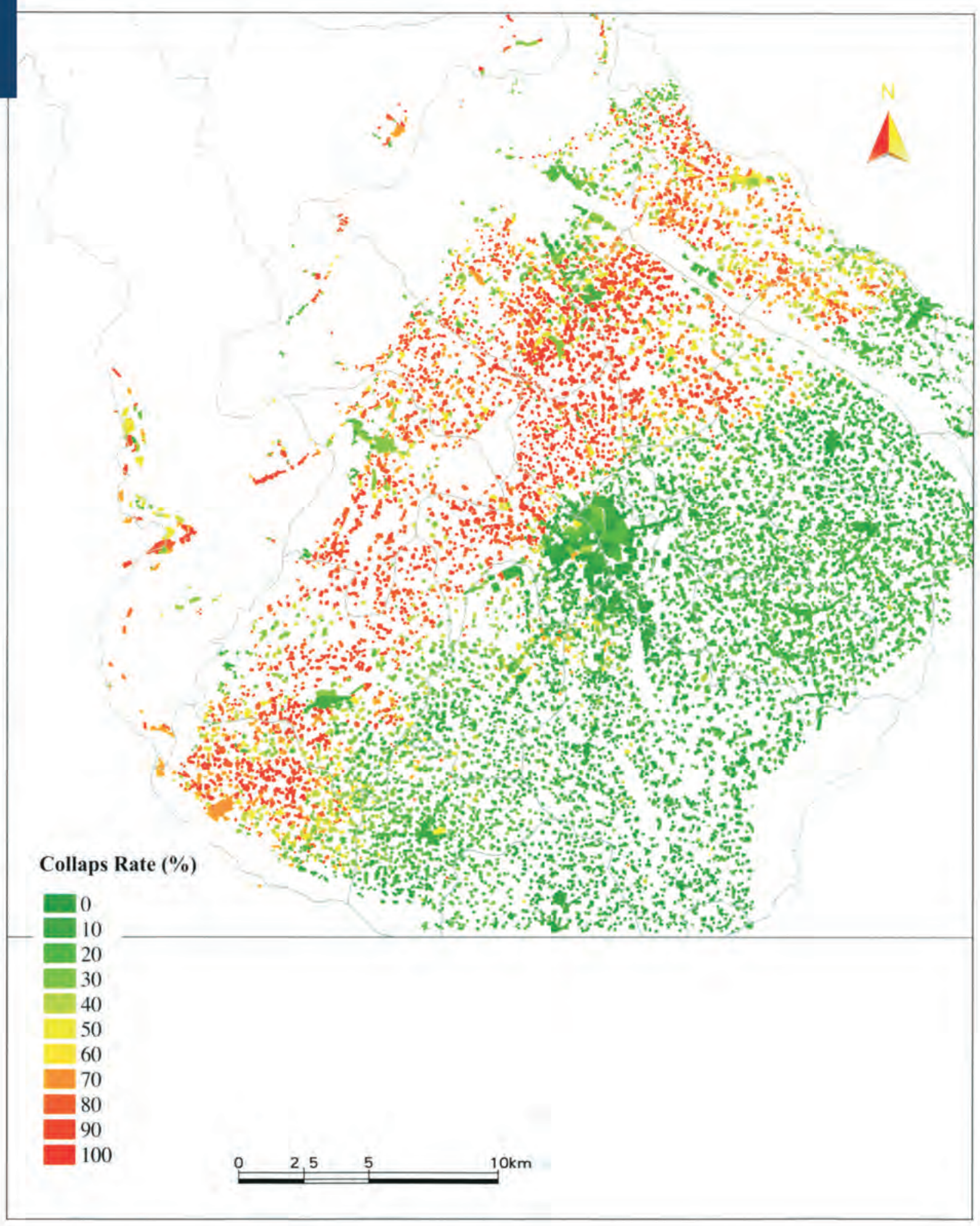




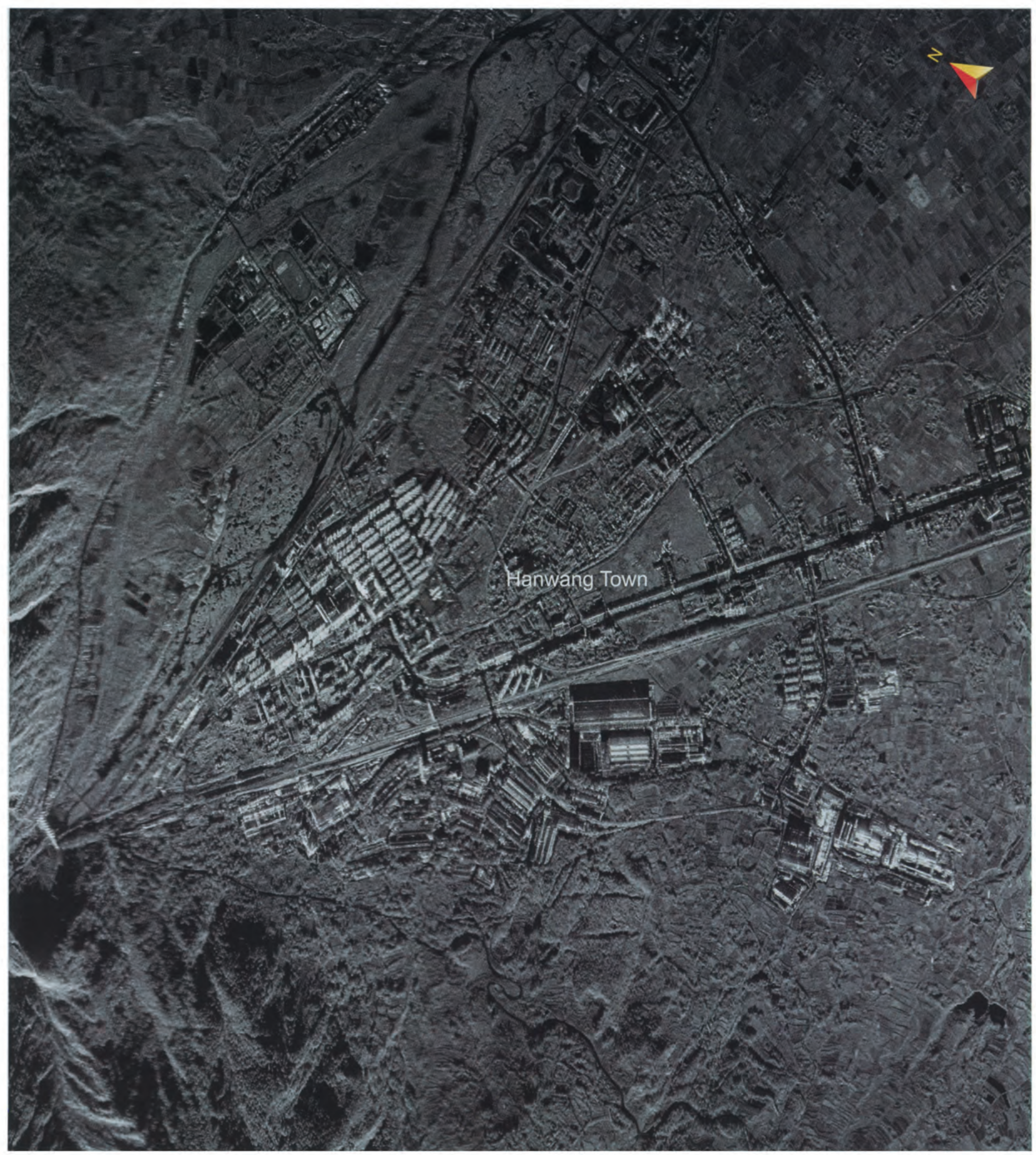

- Radar image in the town of Hanwang, in the city of Mianzhu

Acquired May 24, 2008. The radar image shows that the collapse and destruction was serious and some adjacent houses collapsed together. 


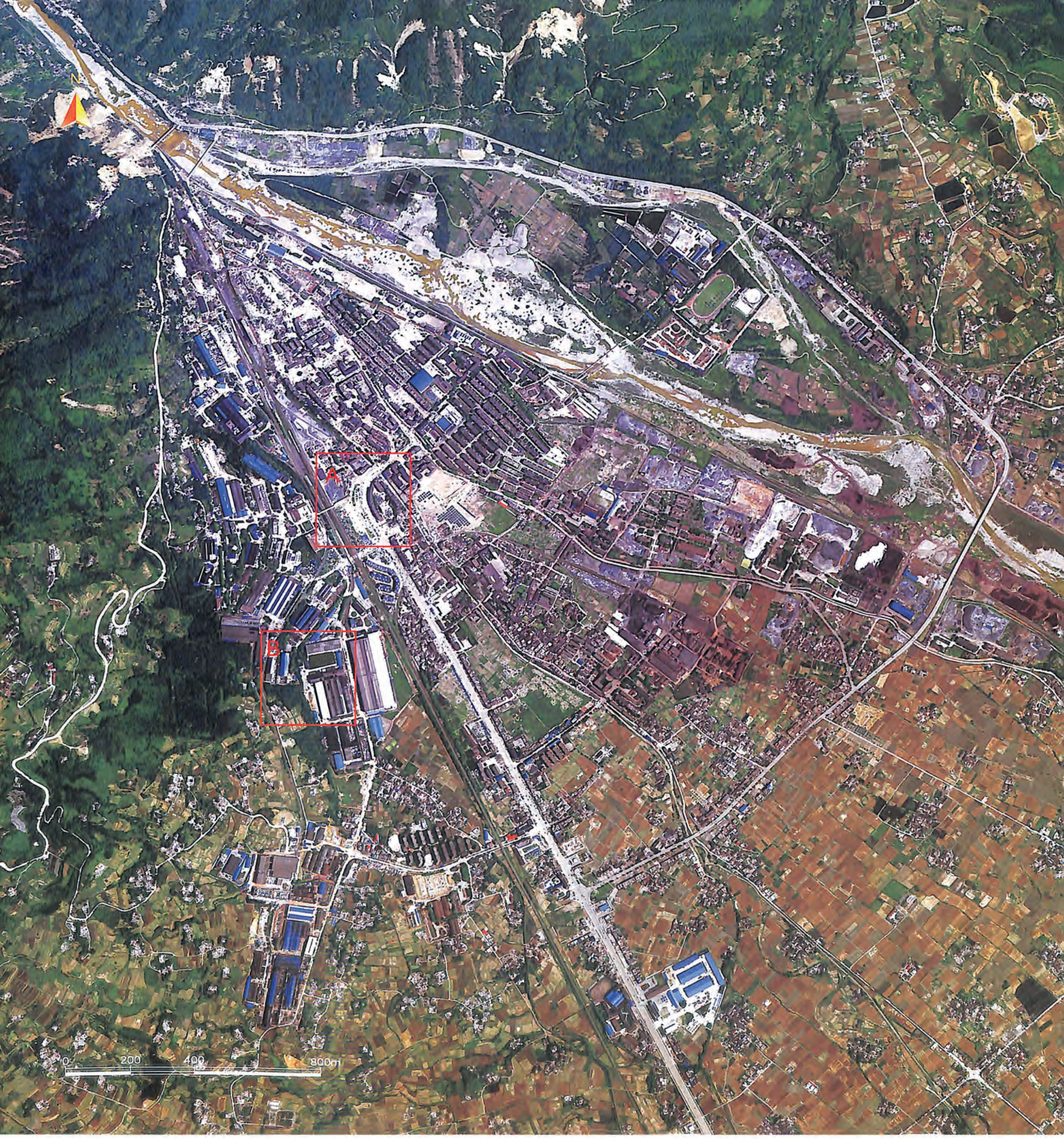




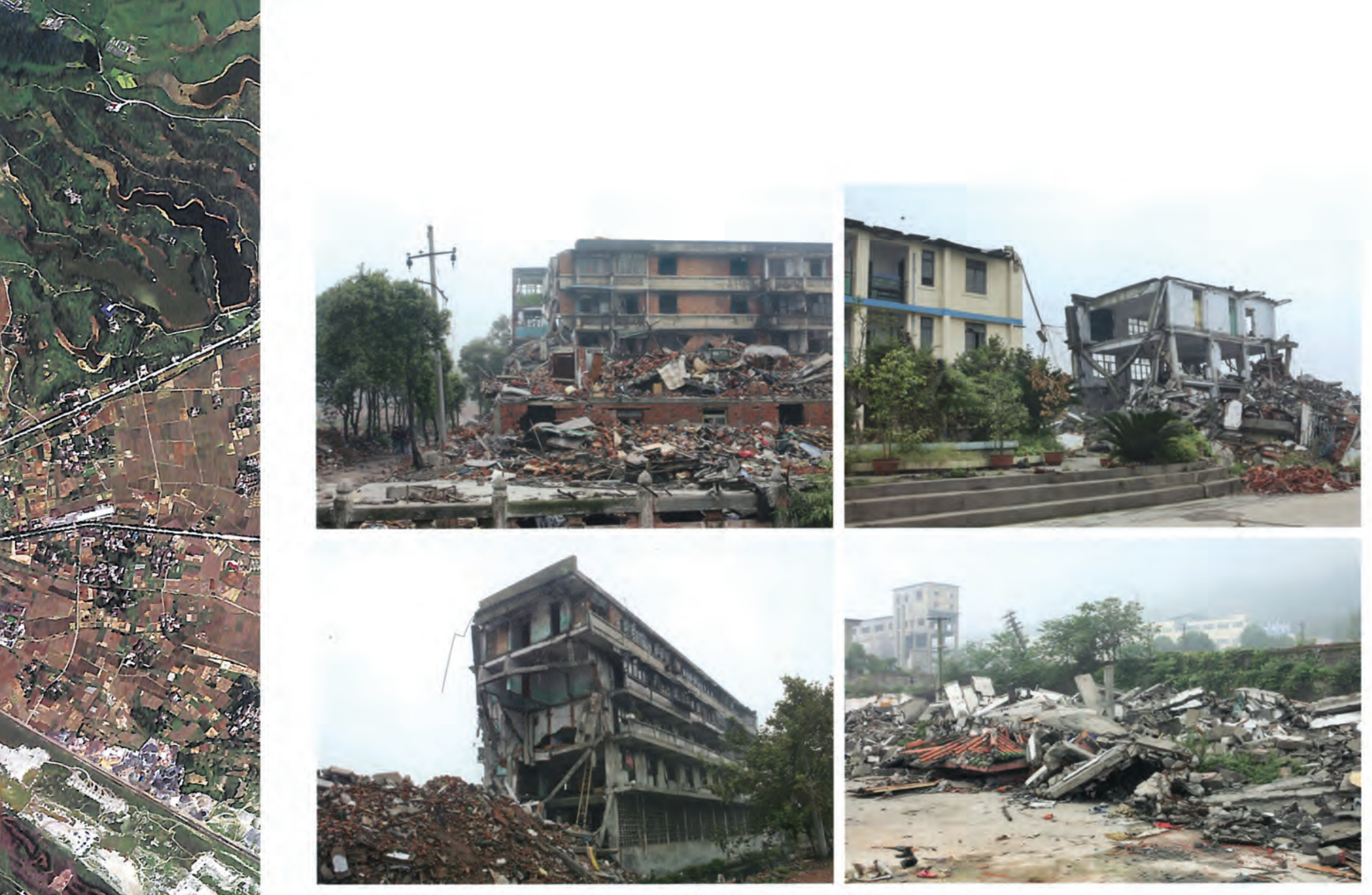

A Houses collapsed or destroyed by the earthquake in the town of Hanwang

Airborne optical image of the town of Hanwang, in the city of Mianzhu

Acquired May 19, 2008. The town of Hanwang is between the Yingxiu-Beichuan Fault and the Anxian-Guanxian fault. The damage was extremely serious, about $50 \%$ of the houses were collapsed, and more than 20,000 people were killed in this disaster. (A) Collapsed and destroyed houses (B) Destroyed Dongfang Turbine Factory. 


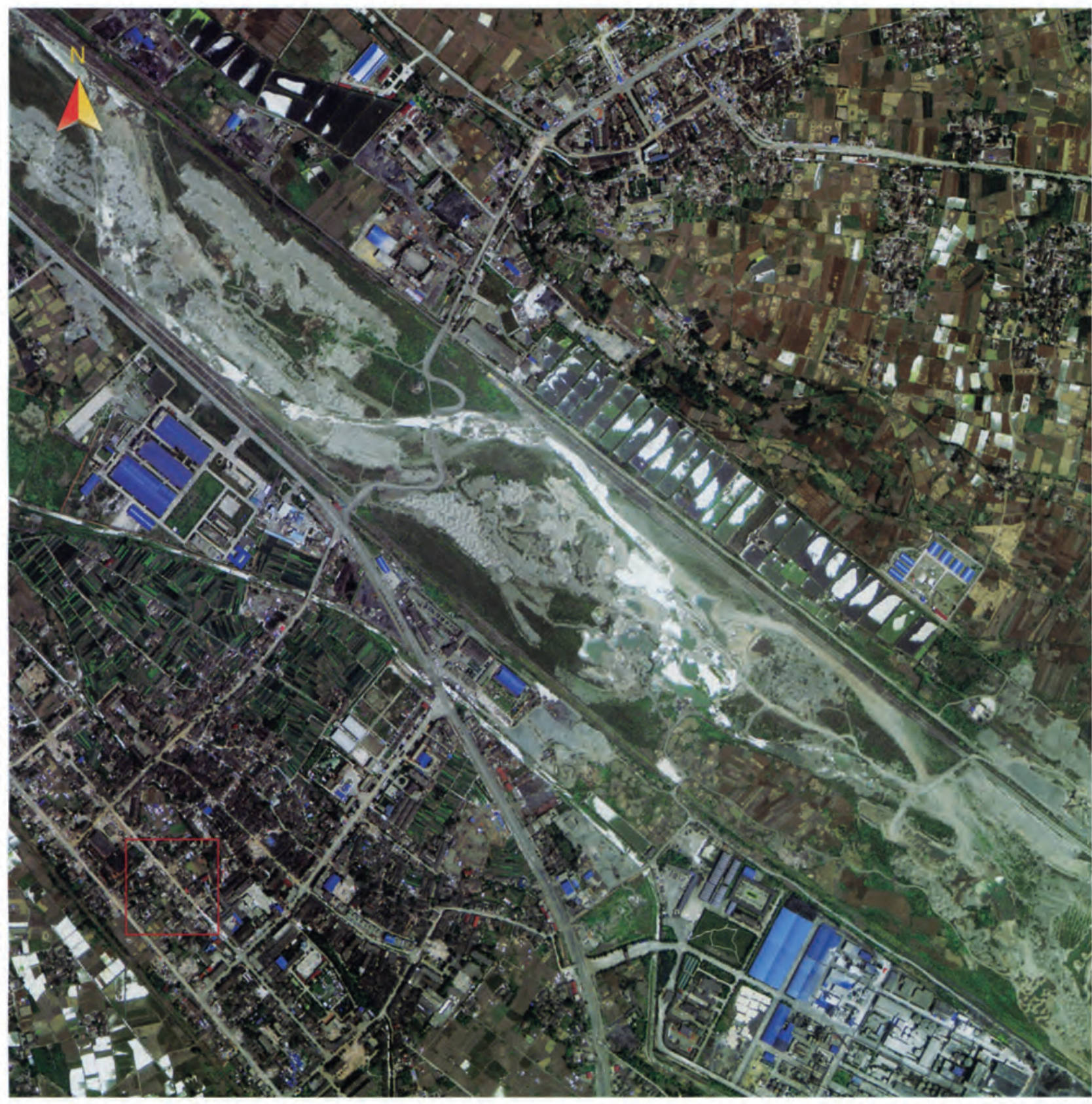

$100 \quad 200$
4 Airborne optical image of the town of Guangji, in the city of Mianzhu

Acquired May 19, 2008. The town of Guangii is in the piedmont transition region of Longmen Mountain and between the Yingxiu-Beichuan Fault and the Anxian-Guanxian Fault. Approximately $75 \%$ of the houses in the town of Guangii collapsed. The red frame shows collapsed and seriously damaged houses.

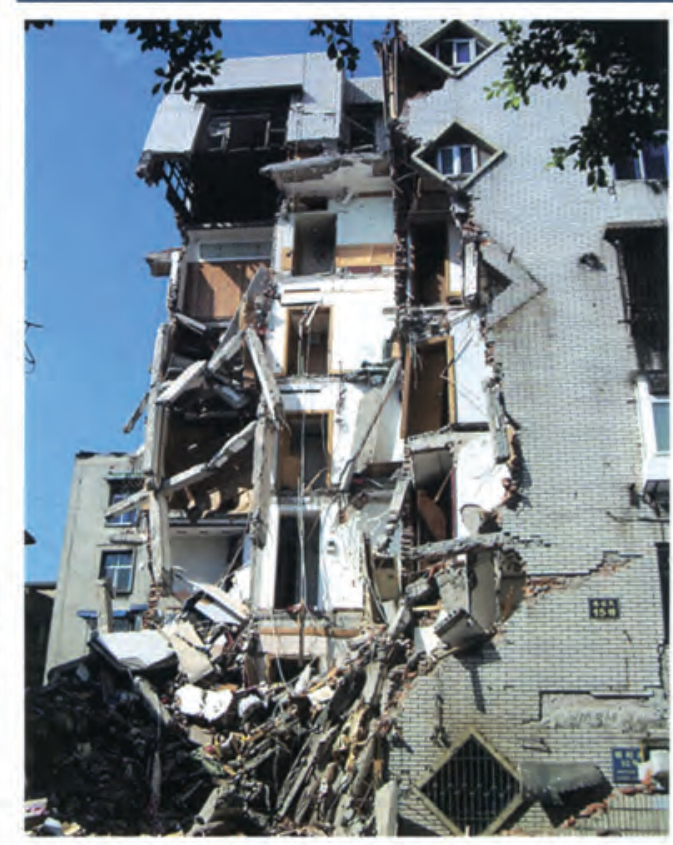

$\Delta$ Collapsed building in the town of Guangji

- Airborne optical image of the town of Zundao, in the city of Mianzhu

Acquired May 19, 2008. The town of Zundao is in the piedmont transition region of Longmen Mountain, and between the Yingxiu-Beichuan Fault and the Anxian-Guanxian Fault. The houses in the town of Zundao were seriously damaged, and the collapse rate approached $75 \%$. The red frame shows the collapsed and damaged houses.

120 I Atlas of Remote Sensing of the Wenchuan Earthquake 


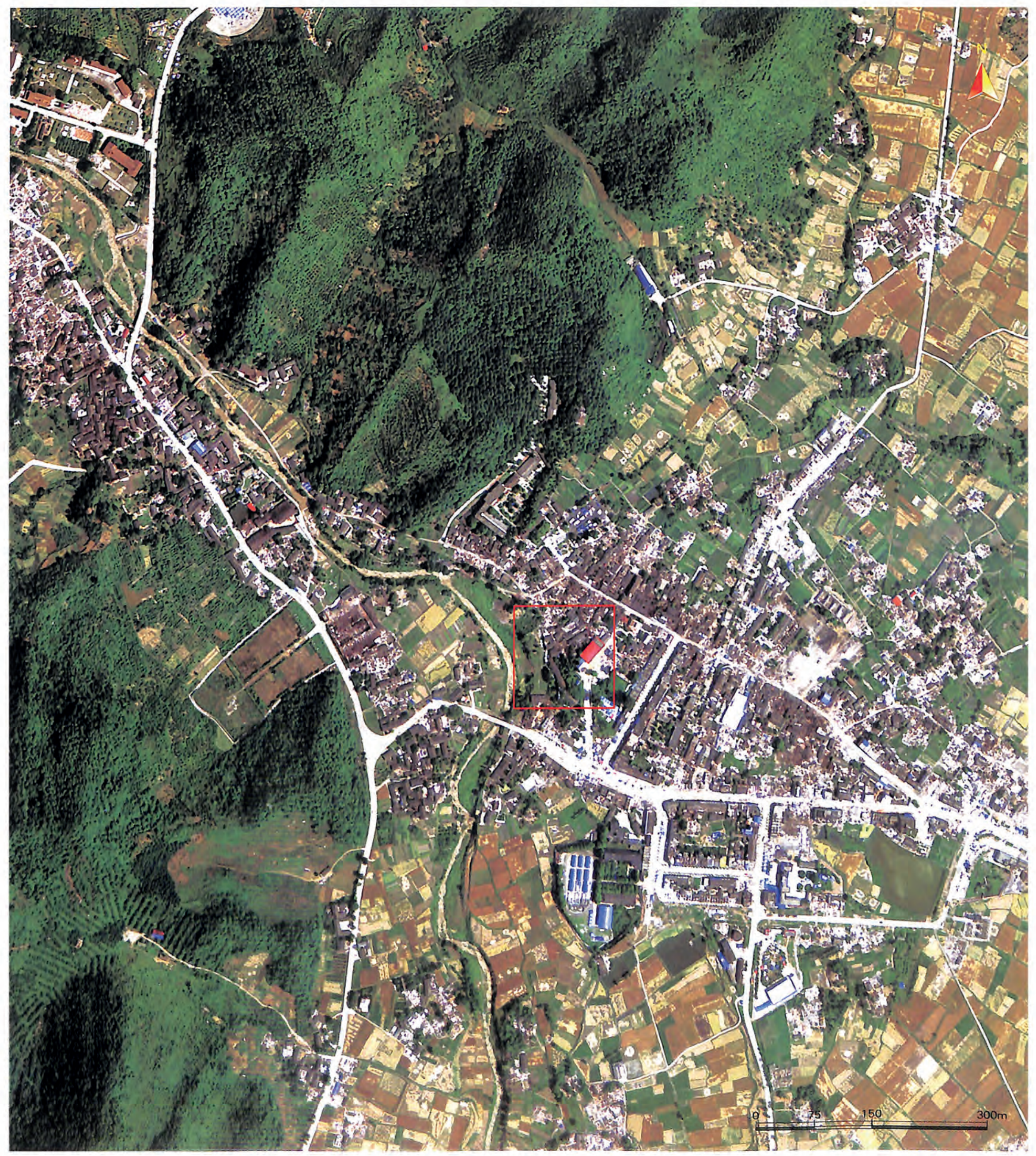




\section{Distribution of collapsed}

\section{buildings in Anxian}

\section{County}

Anxian County is located in the northwest portion of the Sichuan Basin, with a population of 500,000 and about $1,404 \mathbf{~ k m}^{2}$ of land. Anxian County was seriously damaged in this earthquake. Analysis based on airborne images shows that about one-seventh houses in Anxian County collapsed; houses along both the Yingxiu-Beichuan Fault and the Anxian-Guanxian Fault were destroyed. The towns of Gaochuan, Qianfo, Chaping, Xiaoba and several other towns that lie across the YingxiuBeichuan Fault suffered $60 \%$ collapse rate.

Collapse Rate (\%)

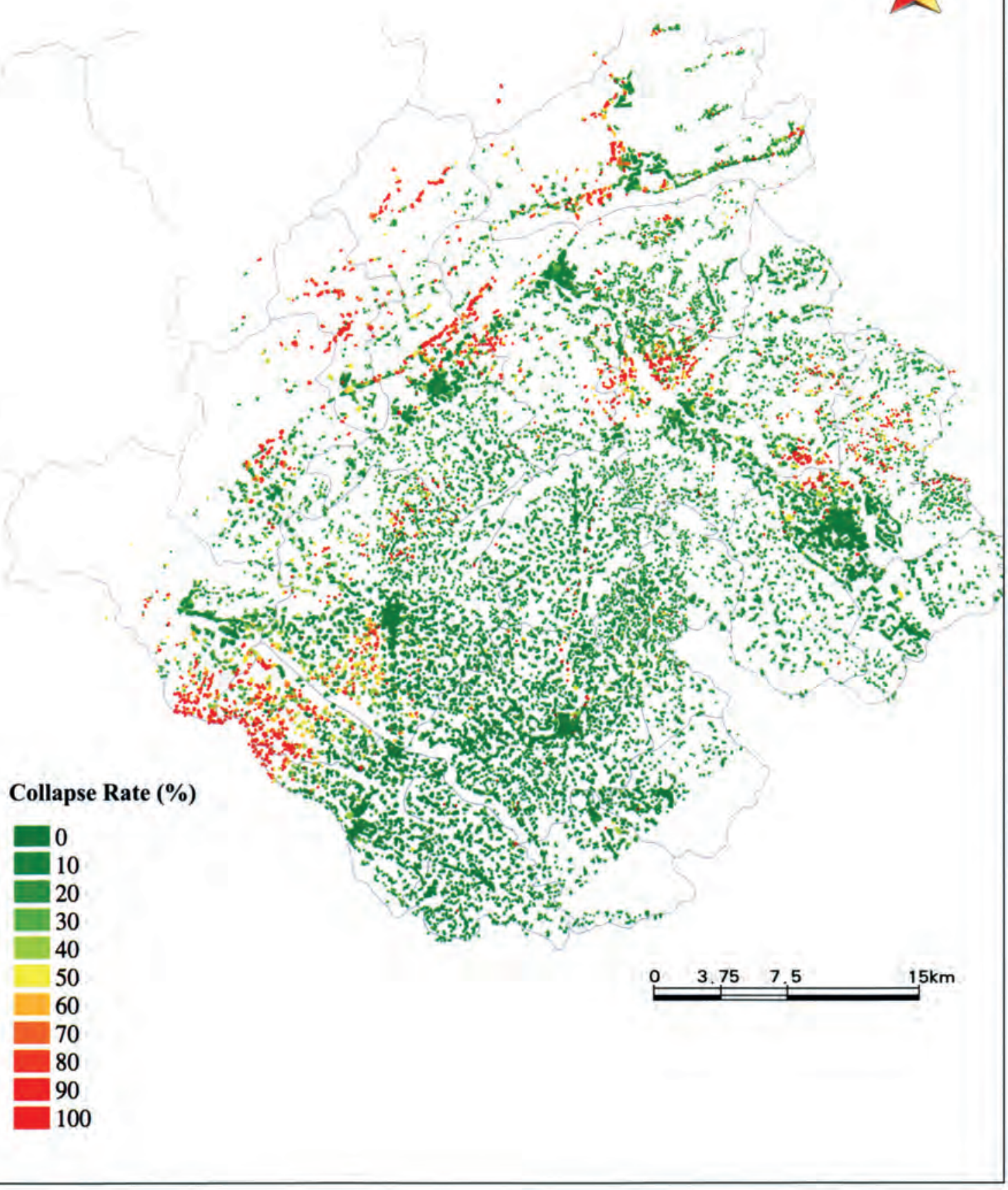

122 I Atlas of Remote Sensing of the Wenchuan Earthquake 


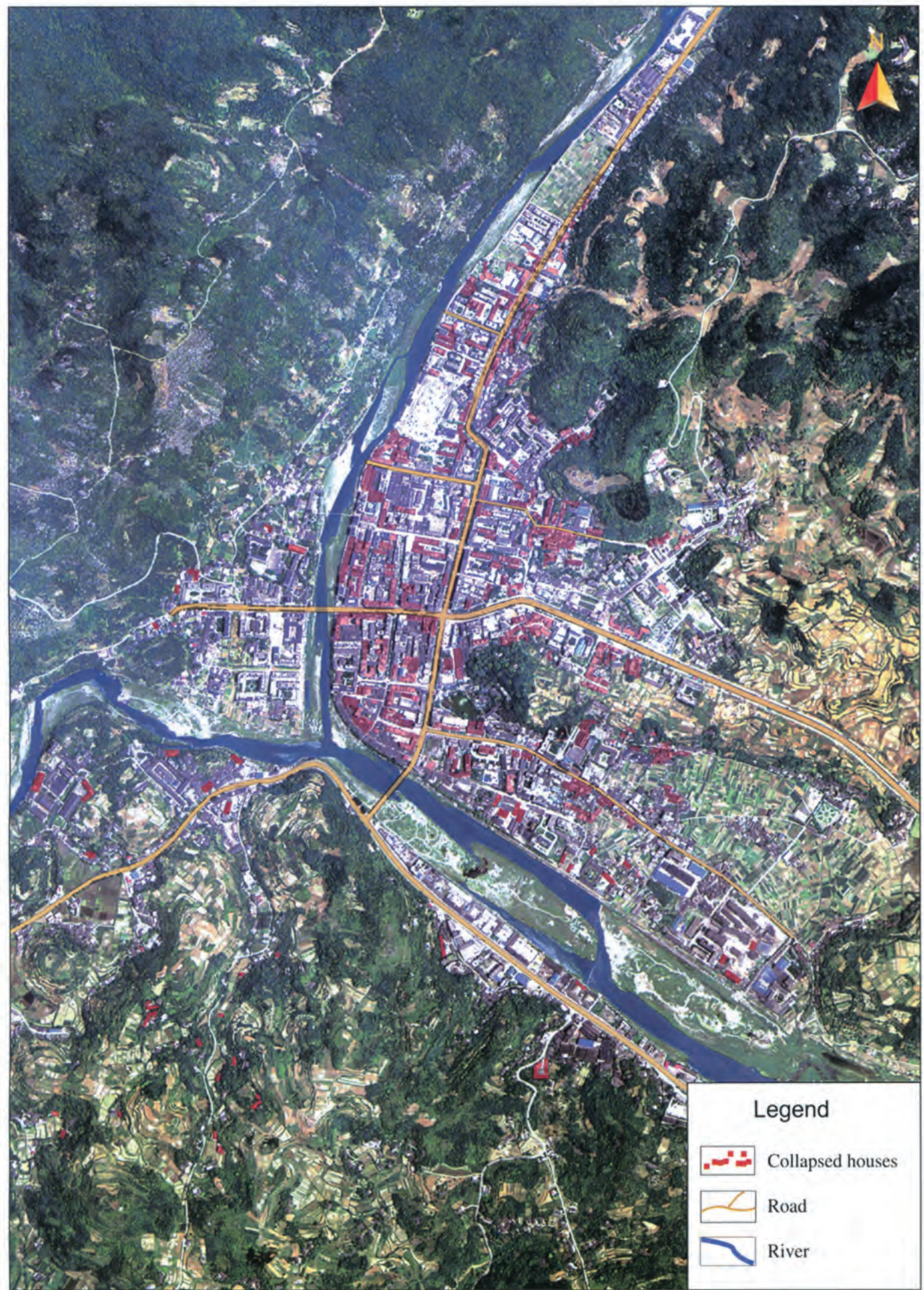

$125 \quad 250$
$500 \mathrm{~m}$

\section{Distribution of the} destroyed houses in the town of Anchang, in Anxian County

The town of Anchang is an old urban district of Anxian County; Longmen Mountain is northwest of the town of Anchang. Topography southeast part of the town of Anchang features plains and hills, and landslides there were not severe. In the town of Anchang, in the AnxianGuanxian Fault, almost $20 \%$ of the houses collapsed, while in the country the situation was much worse. 


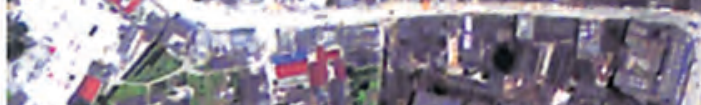

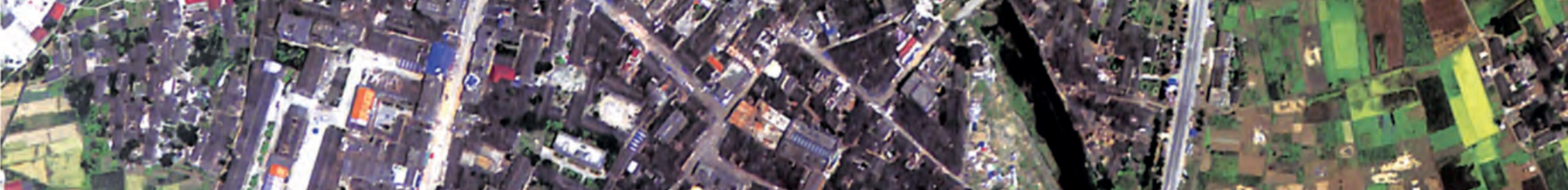

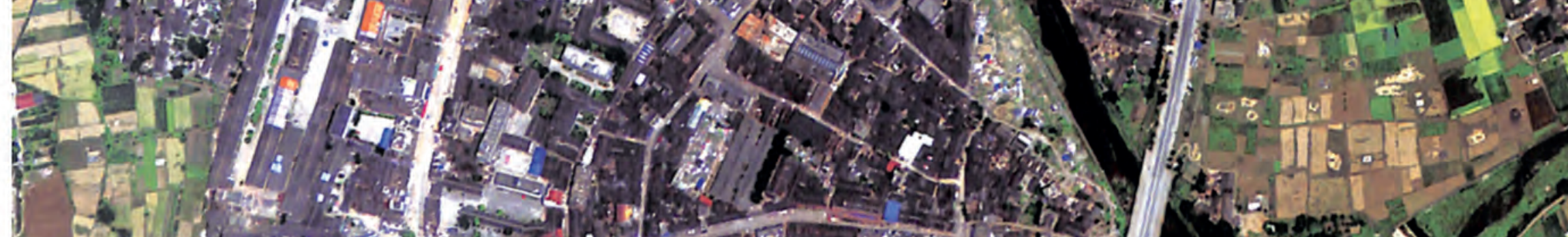

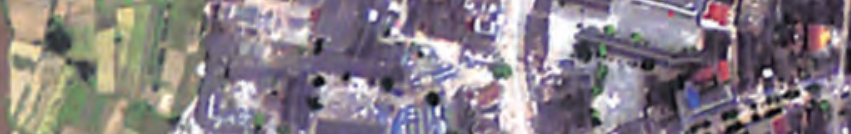

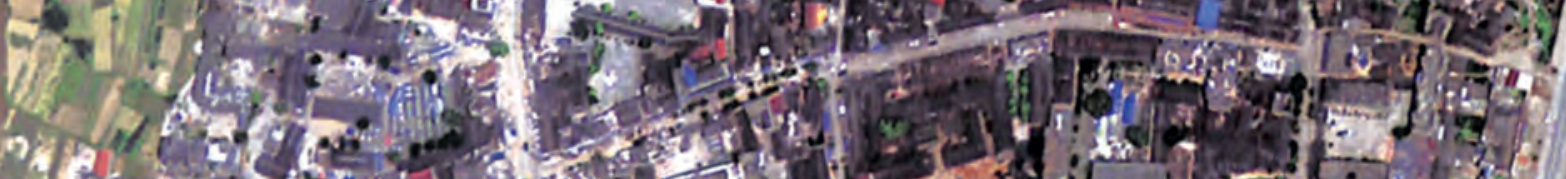

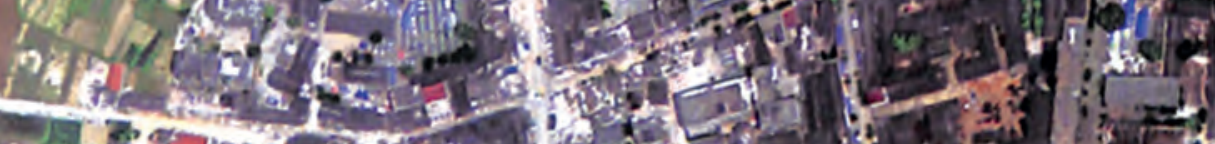
4. 150 ,

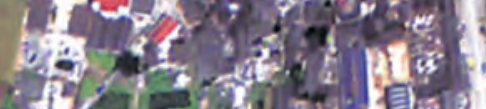

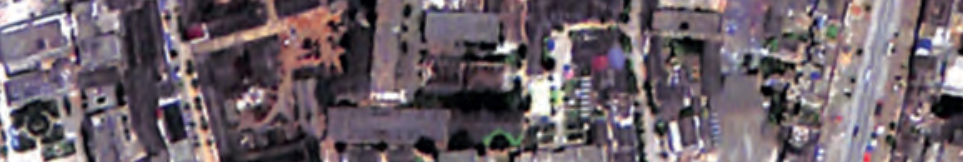

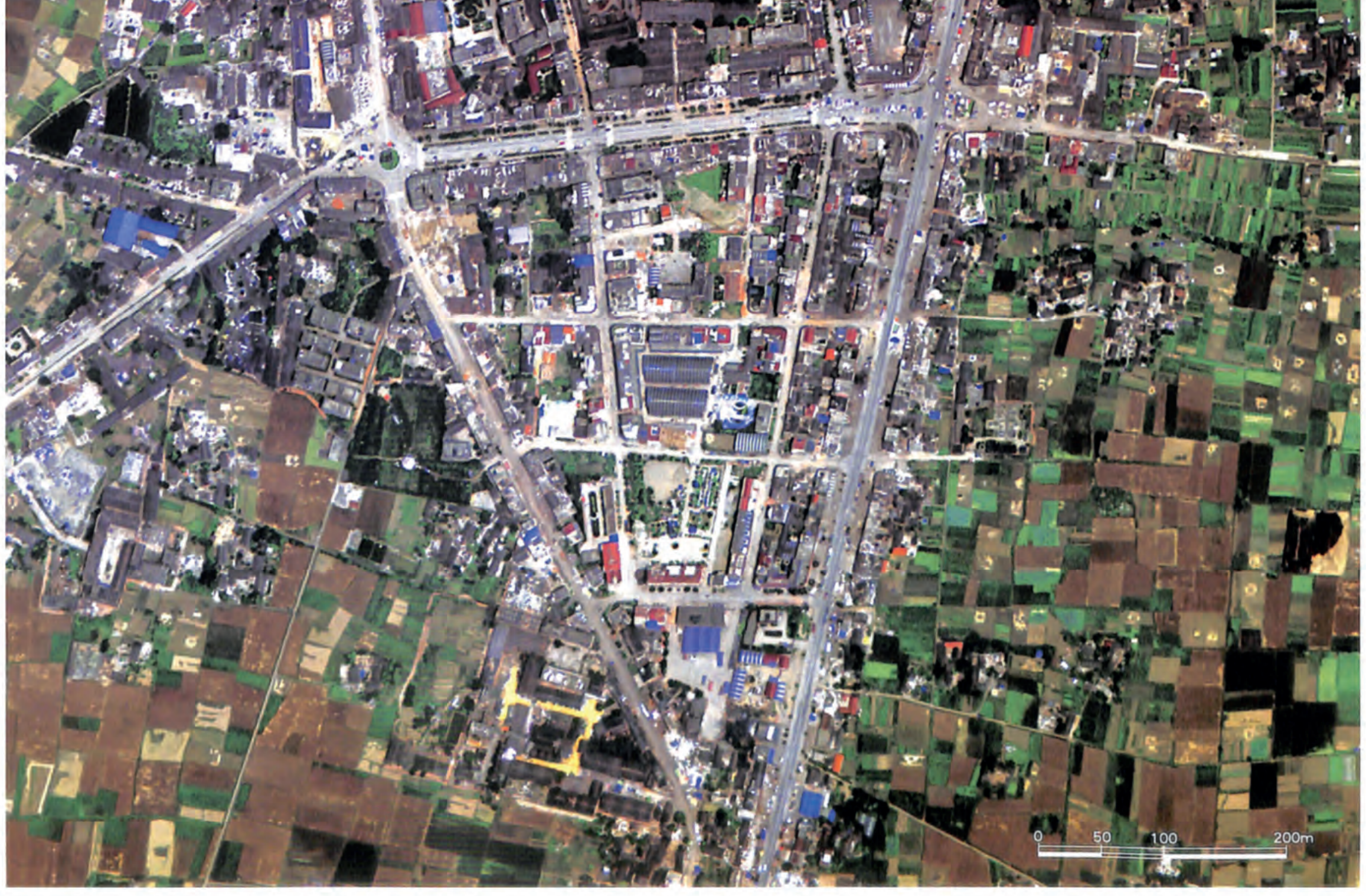

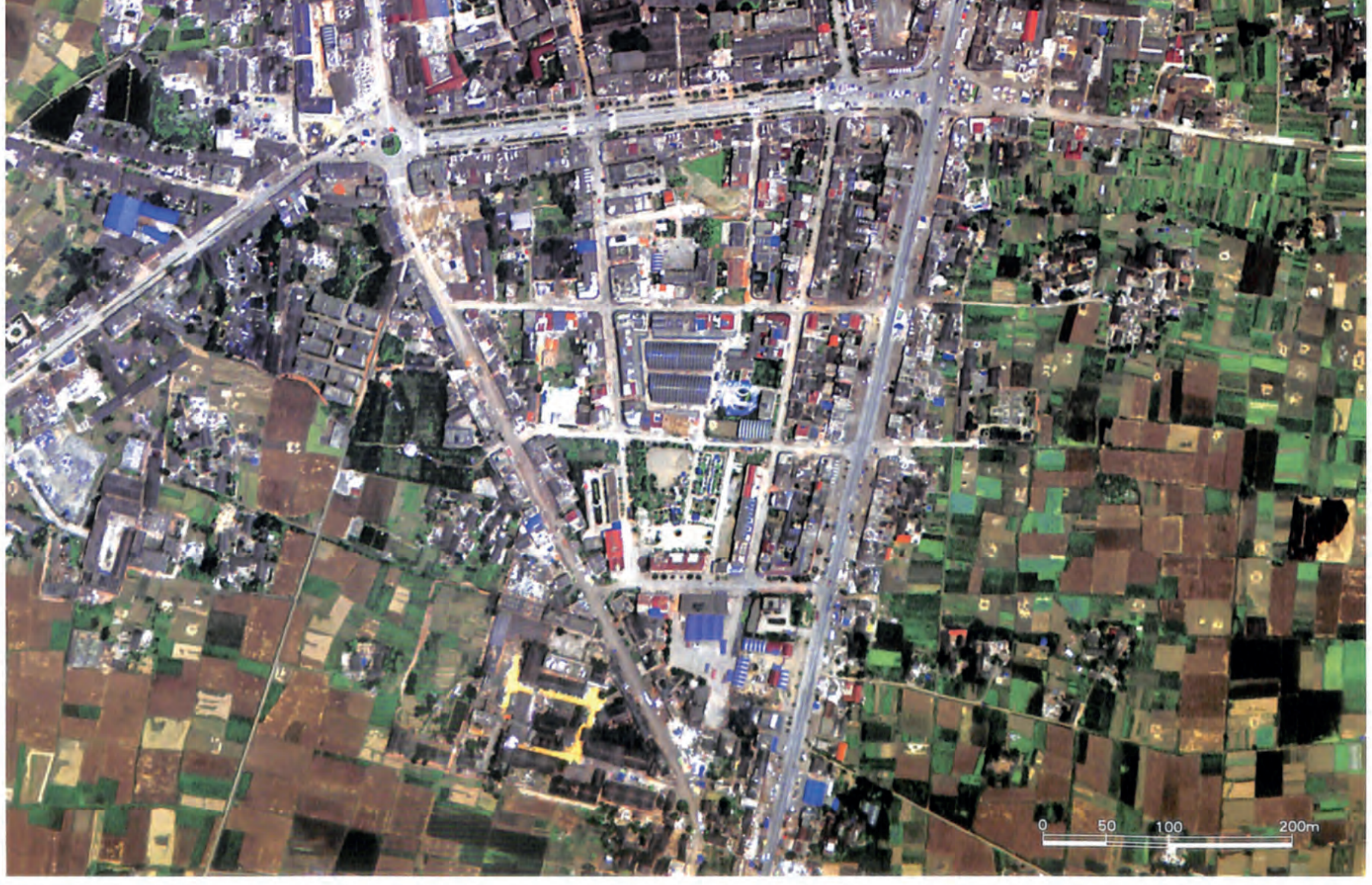




\section{Airborne optical image of the town of Xiushui, in Anxian County}

Acquired May 19, 2008. The town of Xiushui, located in the Anxian-Guanxian Fault, is the largest town in northwest Sichuan, with a population of more than $\mathbf{6 0 , 0 0 0}$. Houses were seriously damaged, at a rate of more than $60 \%$.

\section{$\nabla$ Airborne optical image of the town of Xiaoba, in Anxian County}

Acquired May 19, 2008. Xiaoba is located between the Yinxiu-Beichuan Fault and the AnxianGuanxian Fault, so houses were heavily damaged; the collapse ratio was more than $60 \%$.

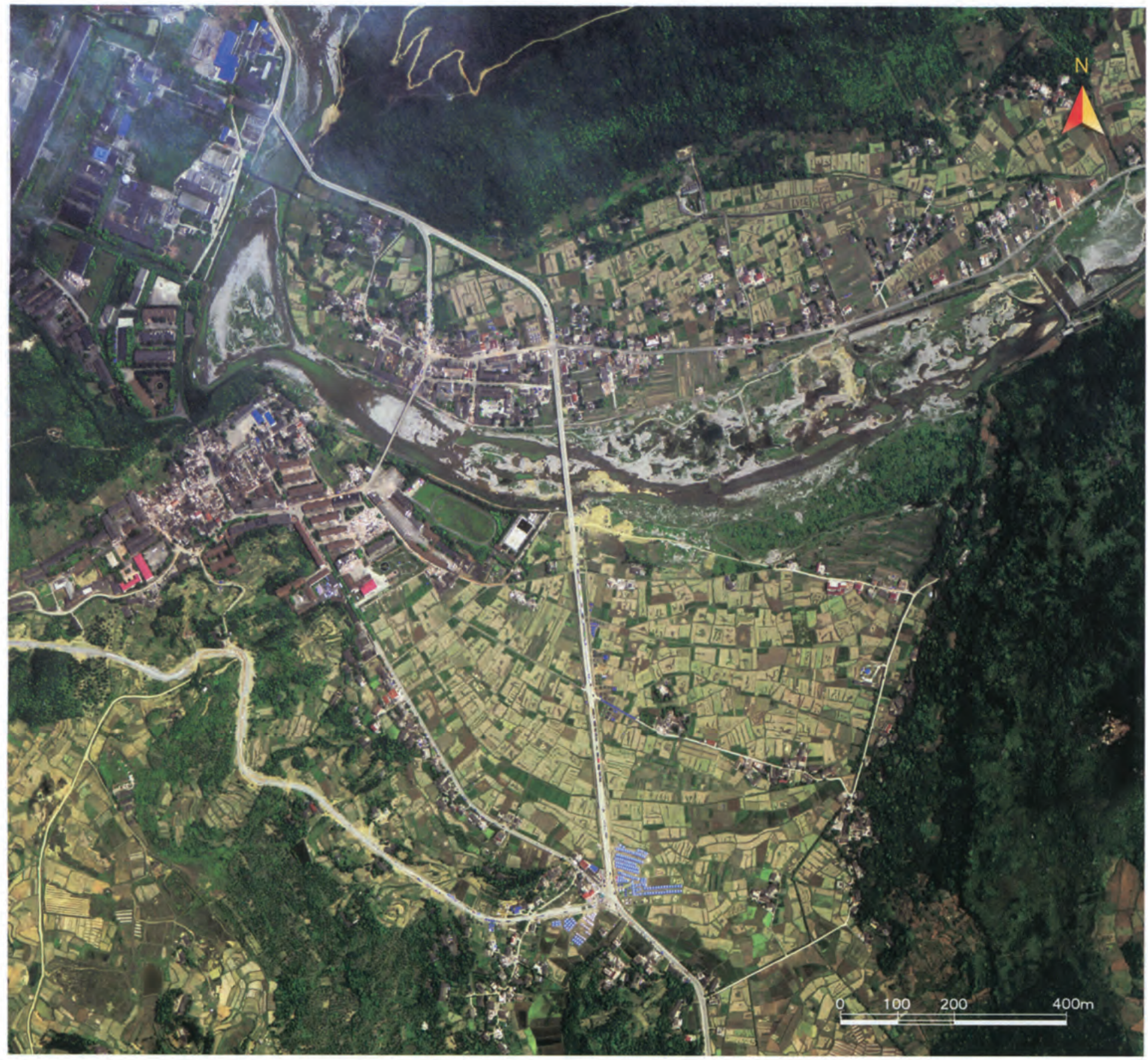




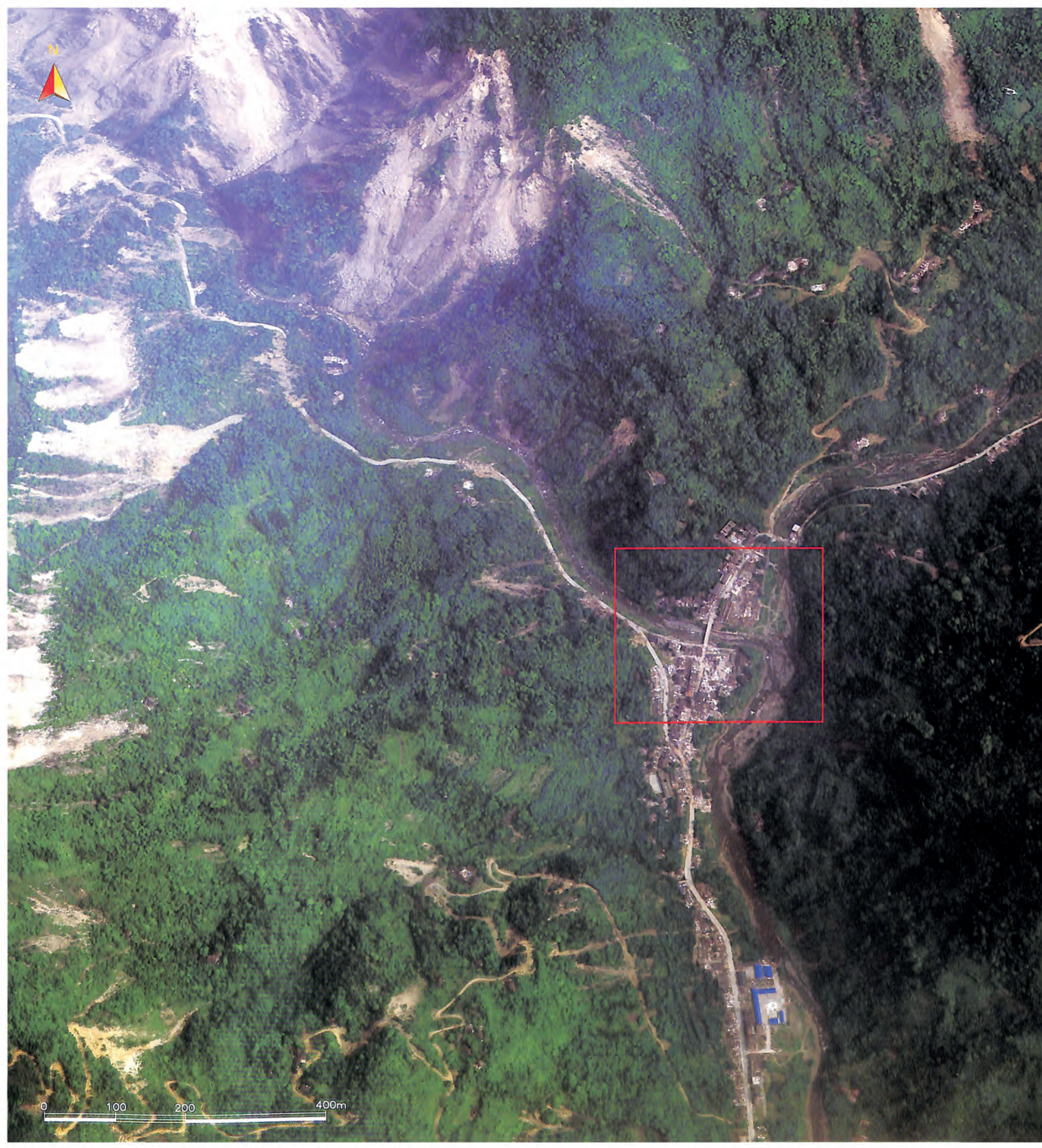

126 I Atlas of Remote Sensing of the Wenchuan Earthquake 

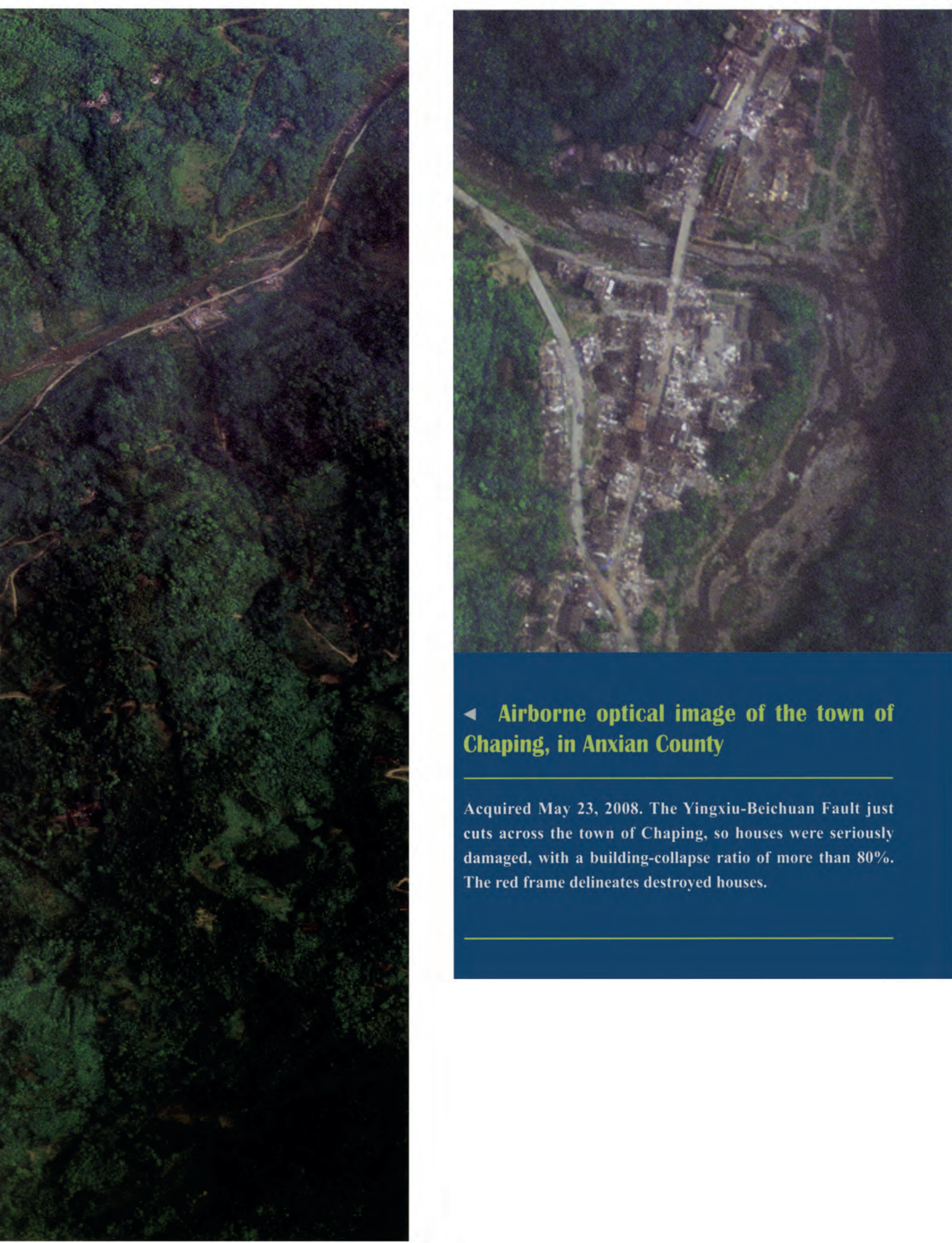


\section{Distribution of} destroyed houses and buildings in the city of Mianyang

Maoxian County is located in the southeast section of Aba Tibet and Qiang Autonomous Prefecture, which is the transitional zone from the Qinghai-Tibet Plateau to the Sichuan Plain, and is the main residential area of the Qiang people. Maoxian County lies along the Wenchuan-Maoxian seismic belt, and nearly $20 \%$ of the houses were either severely damaged or collapsed in the urban area of the Maoxian County.

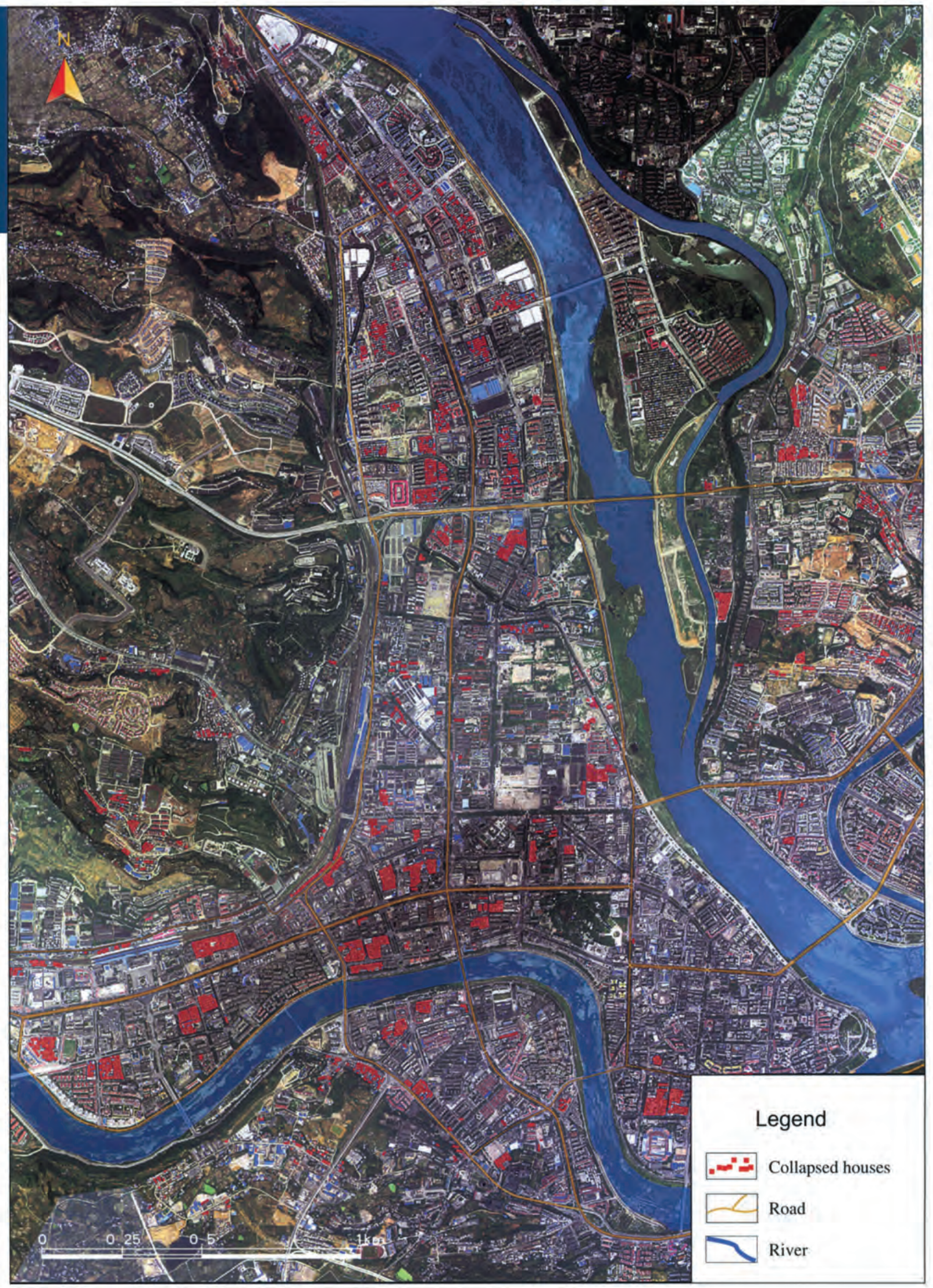

128 I Atlas of Remote Sensing of the Wenchuan Earthquake 


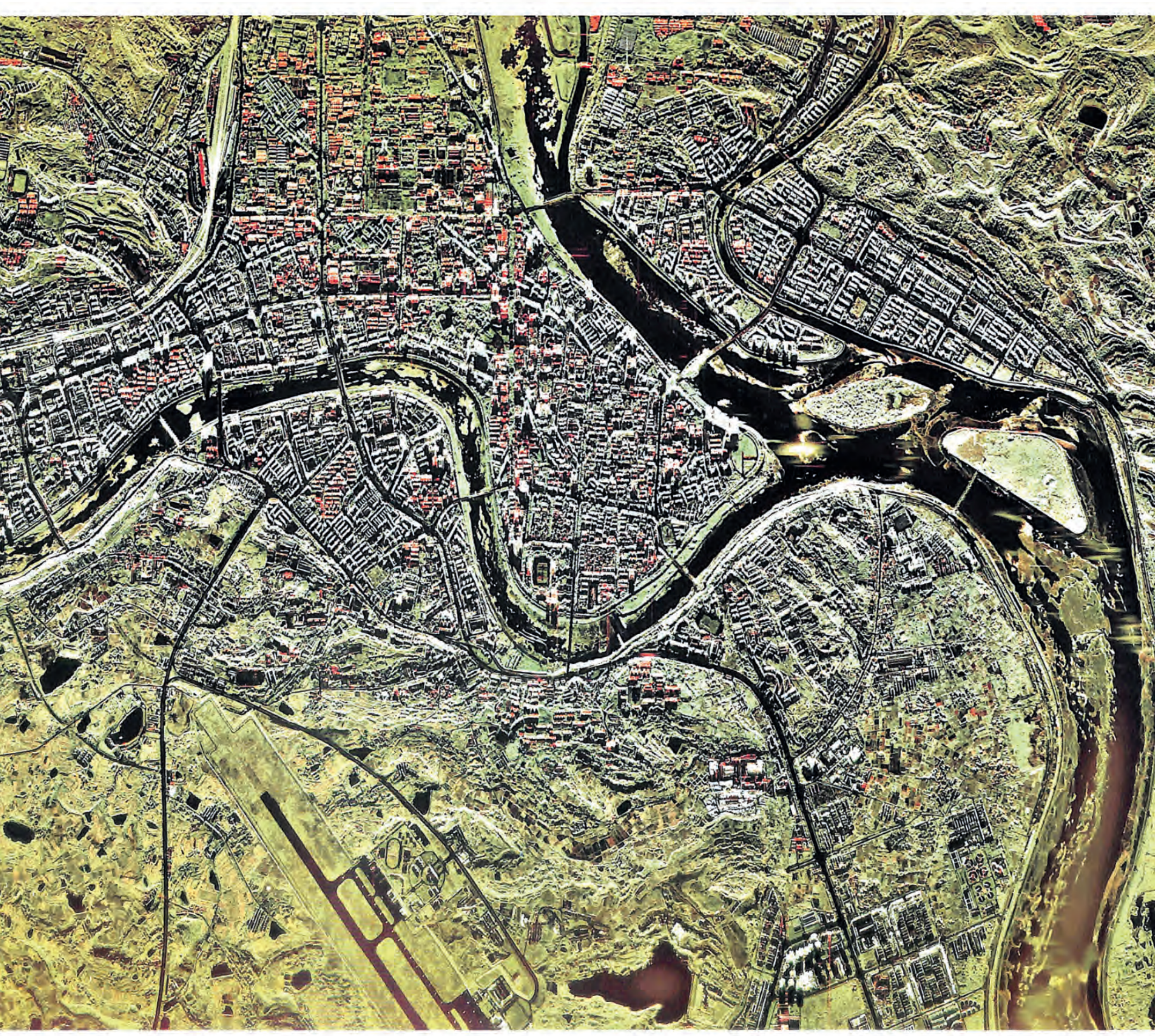




\section{Post-earthquake and pre-earthquake Radarsat images of the city of Mianyang}

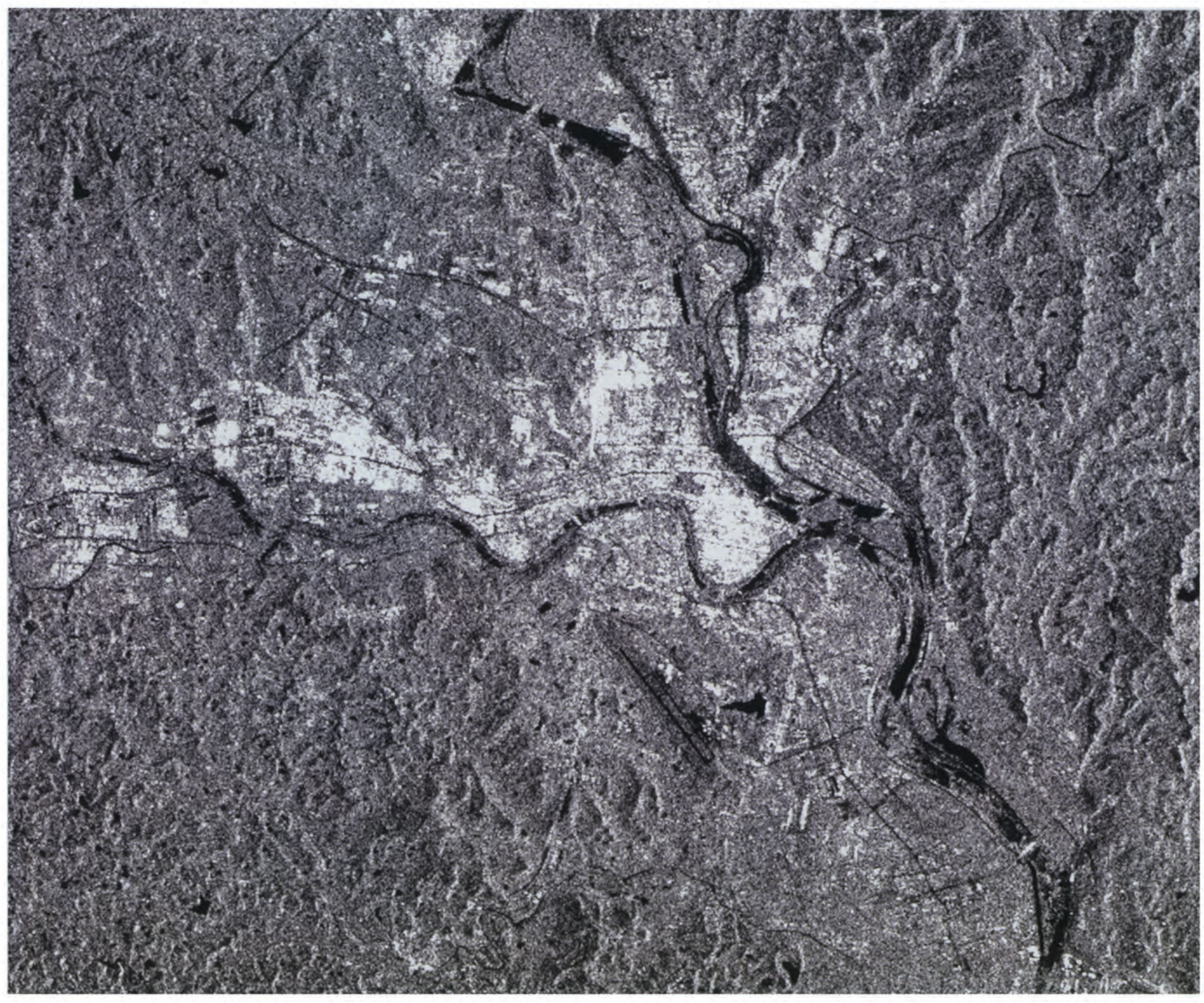

130 I Atlas of Remote Sensing of the Wenchuan Earthquake 


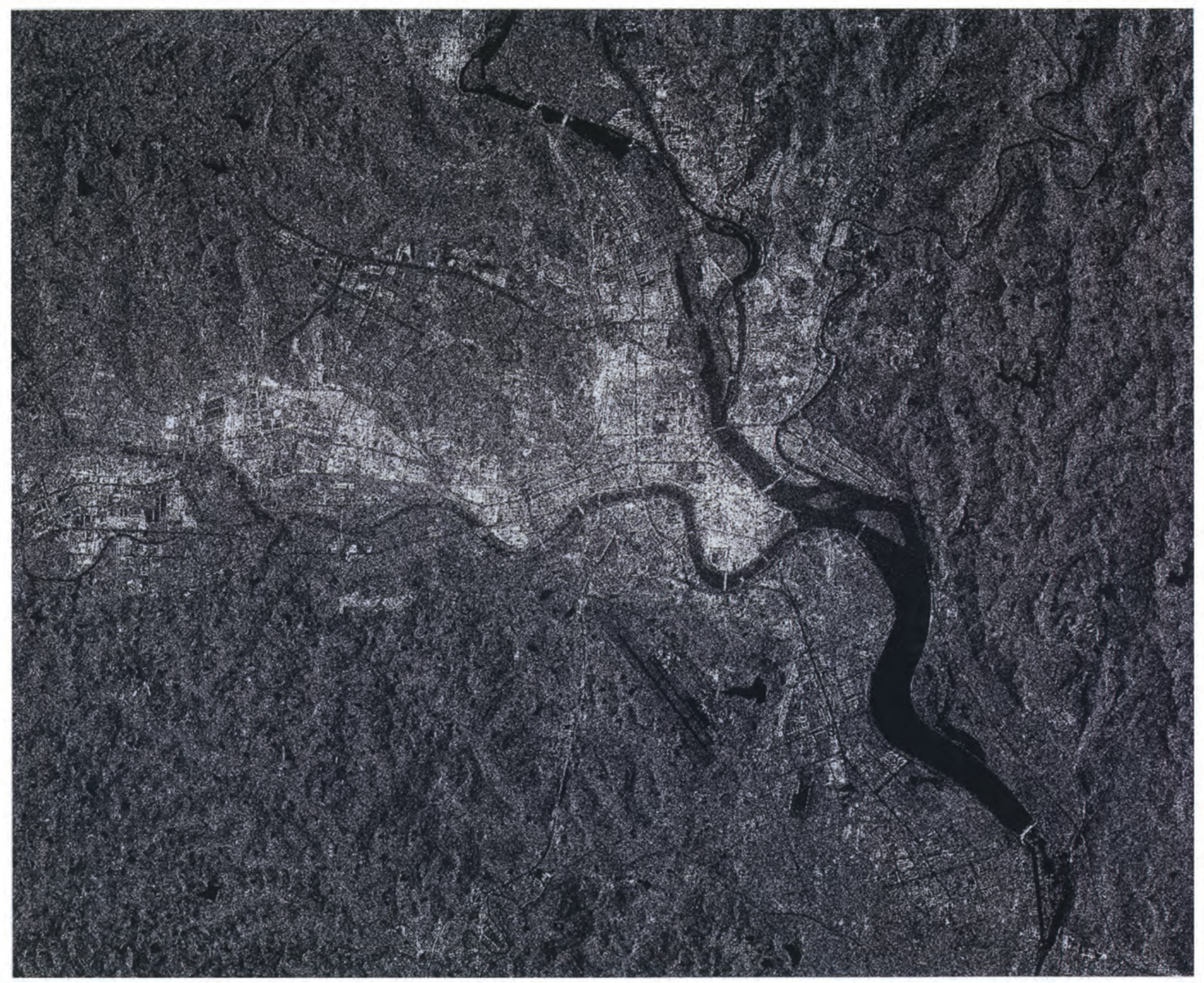

Pre-earthquake image: December 26. 2007 


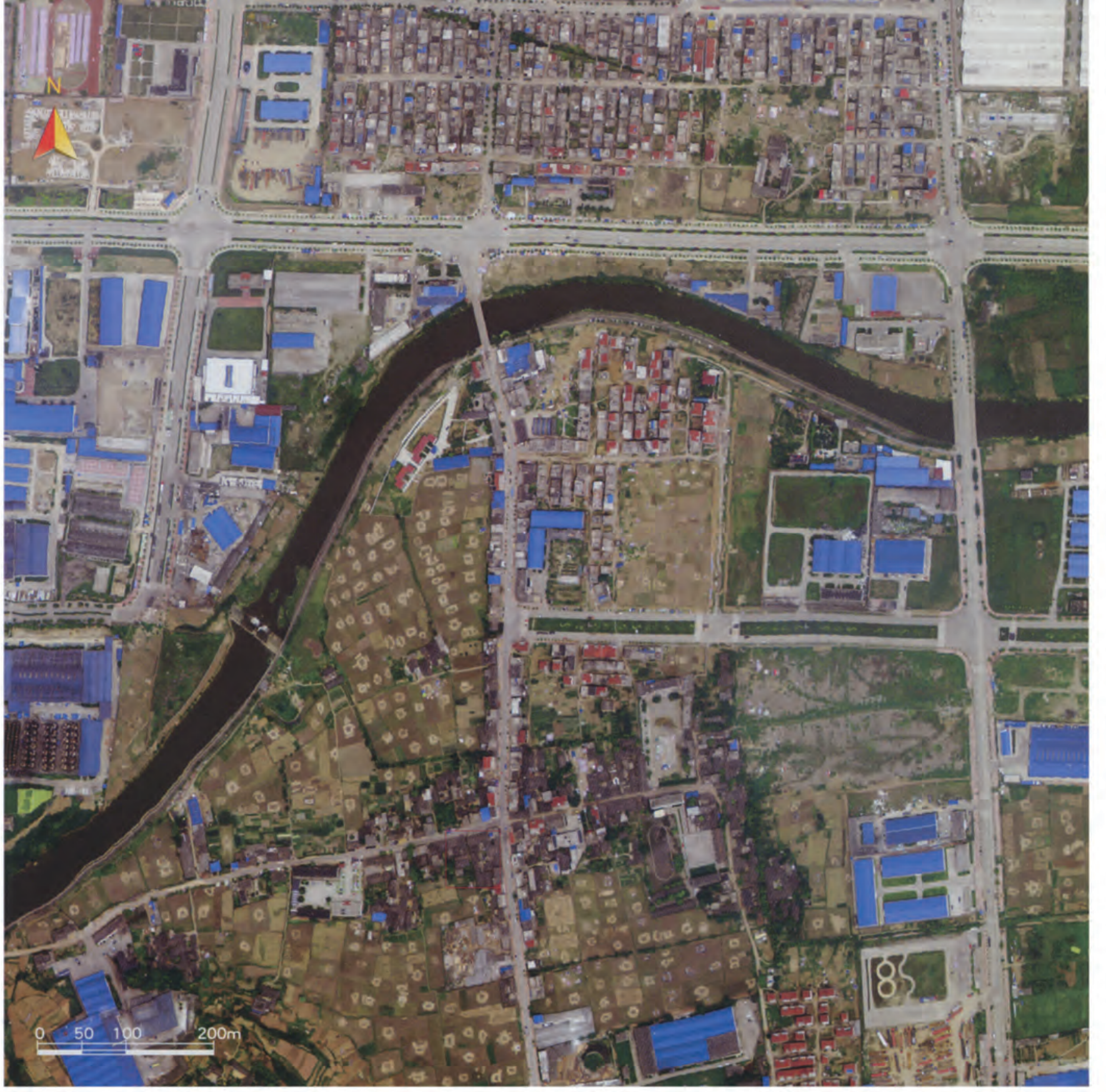

\section{A Airborne optical image of the town of Xinzao, in the city of Mianyang}

Acquired May 18, 2008. The town of Xinzao, a rural town in the city of Mianyang, was quite seriously affected. The house collapse rate was more than $40 \%$, and was higher than the collapse rate for the factories and the other buildings. The red frame within the image shows the collapsed and severely damaged houses and buildings.

Airborne optical image in the town of Qingyi, in the city of Mianyang

Acquired May 18, 2008. The town of Qingyi is another heavily hit rural town in the city of Mianyang. The rate of collapsed houses was more than $20 \%$, and was higher than the rate of collapsed factories and other buildings. (A) The new campus of the Southwest University of Science and Technology. There are slight property losses, that is, some buildings were damaged, but did not collapse.

132 I Atlas of Remote Sensing of the Wenchuan Earthquake 


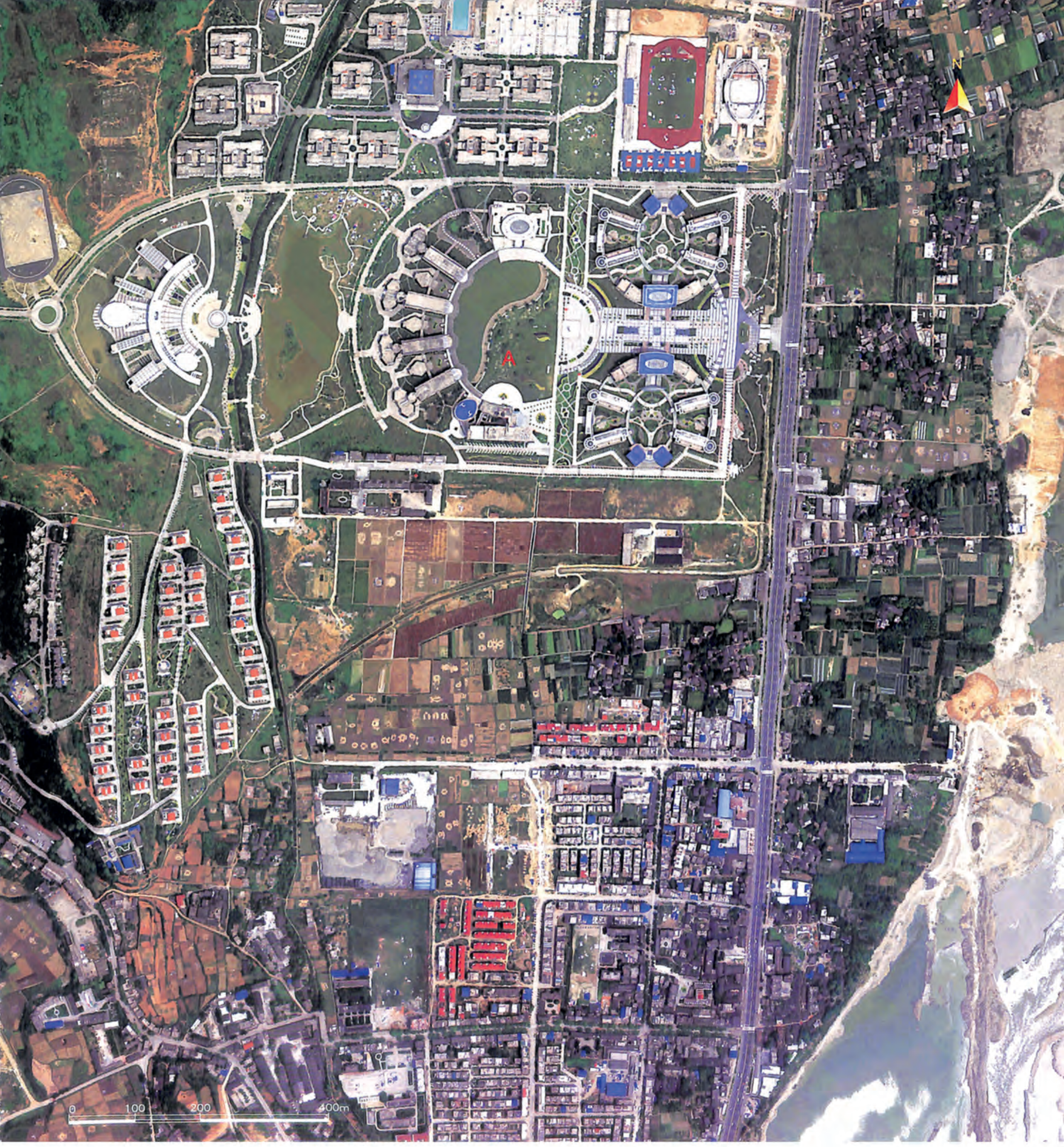




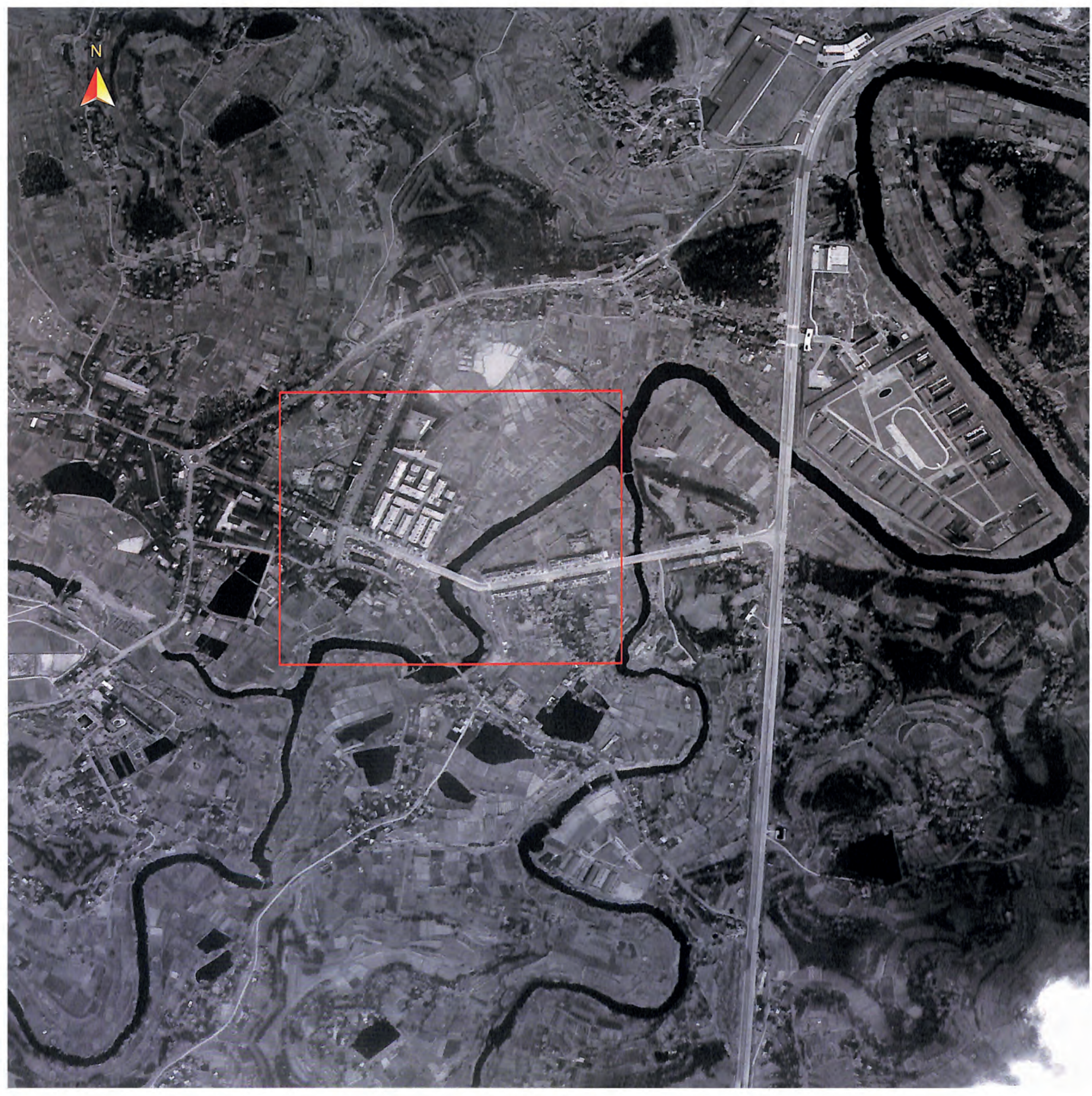

$0 \quad 100 \quad 200 \quad 400 \mathrm{~m}$ 

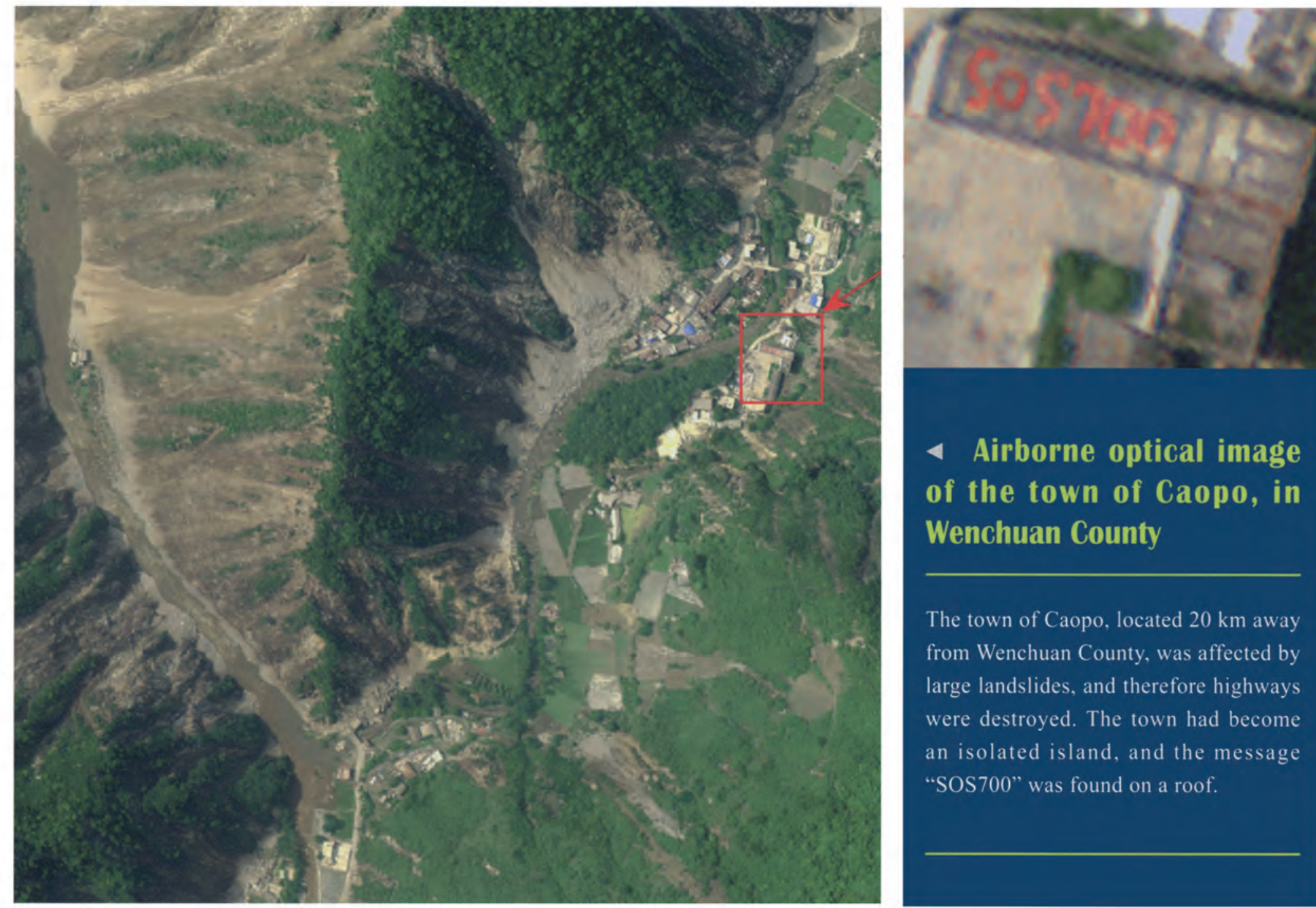

The town of Caopo, located $20 \mathrm{~km}$ away from Wenchuan County, was affected by large landslides, and therefore highways were destroyed. The town had become an isolated island, and the message "SOS700" was found on a roof.

\section{WorkdView image of the town of Wujia, in the city of Mianyang}

In this image, acquired May 16, 2008, which compares a post-earthquake WorldView satellite image with a high-resolution airborne optical image, some collapsed houses can be identified by the WorldView panchromatic band. But it is harder to identify collapsed houses in this image than it is with an airborne image under the same resolution. 


\section{Distribution of collapsed}

houses in the city of Jiangyou

The city of Jiangyou is located in the northwest part of Sichuan Basin, along the upper reaches of the Fujiang River, southeast of Longmen Mountain. It is the national metallurgy industrial base, and it is a vital energy resource base of Sichuan. The house collapse here was severe, with about $5 \%$ of buildings collapsed in the urban area of the city of Jiangyou.

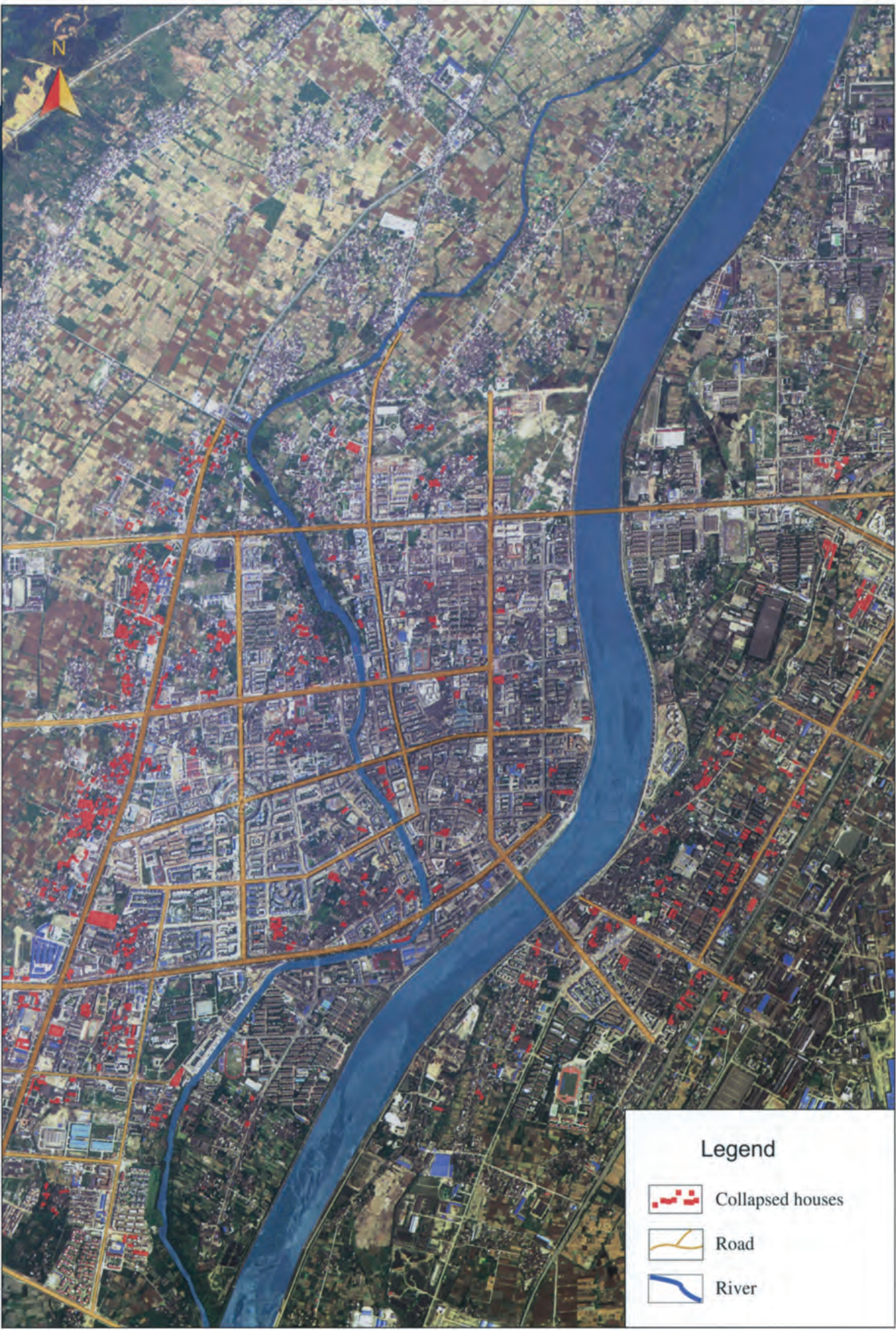

0 $200 \quad 400$ $800 \mathrm{~m}$ 


\section{Postearthquake and preearthquake Radarsat images of urban area of the city of Jiangyou}
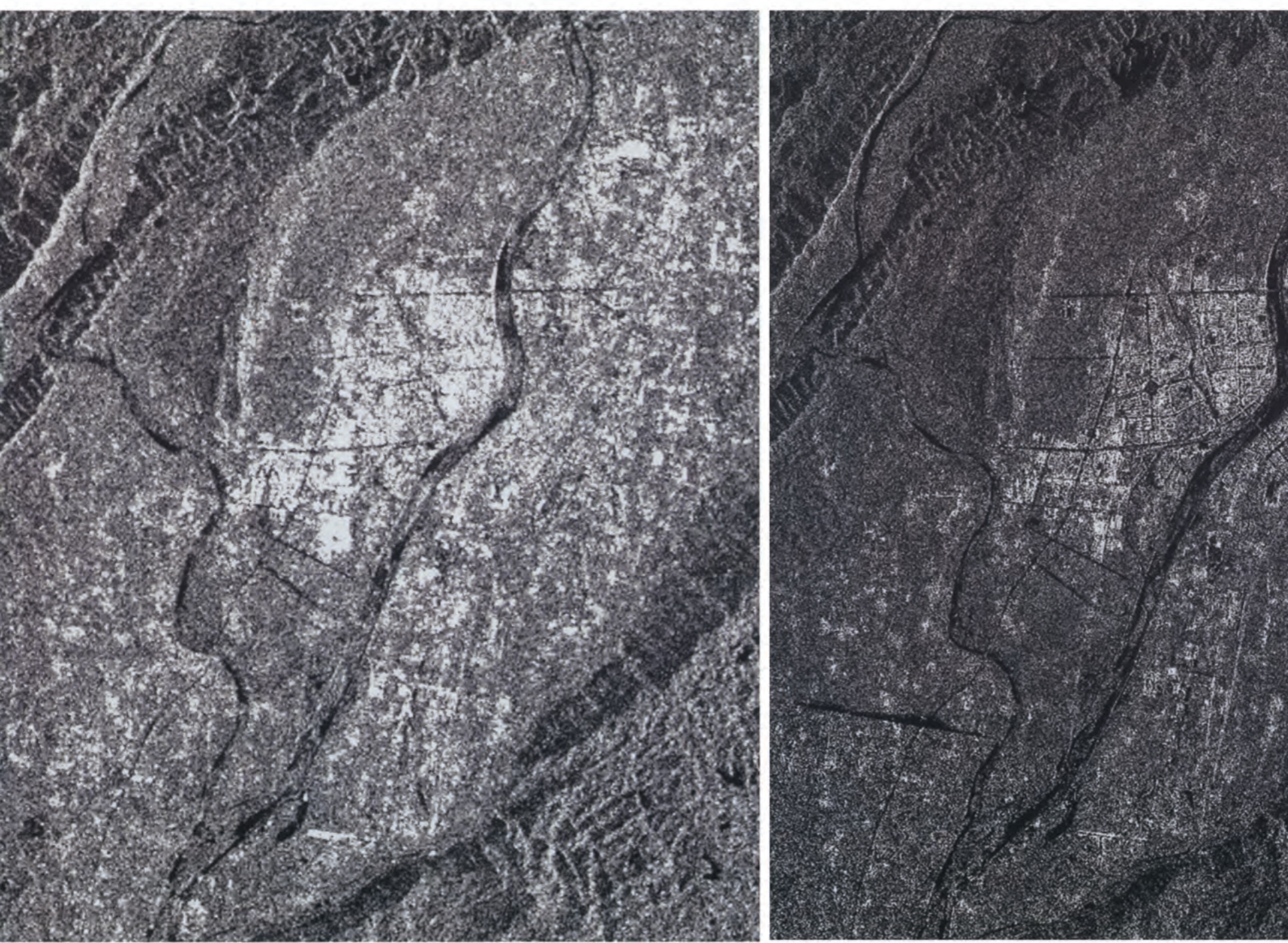


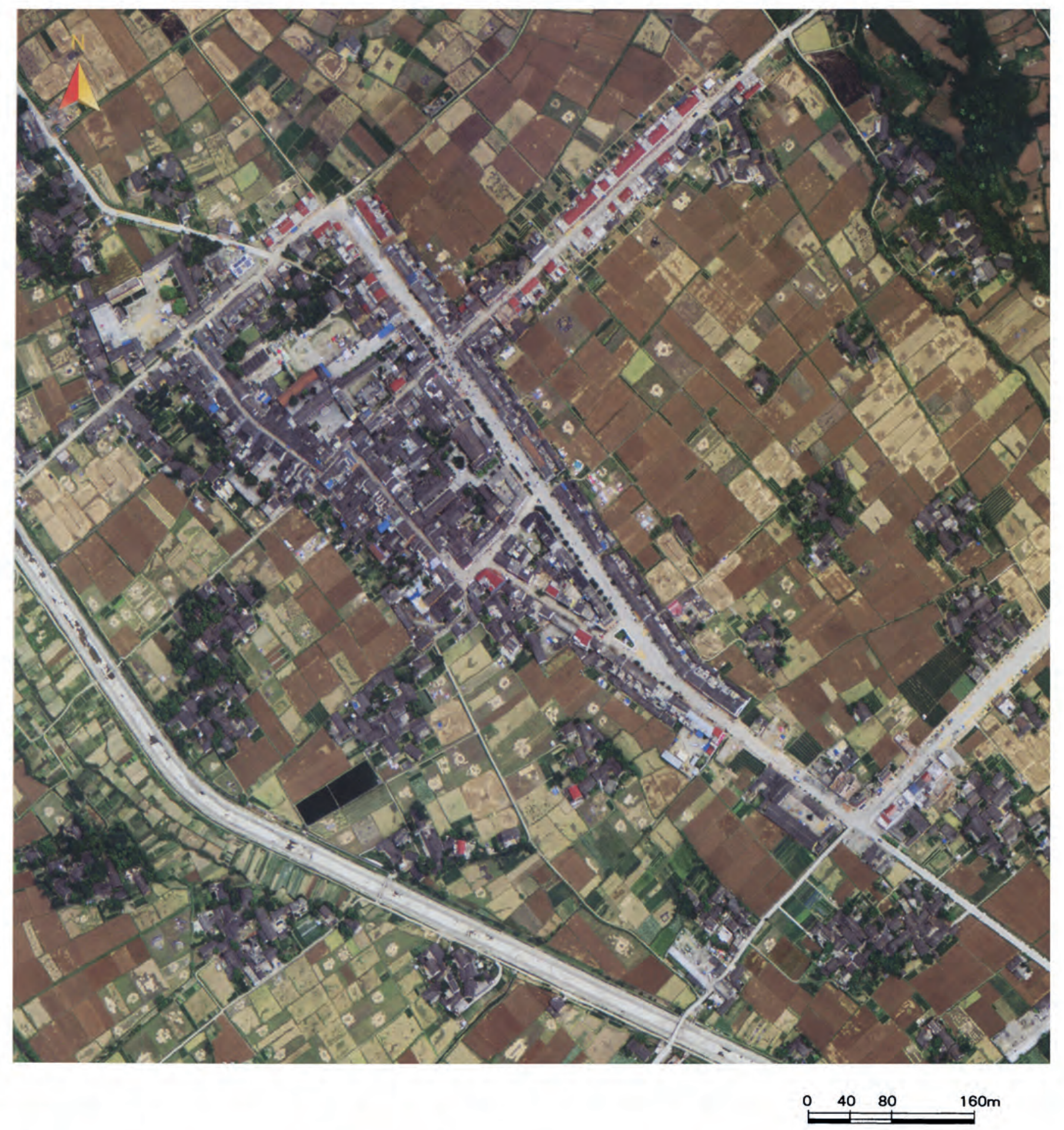

$\Delta$ Airbome optical image of the town of Xiping, in the city of Jiangyou

Acquired May 18, 2008. The distance from Xinping to the urban area of Beichuan County is just $20 \mathrm{~km}$. The houses in the town of Xinping were severely damaged, and the house collapse rate was over $25 \%$.

- Airborme optical image of the town of Sandui, in the city of Guangyuan

Acquired May 18, 2008. The town of Sandui lies on the Yingxiu-Beichuan Fault but only a few houses, less than $10 \%$, collapsed.

138 I Atlas of Remote Sensing of the Wenchuan Earthquake 


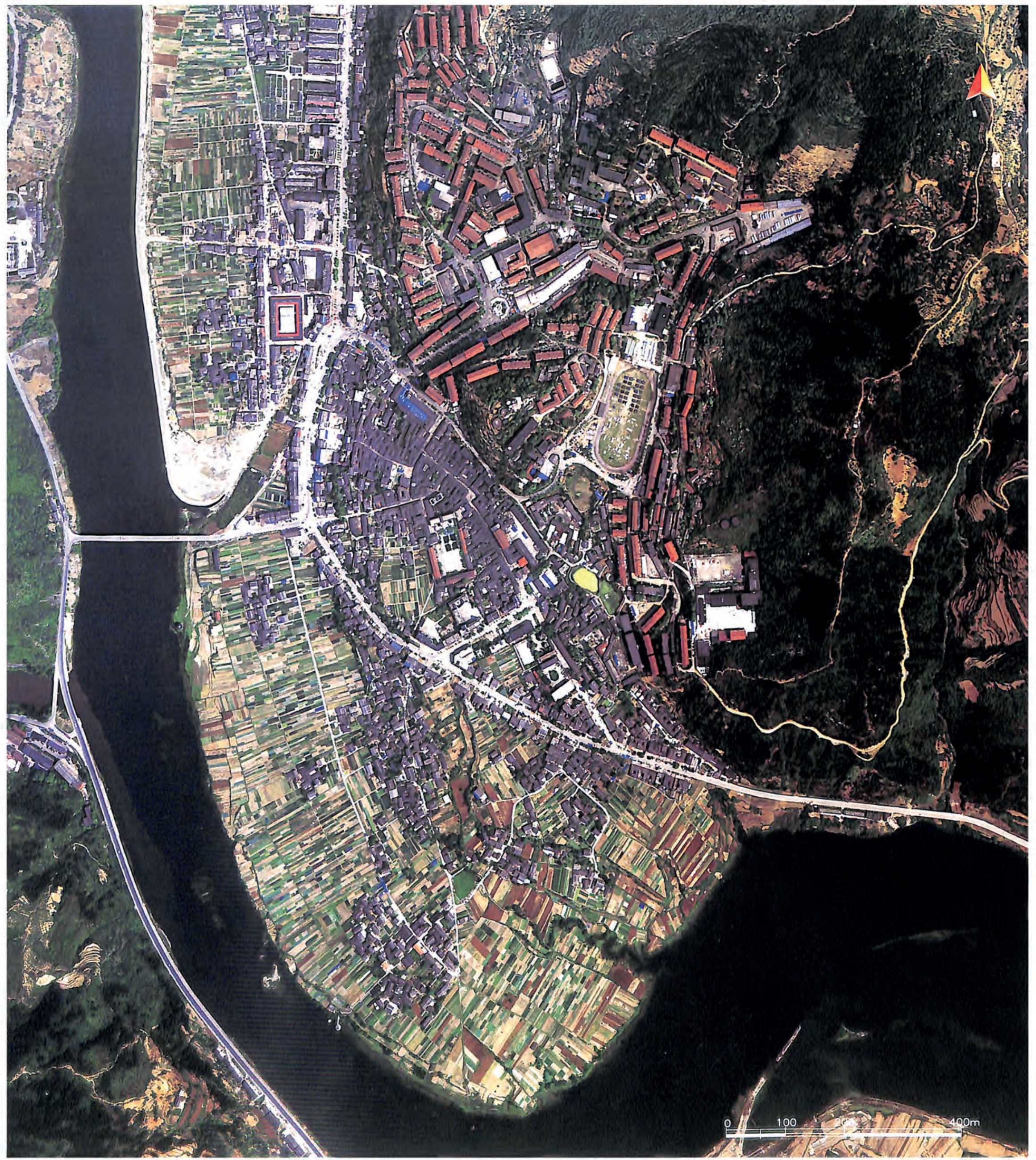




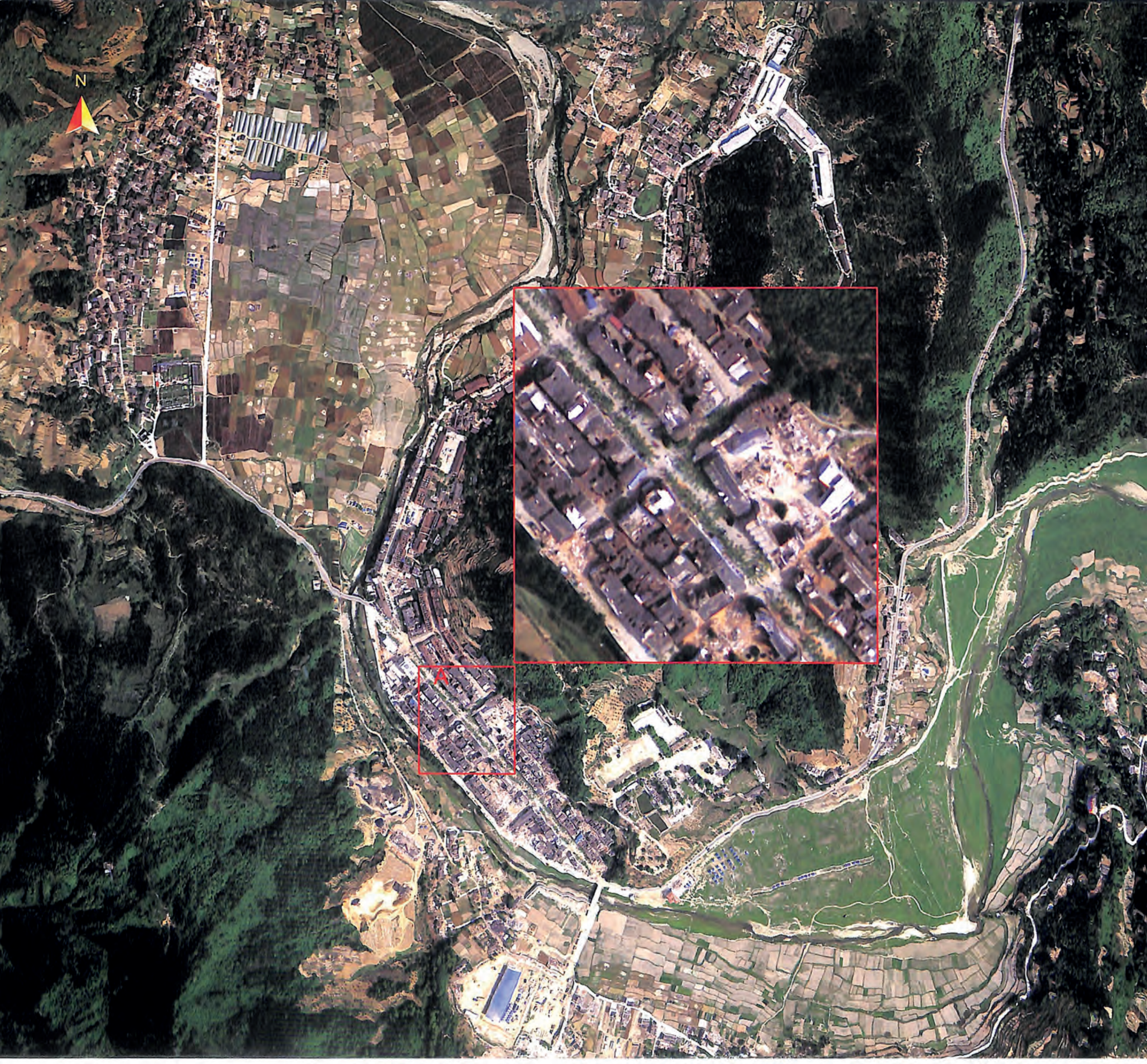




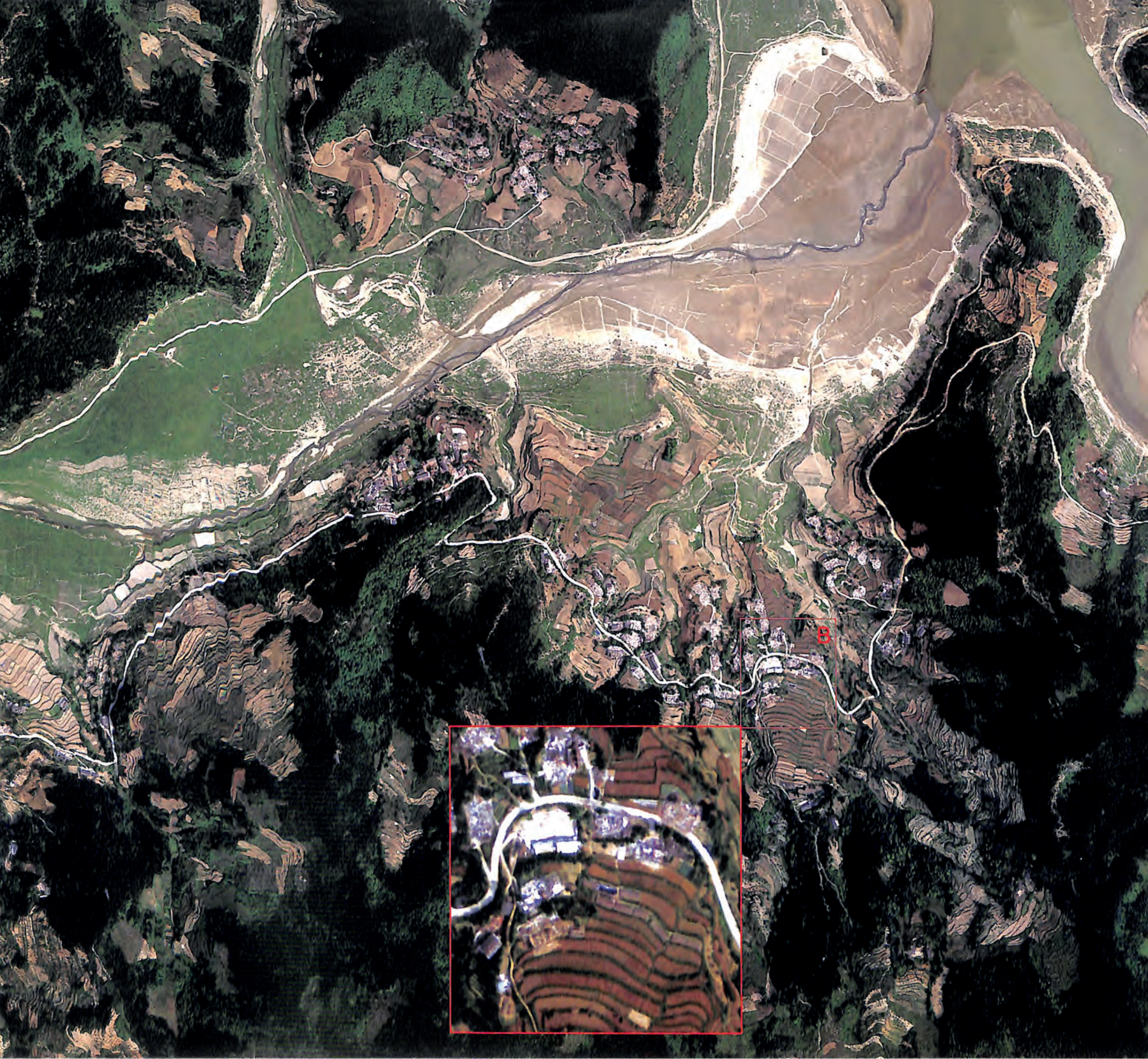




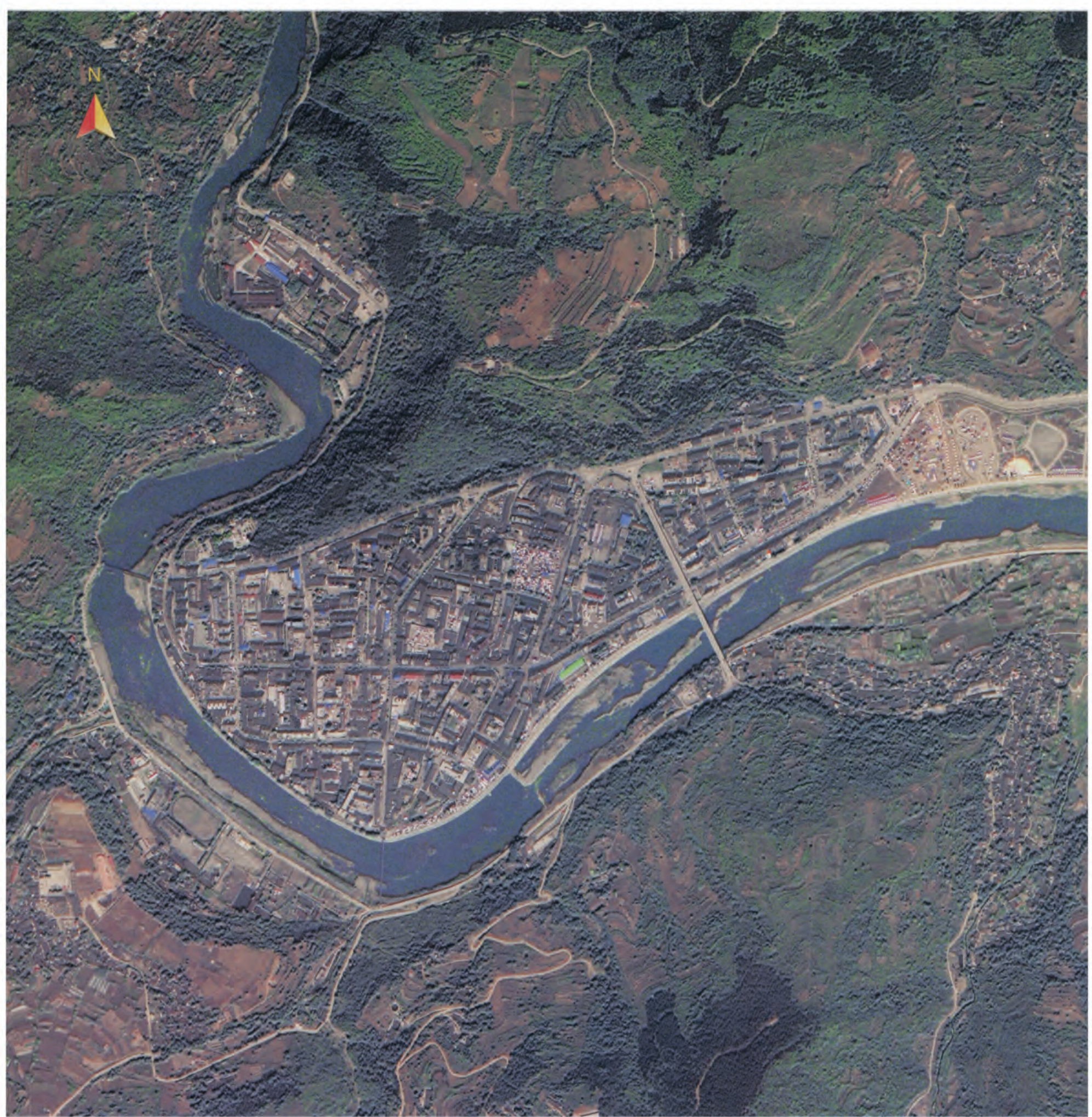

\section{$\Delta$ Airborne optical image of the town of Long'an, in Pingwu County}

Acquired May 23, 2008. The urban area of Pingwu County is located in the town of Long'an. In the 1976 Songpan-Pingwu earthquake, losses were very heavy. Since much attention was paid to house construction when the area was rebuilt after the 1976 Songpan-Pingwu earthquake, and because the earthquake intensity in the town during the Wenchuan earthquake was low, losses were light, and very few houses collapsed. 
Acquired May 28, 2008. The town of Nanba is located between the Yingxiu-Beichuan Fault and the Wenchuan-Maoxian Fault. More than $80 \%$ of the houses in the town of Nanba were severely damaged or collapsed. The red frame in the figure shows Nanba Primary School. Two three-story buildings of this school completely collapsed, and many teachers and students in this school died. The heroic actions that 48 -year-old teacher Du Zhengxiang took in saving her students moved the whole country.
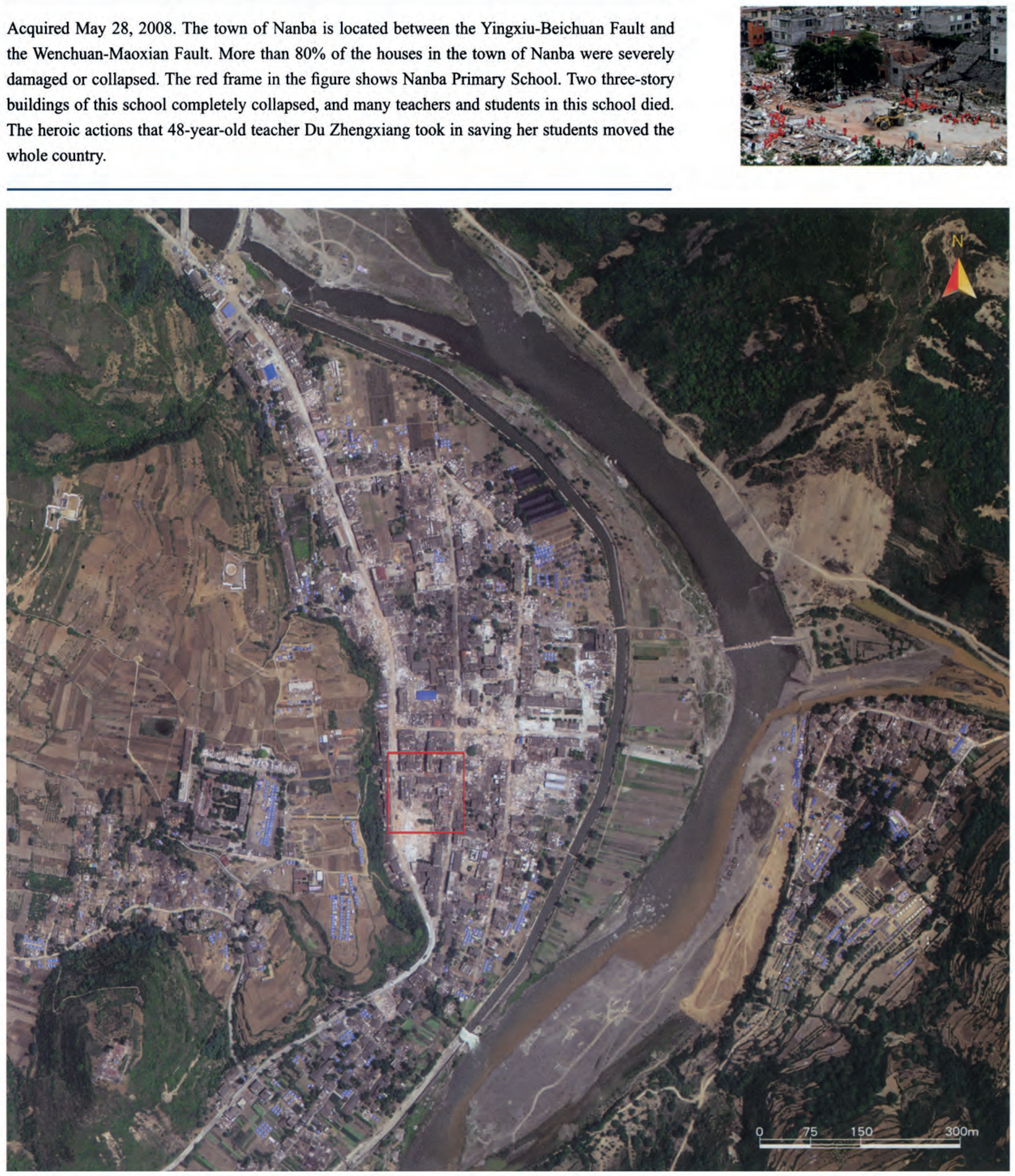

Collapsed Buildings ～ 145 


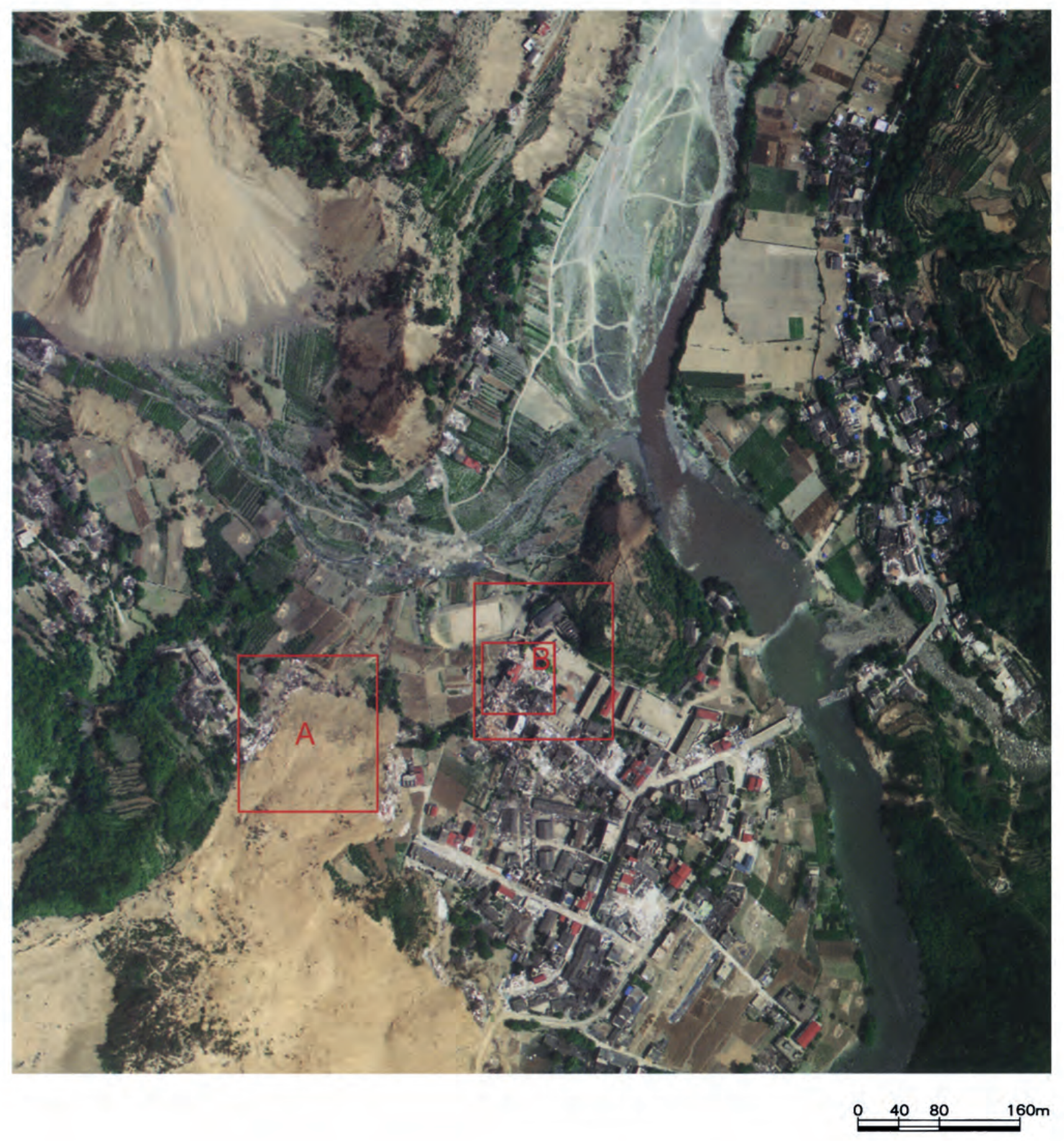

\ Airborme optical image of the town of Chenjiaba, in Beichuan County

Acquired May 28, 2008. In Chenjiaba, a town crossed by the Yingxiu-Beichuan Fault, the houses were heavily damaged, with over $80 \%$ of them destroyed. (A) A landslide split the town into two parts and caused heavy casualties. (B) Collapsed houses.

\section{- IKONOS image of the town of Yuli, Beichuan County}

Acquired May 23, 2008. The image shows that the floodwater of the Tangjiashan Barrier Lake began to submerge the town of Yuli.

146 I Atlas of Remote Sensing of the Wenchuan Earthquake 


\section{Postearthquake and preearthquake Radarsat images of urban area of the city of Deyang}

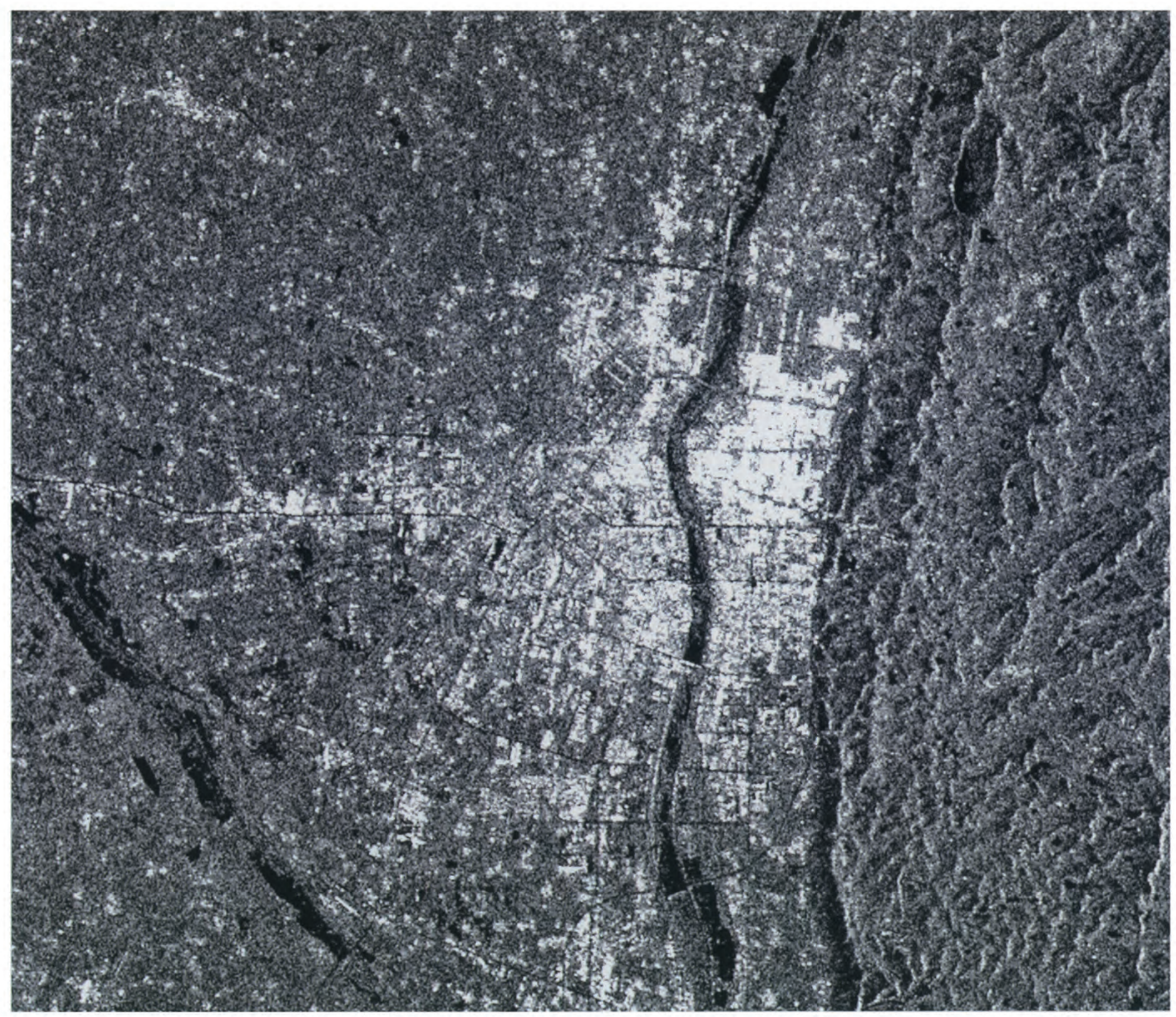

Pre-earthquake image: December 18, 2007 


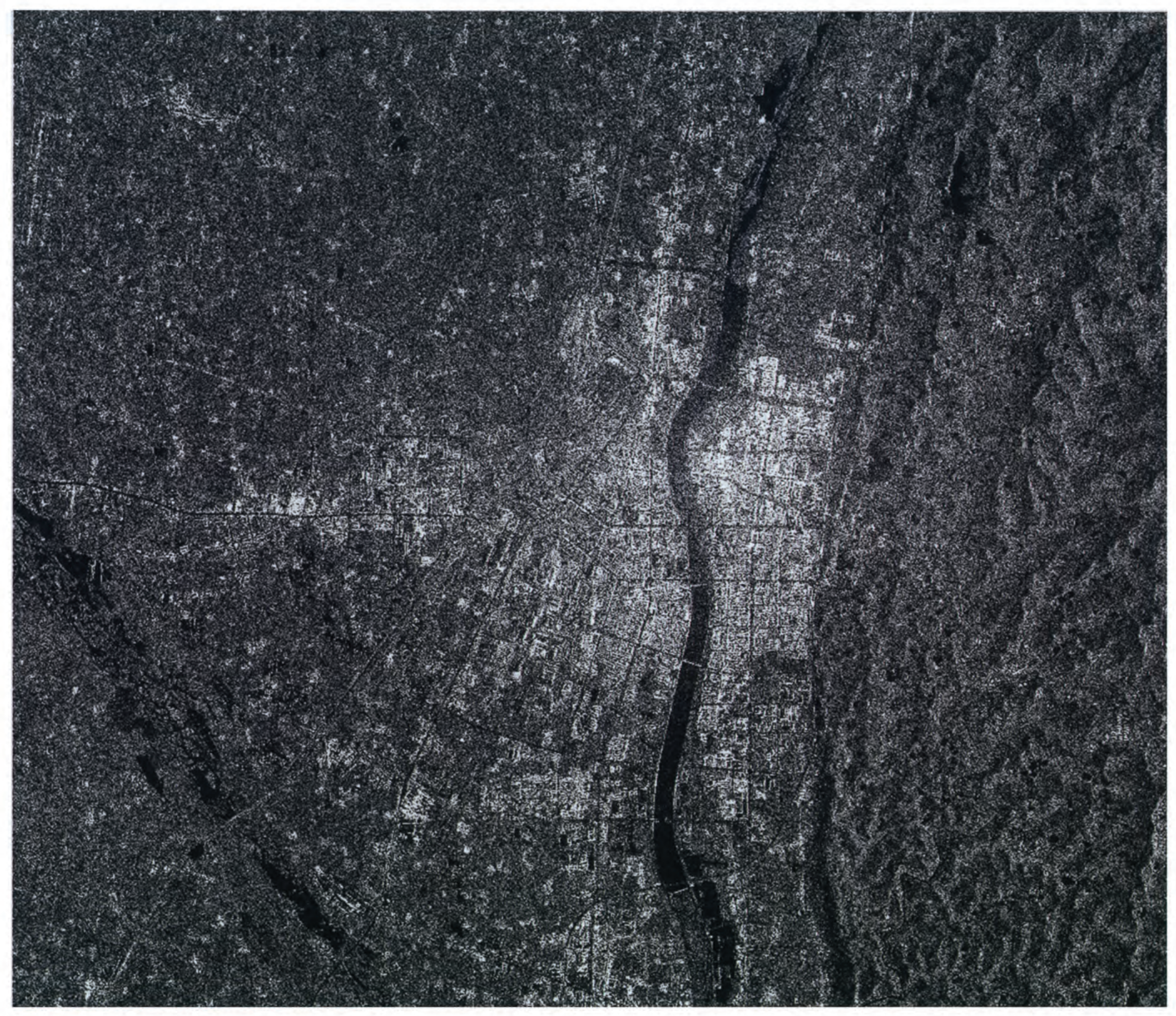

Post-earthquake image: May 14. 2008 


\section{v Airborne optical images of the town of Yuli, in Beichuan County}

Acquired May 16, 2008. The town of Yuli is the hometown of $\mathrm{Da} \mathrm{Yu}$ and is located between the YingxiuBeichuan Fault and the Wenchuan-Maoxian Fault. Houses and buildings in this town were severely damaged, over $60 \%$ of the buildings collapsed. "SOS" did not show up in the farmland of the town of Yuli in the red frame of this image until 19 May.

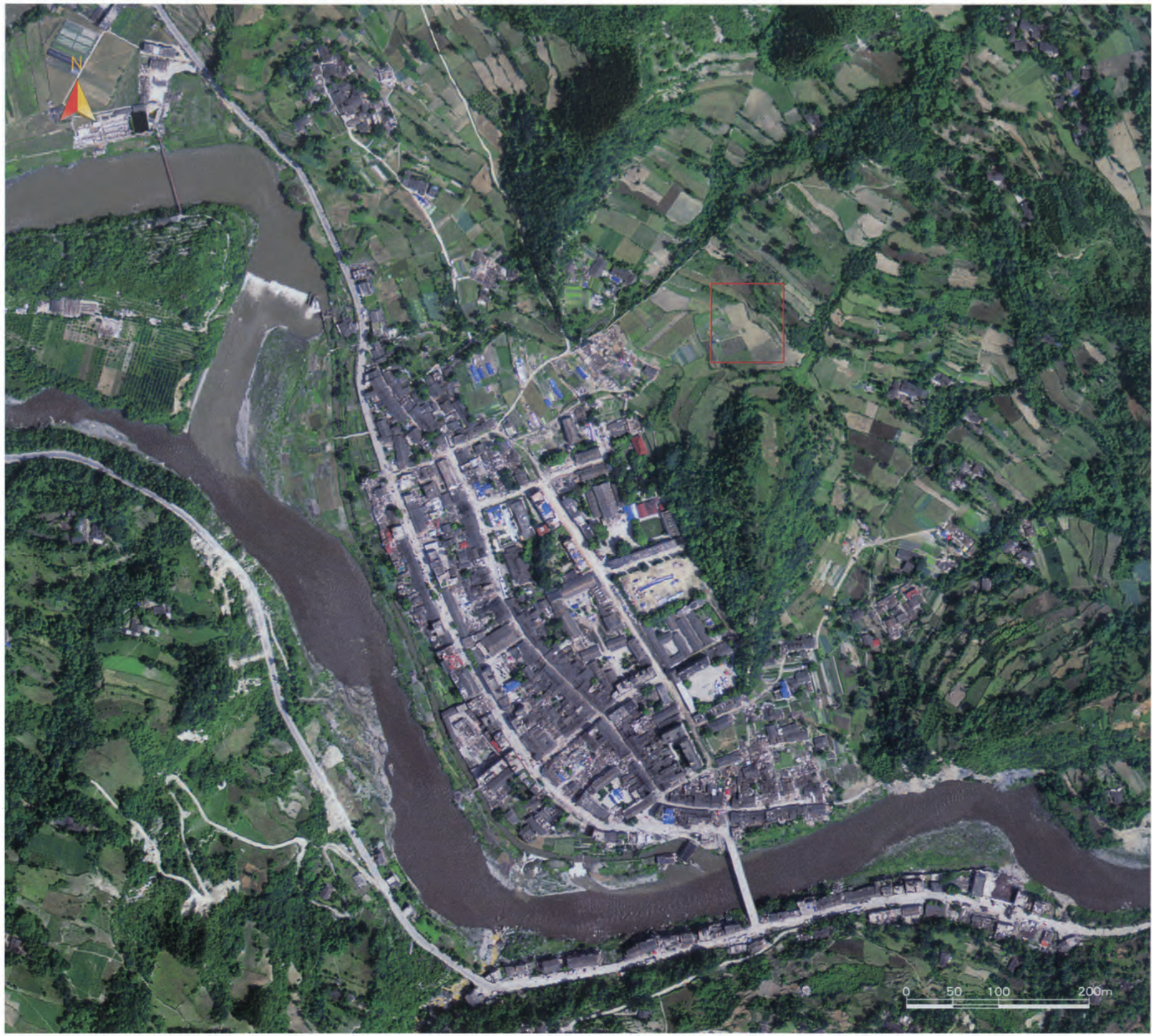

150 I Atlas of Remote Sensing of the Wenchuan Earthquake 


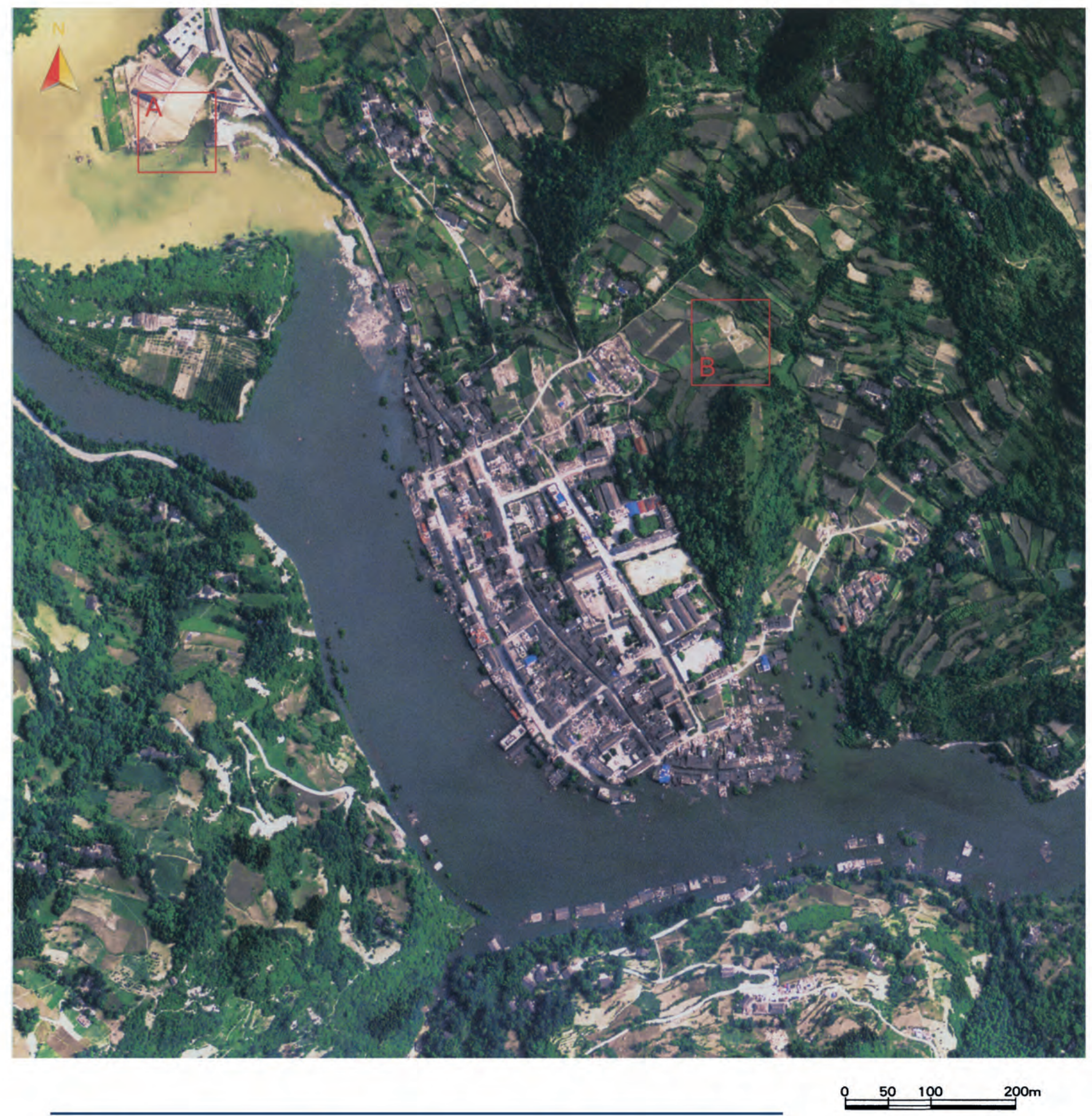

A Airborne optical images of the town of Yuli, in Beichuan County

Acquired May 27, 2008. The floodwater of Tangjiashan Barrier Lake inundated some houses in the town of Yuli. (A) The flooded area. (B) The "SOS" sign marked by local residents. 

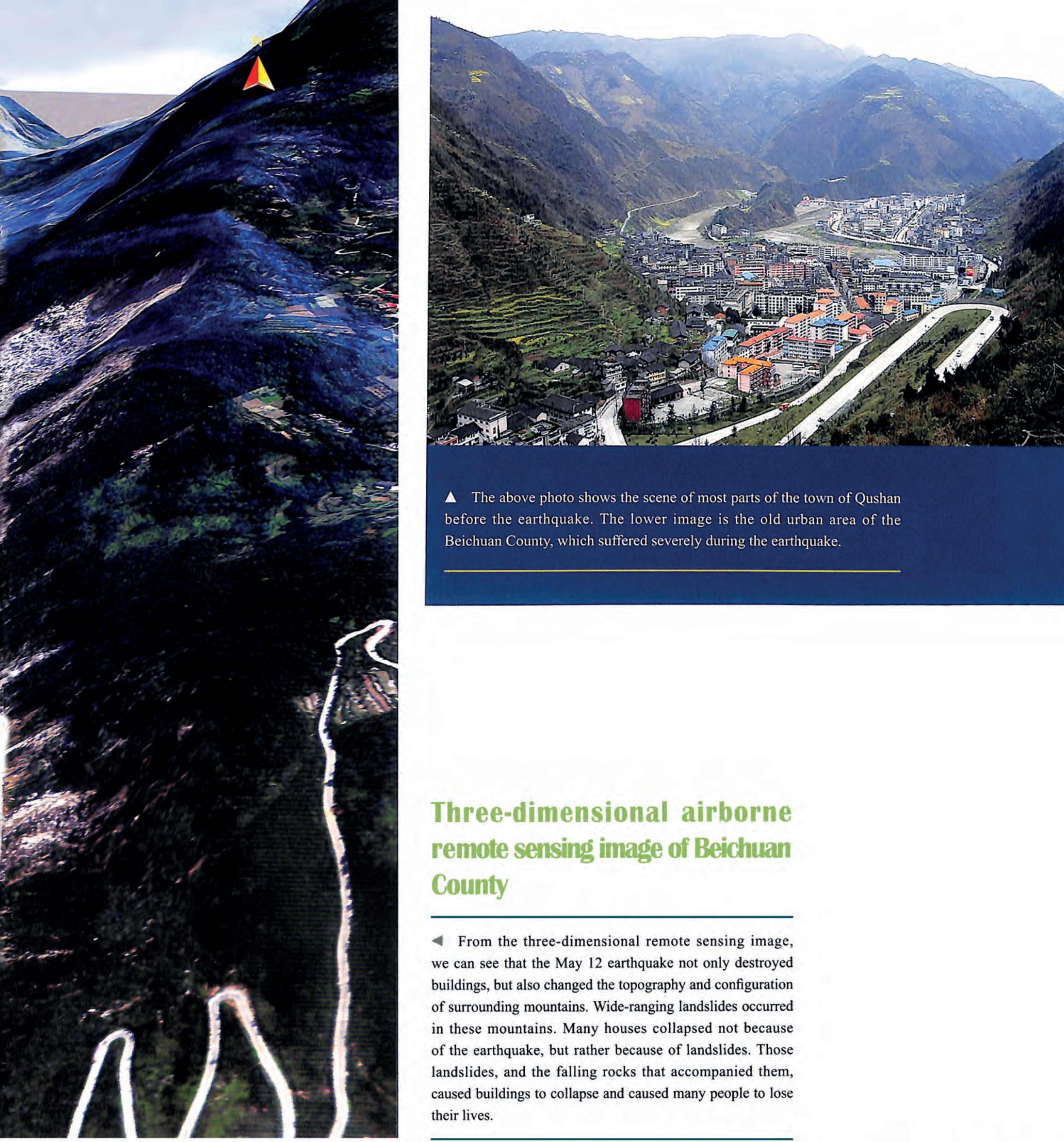

$\Delta$ The above photo shows the scene of most parts of the town of Qushan before the earthquake. The lower image is the old urban area of the Beichuan County, which suffered severely during the earthquake.

\section{Three-dimensional airborne remote sensing image of Beichuan County}

4 From the three-dimensional remote sensing image, we can see that the May 12 earthquake not only destroyed buildings, but also changed the topography and configuration of surrounding mountains. Wide-ranging landslides occurred in these mountains. Many houses collapsed not because of the earthquake, but rather because of landslides. Those landslides, and the falling rocks that accompanied them, caused buildings to collapse and caused many people to lose their lives. 


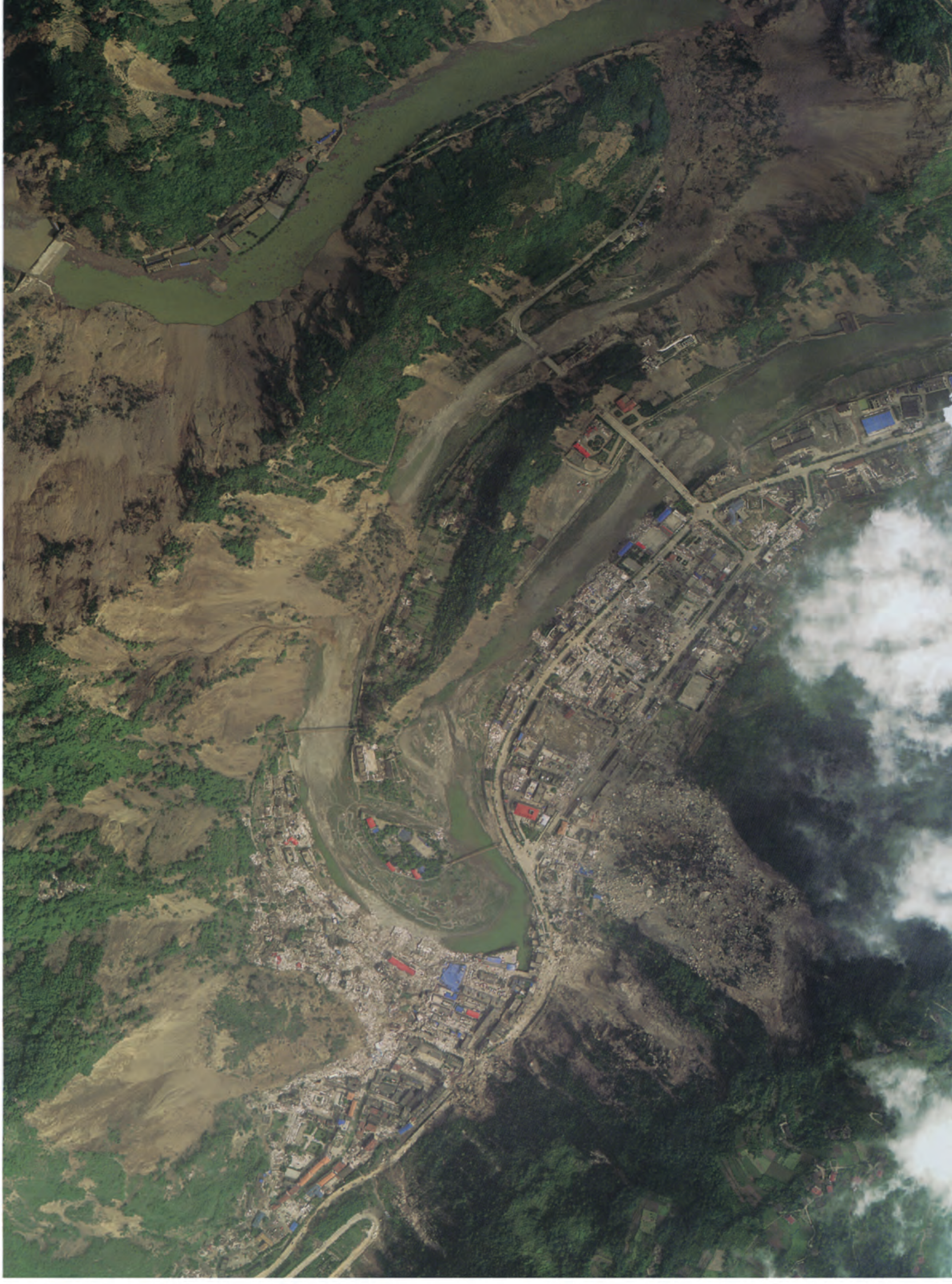




\section{The airborne optical image of Beichuan County}

4 Beichuan County is located between two mountains: one is an offshoot of the Himalayas, and another is an offshoot of Longmen Mountains. One side is a lively, multi-alley, old urban district; another side is a quiet, comfortable, new urban district. All the buildings in the urban district were constructed against the hill and along the river. Longmenshan Fault runs northwest beginning in Qingchuan County in the north, then westward past Beichuan County, Maoxian County, Dayi County, and near Luding County. The earthquake fault just passes through the urban area of Beichuan County; therefore, the May 12 earthquake caused catastrophic destruction to Beichuan County. More than $80 \%$ of the houses in the urban area of Beichuan County collapsed, and heavy casualties occurred. Meanwhile, secondary geological disasters such as barrier lakes and landslides also occurred.

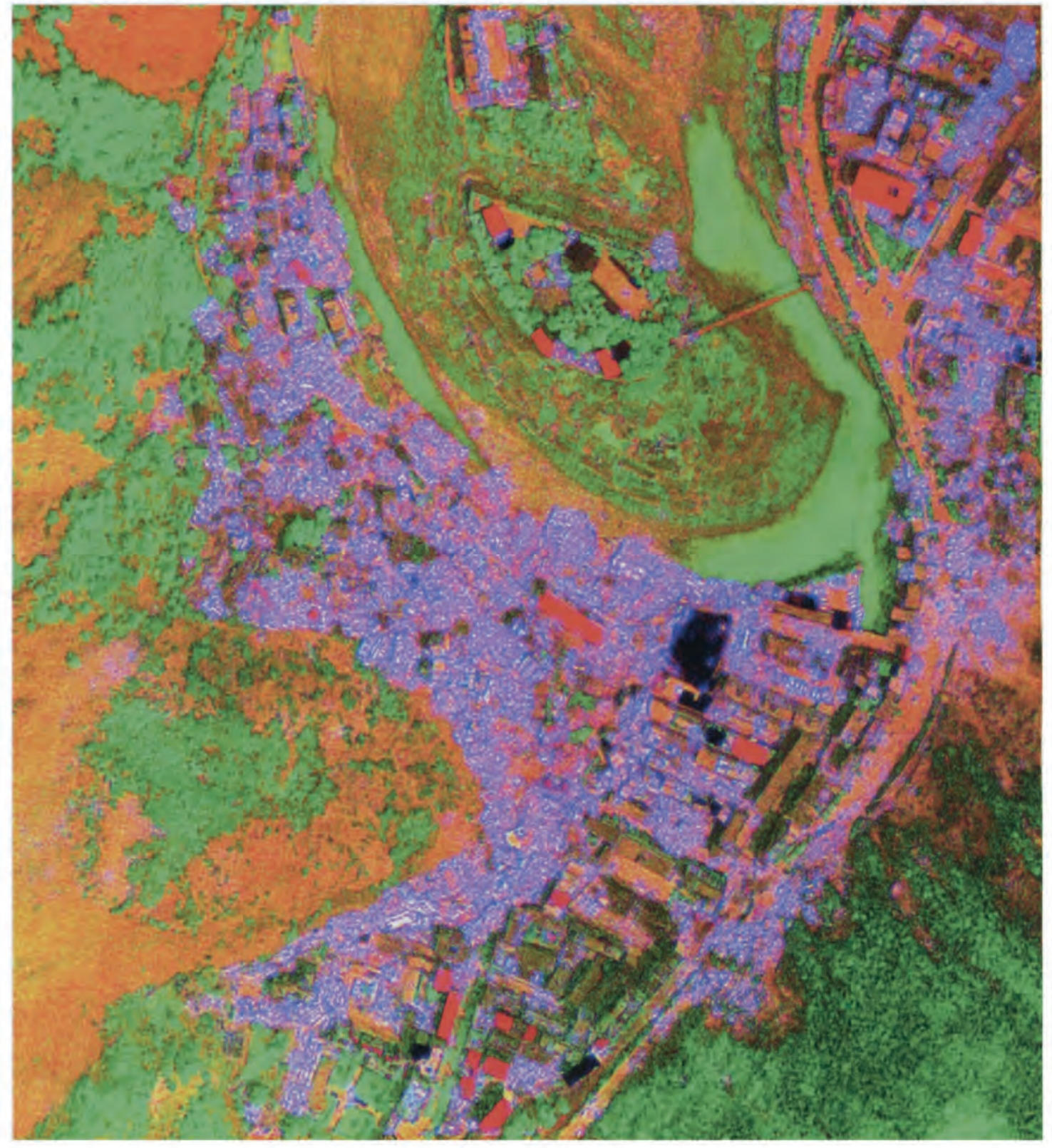

\section{Airborne remote sensing classification image for collapsed houses in the old urban district of Beichuan County}

We used airborne ADS40 optical image (acquired May 16, 2008) of collapsed houses in the old urban district of Beichuan County to classify buildings such that the pink regions represent collapsed houses and red regions represent houses that did not collapsed during the earthquake.

4 Airborne optical image Beichuan County, downtown (acquired May 16, 2008) 
Three-dimensional ainboune image of an urban area

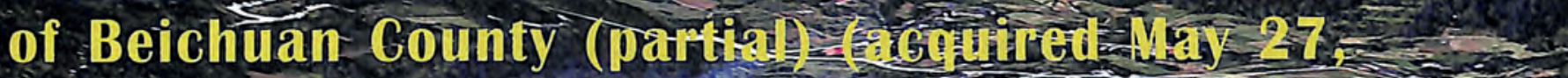

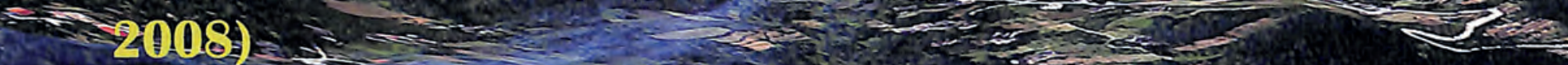

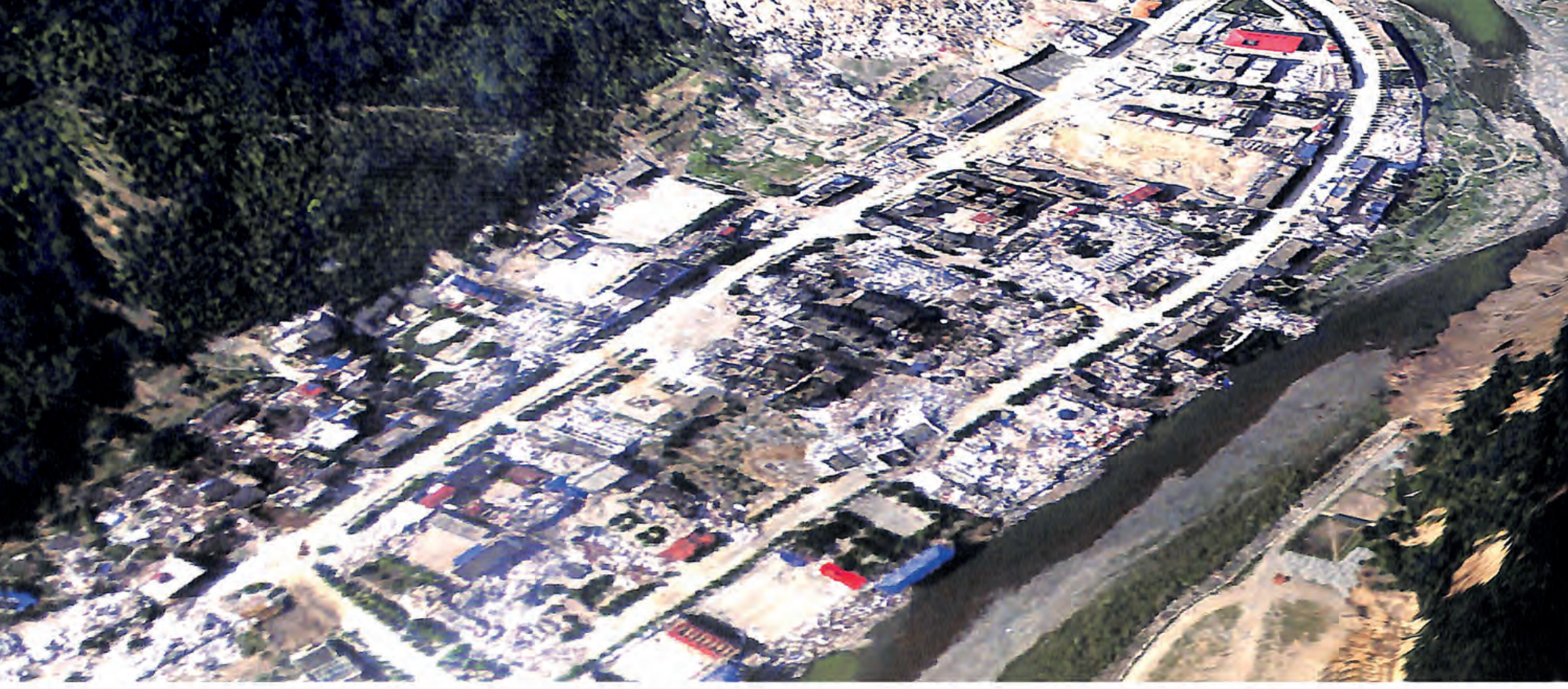

158 I Atlas of Remote Sensing of the Wenchuan Earthquake 


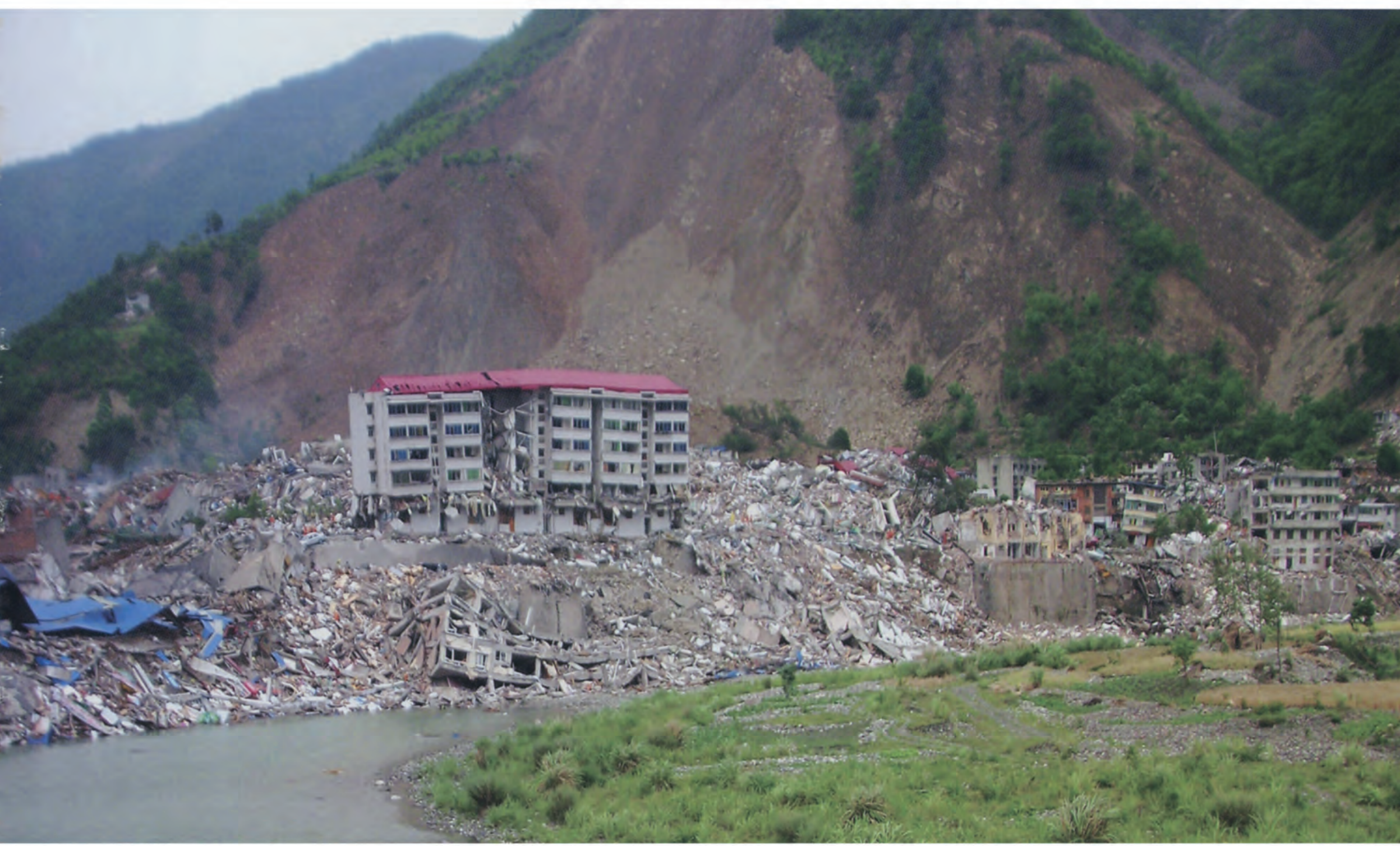

The old urban district in Beichuan after the earthquake

The old urban district is located in the foothills of the Wangiiayan Mountains. The large-scale landslides induced by the earthquake caused complete burial of several streets near the foothills. 
Threatlimensional airborne image of the new urban district of Beichuan County (acquired May 27, 2008)
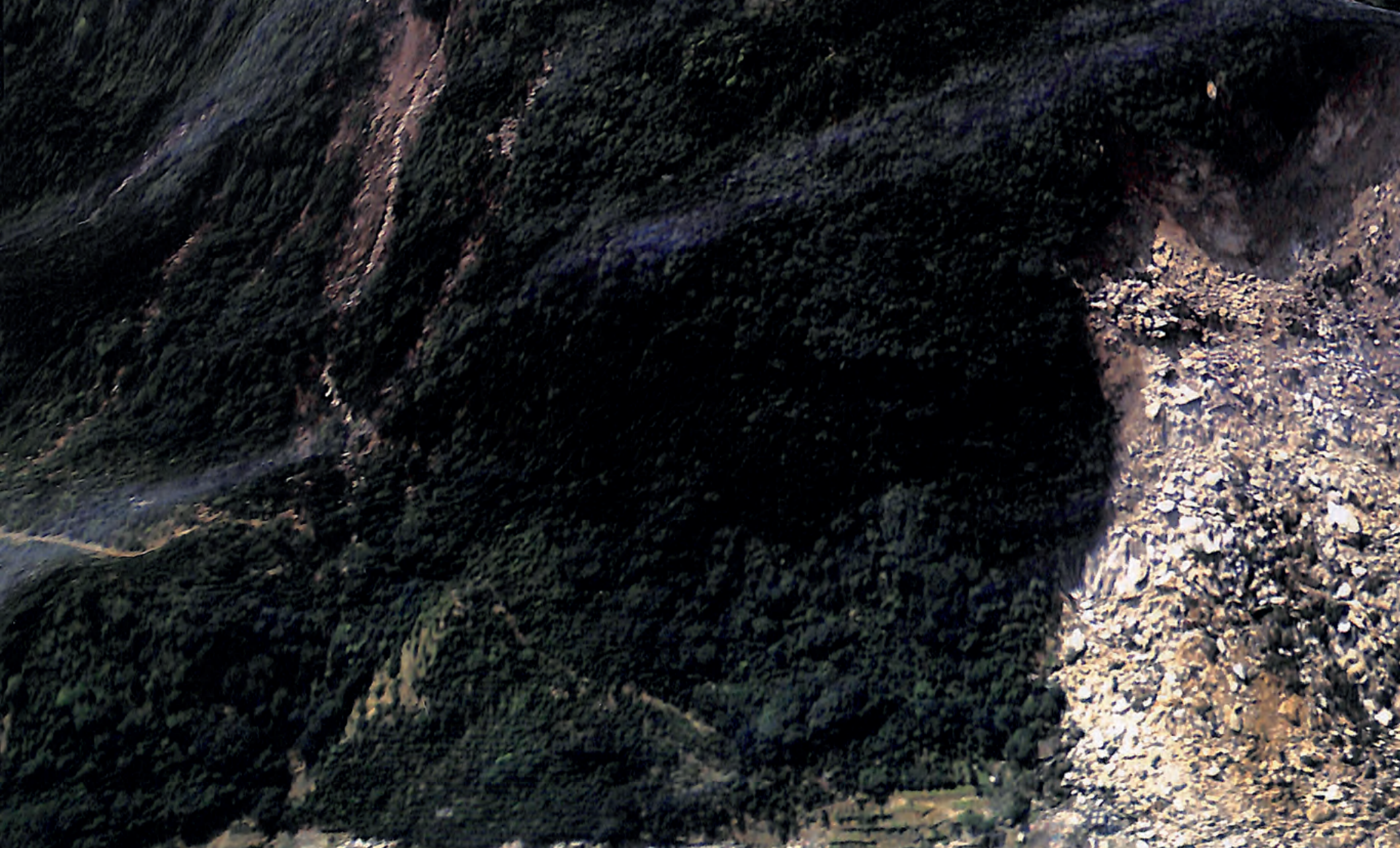

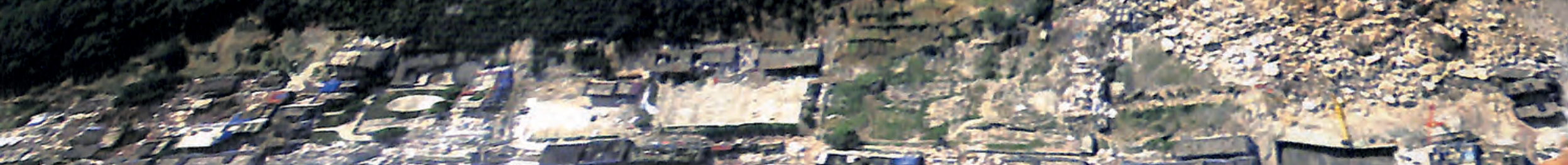

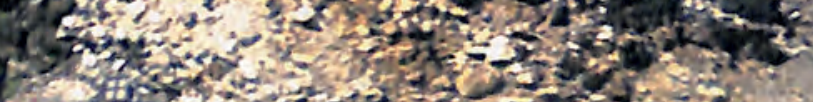

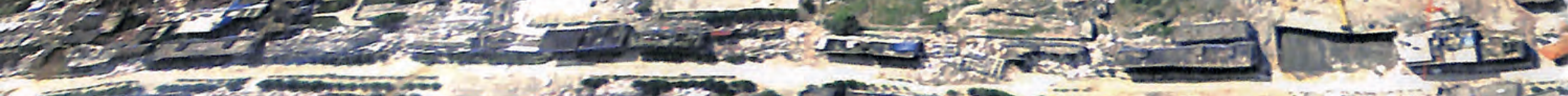

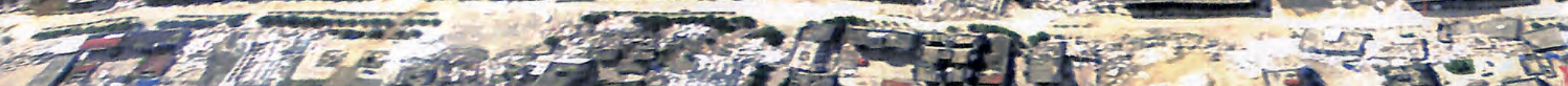
2. (5) 


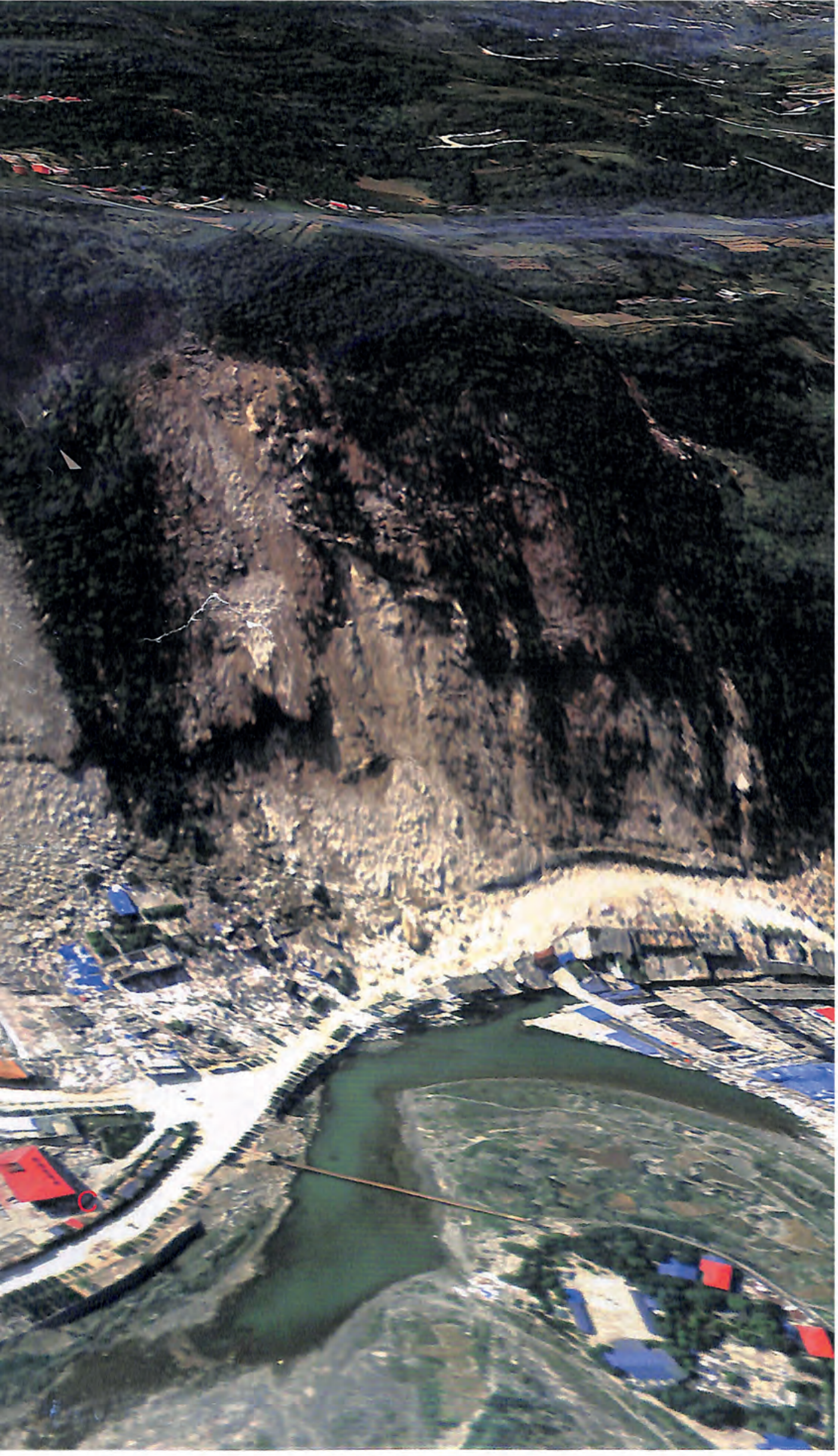

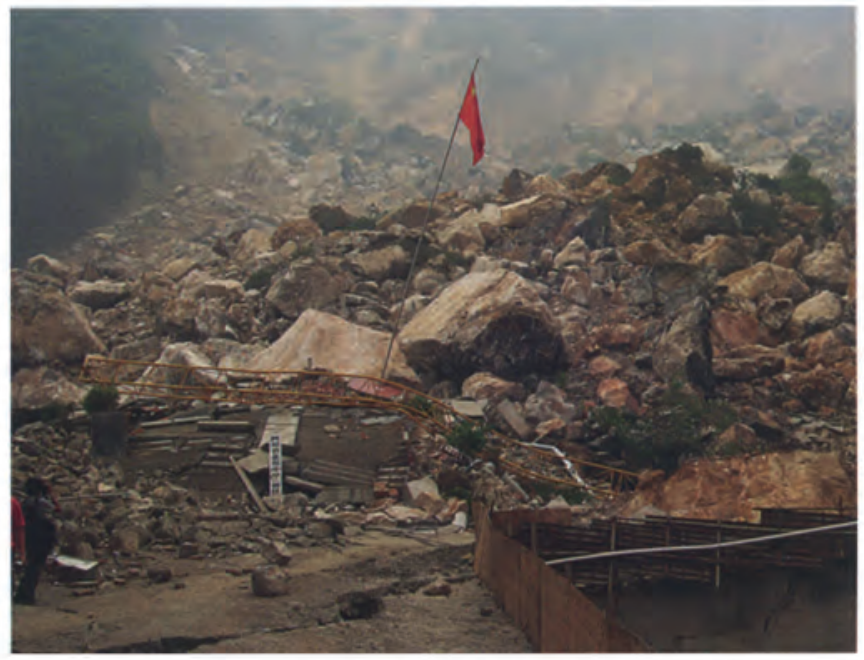

New campus of Beichuan Middle School

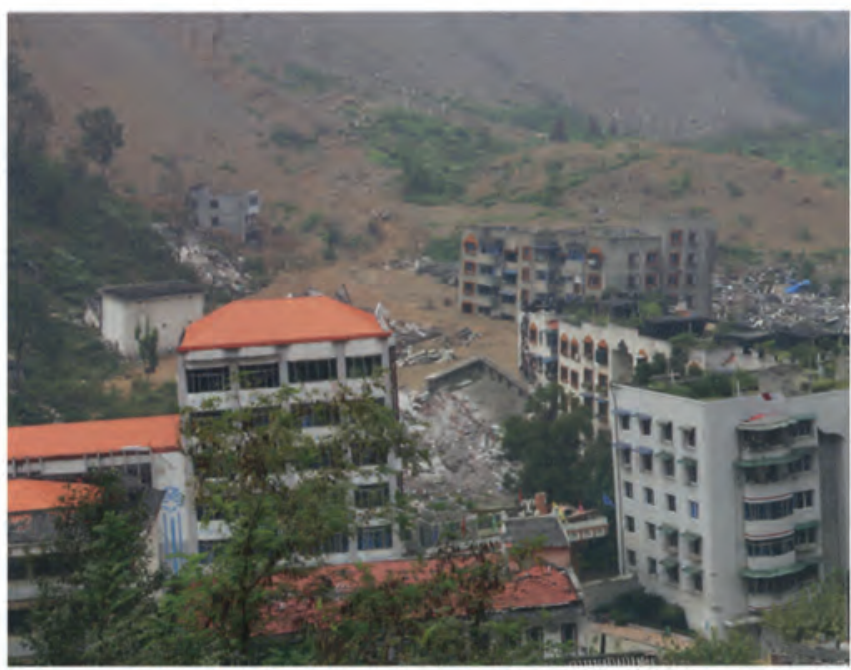

Administration building of Beichuan County

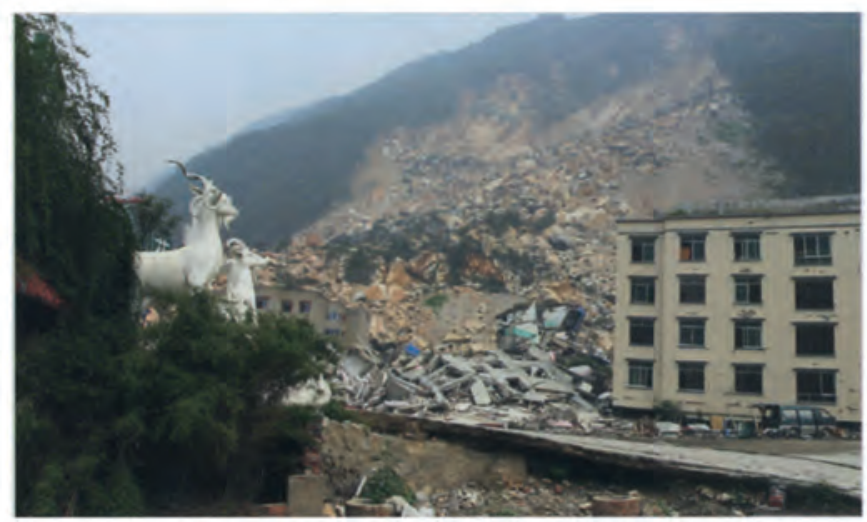

Front of Beichuan Grand Hotel

The new urban district in Beichuan County is located near Jingjia Mountain. The landslides mercilessly buried Beichuan Middle School and many surrounding buildings, causing heavy casualties. 


\section{Chapter

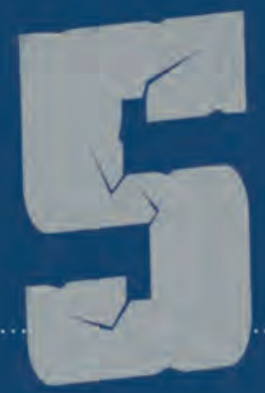

Damaged RoAds

This chapter presents images of badly damaged roads and estimates of the amount of road damage. Images used are from Airborne ADS 40 and Airborne SAR and elsewhere. The images were selected to show the massive damage caused by the disastrous earthquake, as well as the secondary disasters that followed.

Using mainly airborne ADS40 data, we estimated road damage as follows: First we semi-automatically digitized the four road types, national roads (NR), provincial roads (PR), county roads (CR), and village roads (VR). Then we marked road damage by section with five different damage grades. The damage grades are hardly damaged, blocked by rolling rocks, covered by earth and rocks, roadbed ruined, and flooded. There are also four attributions for bridges, hardly damaged, ruptured, fallen, and inundated. On qualitatively attributed roads, statistical analysis was done, and thematic charts were mapped. The ADS40 images do not cover all the heavily damaged areas, and not all the areas covered are heavily damaged. Since the main roads and the most damaged roads were almost all along rivers and on hillsides, the estimation was not carried out on the whole affected area, but only in those areas that were seriously damaged.

Our damage analysis concluded that the length and grade of damaged roads are highly correlated to the northeast-trending Longmenshan Fault, so the roads near the fault between Yingxiu and Beichuan as well as the roads between Xuankou, Dujiangyan, and Maoxian were highly damaged, with longer sections and higher grades more likely to be damaged. Also, roads along the steep Minjiang River and Jianjiang River valleys were more heavily damaged. Some flooded sections located along the river valley were inundated by the dammed lakes. Statistical analysis was also done with respect to county and road hierarchy. The result shows that although there are fewer roads in the mountainous area than in the plains area, road damage was heavier in the mountains. In the area covered by the ADS40 images, with Longmen Mountain as a boundary, the west and northeast areas were more damaged by the earthquake and its after effects, mostly geological disasters, than the east and southeast part, where the roads were also less damaged. The damaged national roads are the sections of NR317 around Lixian County and NR213 around Wenchuan and Maoxian counties. Roads along the Laisuhe River banks, as well as the Minjiang and Caobahe rivers, were seriously affected by landslides and debris flow; up to $40 \%$ of these roads are damaged. When broken down by county, Wenchuan saw the highest damage. Amazingly, NR108, which passes though the city of Mianyang, was hardly affected. Provincial road 303 passing through Wenchuan County; PR302 passing through Beichuan County, Maoxian County, and the city of Jiangyou; and PR105 in Qingchuan and Pingwu counties were all badly damaged, which again follows the trend along the fault. This trend is also seen with county roads and village roads, which are more heavily damaged near the fault than those far away from the fault.

Out of 300 bridges, 49 were ruined. Destroyed bridges were located in Lixian County, Wenchuan County, and along both sides of the Longmenshan Fault, where more of the damaged bridges collapsed completely than cracked or broke in parts. The results of our statistical analysis show total damage length by different grades: $125 \mathrm{~km}$ of roads were piled with rocks; $233 \mathrm{~km}$ of roads were covered by landslide debris; $128 \mathrm{~km}$ of roadbeds were ruined; and $19 \mathrm{~km}$ of roads were flooded. 


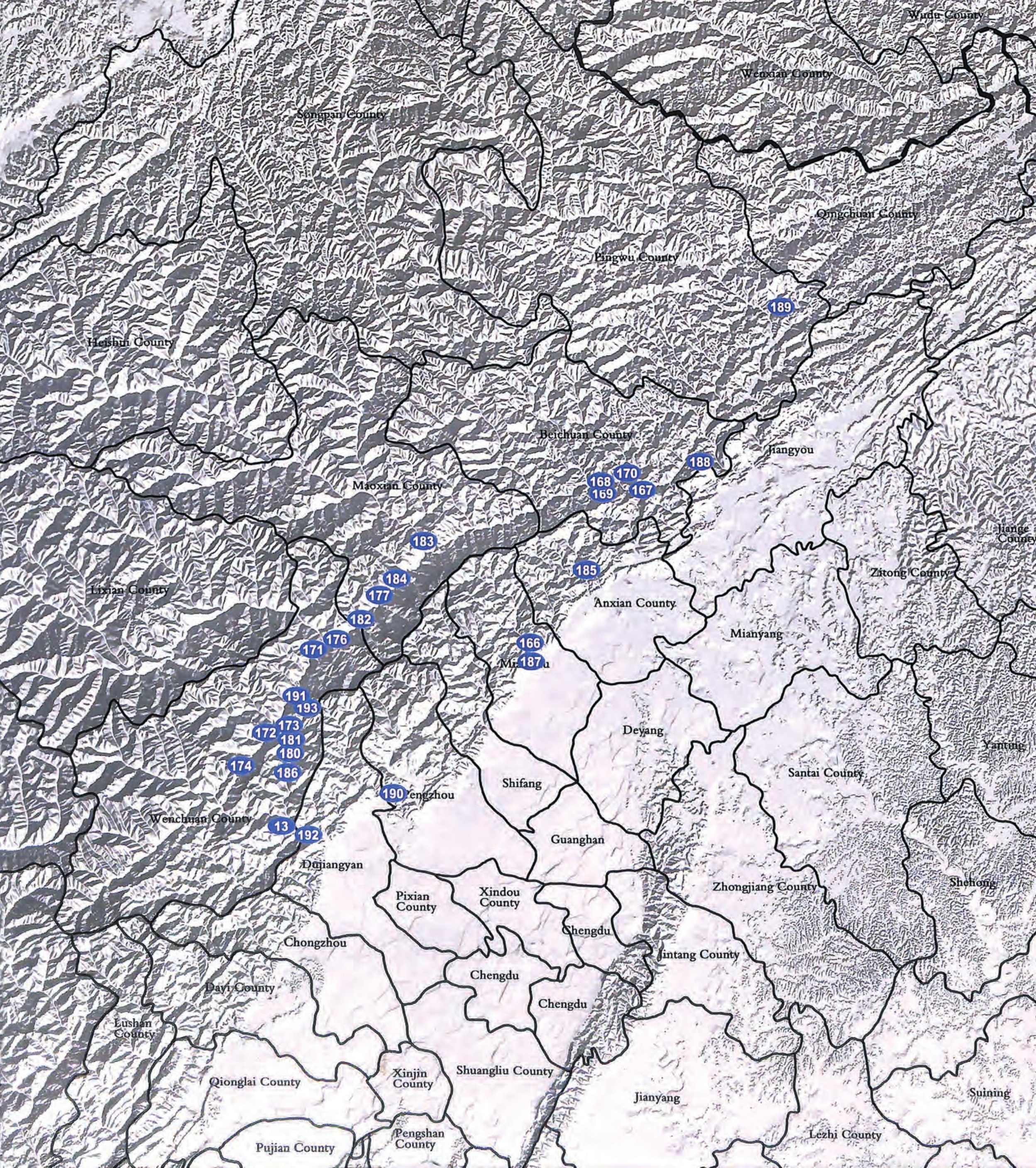




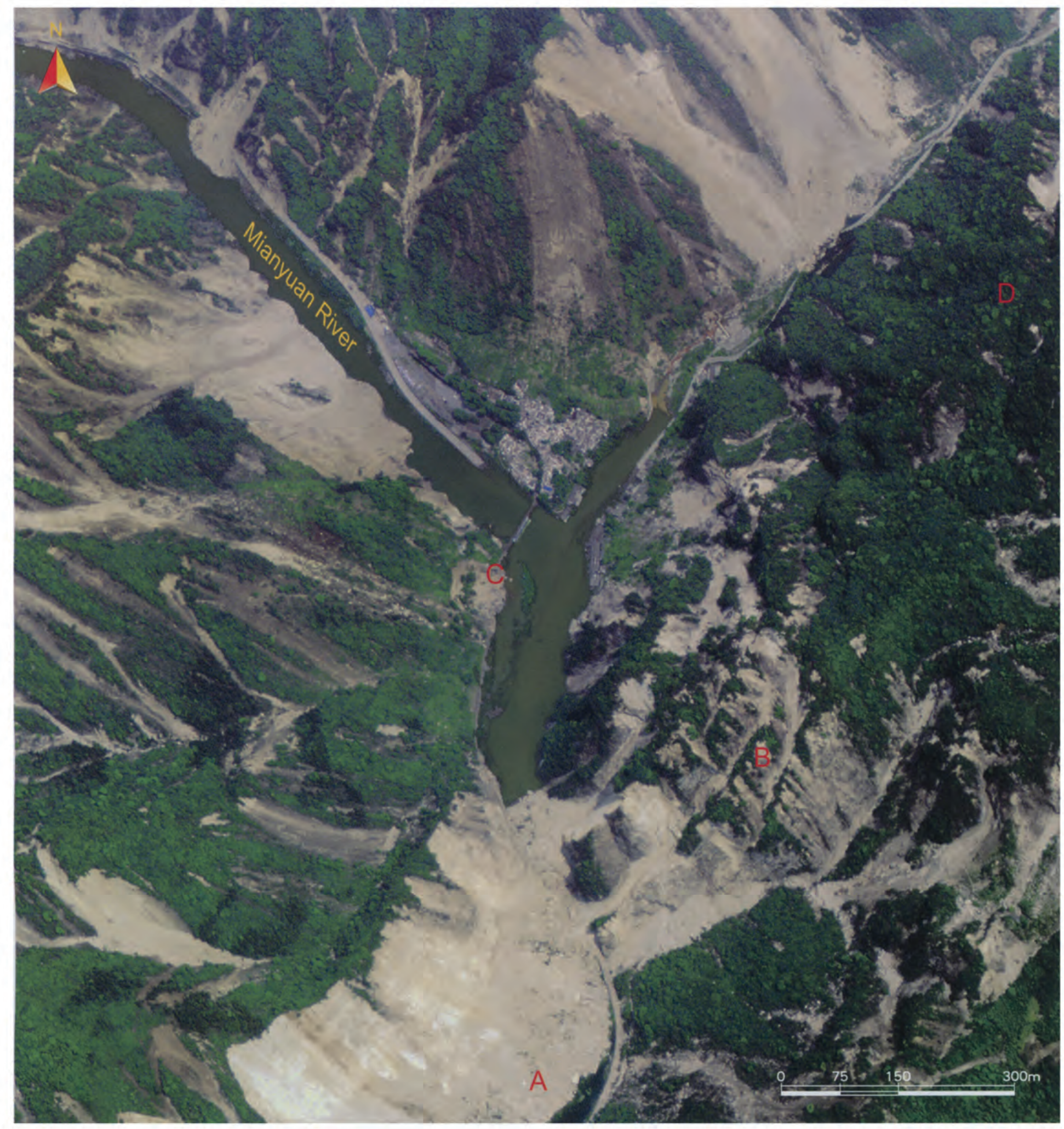

A Airborne ADS40 image of the village of Xiejunmen, in the town of Tianchi, in the city of Mianyang

Airborne ADS40 image acquired on May 16, 2008 shows that the earthquake caused quite a few landfalls and landslides, which then blocked nearly $30 \%$ of the roads in this image. From (A) one can see huge rocks blocking the road at the bottom of the image. On the west bank of the Mianyuan River (B) and (C) dammed lake submerging more than $300 \mathrm{~m}$ of roads along the Mianyuan River. (D) Heavy landslides on one side of the river even affected the road on the other side.

166 I Atlas of Remote Sensing of the Wenchuan Earthquake 

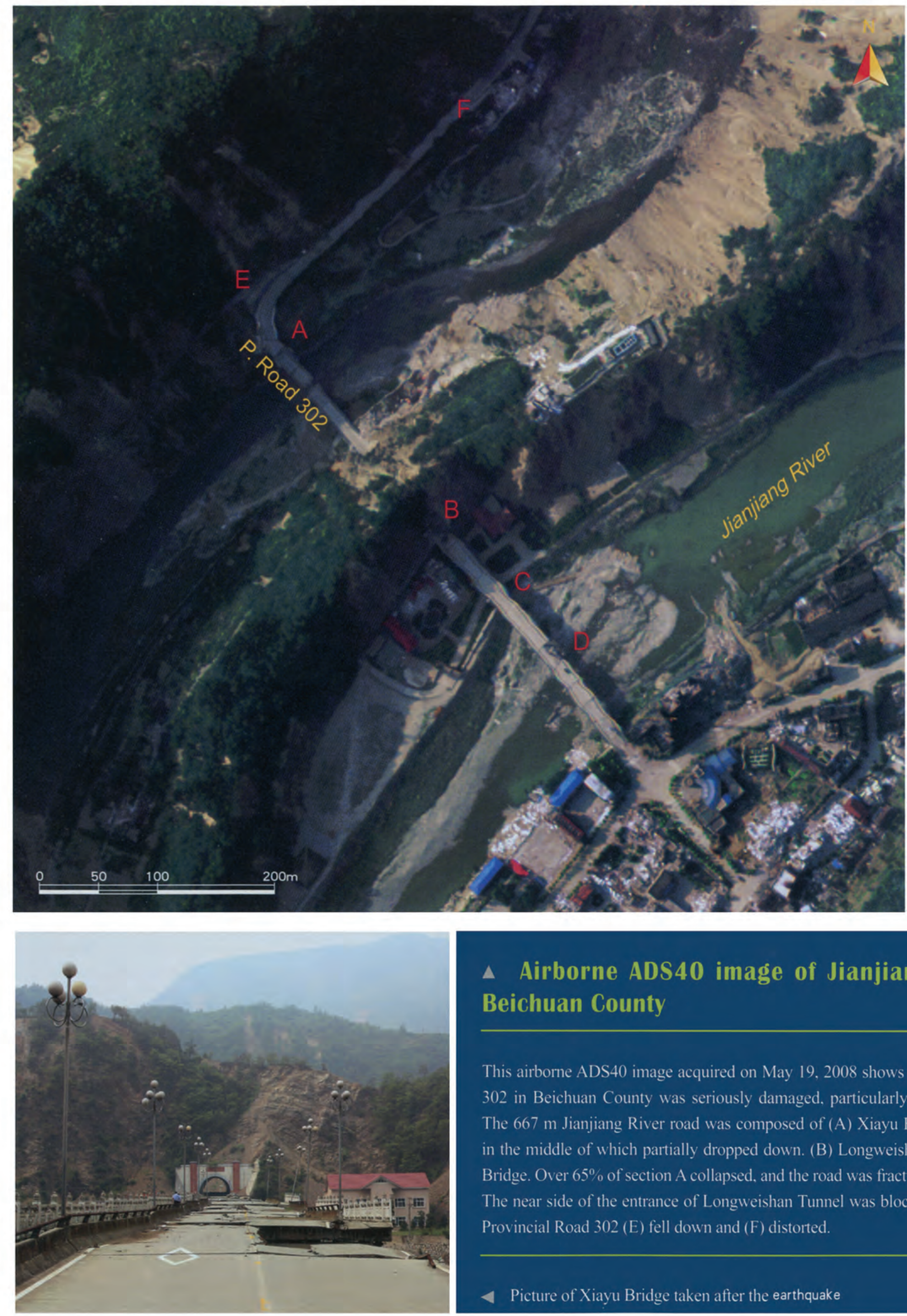

$\triangle$ Airborne ADS40 image of Jianjianghe highway, in Beichuan County

This airborne ADS40 image acquired on May 19, 2008 shows a section of Provincial Road 302 in Beichuan County was seriously damaged, particularly in the Jianjiang Road area. The $667 \mathrm{~m}$ Jianjiang River road was composed of (A) Xiayu Bridge, of which about $50 \mathrm{~m}$ in the middle of which partially dropped down. (B) Longweishan Tunnel and (C) Shisuoyi Bridge. Over $65 \%$ of section A collapsed, and the road was fractured to the west, marked (D). The near side of the entrance of Longweishan Tunnel was blocked by landfall. A section of Provincial Road 302 (E) fell down and $(F)$ distorted.

4 Picture of Xiayu Bridge taken after the earthquake 


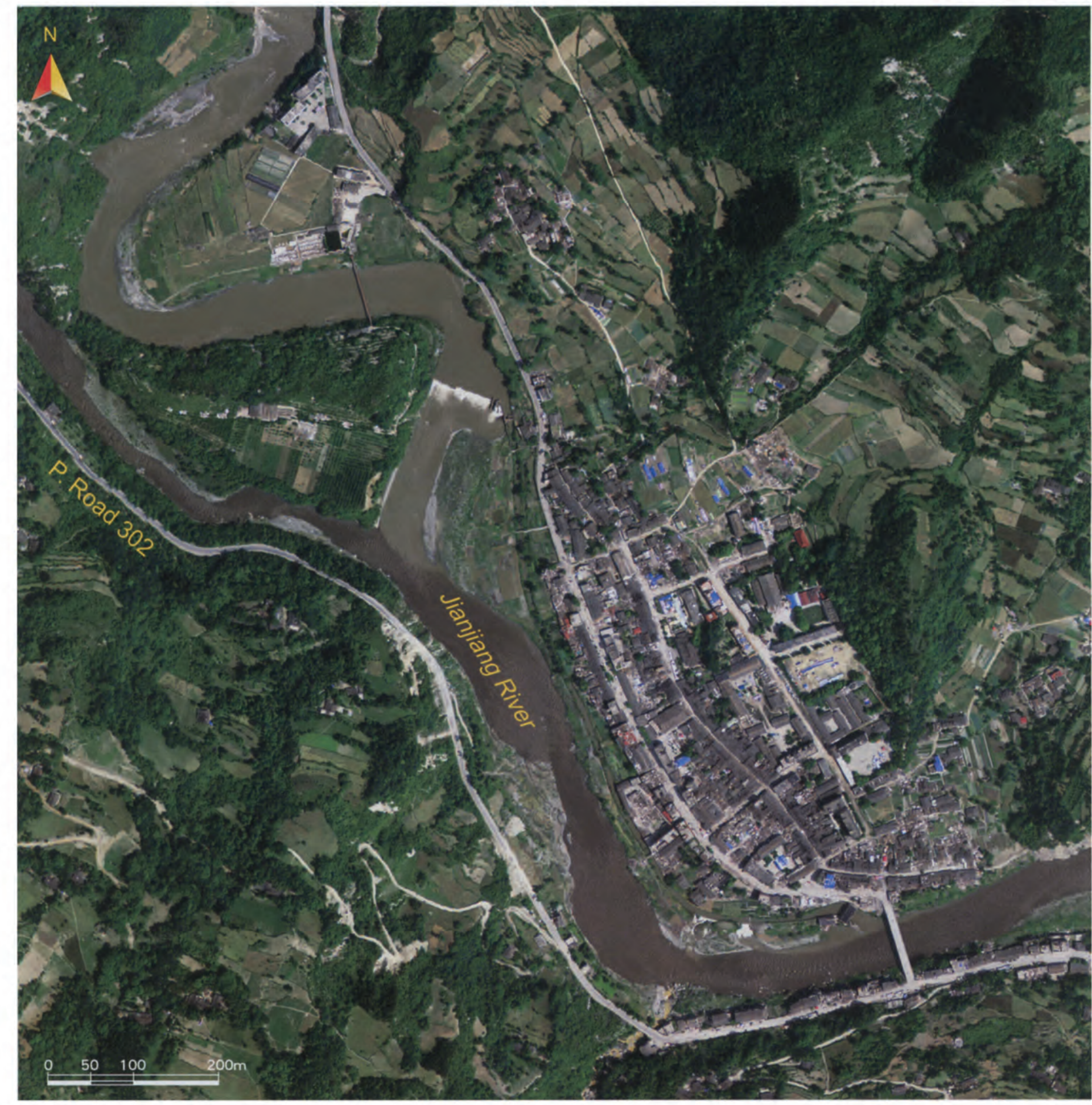

$\Delta$ Airborne ADS40 image of the village of Zhicheng, in the town of Yuli, in Beichuan County, May 16, 2008

On the airborne ADS40 image acquired on May 16, 2008 (the left one), the roads were visible, although there was a dammed lake in the lower Jianjiang River. But the water level kept rising and the town of Yuli was flooded afterward. (This area was in danger of flooding when the image was acquired 19 May 2008 , which is not shown here). The image on the next page was acquired on May 27, 2008, when the government began to discharge from the dam holding the lake.

168 I Atlas of Remote Sensing of the Wenchuan Earthquake 


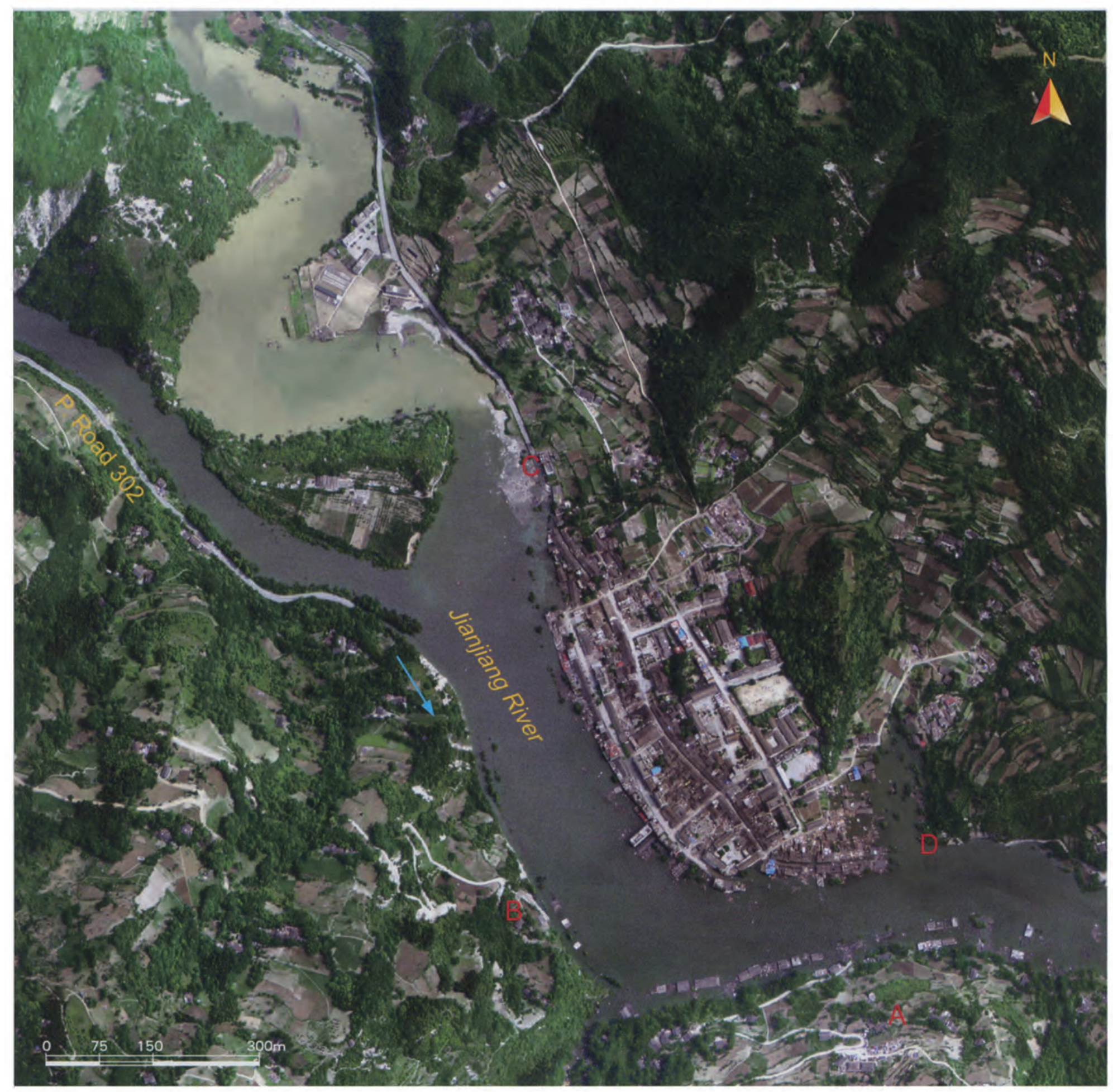

A Airborne ADS40 image of the village of Zhicheng, in the town of Yuli, in Beichuan County, May 27, 2008

This image was acquired on May 27, 2008, when the government began to discharge from the dam holding the lake. However, the roads of the village of Zhicheng were still under water, including (A) a bridge, (B) a 1700-m-long section of Provincial Road 302, as well as (C) and (D) some other roads, where the flooded section (C) was $1700 \mathrm{~m}$ long, and (D) $1300 \mathrm{~m}$. An "SOS" message was found on the image from May 18, 2008 (not shown here), which indicated that traffic in and out of the area was blocked, and as a result, food and supplies would need to be airlifted in. 


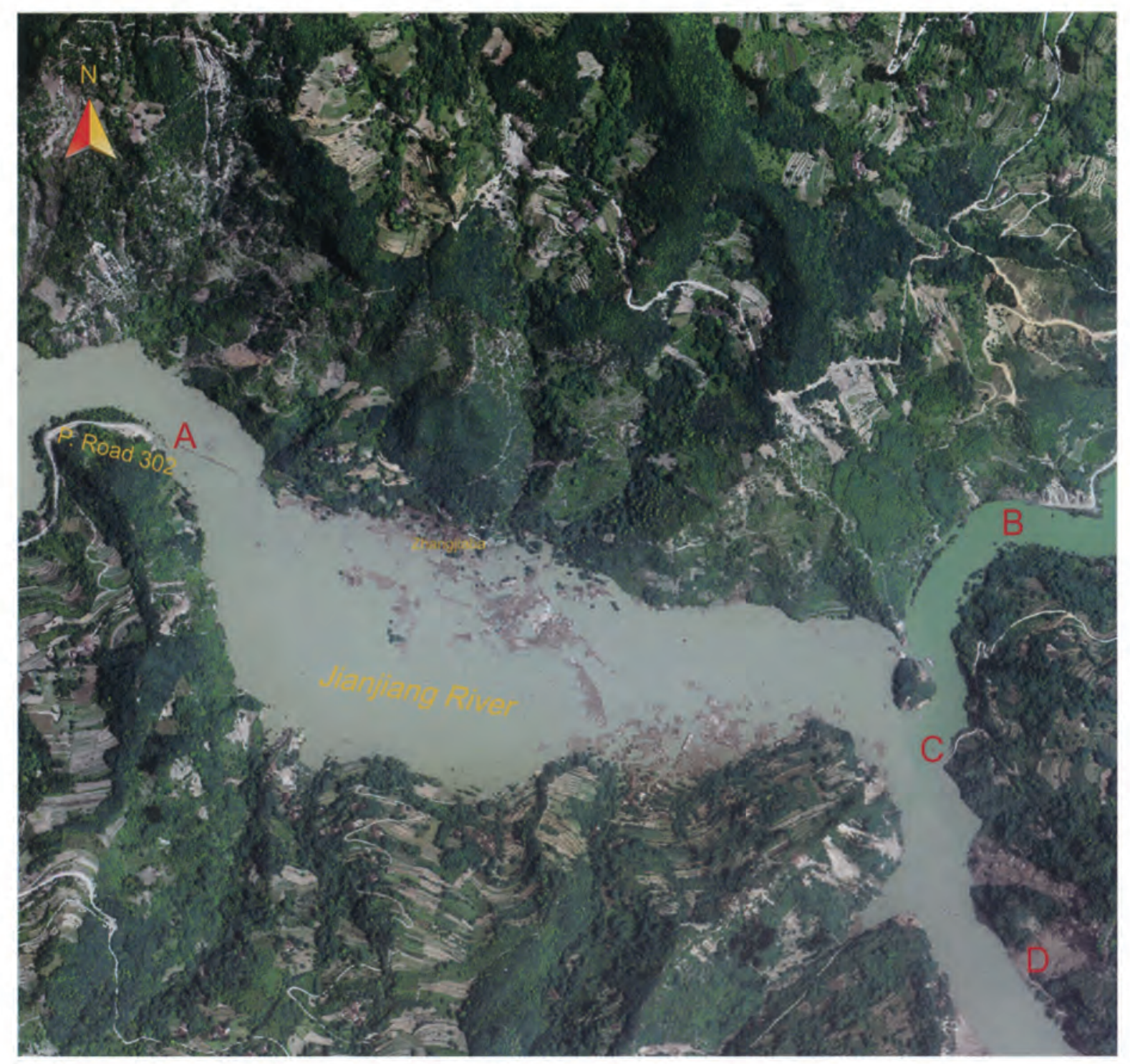

\section{A Airborne ADS40 image of the village of Zhangjiaba, in the town of Xuanping, in Beichuan County}

This ADS40 image was acquired on May 16, 2008, at the same time as the image of the town of Yuli on the previous page. This area is a bit downstream of the town of Yuli, so it was flooded on May 16. Almost the whole section of Provincial Road 302 in this area was completely inundated, see (A). Other roads along the Jianjiang River were flooded as well, for example, (B), (C). Still some sections like (D) were obstructed by landfalls, though not really affected by flood.

\section{- Airborne ADS40 image of the town of Guozhupu, in Wenchuan County}

This ADS40 image was acquired on May 15, 2008. To the south of Wenchuan County, many landfalls, landslides, and debris flows took place, destroying quite a few roads. Some sections of National Road 213 were obstructed, such as (A) and (B) labeled on the image. (C) shows a more than 1400-m-long section of county road that was ruined by heavy debris flow.

170 I Atlas of Remote Sensing of the Wenchuan Earthquake 


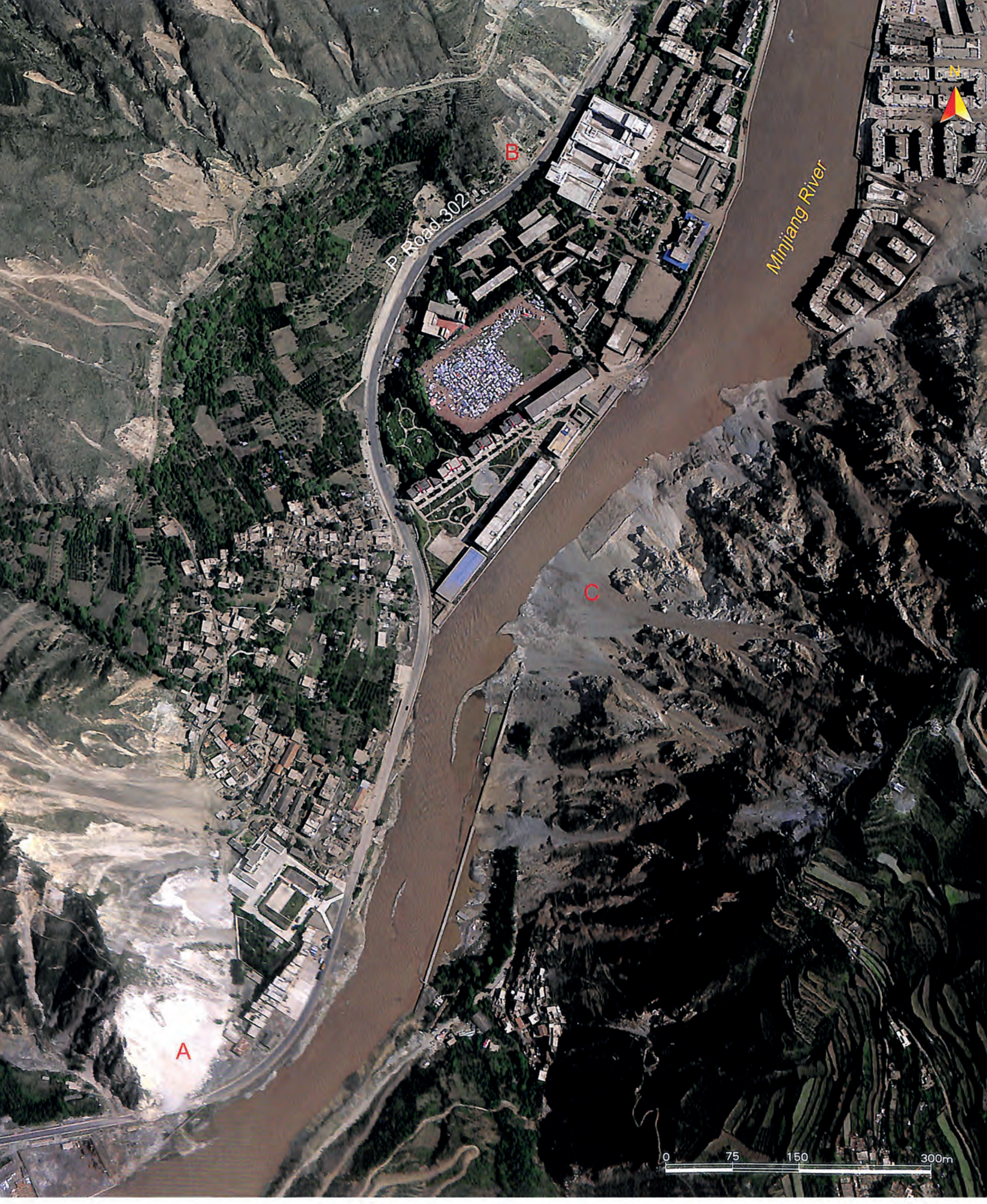

Damaged Roads I $\mathbf{~ m ~}$ 


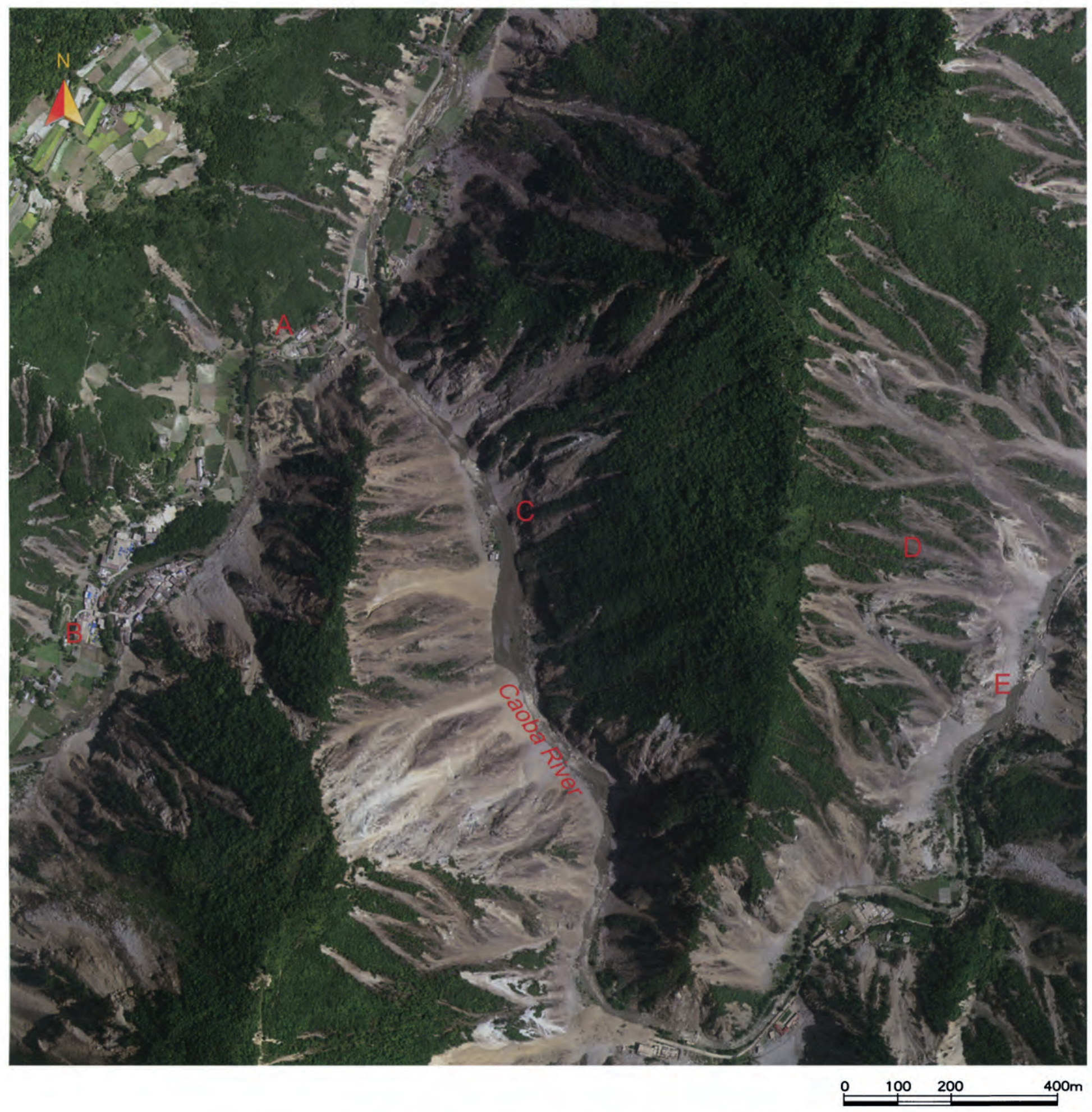

\section{- Airborne ADS40 image of the town of Caopo, in Wenchuan County}

From the ASD40 image acquired on May 15, 2008, numerous debris flows and landslides occurred along the Caoba River, as well as in the town of Caopo, which is a town with a population of about 4,000 . These secondary geological disasters caused by the earthquakes badly damaged more than $80 \%$ of the roads along the river banks, marked (A), (B), (C), and (D) on the image. Some of the roads, which did not seem to be badly damaged, were obstructed by rocks or earth rolling from the adjacent mountain, such as the road around (E). The traffic of the town of Caopo did not recover until the end of June, so during this period, all daily supplies and groceries had to be sent by air or by foot.

172 I Atlas of Remote Sensing of the Wenchuan Earthquake 
$\checkmark$ Airborne ADS40 image of the village of Zaojiaotuo, in the town of Yinxing, in Wenchuan County

This ADS40 image was acquired on May 16, 2008. It shows a bridge over the Minjiang River near the village of Zaojiaotuo that fell down as a direct result of the earthquake, marked (A). The east end of the bridge was broken, and there is a visible crack west of the bridge. (B) $280 \mathrm{~m}$ of heavily damaged county road, which was connected to the bridge. The road was almost completely covered by landfalls and debris flows, which are secondary geological disasters resulting from the earthquake. Because it is mountainous nearby and the slopes are steep (seen in this ADS40 image), geological disasters are overwhelming. West of the bridge, landfalls and landslides blocked more than $90 \%$ of National Road 317, marked (C). On the left corner of this image, the surface of the land is fragmented, hardly any vegetation or roads are visible.
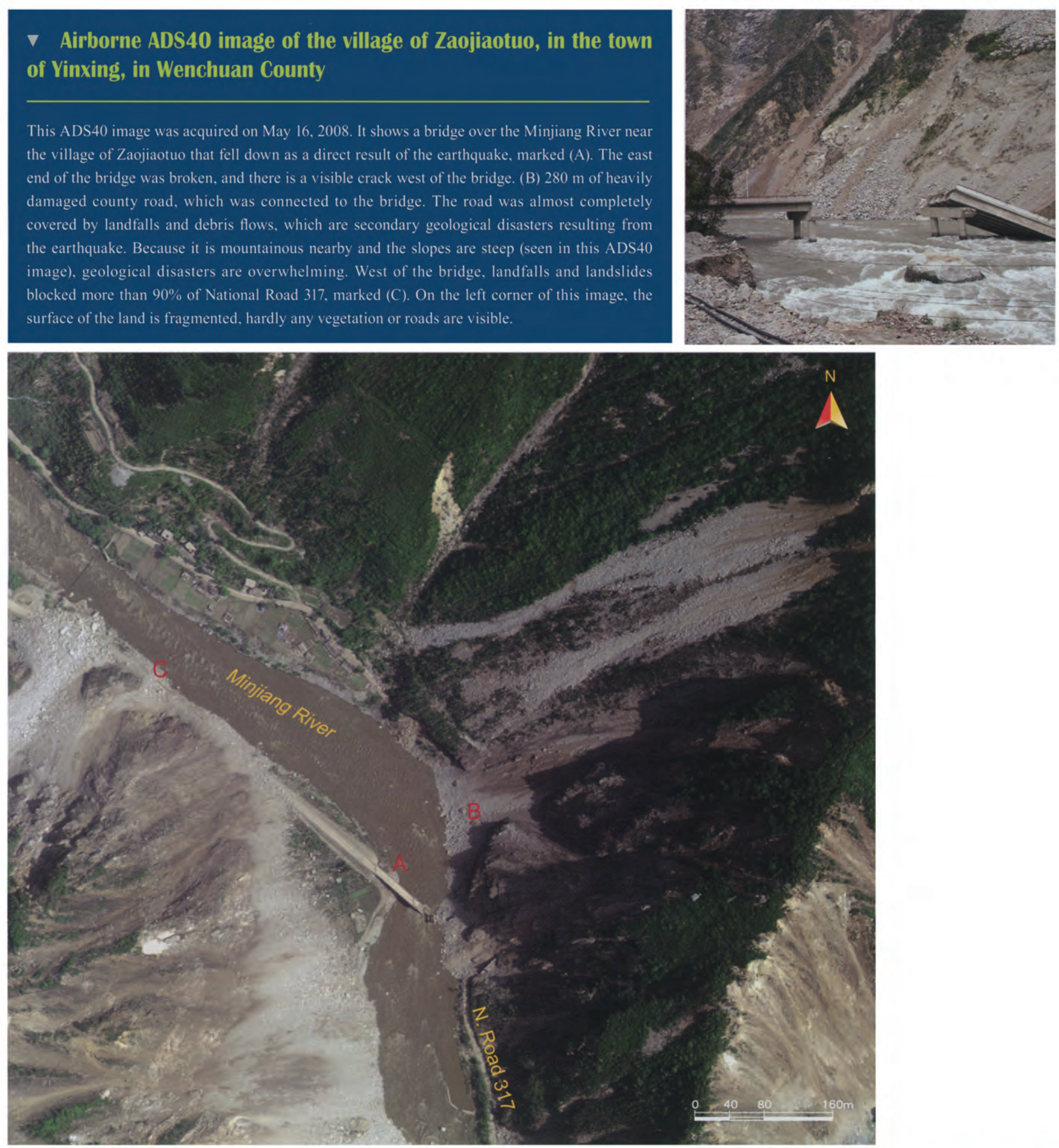

Damaged Roads I 173 


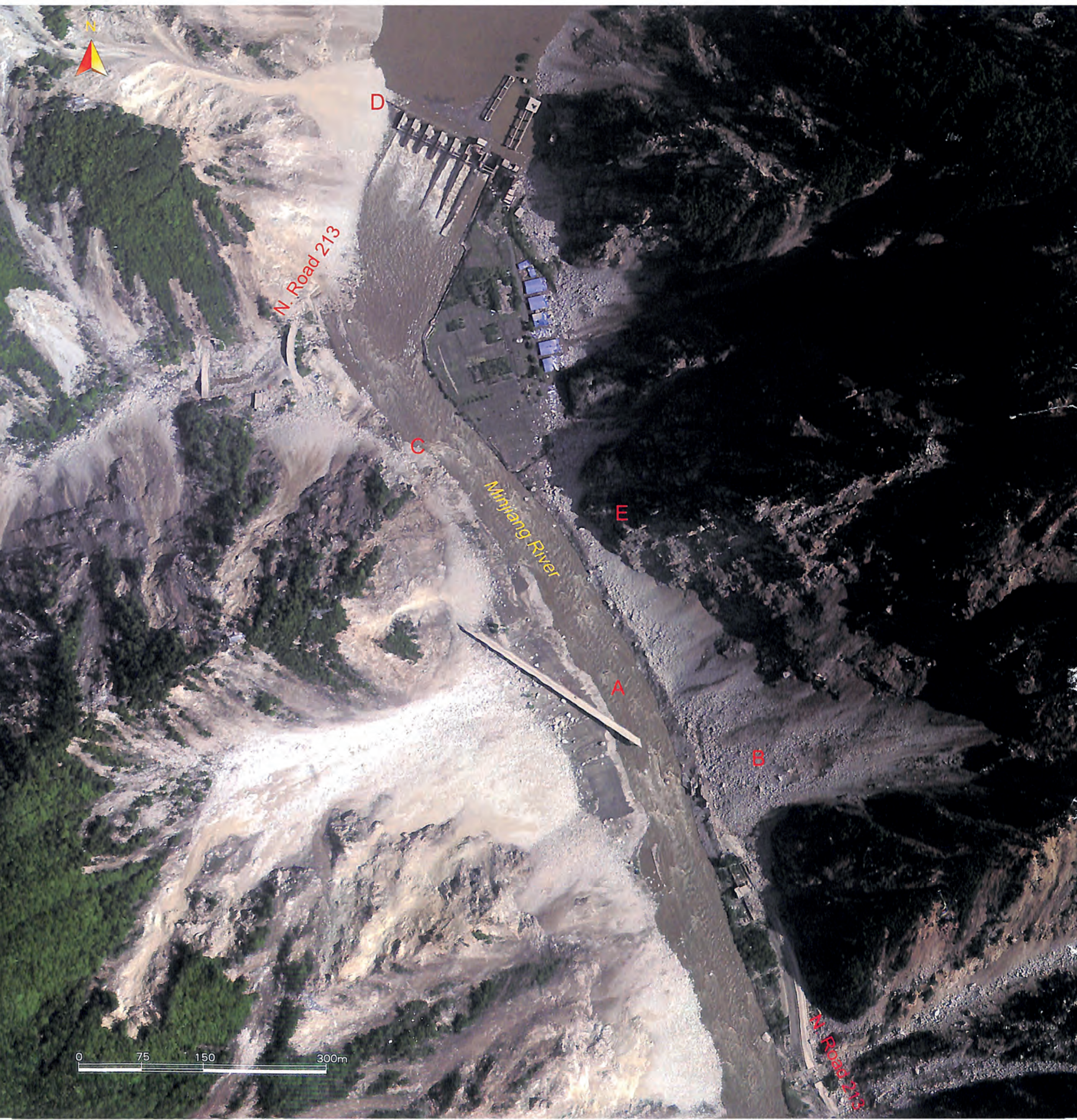

174 I Atlas of Remote Sensing of the Wenchuan Earthquake 


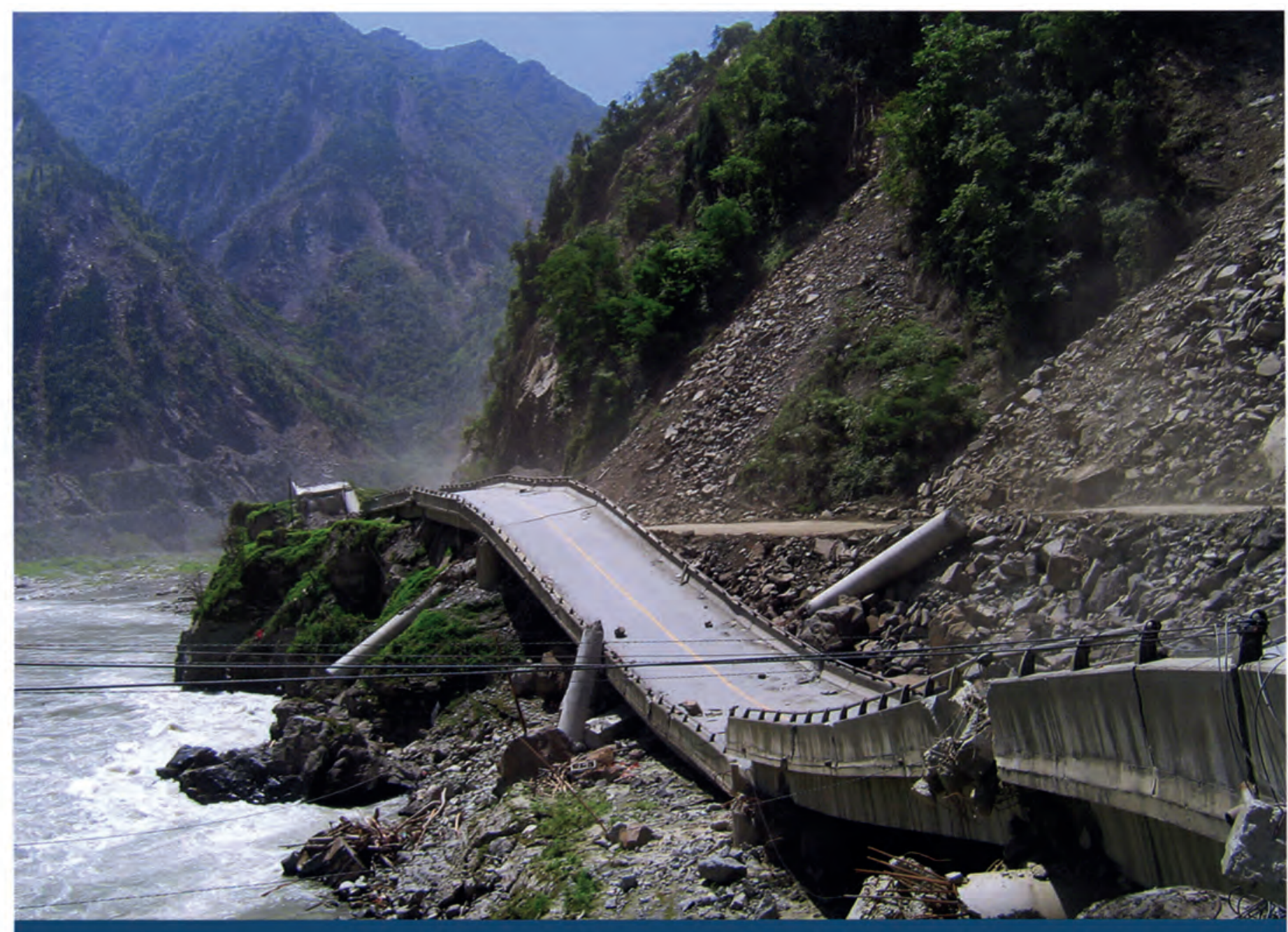

4 Airborne ADS40 image of Taipingyi Reservoir, in Wenchuan County

This ADS40 image acquired on 16 May 2008 shows severe damage of roads around Taipingyi Reservoir and the low-lying lands surrounding it. The upper part of the image shows the Taipingyi Reservoir. which was built from the Minjiang River. A bridge carrying National Road 213 across the Minjiang River, labeled (A), collapsed, and about $100 \mathrm{~m}$ fell down. East of the bridge, there were (B) heavy landslides and debris flows, which covered several sections of National Road 213. There were also landslides and debris flows on sections of National Road 213 (C) and (D) on the left bank of Minjiang River. Some of the other highways were also heavily affected: (E) the east bank of the Minjiang River is a case in point. 


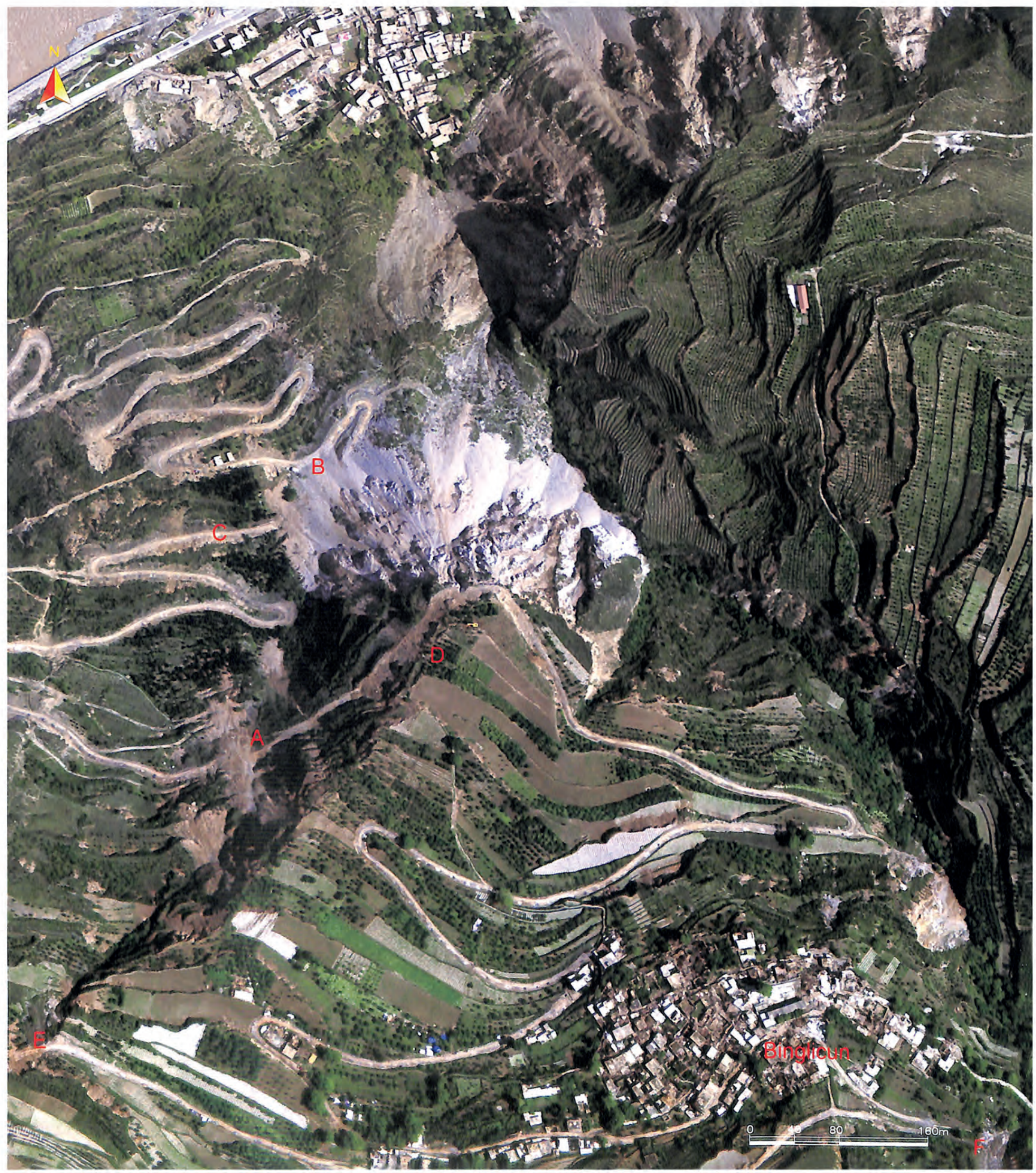

176 I Atlas of Remote Sensing of the Wenchuan Earthquake 


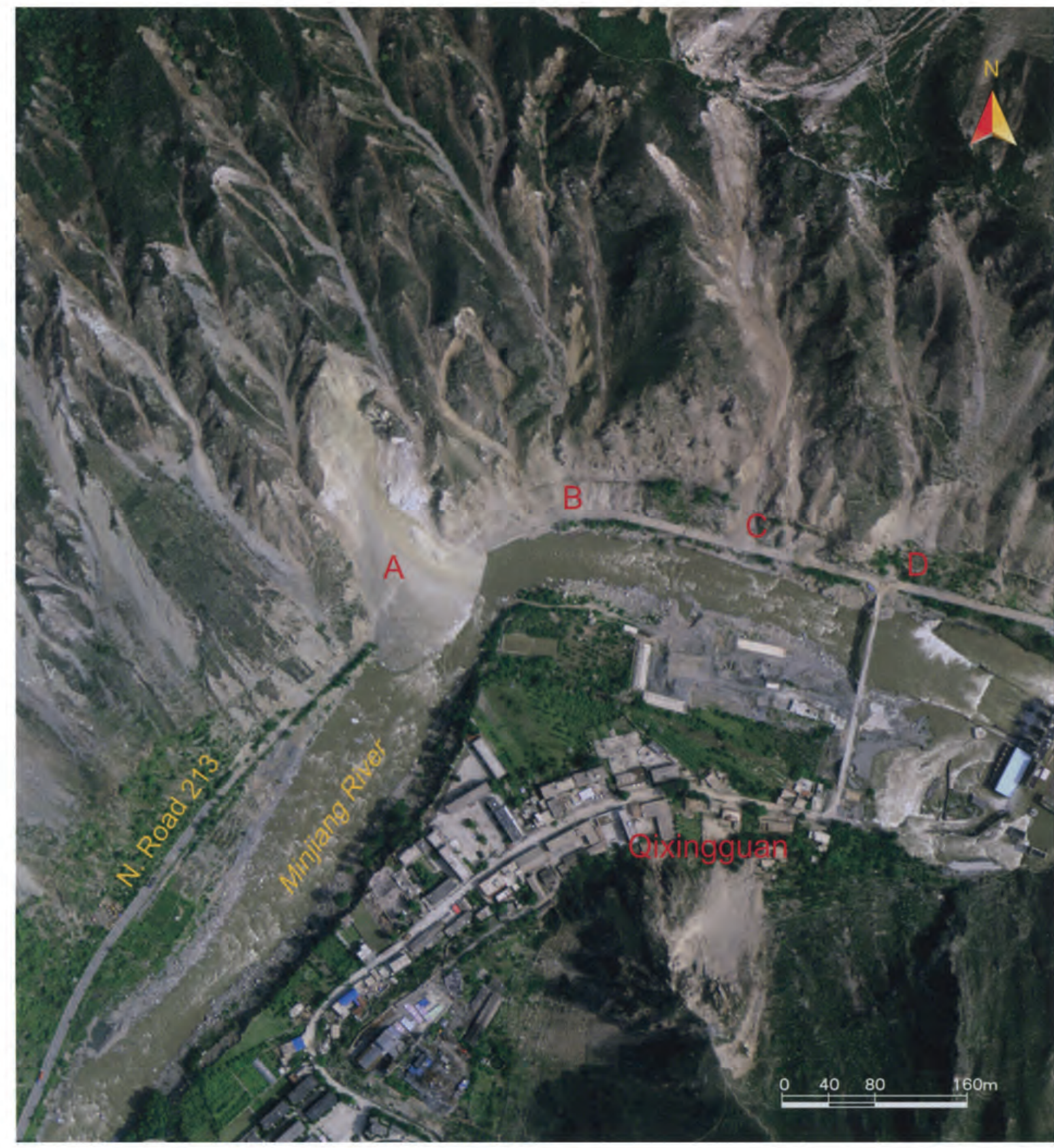

4 Airborne ADS40 image of Bingli Yanmen in Wenchuan

Acquired on May 15, 2008, this image shows damaged village roads. According to ancillary data from the local government, one of these roads had just been built to facilitate traffic between the small villages and between villages and towns, but the road foundations under several sections of the roads were ruined by landfalls and landslides, and some sections were covered with rocks and debris. The total length of damage was up to $1,360 \mathrm{~m}$. As labeled, (A) was affected by a small landfall, which then blocked this section of the newly built road. The outer side the roadbed near (B) fell, and the road was blocked to traffic. Lands near (C) fell down and covered over $600 \mathrm{~m}$ of the new village road. (D) seemed less affected, except for some rocks blocking in the way and the falling of outer side, but it is doubtful that vehicles could even access this section of the road, since (A) is impassable. There is slight damage on section $(\mathrm{E})$, compared to section $(\mathrm{F})$, where the roadbed fell completely.
4 Airborne ADS40 image of Qixingguan, in the town of Nanxin, in Maoxian County

On this ADS40 image on May 15, 2008, National Road 213 travels along the right bank of the Minjiang River, which runs southwest around the area within this image. A huge landfall (A) occurred in the middle. The landslide made National Road 213 impassable for a length of $260 \mathrm{~m}$. We do not know whether the roadbed beneath the landslide is passable, but considering the amount of weight placed on the roadbed by the slide material, it seems unlikely that the road underneath will be usable even after the debris is cleared. Along National Road 213, some medium landslides also brought debris and rocks that blocked the road. The road section marked (B) was covered by debris, which fell from the adjacent mountain. As we can see from the image, this debris has traveled rather far, moving along the valleys between mountains. (C) and (D) were about the same, except that road section (C) was a bit more heavily covered than (D). The bridge connected to (D) was broken, which is also visible from the image, and across the river, landslide or landfall is also visible. 

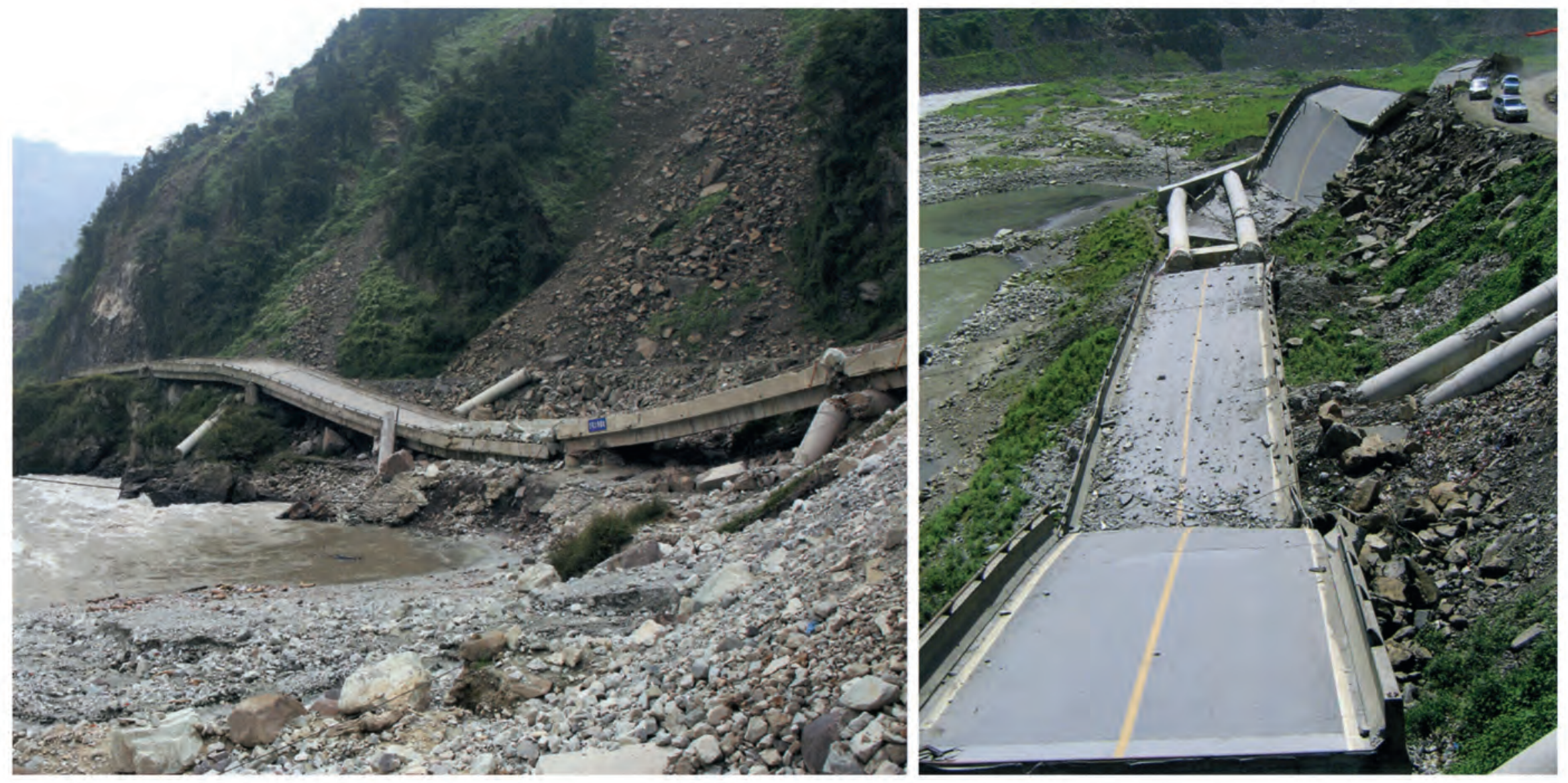

Post-earthquake photos of Baihua Bridge

\section{- Airborne ADS40 Image of the village of Zhangjiaping, in the town of Yingxiu, in Wenchuan County}

Acquired on May 16, 2008, this ADS40 image shows a damaged section of National Road 213 along the west river bank in the village of Zhangjiaping, in the town of Yingxiu. As the image shows, about $100 \mathrm{~m}$ of the road was destroyed, marked (A). (B) shows a ruptured highway approach bridge, with a visible crack. Landfalls and slides took place where the foundation was soft. (C), (D), and (E) show road sections that were blocked by rocks rolling from the landfalls or landslides nearby.

178 I Atlas of Remote Sensing of the Wenchuan Earthquake 


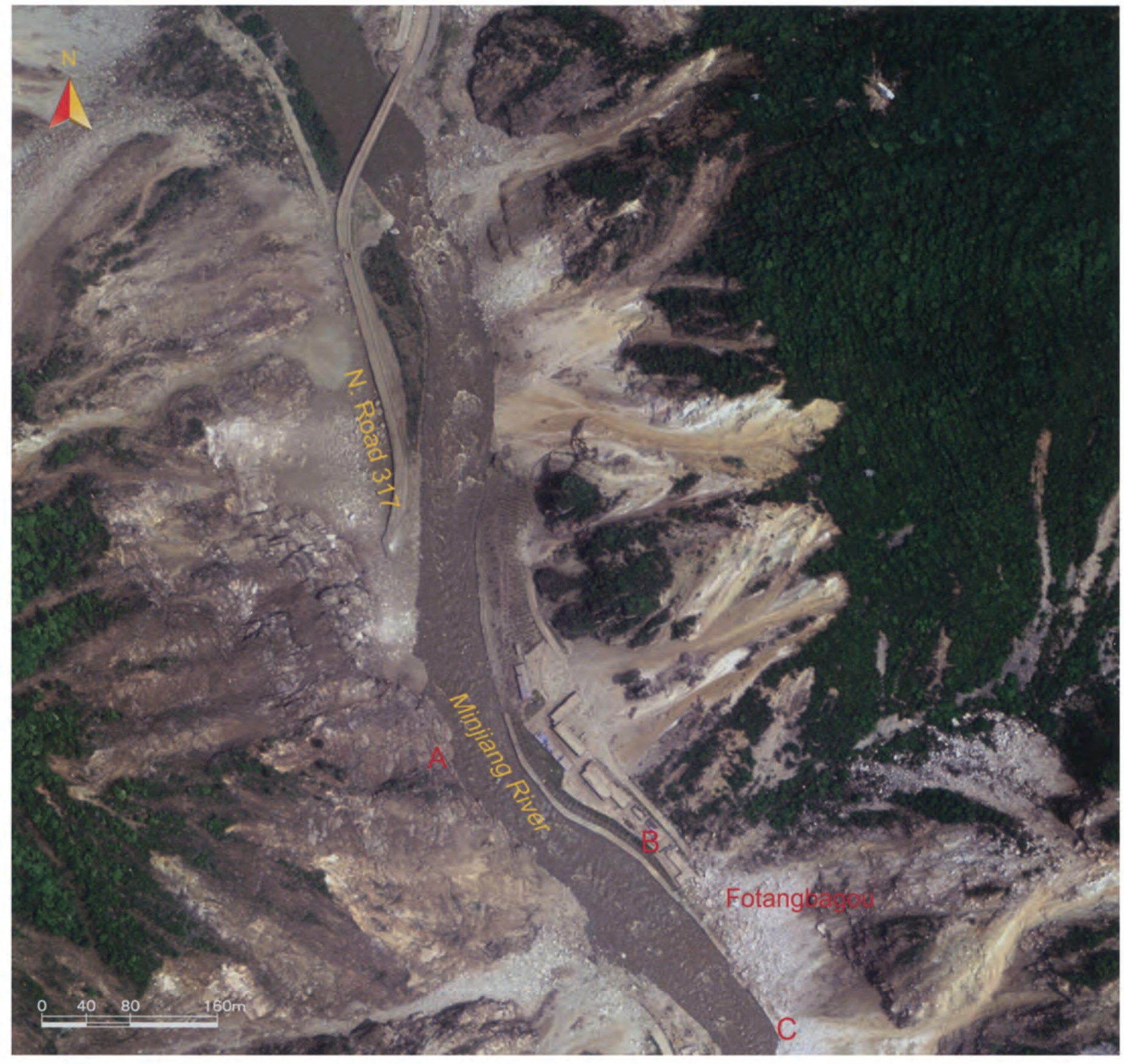

$\Delta$ Airborne ADS40 image of the village of Fotangbagou, in the town of Yingxing, in Wenchuan County

Acquired on May 16, 2008, this ADS40 image shows the damage of National Road 317 around the village of Fotangbagou, in the town of Yinxing. (A) A 400-m-long section of National Road 317 was covered by debris from landslides. (B) and (C) Sections of county roads that were heavily covered by debris flow and landslides. It is estimated that over $70 \%$ of the road surfaces along the Minjiang River were blocked. As we see from the image, there are two or possibly more roads that were almost parallel along the east bank of the Minjiang River, of which the sections around $(\mathrm{B})$ and $(\mathrm{C})$ were all badly affected. Given the number and weight of the rocks, it is doubtful that the road underneath remains undamaged.

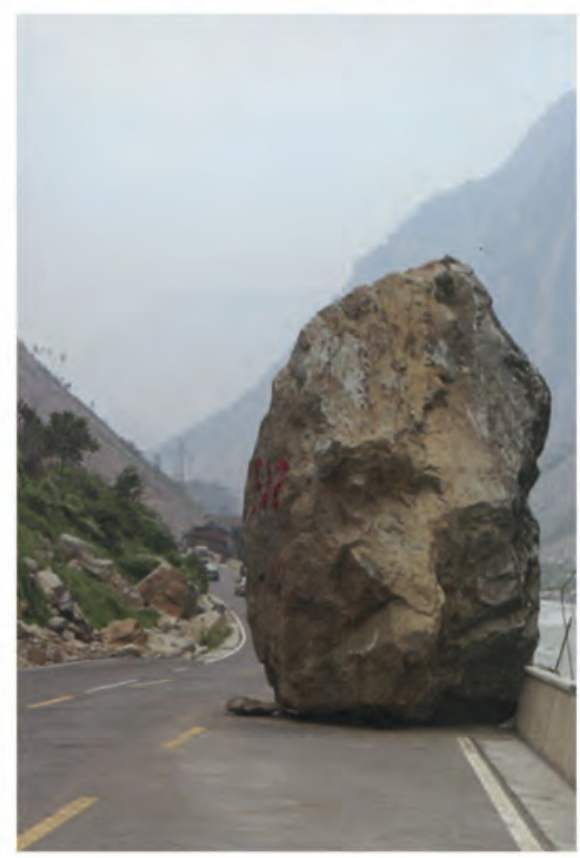

180 I Atlas of Remote Sensing of the Wenchuan Earthquake 


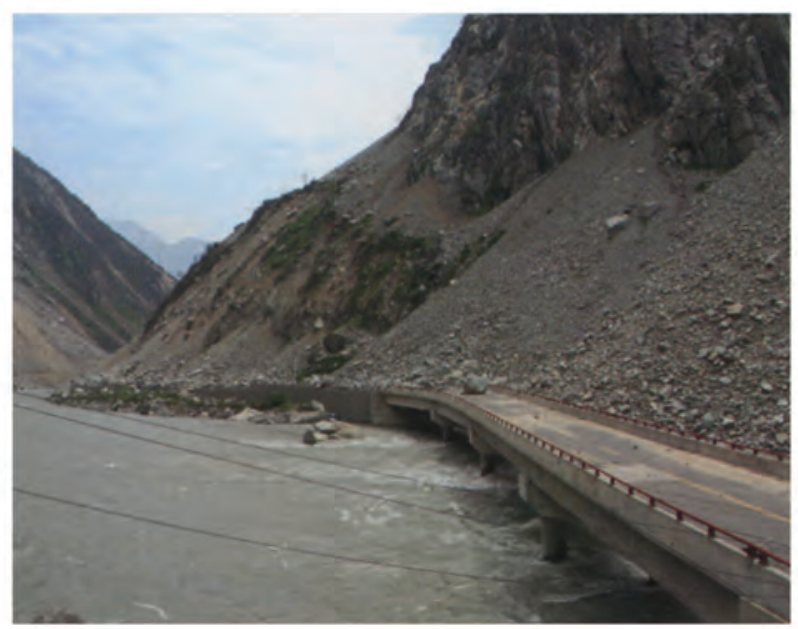

v Airborne ADS40 image of the village of Taoguancun, in the town of Vingxing, in Wenchuan County

Acquired on May 16, 2008, this ADS40 image shows another section of National Road 317, a tunnel of which was blocked by landfall, marked (A). The image also shows that on the west bank of the Minjiang River the roads were totally covered as a result of unbelievably heavy landslides and debris flows. (B) and (C) Sections of the road were invisible, but since there is a bridge connected to it, there must have been roads or tunnel. The image also shows (D) huge rocks blocking the road that have a diameter of over $8 \mathrm{~m}$.

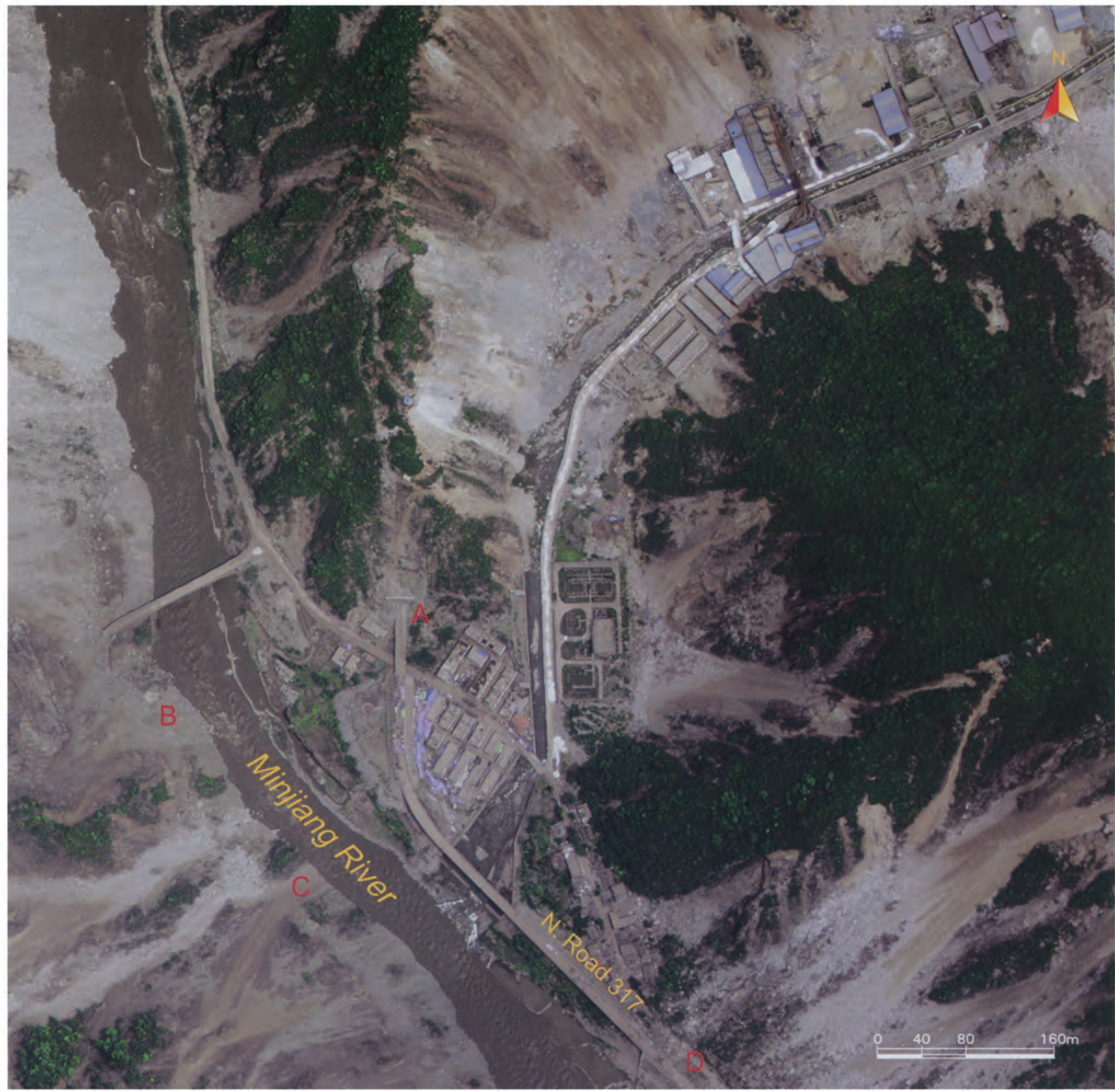




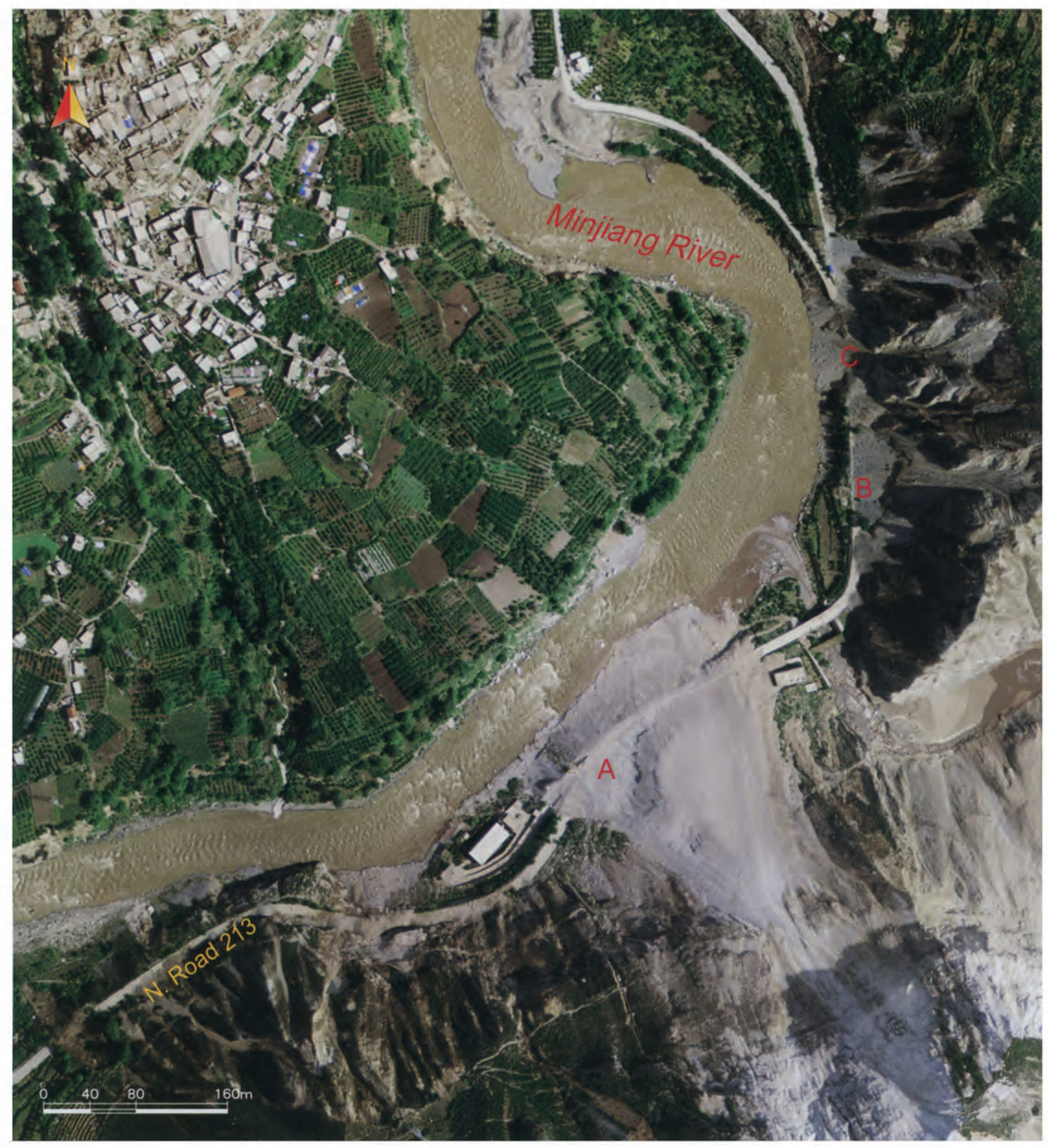

$\Delta \quad$ Airborne ADS40 image of the village of Wenzhen, in the town of Nanxin, in Maoxian County

In the middle of this ADS40 image acquired on May 15, 2008, there was a chain of landslides along the east Minjiang River bank, which then caused destruction to National Road 213 for over $1,000 \mathrm{~m}$. As shown on the image, (A), (B), and (C) marked the damaged sections, with the longest section (A) up to $230 \mathrm{~m}$. The extent of the road blockage made quick repair impossible, as a result people were traversing the roadway by foot, but cars could not get through.

182 I Atlas of Remote Sensing of the Wenchuan Earthquake 


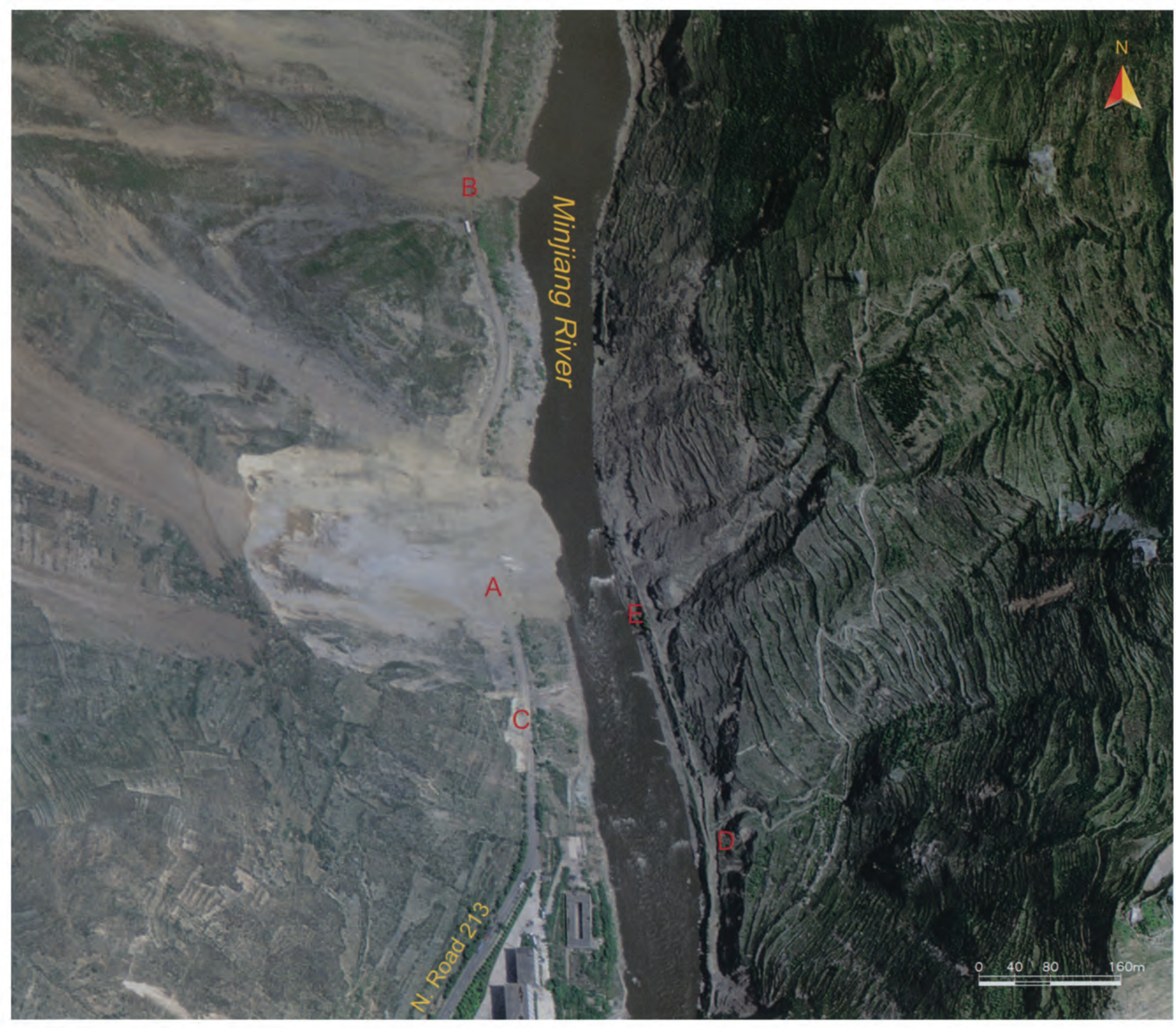

$\Delta$ Airborne ADS40 image of the village of Van'eryan, in the town of Fengyi, in Maoxian County

This ADS40 image acquired on May 15, 2008 shows the damage of National Road 213 along the west Minjiang River bank around the town of Fengyi. There were more landslides, landfalls, and debris flows on left side of the image than on the right. About $30 \%$ of the National Road 213 in this image was blocked or ruined, the most severley damaged areas are labeled (A), (B), and (C). The county road on the east river bank was affected as well; see sections marked (D) and (E). 


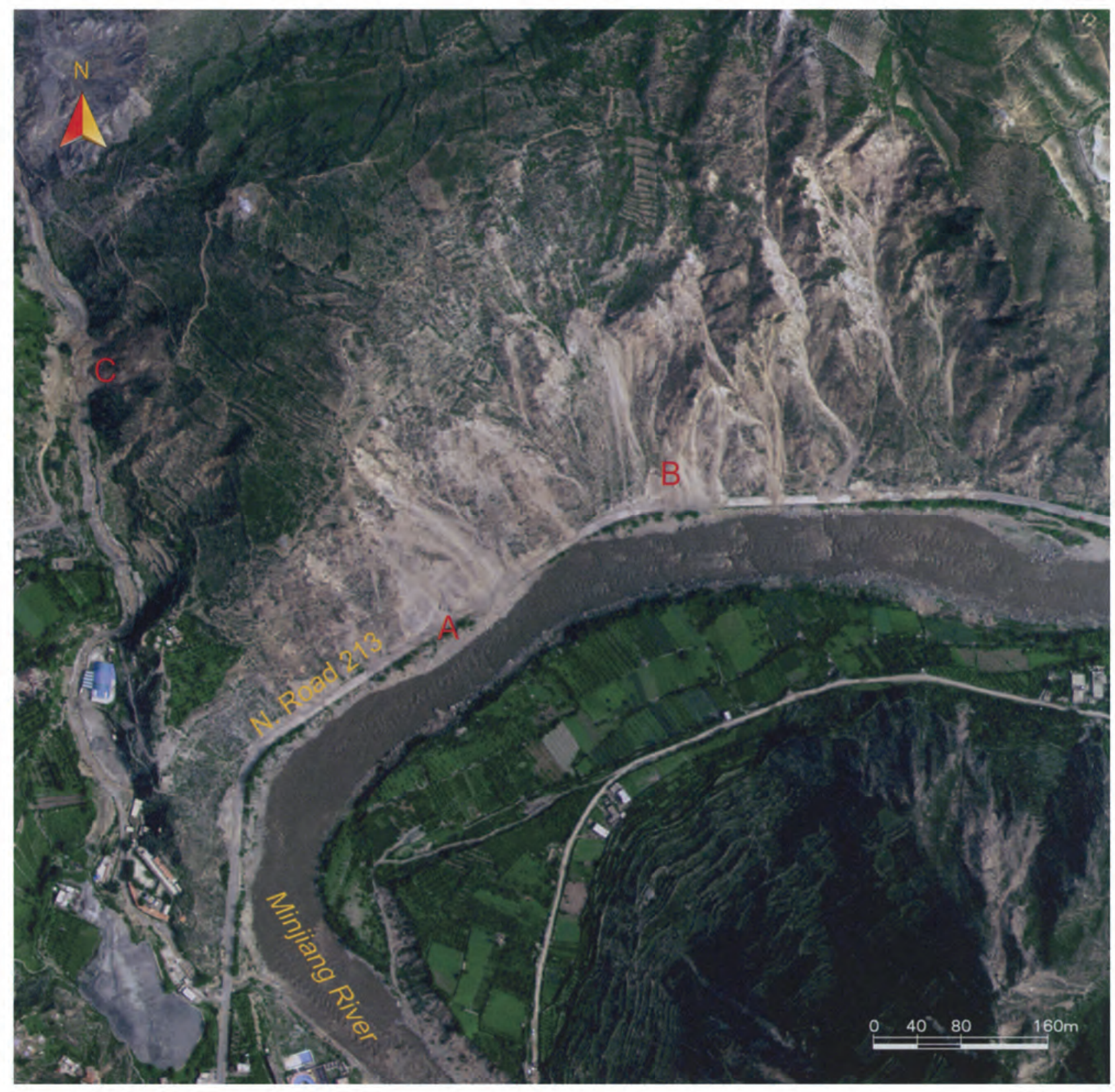

\section{A Airborne ADS40 image of the village of Jiyu, in the town of Fengyi, in Maoxian County}

As shown on this ADS40 image on May 15, 2008, on the right bank of Minjiang River a series of landslides and debris flows blocked National Road 213 for over $400 \mathrm{~m}$. More than $60 \%$ of the small road around the village Jiyu was affected by debris flows. (A) and (B) Road sections of National Road 213 affected by geological disasters. (C) A section of country road covered by debris.

- Airborne ADS40 image of the village of Xiaojiaqiao, in the town of Qianfo, in Anxian County

On May 19, 2008, more than 10 cars were seen to be stranded on the road around the village of Xiaojiaqiao, in the town of Qianfo, as a result of (A) disastrous landfalls. (B) Rocks densely littered over the road. (C) The landfalls also formed a dammed lake, which then flooded the road.

184 I Atlas of Remote Sensing of the Wenchuan Earthquake 


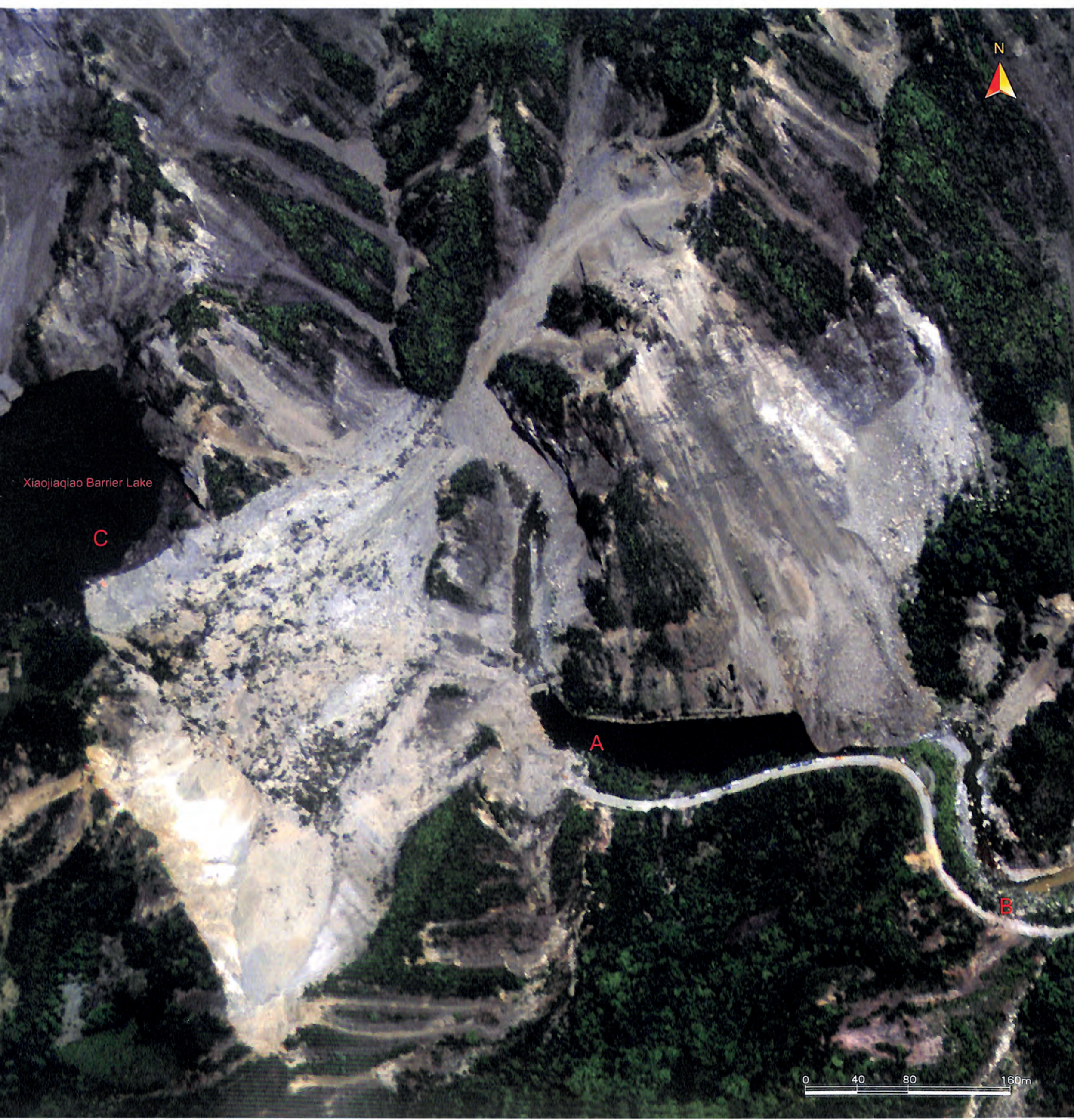

Damaged Roads ～ 185 
Along the Minjiang River banks, quite a few landfalls and debris flows occurred and brought great damage to National Road 317 and other county roads. As shown on this ADS40 image, which was acquired on 16 May 2008 , up to $70 \%$ of National Road 317 was badly damaged, labeled (A), (B), (C), where the longest section (C) covered by debris was $1,440 \mathrm{~m}$. The county road was also affected by landfalls; see (D). Even some sections not blocked had collapsed as a direct result of the earthquake or the fall of rocks nearby, as shown by (E), (F), and (G).

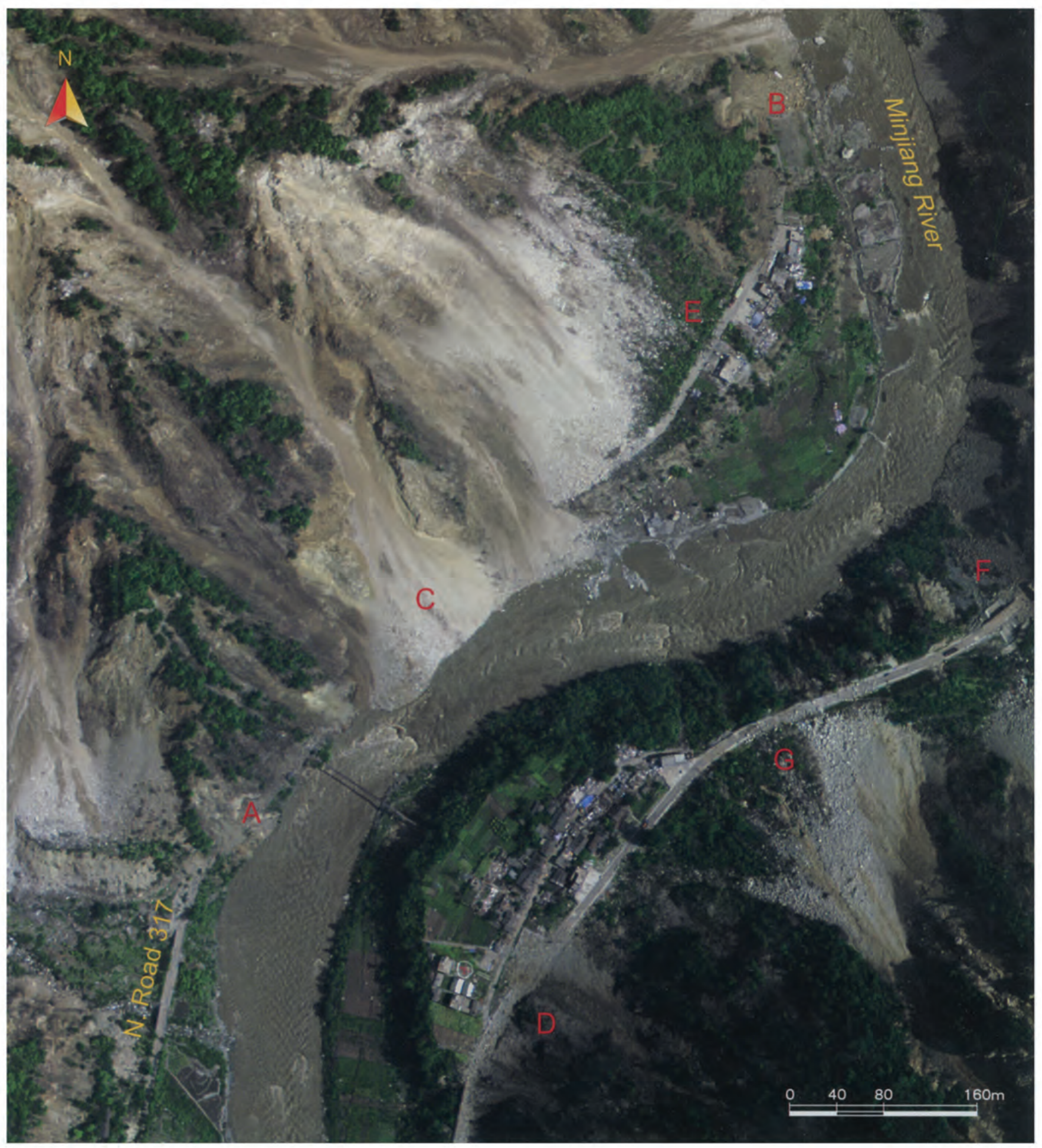

186 I Atlas of Remote Sensing of the Wenchuan Earthquake 


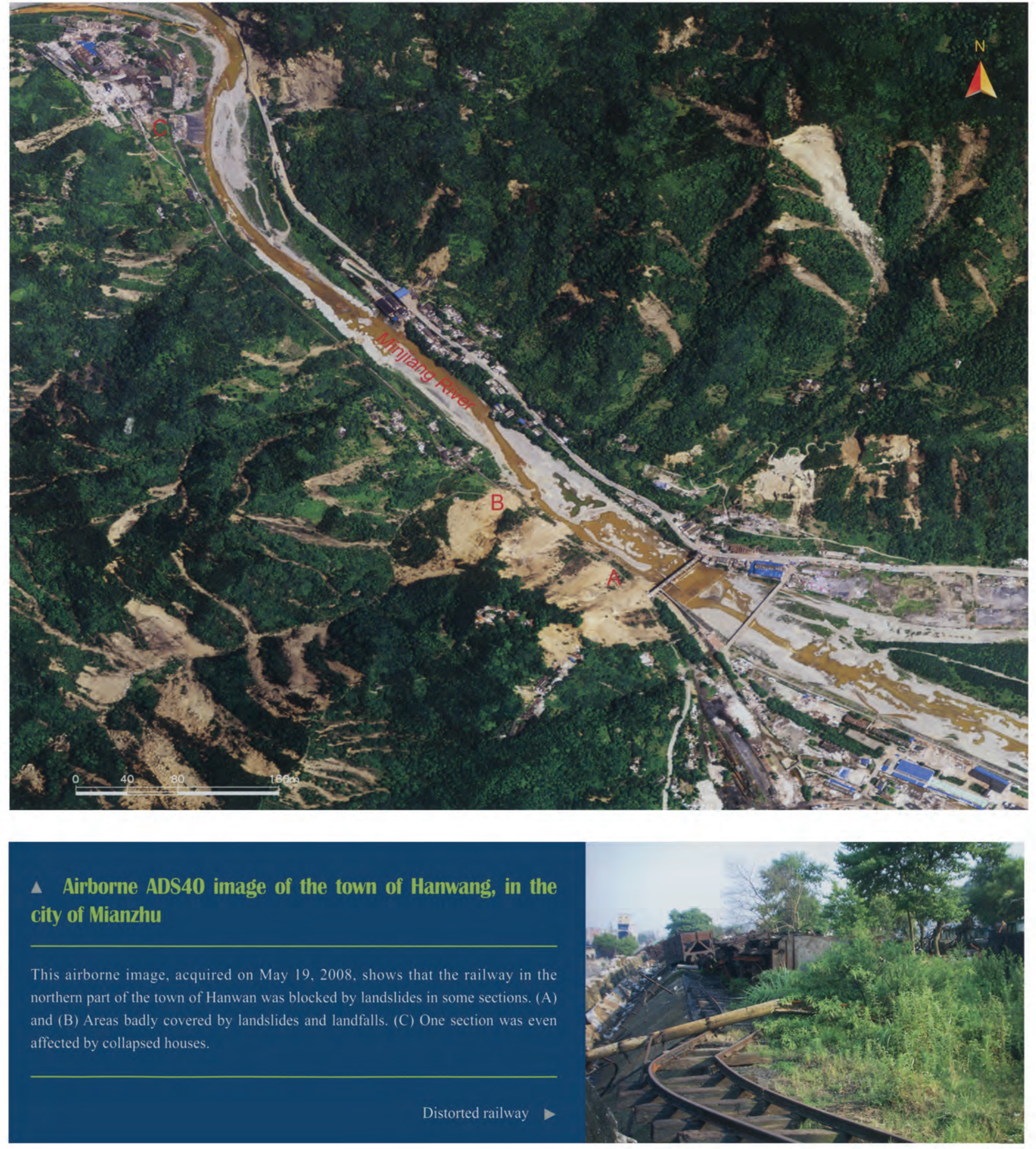




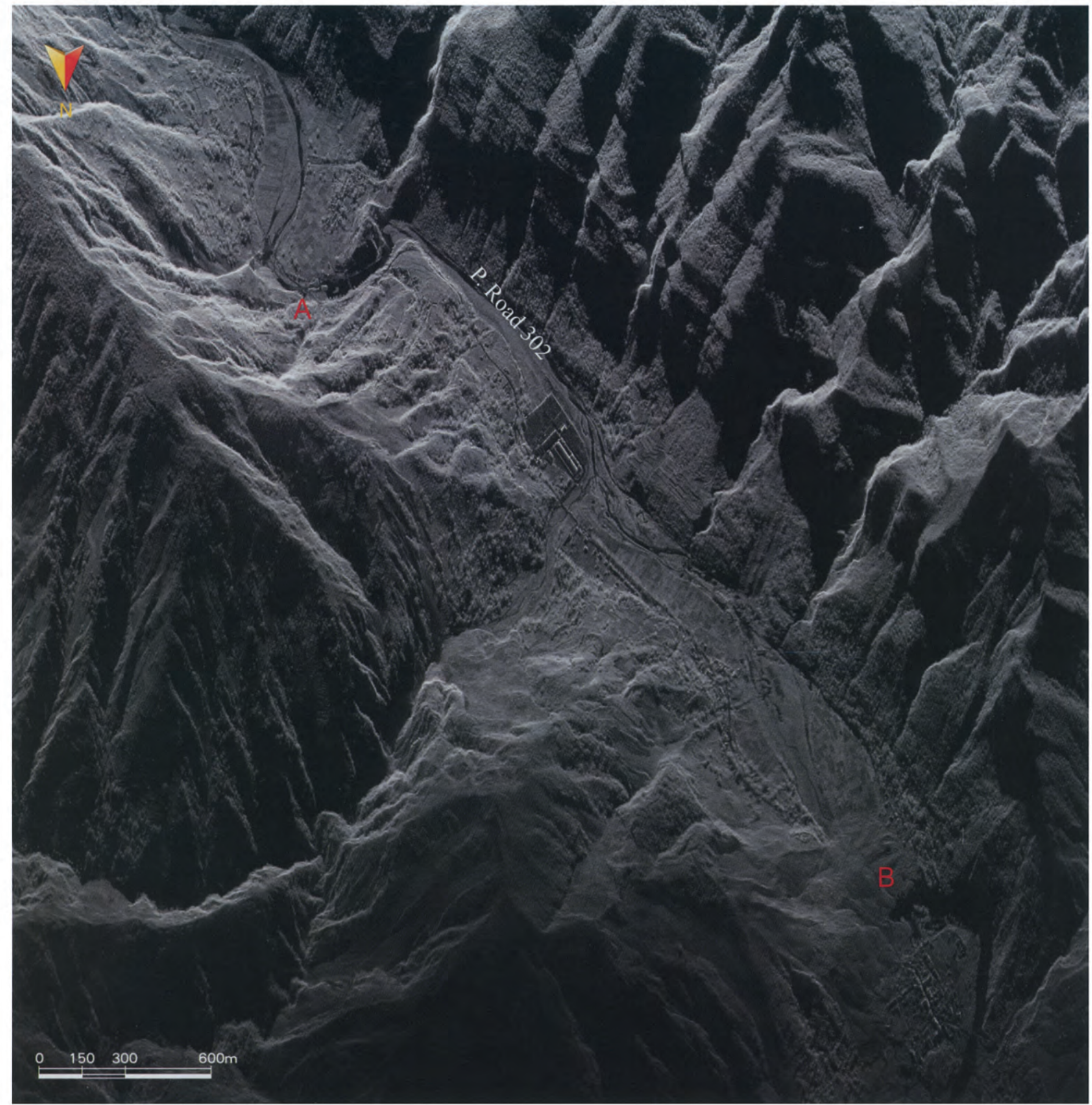

A Airborne radar image over the village of Laochang, in the town of Chenjiaba, in Beichuan County (May 25, 2008)

This image shows that there were several segments of Provincial Highway 302 destroyed by landslides in the town of Chenjiaba, northwest of Beichuan County. (A) The area between the villages of Xibahe and Laochang that was being threatened by the landslide along the road line. (B) An area blocked by a large landslide, located between the villages of Laochang and Chenjiaba.

188 I Atlas of Remote Sensing of the Wenchuan Earthquake 


\section{$\checkmark$ Airborne radar image over the town of Nanba, in Pingwu}

County (May 26, 2008)

This image shows that provincial highways S105, S205, and their bridges in the town of Nanba were destroyed by the devastating earthquake and the debris flow. (A) A bridge of S205 that collapsed. (B) S105 blocked by landslide. (C) A large landslide where S105 was seriously damaged. (D) A collapsed bridge downtown (see enlarged image).

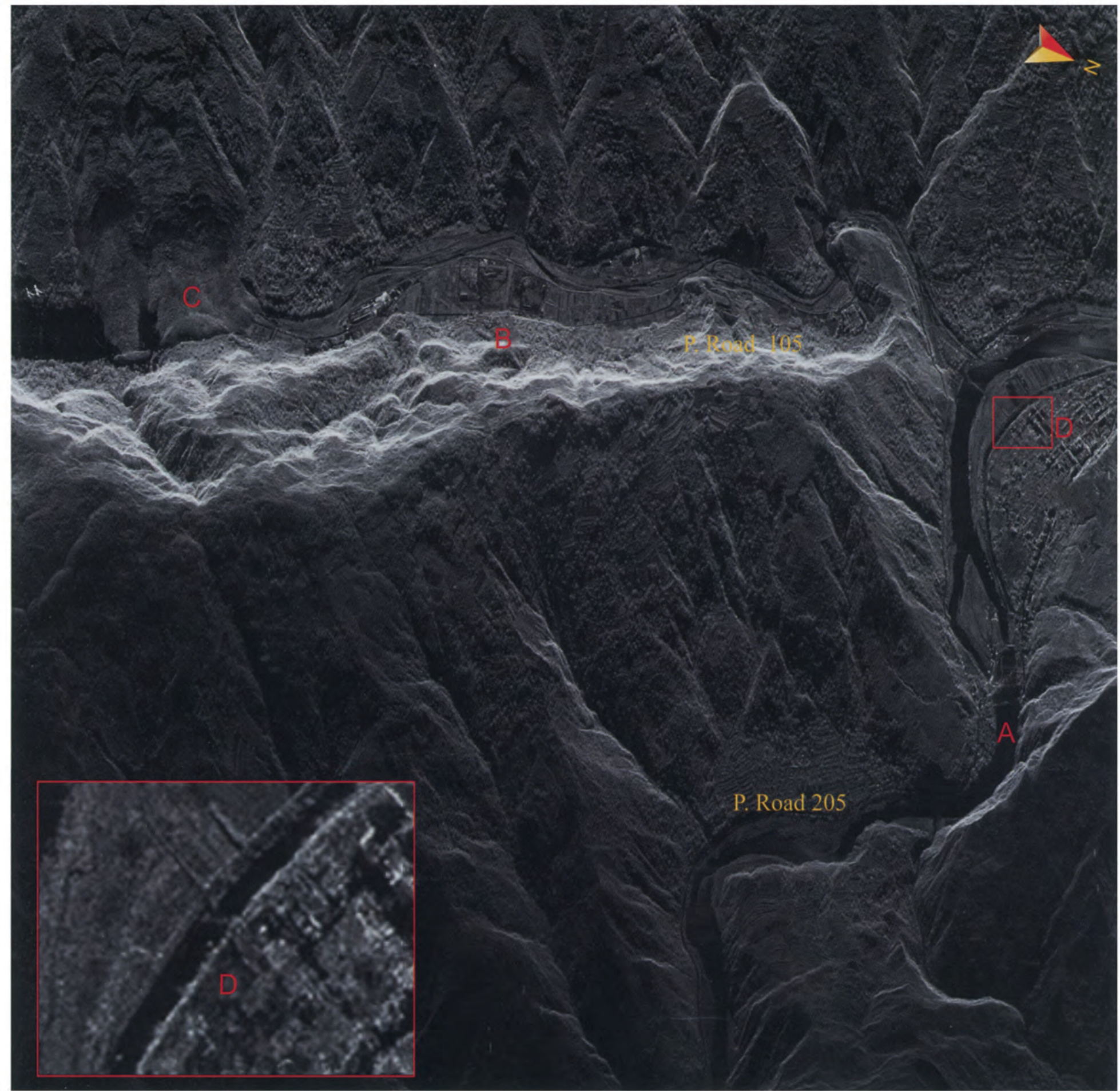


v Airborne radar image over the town of Xiaoyudong, in the cilty of Pengzhou (May 17, 2008)

This image shows the region from the town of Xiaoyudong to the town of Longmenshan that was affected by the earthquake and debris flow. Several parts of roads and railways through this region were ruined. (A) A road blocked by debris flow. (C) The collapsed Xiaoyudong Bridge (see the in situ photo), which lies in the northwest section of the city of Pengzhou.
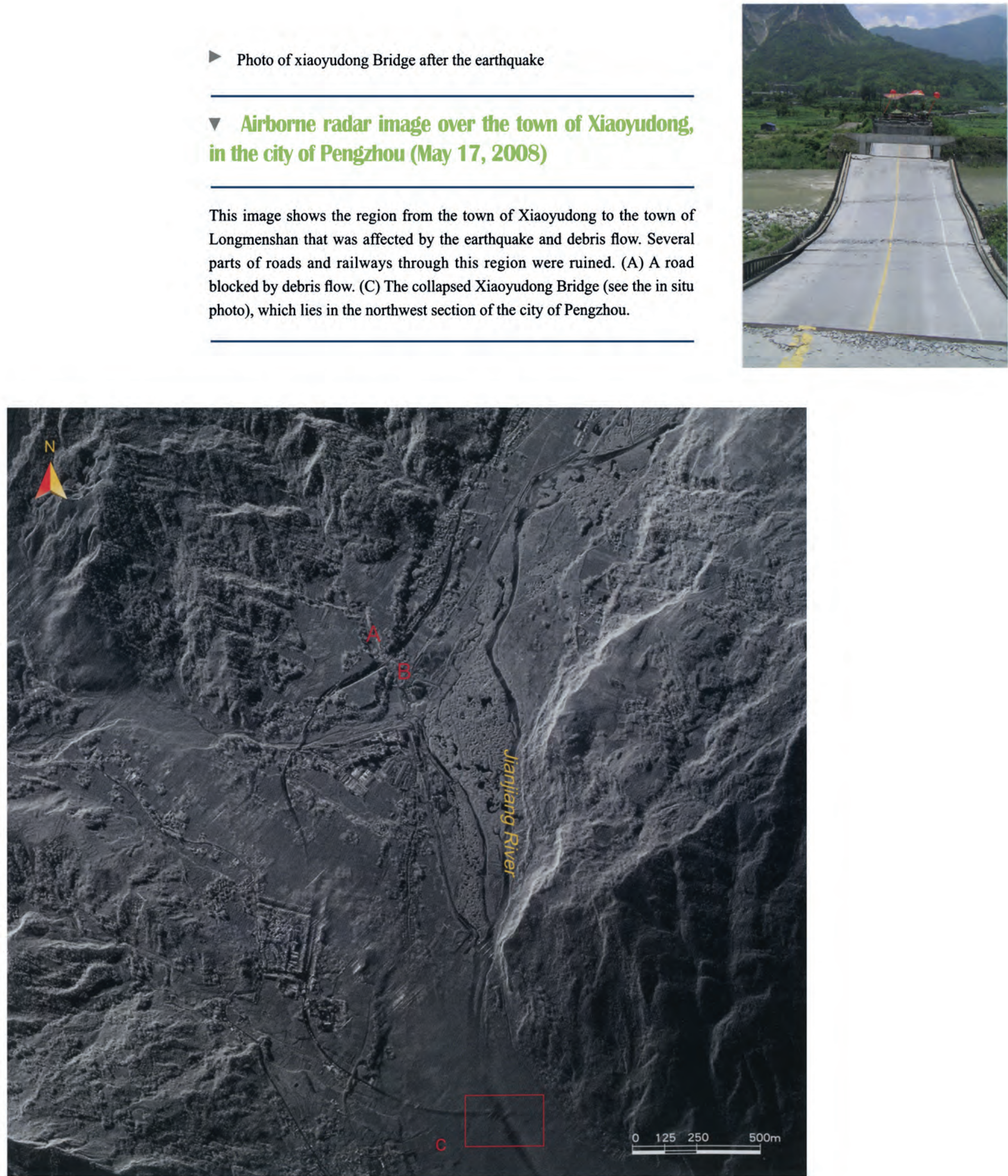

190 I Atlas of Remote Sensing of the Wenchuan Earthquake 


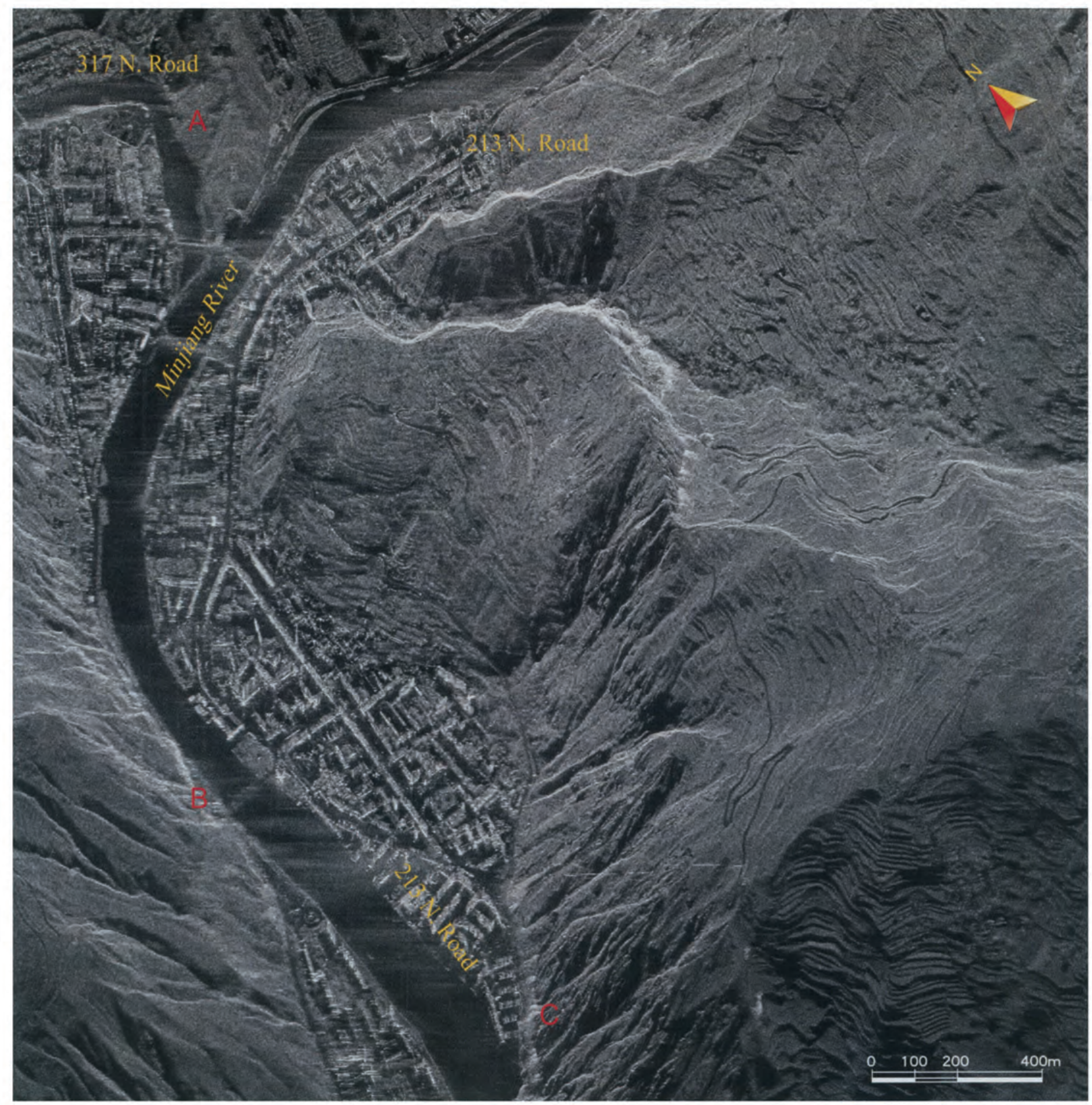

\section{$\checkmark$ Airborne radar image over the urban district of Wenchuan County (May 15, 2008)}

This image shows national highways G213 and G317 passing through Wenchuan County blocked by mountain landslides. (A) A damaged segment of G317, which leads to Lixian County. (B) Part of the highway that was blocked. (C) A portion of G213 that connects Wenchuan County with the city of Dujiangyan that was completely blocked by a huge landslide. 
- Airborne radar image over the Ziping pu Reservoir (May 17, 2008)

This image shows roads in the north and south of the Zipingpu Reservoir that were blocked by landslides. (A) and (B) Roadways located in the town of Longchi north of the reservoir that were both ruined by the landslides. (C) and (D) Portions of national highway G213 that were also blocked, which is the only road leading to Wenchuan County and Maoxian County
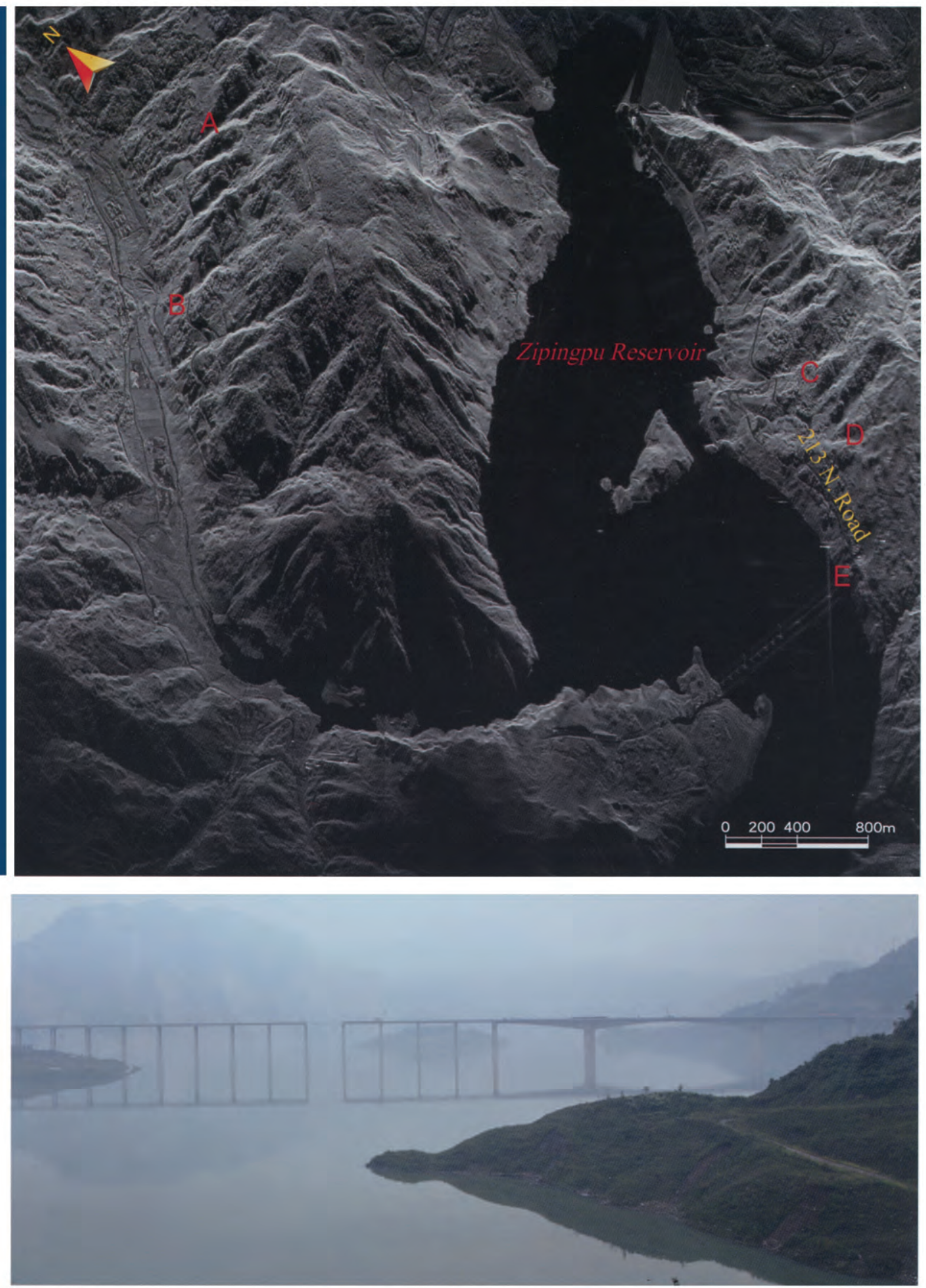

192 I Atlas of Remote Sensing of the Wenchuan Earthquake 


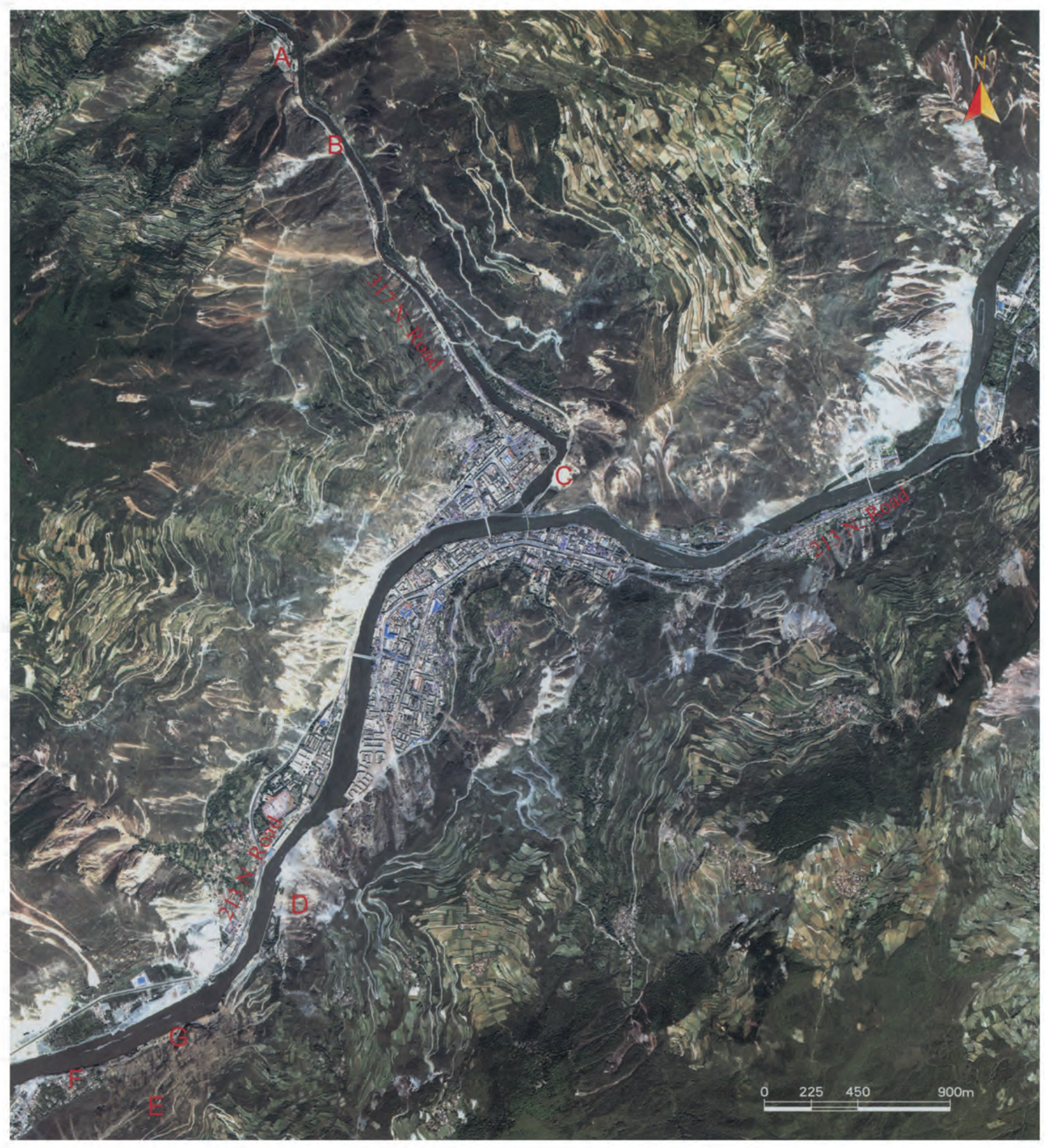

- IKONOS image over the urban district of Wenchuan County (May 18, 2008)

This image shows that many sections of national highways G213 and G317 through the county were destroyed by landslides triggered by the strong earthquake. (A) and (B) Segments of National Highway G213 were blocked. (C) A segment covered by debris. (D) and (E) Heavily damaged roadways. And the road from $(\mathrm{F})$ to $(\mathrm{G})$ was also blocked. 


\section{Road damage in the city of Jiangyou}
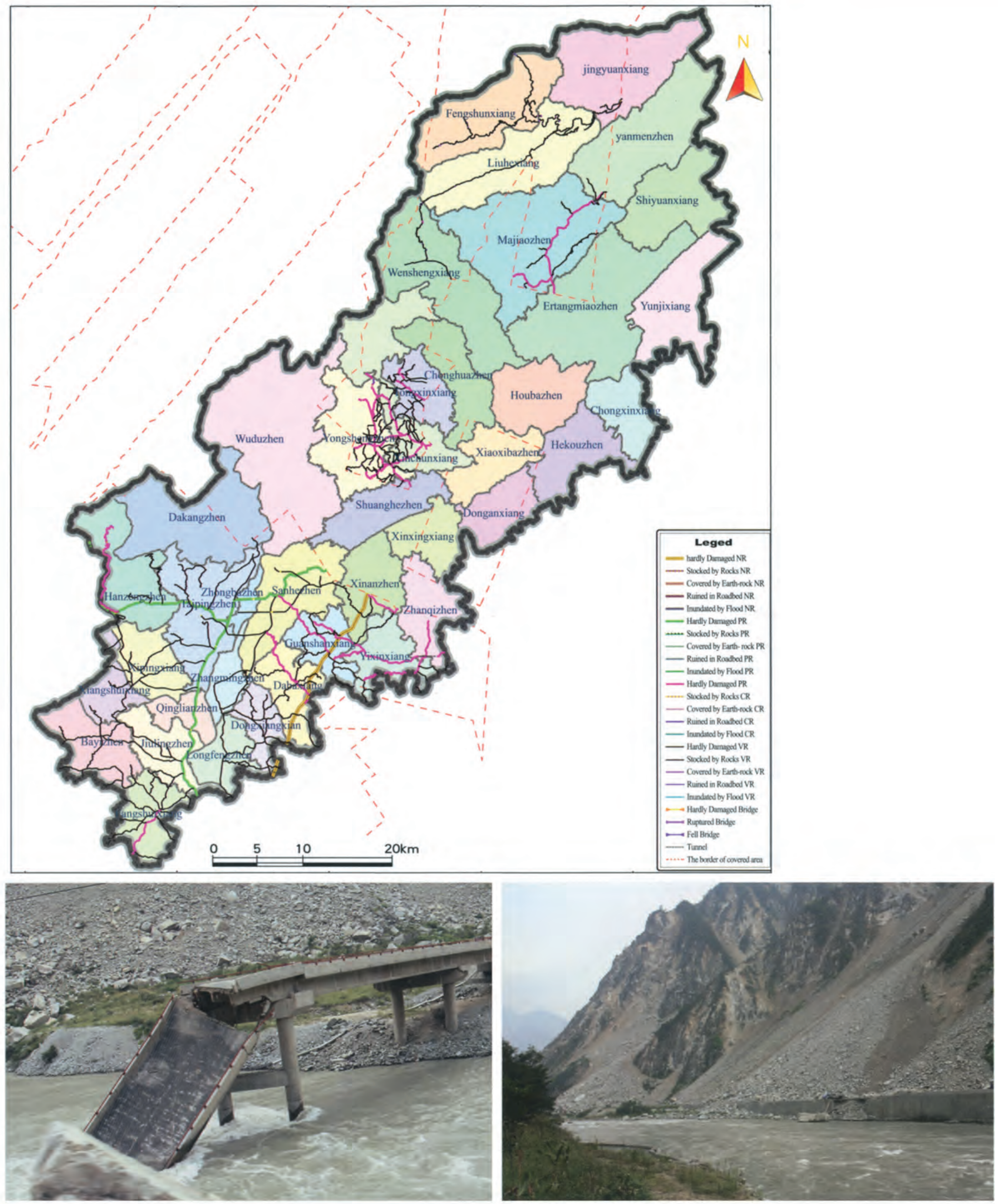

194 I Atlas of Remote Sensing of the Wenchuan Earthquake 


\section{Road damage in Qingchuan County}

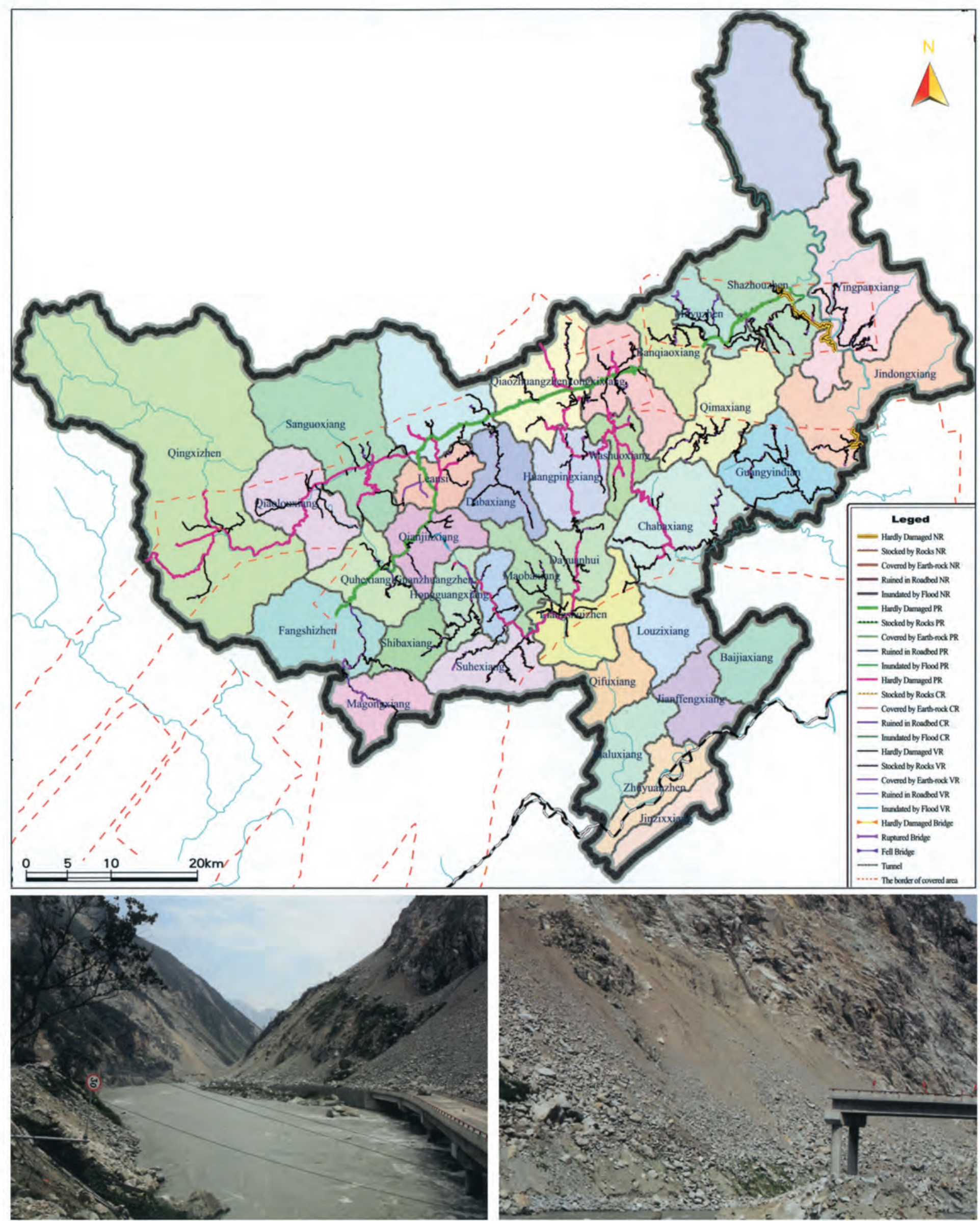




\section{1}

DESTROYED FARMLANDS AND FORESTS

Most of the farmlands and forests that were destroyed in the Wenchuan earthquake were located in the mountainous areas of the northwest Sichuan Basin in the Minshan Mountain Range between 2000 and $5000 \mathrm{~m}$ altitude. In this region, there are high mountains and many rivers, the main rivers being the Minjiang, Jianjiang, and Fujiang. Most of the river valleys are V shaped. This region is covered with high-density forests that contain a wide variety of trees and plants, encompassing more than 4000 species. The forest cover primarily comprises dense trees and shrubs, while sparse forest, younger forests, and reforested clear-cut areas make up less than $20 \%$ of the total forest. Larger areas of farmlands distributed in the mountains and hills of the earthquake region are mainly terraced. Moreover, local and national governments have established more than 20 natural conservation areas for giant panda protection in this region. About $40 \%$ of giant pandas around the country live in these conservation areas.

Many geological disasters, such as landslides, avalanches, rock debris flows, and mud-rock flows were triggered by aftershocks of the Wenchuan earthquake. These secondary geological disasters directly caused widespread ecological destruction of vegetation and farmlands. The secondary geological disasters are mainly distributed along human activity areas such as roads and rivers, deeply incised valleys that lie mainly along the rivers Minjiang, Jianjiang, Fujiang, and their tributaries. The cultivated environments around these farmlands were severely damaged, which will make recovery of cultivation very difficult. Landslides, avalanches, rock debris flow, and mud-rock flow present different characteristics of spectral and textural structure in the remote sensing images, so we can study changes of spectrum and texture to analyze and assess the degree of damage to the ecological environments of vegetation and farmlands.

This chapter presents various remote sensing images of destroyed farmlands, vegetation landscape, and panda habitats that are interpreted and analyzed using remote sensing satellite and aerial images collected from May 14 to May 28 , 2008. The counties that sustained the most damage to farmlands and vegetation were Wenchuan and Beichuan counties. 



\section{The beautiful terraces in Sichuan Province}

The terraces that are cultivated in Sichuan Province were developed during the Tang Dynasty over 1000 years ago. These terraces make agricultural development in the mountainous area possible. However, after the May 12 Wenchuan earthquake, many terraces were destroyed by secondary geological disasters such as landslides, mud-rock flows, rock debris flow, barrier lakes, and so on.
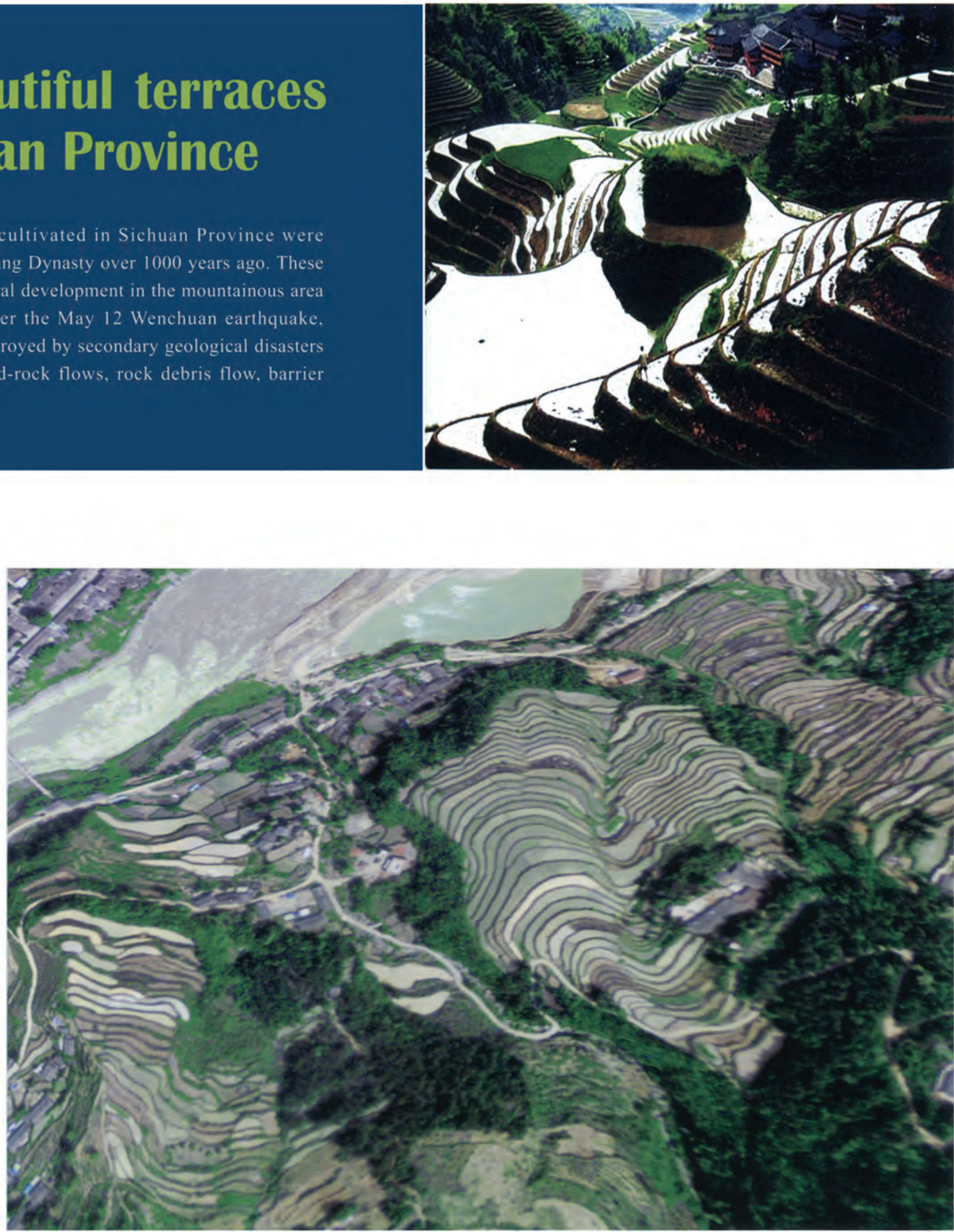

198 I Atlas of Remote Sensing of the Wenchuan Earthquake 


\section{Distribution of destroyed farmlands in counties hit by the Wenchuan earthquake}

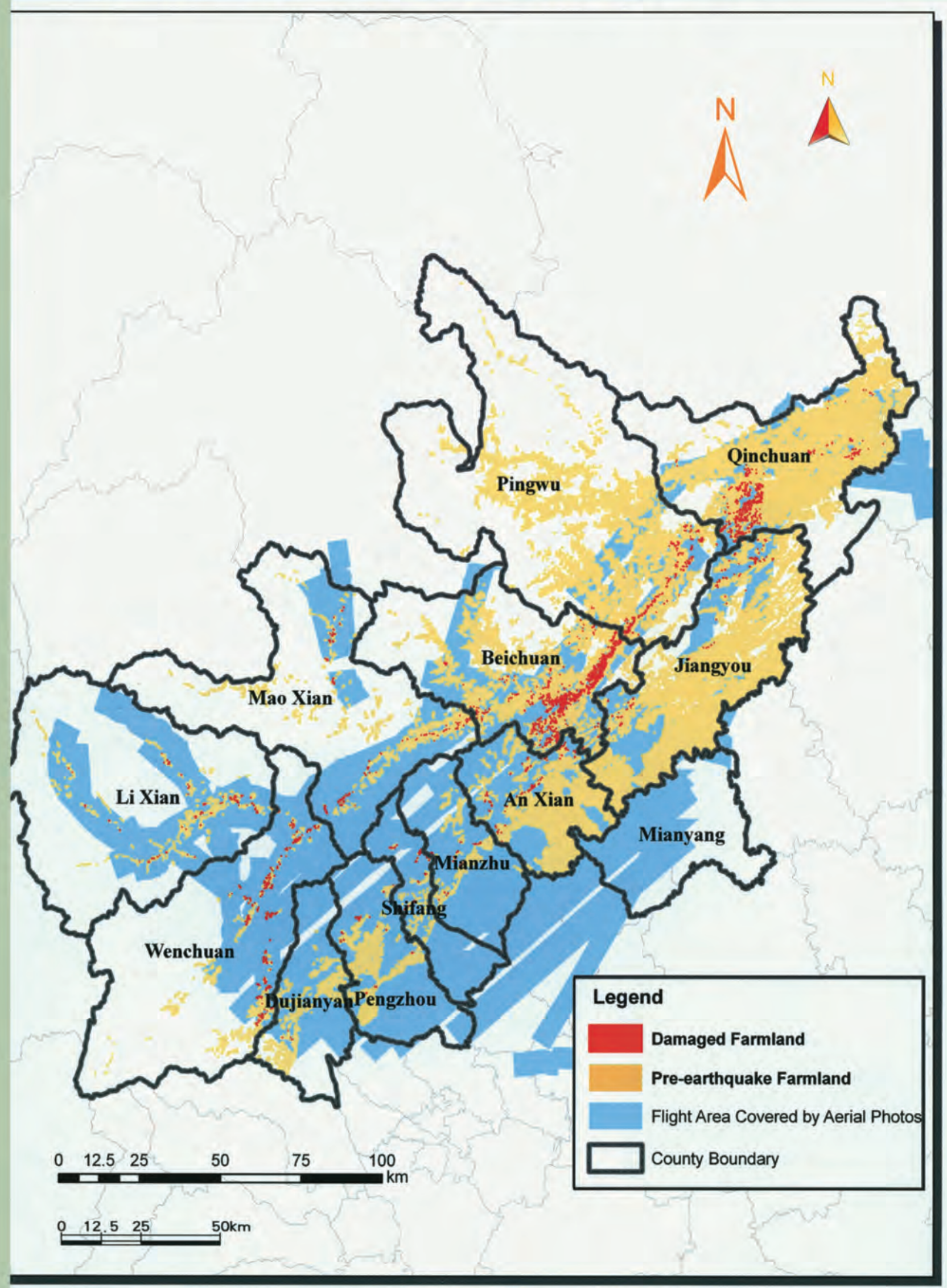

This map shows the distribution of destroyed farmlands in 13 hard-hit counties in the May 12 Wenchuan earthquake. We determined which counties were most affected by analyzing airborne images acquired from May 14 to May 28, 2008. This analysis indicated that Wenchuan, Beichuan, and Qingchuan counties suffered the greatest damages. 


\section{$\checkmark$ Terraces before and after the earthquake}

The terraces show gray or light-green colors, and the downslope area shows green color in the SPOT image on 9 May 2007. The farmlands that were buried or submerged by landslides, avalanches, or floods during the earthquake appear as white or gray colors in the airborne optical image on May 16, 2008. The earthquake not only destroyed farmlands, but also changed the cultivation environment. (A), (B), and (C) marked in the image (right) indicate the locations of destroyed terraces.

SPOT 5 image (May 9, 2007) before the earthquake

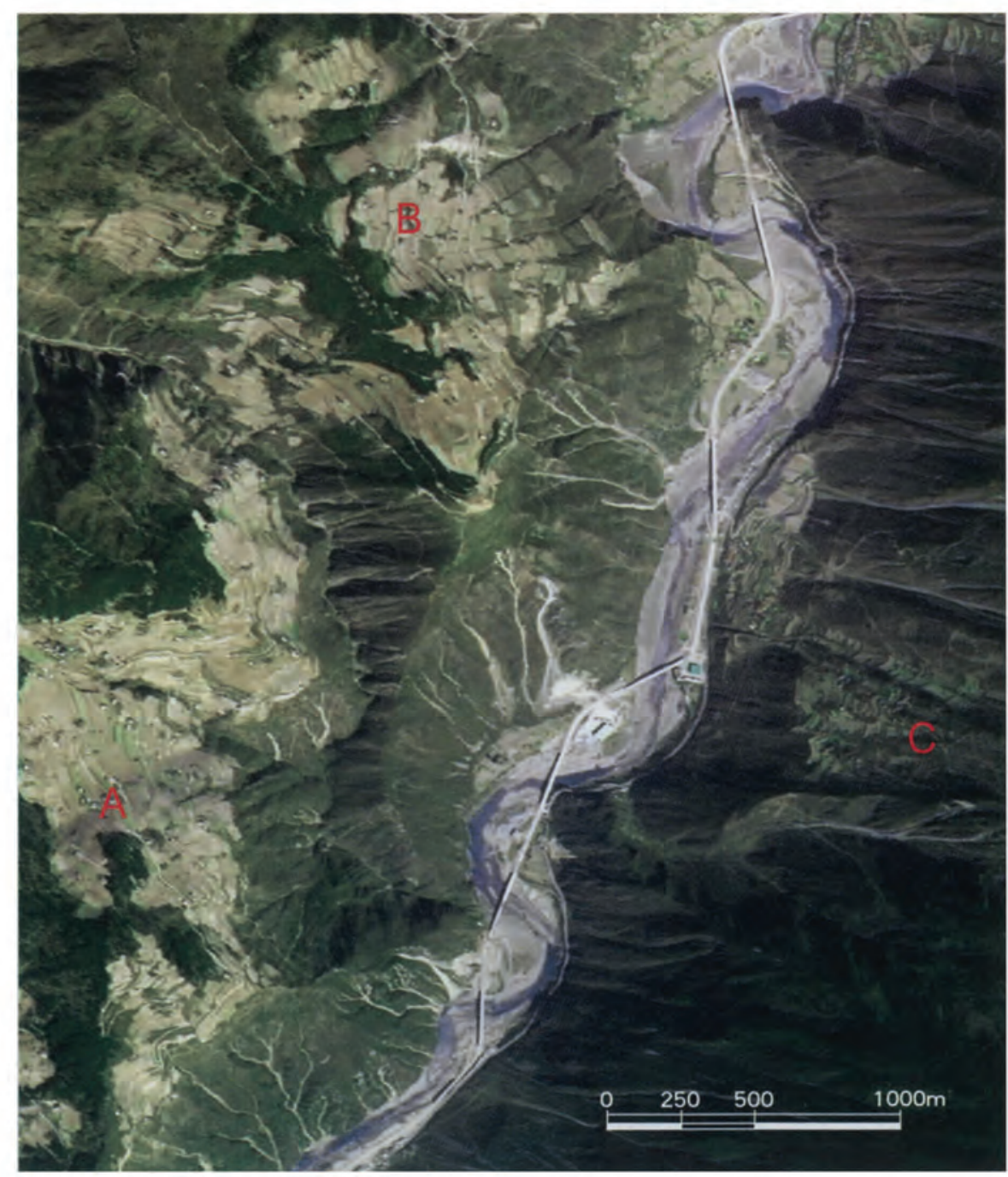

Airborne optical image (May 16, 2008) after the earthquake

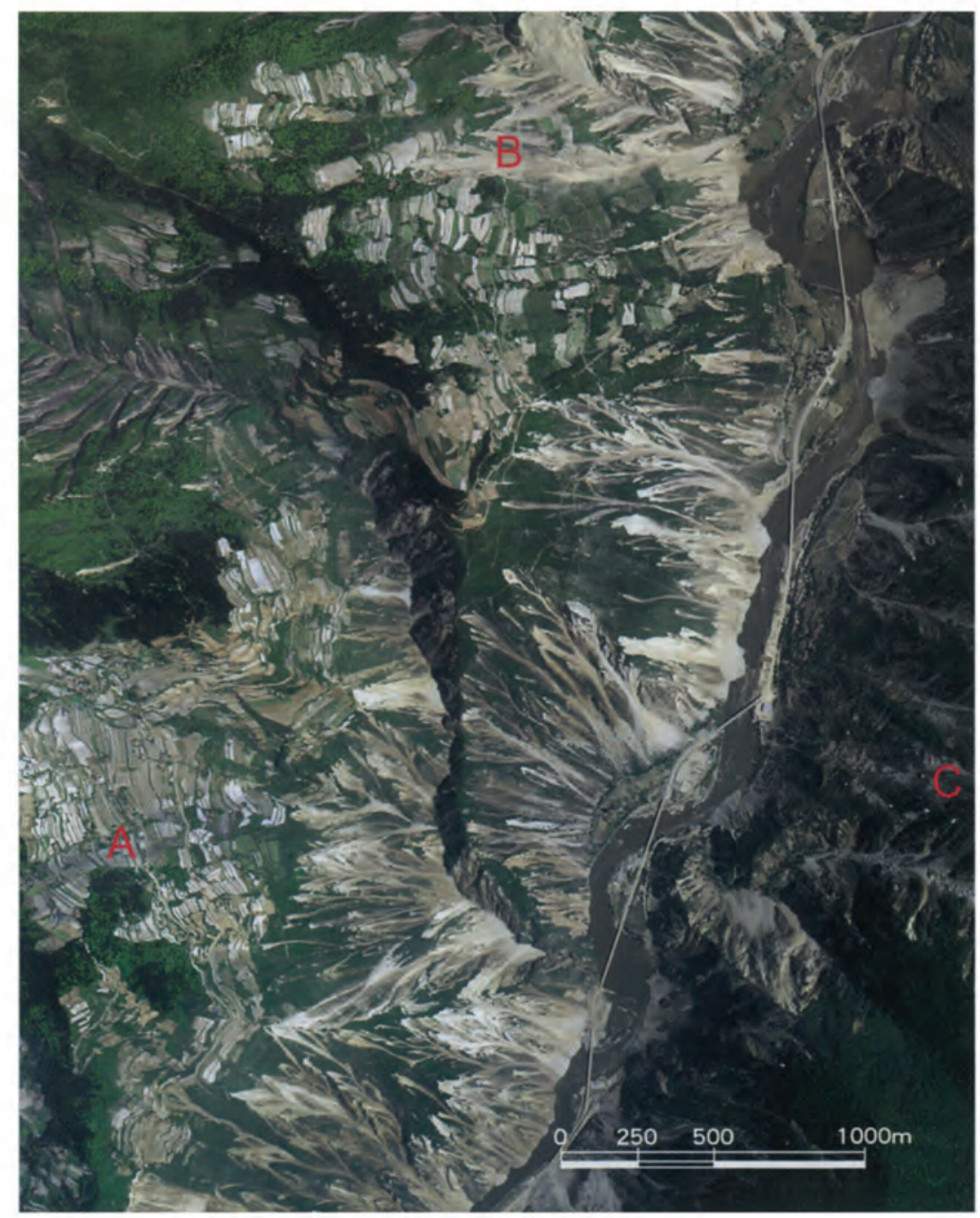

200 I Atlas of Remote Sensing of the Wenchuan Earthquake 


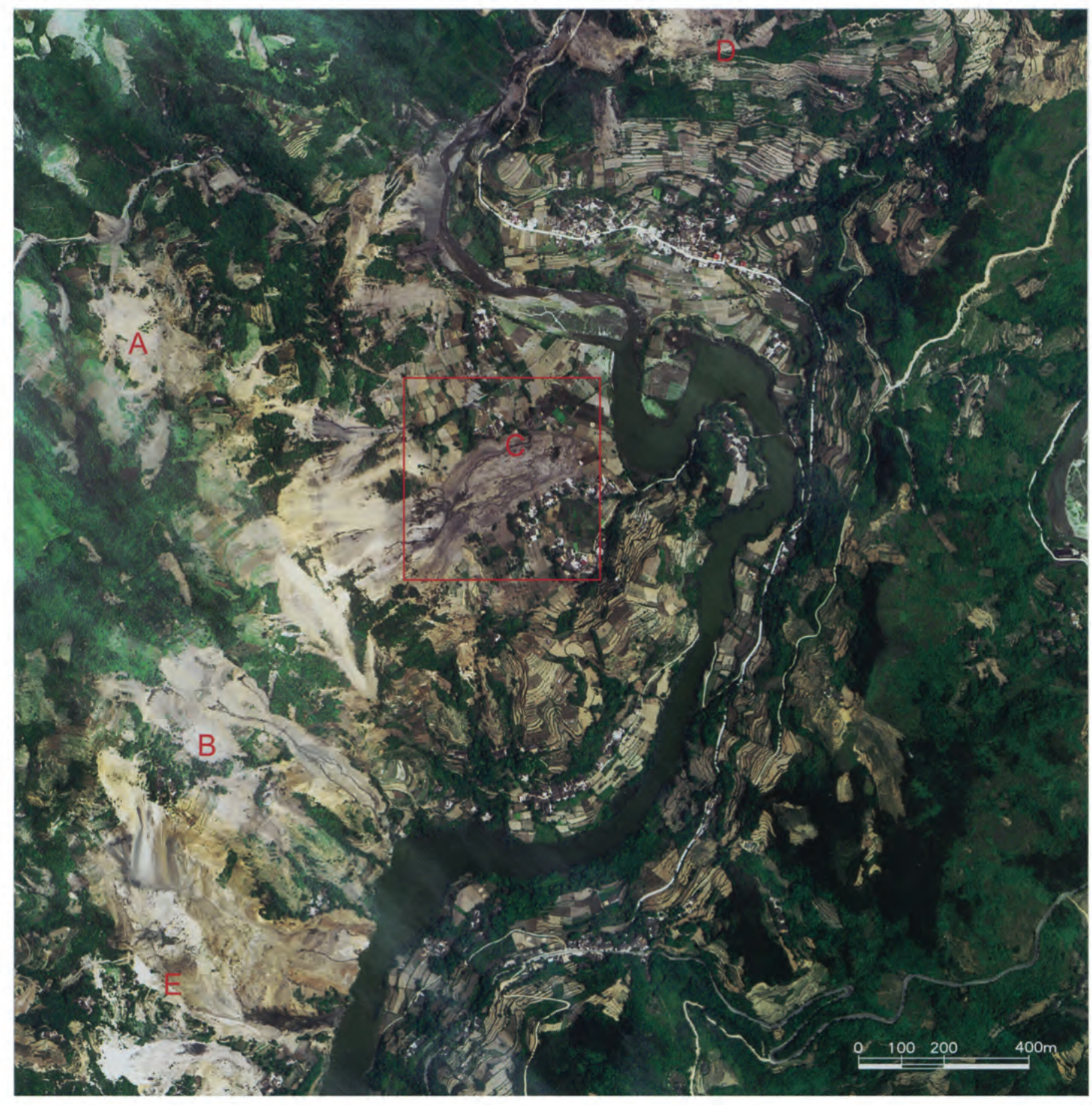

$\Delta$ Airborne optical remote sensing image of the town of Xupingba

Data were acquired on May 28, 2008. (A), (B), (C), (D), and (E) indicate destroyed terraces, and the red frame shows the location of the close-up image in the lower right-hand corner.

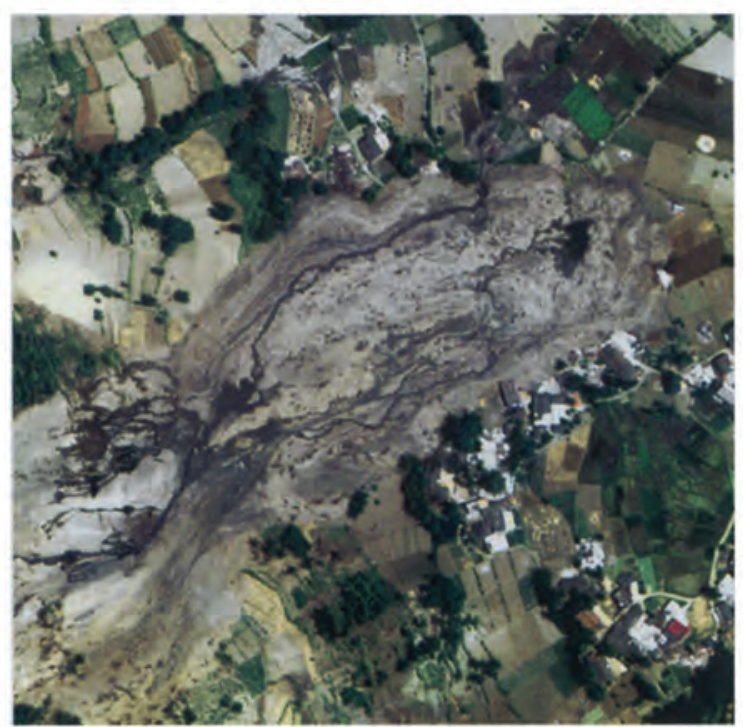

Destroyed Farmlands And Forests ～ 201 


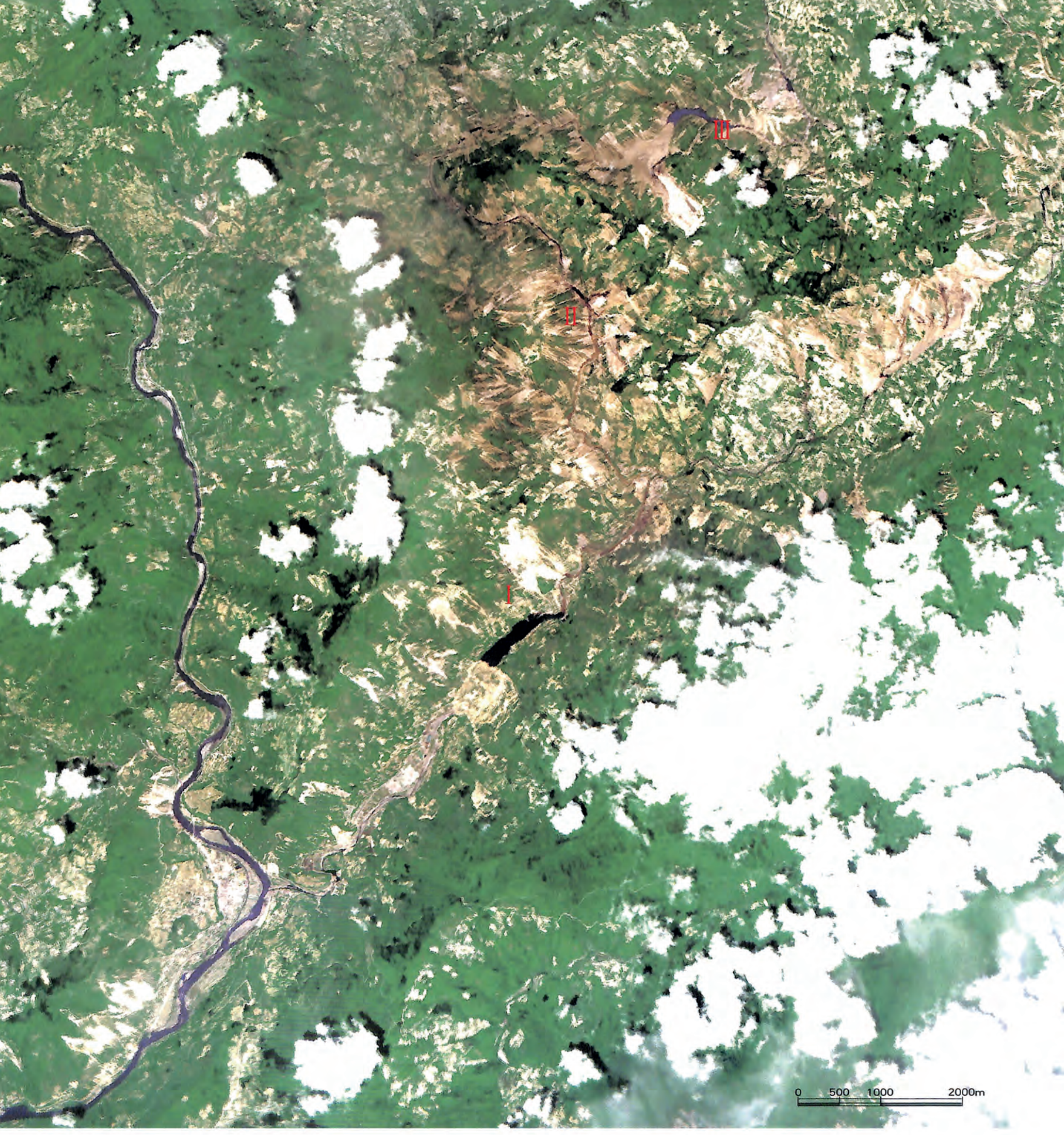

202 I Atlas of Remote Sensing of the Wenchuan Earthquake 


\section{Pingwu County}

This SPOT 5 image was acquired on May 16, 2008. Secondary geological disasters such as landslides, mud-rock flows, and so on (shown as the yellow or yellow-black in the image), in the town of Nanba and the town of Shuiguan, caused many barrier lakes to appear. (I), (II), and (III) marked in this image indicate the locations of the following three airborne color images.

V Image I: airborne optical remote sensing image acquired on May 28, 2008 around the village of Tangjialoa, in Pingwu County

(A), (B), (C), and (D) indicate the locations of destroyed farmlands

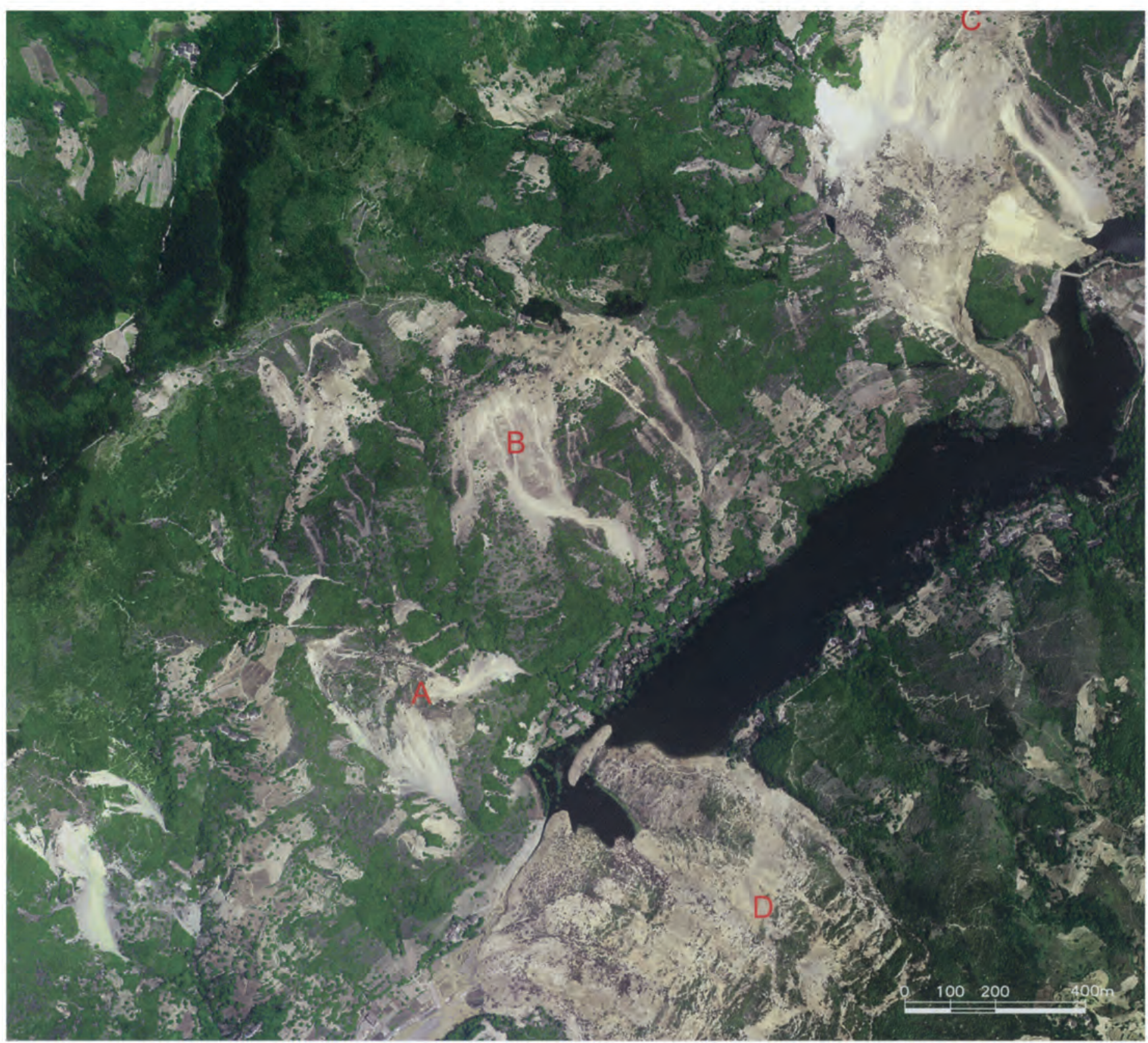




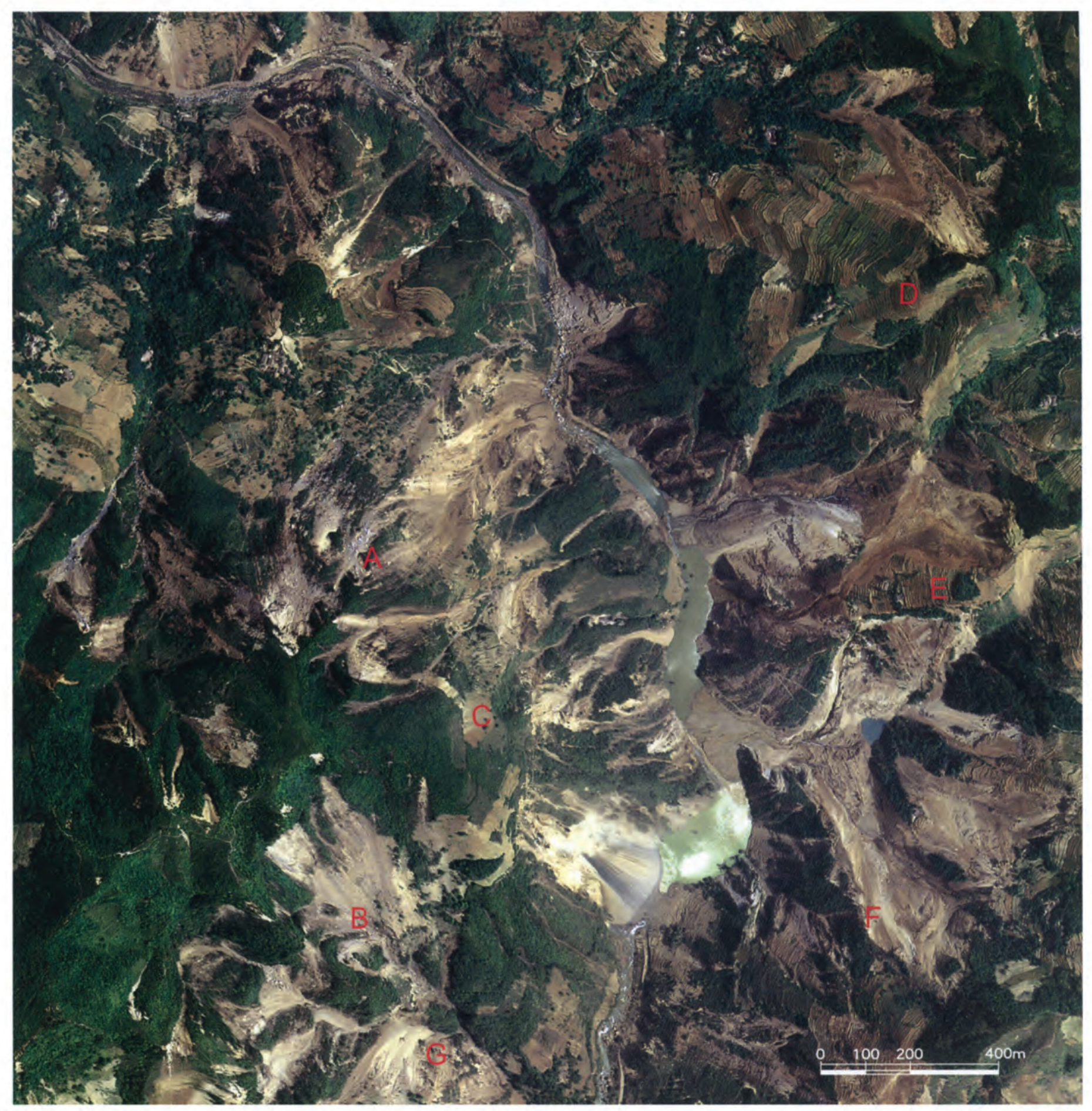

A Image II: airborne optical remote sensing image acquired on May 28, 2008 of the village of Liangjiasan, in Pingwu County

(A), (B), (C), (D), (E), (F), and (G) indicate the locations of destroyed farmlands. 
v Image III: airborne optical remote sensing image acquired on May 28, 2008 around the village of Leidashu, in Pingwu County

(A), (B), (C), (D), (E), (F), and (G) indicate the locations of destroyed farmlands.

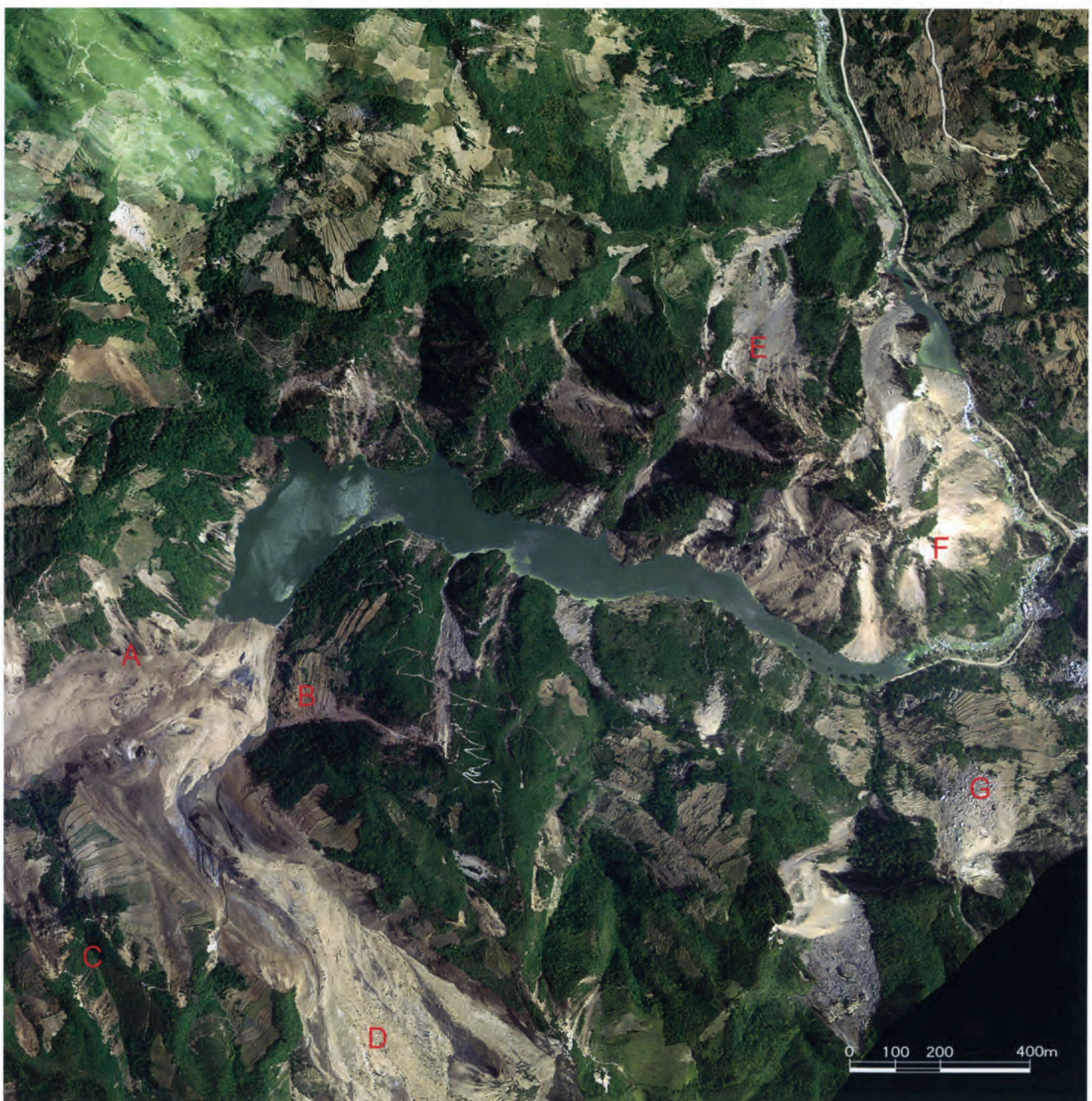



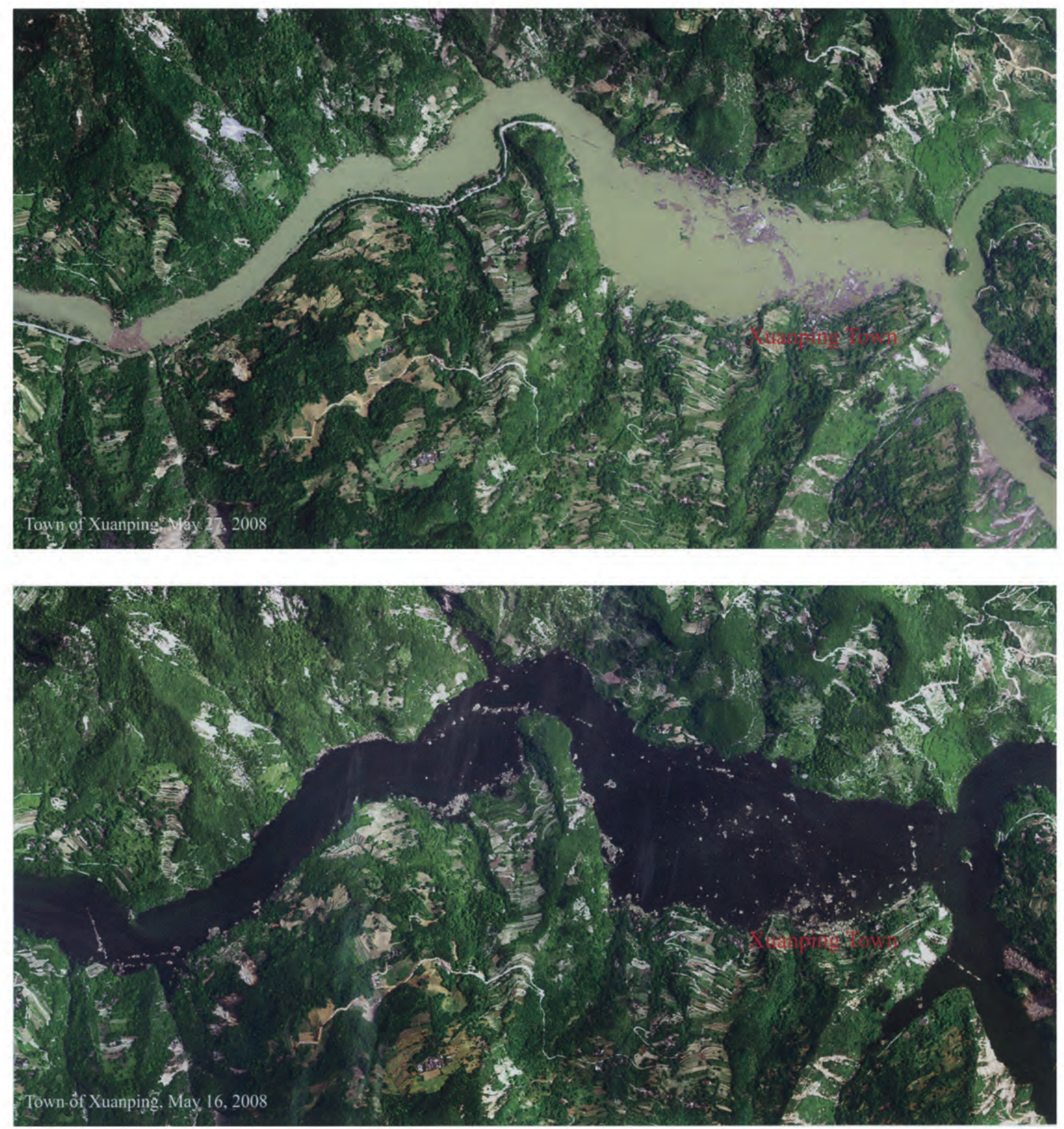

\section{\ The inundated farmlands of Beichuan County}

The two images above were acquired on May 16, 2008 and May 28, 2008, respectively, after the earthquake. Comparing these two images shows that many farmlands and houses of the town of Xuanping in the upper reaches of the Jianjian River were inundated by water, which was caused by the barrier lakes of Tangjiashan in Beichuan County.

206 I Atlas of Remote Sensing of the Wenchuan Earthquake 


\section{Destroyed landscape in the Minjiang River Valley}

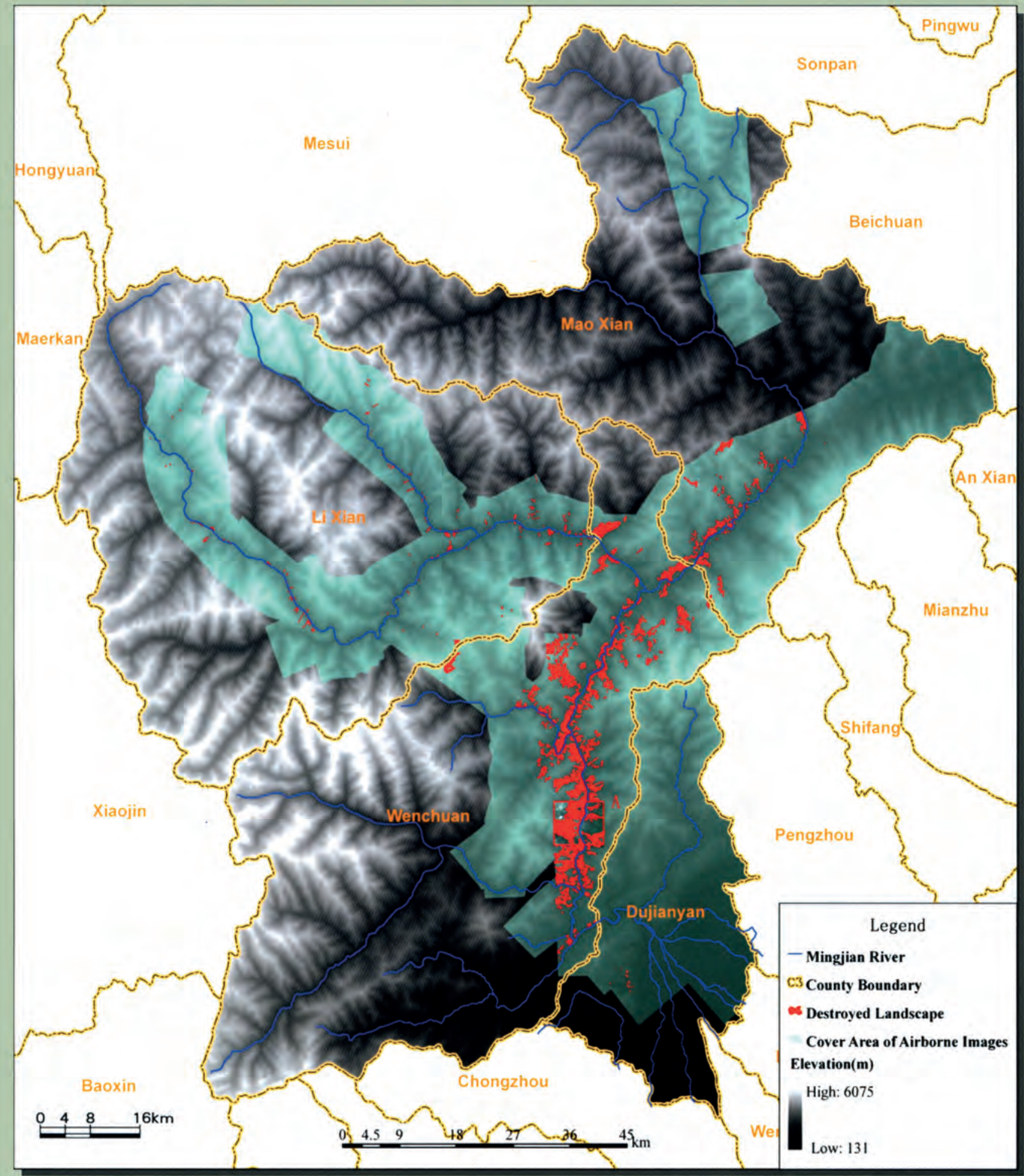

This is a composite remote sensing image of destroyed landscape that was created by overlaying digital terrain elevation generated from the airborne imagery onto an image of the area along the Minjiang River.

The image shows that the destroyed landscape is distributed along the valleys of the Minjiang, Jianjiang, and Fujiang rivers and their tributaries. The landscape destruction was caused by secondary geological disasters after the earthquake, including landslides, avalanches, and rock debris flows. The landscape changes will lead to the changes in the local ecological environment. Assessment of the landscape changes after the earthquake can provide scientific support for developing environmental reconstruction programs during the disaster recovery efforts.

There is a red rectangle in the lower left marked (A), showing the location of the remote sensing image in the typical natural landscape changes shown on the next page.

Destroyed Farmlands And Forests । 207 


\section{Destroyed landscape caused by secondary geological disasters}

In Wenchuan County, large areas of forests, farmlands, and grass were destroyed by secondary geological disasters that followed the earthquake. Comparing the SPOT 5 images on May 9, 2007 (before the earthquake) with the airborne images of the same region on May 16, 2008 (after the earthquake), it is obvious that the Wenchuan earthquake annihilated the original surface vegetation.

The images below are three-dimensional natural landscapes derived from images and Digital Elevation Models (DEM) viewing to the west of Xingwenpin of Yinxing Township. Comparing the characteristics of these four images shows the extent of landscape destruction.
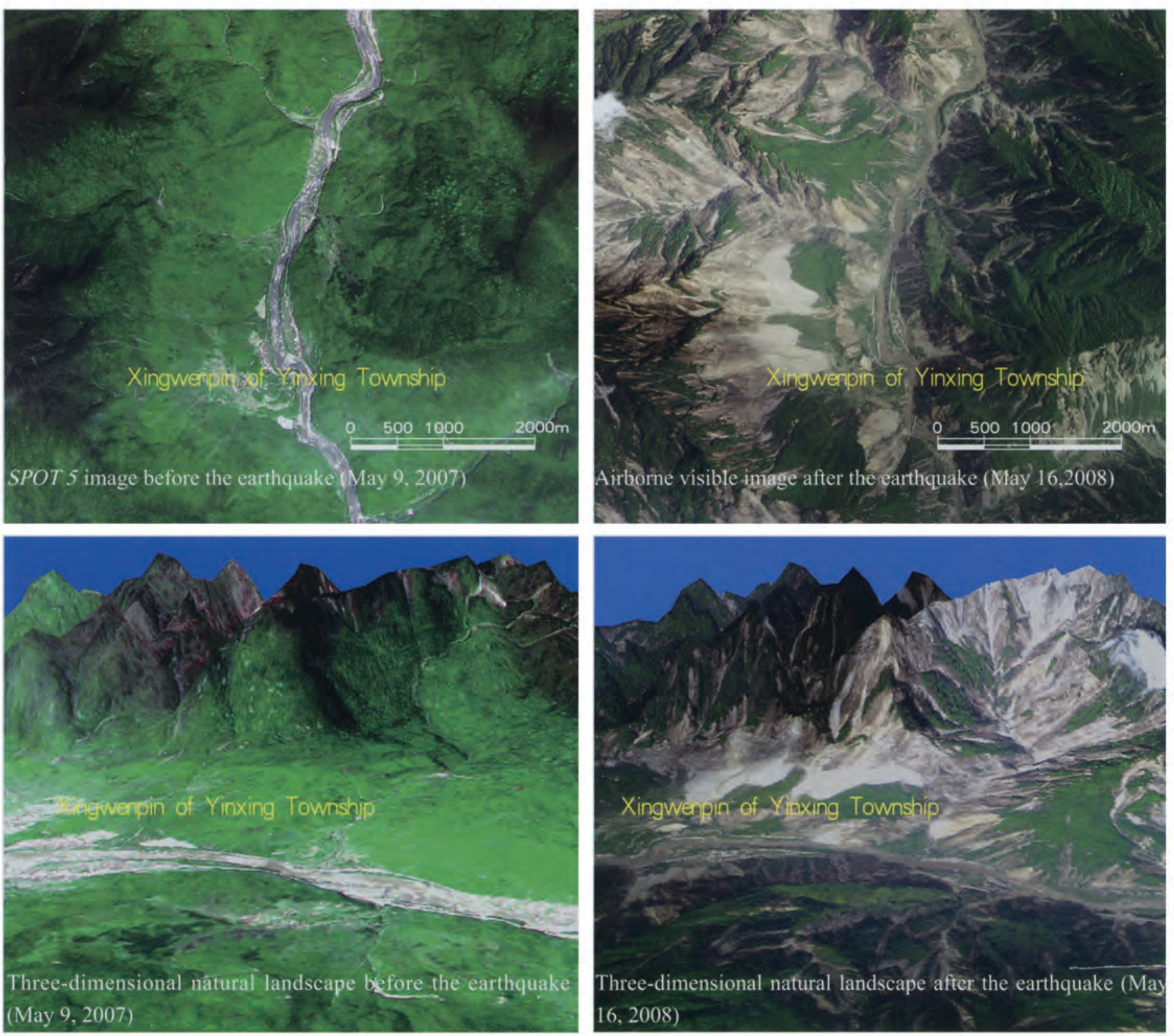

208 I Atlas of Remote Sensing of the Wenchuan Earthquake 

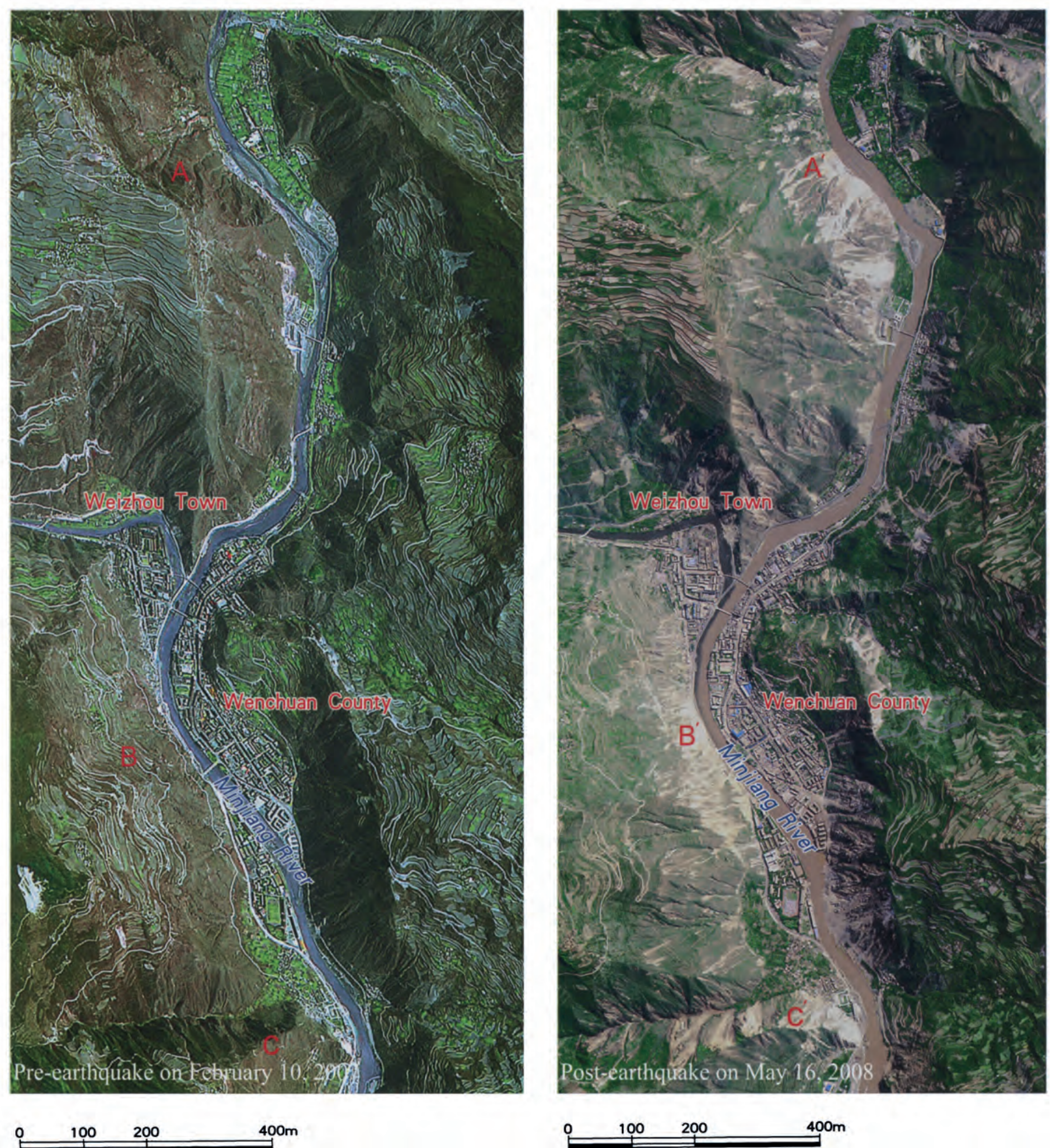

\section{Secondary geological disasters around Wenchuan County}

A SPOT 5 image before the earthquake created on February 10, 2007 appears on the left. An airborne visible image from after the earthquake acquired on May 16, 2008 appears on the right. (A), (B), and (C) in the left-hand SPOT image and the same locations $\left(\mathrm{A}^{\prime}\right),\left(\mathrm{B}^{\prime}\right),\left(\mathrm{C}^{\prime}\right)$ in the right image indicate the severely damage to the landscape caused by landslides, mud-rock flows, and rock debris flows. 


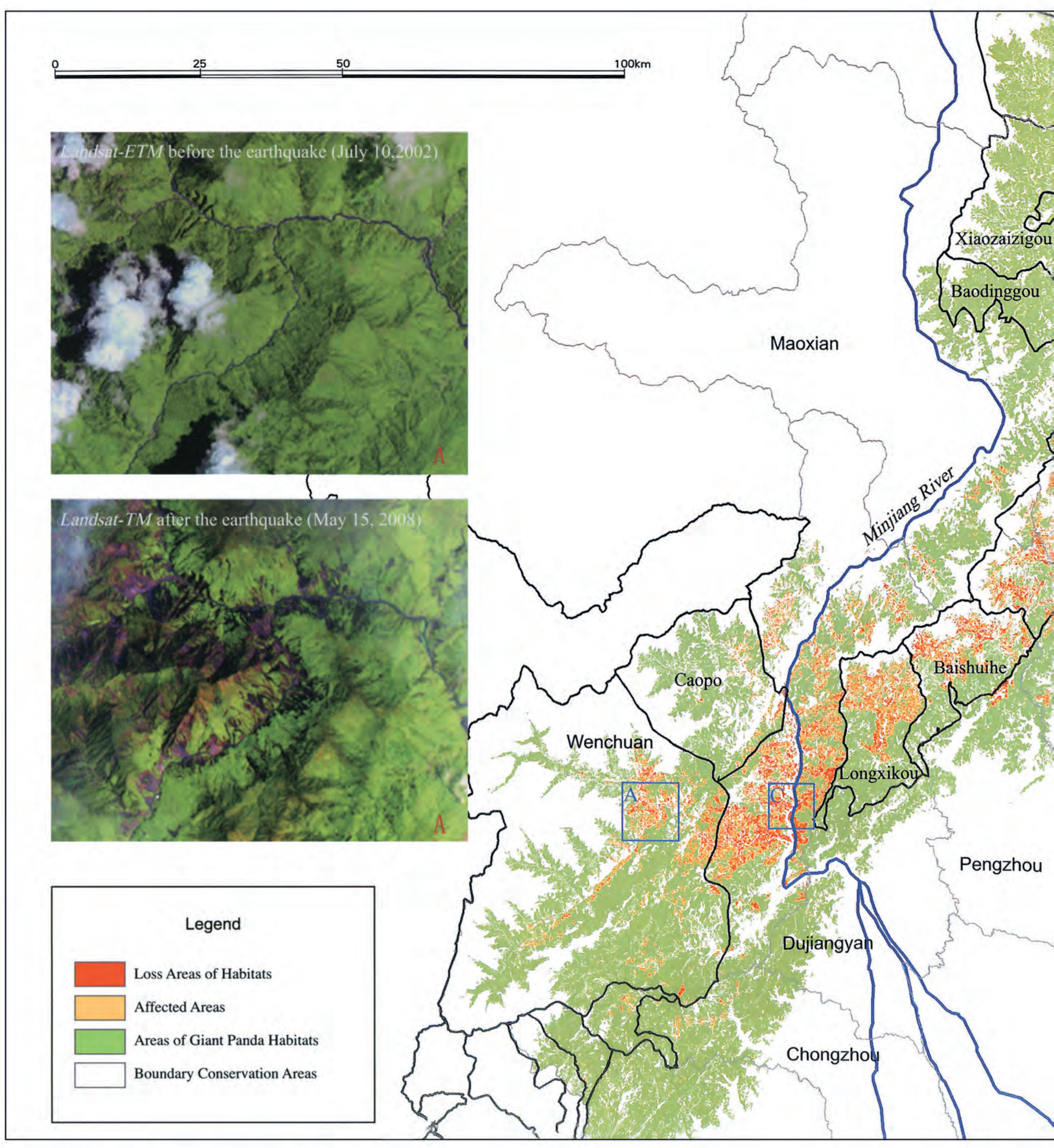

210 I Atlas of Remote Sensing of the Wenchuan Earthquake 


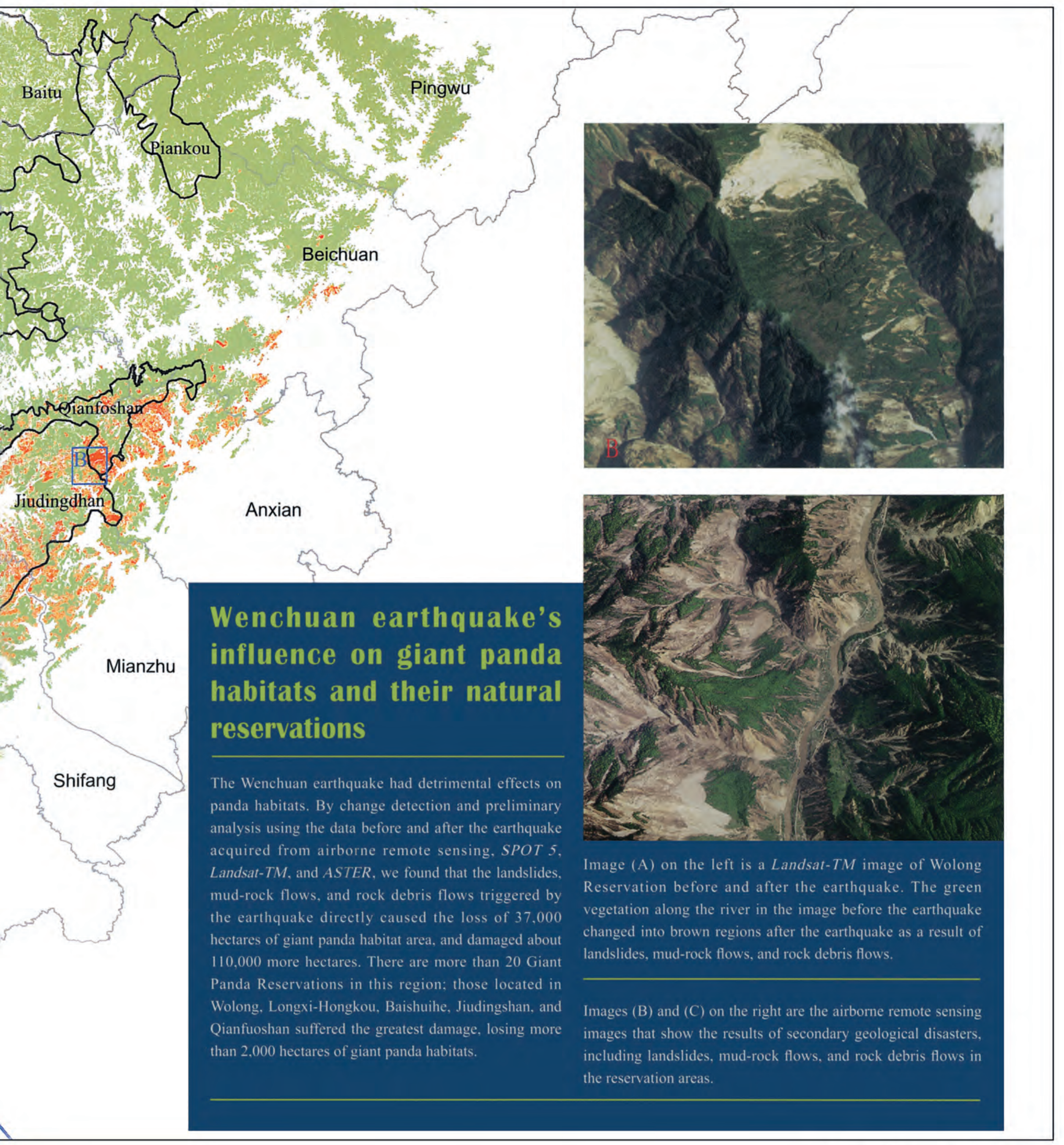




\section{Chapter}

\section{DEMOLISHED INFRA-STRUCTURE}

Not only did the earthquake cause significant losses in human lives and property, it also caused hidden trouble and damage to many infrastructures. After the Wenchuan earthquake, many important infrastructures in quake-hit areas were demolished, and hydrological engineering systems and mining construction areas were particularly badly damaged. Geological disasters, such as landslides, debris flows, and collapse, caused serious problems for these infrastructures. Some reservoir dams were buried by landslides, or damaged by debris flows, and the earthquake threatened dam security. Barrier lakes in the upper reaches of dam reservoirs filled some dams with mud and sands, and the dam system buildings were flooded and damaged, shutting down dam operations. Although some dams were not damaged because they were positioned on stable ground, the landslides, debris flows, and collapse that occurred near the reservoirs weakened the stability of the reservoirs. Moreover, some mining area construction faced severe losses because mines were blocked and mine buildings and houses were damaged.

Analysis of airborne and space-borne remote sensing images revealed many demolished infrastructures. This chapter shows the damage to important hydrological engineering systems and mining construction areas, including the Taipingyi power station in the town of Yinxing in Wenchuan County, the Shapai power station in the town of Caopo in Wenchuan County, the Futangba power station and Banpocun power station in the town of Miansi in Wenchuan County, the town of Nanxin power station in Maowen County, the Kuzhuba power station in the town of Qushan in Beichuan County, the Zipingpu Reservoir in the city of Dujiangyan, and the Jinhe Phosphate Mine in the town of Hongbai in the city of Shifang. Moreover, because radar images are sensitive to high-voltage wire transmission towers, we detected the towers affected by the landslides near National Highway 317 in western Wenchuan County and warned that the landslide could cause the towers to collapse and could interrupt power transmission. 


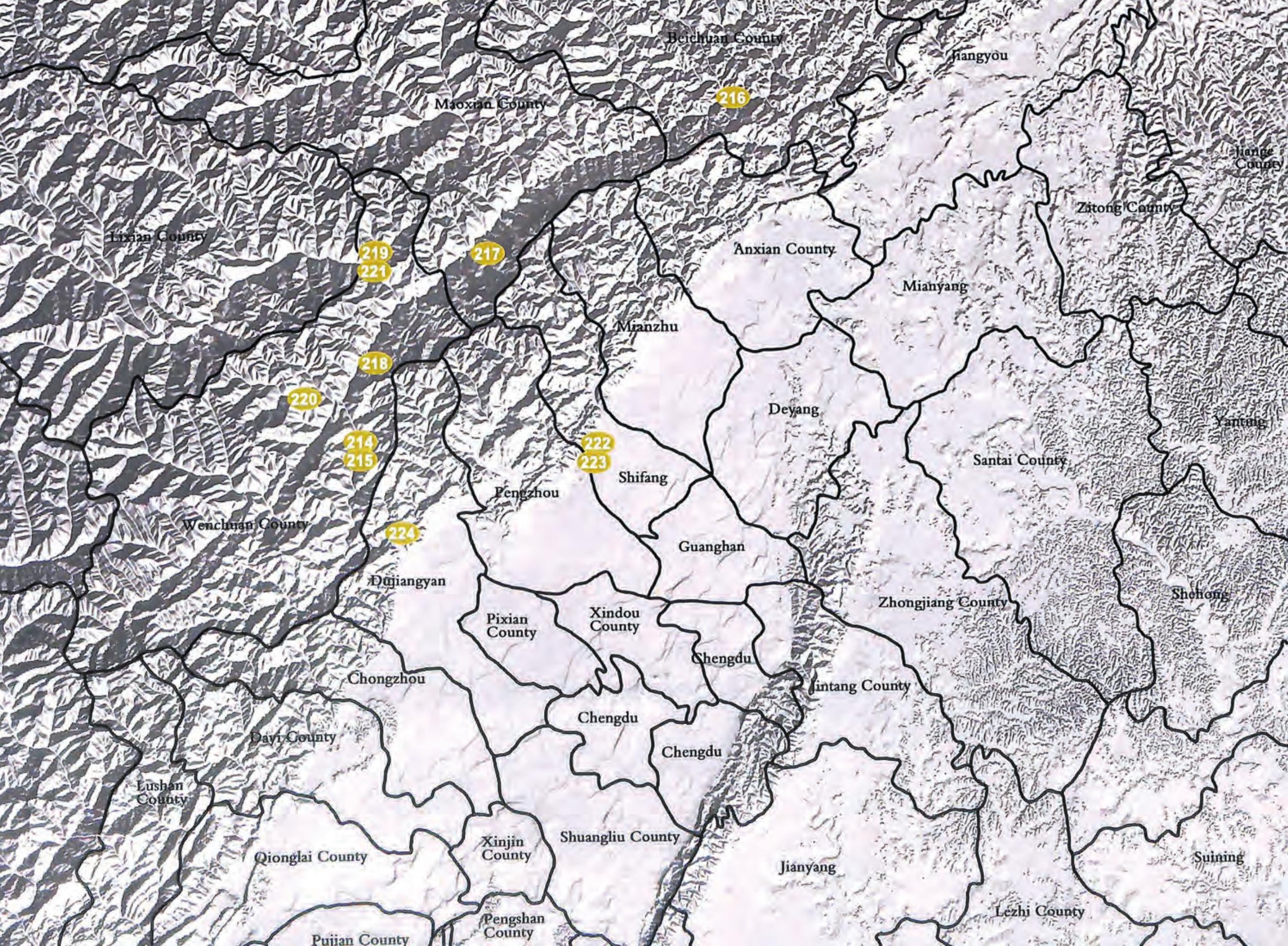




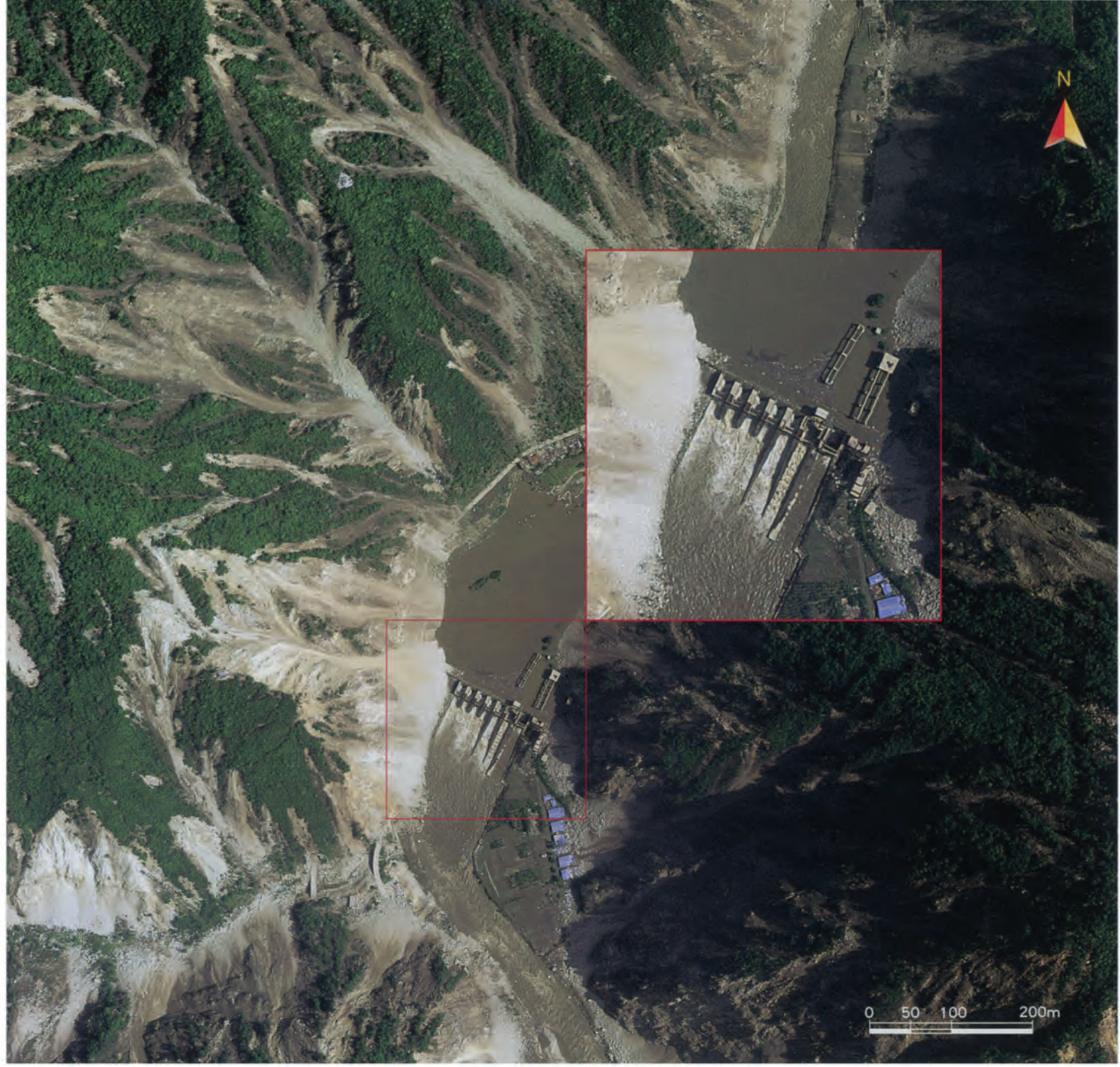

A Airborne optical remote sensing image of Taipingyi power station in the town of Yinxing, in Wenchuan County

This image, acquired on May 15, 2008, shows the Taipingyi power station, which was damaged by the landslides. A large landslide with a length of $530 \mathrm{~m}$ and a width of $500 \mathrm{~m}$ to the left of the station is threatening dam security. SPOT 5 remote sensing image of the Taipingyi power station
in the town of Yinxing, in Wenchuan County

This image, acquired on December 1, 2006, shows the Taipingyi power station and dam functioning properly before the earthquake. 


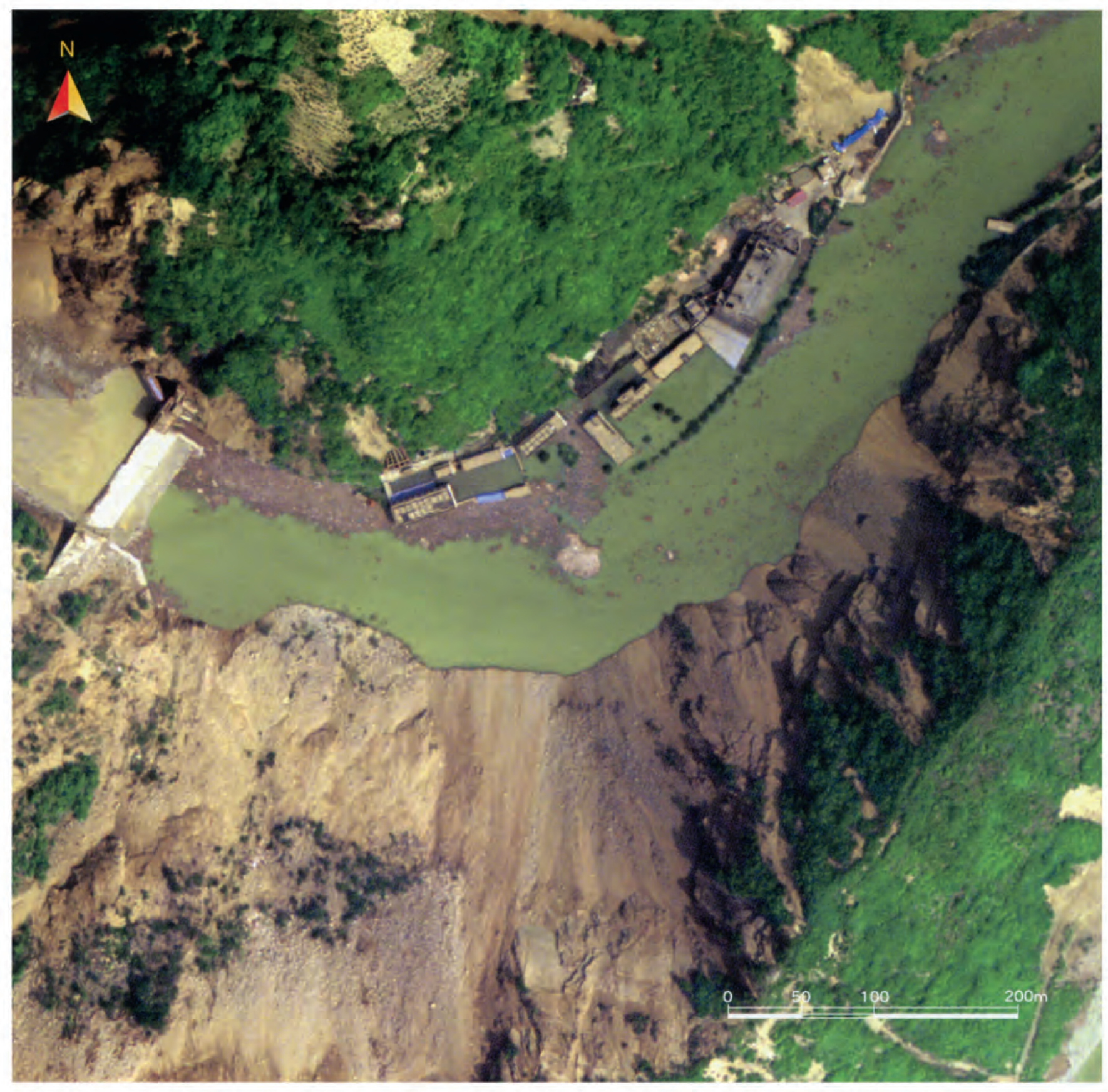

A Airborne optical remote sensing image of the Kuzhuba power station in the town of Qushan, in Beichuan County

This image, acquired on May 16, 2008, shows the Kuzhuba power station affected by the barrier lake, Mud and sand filled up the dam, and the station buildings were flooded.

- Airborne optical remote sensing image of the power station in the town of Nanxin, in Maoxian County

This image, acquired on May 15, 2008, shows damage to the dam and the power station, which were inundated with water after the earthquake.

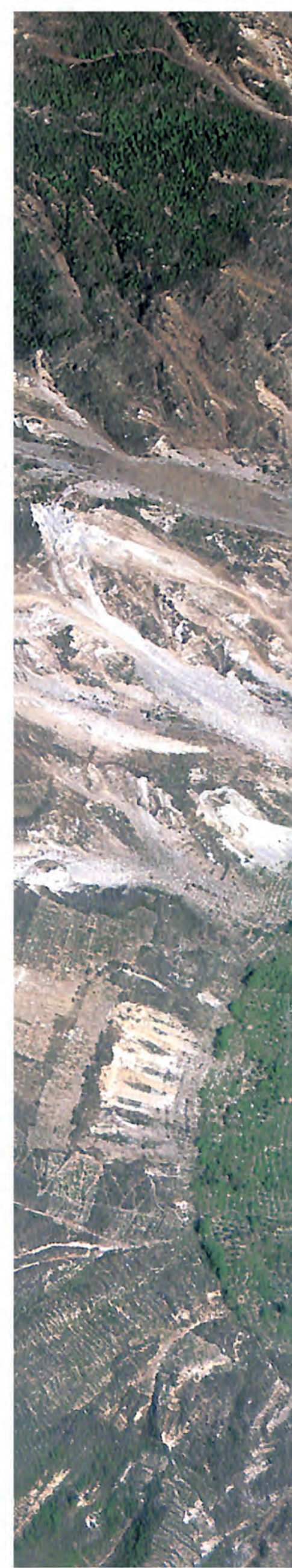

216 I Atlas of Remote Sensing of the Wenchuan Earthquake 


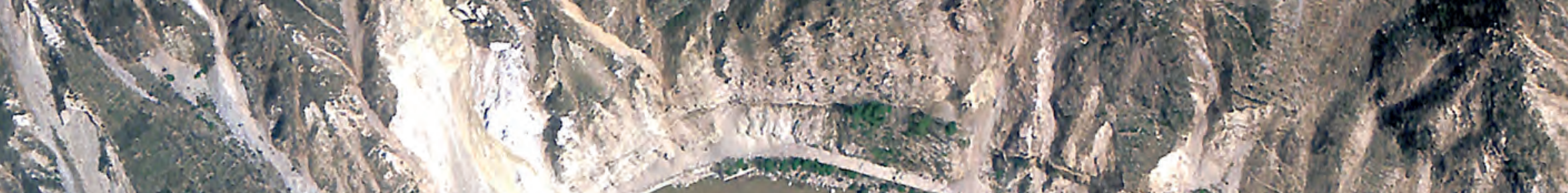

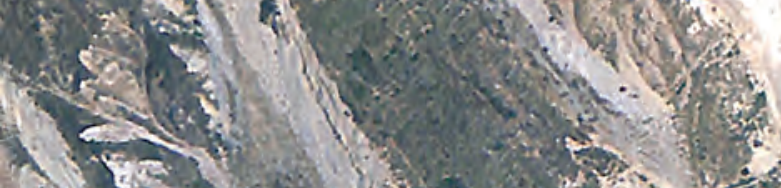

(2) $1,2,4$

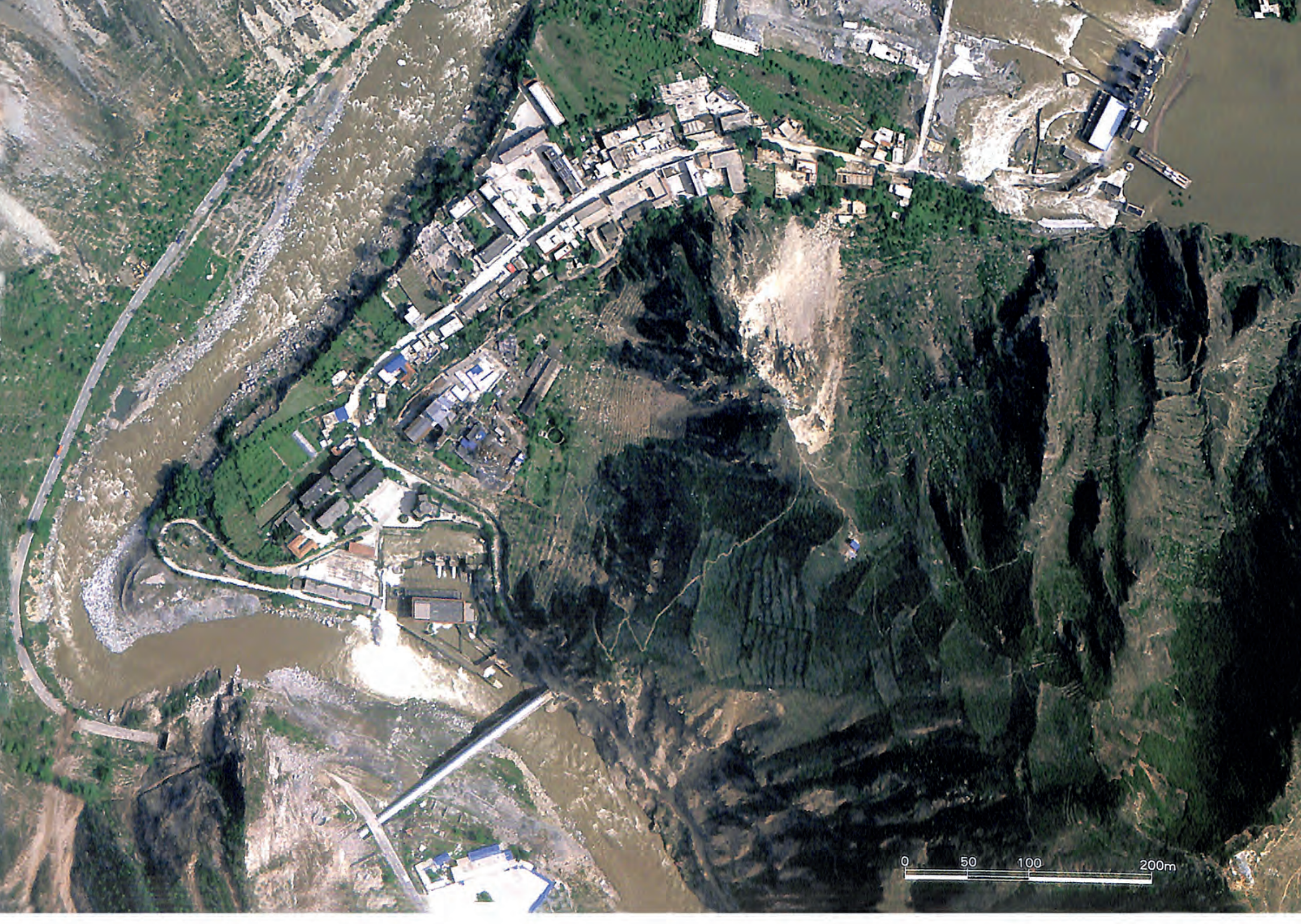


- Airborne optical remote sensing image of the Banpocun power station in the town of Miansi, in Wenchuan County

This image, acquired on May 17, 2008, shows that the dam of the Banpocun power station was badly affected by the earthquake. The west side of the dam was damaged by landslides.

$\nabla$ Airborne optical remote sensing image of the Futangba power station in the town of Miansi, in Wenchuan County

This image, acquired on May 17, 2008, shows that the Futangba power station was affected by the earthquake. The roads to the station were destroyed by landslides, and the buildings were also damaged.

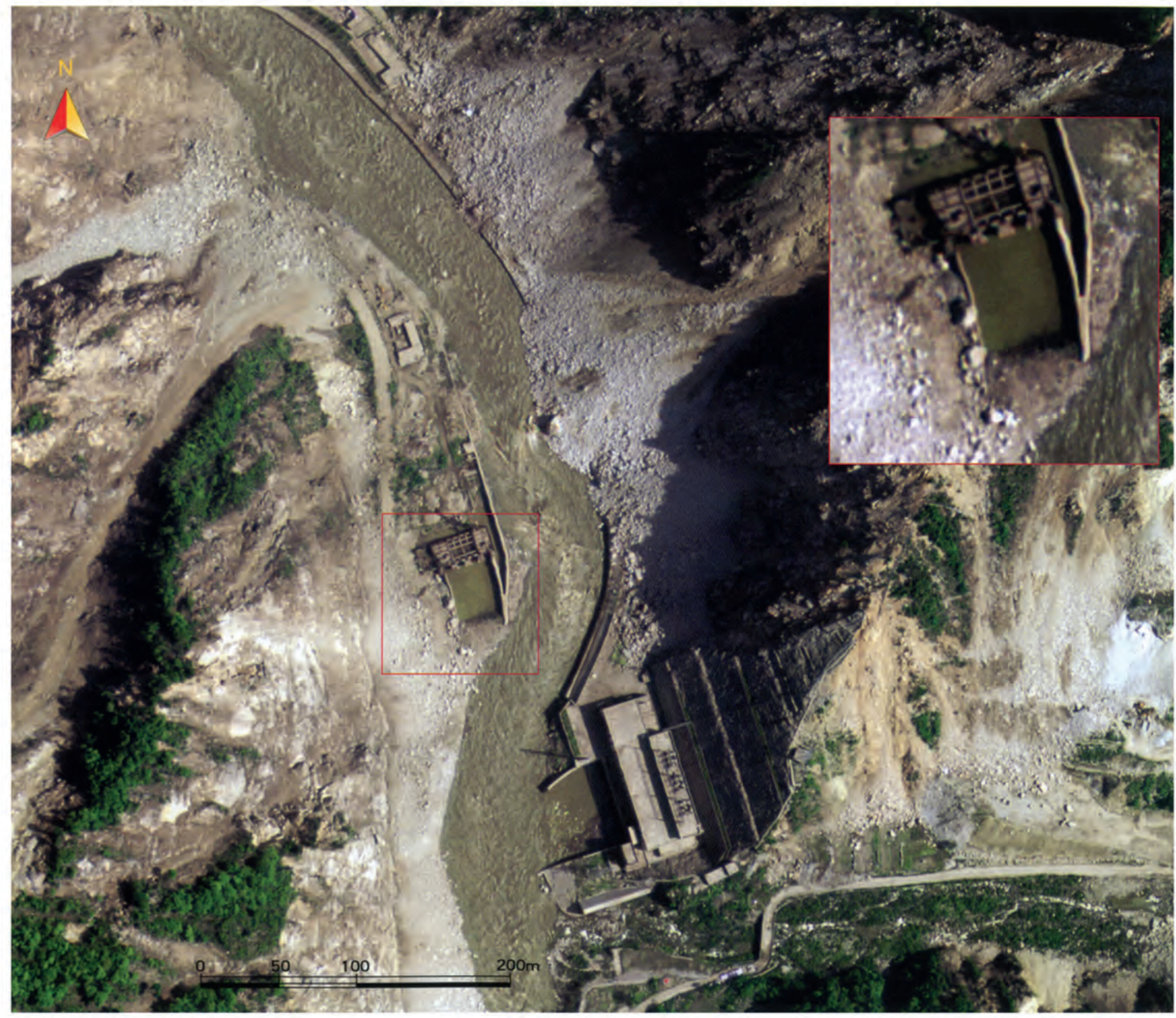

218 I Atlas of Remote Sensing of the Wenchuan Earthquake 


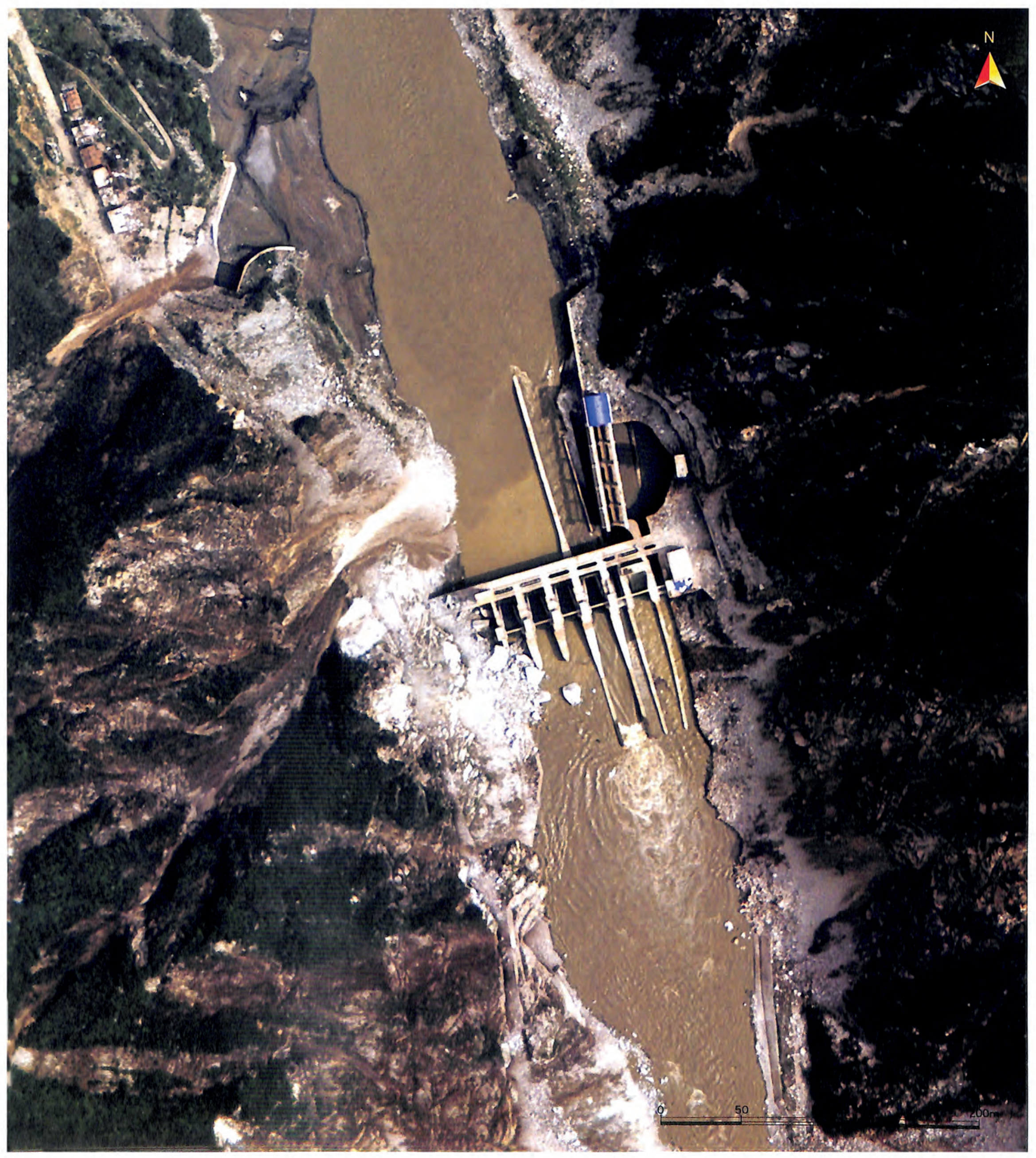




\section{- Airborne radar remote sensing image of the village of Xiazhuang, in Wenchuan County}

This image, acquired on May 16, 2008, shows many high-voltage wire power transmission towers (A) located on the mountain beside National Highway 317 in western Wenchuan County. Some landslides $(\mathrm{B}, \mathrm{C})$ resulted from the earthquake. The location of a landslide that occurred several years ago on this mountain is marked (D); the earthquake produced new landslides, knocked over the towers, and damaged the power transmission equipment.

\section{v Airborne optical remote sensing image of the Shapai power station in the town of Capo in Wenchuan County}

This image, acquired on May 17, 2008, shows that the dam of the Shapai power station has not been affected by the landslide and debris flow caused by the earthquake, but a large landslide occurred in the lower reaches of the dam.

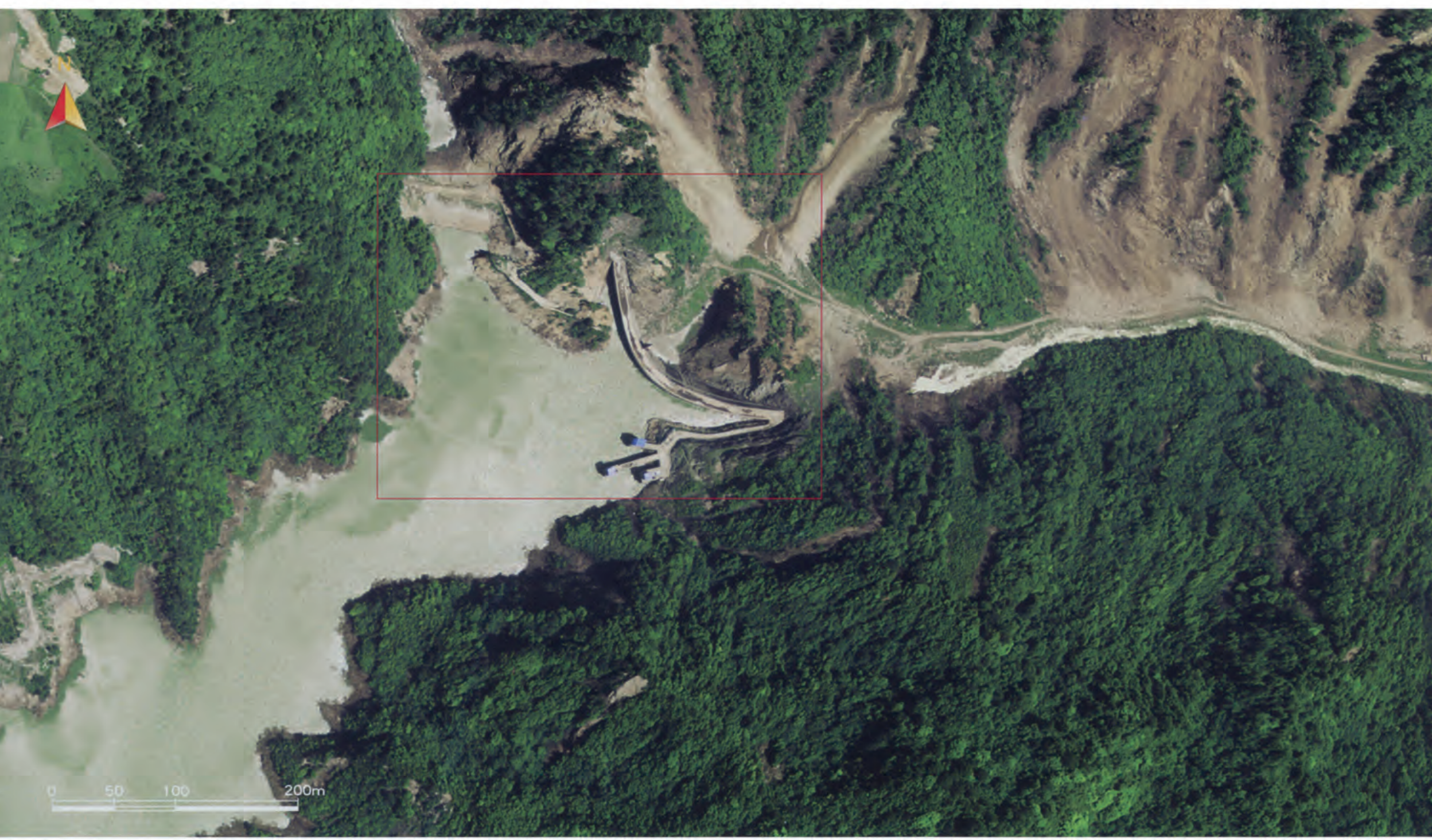

220 I Atlas of Remote Sensing of the Wenchuan Earthquake 

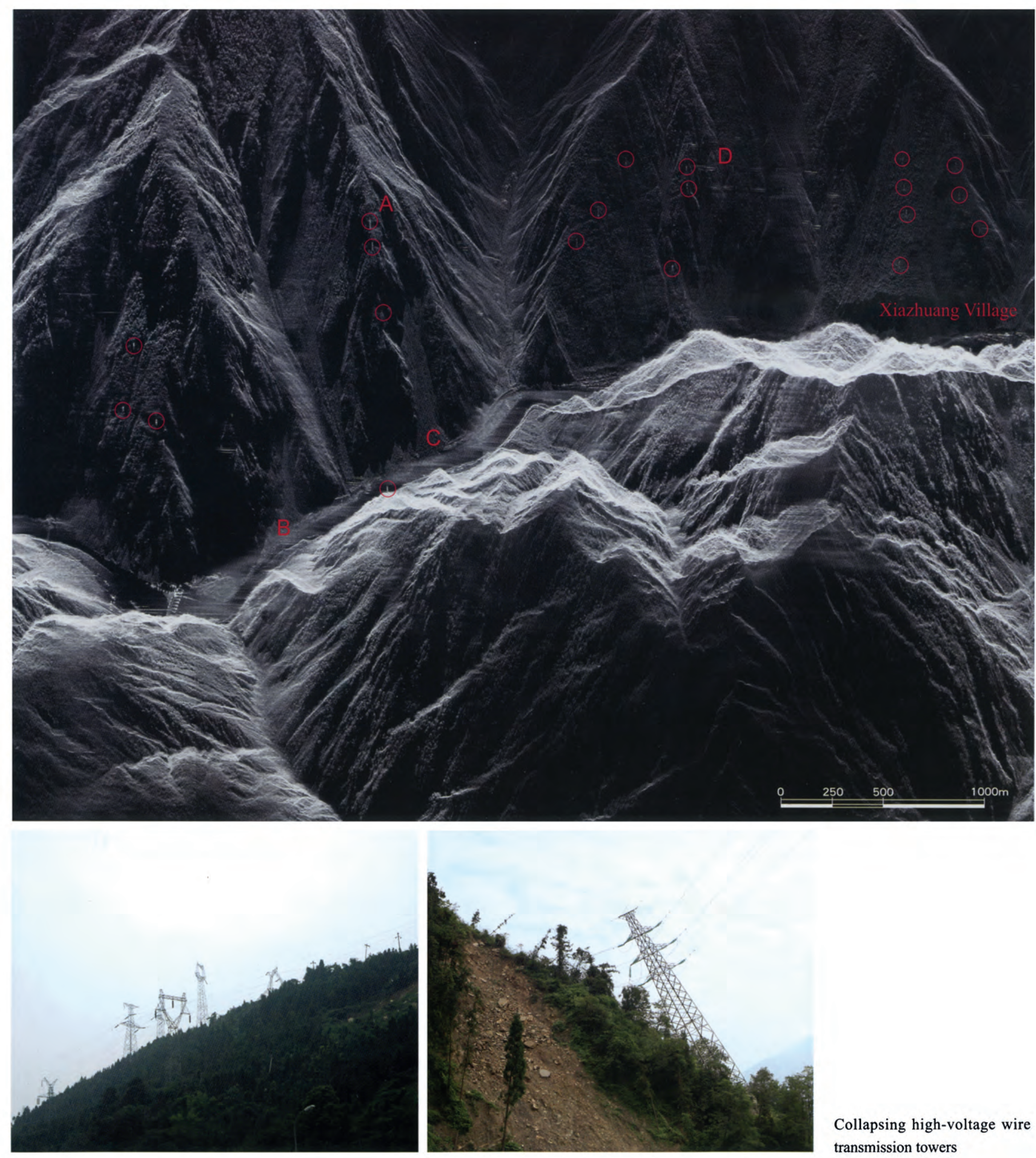

Collapsing high-voltage wire transmission towers 


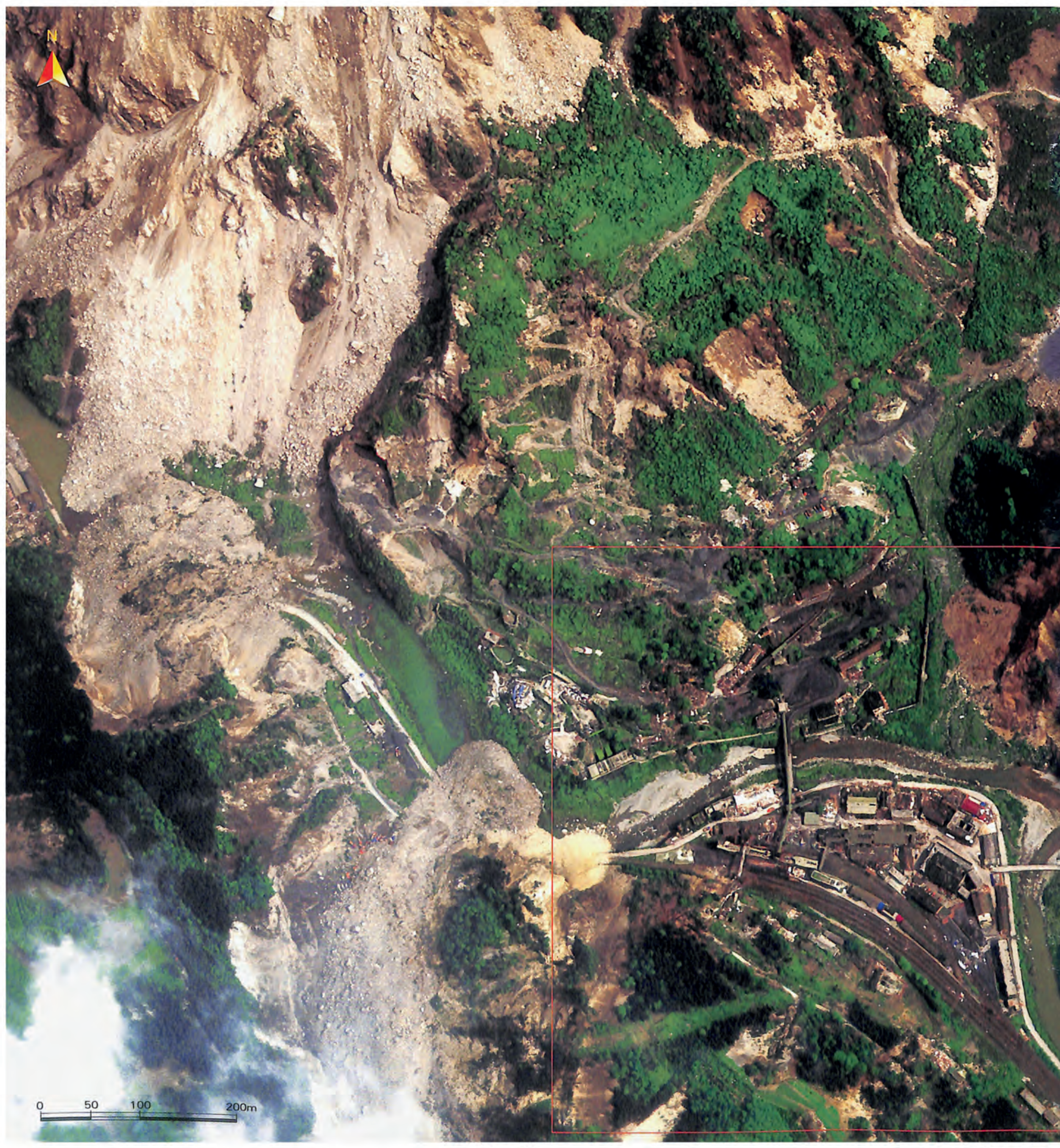

222 I Atlas of Remote Sensing of the Wenchuan Earthquake 


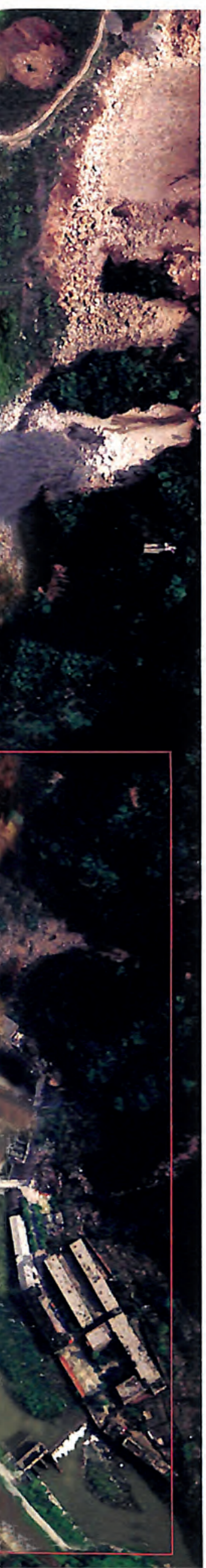

4 Airborne optical remote sensing image of the Jinhe Phosphate Mine in the town of Hongbai, in the city of Shifang

This image, acquired on May 16, 2008, shows that the mining area was badly damaged. The mine was blocked off and the buildings and houses of the mining area collapsed because of the earthquake.

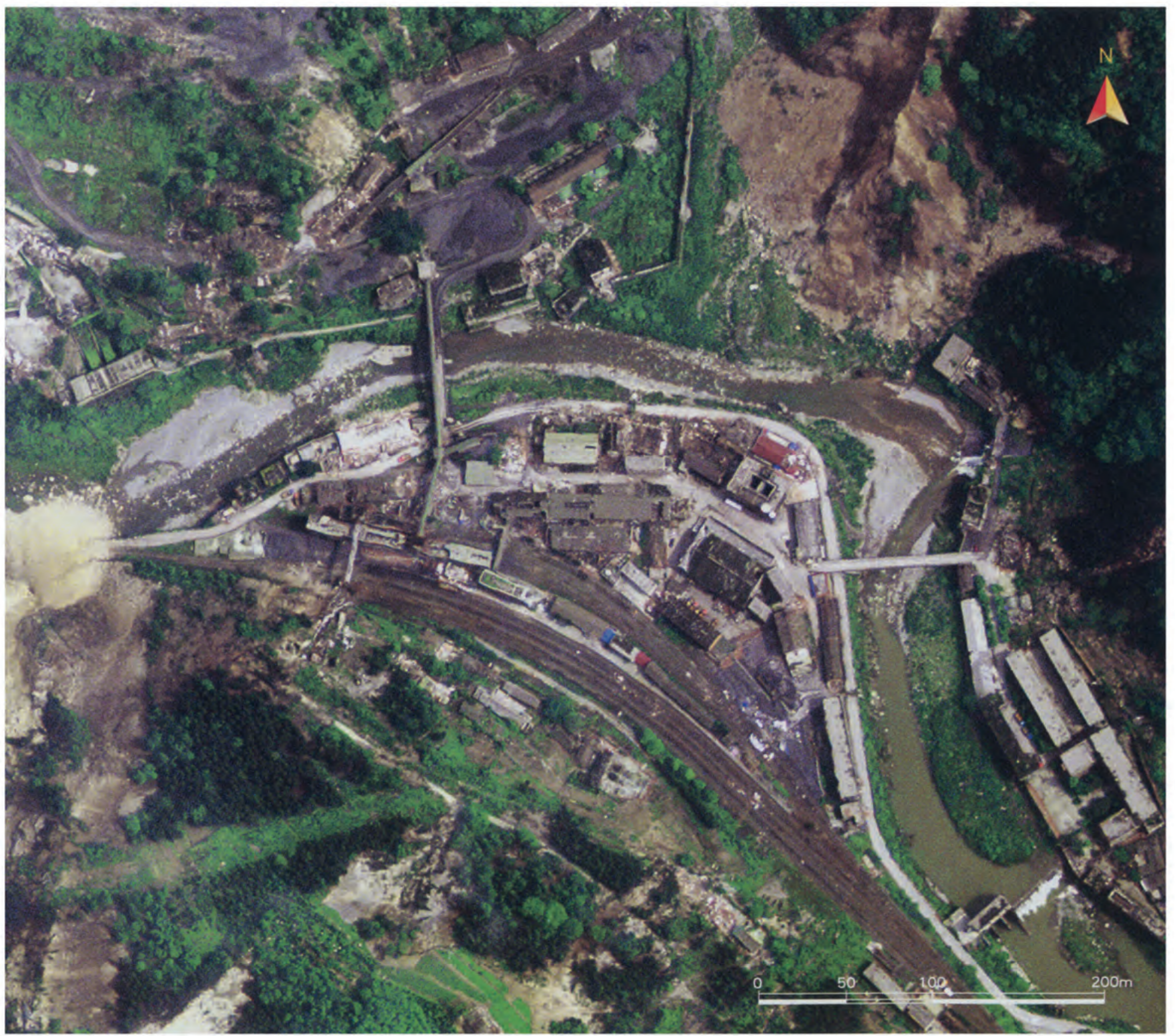



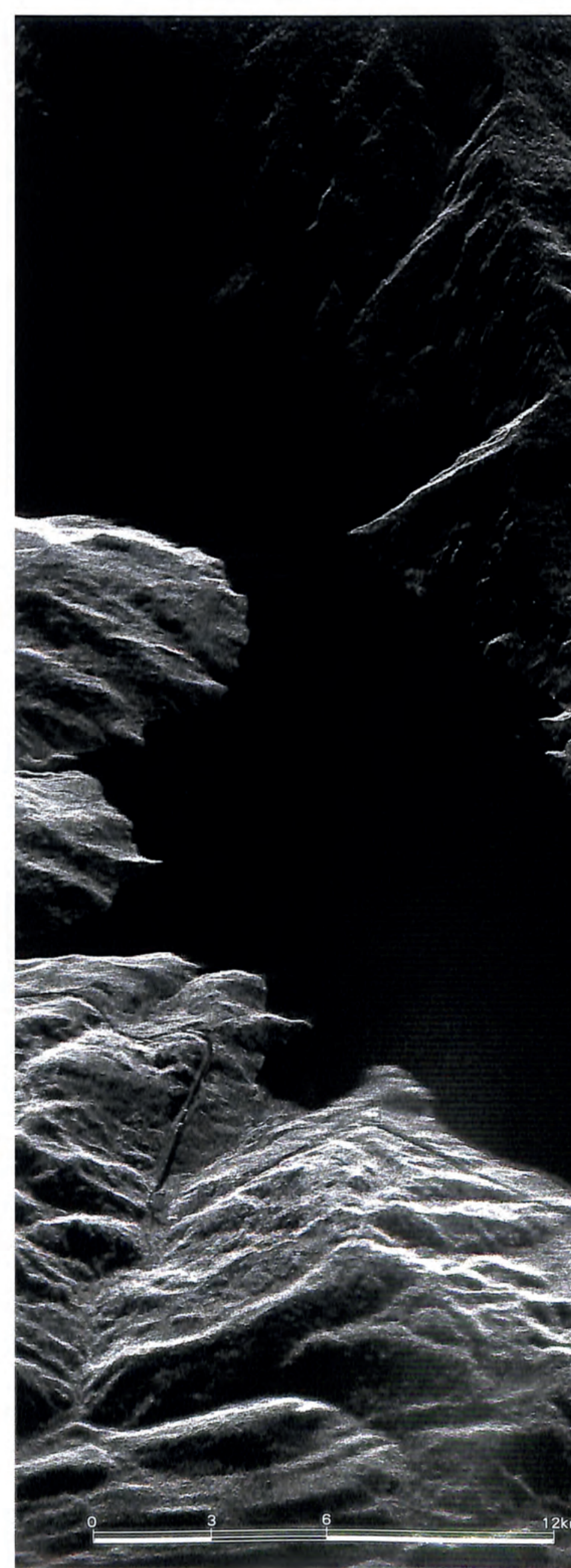


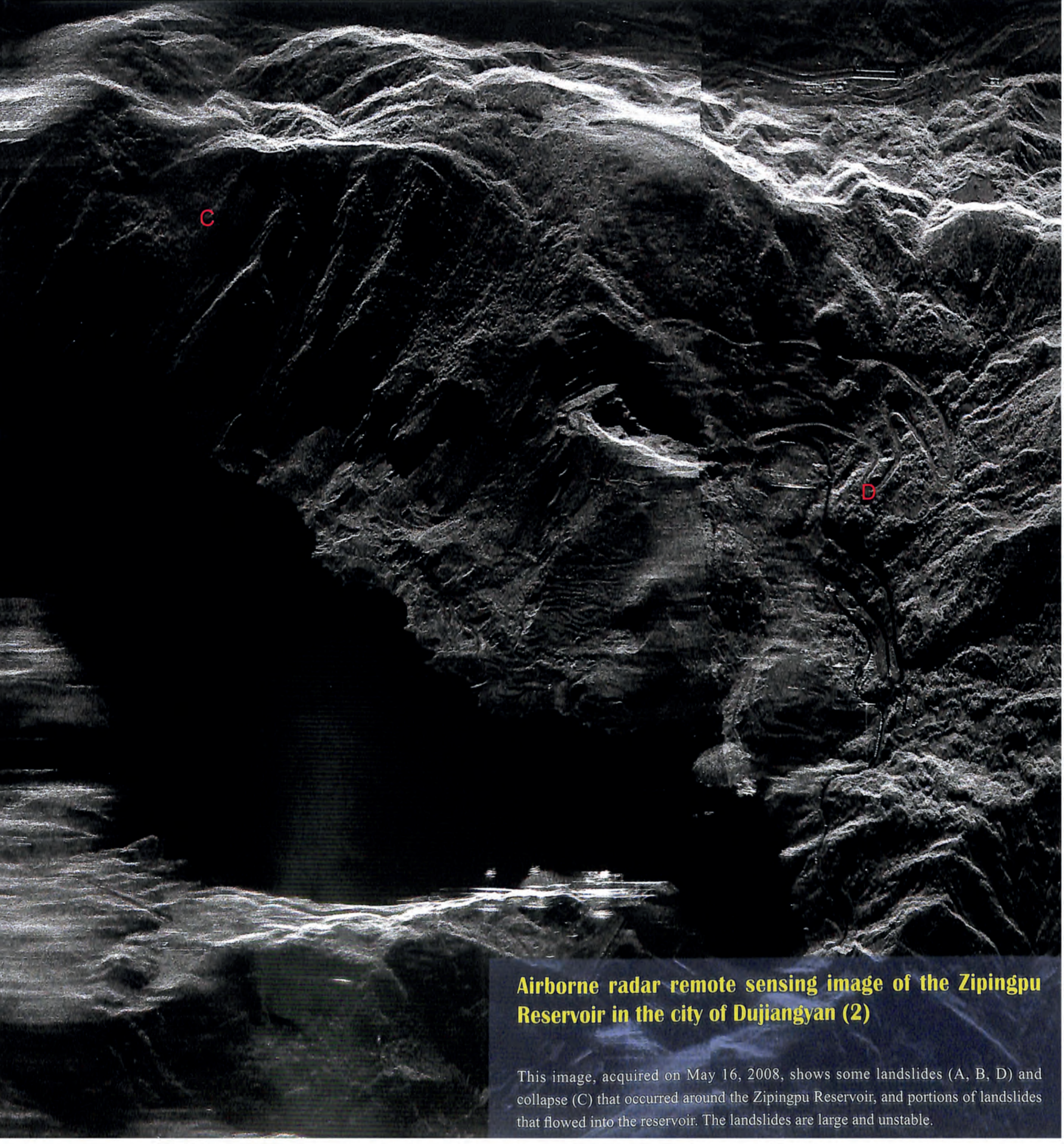




\section{Chapter

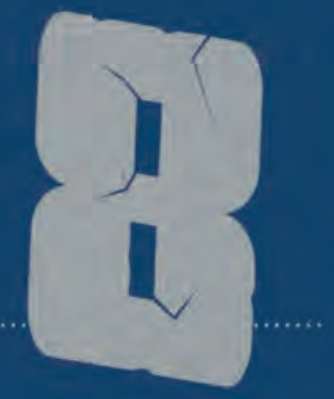

\section{Civilization Perseveres}

The Wenchuan earthquake-hit area includes many important national and cultural sites, including the world heritage Dujiangyan Irrigation Project, giant panda sanctuaries, Mount Qingcheng and the Dazu Rock Carvings, as well as homelands for ethnic minorities such as Tibetans, Qiangs, and Huis, and their cultural heritage sites. According to the statistics of the State Administration of Cultural Heritage of China (http://culture.people.com.cn/GB/87423/7235130.html), the Wenchuan earthquake affected area contains one site of world cultural heritage importance (the Dujiangyan Irrigation Project), 49 important heritage sites under state protection, 225 provincial-level cultural heritage sites, and 684 county-level cultural relic preservation areas.

After the earthquake, collapsed buildings in Dujiangyan were mainly reconstructions of ancient buildings (replicas of cultural relics); however, the genuine cultural relics were almost unaffected. While the buildings in the front part were partly destroyed, Mount Qingcheng as a whole was unaffected. The main hall of Erwang Temple, built during the Qing Dynasty, remains intact (http:// news.sina.com.cn/pl/2008-05-30/135215650932.shtml). The Dujiangyan Irrigation Project is still solid and functions normally after the great earthquake, except for some fissures in the Yuzui Bypass Dike.

[1] http://culture.people.com.cn/GB/87423/7235130.html

[2] http://news.sina.com.cn/pl/2008-05-30/135215650932.shtml 


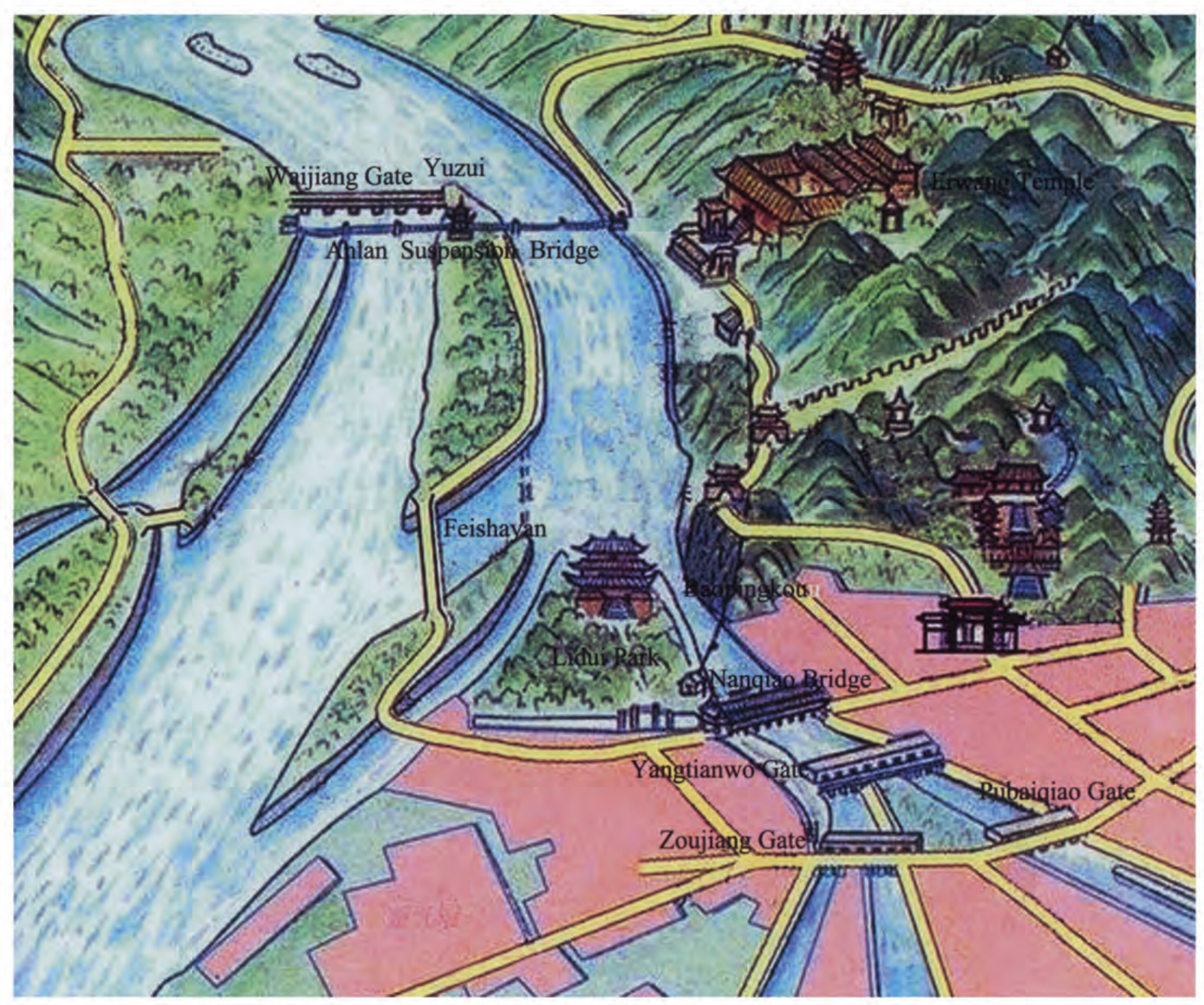

The Dujiangyan Irrigation System is the world's oldest and only remaining large hydraulic water project characterized by damless diversion. It consists of the Yuzui Bypass Dike, the Feishayan Floodgate, and the Baopingkou Diversion Passage. These three elements operate synchronously with one another to prevent flooding and to preserve the water supply to farmlands. The system automatically adjusts the capacity of the inner river for irrigation such that it carries $40 \%$ of upstream Minjiang water during flood seasons and $60 \%$ during dry seasons. Since the irrigation system was completed, the western Sichuan Plain has never flooded. This system has helped the Sichuan Plain earn the name "the Land of Abundance" in all seasons and all weather conditions.

The Yuzui Bypass Dike, named for its conical head said to resemble the mouth of a fish, is an artificial levee. The levee, which was built in the middle of the Minjiang River, functions to divide the river into inner and outer rivers. The outer river, situated in the west and known as
"Jinma River." functions as the main stream and is mainly used to drain excess water and sand. The inner river, to the east along the foothills of Yulei mountain, is used for irrigation.

The Feishayan Floodgate, connecting the inner and outer rivers, primarily functions to control the flow of water. During the dry seasons it is not needed as much. When flooding occurs, it allows excess water to flow over the Feishayan Floodgate into the outer river. It can also help reduce the amount of silt and stone carried by the inner river before it flows into the Baopingkou.

The Baopingkou Diversion Passage, which Li Bing gouged through the mountain, is the final part of the system. Its name comes from the resemblance of Chengdu Plain to a large bottle and the passage's resemblance of the bottle neck. It works as a check gate to automatically control the volume of the water of the inner river. 


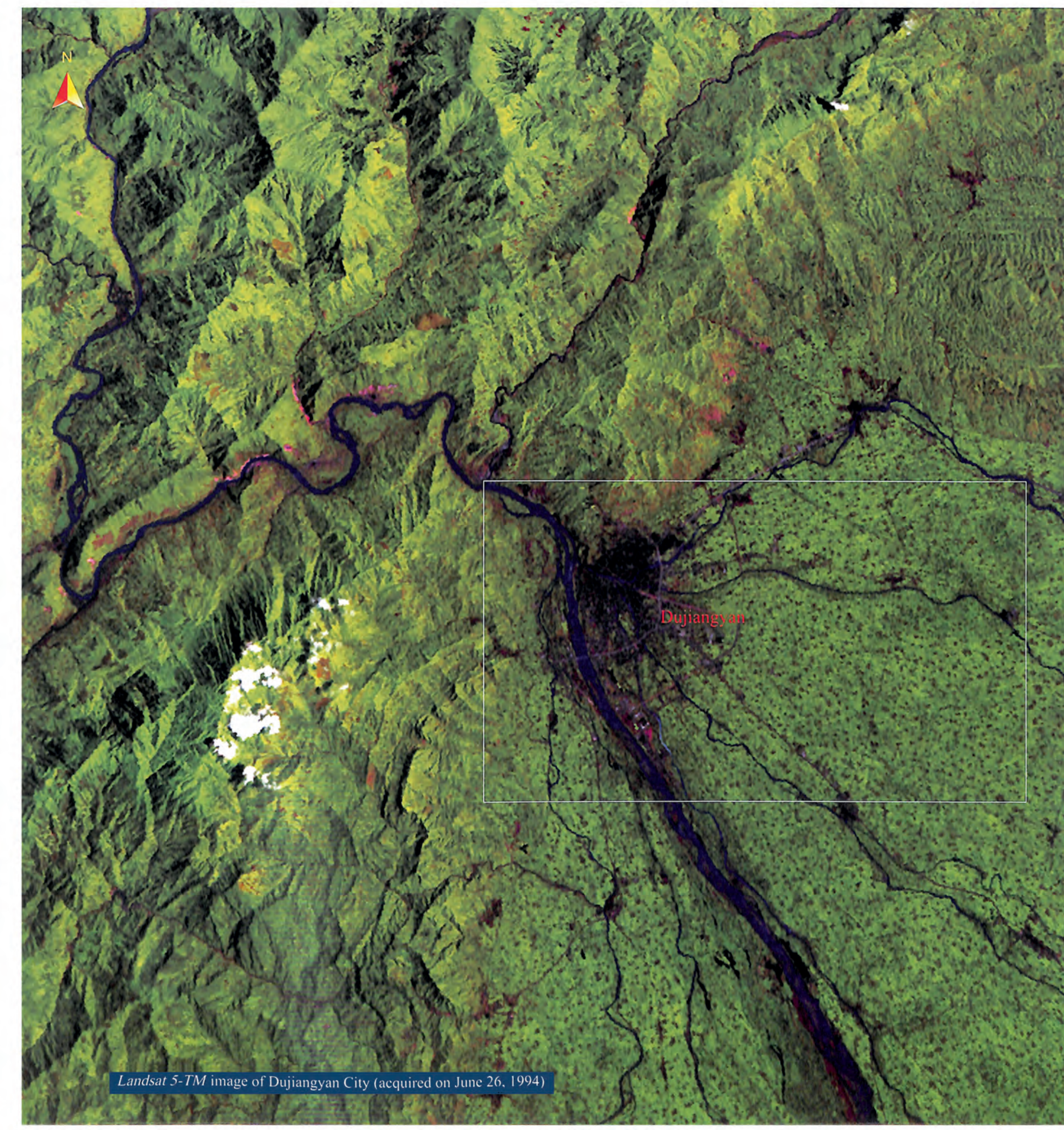




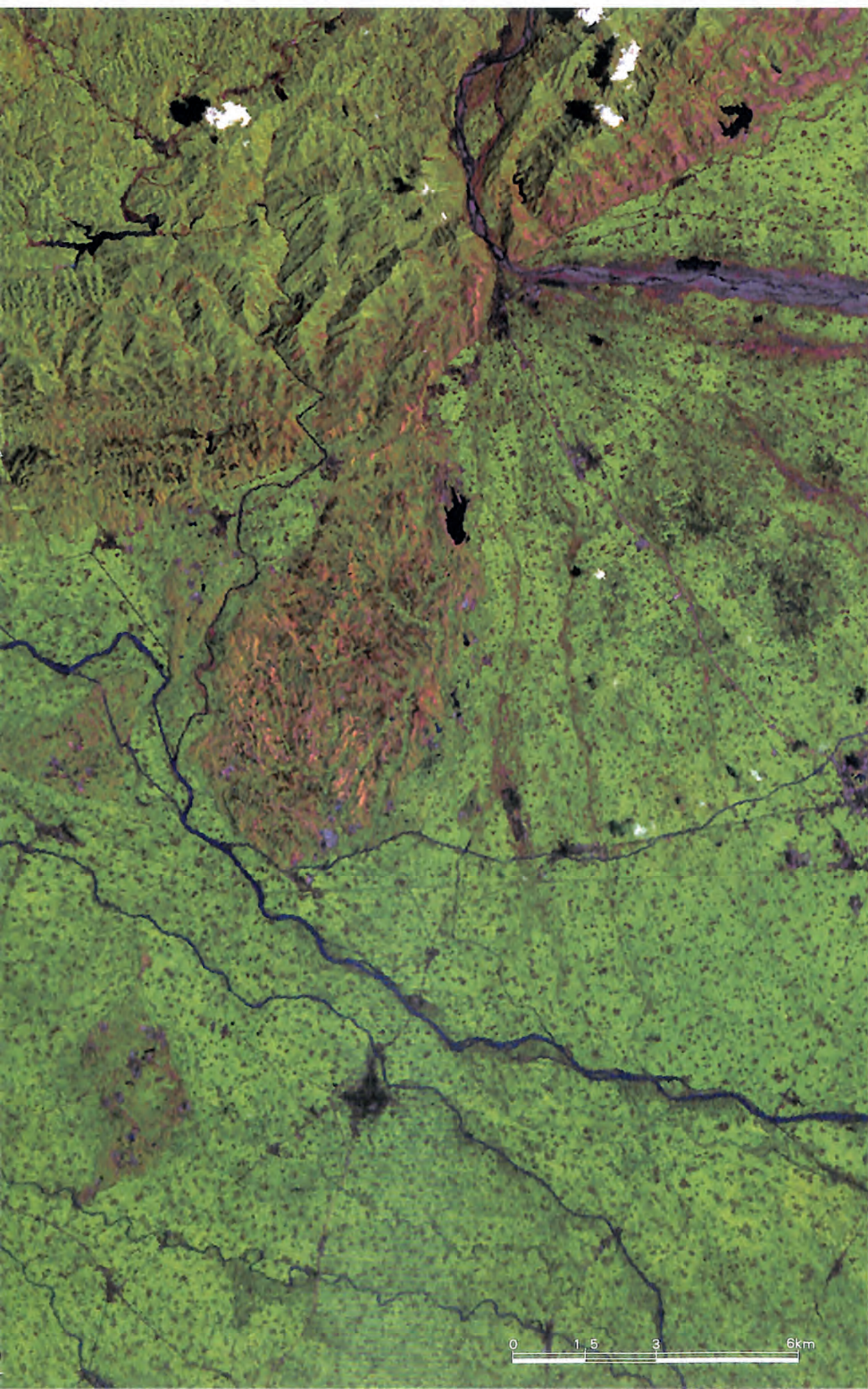

\section{Landsat 5-TM image of Dujiangyan City (acquired on June 26th,1994)}

Dujiangyan city is on the northwest edge of the Chengdu Plain, crossing the Longmenshan seismic belt in western Sichuan and the apex of the alluvial fan of the Minjiang River in the Chengdu Plain. The Landsat 5-TM image shows the topography gradually declining from northwest to southeast. With mountain in the northwest and plains in the southeast, the topography is ladder shaped. The proportion of mountains, plains, and water in the area is approximately $6: 3: 1$, according to the saying "six parts mountain, three parts farmland and one part water." Designed by Li Bing, a governor of Shu Prefecture in the Kimdom of Qin during the Warring States period (over 2000 years ago), and his son, the worldfamous Dujiangyan Irrigation System was erected on the Minjiang River at the foot of Yulei Mountain. Here the Minjiang River, after being joined by many tributaries in its upper reaches, runs toward the Chengdu Plain. With "digging deep for low dykes" as its motto, the Dujiangyan Irrigation System is characterized by damless diversion. After the Dujiangyan Irrigation System was built, the Minjiang River was divided into six canals for irrigation purposes, as well as the Jinma River, which carries the main stream. The whole system has been a crucial part of local agriculture for over 2000 years, and has contributed to the richness of Chengdu Plain and to earning its reputation as "The Land of Abundance." We are relieved that the Dujiangyan Irrigation Project was almost unaffected by the May 12 Wenchuan Earthquake.

Givilization Perseveres 


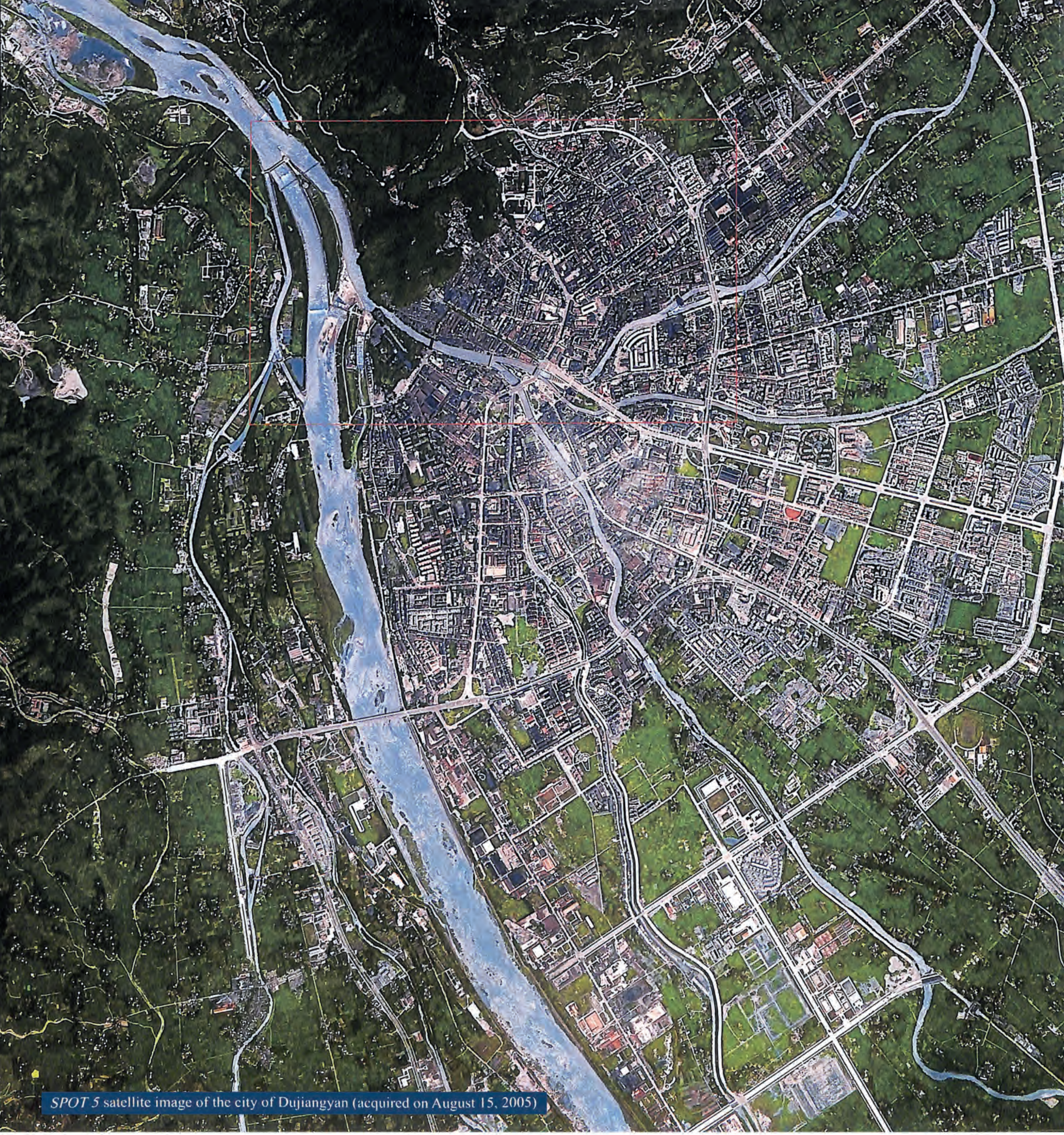




\section{A distribution map of the main parts of the Dujiangyan Irrigation Project and other important scenic spots}

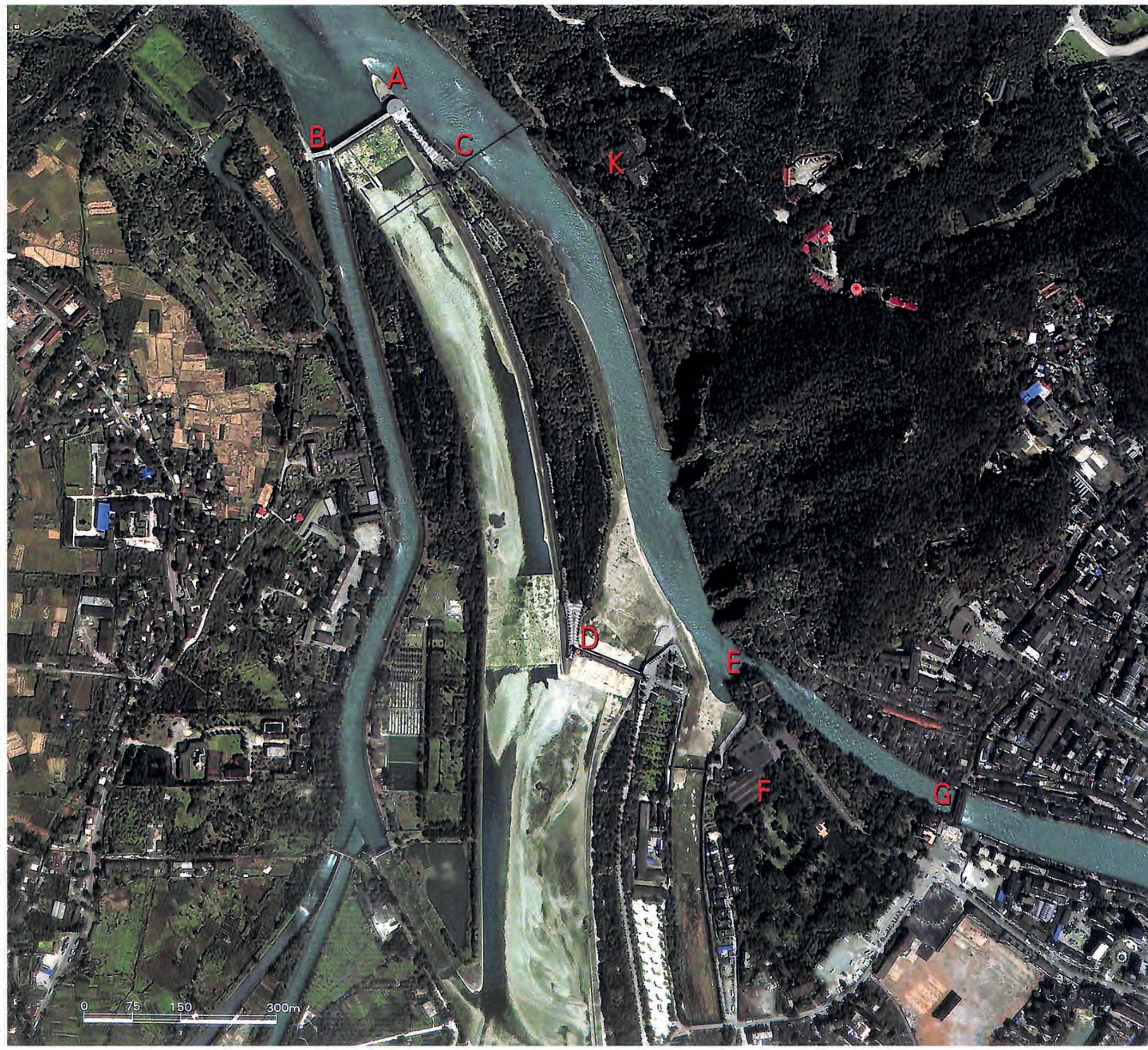




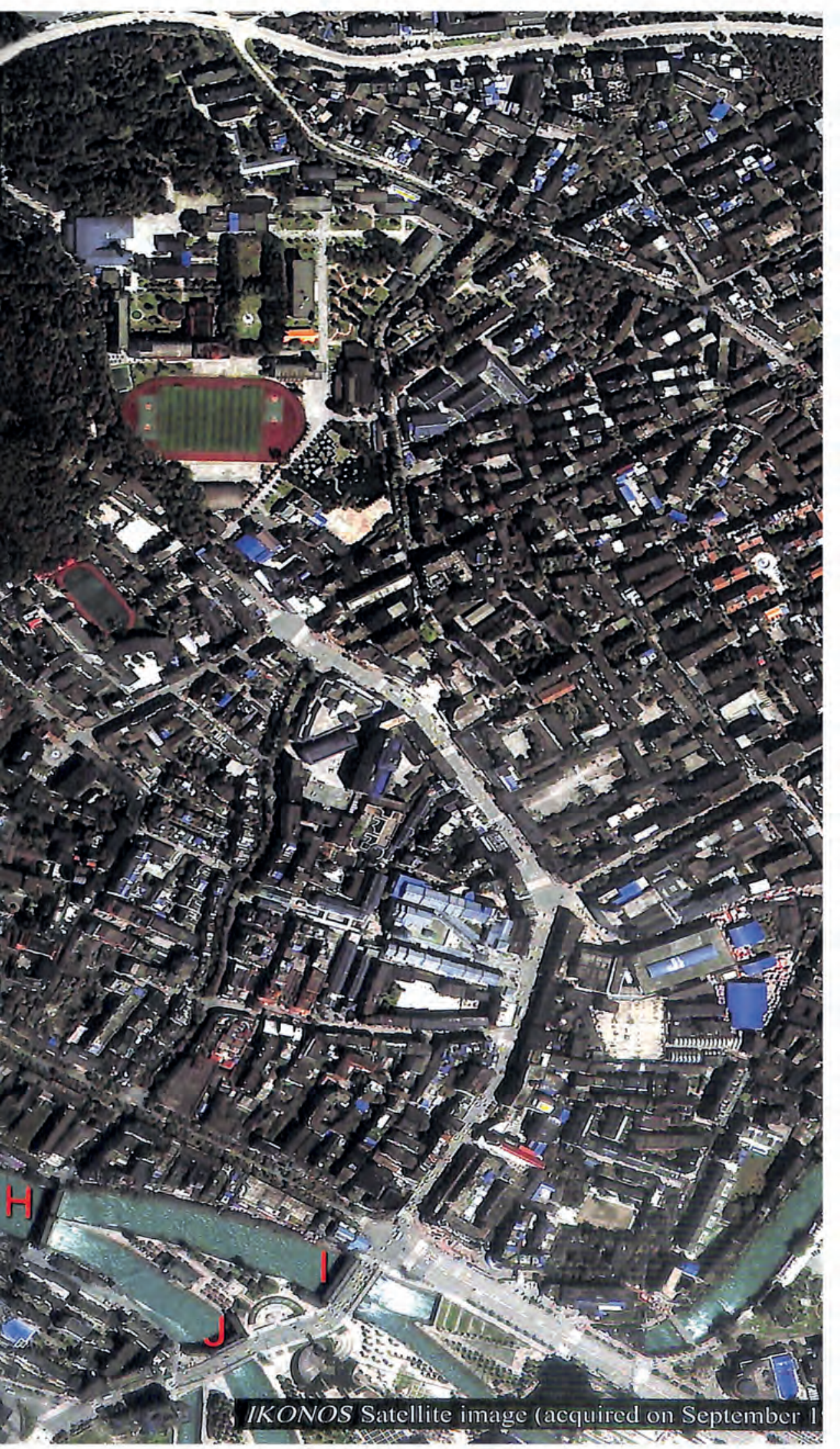

A. The Yuzui Bypass Dike
B. Waijiang Gate
C. Anlan Suspension Bridge
D. The Feishayan Floodgate
E. The Baopingkou Diversion Passage
F. Lidui Park
G. Nanqiao Bridge
I. Pubai qiao Gate
H. Yangtianwo Gate




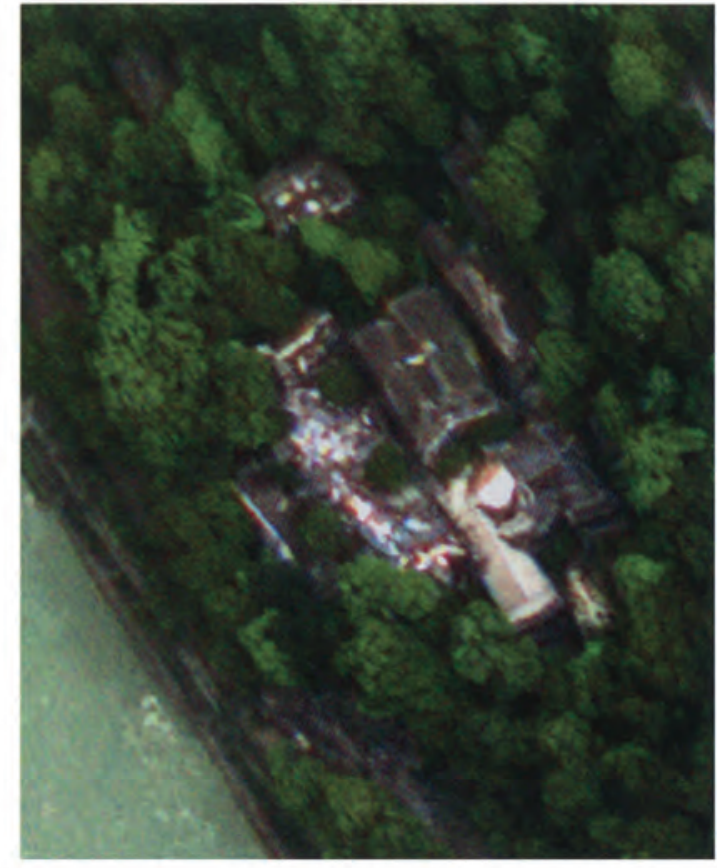

Airborne remote sensing image of Erwang Temple acquired after the earthquake (on May 18, 2008)
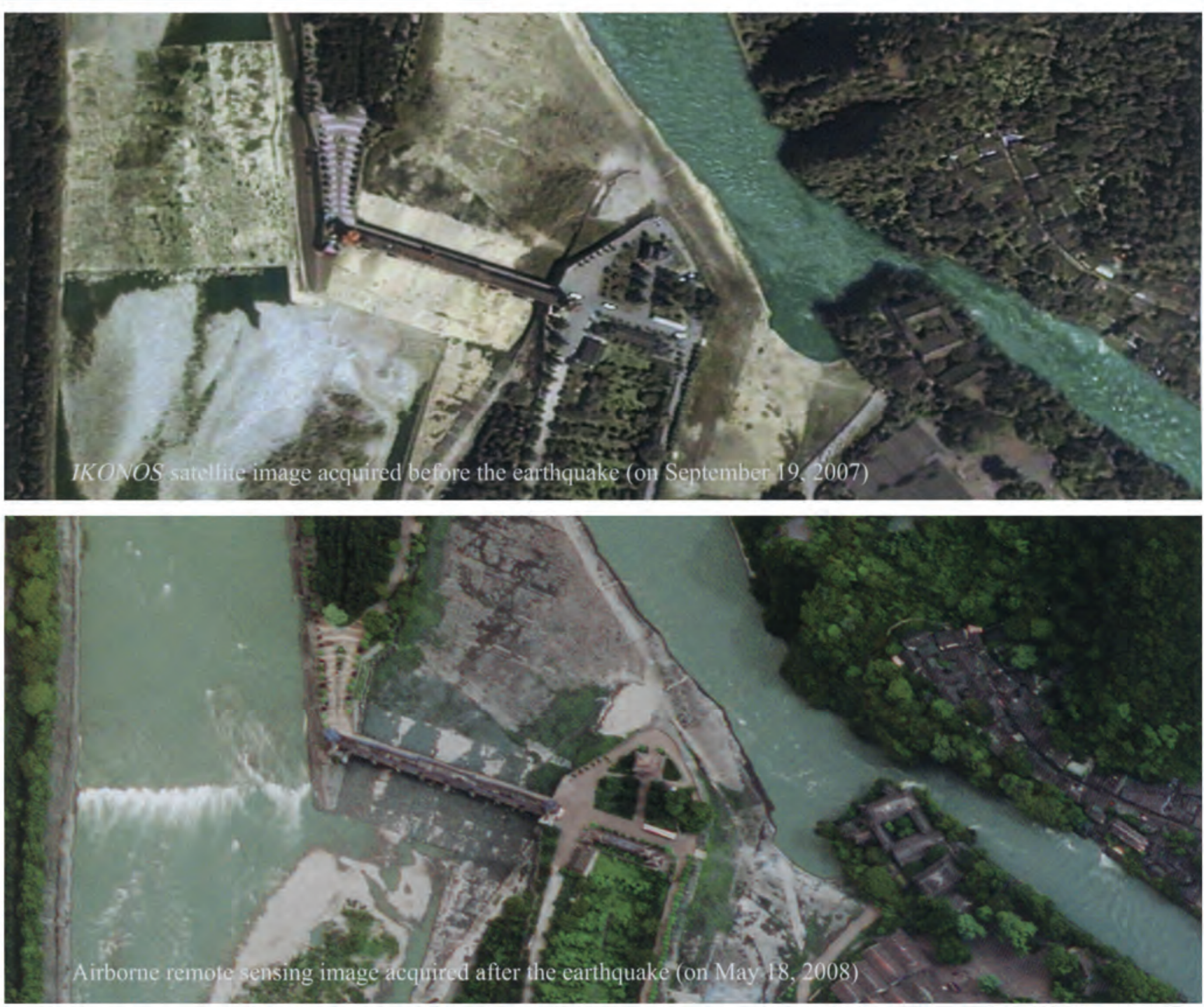

The Baopingkou Diversion Passage and the Feishayan Floodgate were unaffected

236 I Atlas of Remote Sensing of the Wenchuan Earthquake
Picture of Erwang Temple after the earthquake
Erwang temple built in memory of Li Bing and his son for their great contribution in leading the construction of the Dujiangyan Irrigation System

Two main halls built during the Qing Dynasty remained mostly intact; however, the front gate, the side halls, the slope protection works, and the rocky mountain paths, all built in 1990s, were badly damaged. 
The Dujiangyan Irrigation System is so astonishing not only because it is 2200 years old and continues to function properly, providing irrigation to the Chengdu Plain, but also because its importance to the valley increases as fresh water becomes a scarcer and more valuable resource. The Dujiangyan Irrigation System is also a unique architectural work, creating a model of harmonious coexistence between mankind and nature. It makes man, earth, and water a highly synchronous unity while making full use of rather than destroying natural resources, turning bane into boon, automatically dividing water, automatically removing silt, and automatically irrigating. The Dujiangyan Irrigation System represents a crystallization of ancient Chinese wisdom and an epoch-making masterpiece of Chinese civilization. It writes down a glorious page in the history of water conservancy in the world.
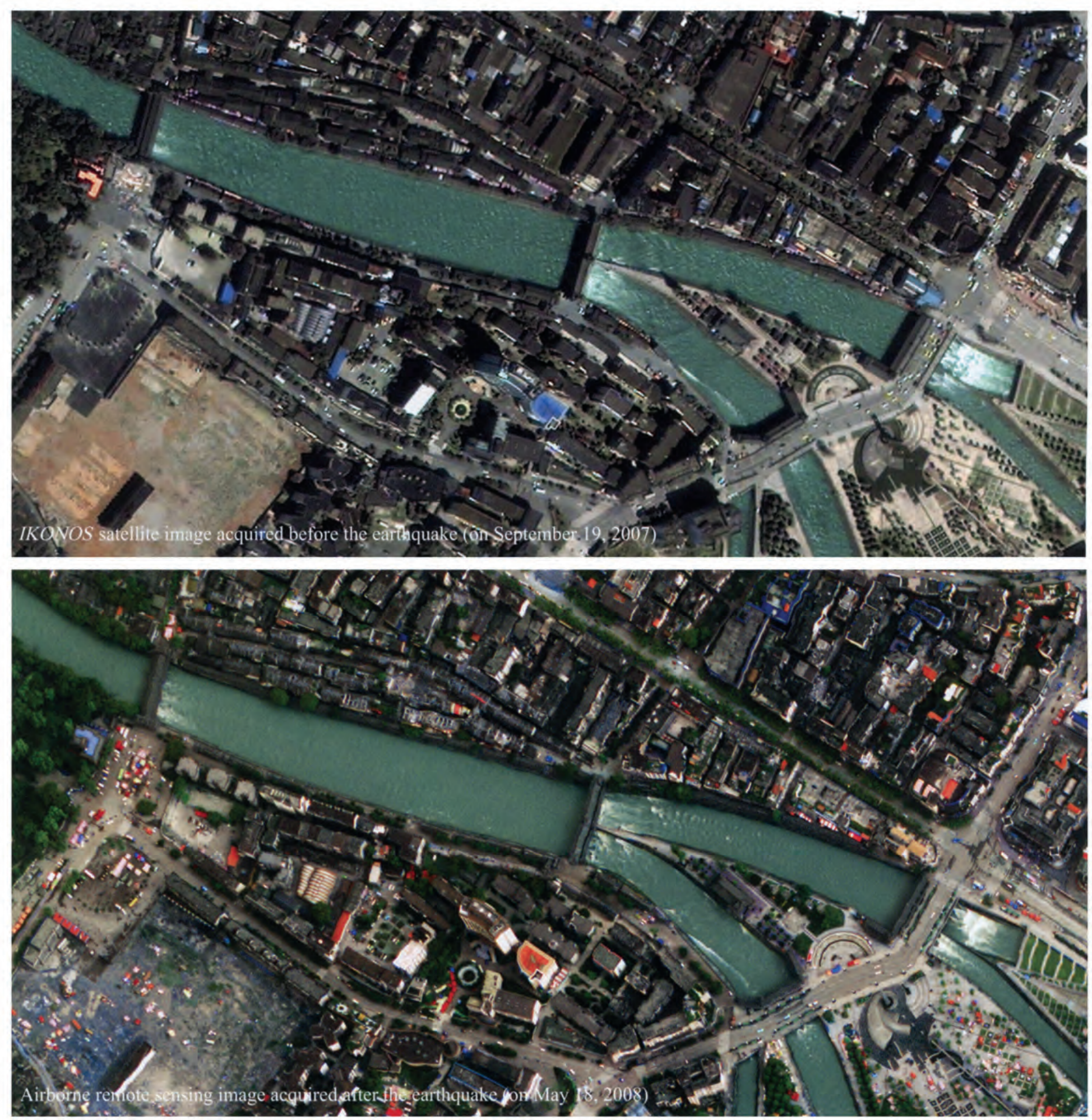

Nanqiao Bridge, Liutianwo Gate, Pubaiqiao Gate, and Zoujiang Gate all remain intact. 


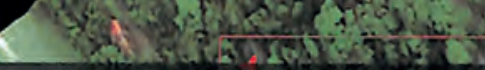

Compared with the IKONOS satellite image acquired before the earthquake, this airborne remote sensing image acquired after the earthquake shows that the main parts of Dujiangyan Irrigation System are unaffected by the earthquake
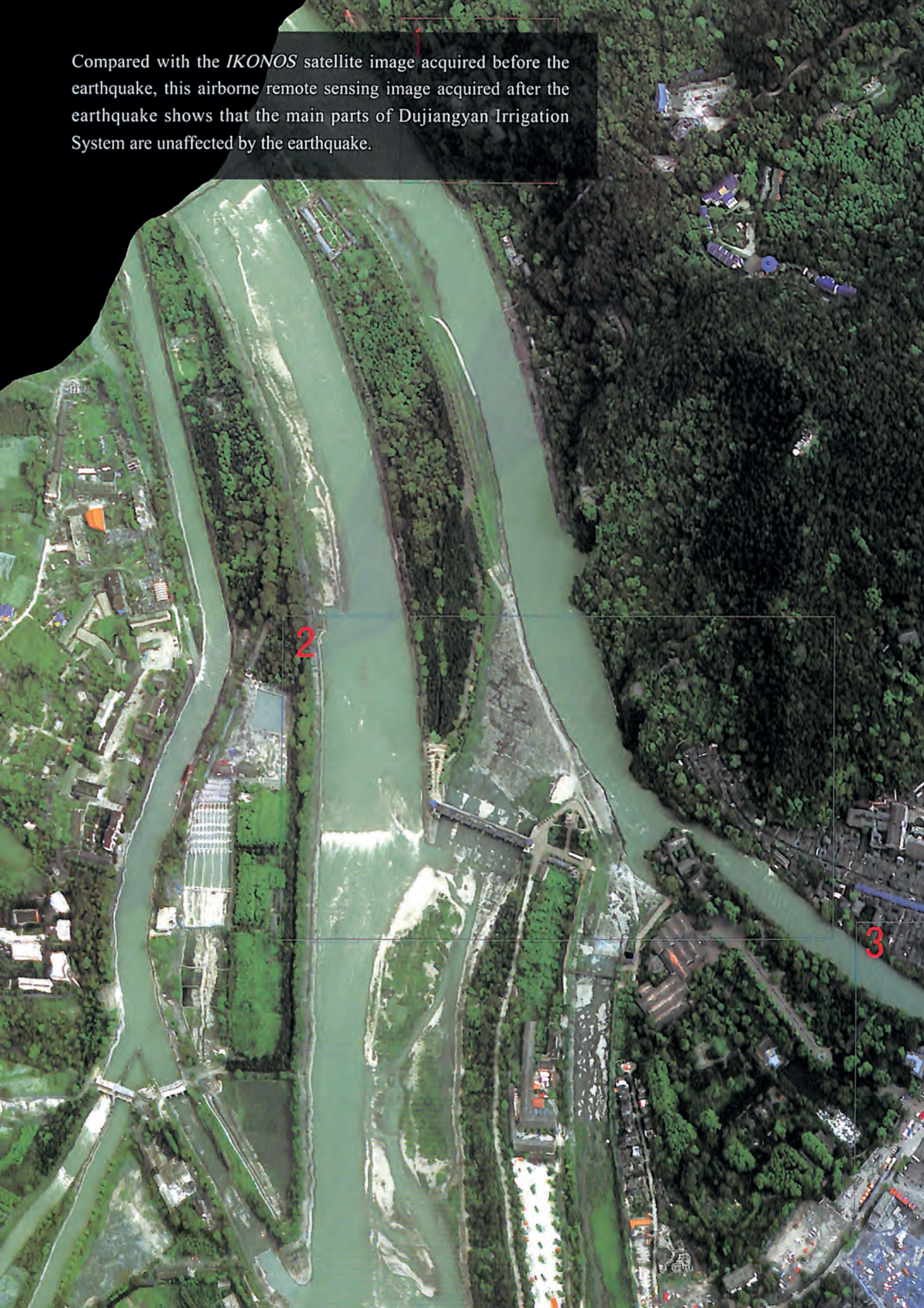

39

if 1 Airborne optical remote sensing image of Dujiangyan City

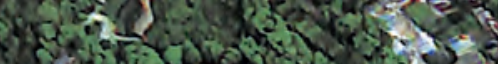

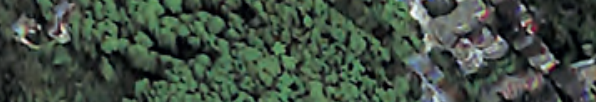

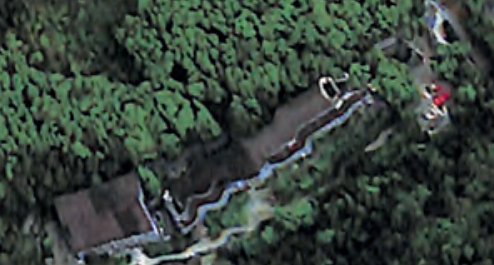

एकe
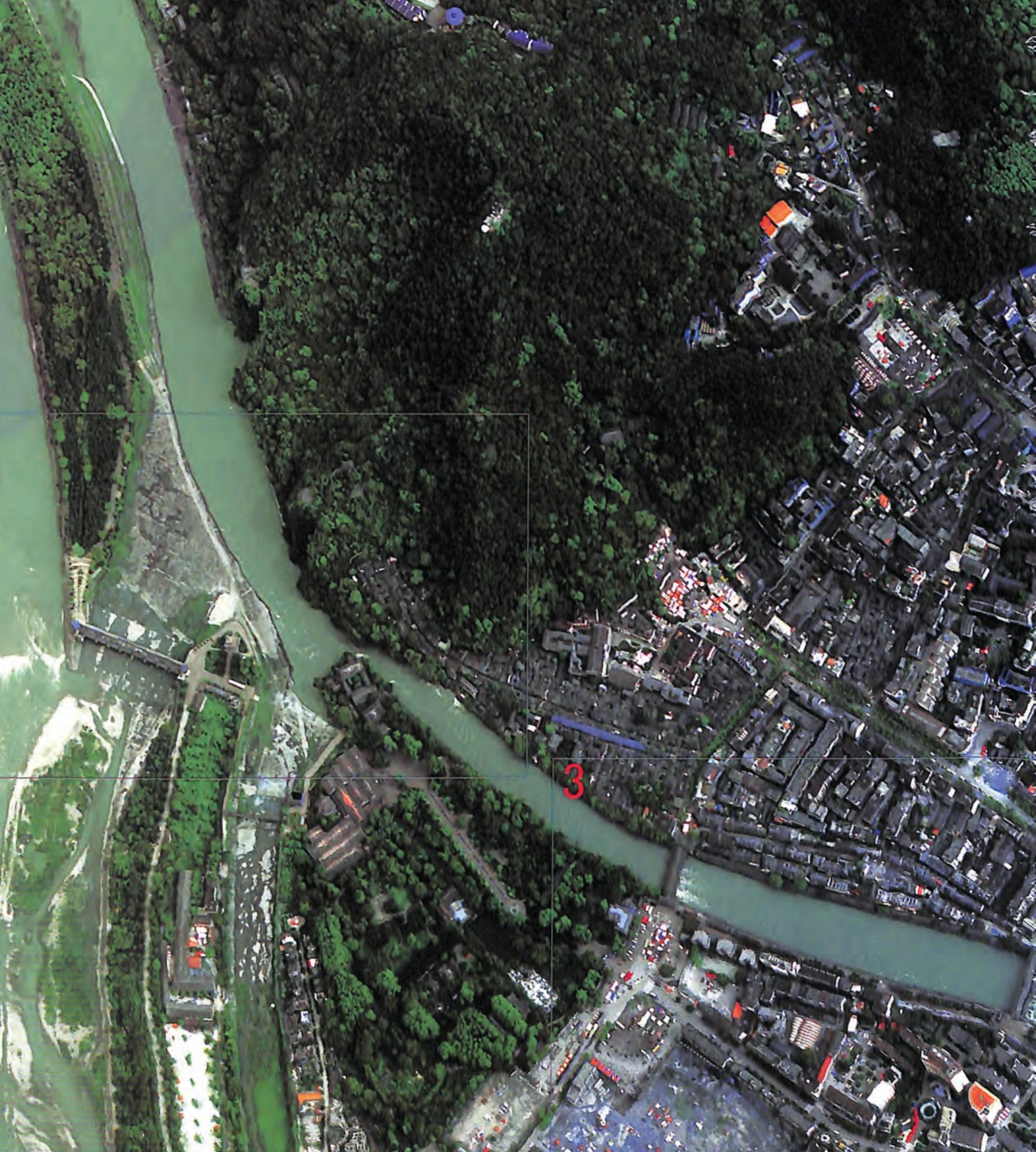

$a_{2} \mathrm{~s}^{2}$

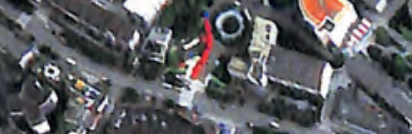

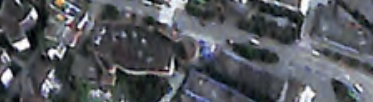
$\left.\left(y^{2} y^{2}, y\right\}\right)$ 
1)Lry

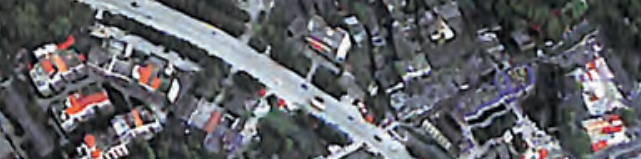

ב.e.

L N.7. . .

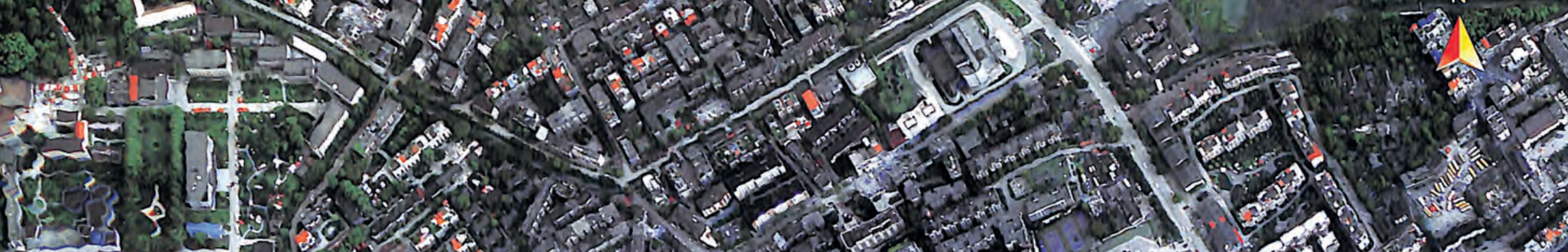

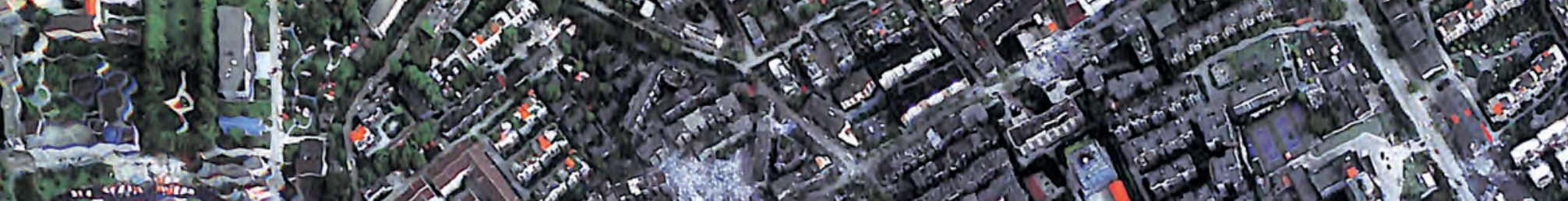

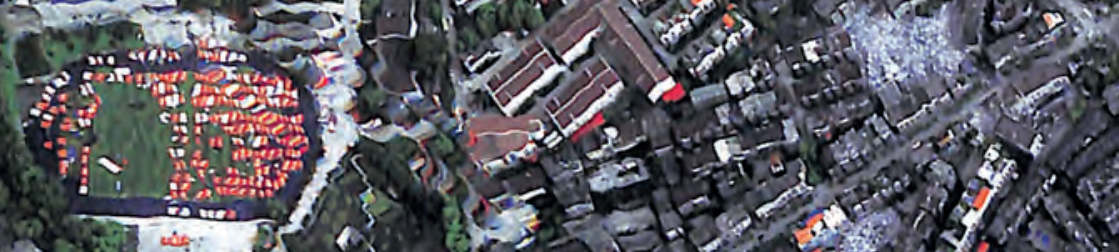

$+2+2,0$

$x^{2}+2,2+2 \times 10$

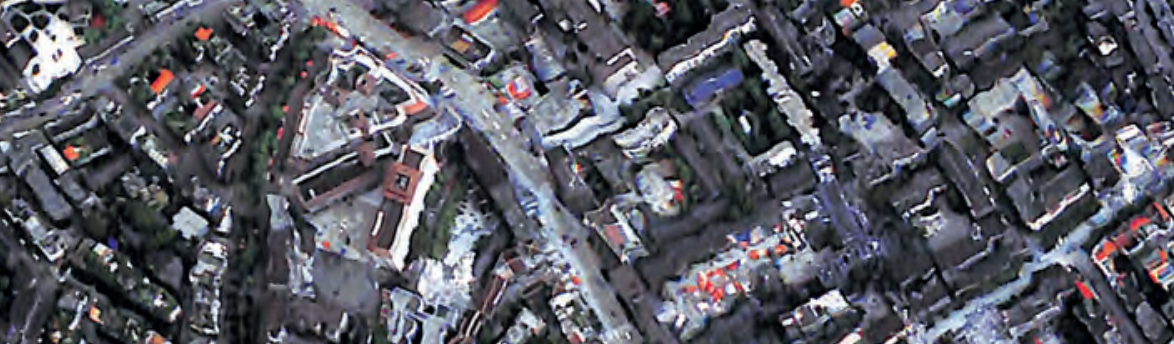

(6)

$x(25)$

2710. 15

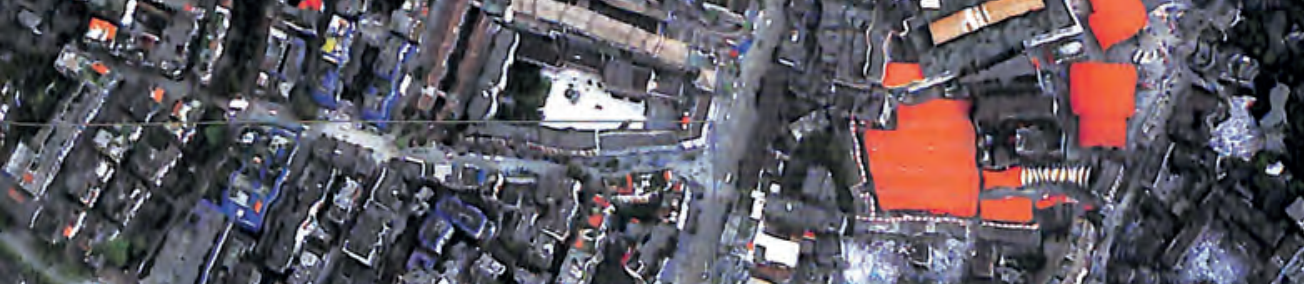

(4.2)

(2)

a)

(6)

$\frac{(15)}{1}$ yes 


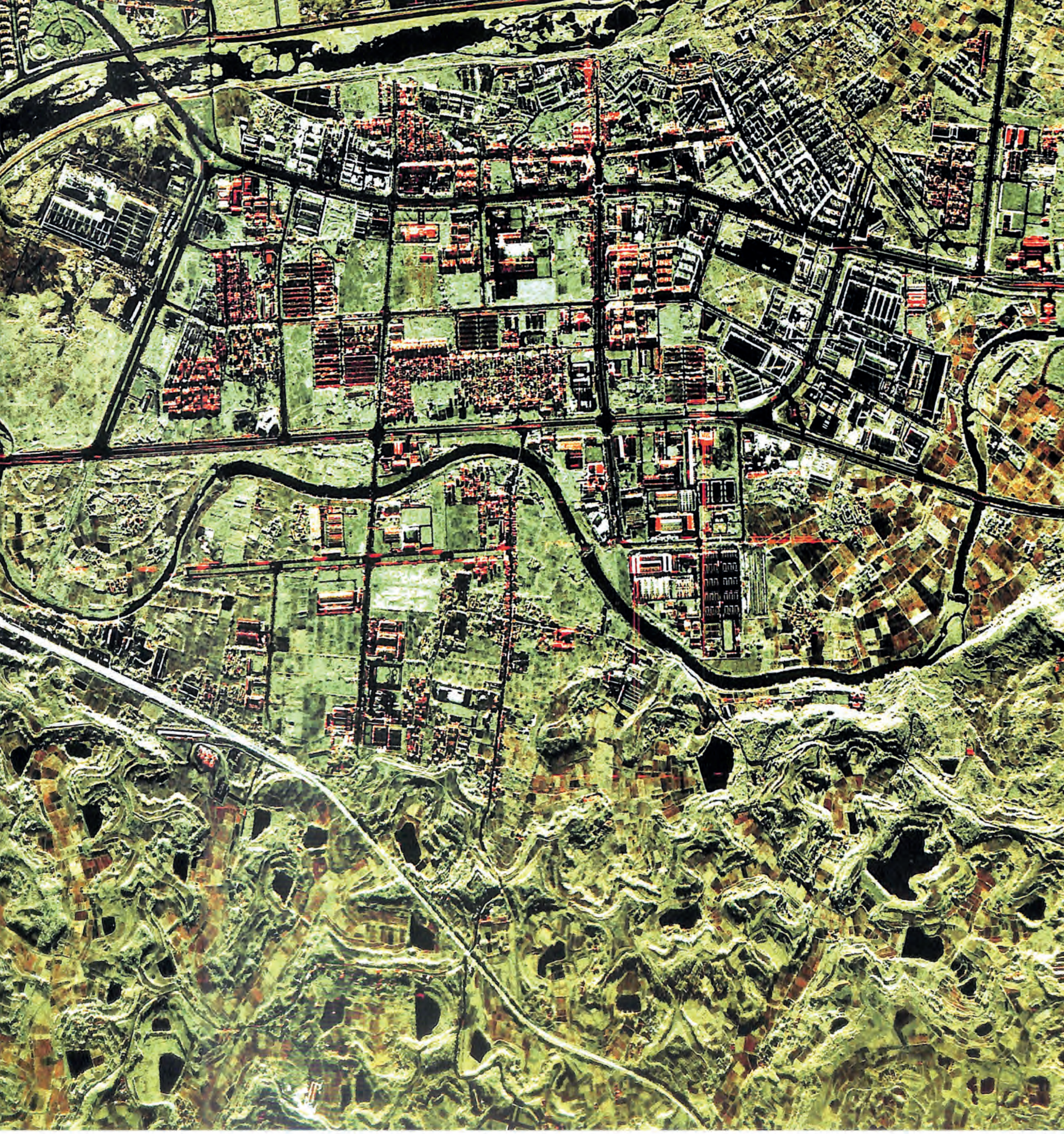




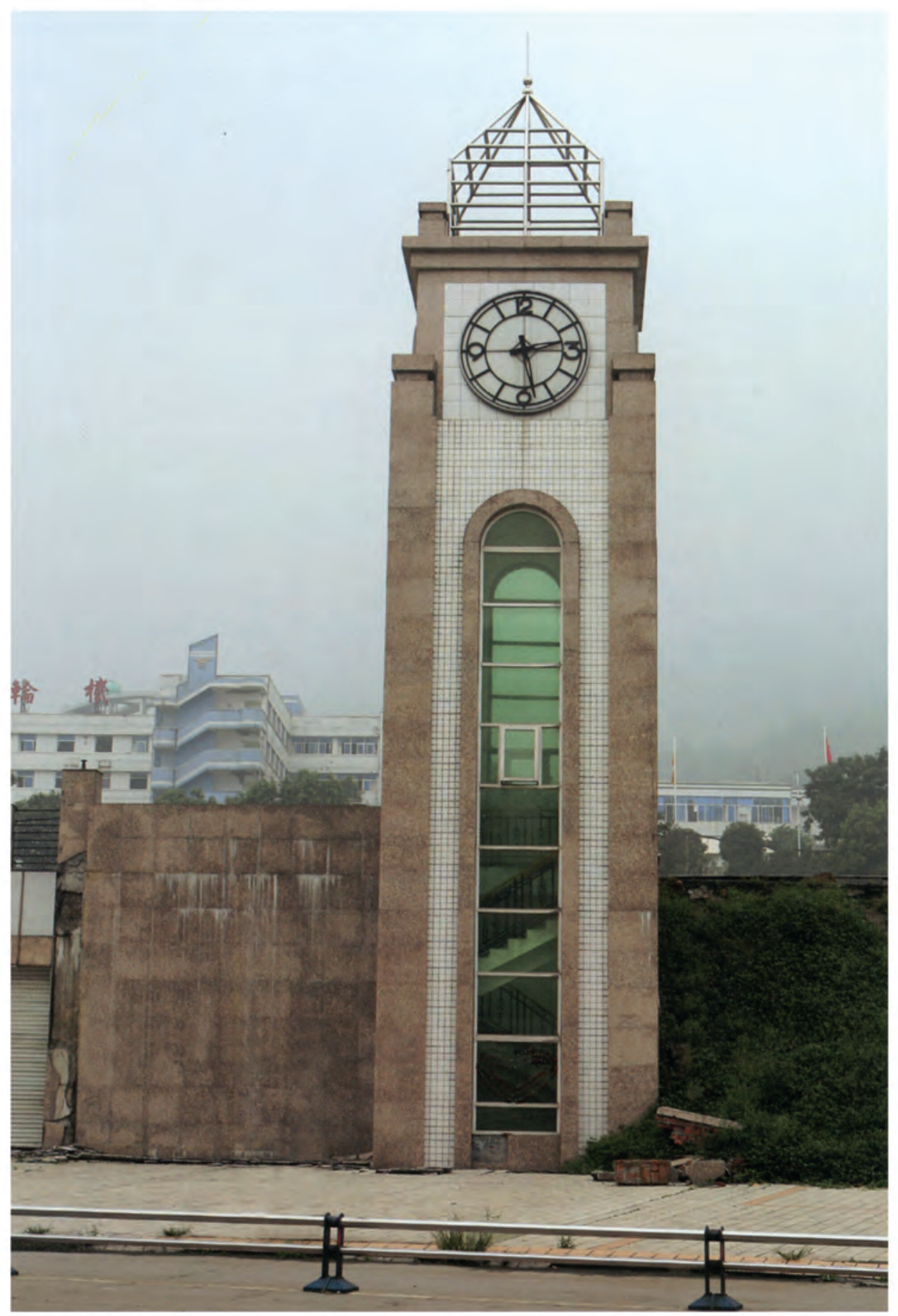

A bell tower in Hanwang town, Mianzhu city, Sichuan Province, and the time stopped permanently at 14:28 on May 12, 2008. 
A

Active fault
ALOS
Anchang
Anxian
B
Banpo
Banpocun power station
Banzigou
Barrier lake
Bayi
Beichuan

Beichuan Middle School

Bingli

C

Caoba River

Caopo

Changheba

Chaping

Chengdu

Chenjiaba

County Road

D

Dabao

Daojiaoli

Debris flood

Deyang

Digital Elevation Model

(DEM)

Donghekou

Dongjienao

Dujiangyan

E

Earthquake intensity

Envisat

EROS-B

Erwang

F

Fengyi

Fotangbagou

Fujiang River

Futangba

Futangba power station

55

53

83

48
29,30

$3,10,59$

123

$59,90,93,110,114-116,119,120,122,123,125,127,184$

218

212,218

$59,62,64-75,77-87,89,146,151,157,185,198,203,206,212,216$

$11,23,30,31,36,43,53,64-73,77,78,81,87,90,93,110-112,114,116$, $119,120,122,125,127,128,138,143,145,146,150-153,155,157-164$, $167-170,188,196,199,206,212,216$

163

177

164,172

$135,172,212,220$

$65,122,127$

$4,99,128,229,231,237$

$43,146,188$

$170,173,183,186$

\section{1}

45

47,48

148,149

208

74,77

$9,10,16,90,99-101,103,164,191,212,225,227-234,236-238$

$$
\begin{aligned}
& 144 \\
& 3,12,17 \\
& 3 \\
& 236
\end{aligned}
$$

\section{3,184}

180

$86,136,196,207$

212,218

212,218
G

Ganhekou

Ganxipu

Gaochuan

Geological disaster

Giant panda

Guandili

Guangii

Guangyuan

Guanzhuang

Guanzipu

Gujing

Guozhupu

H

Hanwang

Hongbai

Hongguang

I

IKONOS

Intensity

J

Jiangyou

Jianjiang River

Jintiaogou

Jiyu

Jiyu power station

Juyuan

Juyuan High School

K

Kuzhuba $\quad 77,212,216$

Kuzhuba power station $\quad 212,216$

L

Lamamiao $\quad 37$

Landsat

Landslide

Laochang

Leidashu

Leigu

Liangjiashan

Lixian

Long'an

Longfeng

84

48

59,122

44

116,120

$90,93,138$

143

78

59

170

$112,212,223$

47,74 141,144

50

109,184

109

101

101

188

205

152,153

37

144

110
$20,50,78,157,164,172,173,184,196,198,203,207-209,211,212$ $94,196,210,211,228$

$82,117,119,187,242$

$3,8,47,50,62,89,90,105,146,193,235-238$

$23,90,136,137,138,164,194$

$20,24,25,30,70,72,73,80,81,164,167-170,190,196,207$

$3,5,17,210,211,230,231$

$20,25,27,43-45,47,48,50,59,62,65,66,70,72,74,77,78,81-83,85-$ $87,89,98,100,104,108,109,111,123,128,135,136,146,155,157,159$. $161,163,164,166,170,172,173,175,177,178,180-184,187-189,191$ $-193,196,198,200,203,207,209,211,212,215,218,220,225,227$

$90,108,164,191$ 
SPOT

Synthetic aperture radar

T

Macaotan

Maliuwan

Maoxian

Miansi

Mianyang

Mianyuan River

Mianzhu

Minjiang River

Muyu

N

Nanba

Nanba Primary School

Nanxin

Nanxin power station

National Road

O

Optical Image

\section{$\mathbf{P}$}

Pengzhou

Pingtong

Pingwu

Provincial Road

\section{Q}

Qianfo

Qingchuan

Qinghai-Tibet Platean

Qingjiang River

Qingxi

Qingyi

QuickBird

Qushan

$\mathbf{R}$

Radar image

Radarsat

Resouresat

S

Sandui

SAR

Seismic belt

Seismic intensity

Shaba

Shangheba

Shapai power station

Shiba

Shibangou

Shifang

Shigu

Shikan

Shuiguan

Songpan

SOS
$23,37,38,50,90,93,94,97,104-107,109,141,143,145,150,157,16$ $4,177,182-184,192,216$

212,218

$5,6,90,128,129,130,132,135,164,166$

166

$36,40,59,82,83,116,117,119,120,187,242$

$20,26-29,38,39,48,50,54-56,89,100,106,109,164,171,173-175$, $177,179-184,186,187,191,196,207,209,211,229,231$

141

$145,189,203$

145

$37,38,177,182,212,216$

212

$164,170,173,175,177,178,180-184,186$

$37,40,50,53,54,66-69,74,77,78,83,85,86,101,103,110-112,114,115$, $119,120,125,127,132,135,138,141,143,144,146,152,153,157,200$

$90,110-112,190$

32,33

$33,34,37,44,45,85,86,90,93,144,145,164,189,203-205$ $164,167,169,170$

\section{2,184}

$47,53,59,74,77,78,90,93,141,143,157,164,195,199$

104

77

143

132

$3,4,90,99$

$30,155,212,216$

$81,87,117,188-192$

$3,9,17,62,72,130,137,148$

\section{8}

$2,9,11,13,14,16,62,82,84,90,101,106,129,164$ 104,231

141

53

186

212,220

53

$47,74,77$

$84,90,112,114,115,212,223$

109

34,35

203

144

$135,150,151,169$
Taipingyi power station

Taipingyi Reservoir

Tangjiashan

Taoguancun

TerraSAR-X

Thrust fault

Tianchi

Tongkou River

V

Village Road

W

Wenchuan

Wenjiaba

Wujia

$\mathbf{X}$

Xiaoba

Xiaojiaqiao

Xiaomaoping

Xiaoyudong

Xiazhuang

Xiejunmen

Xindian

Xinjian Elementray

School

Xinzao

Xiping

Xiushui

Xuankou High School

Xuanping

Xupingba

Y

Yan'eryan

Yangdian

Yanmen

Yanyangtan

Yinghua

Yingxiu

Yingxiu Primary School

Yinxing

Younian

Yuli

Yunxi

Z

Zagunao

Zesang

Zhangjiaba

Zhangiaping

Zhicheng

Zhongxing

Zipingpu Reservoir

Zundao
$3,6,17,62,73,90,106,107,200,203,208,209,211,215,232$

212,215

$64,65,66,67,68,69,70,72,146,151,206$

$3,11,62,81,100$

82,166

81,87

177

$20,23,29,38,40,47,48,50,54-56,90,93,94,97,104,105,135,141,1$ $43,145,150,164,170,172,173,175,177,178,180,181,186,191-19$ $3,196,208,209,212,215,218,220$

85,86

135

122,125

$74,184,185$

54

190

220,221

166

54

100,101

132

138

125

97

$64,170,206$

201

183

56

177

78

114

$23,28,29,36,48,50-61,89,93,94,97,99,101,103,108,110-112,11$ $4,116,119,120,122,127,138,143,145,146,150,152,164,178$

$173,180,208,212,215$

40

$64,65,146,150,151,168-170$

115

108

55

170

178

168,169

103

$192,212,224-227$

120 


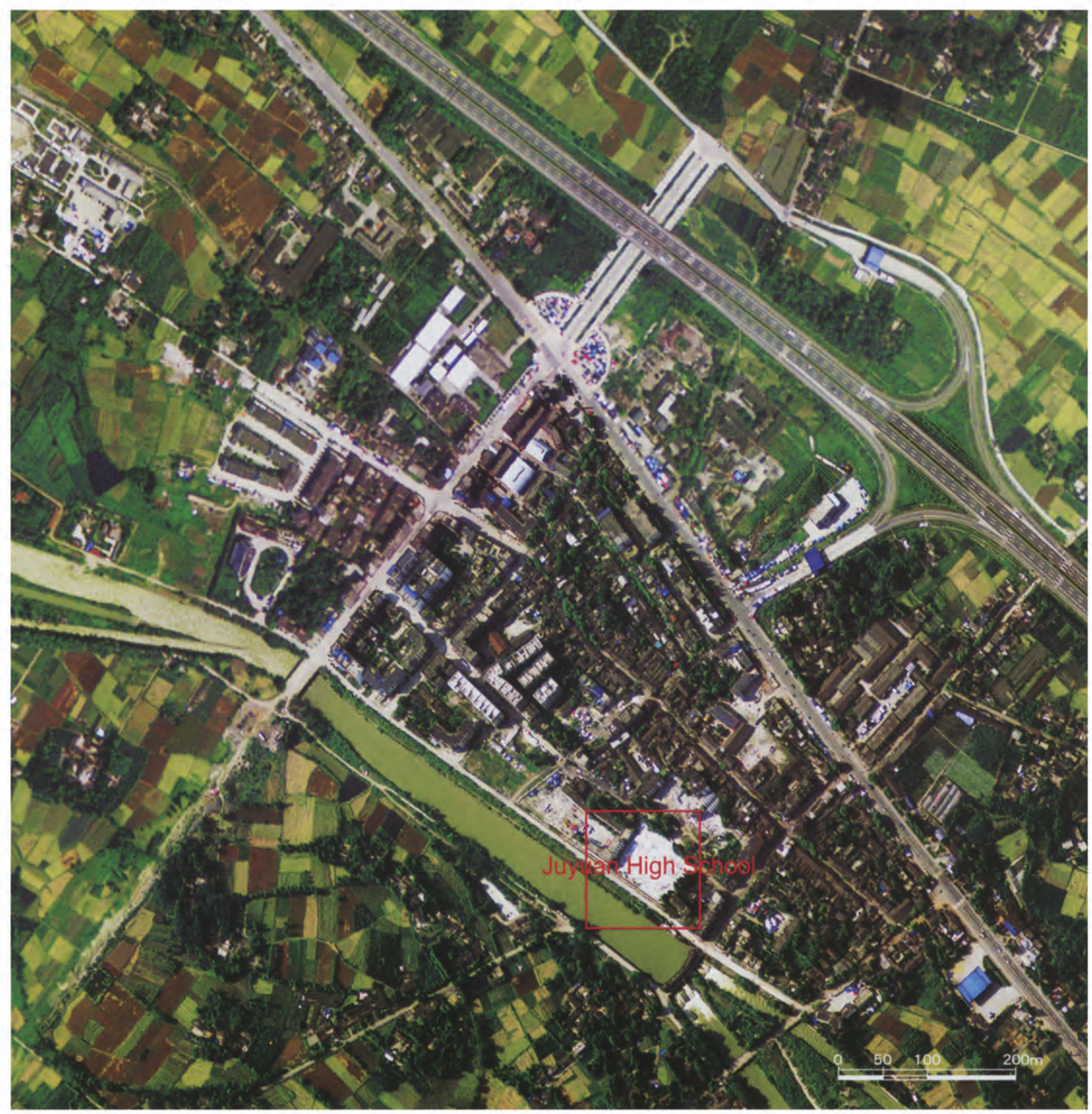

$\Delta$ Airborne optical image of the town of Juyuan, in the city of Dujiangyan

Acquired May 18, 2008. The town of Juyuan is no more than $25 \mathrm{~km}$ away from the town of Yingxiu. The houses in the town of Juyuan were also seriously damaged, and over one-fifth of them collapsed. The red frame inside the image marks Juyuan High School, where heavy casualties occurred.

4 SAR image on May 15, 2008 also shows collapsed houses and buildings in the city of Dujiangyan. Examples include Xinjian Elementary School and the Traditional Chinese Medicine Hospital of the city of Dujiangyan. 


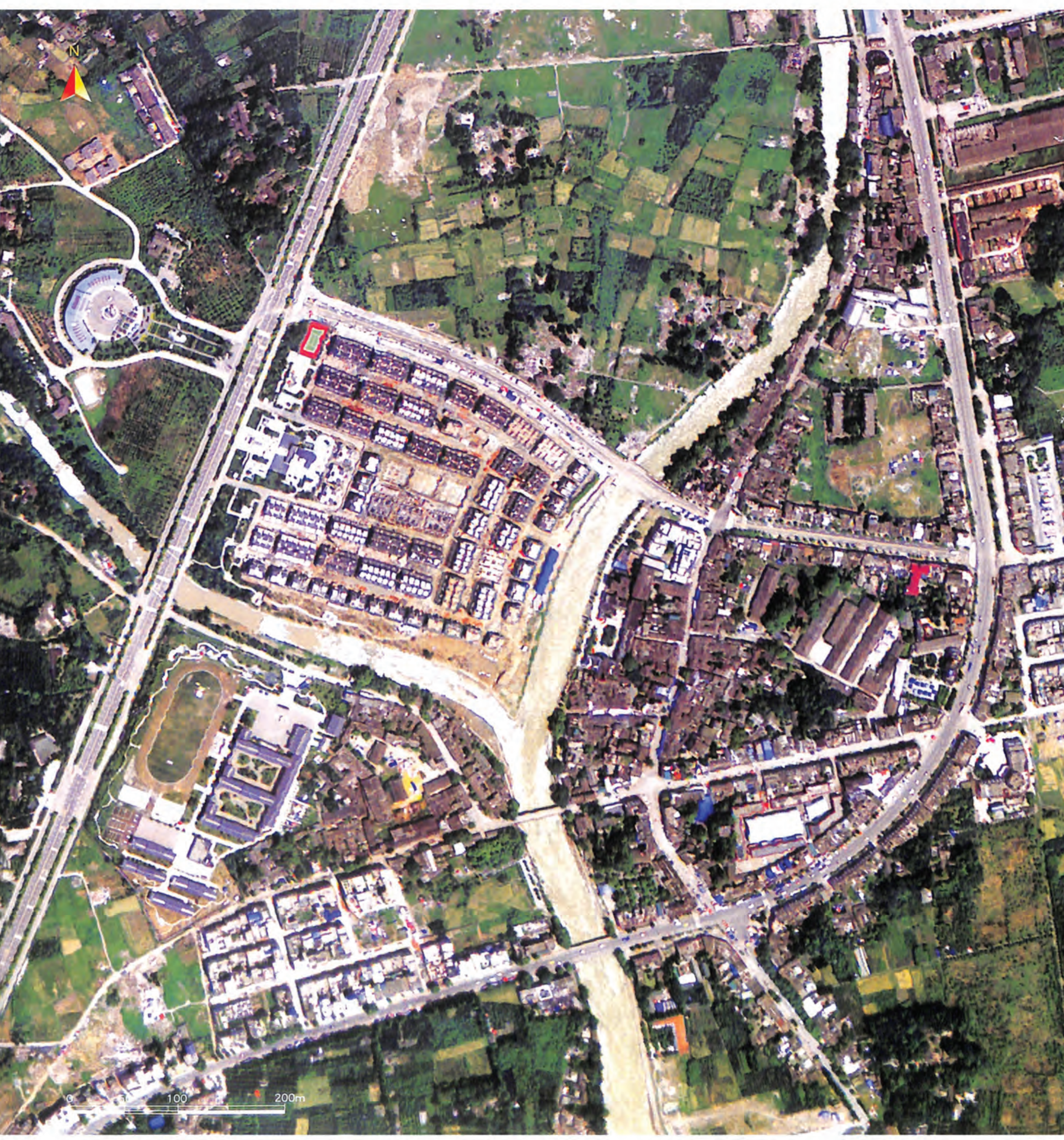

102 I Atlas of Remote Sensing of the Wenchuan Earthquake 

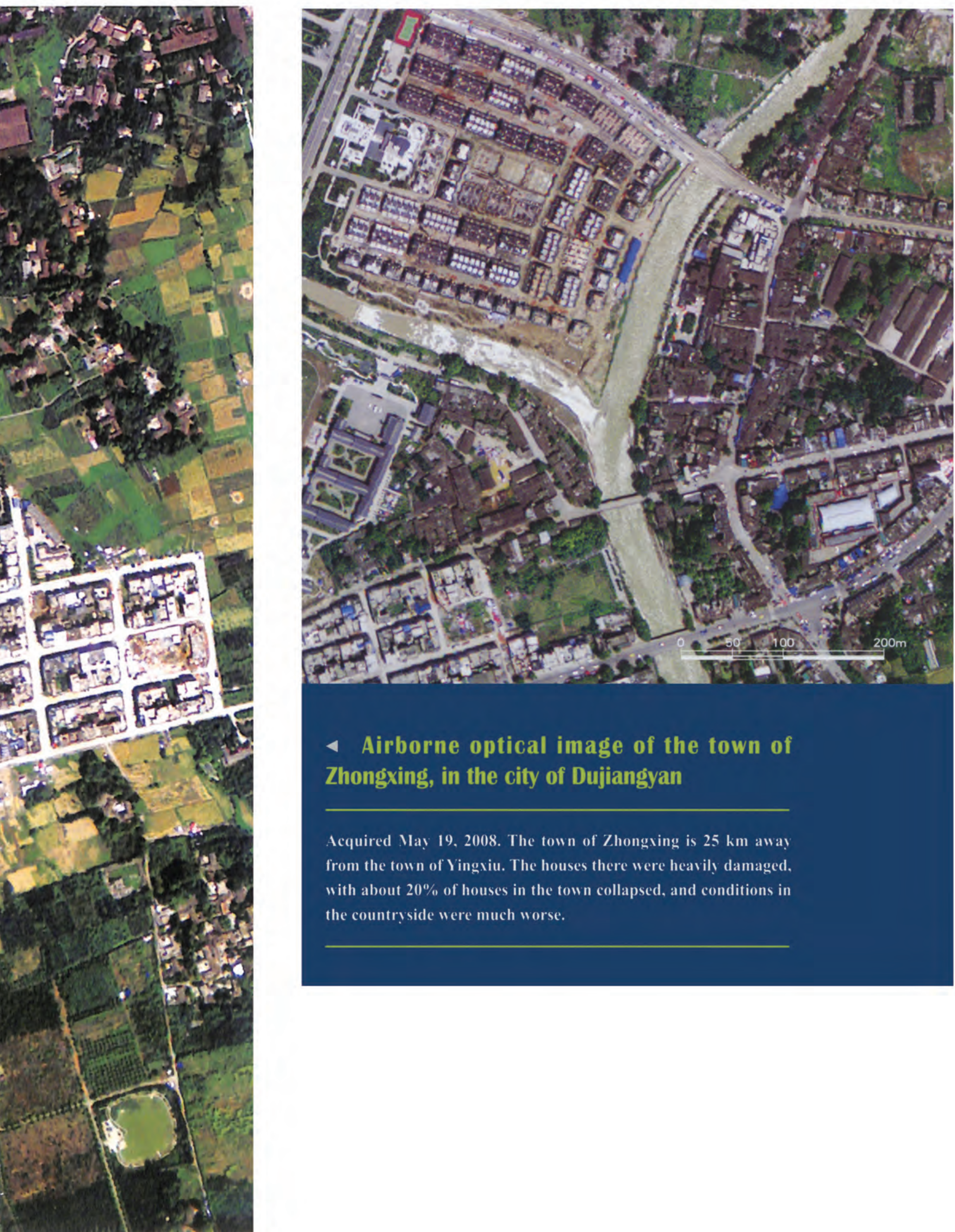

4 Airborne optical image of the town of

Zhongxing, in the city of Dujiangyan

Acquired May 19, 2008. The town of Zhongxing is $25 \mathrm{~km}$ away from the town of Yingxiu. The houses there were heavily damaged, with about $20 \%$ of houses in the town collapsed, and conditions in the countryside were much worse. 


\section{Distribution of the collapsed buildings in Maoxian County}

Maoxian County is located in the southeast section of Aba Tibet and Qiang Autonomous Prefecture, which is the transitional zone from the Qinghai-Tibet Plateau to the Sichuan Plain, and is the main residential area of the Qiang people. Maoxian County lies along the Wenchuan-Maoxian seismic belt, and nearly $20 \%$ of the houses were either severely damaged or collapsed in the urban area of the Maoxian County.

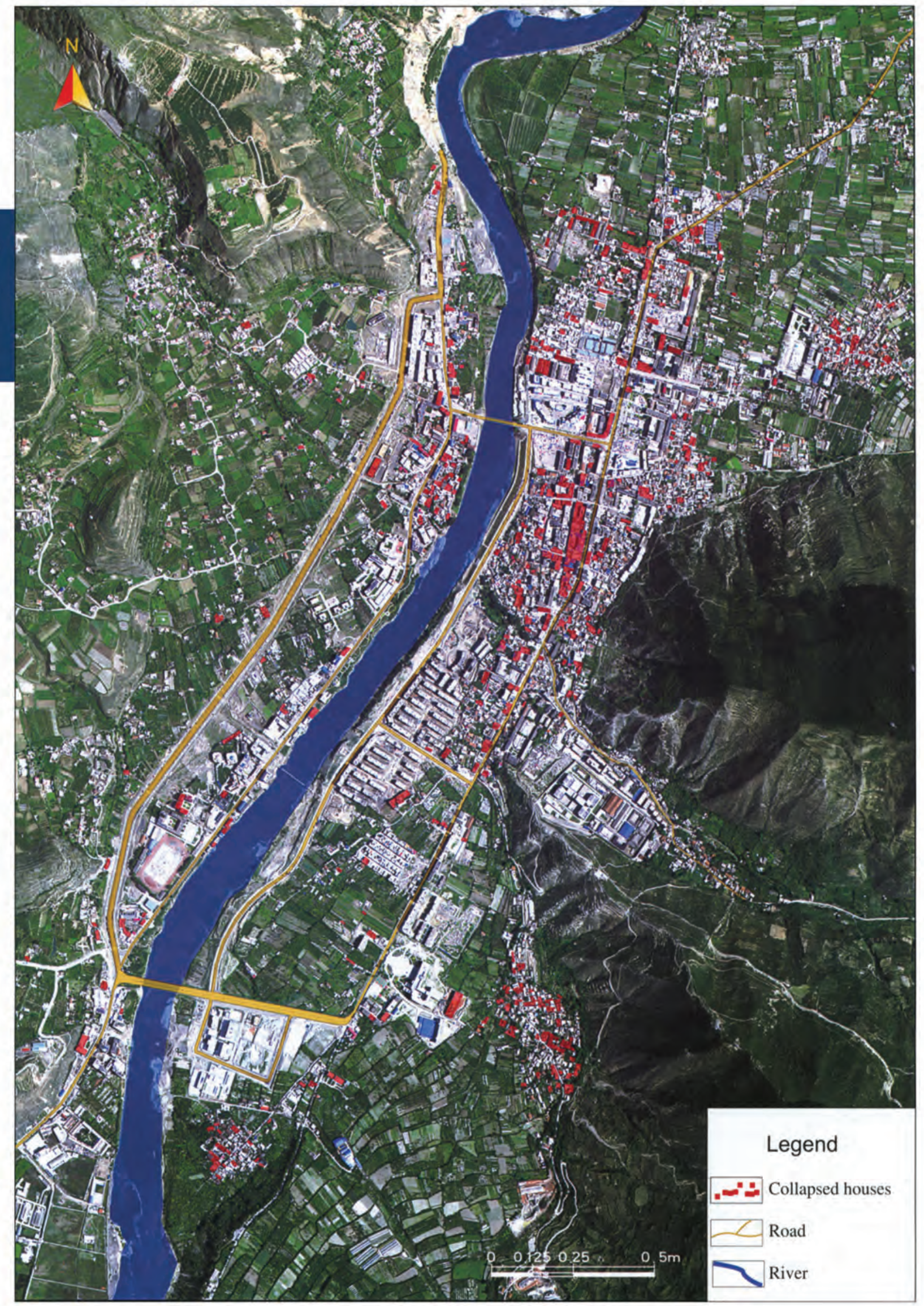


Acquired May 23, 2008. Maoxian County lies on the Wenchuan-Maoxian Fault. In the urban area of the county, about $20 \%$ of the buildings were either collapsed or severely damaged, and these collapsed buildings can be seen clearly on the IKONOS image. The red frame in the image represents the most severe damage.

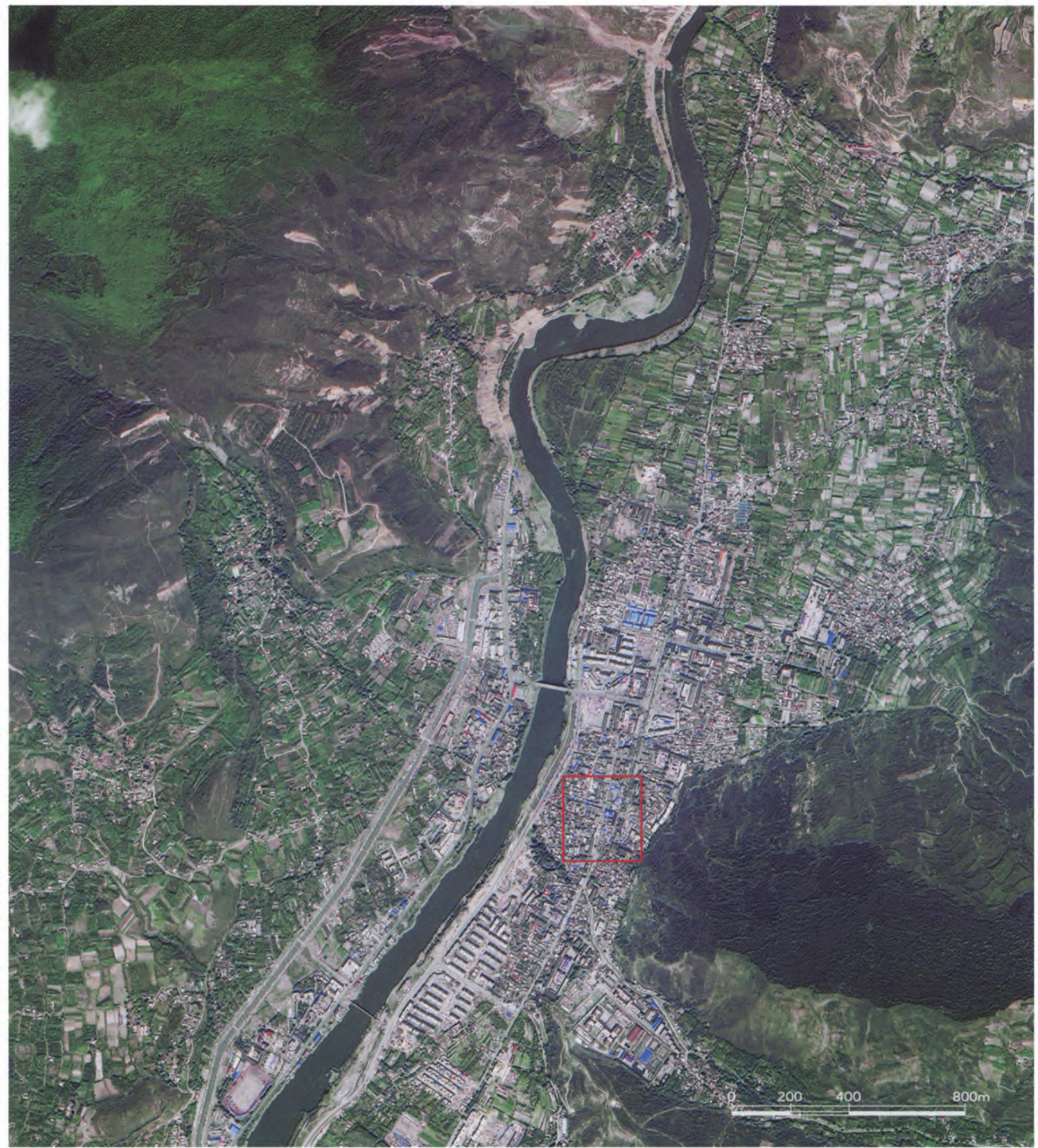


Comparing post-quake X-band high resolution SAR image (acquired May 14, 2008) with prequake 2.5-m resolution SPOT image (acquired November 11, 2005), some collapsed houses in both rural and urban areas were found.

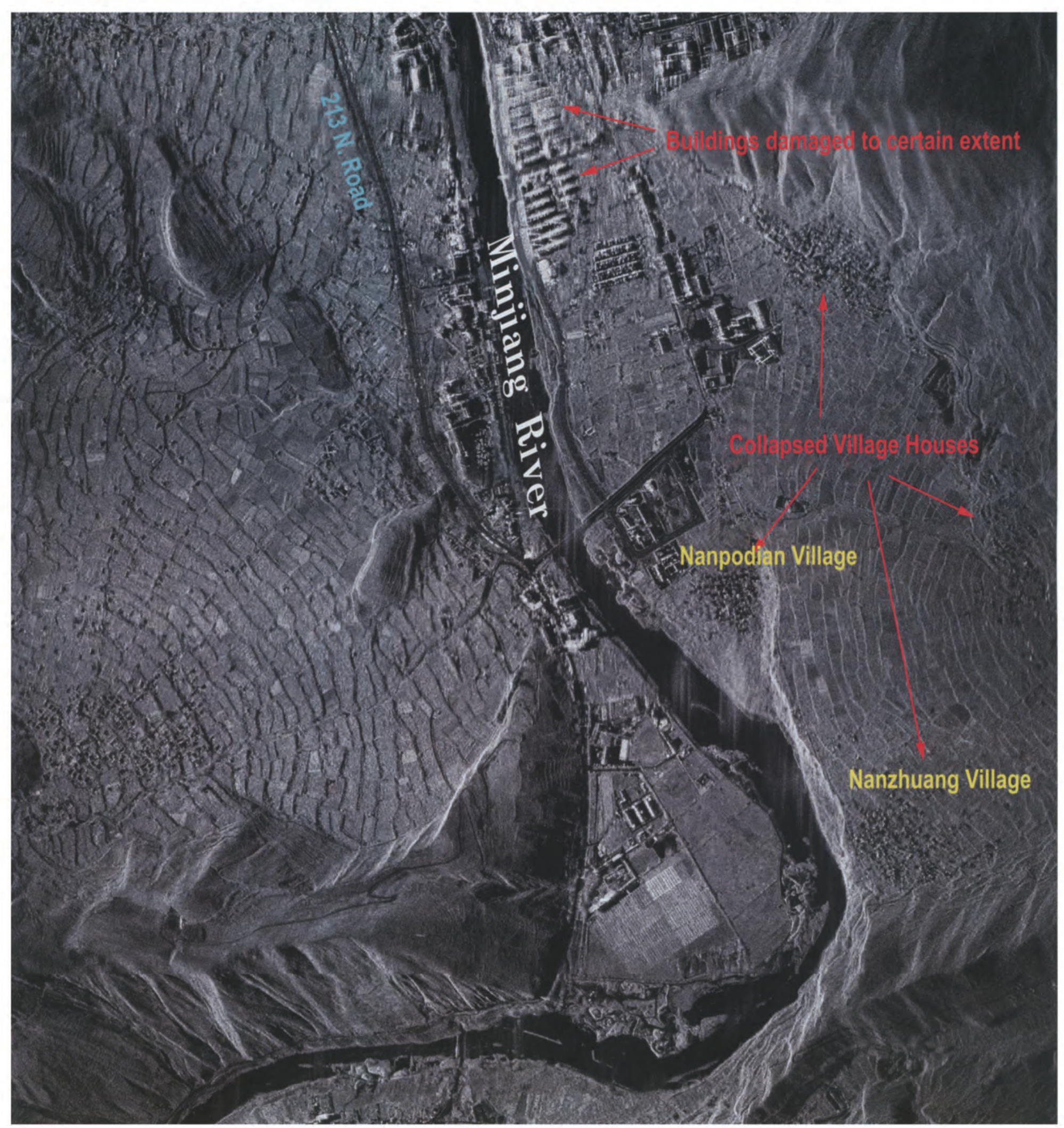


v Pre-earthquake SPOT 5 image of Maoxian County (acquired November 1, 2005)

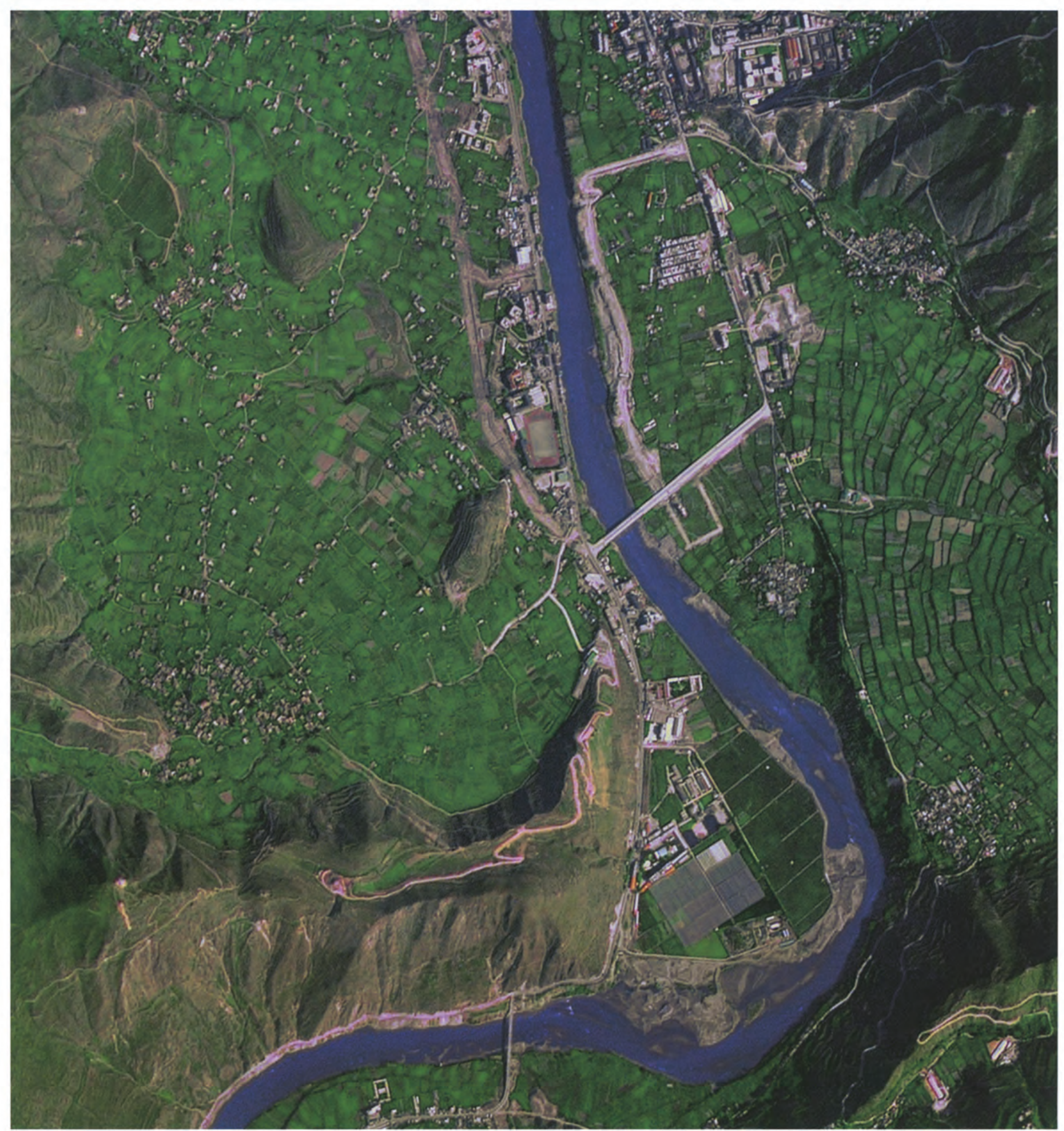




\section{Distribution of the}

\section{collapsed houses in}

\section{the town of Zagunao, in Lixian County}

Lixian County, situated in western Sichuan Province, has a population of more than 40,000 people, most of whom are Tibetan or Qiang. The town of Zagunao, which means "lucky place" in Tibetan, is in the urban district of Lixian County, located in mountain valleys about $54 \mathrm{~km}$ away from the epicenter town, Yingxiu. More than $\mathbf{2 0 \%}$ of houses in Zagunao were either collapsed or seriously damaged by the earthquake.

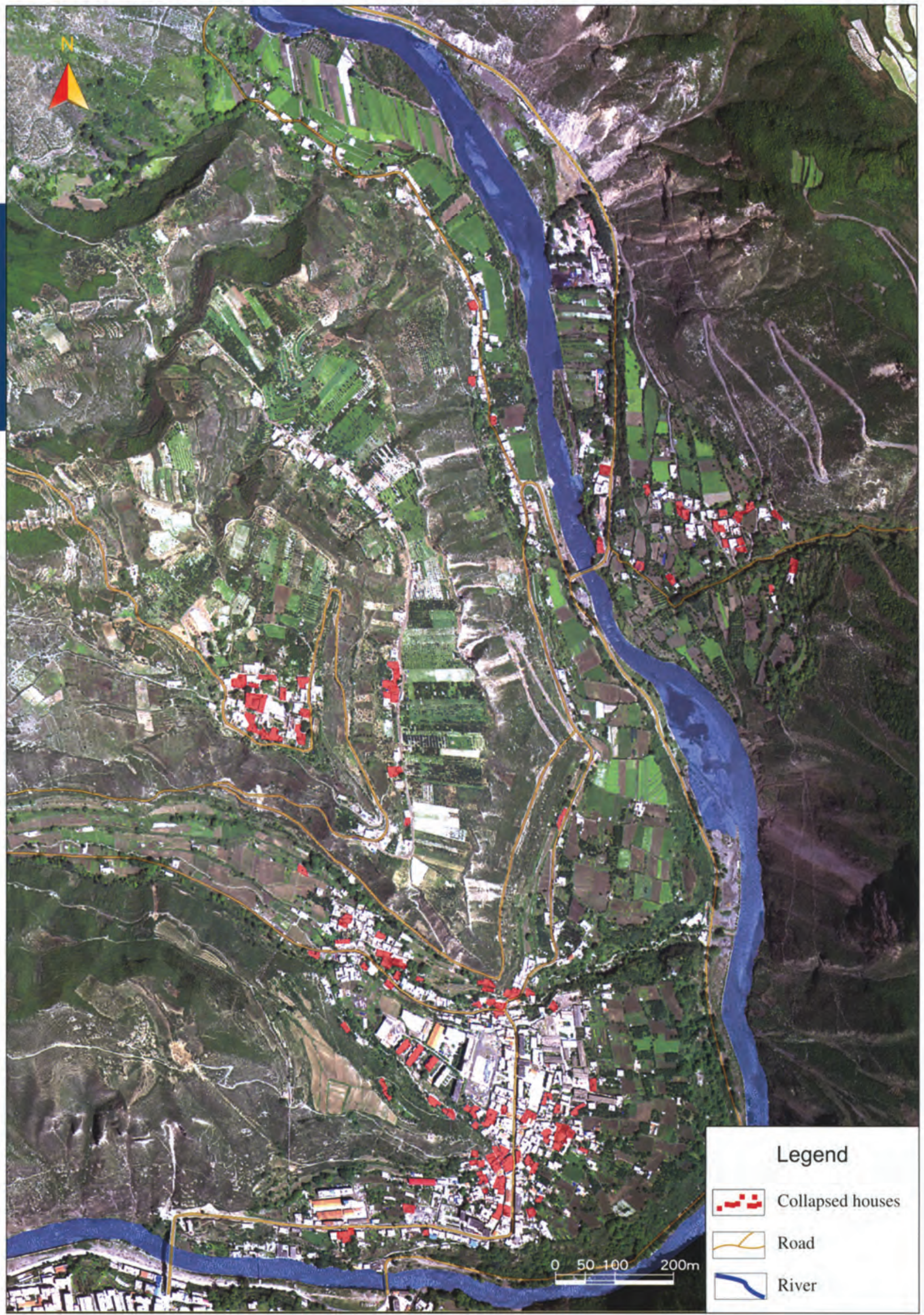

108 I Atlas of Remote Sensing of the Wenchuan Earthquake 


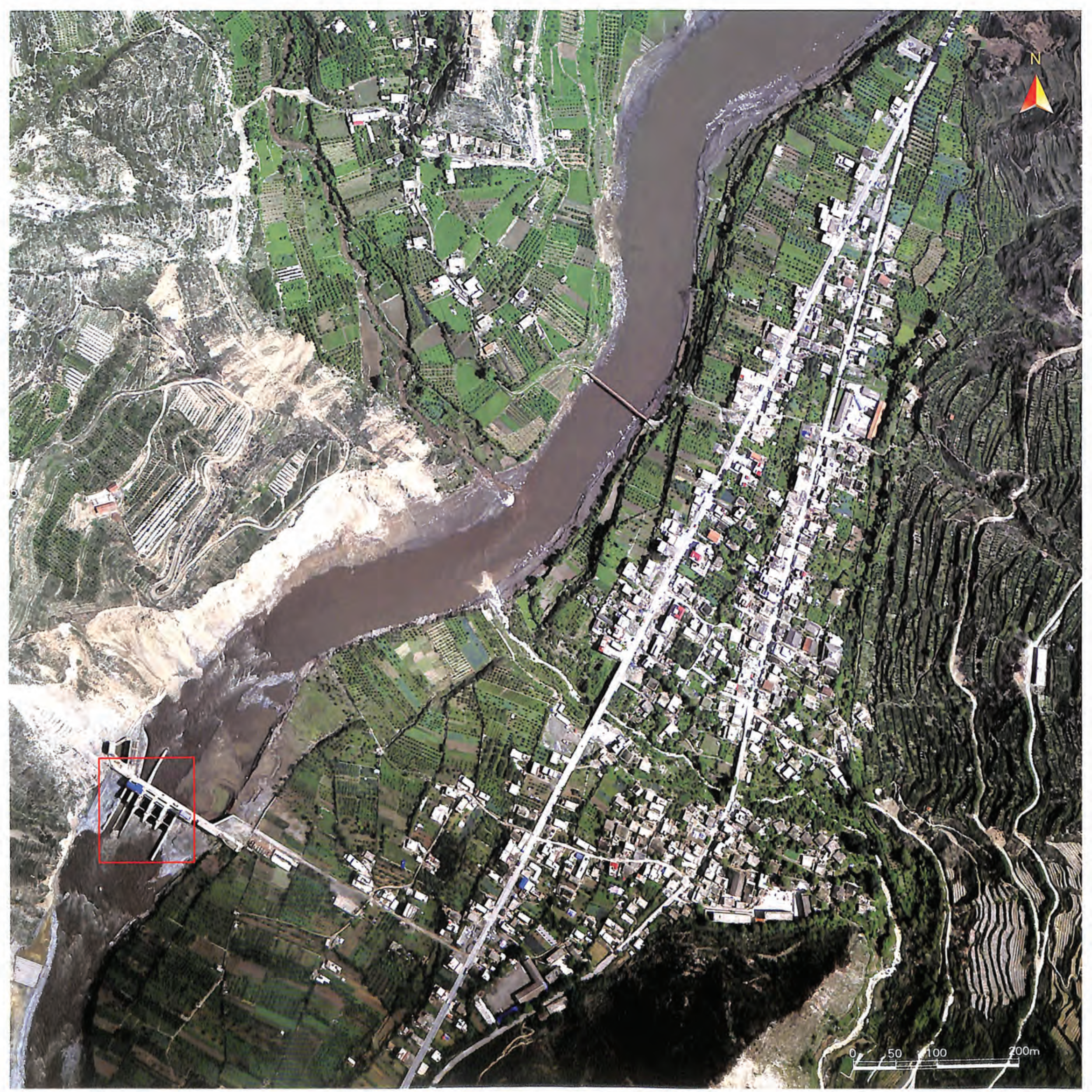

\section{A Airborne optical images of the town of Shigu, Maoxian County}

Acquired May 15, 2008. The town of Shigu is located on the east side of the Minjiang River. The houses and the buildings of the town of Shigu were relatively slightly damaged by the earthquake, and fewer than $20 \%$ of them collapsed. The red frame within the image shows the location of the Jiyu power station of the Baoshan Group, which was at high risk due to the earthquake and the earthquake-induced landslides. 


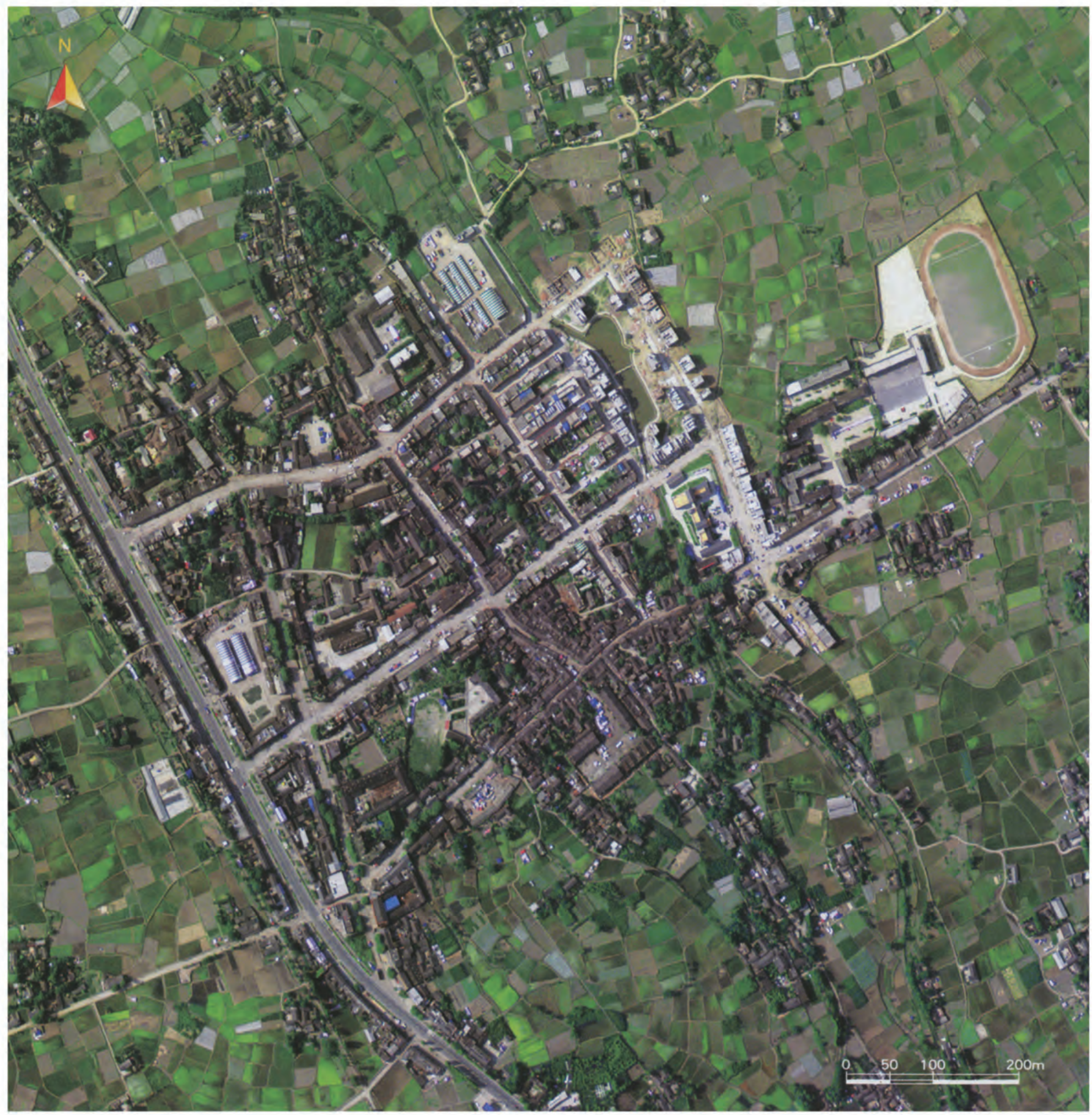

$\Delta$ Airborne optical image of the town of Longfeng, in the city of Pengzhou

Acquired May 19, 2008. The town of Longfeng, located in the piedmont plain of Longmen Mountain, is famous for producing garlic. It is $6 \mathbf{~ k m}$ away from the Anxian-Guanxian Fault and $19 \mathrm{~km}$ away from the Yingxiu-Beichuan Fault. About $20 \%$ of the houses in the town of Longfeng collapsed. 
Acquired May 16, 2008. The town of Dabao is located in the mountainous area of the city of Pengzhou. Since the Yingxiu-Beichuan Fault passes through the town of Dabao, its collapse rate was higher than $\mathbf{9 0 \%}$. No effective disaster-relief could access this area because of a traffic block caused by earthquake-induced landslides. The red frame within the image shows the collapsed houses.

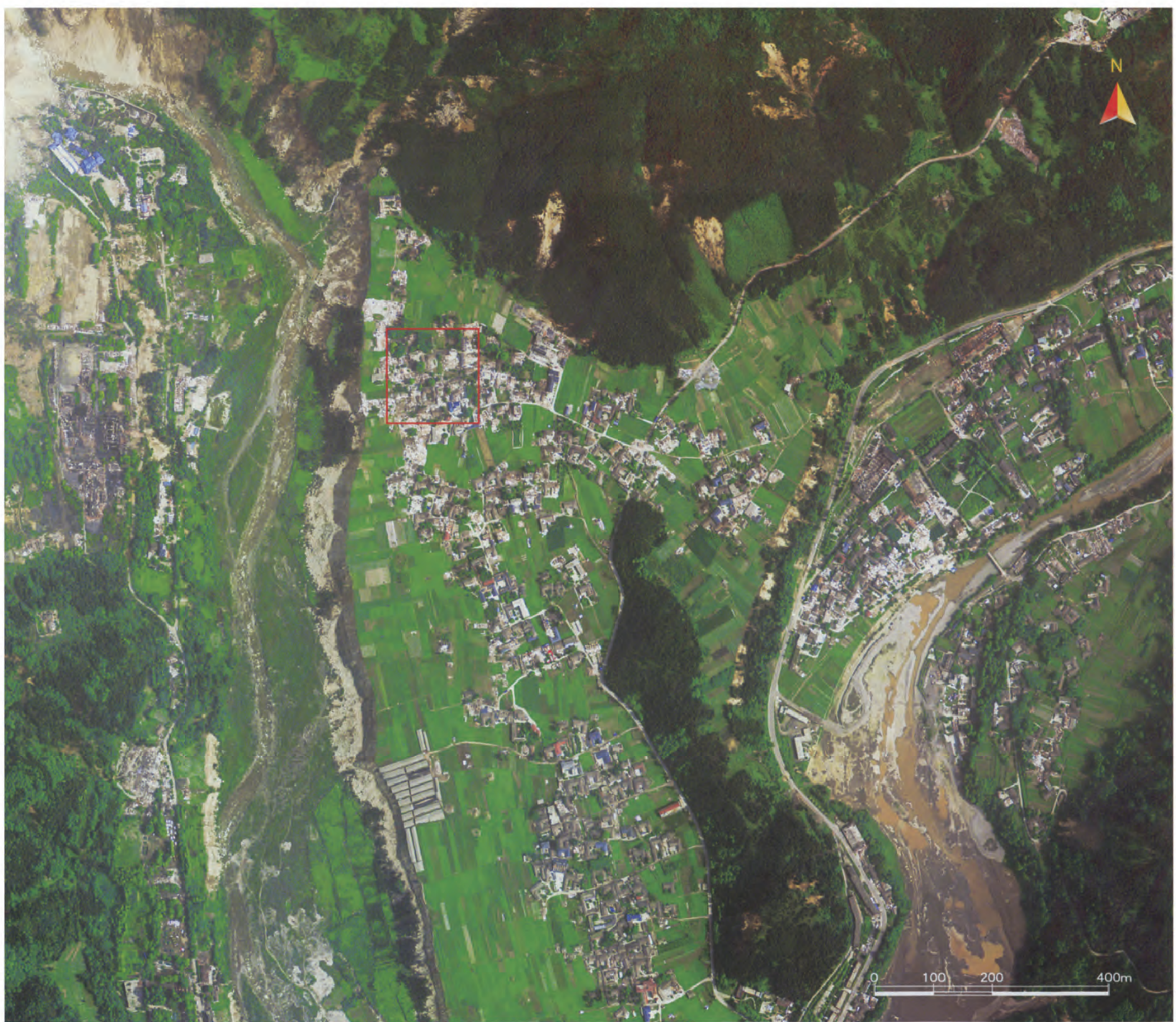


Acquired May 19, 2008. The town of Hongbai lies right above the Yingxiu-Beichuan Fault, so its collapse rate was higher than $90 \%$. The red frame shows collapsed houses and disasterrelief tents.

จ Airborne optical image of the village of Xiaojiaping, in the town of Longmenshan, in the city of Pengzhou

Acquired May 23, 2008. The village of Xiaojiaping is located in the town of Longmenshan, in the city of Pengzhou. The Yingxiu-Beichuan Fault passes through the town of Longmenshan. Therefore, the house collapse rate was higher than $90 \%$.

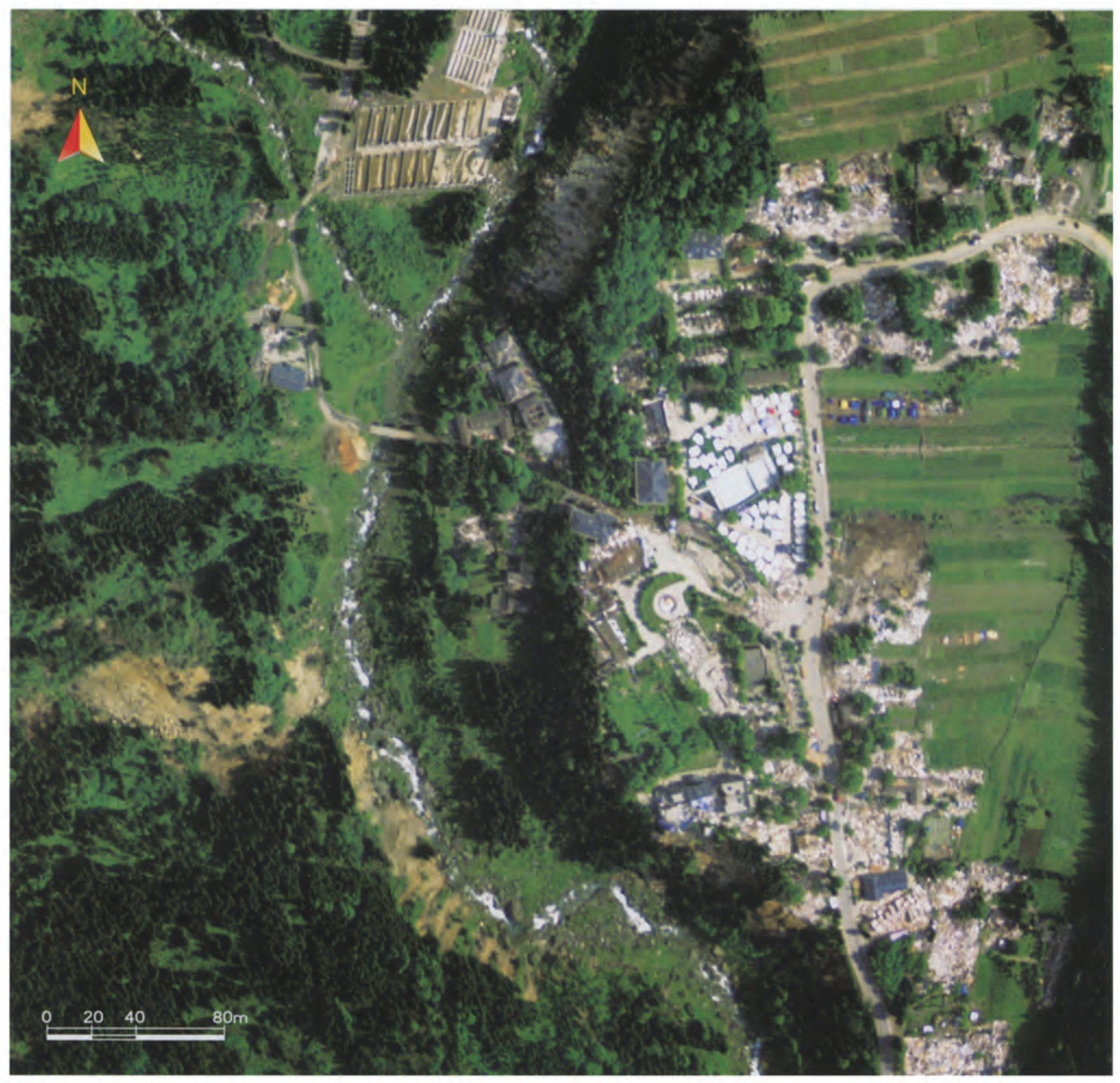

112 I Atlas of Remote Sensing of the Wenchuan Earthquake 


\section{trits 2<smiles>[AlH]</smiles>

ane

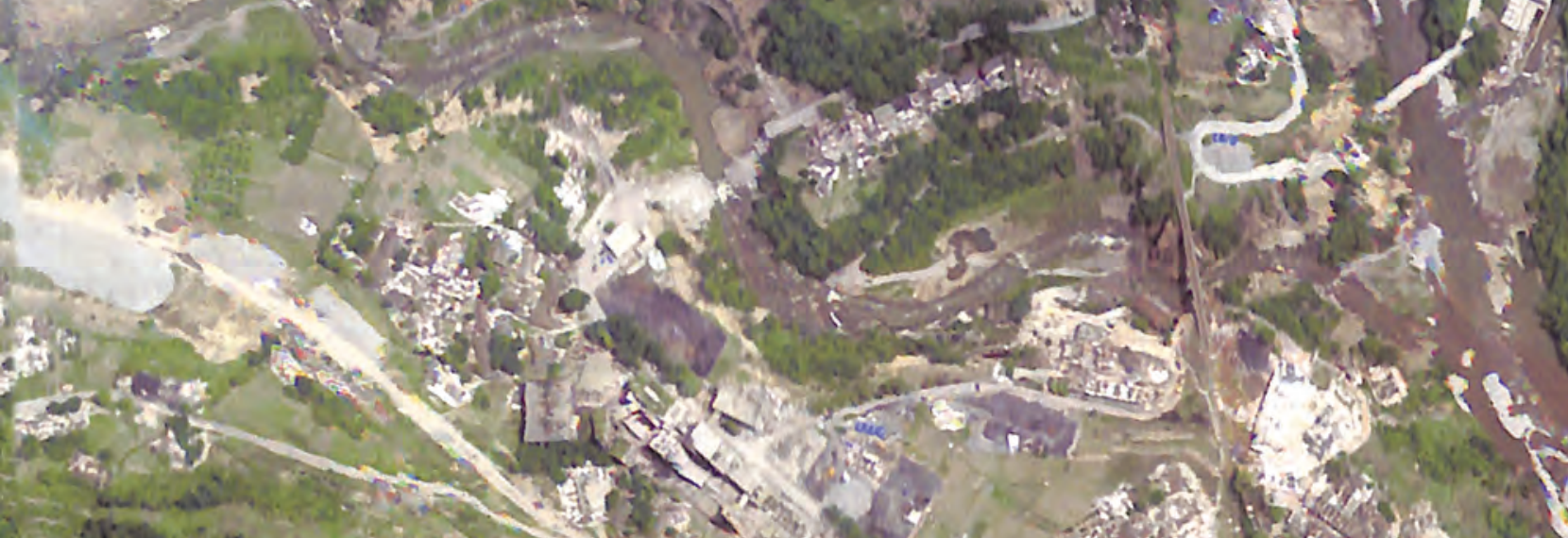

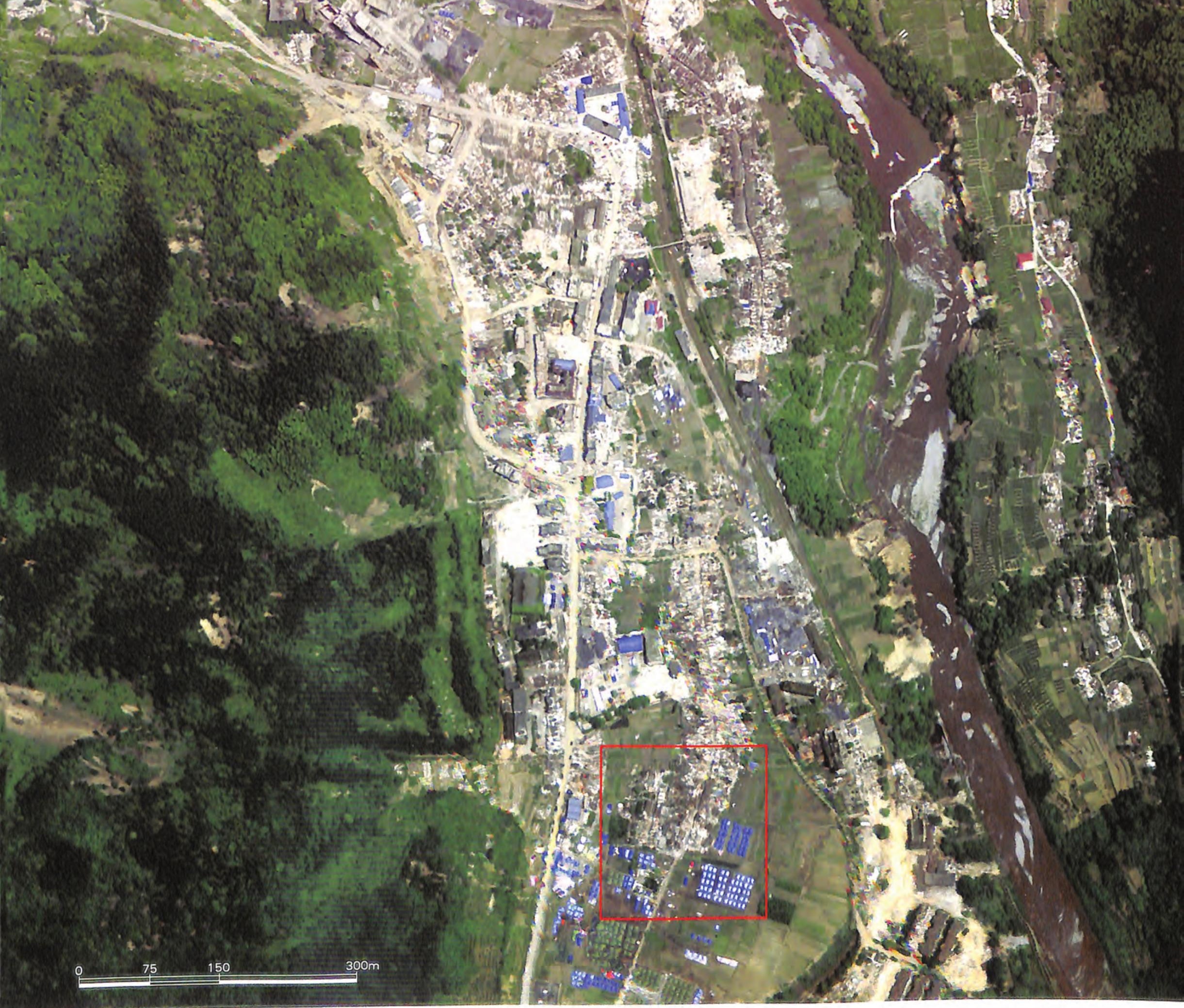


v Airborne optical image of the town of Yunxi, in the city of Shifang

Acquired May 23, 2008. The town of Yunxi is $4 \mathrm{~km}$ away from the Anxian-Guanxian Fault, and had a collapse rate of about $20 \%$. The red frame in the image shows collapsed and

damaged houses.

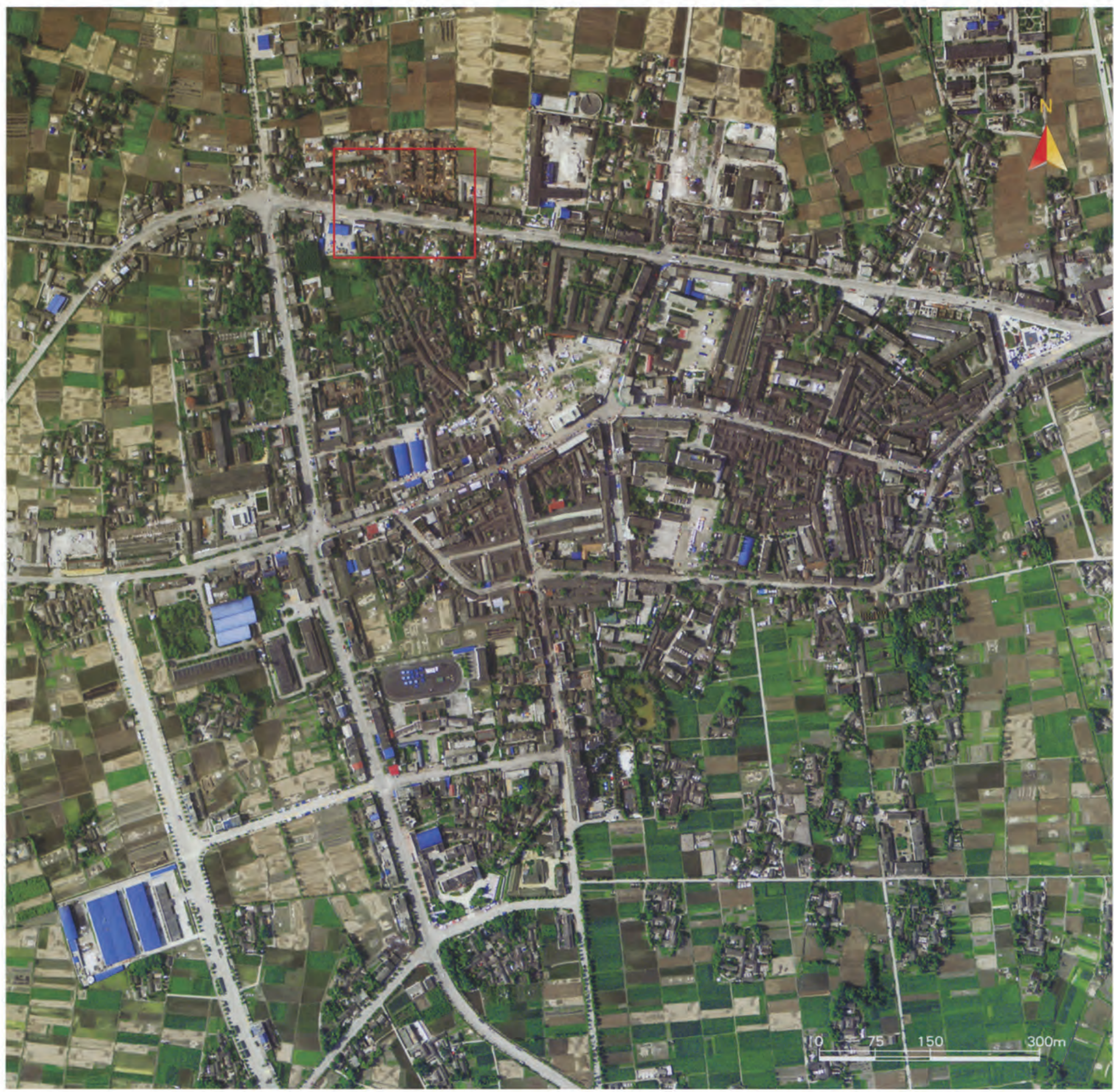




\section{Distribution of col-}

\section{lapsed houses in the city of Mianzhu}

The city of Mianzhu is located in the northwest part of the Sichuan Basin, and has an area of $1,245 \mathrm{~km}^{2}$, and ranges in altitude from $504 \mathrm{~m}$ to $\mathbf{4 , 4 0 6}$ $m$. This city is typically characterized as "Six parts hill land, three parts farm land, and one part water." The YingxiuBeichuan Fault and the AnxianGuanxian Fault pass through this city, so damage was serious and collapse rates were around $40 \%$. The collapse rate increased from the southeast to the northwest, and the collapsed houses were mainly distributed in the nine towns between the town of Guangii and the town of Gongxing. The damage in rural regions was more serious than that in urban areas. The collapse rate in urban regions was less than $\mathbf{1 0 \%}$ on the earthquake fault from the town of Guangii to the town of Gongxing. The collapse rate increased to $25 \%$ in villages and towns, while exceeding $\mathbf{5 0 \%}$ in rural regions.

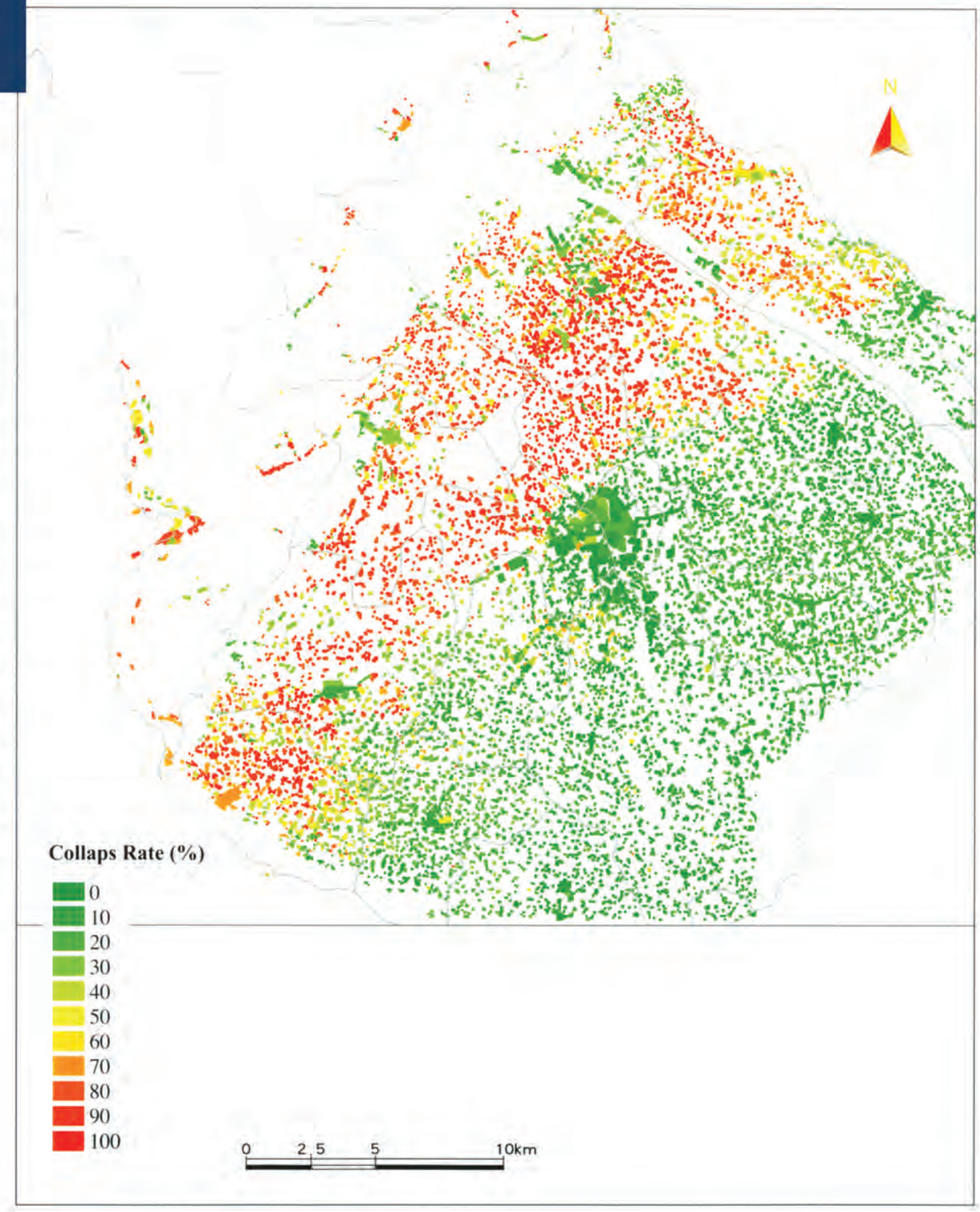




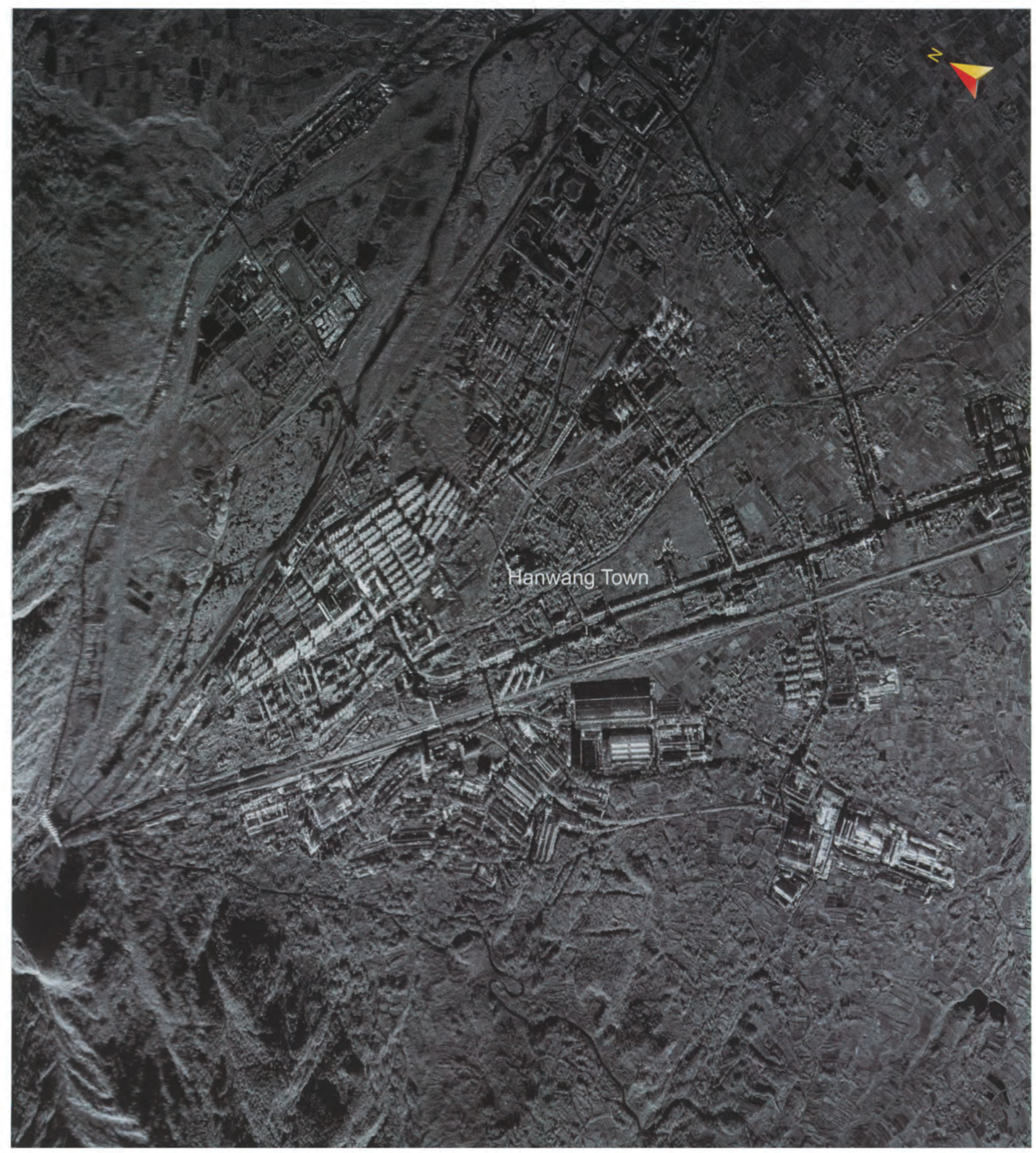

A Radar image in the town of Hanwang, in the city of Mianzhu

Acquired May 24, 2008. The radar image shows that the collapse and destruction was serious and some adjacent houses collapsed together. 


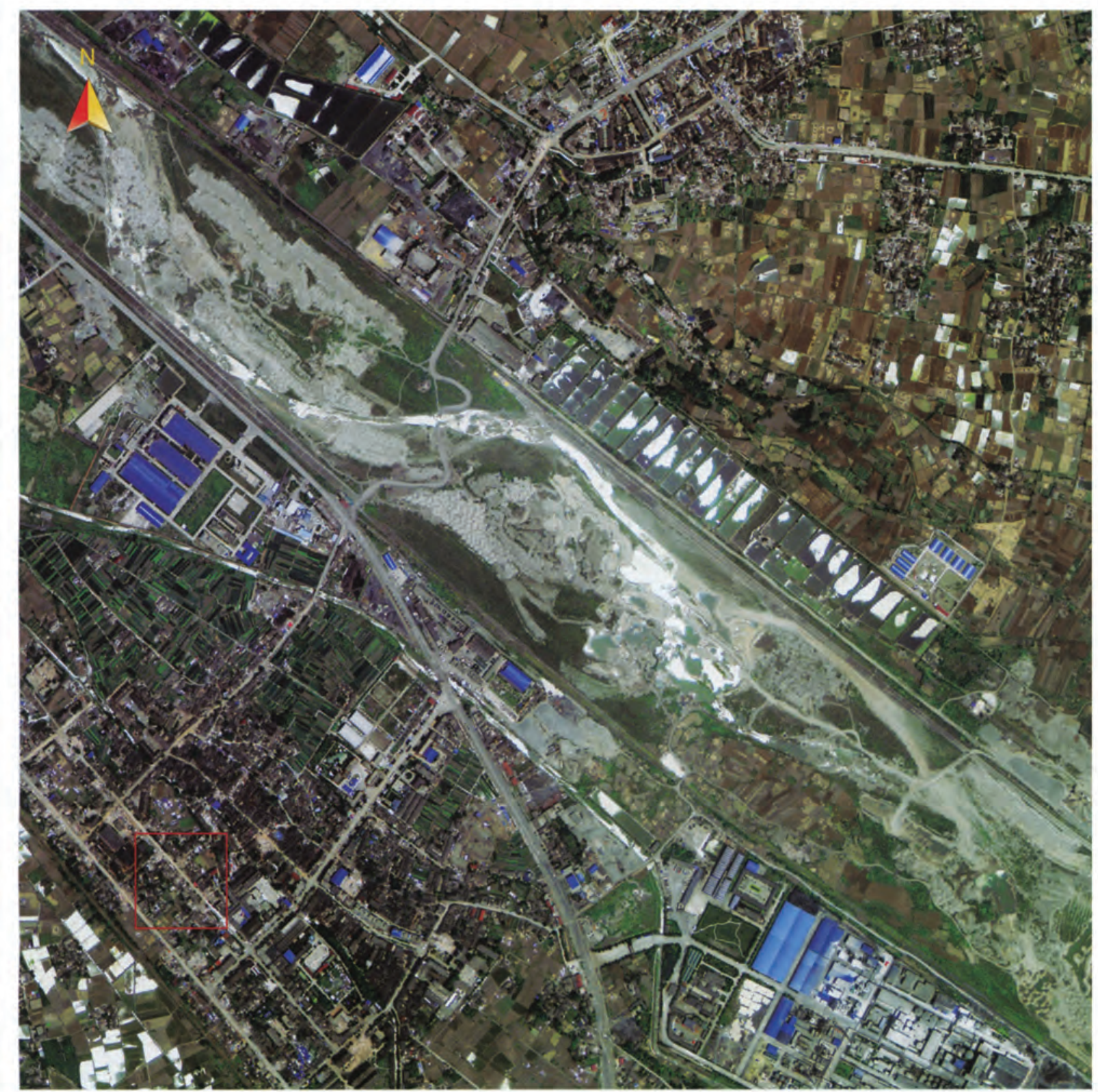

$0 \quad 100 \quad 200 \quad 400 \mathrm{~m}$
4 Airborne optical image of the town of Guangii, in the city of Mianzhu

Acquired May 19, 2008. The town of Guangii is in the piedmont transition region of Longmen Mountain and between the Yingxiu-Beichuan Fault and the Anxian-Guanxian Fault. Approximately $75 \%$ of the houses in the town of Guangii collapsed. The red frame shows collapsed and seriously damaged houses.

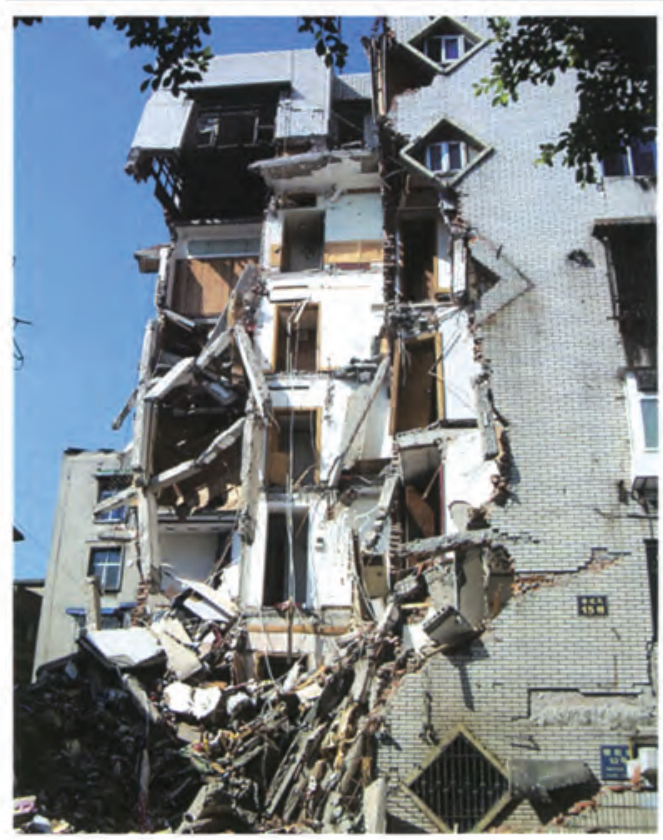

$\Delta$ Collapsed building in the town of Guangji

\section{- Airborme optical image of the town of Zundao, in the city of Mianzhu}

Acquired May 19, 2008. The town of Zundao is in the piedmont transition region of Longmen Mountain, and between the Yingxiu-Beichuan Fault and the Anxian-Guanxian Fault. The houses in the town of Zundao were seriously damaged, and the collapse rate approached $\mathbf{7 5} \%$. The red frame shows the collapsed and damaged houses. 


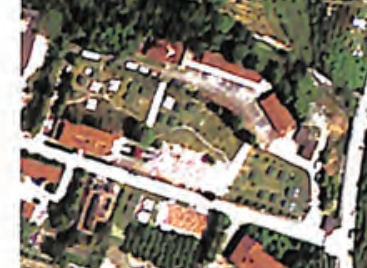

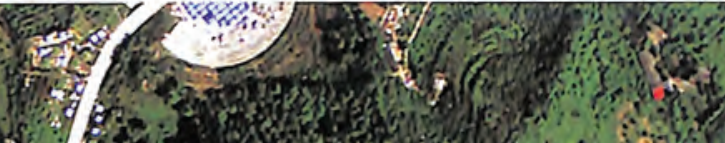

\section{D. $>>$}

4521

atc ind

Sin

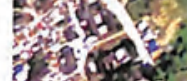

act

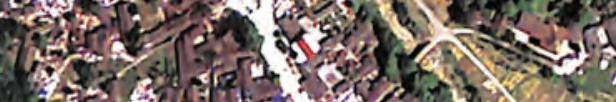

56 d

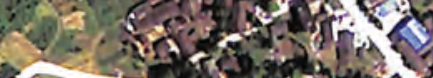

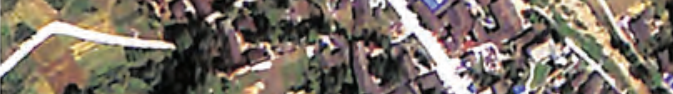

\&.

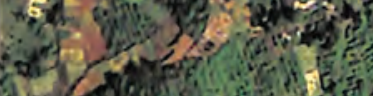

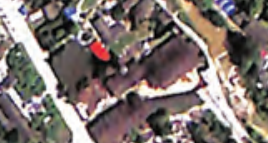

\%

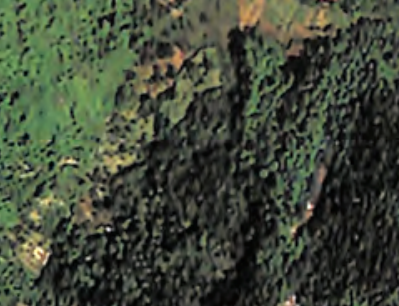

42

(6)

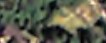
है:

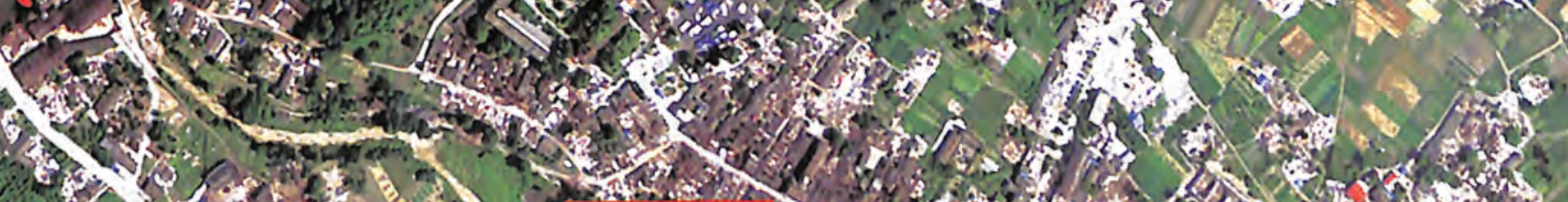
10.

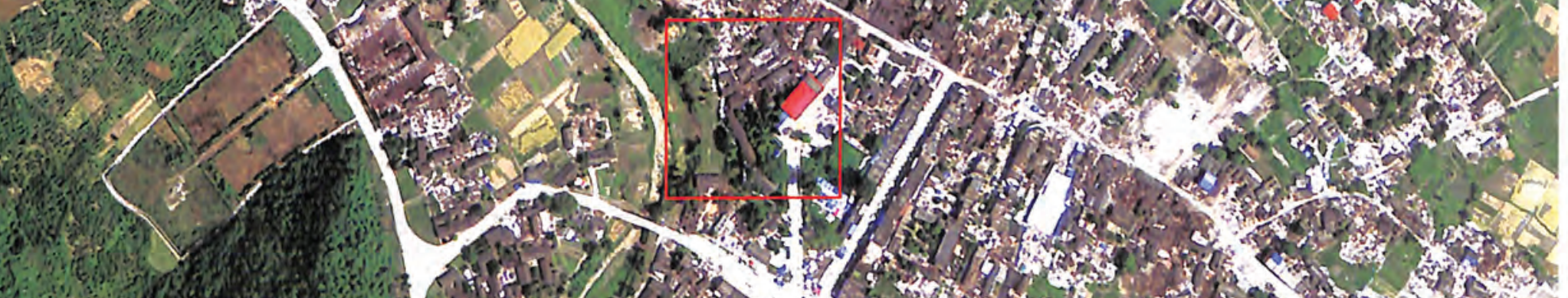
1)

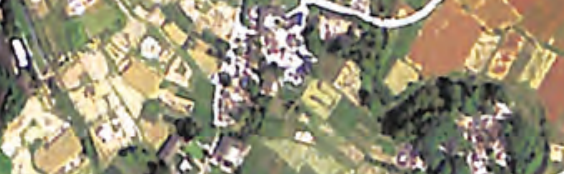
(1) b. 


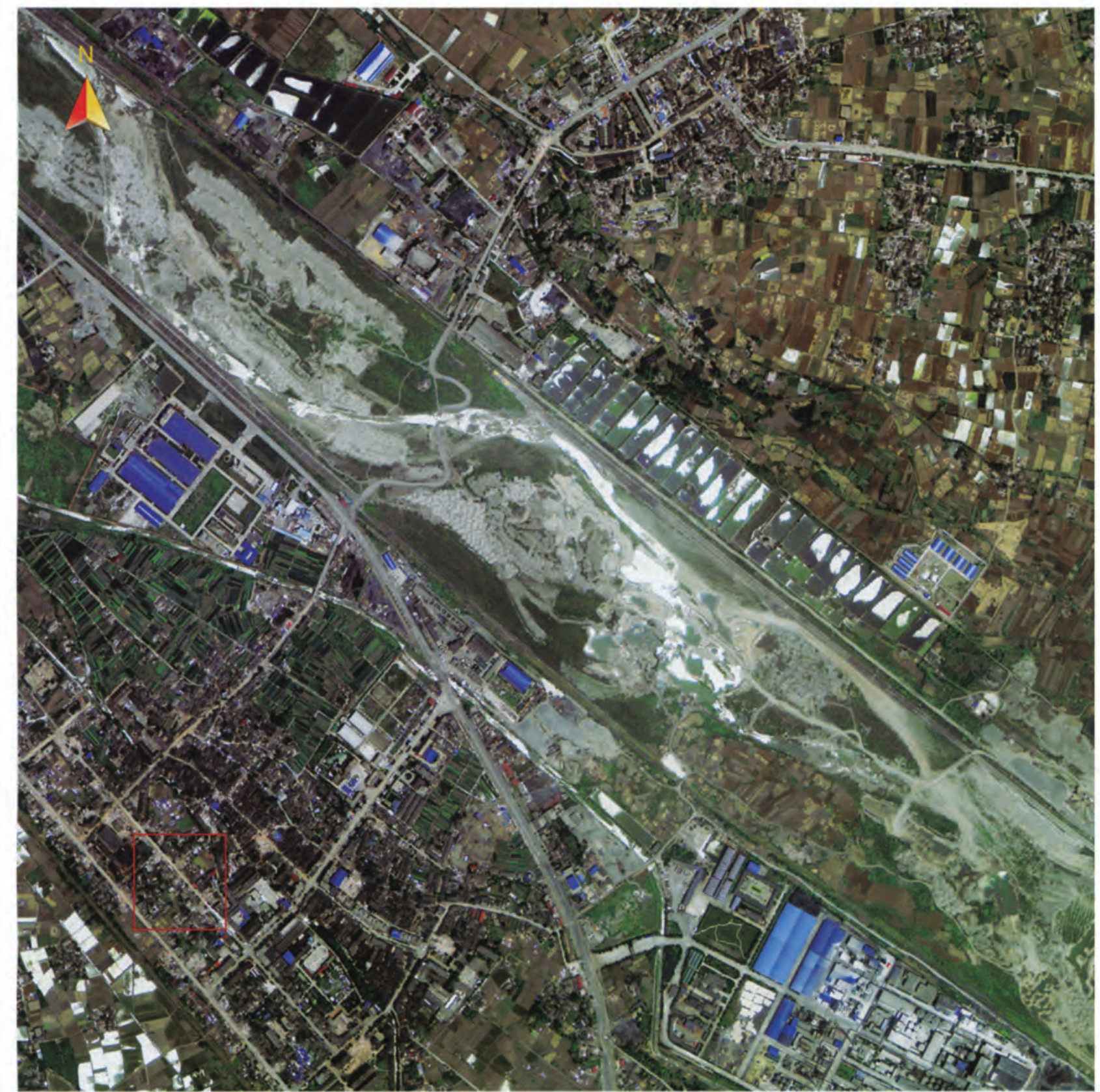

$0 \quad 100 \quad 200 \quad 400 \mathrm{~m}$
4 Airborne optical image of the town of Guangit, in the city of Mianzhu

Acquired May 19, 2008. The town of Guangii is in the piedmont transition region of Longmen Mountain and between the Yingxiu-Beichuan Fault and the Anxian-Guanxian Fault. Approximately $\mathbf{7 5} \%$ of the houses in the town of Guangii collapsed. The red frame shows collapsed and seriously damaged houses.

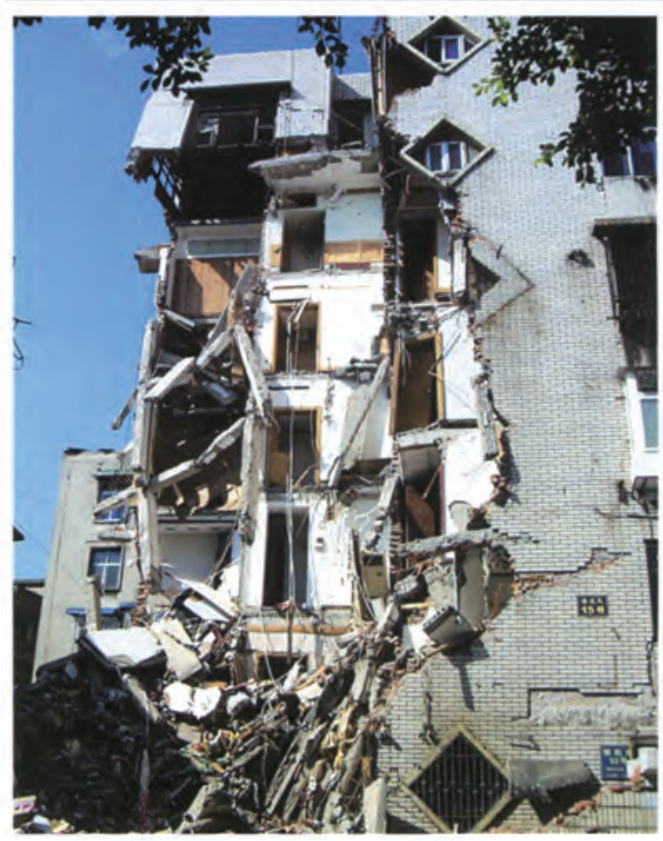

$\Delta$ Collapsed building in the town of Guangji

\section{- Airborne optical image of the town of Zundao, in the city of Mianzhu}

Acquired May 19, 2008. The town of Zundao is in the piedmont transition region of Longmen Mountain, and between the Yingxiu-Beichuan Fault and the Anxian-Guanxian Fault. The houses in the town of Zundao were seriously damaged, and the collapse rate approached $75 \%$. The red frame shows the collapsed and damaged houses. 

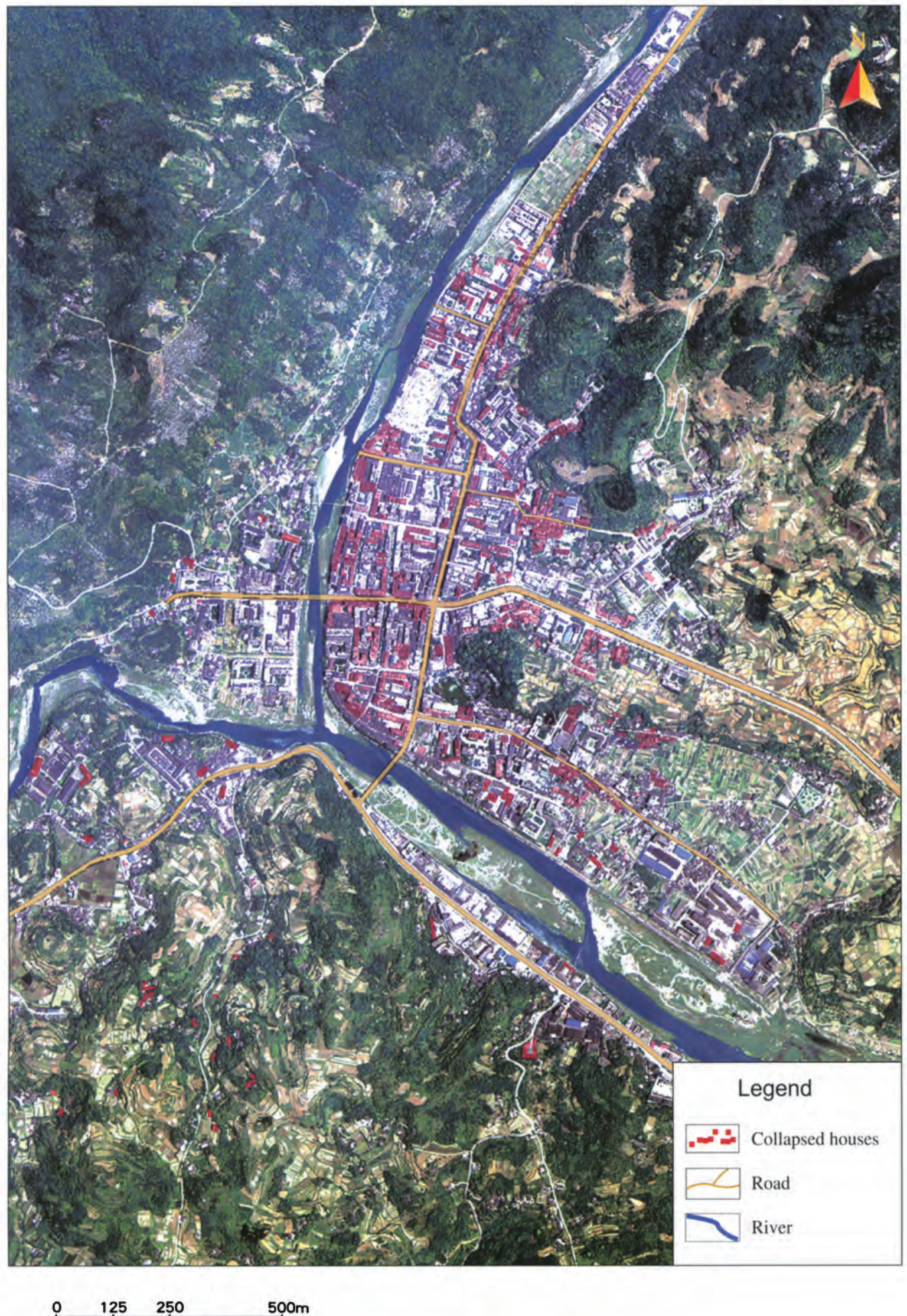

\section{Distribution of the} destroyed houses in the town of Anchang, in Anxian County

The town of Anchang is an old urban district of Anxian County; Longmen Mountain is northwest of the town of Anchang. Topography southeast part of the town of Anchang features plains and hills, and landslides there were not severe. In the town of Anchang, in the AnxianGuanxian Fault, almost $20 \%$ of the houses collapsed, while in the country the situation was much worse. 


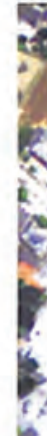

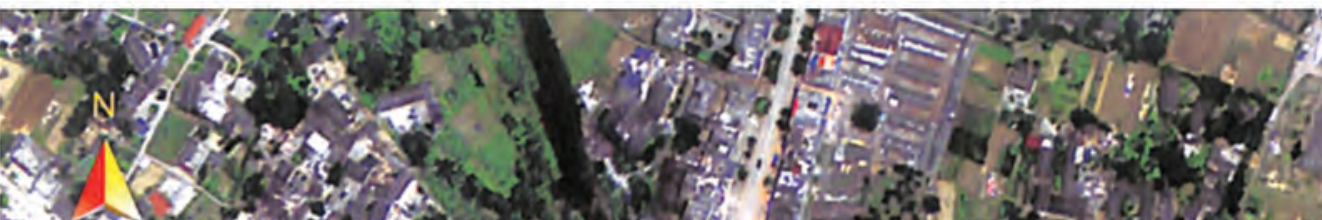

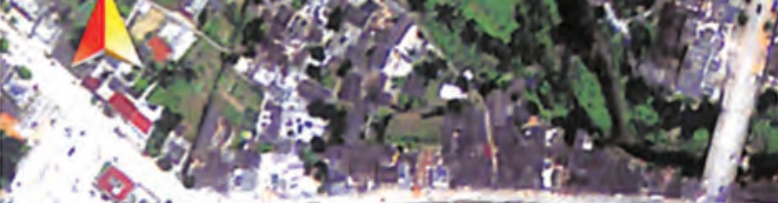

.

EI

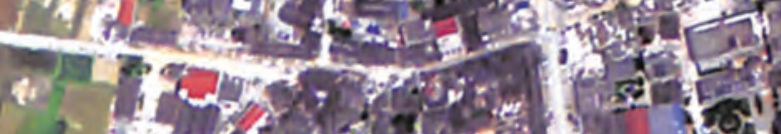

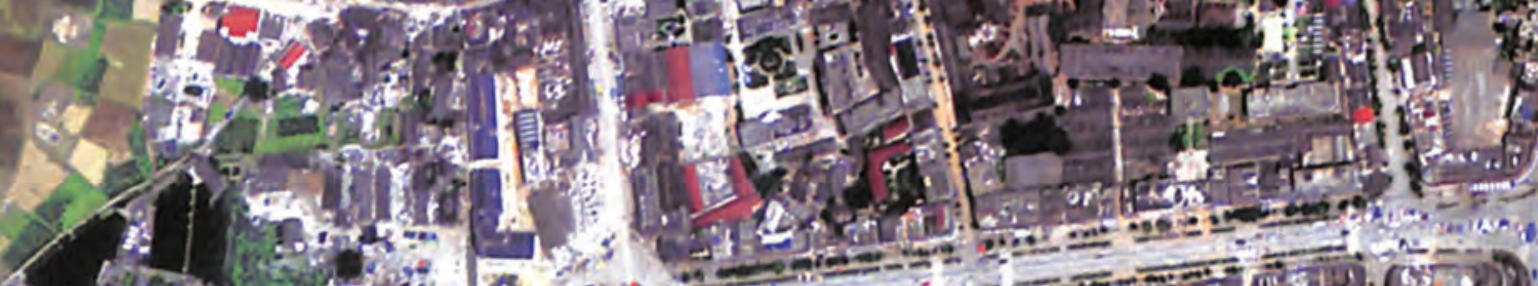

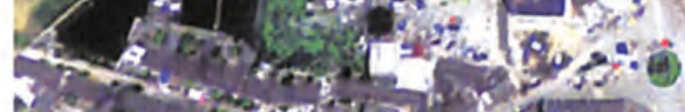

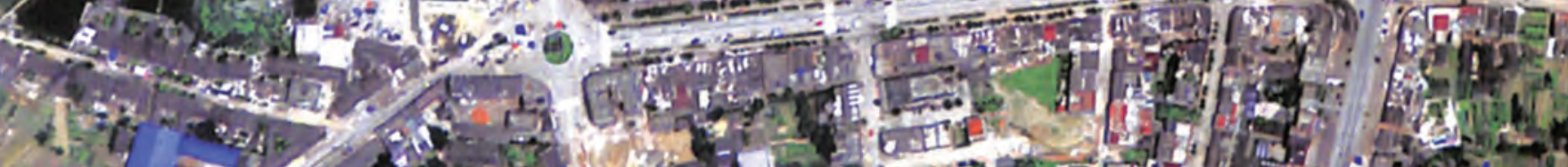

2.

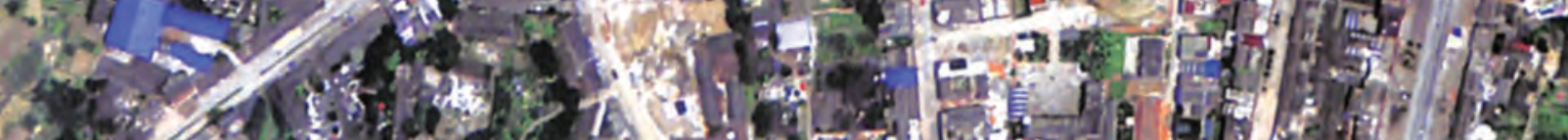

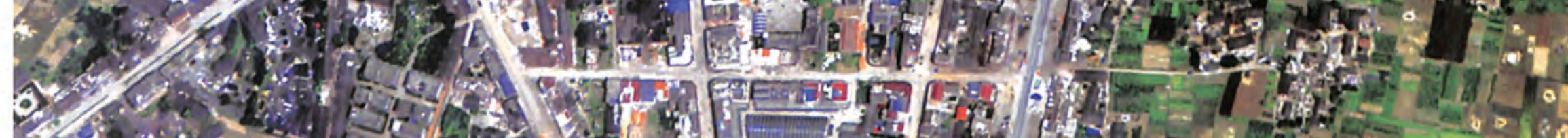

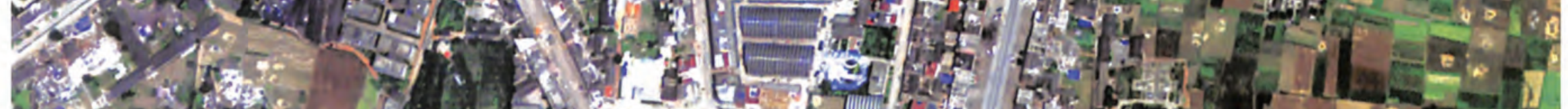

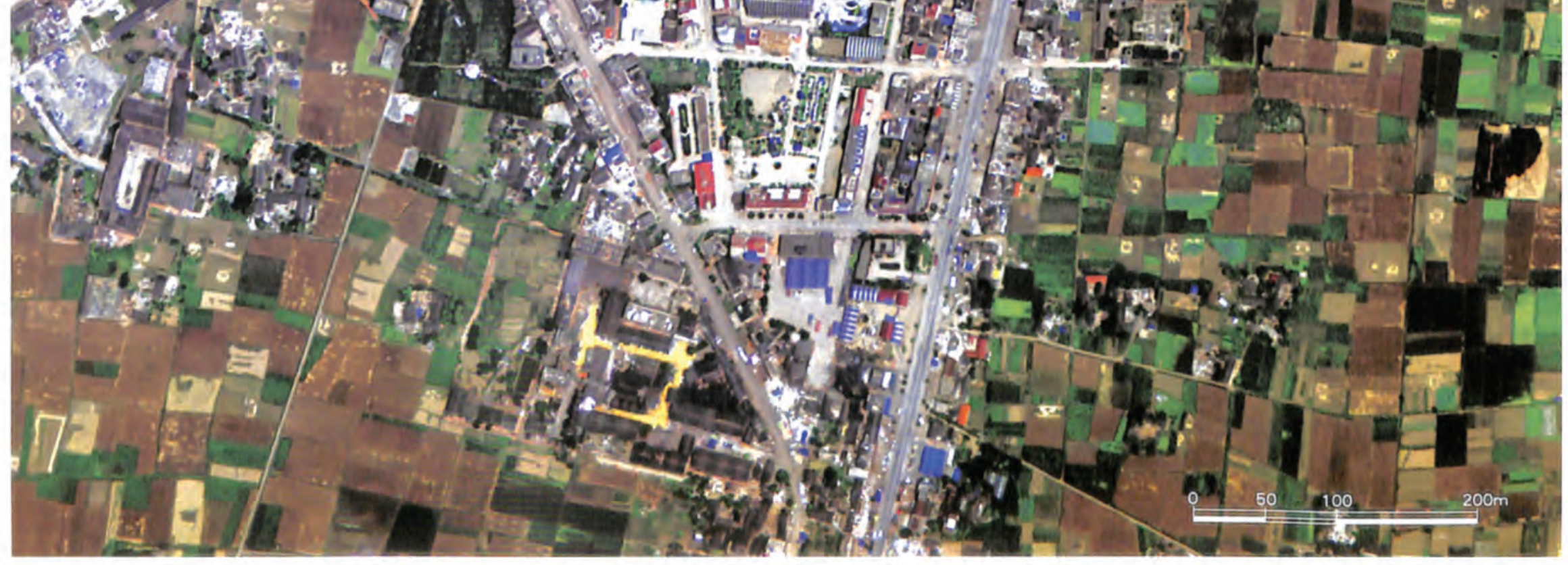

124 I Atlas of Remote Sensing of the Wenchuan Earthquake 
Acquired May 19, 2008. The town of Xiushui, located in the Anxian-Guanxian Fault, is the largest town in northwest Sichuan, with a population of more than 60,000 . Houses were seriously damaged, at a rate of more than $60 \%$.

$\nabla$ Airborne optical image of the town of Xiaoba, in Anxian County

Acquired May 19, 2008. Xiaoba is located between the Yinxiu-Beichuan Fault and the AnxianGuanxian Fault, so houses were heavily damaged; the collapse ratio was more than $60 \%$.

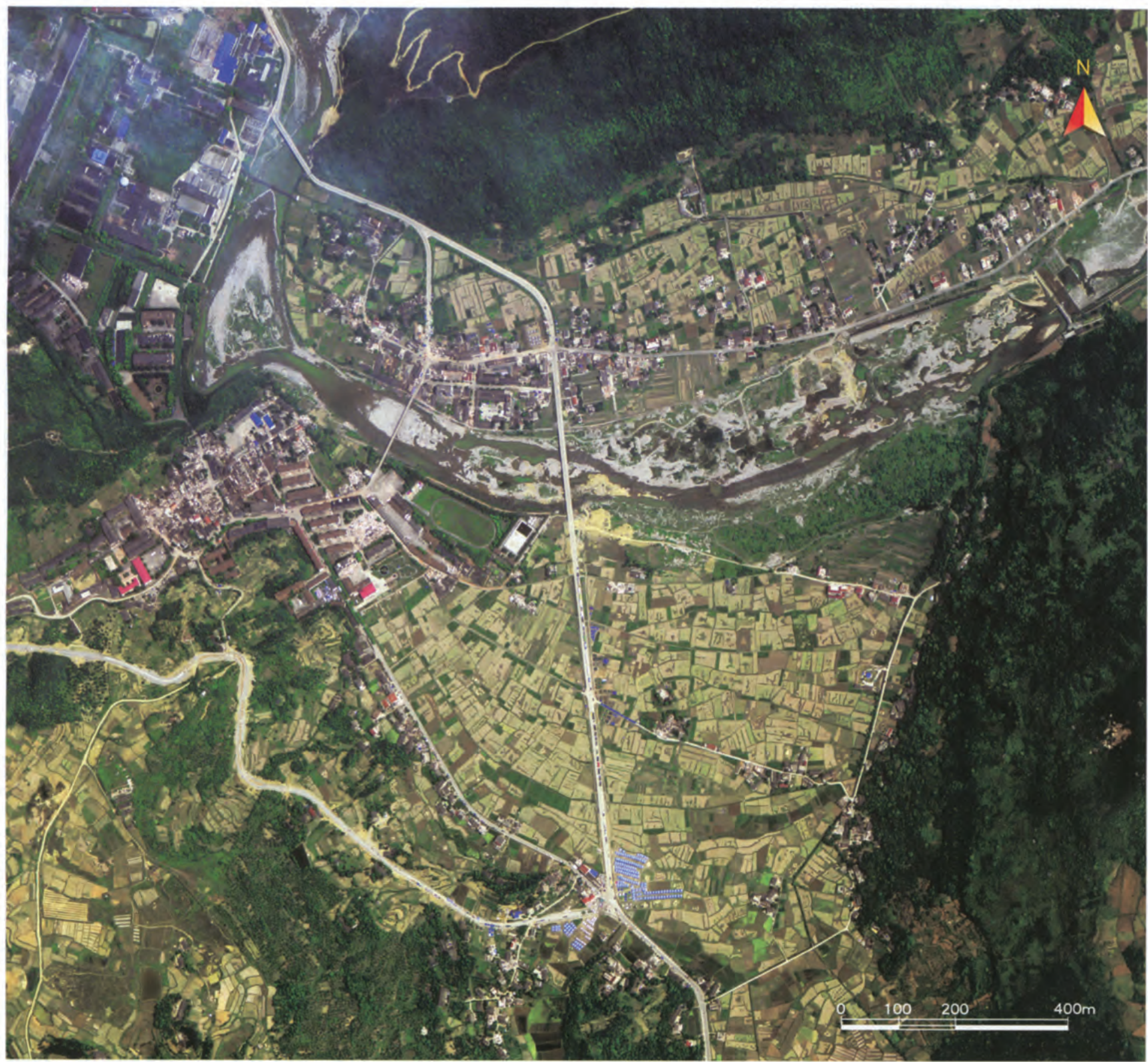




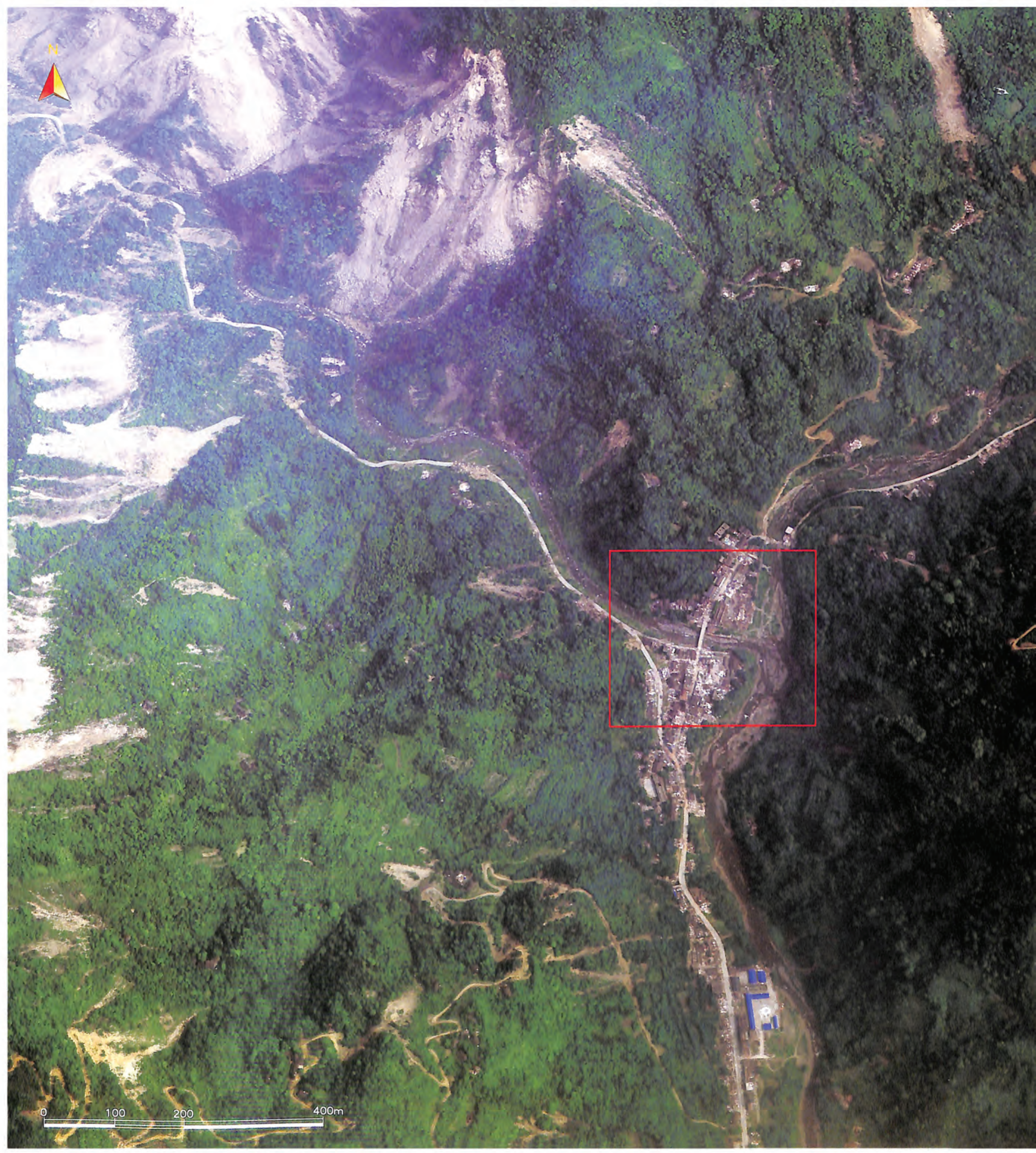

126 I Atlas of Remote Sensing of the Wenchuan Earthquake 

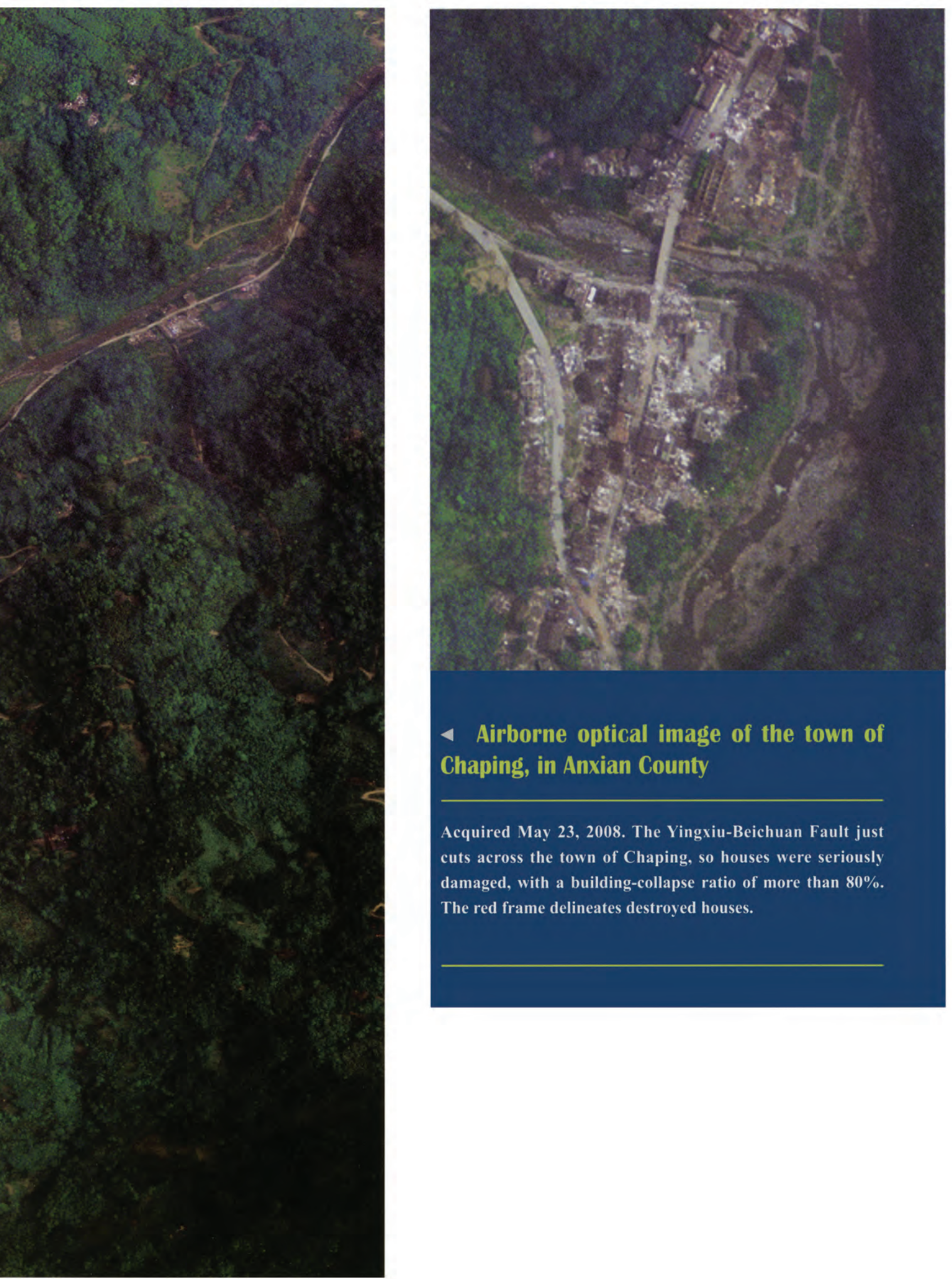


\section{Distribution of}

destroyed houses and buildings in the city of Mianyang

Maoxian County is located in the southeast section of $\mathrm{Aba}$ Tibet and Qiang Autonomous Prefecture, which is the transitional zone from the Qinghai-Tibet Plateau to the Sichuan Plain, and is the main residential area of the Qiang people. Maoxian County lies along the Wenchuan-Maoxian seismic belt, and nearly $20 \%$ of the houses were either severely damaged or collapsed in the urban area of the Maoxian County.

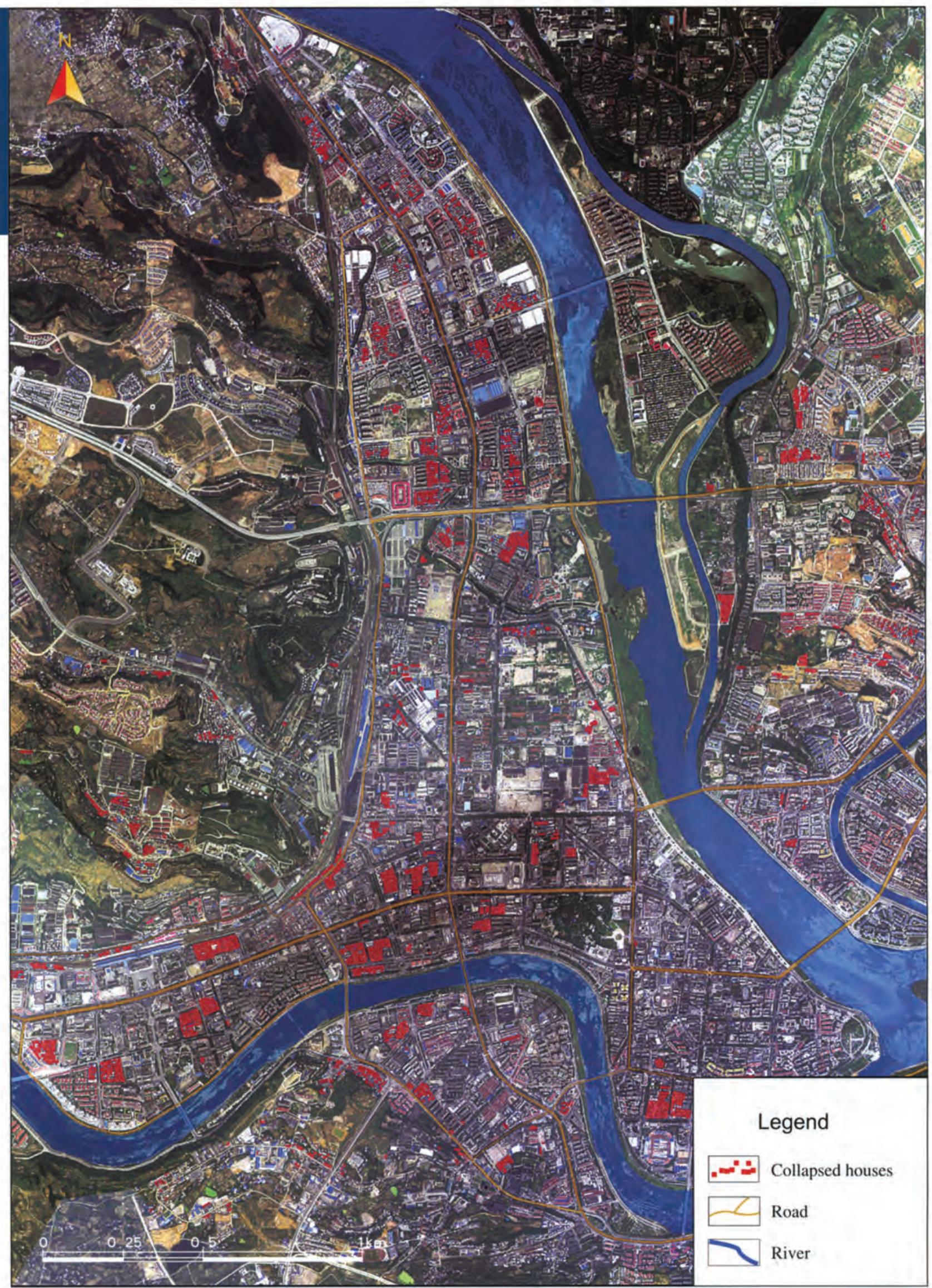

128 I Atlas of Remote Sensing of the Wenchuan Earthquake 


\section{Post-earthquake and pre-earthquake Radarsat images of the city of Mianyang}

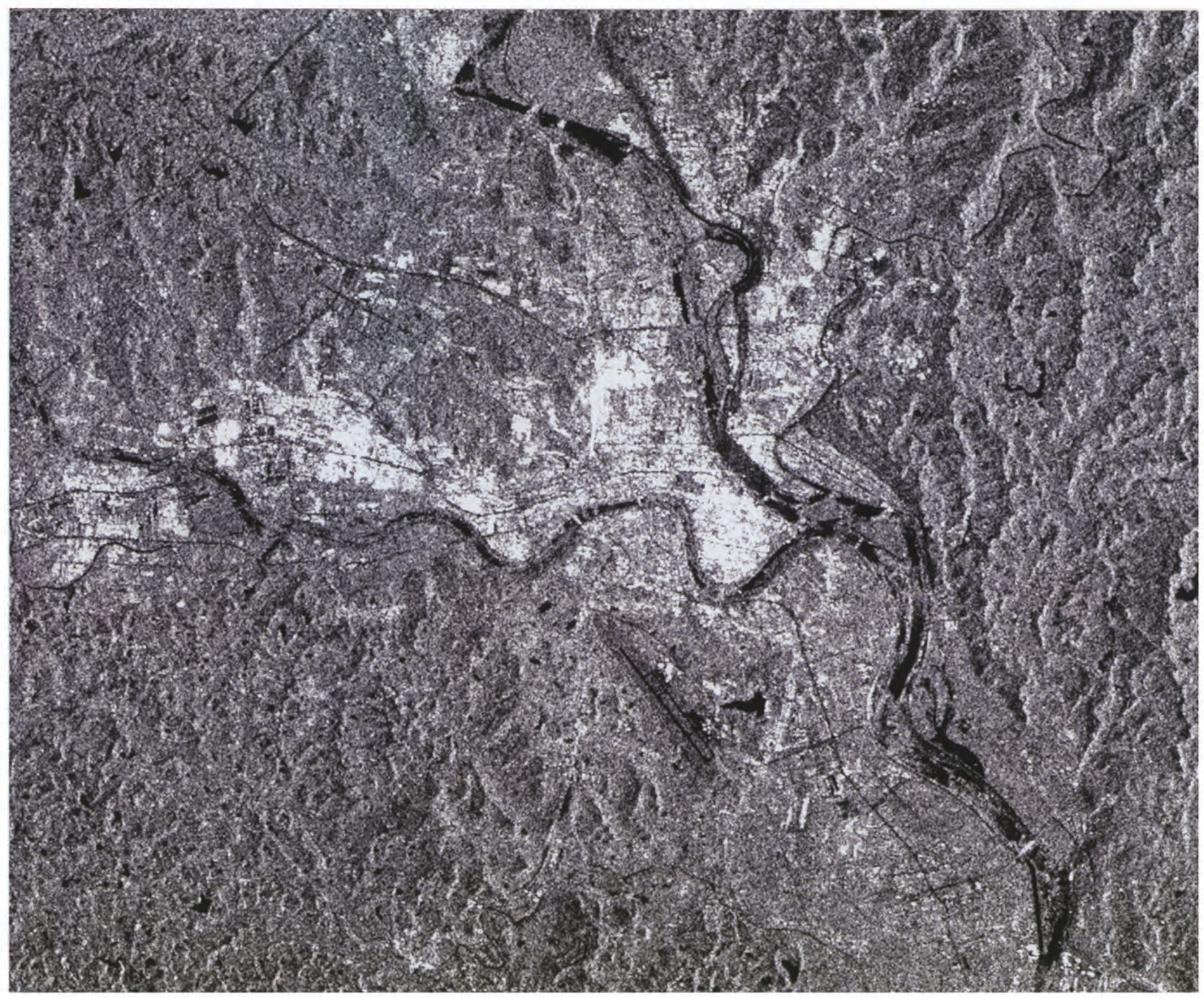

Post-earthquake image: May 14, 2008 


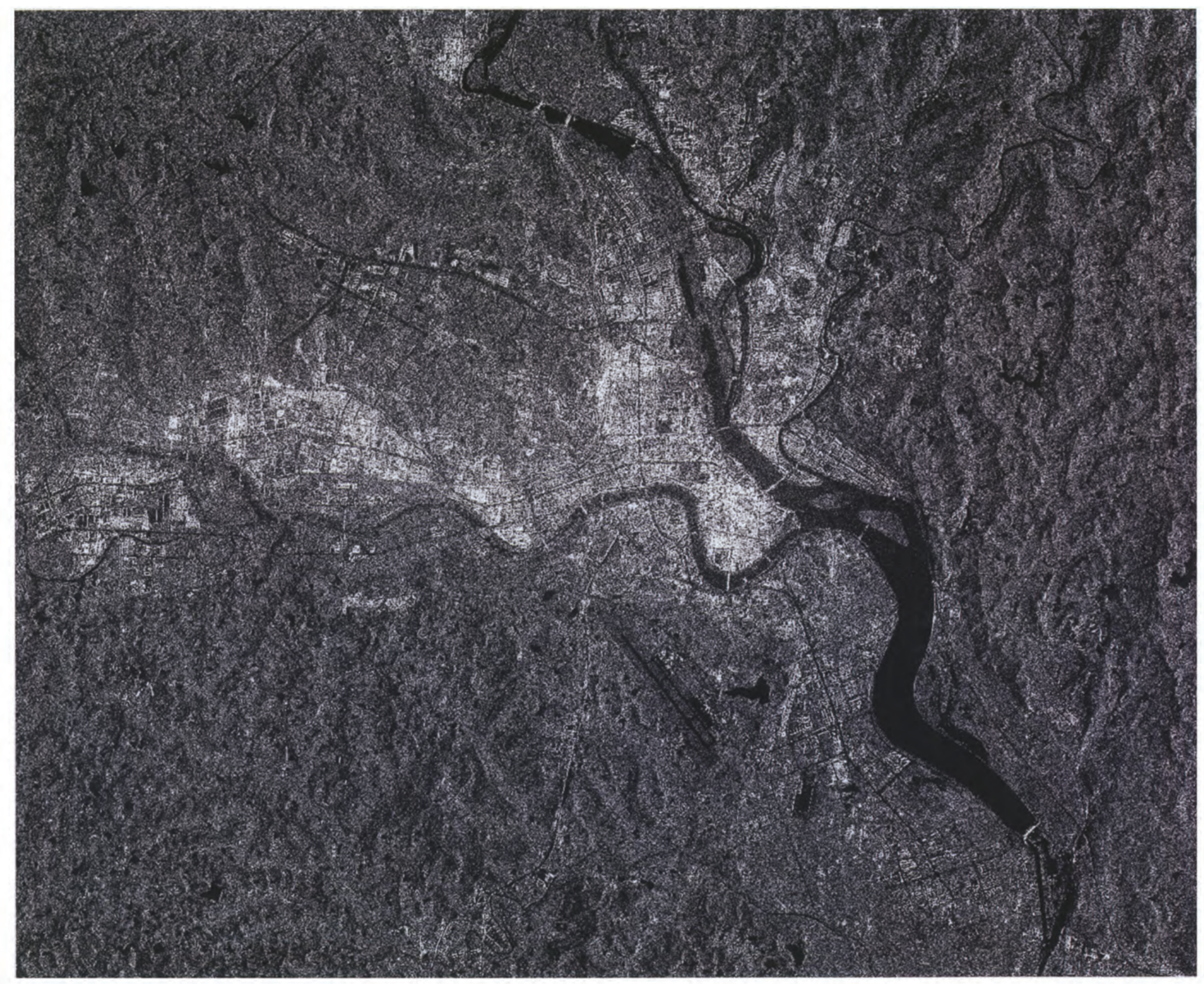

Pre-earthquake image: December 26, 2007 


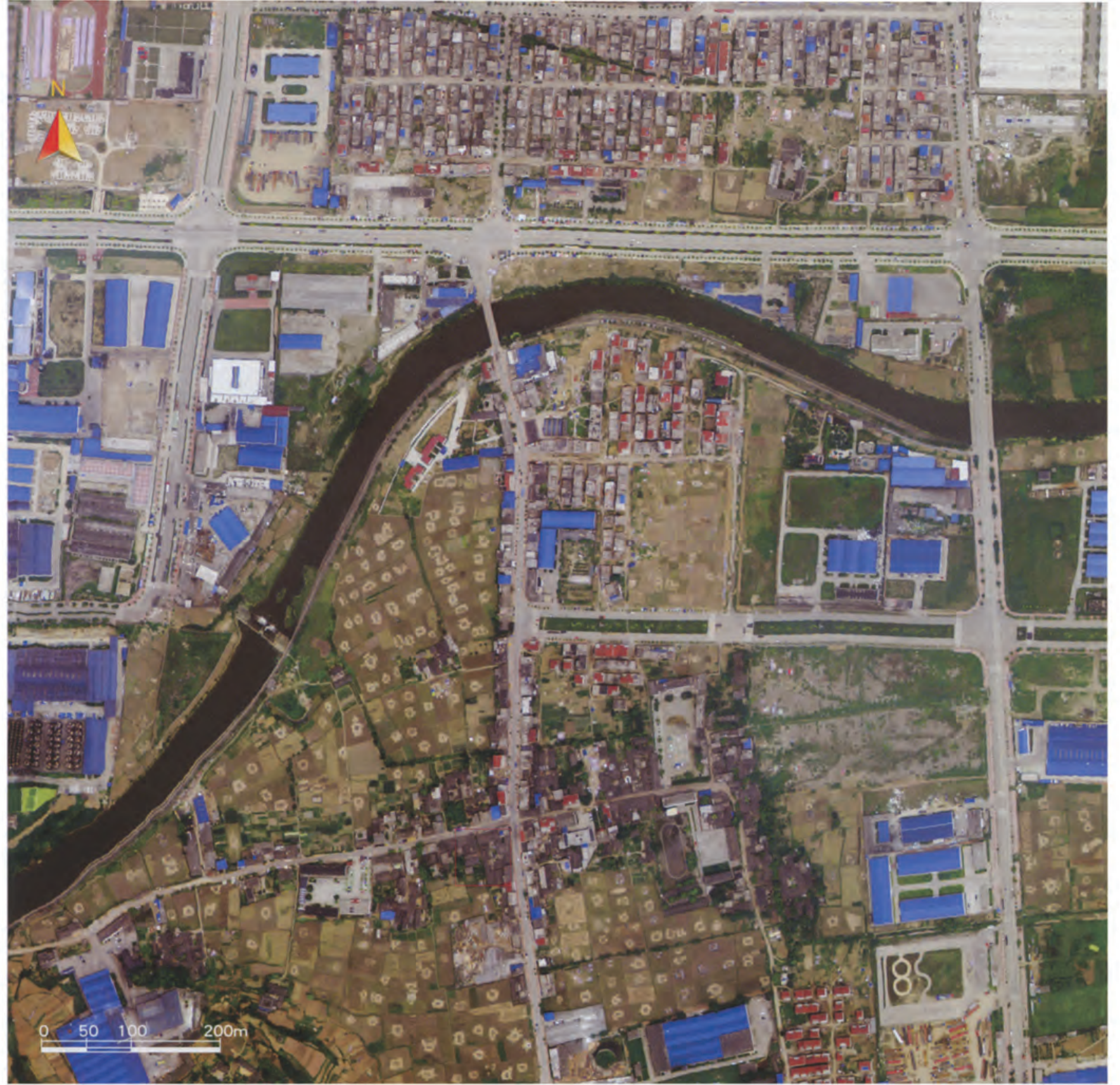

\section{$\Delta$ Airborne optical image of the town of Xinzao, in the city of Mianyang}

Acquired May 18, 2008. The town of Xinzao, a rural town in the city of Mianyang, was quite seriously affected. The house collapse rate was more than $40 \%$, and was higher than the collapse rate for the factories and the other buildings. The red frame within the image shows the collapsed and severely damaged houses and buildings.

- Airborne optical image in the town of Qingyi, in the city of Mianyang

Acquired May 18, 2008. The town of Qingyi is another heavily hit rural town in the city of Mianyang. The rate of collapsed houses was more than $20 \%$, and was higher than the rate of collapsed factories and other buildings. (A) The new campus of the Southwest University of Science and Technology. There are slight property losses, that is, some buildings were damaged, but did not collapse. 


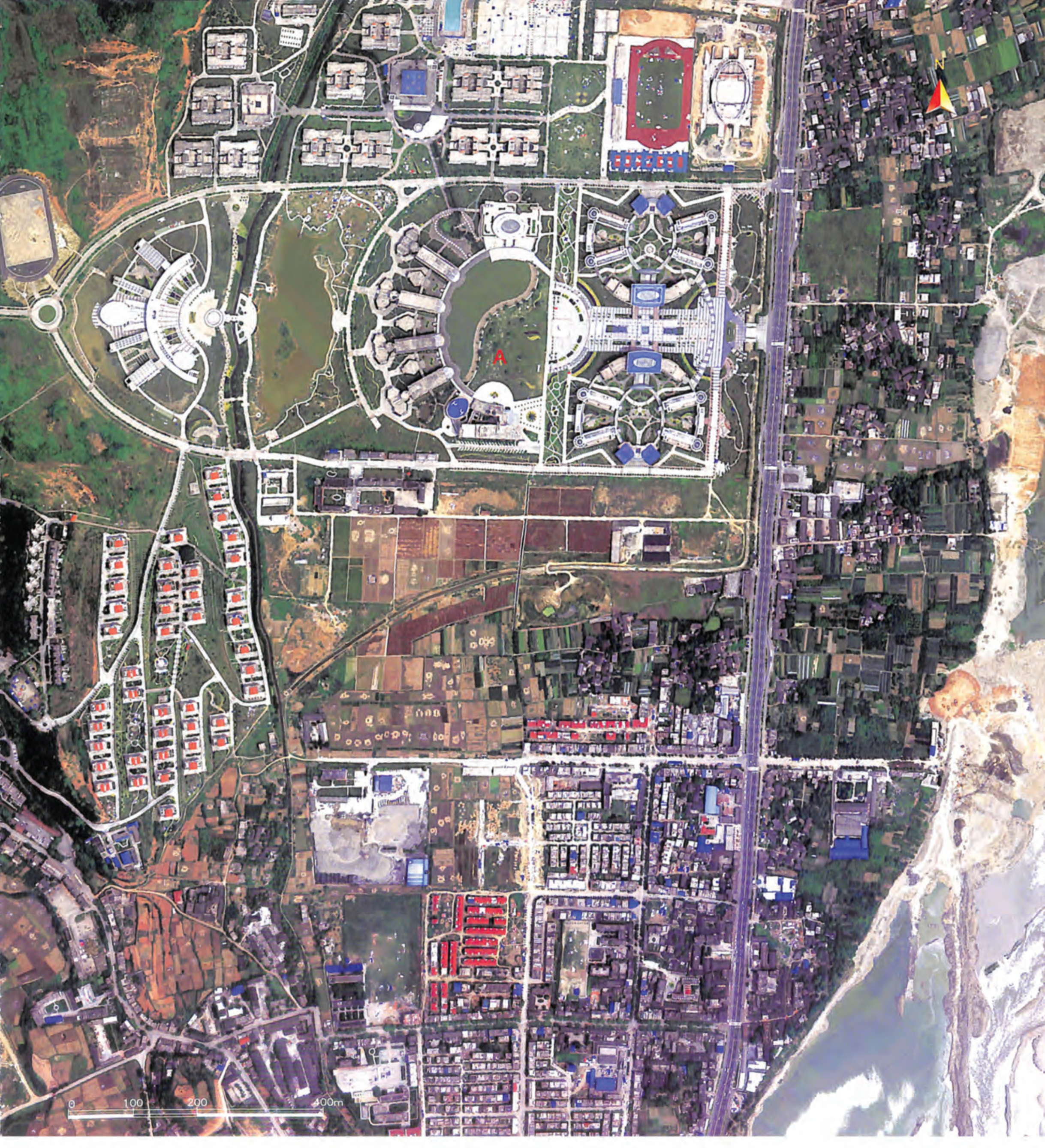




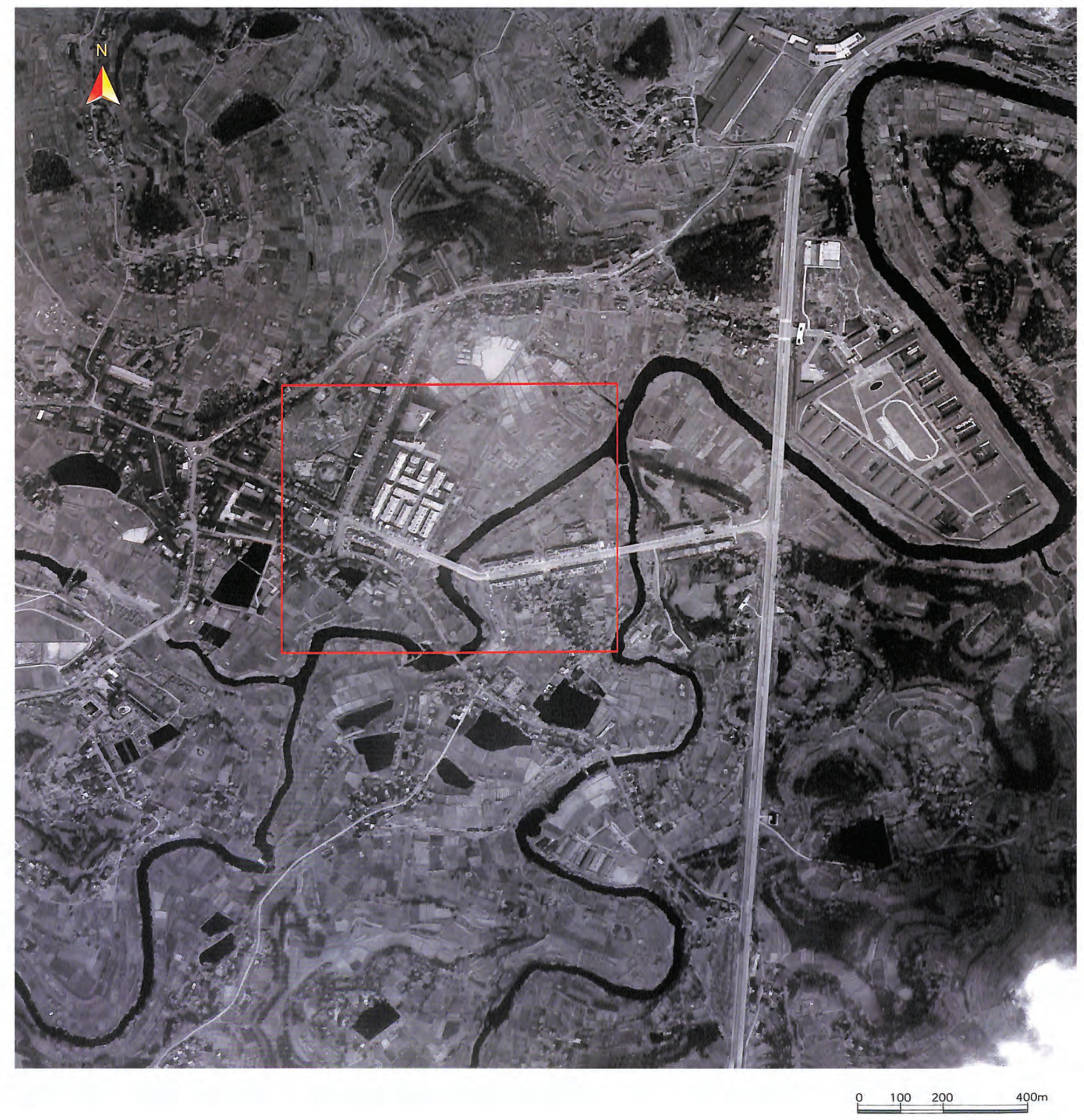

134 I Atlas of Remote Sensing of the Wenchuan Earthquake 

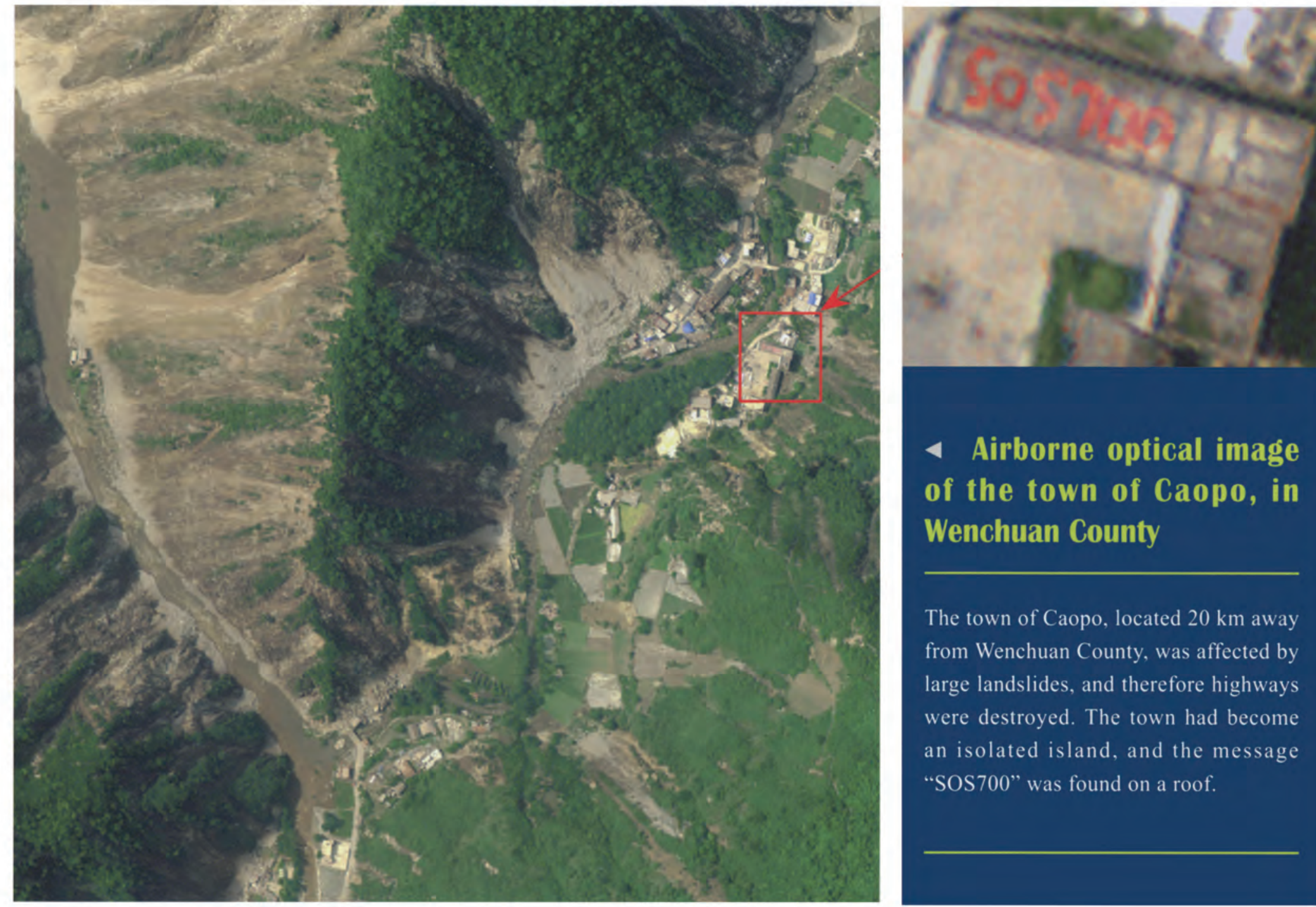

The town of Caopo, located $20 \mathrm{~km}$ away from Wenchuan County, was affected by large landslides, and therefore highways were destroyed. The town had become an isolated island, and the message "SOS700" was found on a roof.

\section{WorkdView image of the town of Wujia, in the city of Mianyang}

In this image, acquired May 16, 2008, which compares a post-earthquake WorldView satellite image with a high-resolution airborne optical image, some collapsed houses can be identified by the WorldView panchromatic band. But it is harder to identify collapsed houses in this image than it is with an airborne image under the same resolution. 


\section{Distribution of collapsed}

houses in the city of Jiangyou

The city of Jiangyou is located in the northwest part of Sichuan Basin, along the upper reaches of the Fujiang River, southeast of Longmen Mountain. It is the national metallurgy industrial base, and it is a vital energy resource base of Sichuan. The house collapse here was severe, with about $5 \%$ of buildings collapsed in the urban area of the city of Jiangyou.

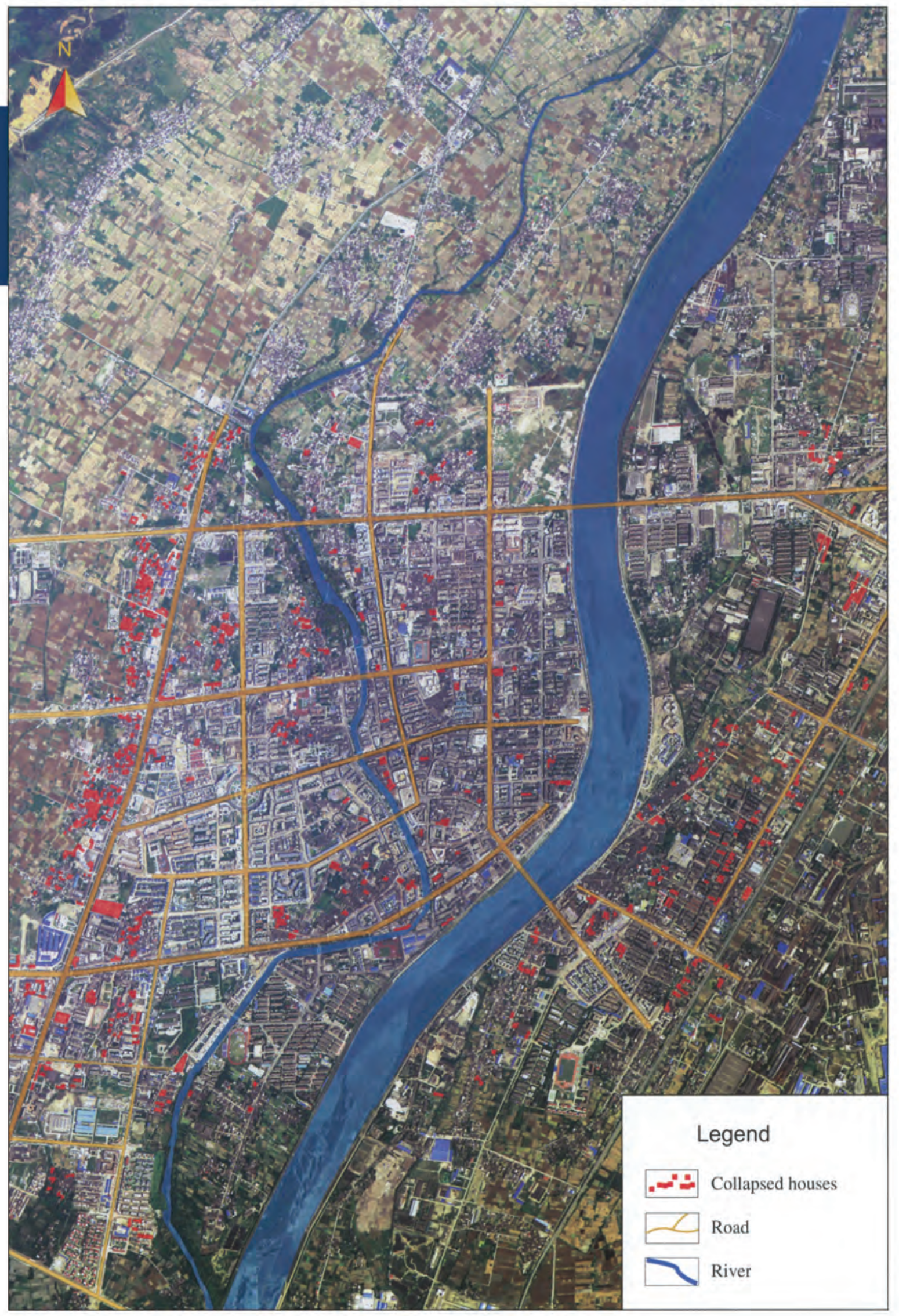

0 


\section{Postearthquake and preearthquake Radarsat images of urban area of the city of Jiangyou}
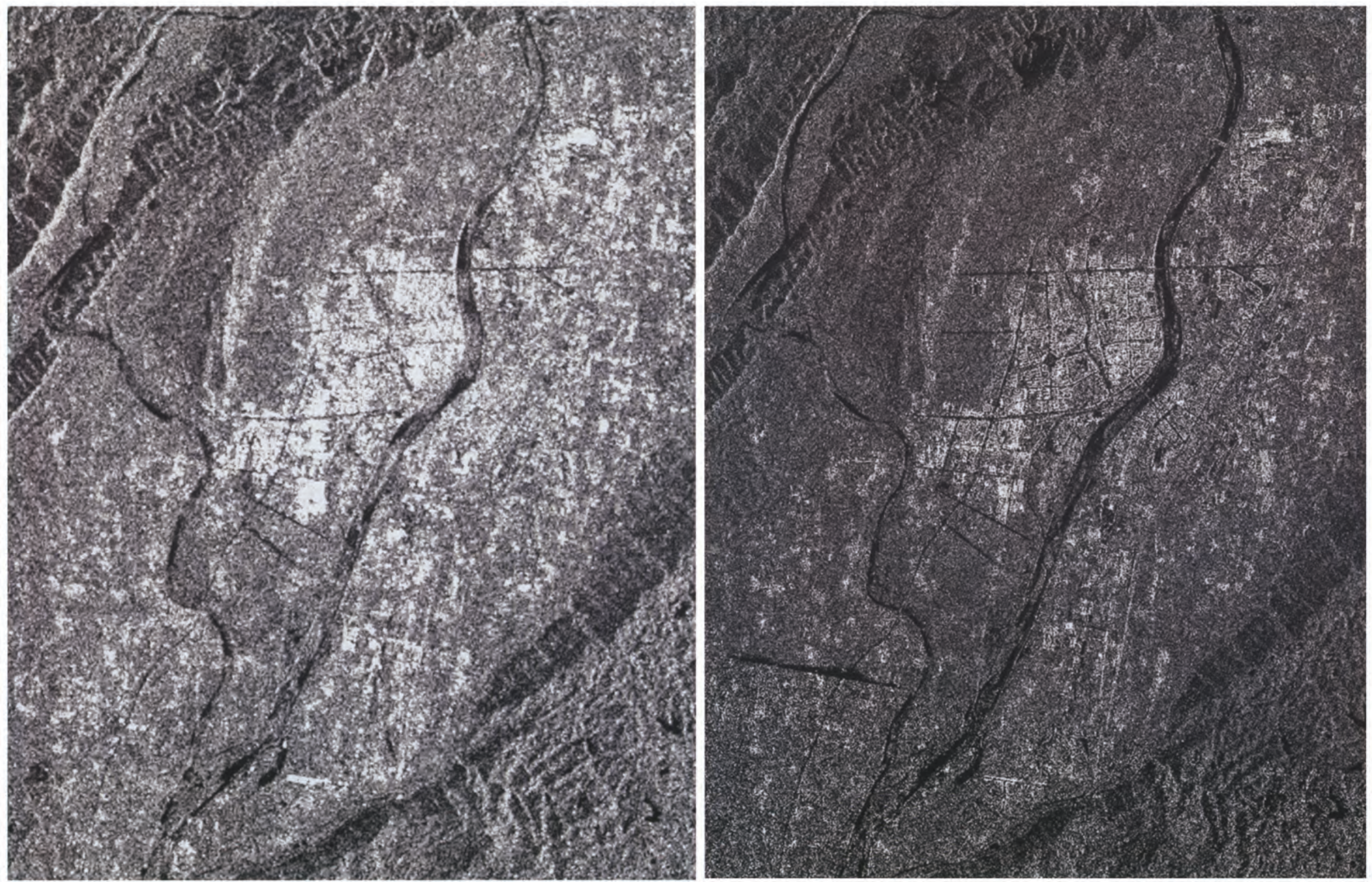

Post-earthquake image: May 14, 2008

Pre-earthquake image: December 19, 2007 


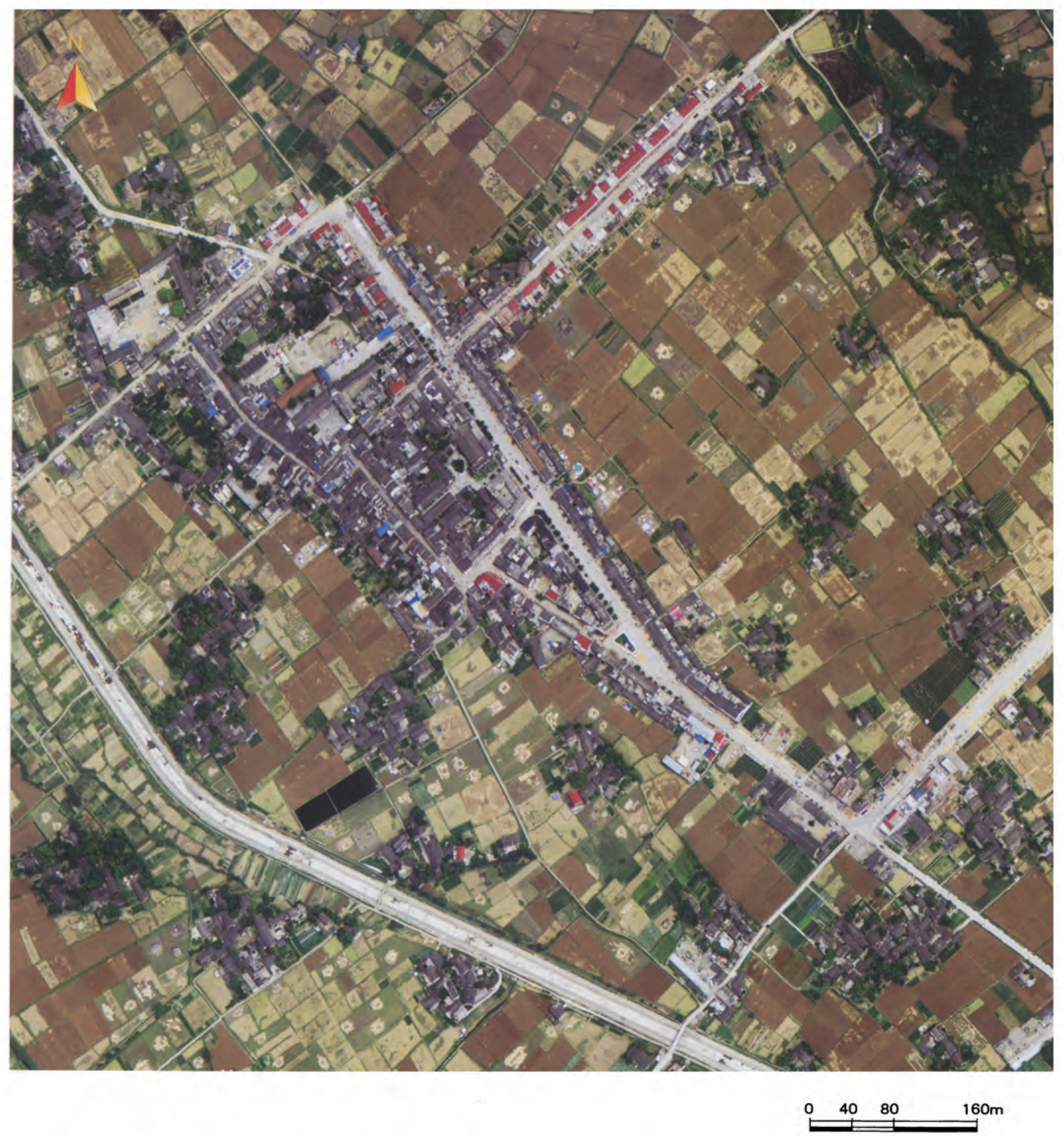

$\Delta$ Airborme optical image of the town of Xiping, in the city of Jiangyou

Acquired May 18, 2008. The distance from Xinping to the urban area of Beichuan County is just $20 \mathrm{~km}$. The houses in the town of Xinping were severely damaged, and the house collapse rate was over $25 \%$.

- Airborme optical image of the town of Sandui, in the city of Guangyuan

Acquired May 18, 2008. The town of Sandui lies on the Yingxiu-Beichuan Fault but only a few houses, less than $10 \%$, collapsed.

138 I Atlas of Remote Sensing of the Wenchuan Earthquake 


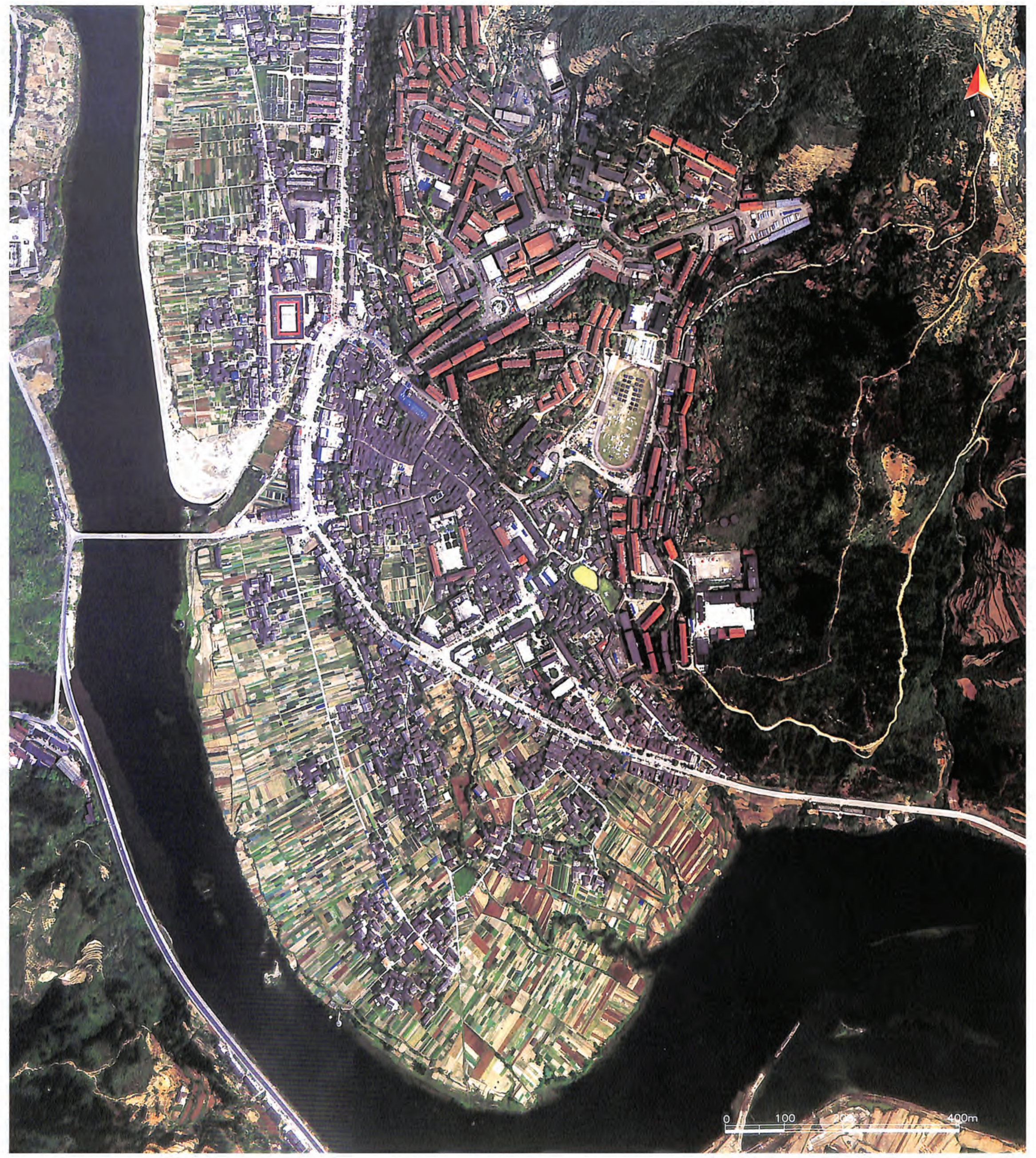


T. 


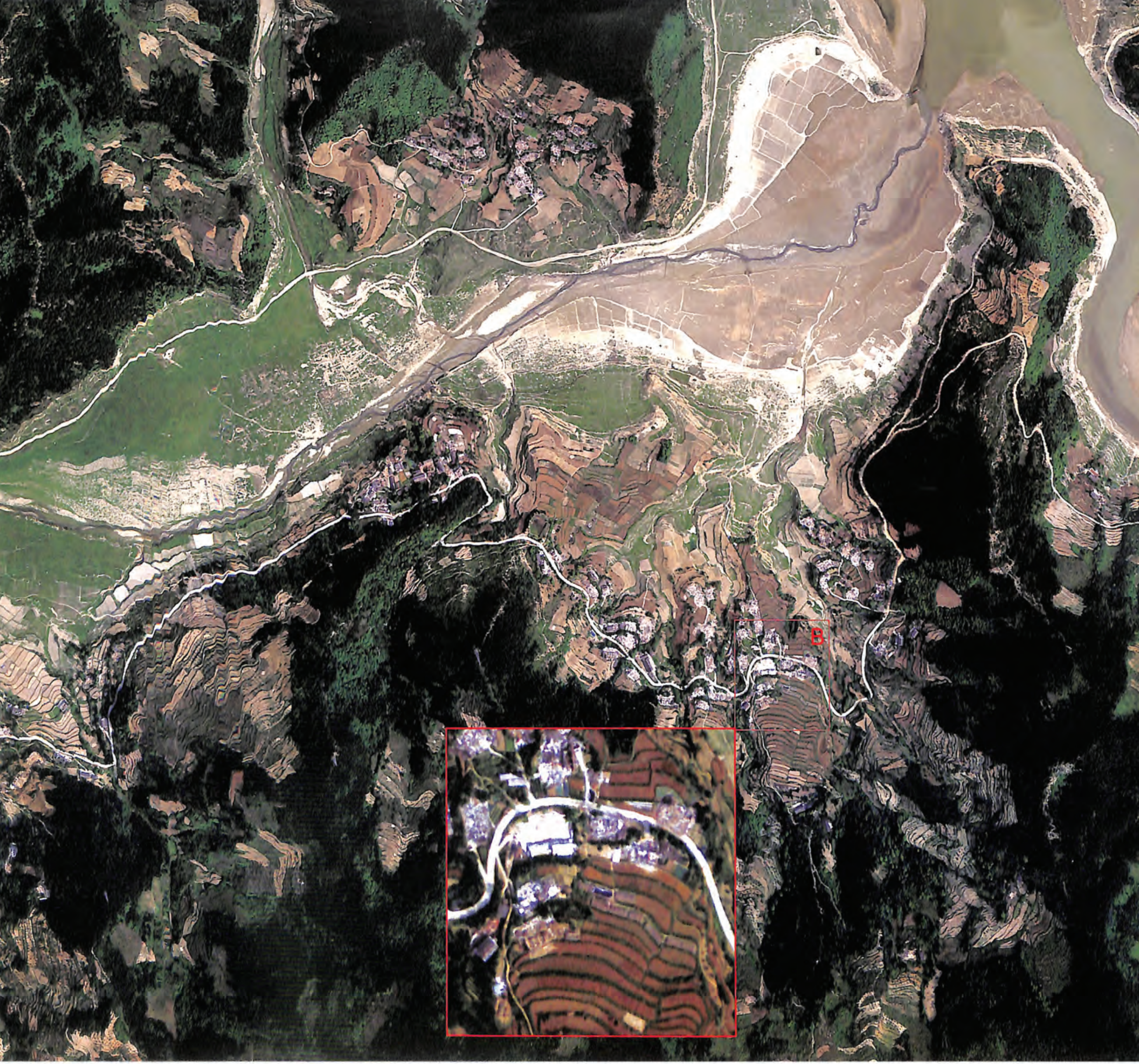




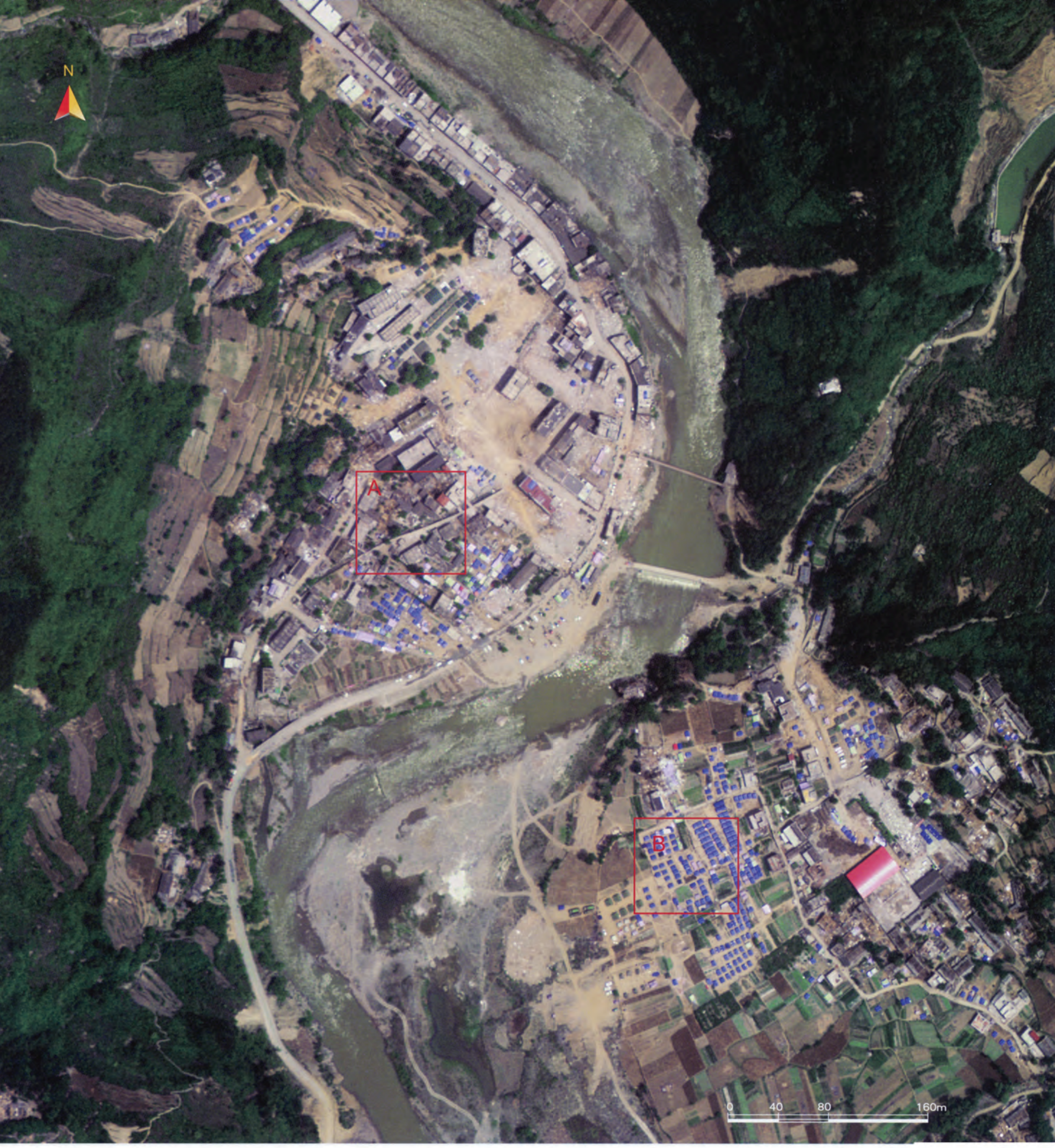




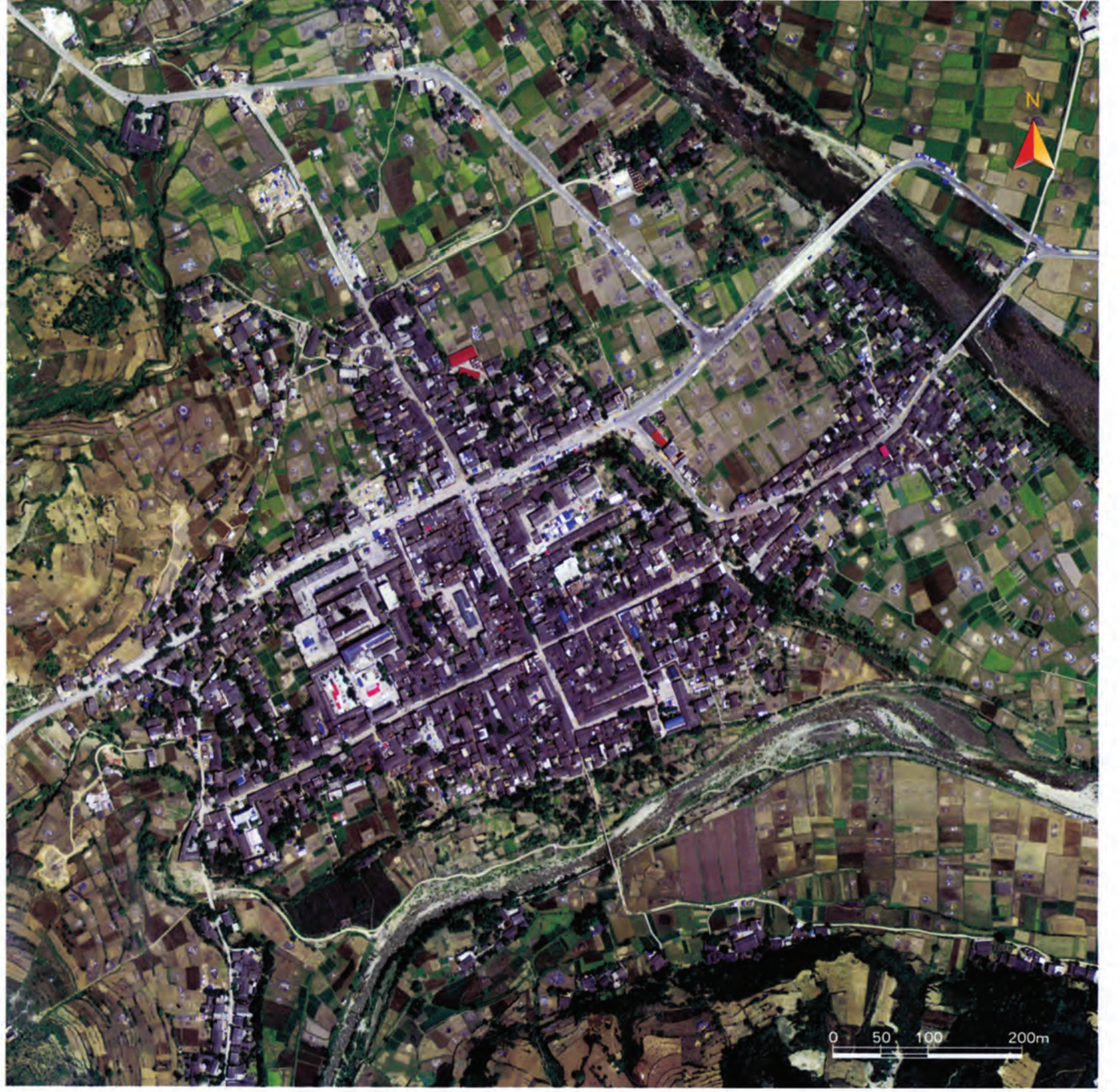

\section{$\checkmark$ Airborne optical image of the town of Qingxi, in Qingchuan County}

Acquired May 28, 2008. The town of Qingxi, built more than 1700 years ago, has many historic sites. Although it is located on the Wenchuan-Maoxian Fault, building collapse here was less severe, with a collapse rate of about one-sixth.

\section{Airborne optical image of the town of Guanzhuang, Qingchuan County}

Acquired May 28, 2008. The town of Guanzhuang is located between the Yingxiu-Beichuan Fault and the Wenchuan-Maoxian Fault. The houses in the town of Guanzhuang were severely damaged; more than $75 \%$ of them collapsed. (A) Collapsed or damaged houses. (B) Disaster-relief tents. 


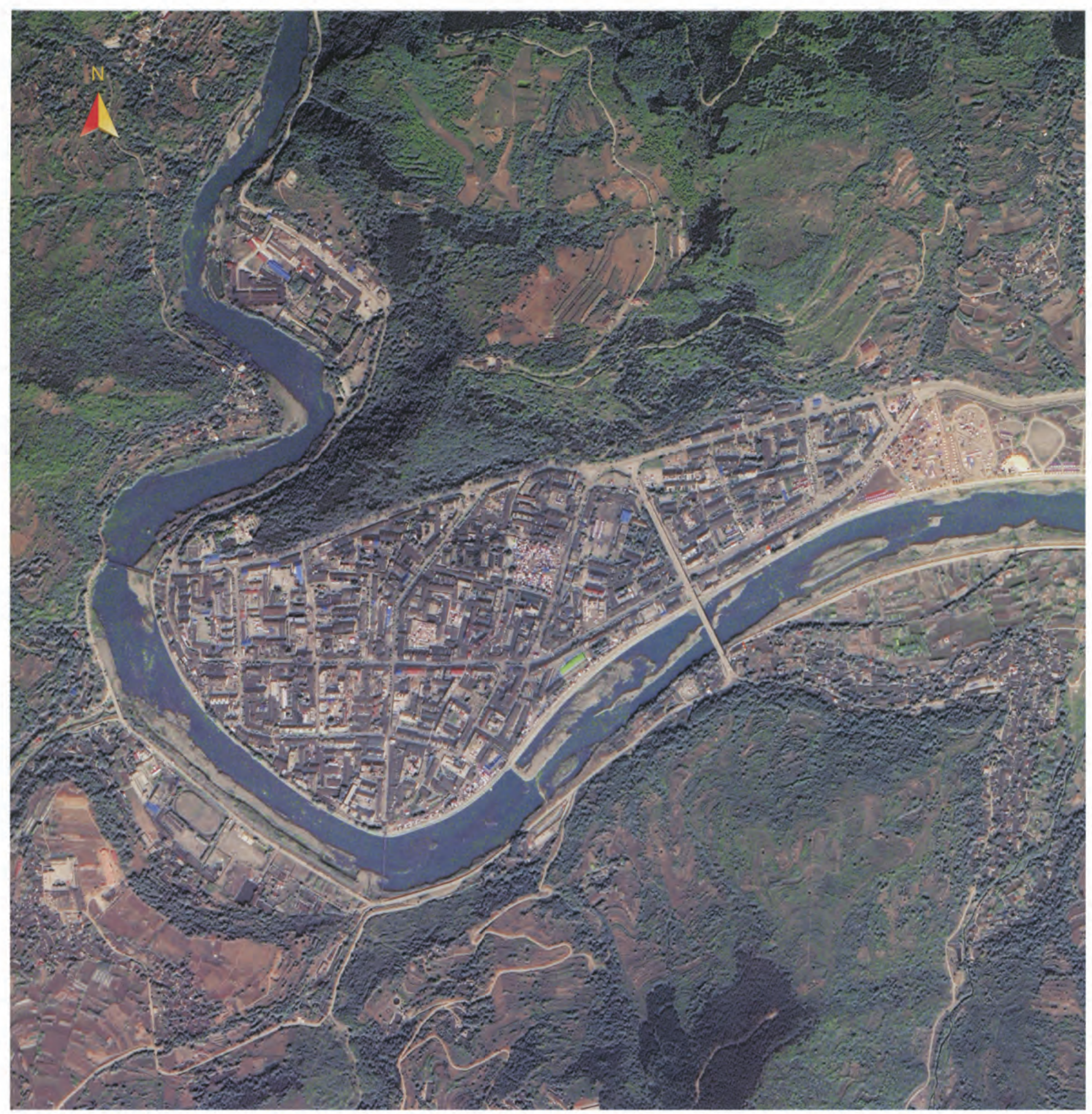

\section{- Airborne optical image of the town of Long'an, in Pingwu County}

Acquired May 23, 2008. The urban area of Pingwu County is located in the town of Long'an. In the 1976 Songpan-Pingwu earthquake, losses were very heavy. Since much attention was paid to house construction when the area was rebuilt after the 1976 Songpan-Pingwu earthquake, and because the earthquake intensity in the town during the Wenchuan earthquake was low, losses were light, and very few houses collapsed. 
Acquired May 28, 2008. The town of Nanba is located between the Yingxiu-Beichuan Fault and the Wenchuan-Maoxian Fault. More than $80 \%$ of the houses in the town of Nanba were severely damaged or collapsed. The red frame in the figure shows Nanba Primary School. Two three-story buildings of this school completely collapsed, and many teachers and students in this school died. The heroic actions that 48-year-old teacher Du Zhengxiang took in saving her students moved the whole country.
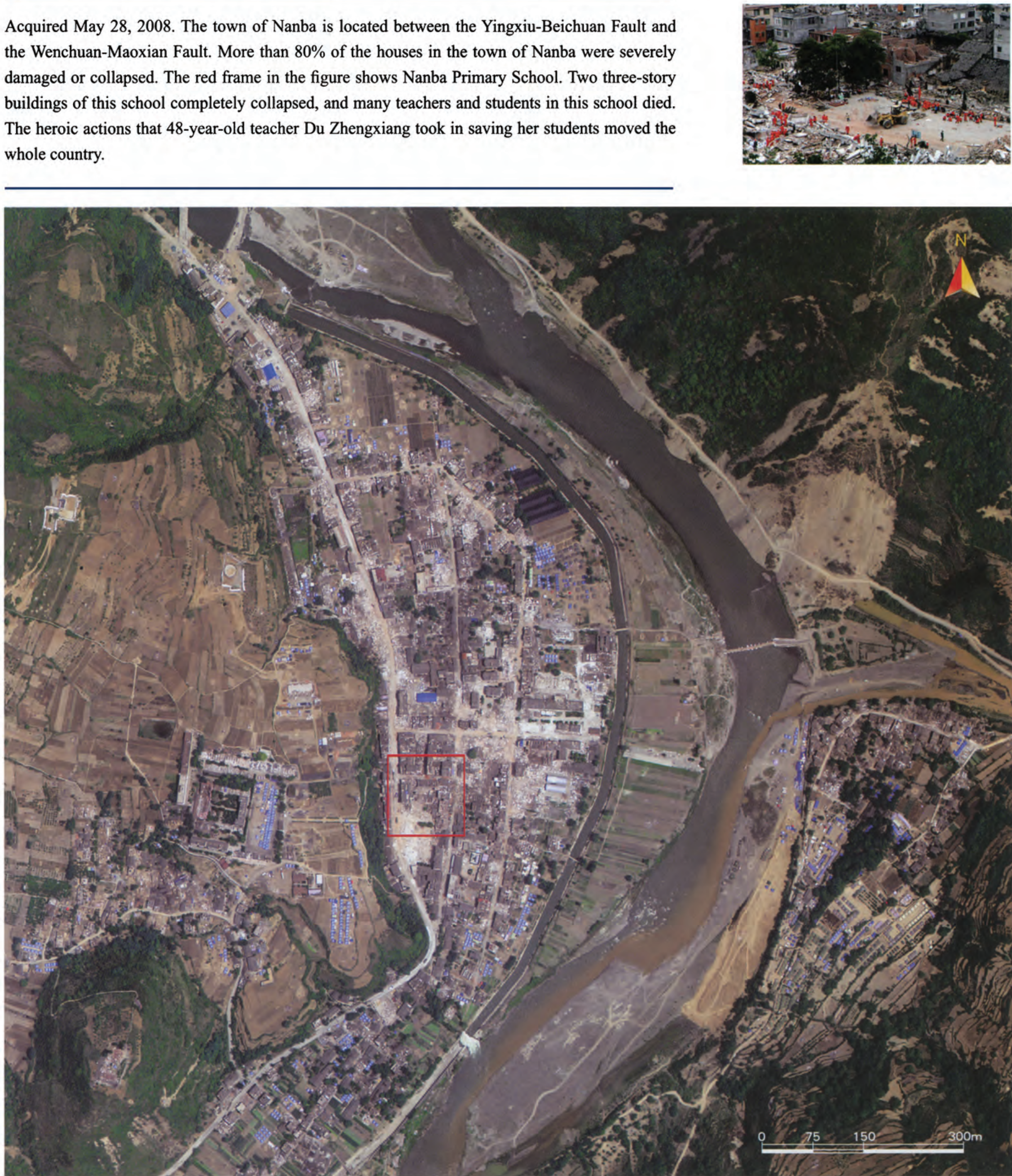


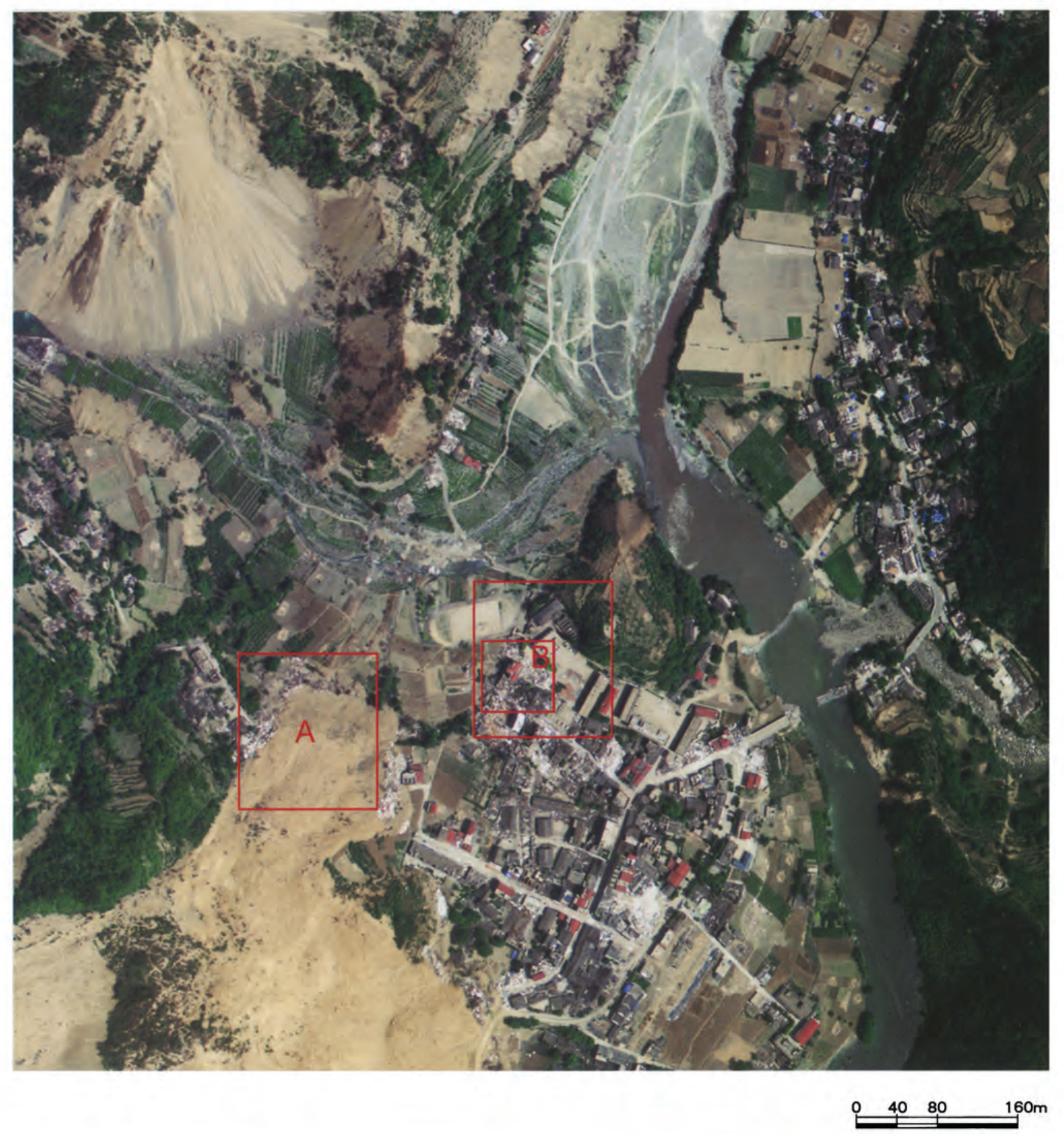

$\Delta$ Airborne optical image of the town of Chenjiaba, in Beichuan County

Acquired May 28, 2008. In Chenjiaba, a town crossed by the Yingxiu-Beichuan Fault, the houses were heavily damaged, with over $80 \%$ of them destroyed. (A) A landslide split the town into two parts and caused heavy casualties. (B) Collapsed houses.

- IKONOS image of the town of Yuli, Beichuan County

Acquired May 23, 2008. The image shows that the floodwater of the Tangjiashan Barrier Lake began to submerge the town of Yuli. 


\section{Postearthquake and preearthquake Radarsat images of urban area of the city of Deyang}

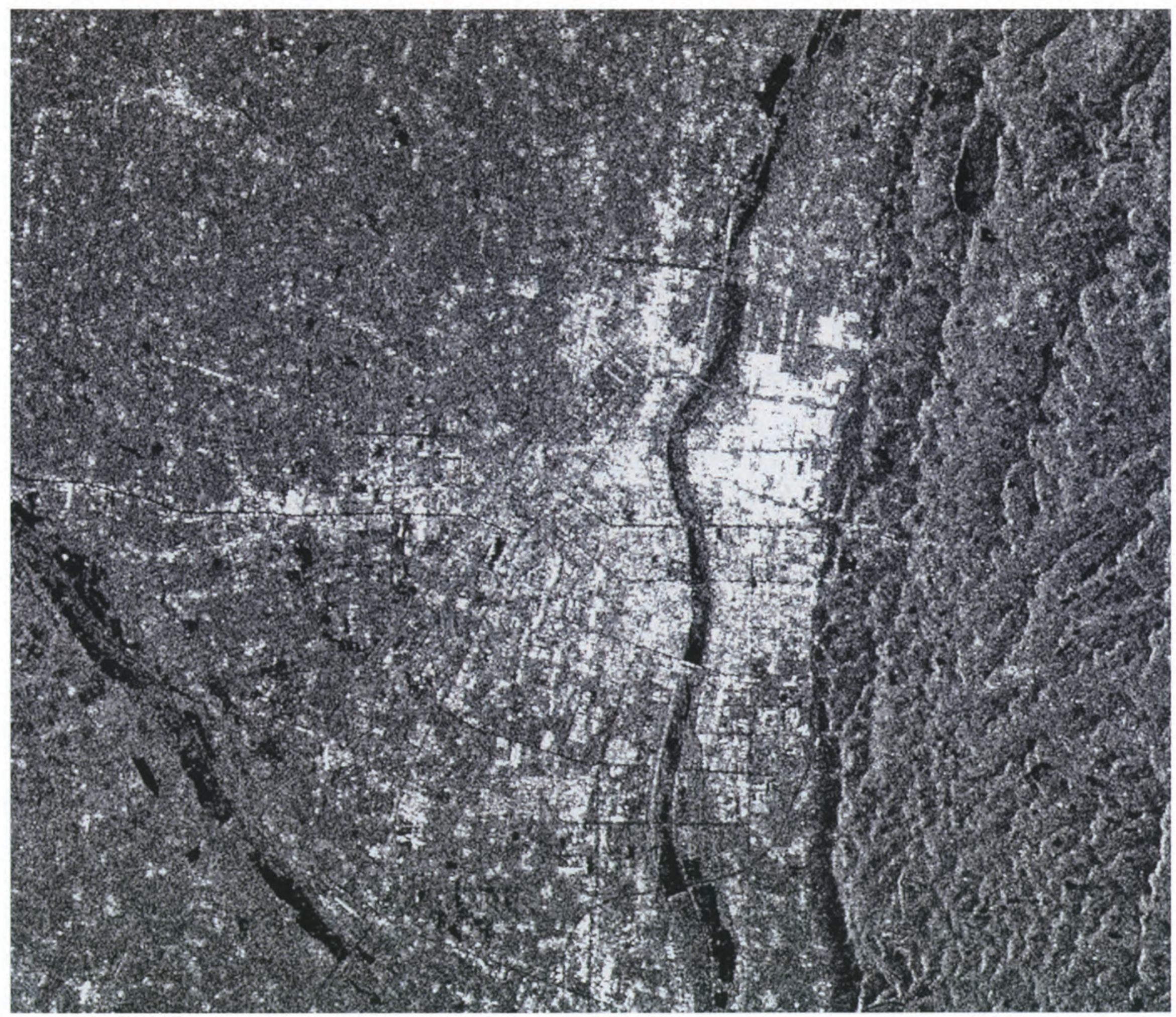

Pre-earthquake image: December 18. 2007 


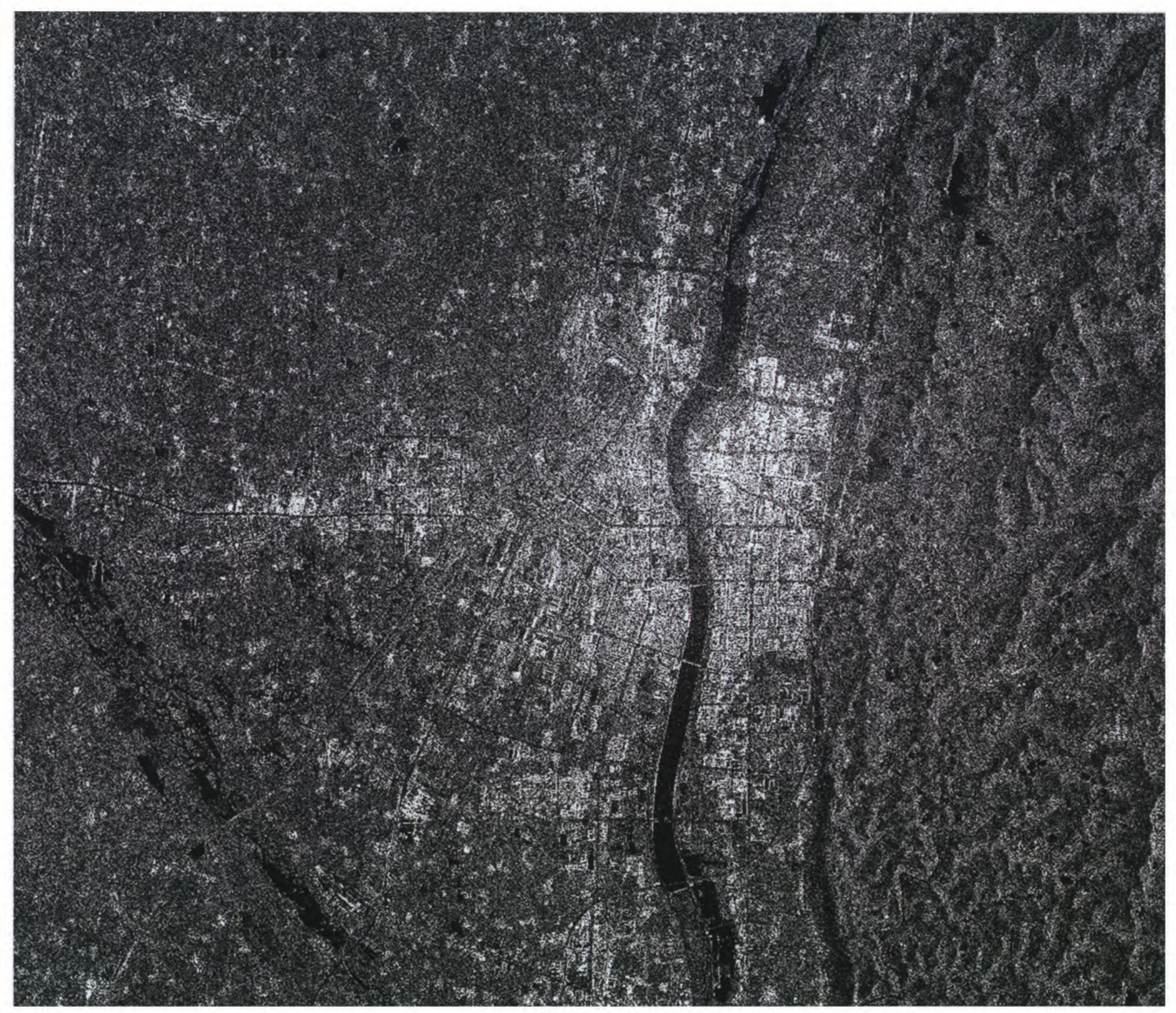

Post-earthquake image: May 14. 2008 


\section{v Airborne optical images of the town of Yuli, in Beichuan County}

Acquired May 16, 2008. The town of Yuli is the hometown of Da Yu and is located between the YingxiuBeichuan Fault and the Wenchuan-Maoxian Fault. Houses and buildings in this town were severely damaged, over $60 \%$ of the buildings collapsed. "SOS" did not show up in the farmland of the town of Yuli in the red frame of this image until 19 May.

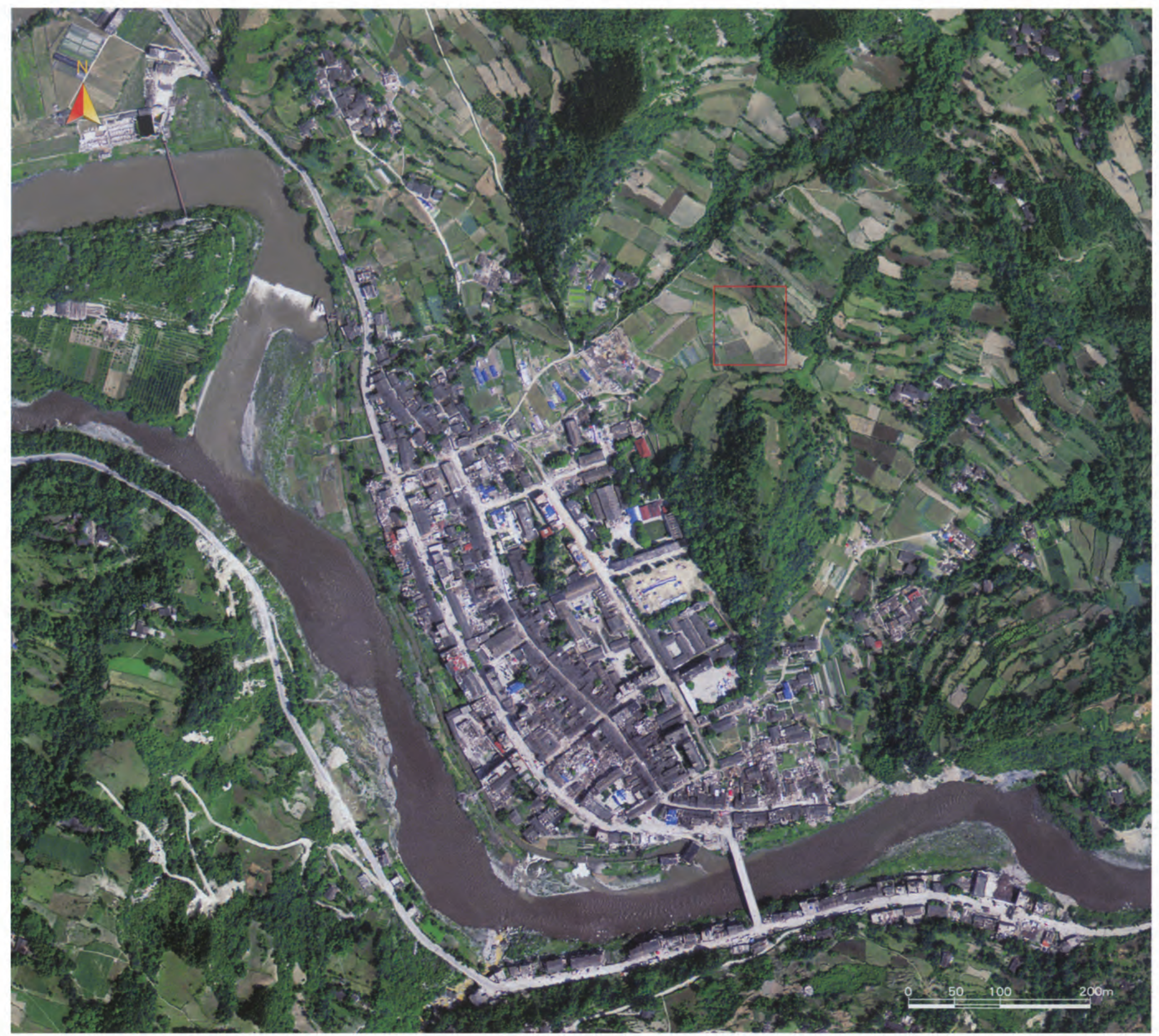

150 I Atlas of Remote Sensing of the Wenchuan Earthquake 


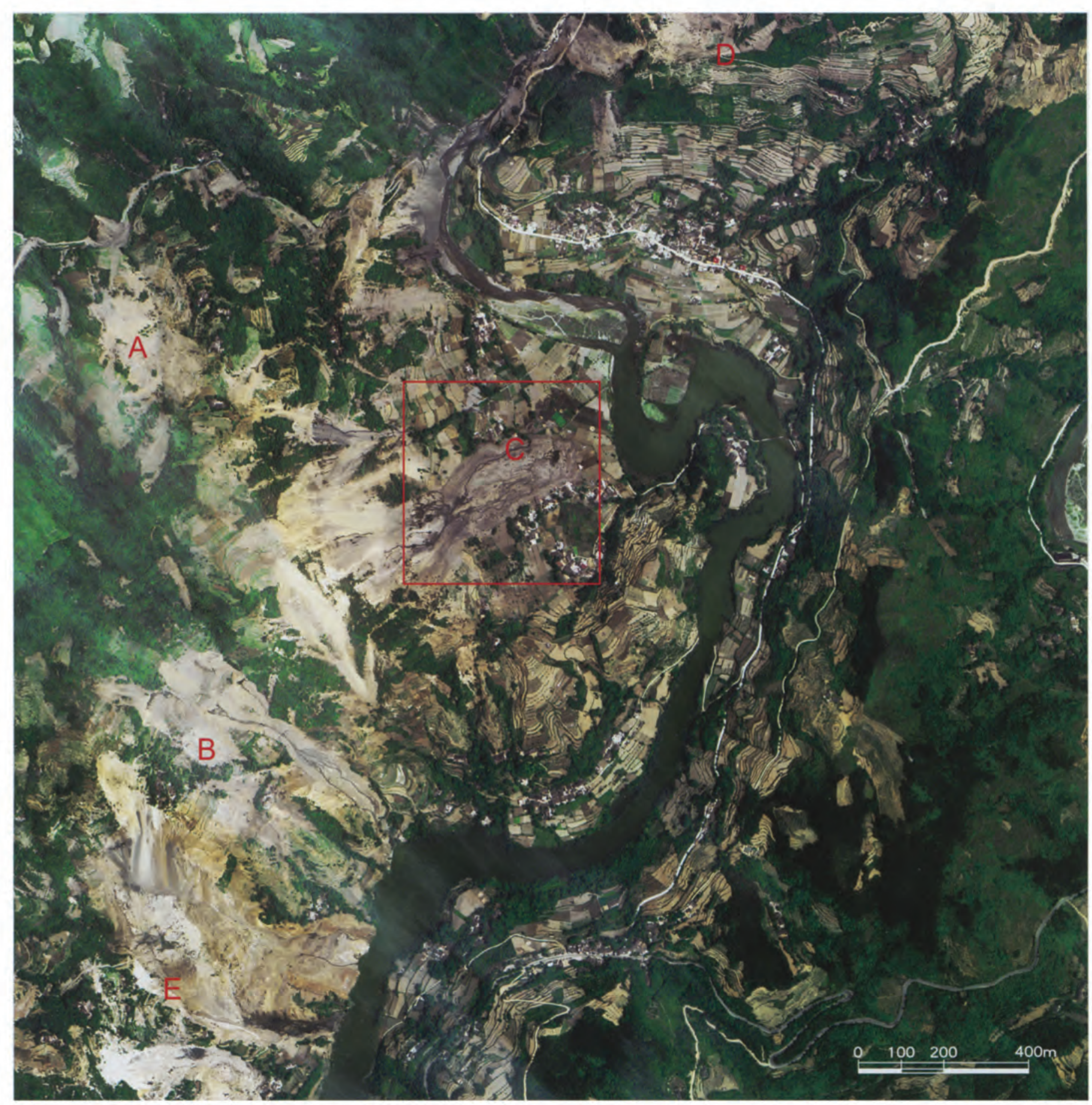

A Airborne optical remote sensing image of the town of Xupingba

Data were acquired on May 28, 2008. (A), (B), (C), (D), and (E) indicate destroyed terraces, and the red frame shows the location of the close-up image in the lower right-hand corner.

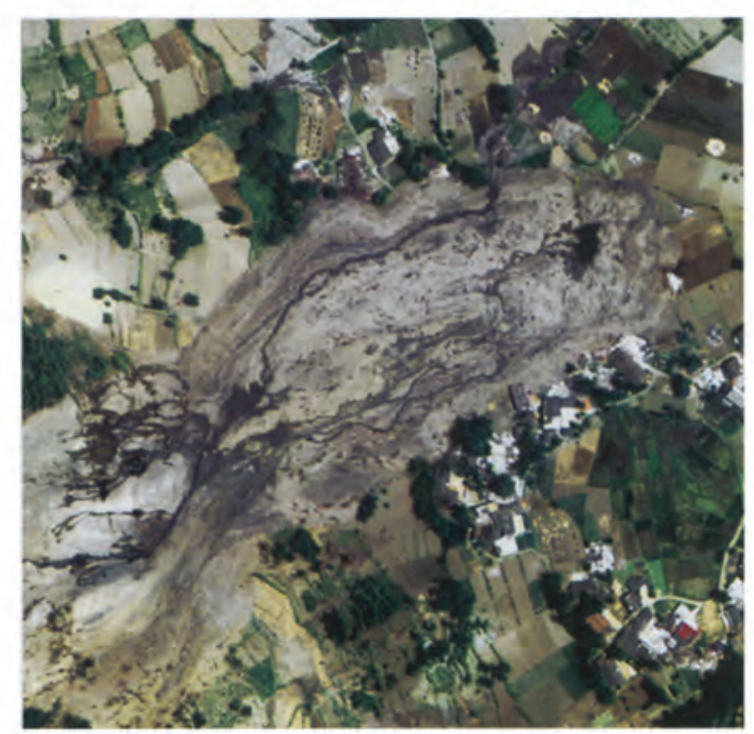




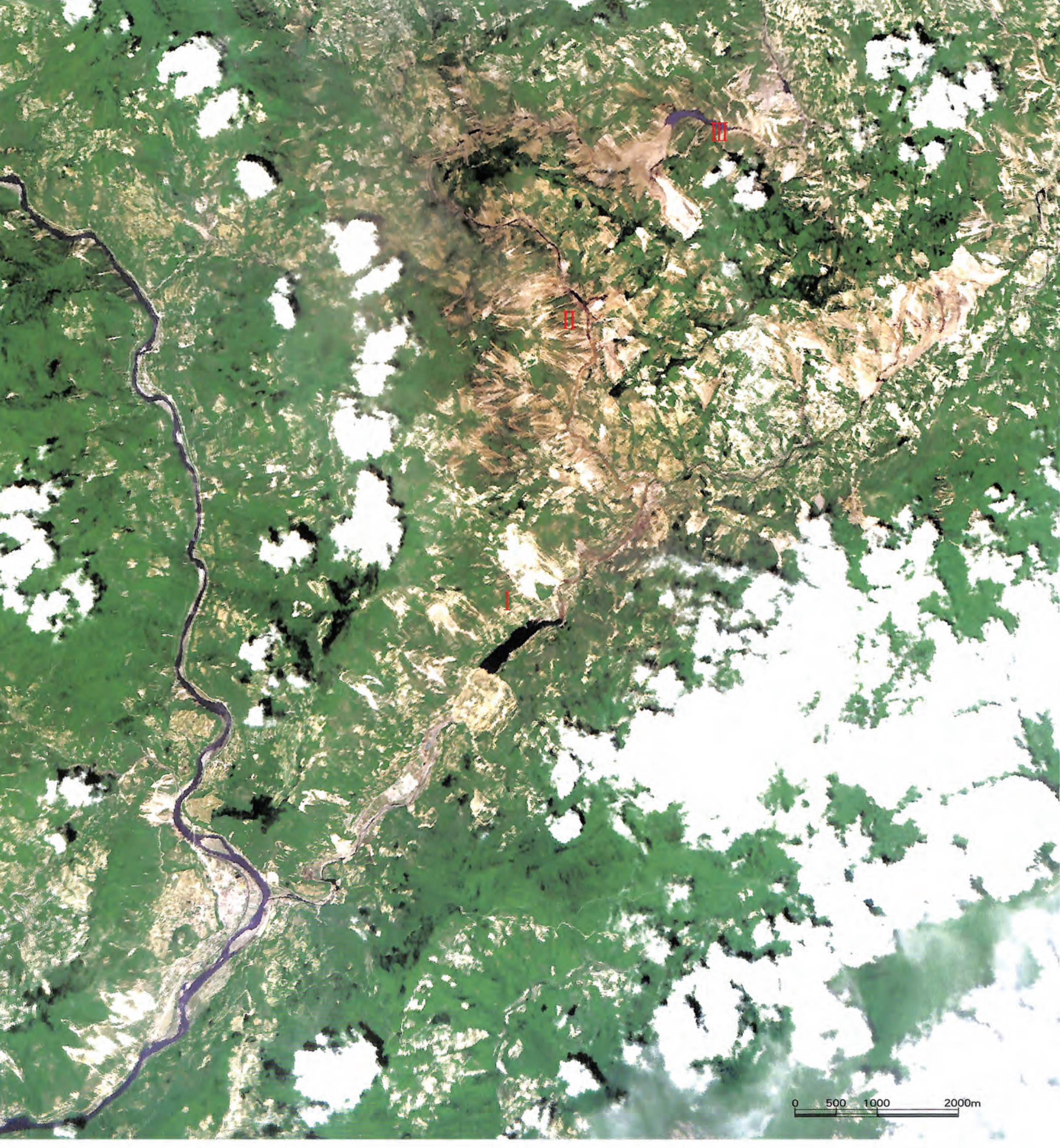

202 I Atlas of Remote Sensing of the Wenchuan Earthquake 
This SPOT 5 image was acquired on May 16, 2008. Secondary geological disasters such as landslides, mud-rock flows, and so on (shown as the yellow or yellow-black in the image), in the town of Nanba and the town of Shuiguan, caused many barrier lakes to appear. (I), (II), and (III) marked in this image indicate the locations of the following three airborne color images.

v Image I: airborne optical remote sensing image acquired on May 28, 2008 around the village of Tangjiaba, in Pingwu County

(A), (B), (C), and (D) indicate the locations of destroyed farmlands

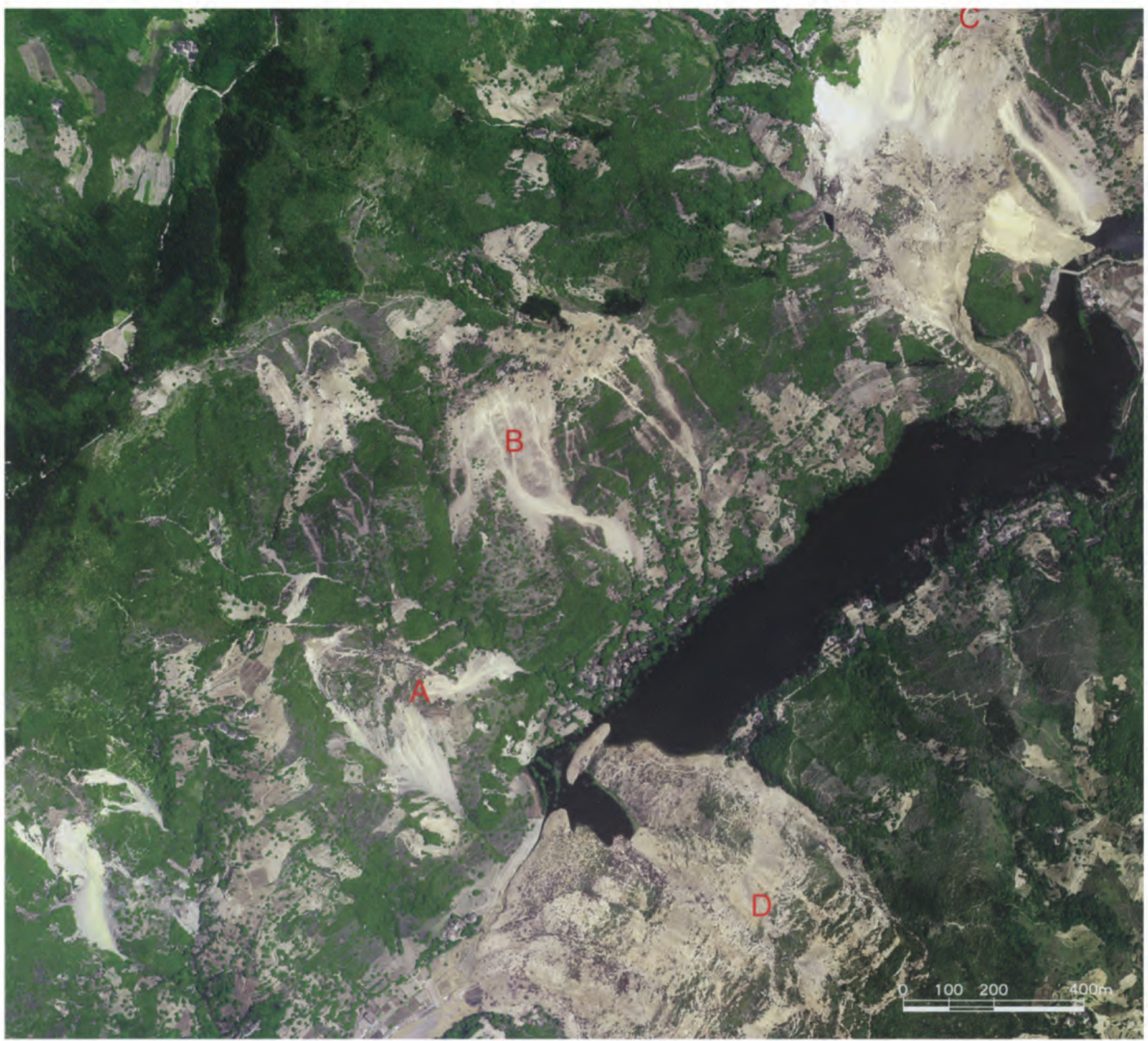




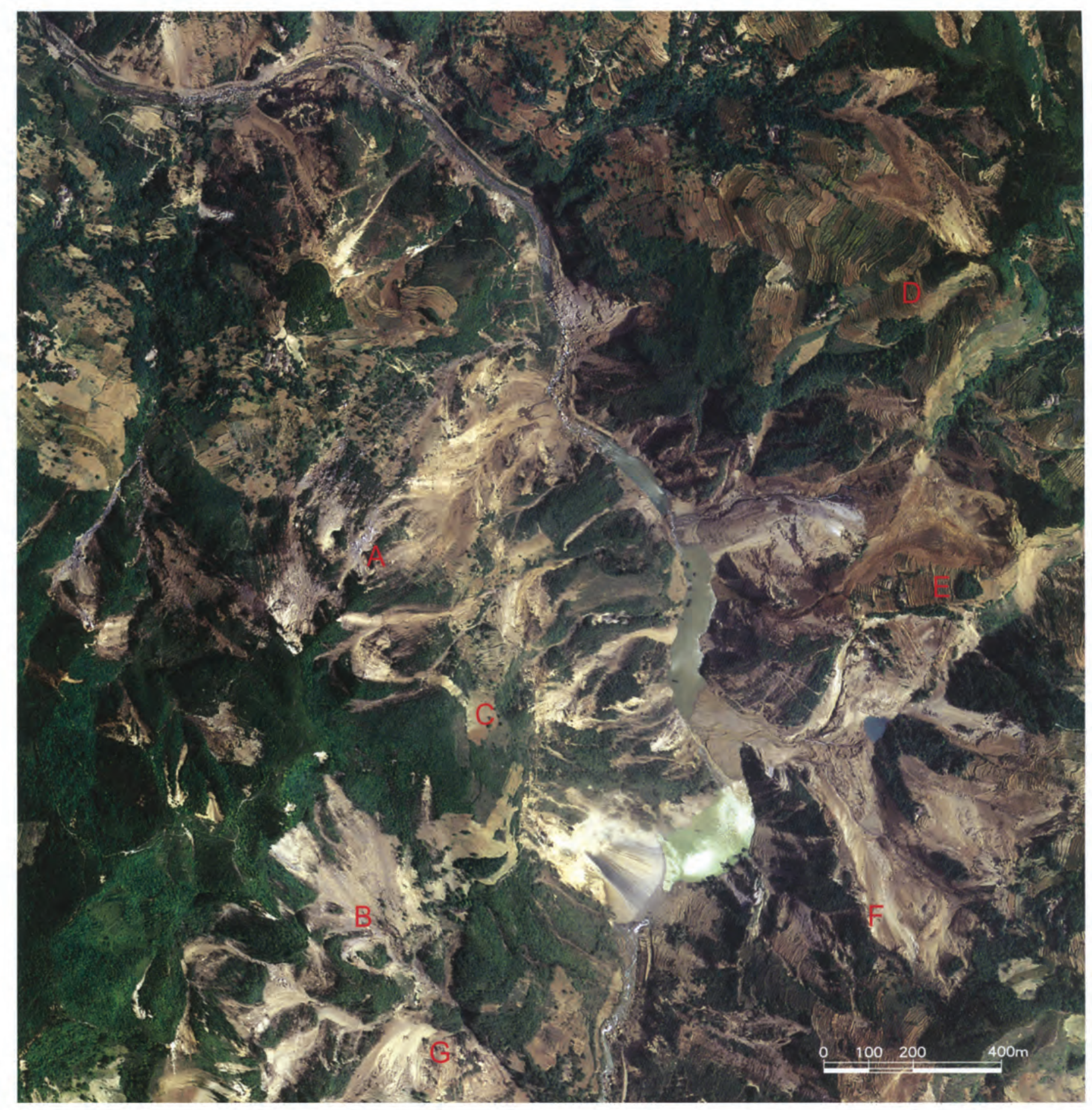

ム Image II: airborne optical remote sensing image acquired on May 28, 2008 of the village of Liangjiasan, in Pingwu County

(A), (B), (C), (D), (E), (F), and (G) indicate the locations of destroyed farmlands. 
$\checkmark$ Image III: airborne optical remote sensing image acquired on May 28, 2008 around the village of Leidashu, in Pingwu County

(A), (B), (C), (D), (E), (F), and (G) indicate the locations of destroyed farmlands.

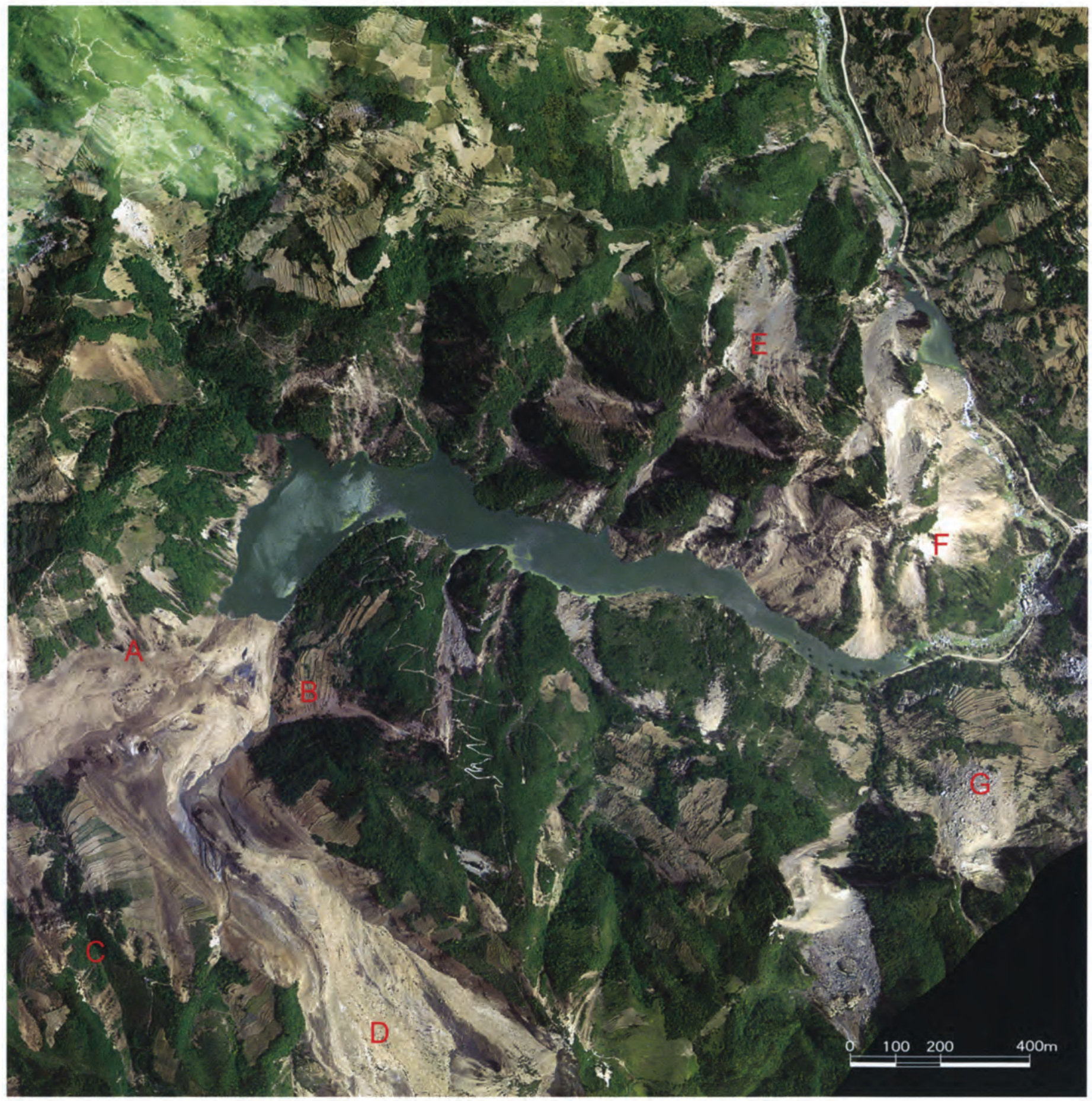



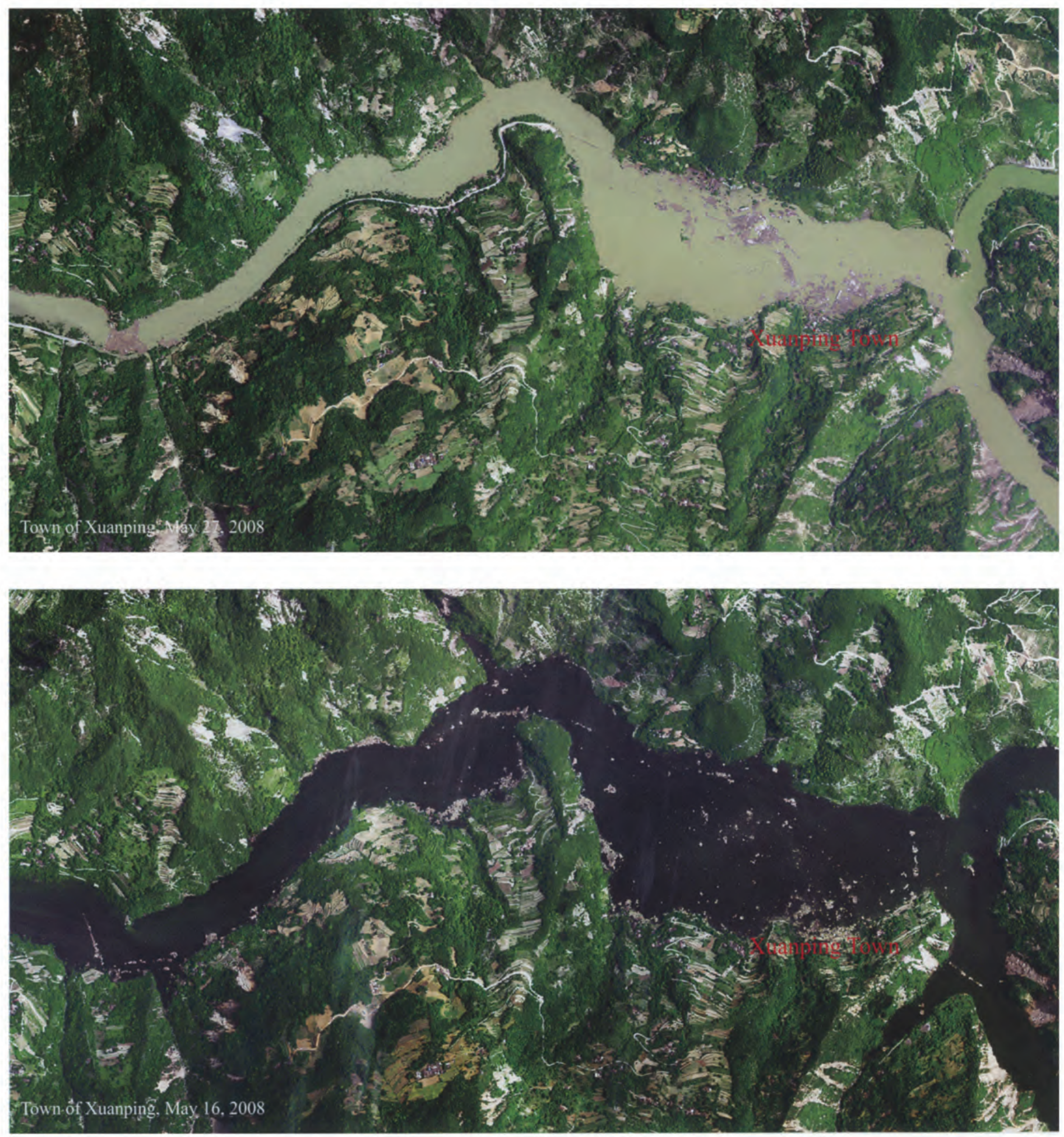

\section{$\Delta$ The inundated farmlands of Beichuan County}

The two images above were acquired on May 16, 2008 and May 28, 2008, respectively, after the earthquake. Comparing these two images shows that many farmlands and houses of the town of Xuanping in the upper reaches of the Jianjian River were inundated by water, which was caused by the barrier lakes of Tangjiashan in Beichuan County. 


\section{Destroyed landscape in the Minjiang River Valley}

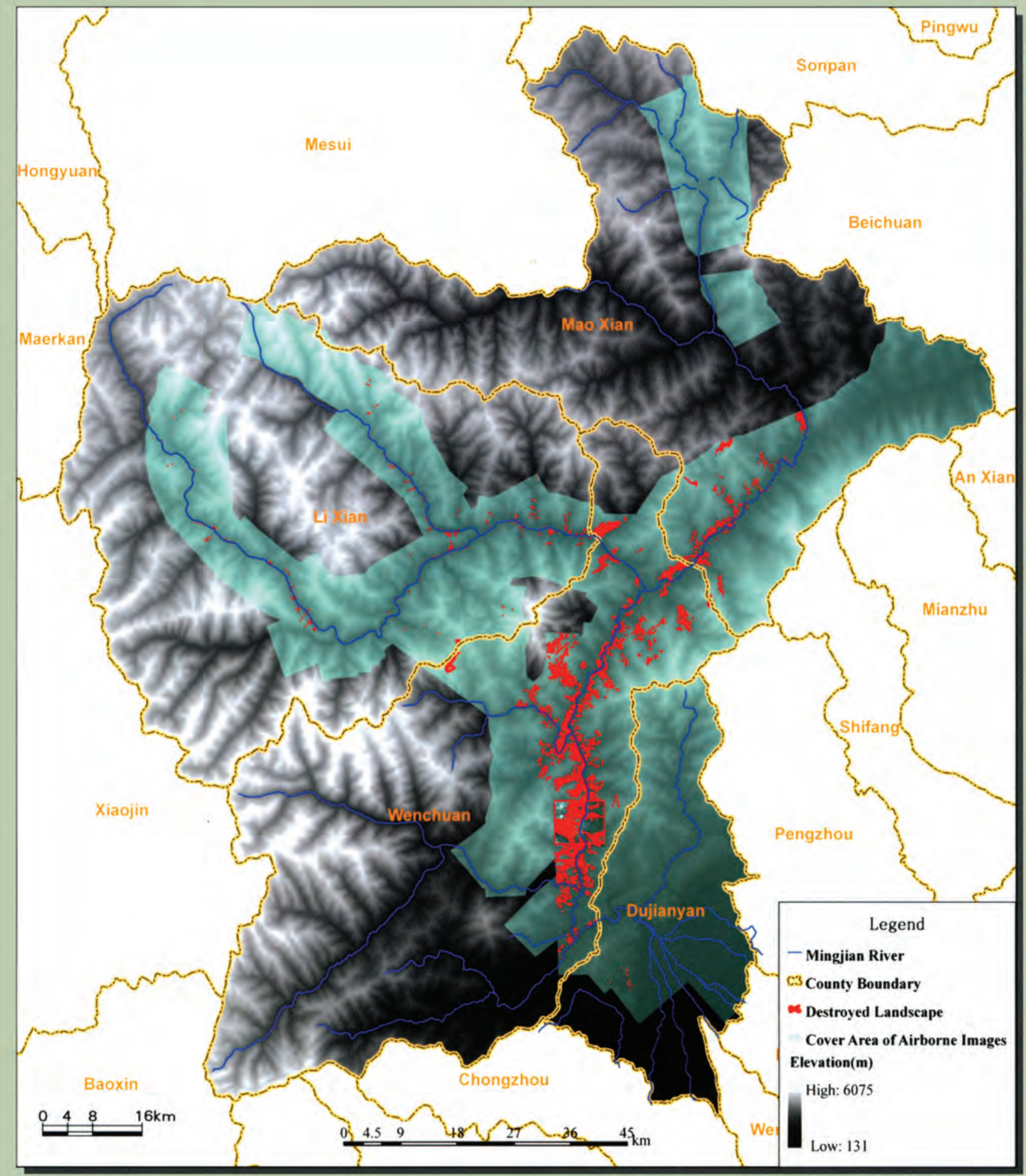

This is a composite remote sensing image of destroyed landscape that was created by overlaying digital terrain elevation generated from the airborne imagery onto an image of the area along the Minjiang River.

The image shows that the destroyed landscape is distributed along the valleys of the Minjiang, Jianjiang, and Fujiang rivers and their tributaries. The landscape destruction was caused by secondary geological disasters after the earthquake, including landslides, avalanches, and rock debris flows. The landscape changes will lead to the changes in the local ecological environment. Assessment of the landscape changes after the earthquake can provide scientific support for developing environmental reconstruction programs during the disaster recovery efforts.

There is a red rectangle in the lower left marked (A), showing the location of the remote sensing image in the typical natural landscape changes shown on the next page. 


\section{Destroyed landscape caused by secondary geological disasters}

In Wenchuan County, large areas of forests, farmlands, and grass were destroyed by secondary geological disasters that followed the earthquake. Comparing the SPOT 5 images on May 9, 2007 (before the earthquake) with the airborne images of the same region on May 16, 2008 (after the earthquake), it is obvious that the Wenchuan earthquake annihilated the original surface vegetation.

The images below are three-dimensional natural landscapes derived from images and Digital Elevation Models (DEM) viewing to the west of Xingwenpin of Yinxing Township. Comparing the characteristics of these four images shows the extent of landscape destruction.
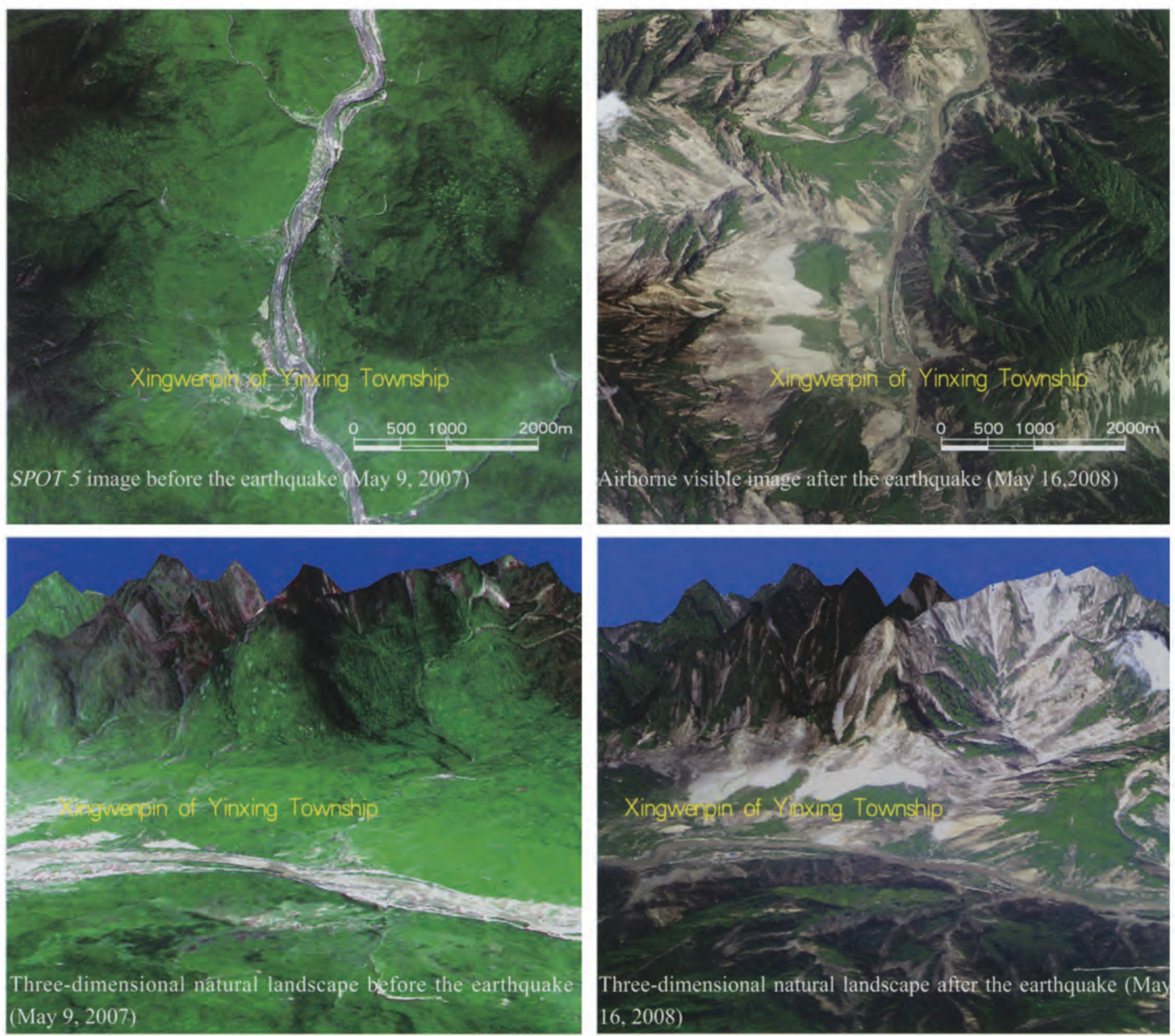

208 I Atlas of Remote Sensing of the Wenchuan Earthquake 

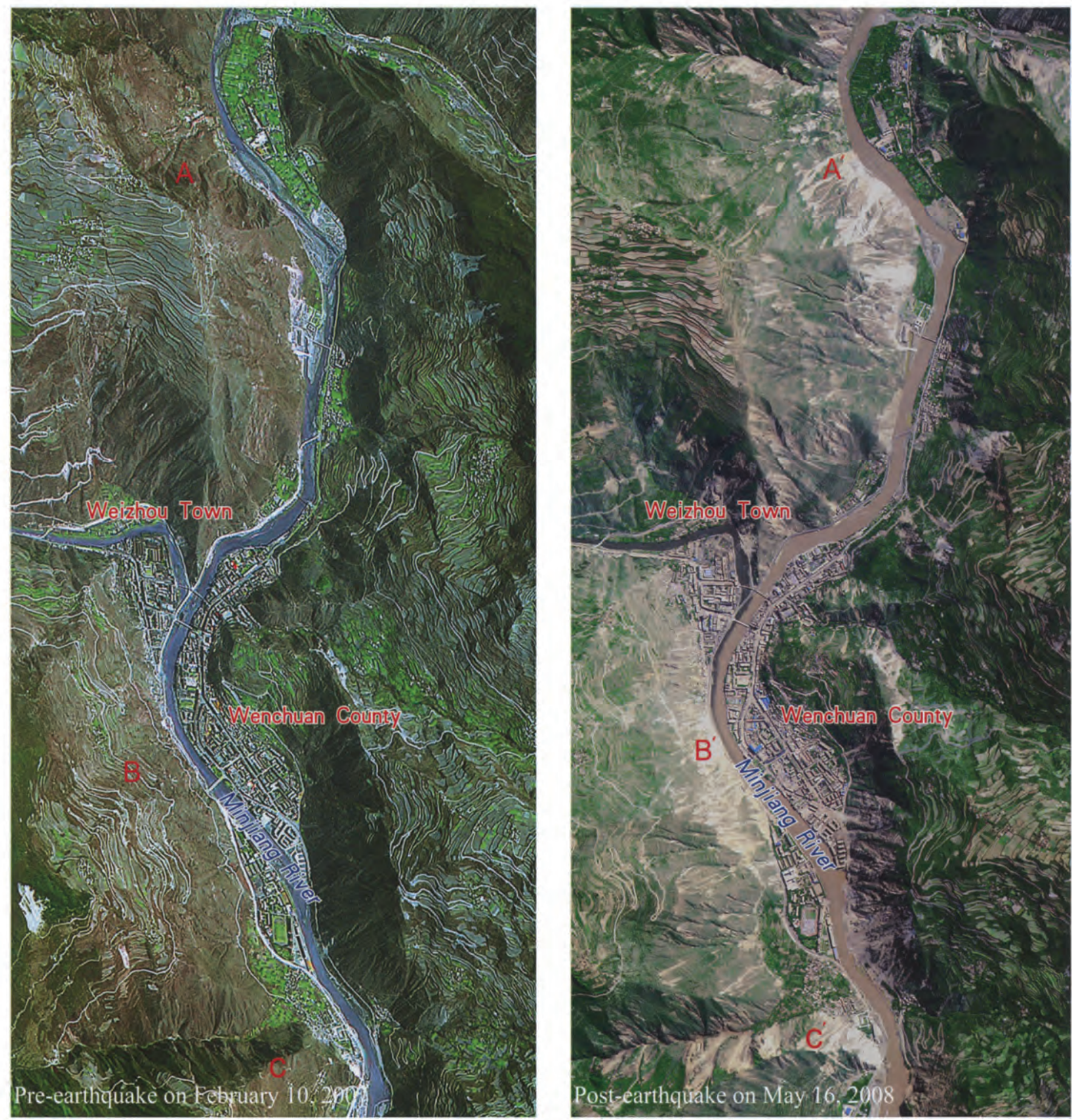

$0 \quad 100 \quad 200 \quad 400 \mathrm{~m}$

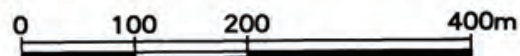

\section{Secondary geological disasters around Wenchuan County}

A SPOT 5 image before the earthquake created on February 10, 2007 appears on the left. An airborne visible image from after the earthquake acquired on May 16, 2008 appears on the right. (A), (B), and (C) in the left-hand SPOT image and the same locations $\left(\mathrm{A}^{\prime}\right),\left(\mathrm{B}^{\prime}\right),\left(\mathrm{C}^{\prime}\right)$ in the right image indicate the severely damage to the landscape caused by landslides, mud-rock flows, and rock debris flows. 


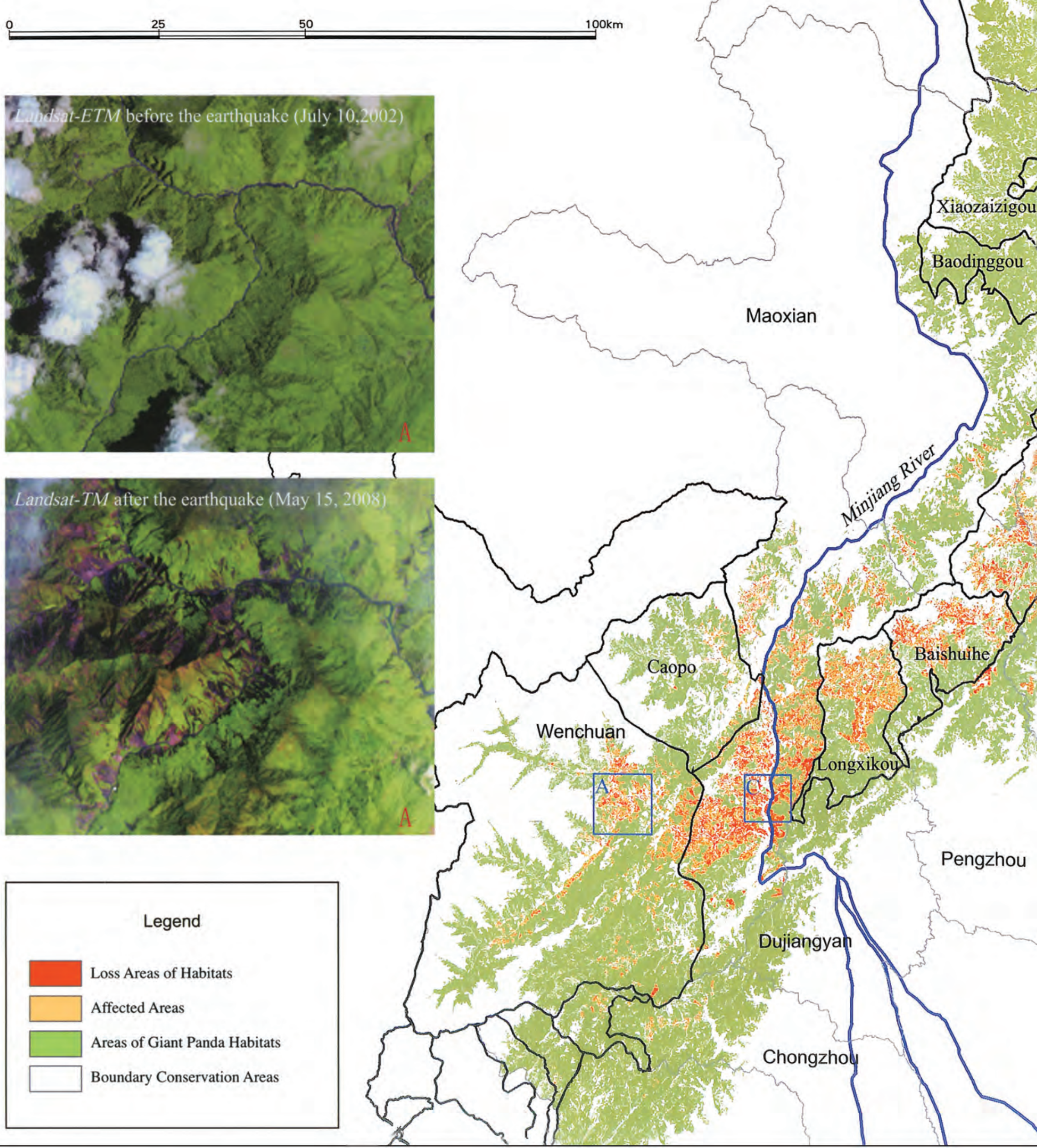




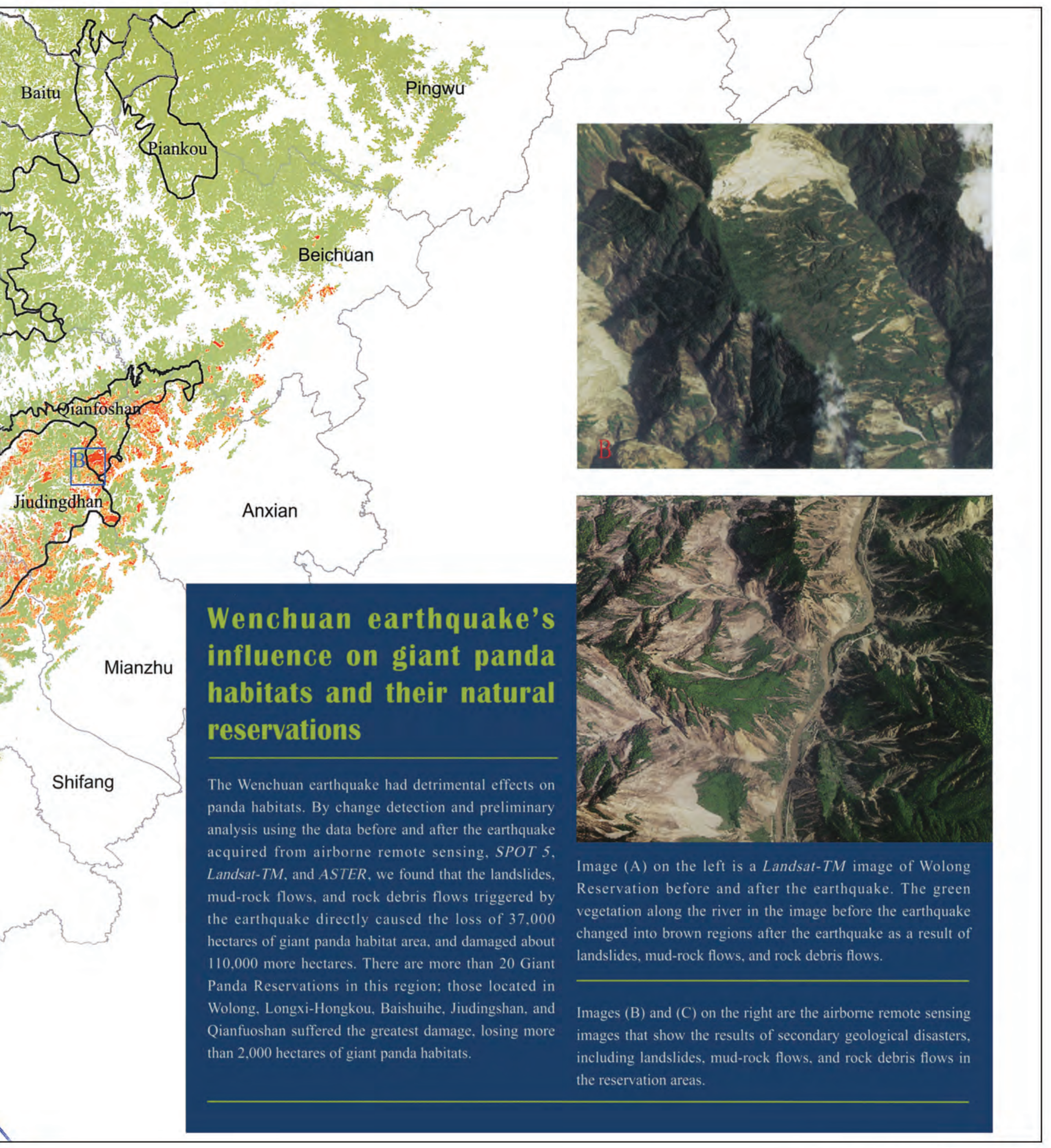




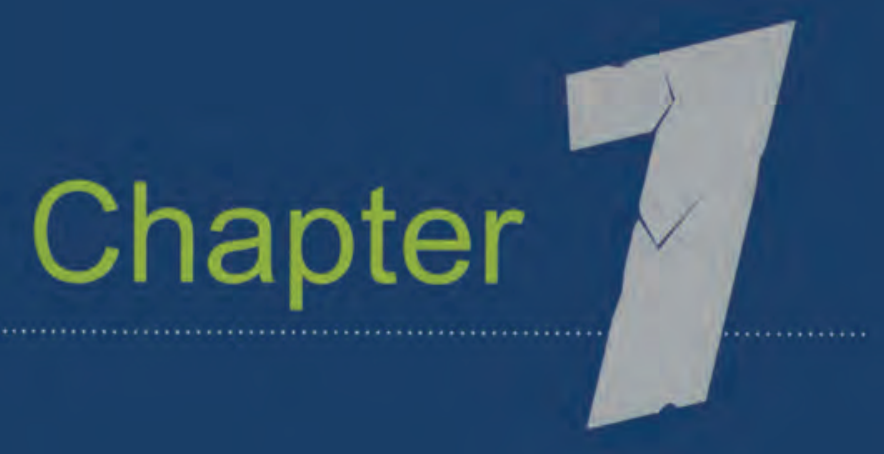

\section{Demolished InfRA-structure}

Not only did the earthquake cause significant losses in human lives and property, it also caused hidden trouble and damage to many infrastructures. After the Wenchuan earthquake, many important infrastructures in quake-hit areas were demolished, and hydrological engineering systems and mining construction areas were particularly badly damaged. Geological disasters, such as landslides, debris flows, and collapse, caused serious problems for these infrastructures. Some reservoir dams were buried by landslides, or damaged by debris flows, and the earthquake threatened dam security. Barrier lakes in the upper reaches of dam reservoirs filled some dams with mud and sands, and the dam system buildings were flooded and damaged, shutting down dam operations. Although some dams were not damaged because they were positioned on stable ground, the landslides, debris flows, and collapse that occurred near the reservoirs weakened the stability of the reservoirs. Moreover, some mining area construction faced severe losses because mines were blocked and mine buildings and houses were damaged.

Analysis of airborne and space-borne remote sensing images revealed many demolished infrastructures. This chapter shows the damage to important hydrological engineering systems and mining construction areas, including the Taipingyi power station in the town of Yinxing in Wenchuan County, the Shapai power station in the town of Caopo in Wenchuan County, the Futangba power station and Banpocun power station in the town of Miansi in Wenchuan County, the town of Nanxin power station in Maowen County, the Kuzhuba power station in the town of Qushan in Beichuan County, the Zipingpu Reservoir in the city of Dujiangyan, and the Jinhe Phosphate Mine in the town of Hongbai in the city of Shifang. Moreover, because radar images are sensitive to high-voltage wire transmission towers, we detected the towers affected by the landslides near National Highway 317 in western Wenchuan County and warned that the landslide could cause the towers to collapse and could interrupt power transmission. 


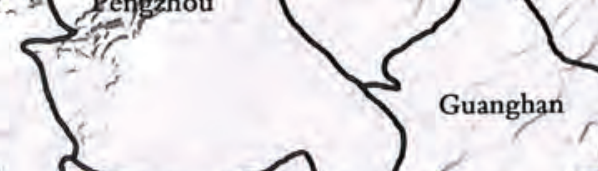




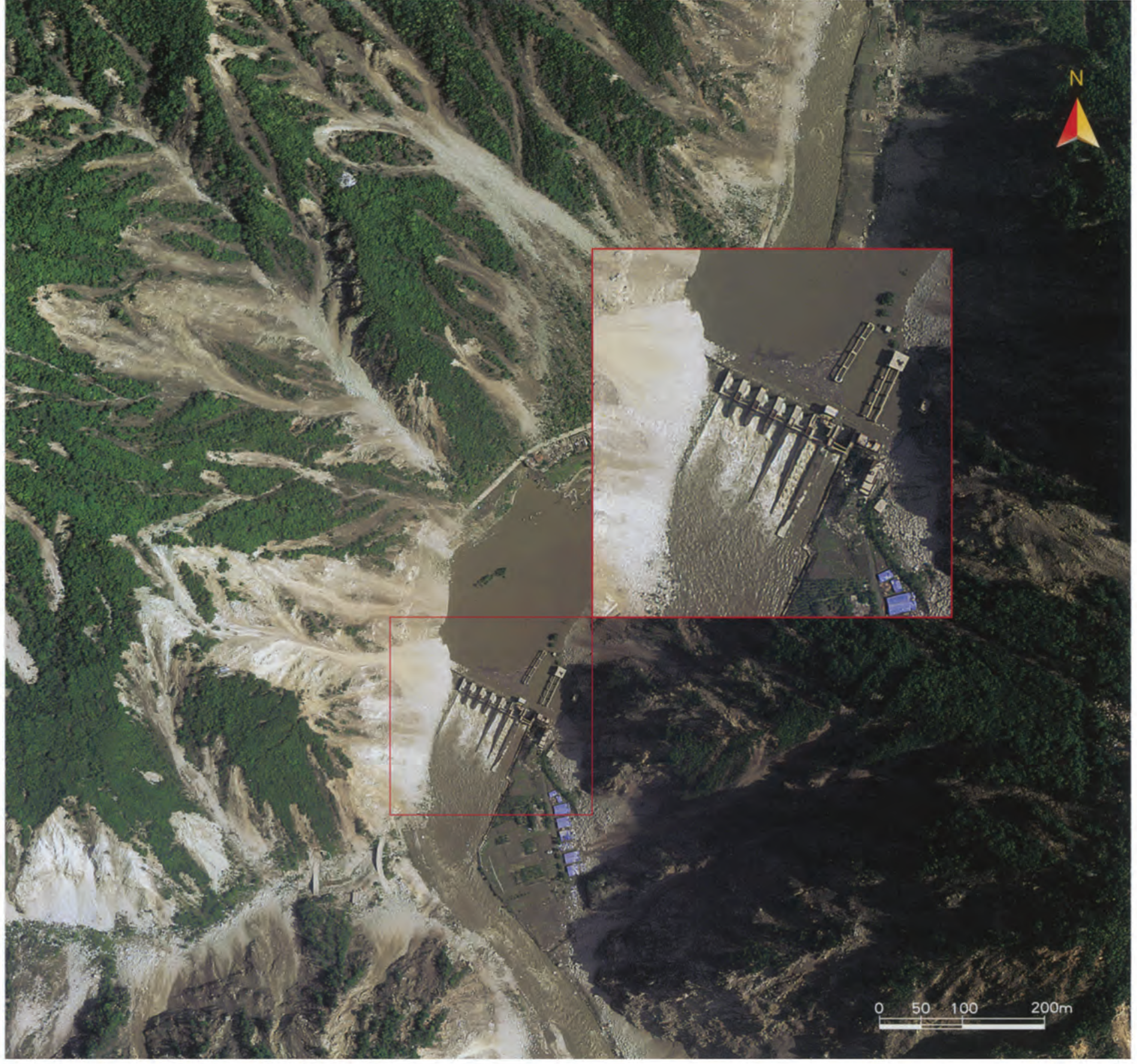

\section{A Airborne optical remote sensing image of Taipingyi power station in the town of Yinxing, in Wenchuan County}

This image, acquired on May 15, 2008, shows the Taipingyi power station, which was damaged by the landslides. A large landslide with a length of $530 \mathrm{~m}$ and a width of $500 \mathrm{~m}$ to the left of the station is threatening dam security.

\section{SPOT 5 remote sensing image of the Taipingyi power station in the town of Vinxing, in Wenchuan County}

This image, acquired on December 1, 2006, shows the Taipingyi power station and dam functioning properly before the earthquake. 


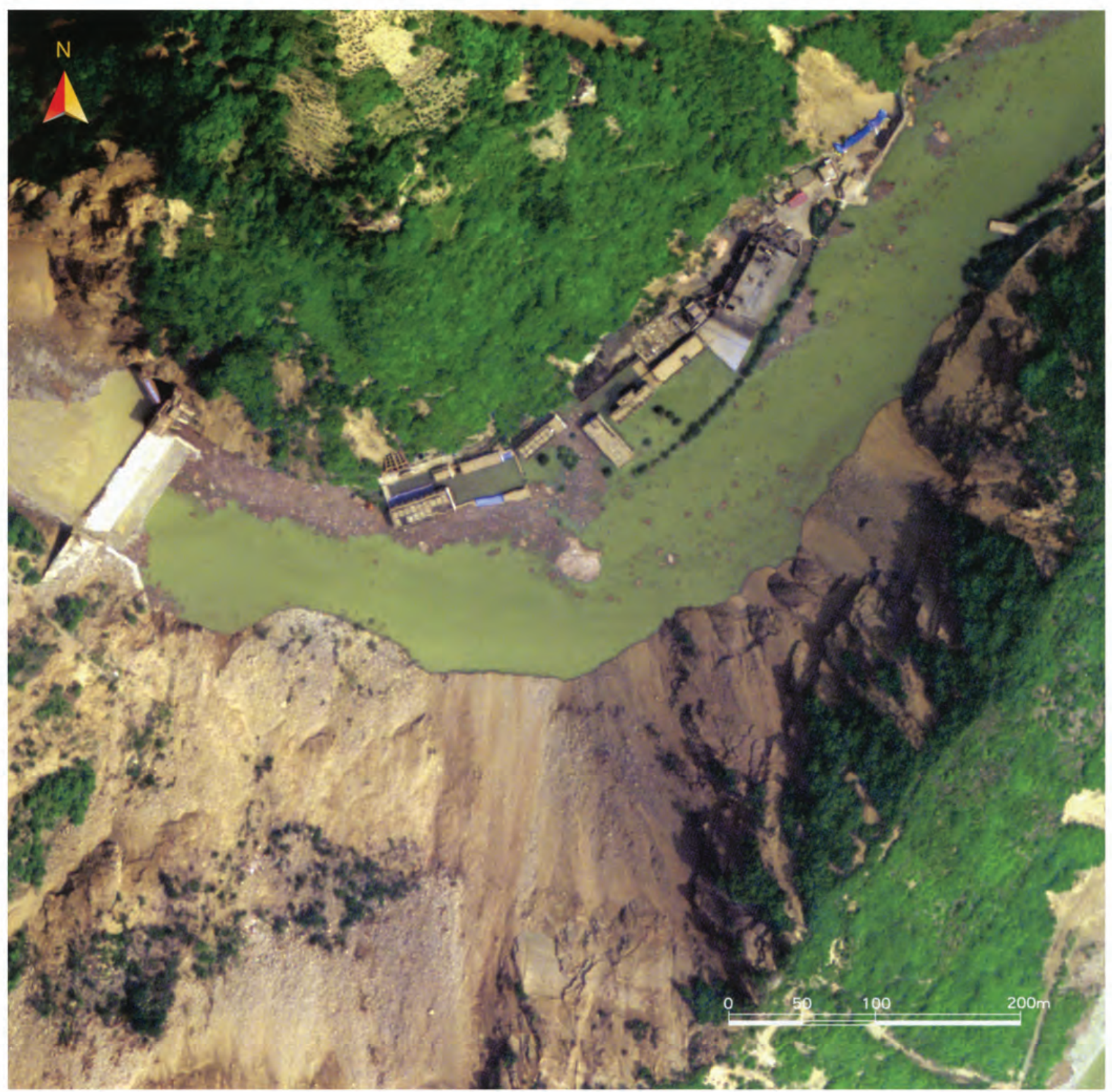

A Airborne optical remote sensing image of the Kuzhuba power station in the town of Qushan, in Beichuan County

This image, acquired on May 16, 2008, shows the Kuzhuba power station affected by the barrier lake, Mud and sand filled up the dam, and the station buildings were flooded.

- Airborne optical remote sensing image of the power station in the town of Nanxin, in Maoxian County

This image, acquired on May 15, 2008, shows damage to the dam and the power station, which were inundated with water after the earthquake.

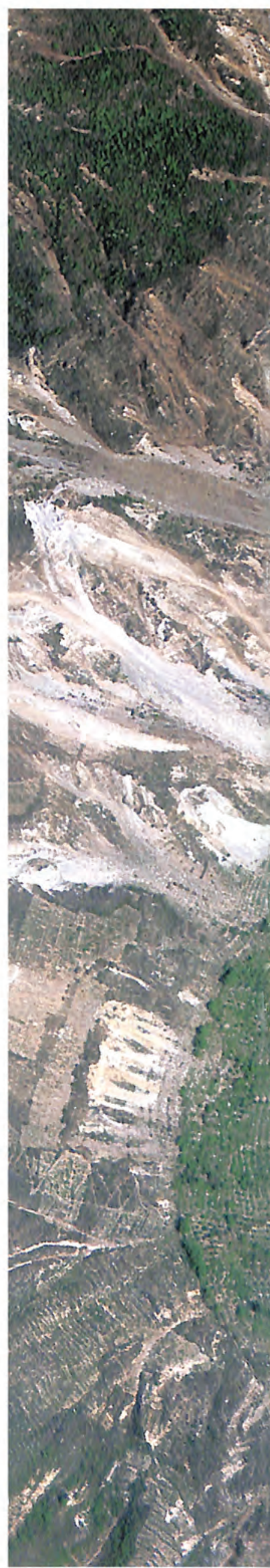




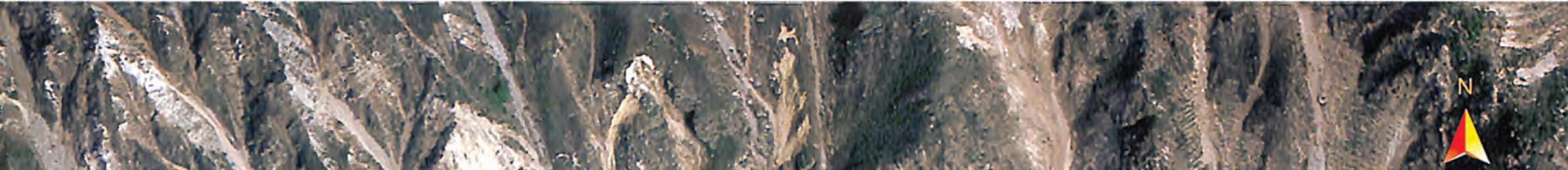

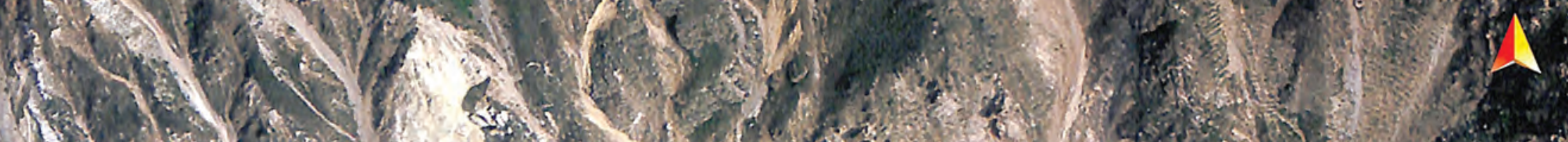

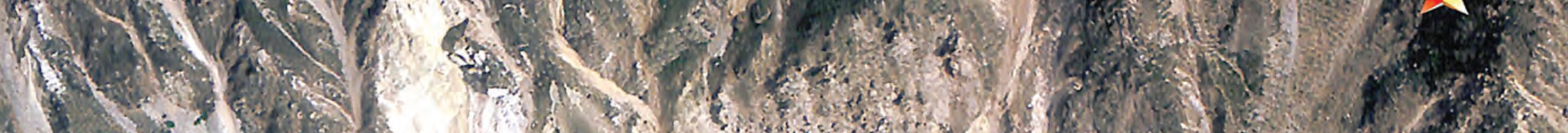

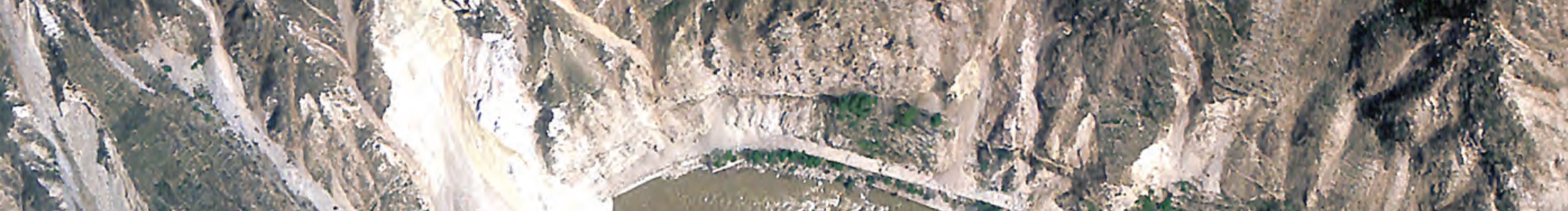

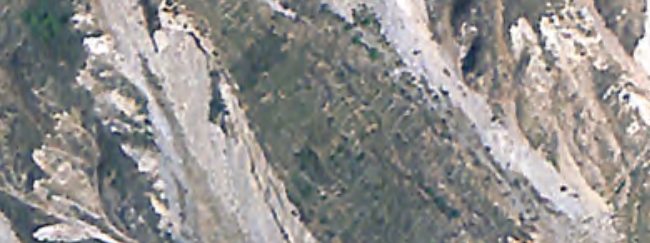

(5)

ent

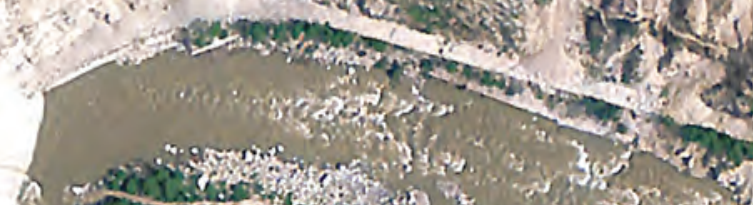

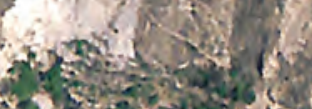
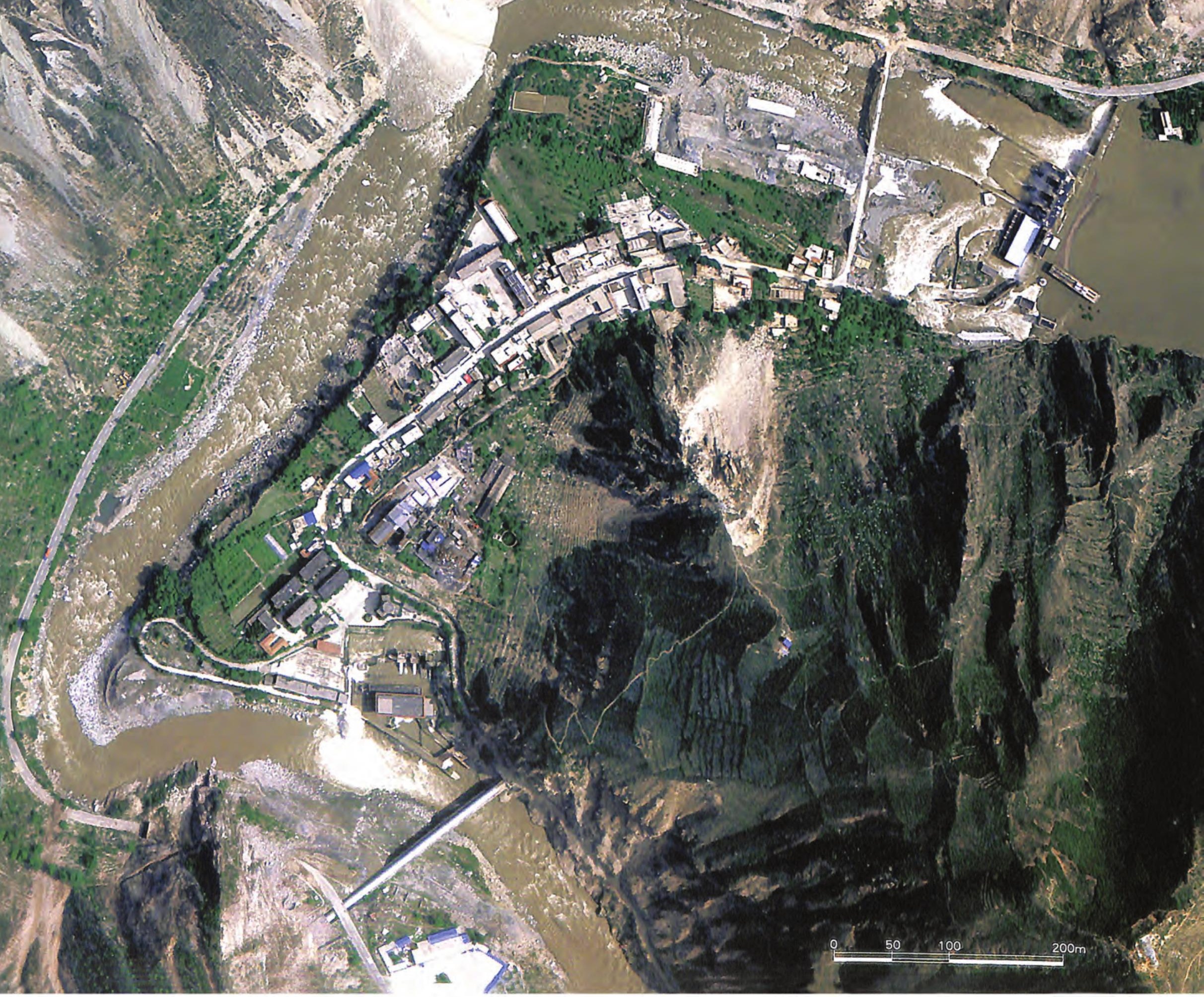

Demolished Infrastructure | 217 
- Airborne optical remote sensing image of the Banpocun power station in the town of Miansi, in Wenchuan County

This image, acquired on May 17, 2008, shows that the dam of the Banpocun power station was badly affected by the earthquake. The west side of the dam was damaged by landslides.

จ Airborne optical remote sensing image of the Futangloa power station in the town of Miansi, in Wenchuan County

This image, acquired on May 17, 2008, shows that the Futangba power station was affected by the earthquake. The roads to the station were destroyed by landslides, and the buildings were also damaged.

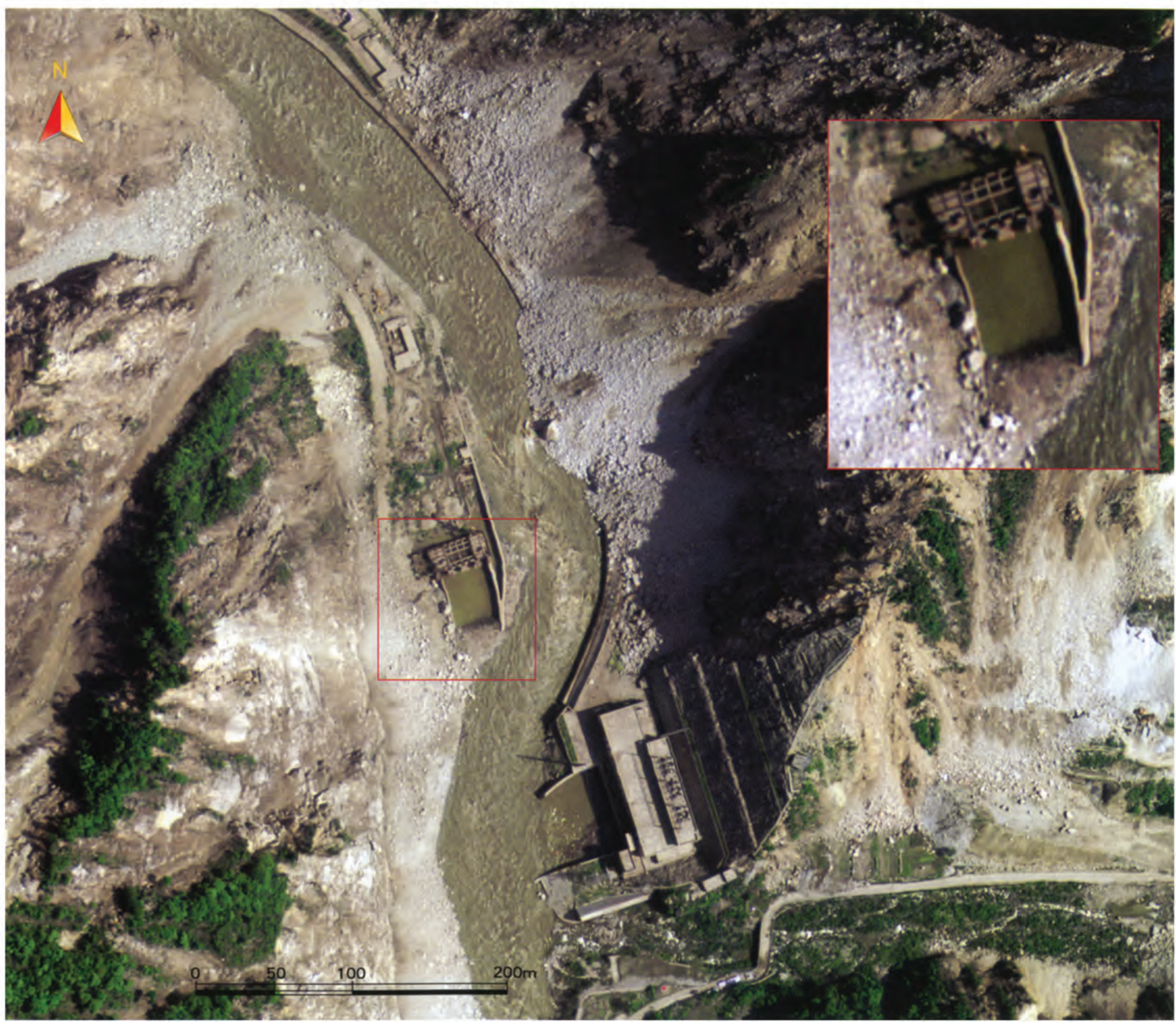




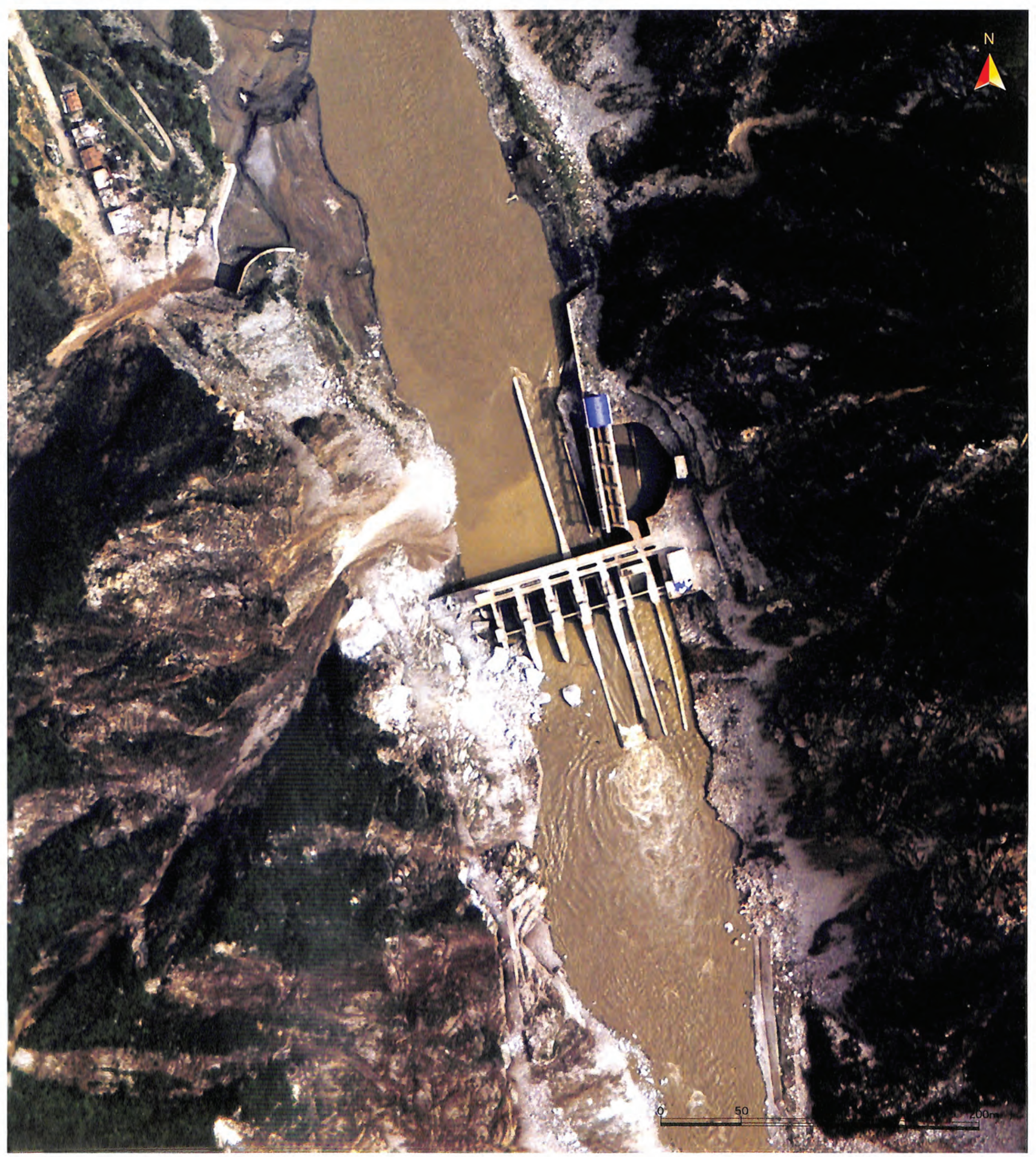



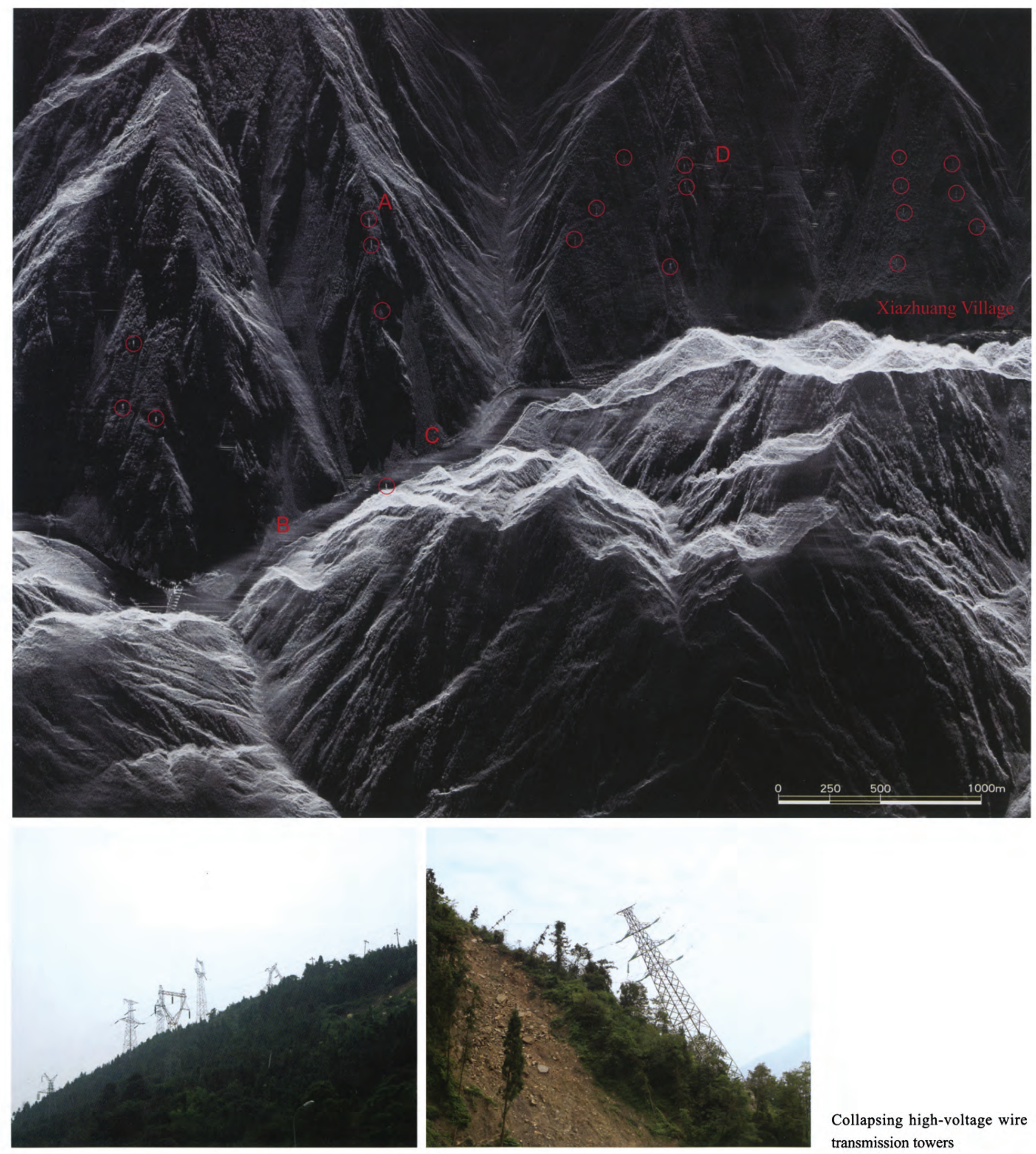

Collapsing high-voltage wire transmission towers 


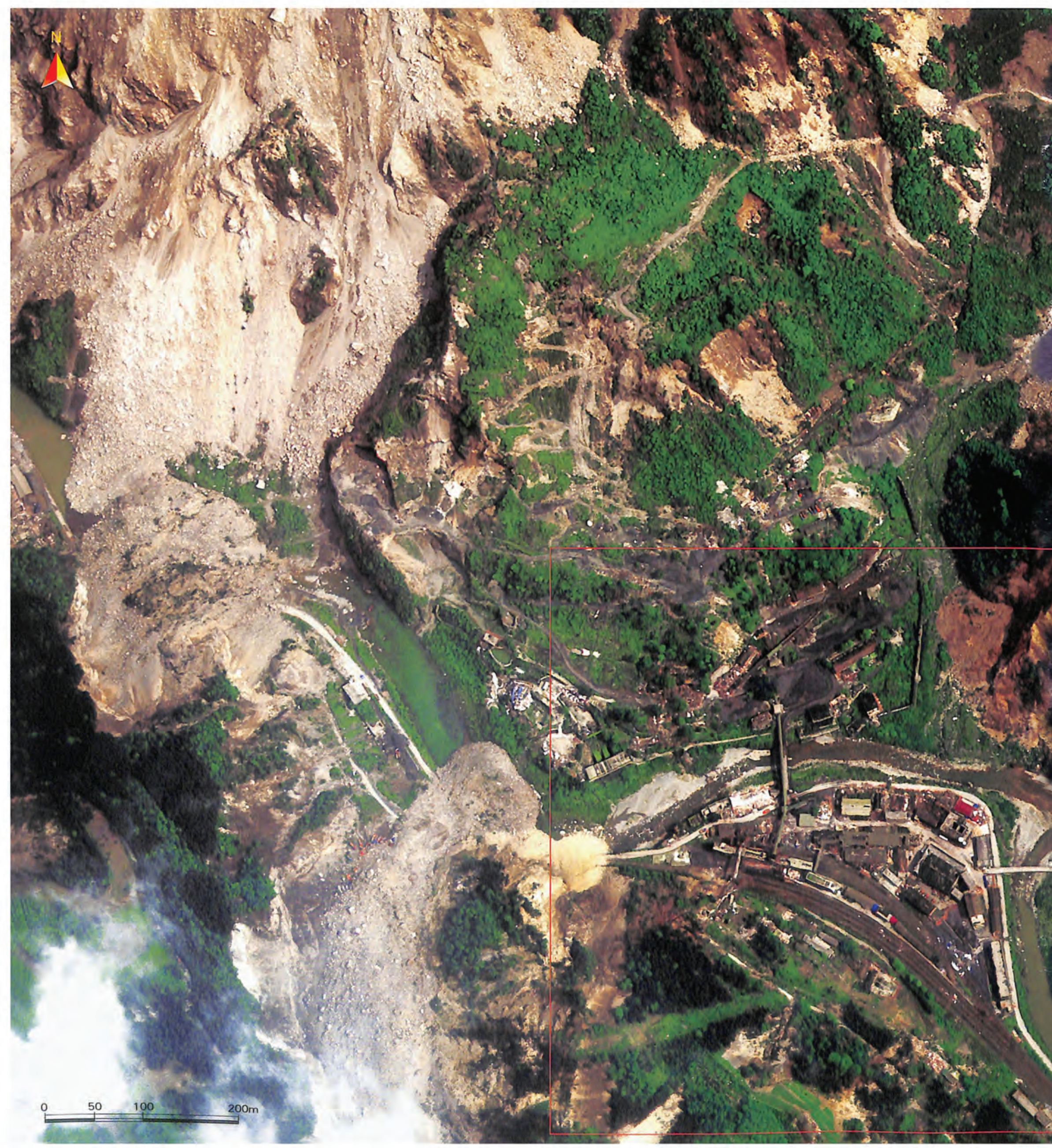




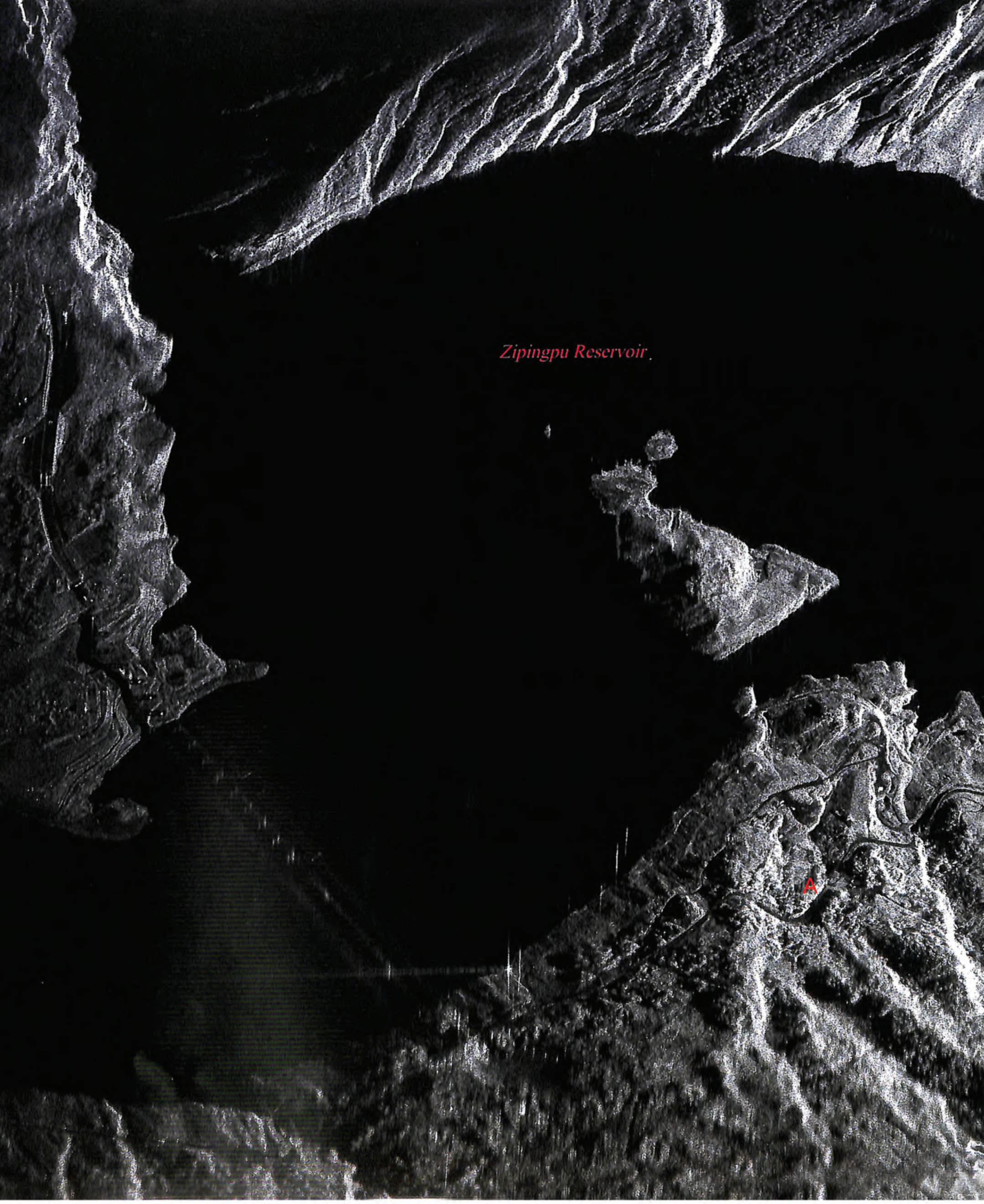



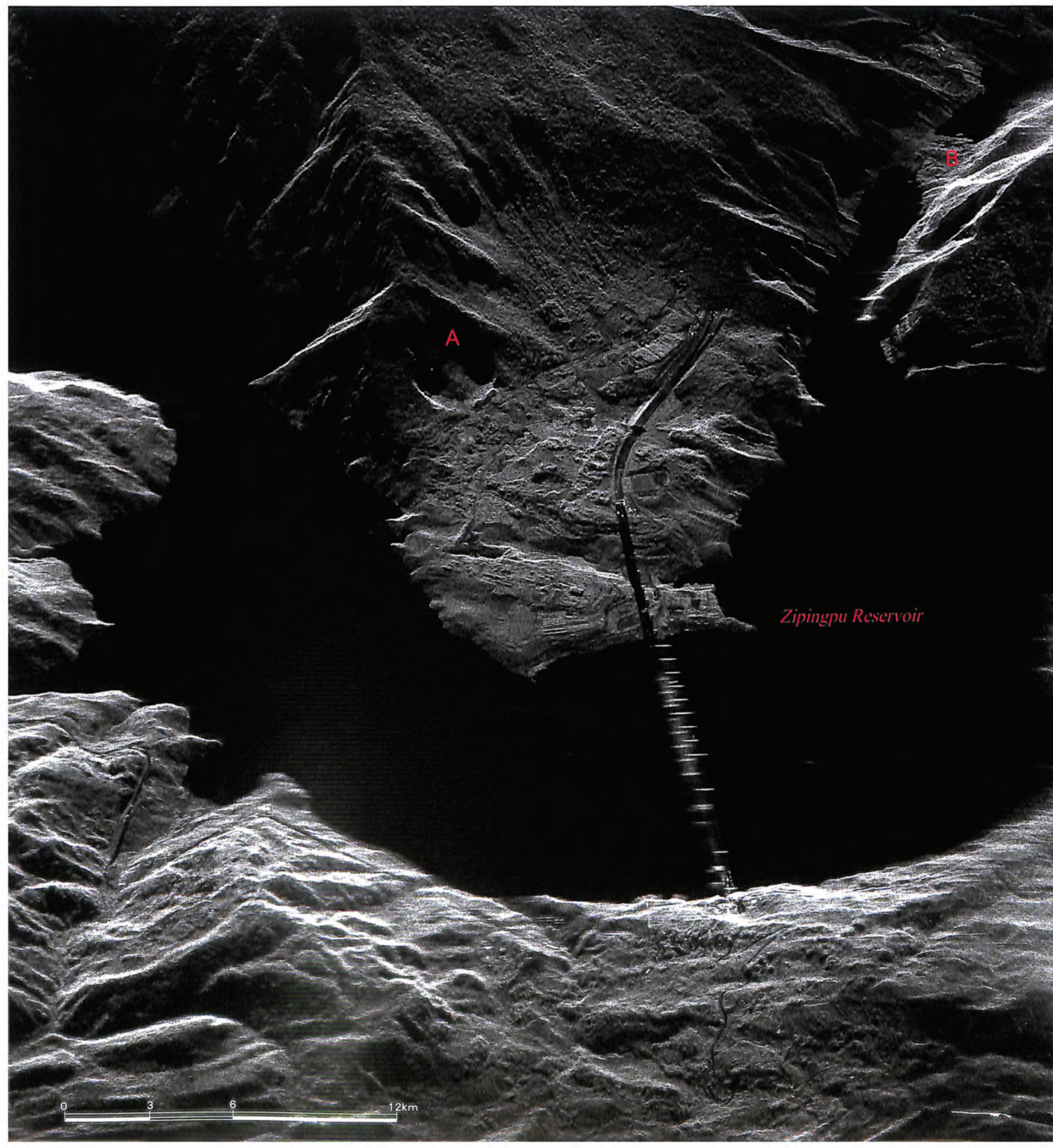

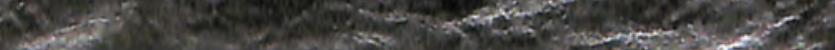




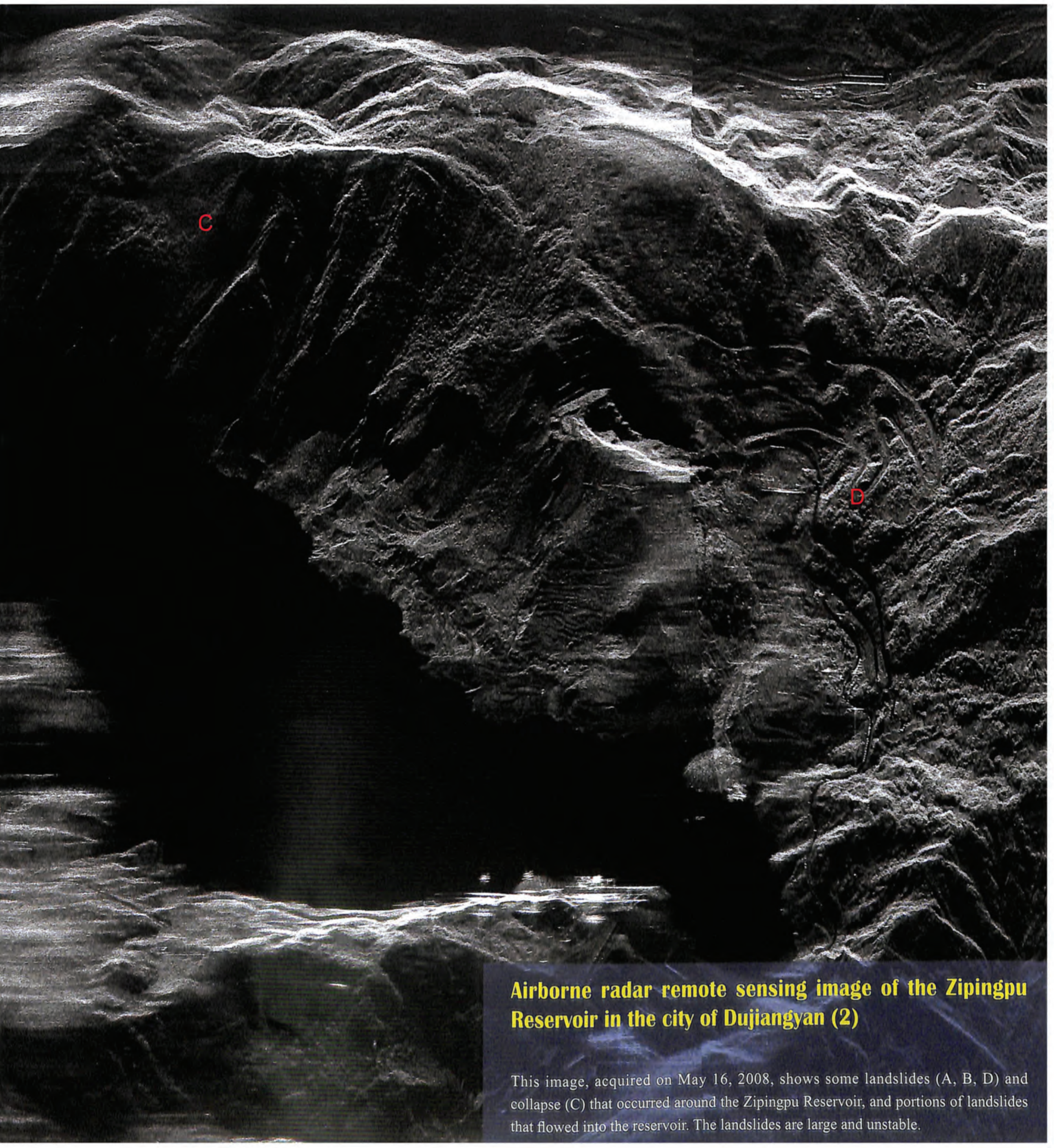




\section{(i)}

\section{Civilization Perseveres}

The Wenchuan earthquake-hit area includes many important national and cultural sites, including the world heritage Dujiangyan Irrigation Project, giant panda sanctuaries, Mount Qingcheng and the Dazu Rock Carvings, as well as homelands for ethnic minorities such as Tibetans, Qiangs, and Huis, and their cultural heritage sites. According to the statistics of the State Administration of Cultural Heritage of China (http://culture.people.com.cn/GB/87423/7235130.html), the Wenchuan earthquake affected area contains one site of world cultural heritage importance (the Dujiangyan Irrigation Project), 49 important heritage sites under state protection, 225 provincial-level cultural heritage sites, and 684 county-level cultural relic preservation areas.

After the earthquake, collapsed buildings in Dujiangyan were mainly reconstructions of ancient buildings (replicas of cultural relics); however, the genuine cultural relics were almost unaffected. While the buildings in the front part were partly destroyed, Mount Qingcheng as a whole was unaffected. The main hall of Erwang Temple, built during the Qing Dynasty, remains intact (http:// news.sina.com.cn/pl/2008-05-30/135215650932.shtml). The Dujiangyan Irrigation Project is still solid and functions normally after the great earthquake, except for some fissures in the Yuzui Bypass Dike.

[1] http://culture.people.com.cn/GB/87423/7235130.html

[2] http://news.sina.com.cn/pl/2008-05-30/135215650932.shtml 


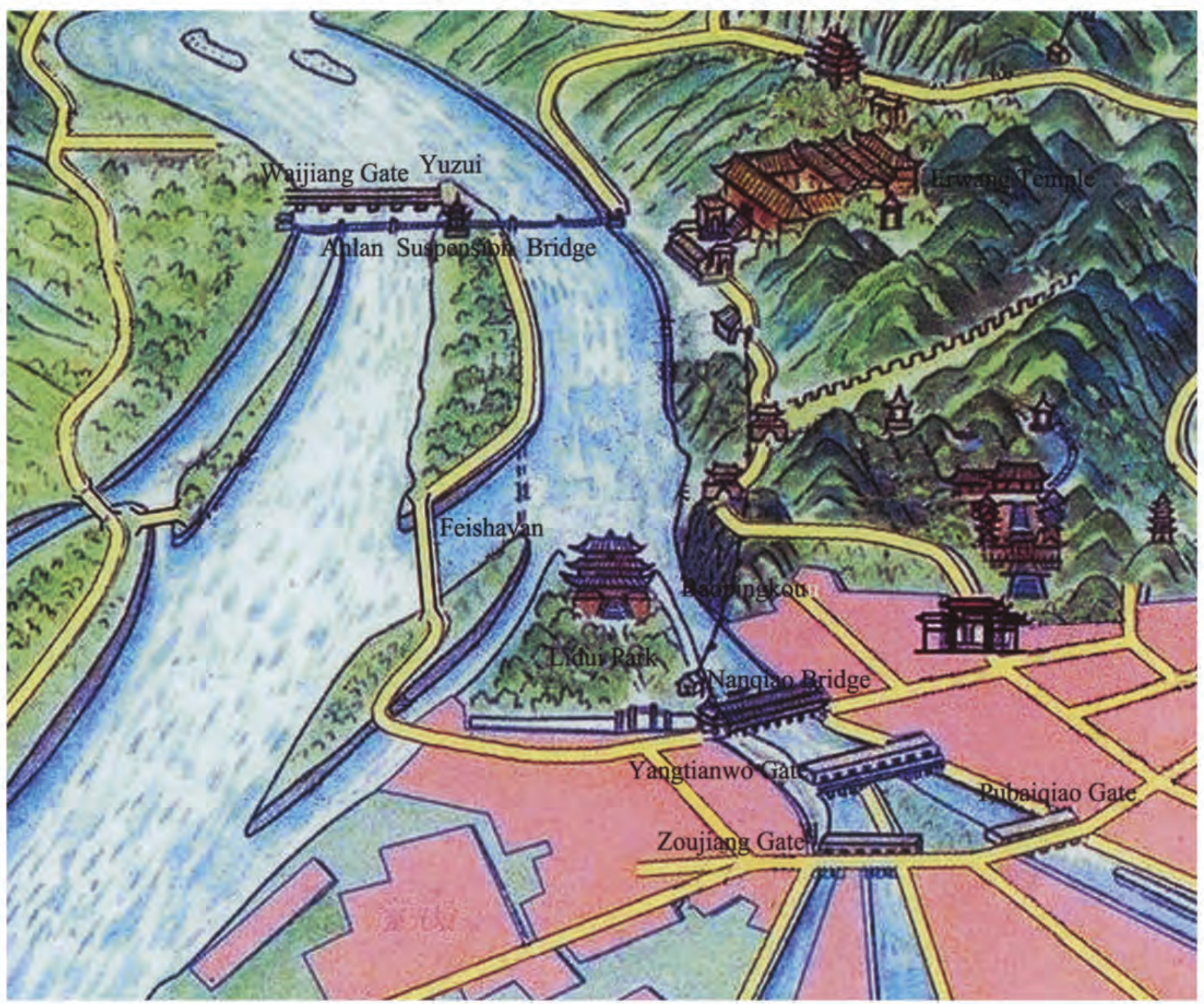

The Dujiangyan Irrigation System is the world's oldest and only remaining large hydraulic water project characterized by damless diversion. It consists of the Yuzui Bypass Dike, the Feishayan Floodgate, and the Baopingkou Diversion Passage. These three elements operate synchronously with one another to prevent flooding and to preserve the water supply to farmlands. The system automatically adjusts the capacity of the inner river for irrigation such that it carries $40 \%$ of upstream Minjiang water during flood seasons and $60 \%$ during dry seasons. Since the irrigation system was completed, the western Sichuan Plain has never flooded. This system has helped the Sichuan Plain earn the name "the Land of Abundance" in all seasons and all weather conditions.

The Yuzui Bypass Dike, named for its conical head said to resemble the mouth of a fish, is an artificial levee. The levee, which was built in the middle of the Minjiang River, functions to divide the river into inner and outer rivers. The outer river, situated in the west and known as
"Jinma River." functions as the main stream and is mainly used to drain excess water and sand. The inner river, to the east along the foothills of Yulei mountain, is used for irrigation.

The Feishayan Floodgate, connecting the inner and outer rivers, primarily functions to control the flow of water. During the dry seasons it is not needed as much. When flooding occurs, it allows excess water to flow over the Feishayan Floodgate into the outer river. It can also help reduce the amount of silt and stone carried by the inner river before it flows into the Baopingkou.

The Baopingkou Diversion Passage, which Li Bing gouged through the mountain, is the final part of the system. Its name comes from the resemblance of Chengdu Plain to a large bottle and the passage's resemblance of the bottle neck. It works as a check gate to automatically control the volume of the water of the inner river. 


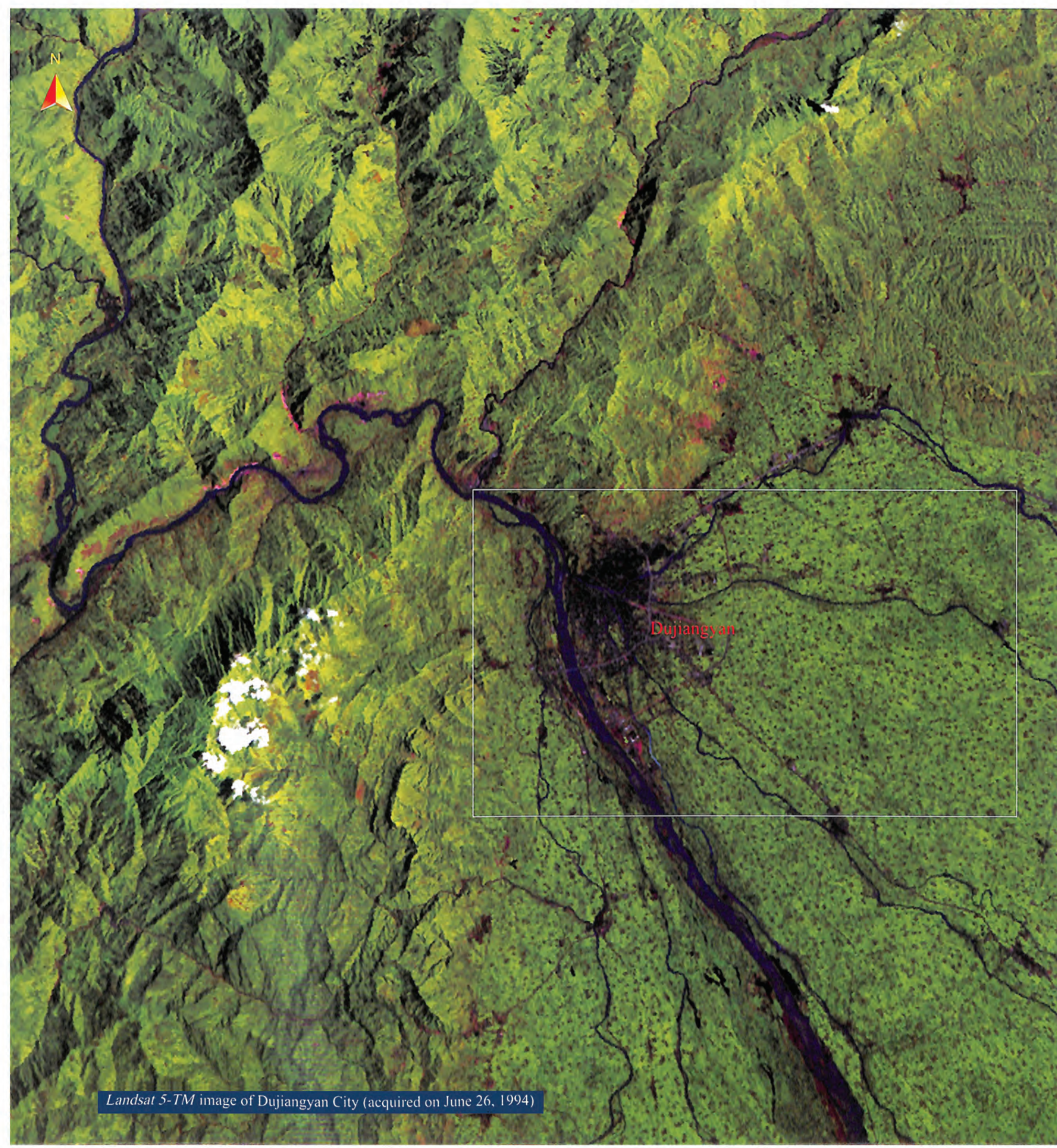




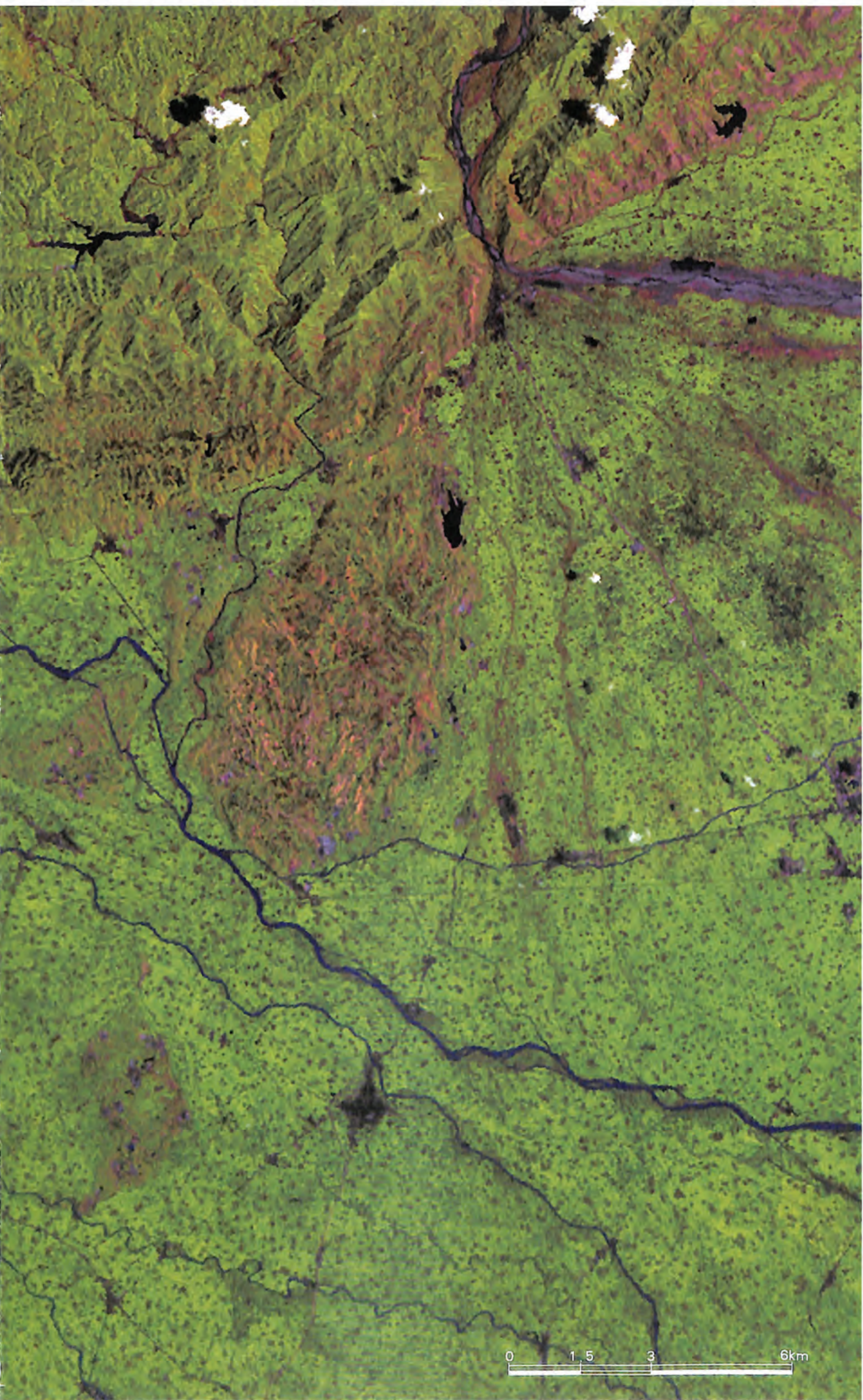

\section{Landsat 5-TM image of Dujiangyan City (acquired on June 26th,1994)}

Dujiangyan city is on the northwest edge of the Chengdu Plain, crossing the Longmenshan seismic belt in western Sichuan and the apex of the alluvial fan of the Minjiang River in the Chengdu Plain. The Landsat 5-TM image shows the topography gradually declining from northwest to southeast. With mountain in the northwest and plains in the southeast, the topography is ladder shaped. The proportion of mountains, plains, and water in the area is approximately $6: 3: 1$, according to the saying "six parts mountain, three parts farmland and one part water." Designed by Li Bing, a governor of Shu Prefecture in the Kimdom of Qin during the Warring States period (over 2000 years ago), and his son, the worldfamous Dujiangyan Irrigation System was erected on the Minjiang River at the foot of Yulei Mountain. Here the Minjiang River, after being joined by many tributaries in its upper reaches, runs toward the Chengdu Plain. With "digging deep for low dykes" as its motto, the Dujiangyan Irrigation System is characterized by damless diversion. After the Dujiangyan Irrigation System was built, the Minjiang River was divided into six canals for irrigation purposes, as well as the Jinma River, which carries the main stream. The whole system has been a crucial part of local agriculture for over 2000 years, and has contributed to the richness of Chengdu Plain and to earning its reputation as "The Land of Abundance." We are relieved that the Dujiangyan Irrigation Project was almost unaffected by the May 12 Wenchuan Earthquake. 


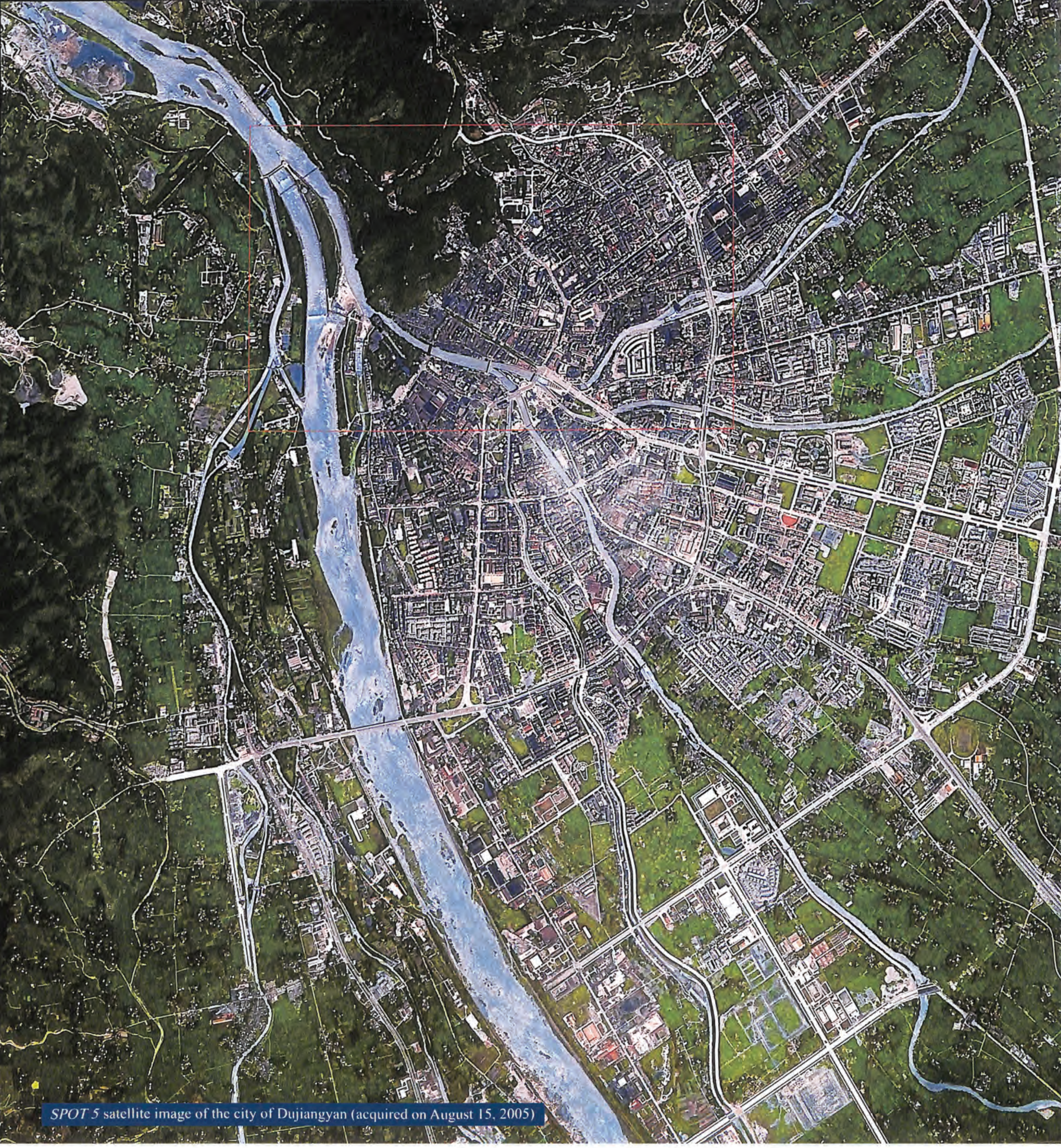




\section{A distribution map of the main parts of the Dujiangyan Irrigation Project and other important scenic spots}

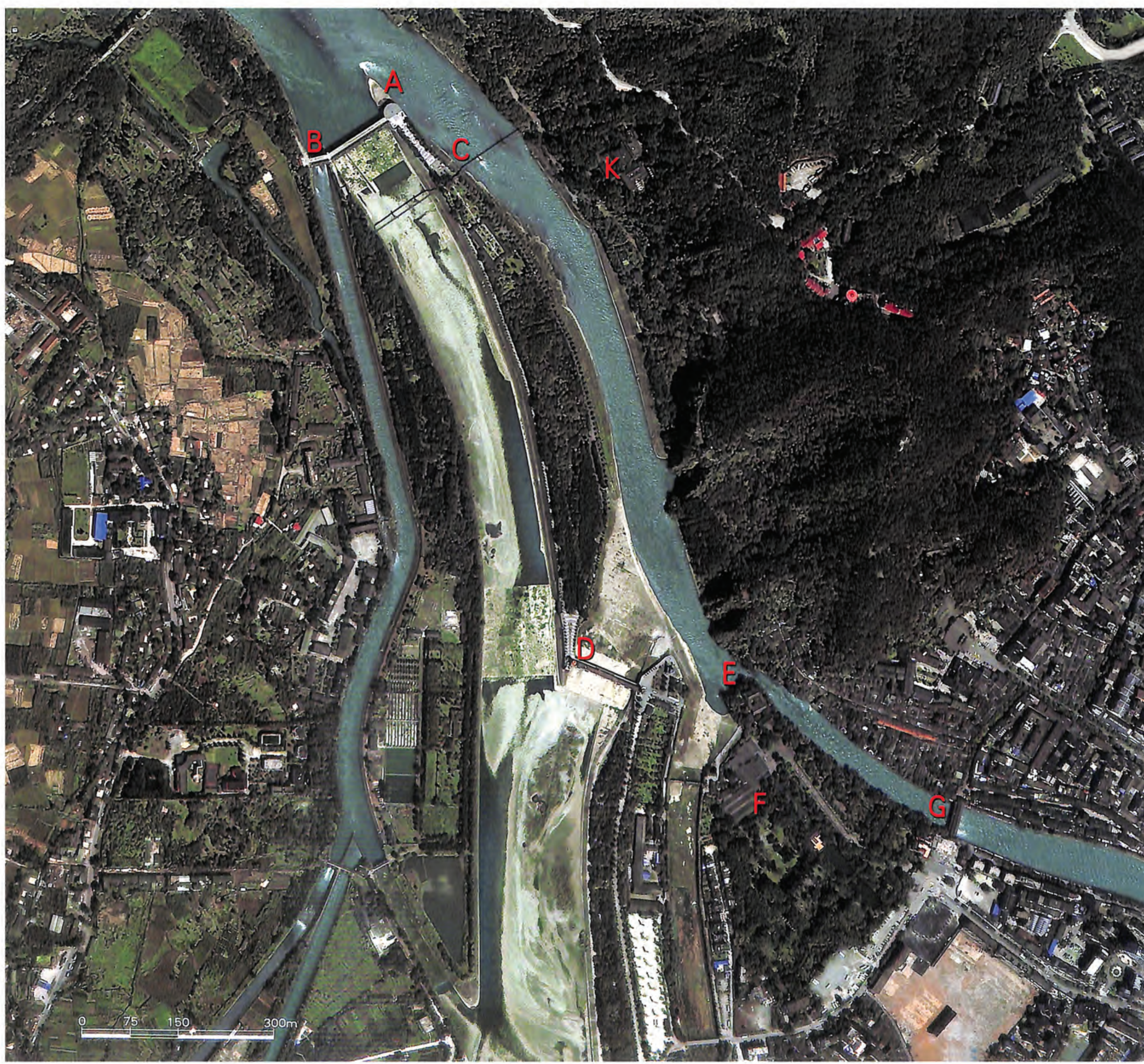




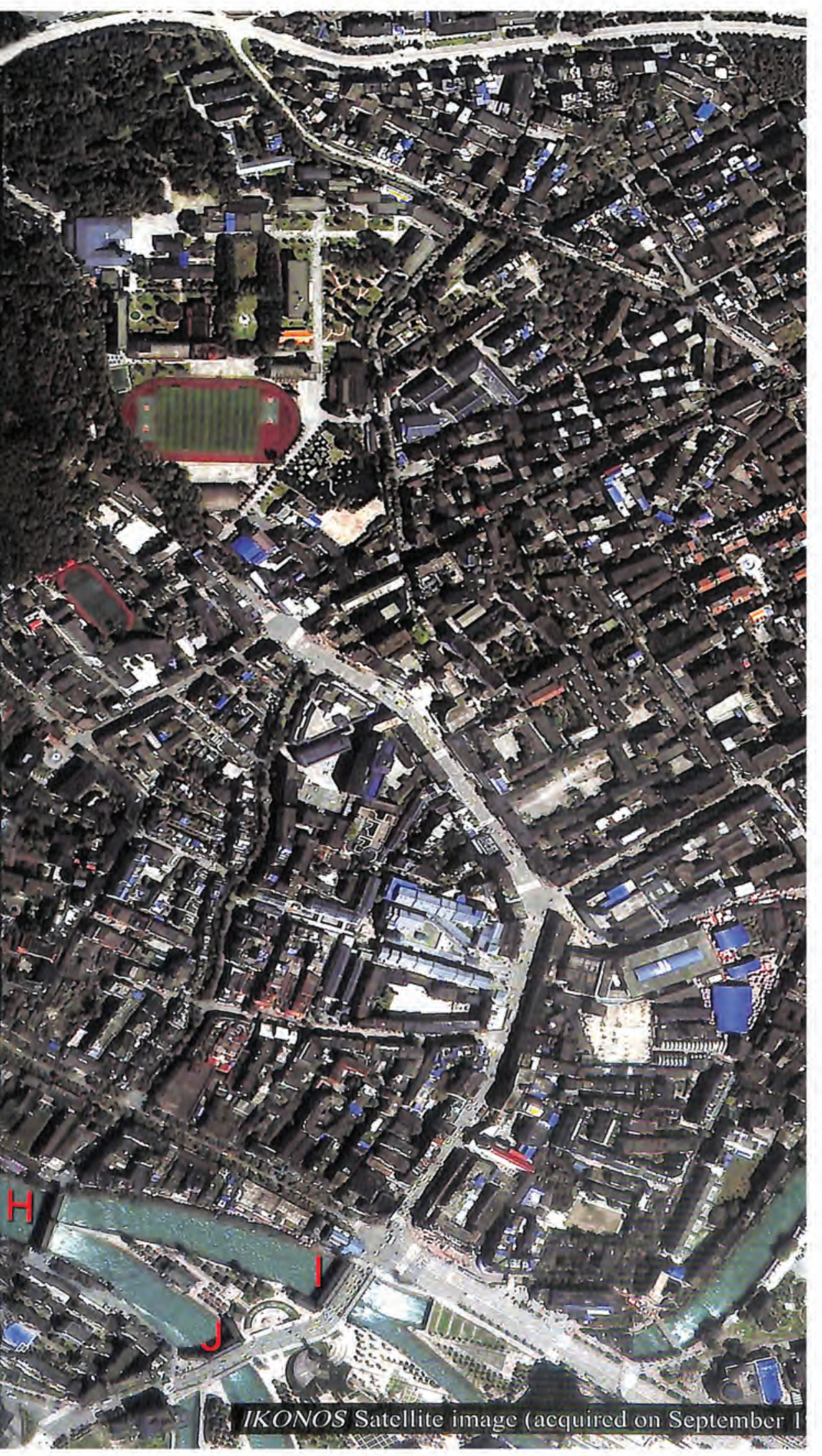

A. The Yuzui Bypass Dike
B. Waijiang Gate
C. Anlan Suspension Bridge
D. The Feishayan Floodgate
E. The Baopingkou Diversion Passage
F. Lidui Park
J. Zoujiang Gate
G. Nanqiao Bridge




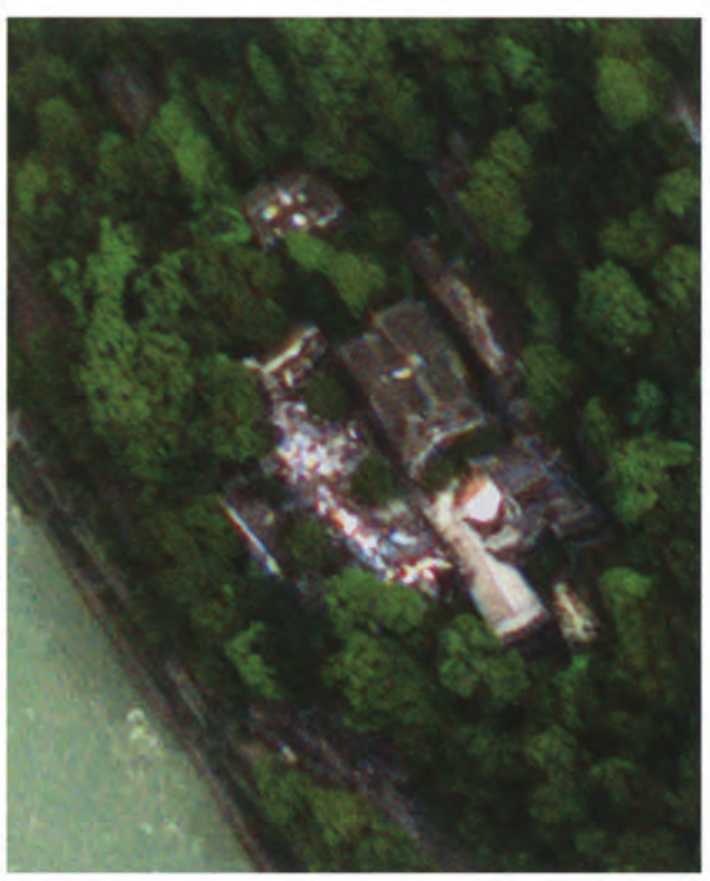

Airborne remote sensing image of Erwang Temple acquired after the earthquake (on

May 18,2008 )

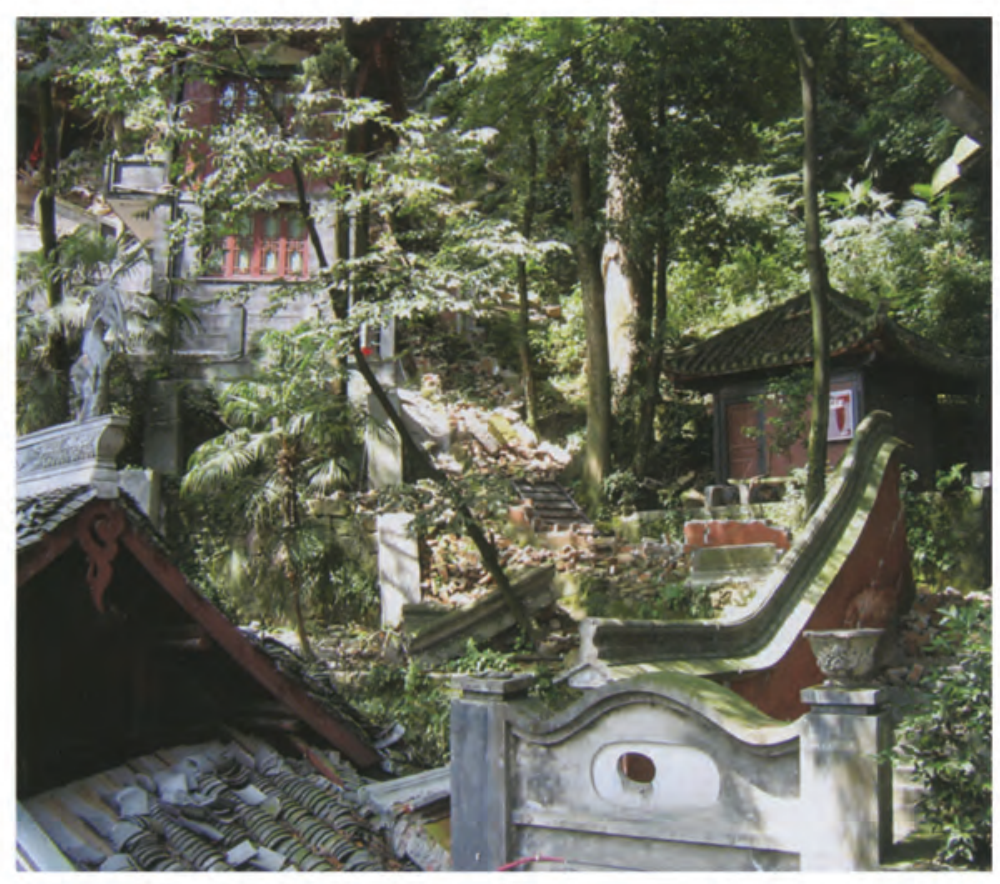

Picture of Erwang Temple after the earthquake
Erwang temple built in memory of Li Bing and his son for their great contribution in leading the construction of the Dujiangyan Irrigation System

Two main halls built during the Qing Dynasty remained mostly intact; however, the front gate, the side halls, the slope protection works, and the rocky mountain paths, all built in 1990s, were badly damaged.
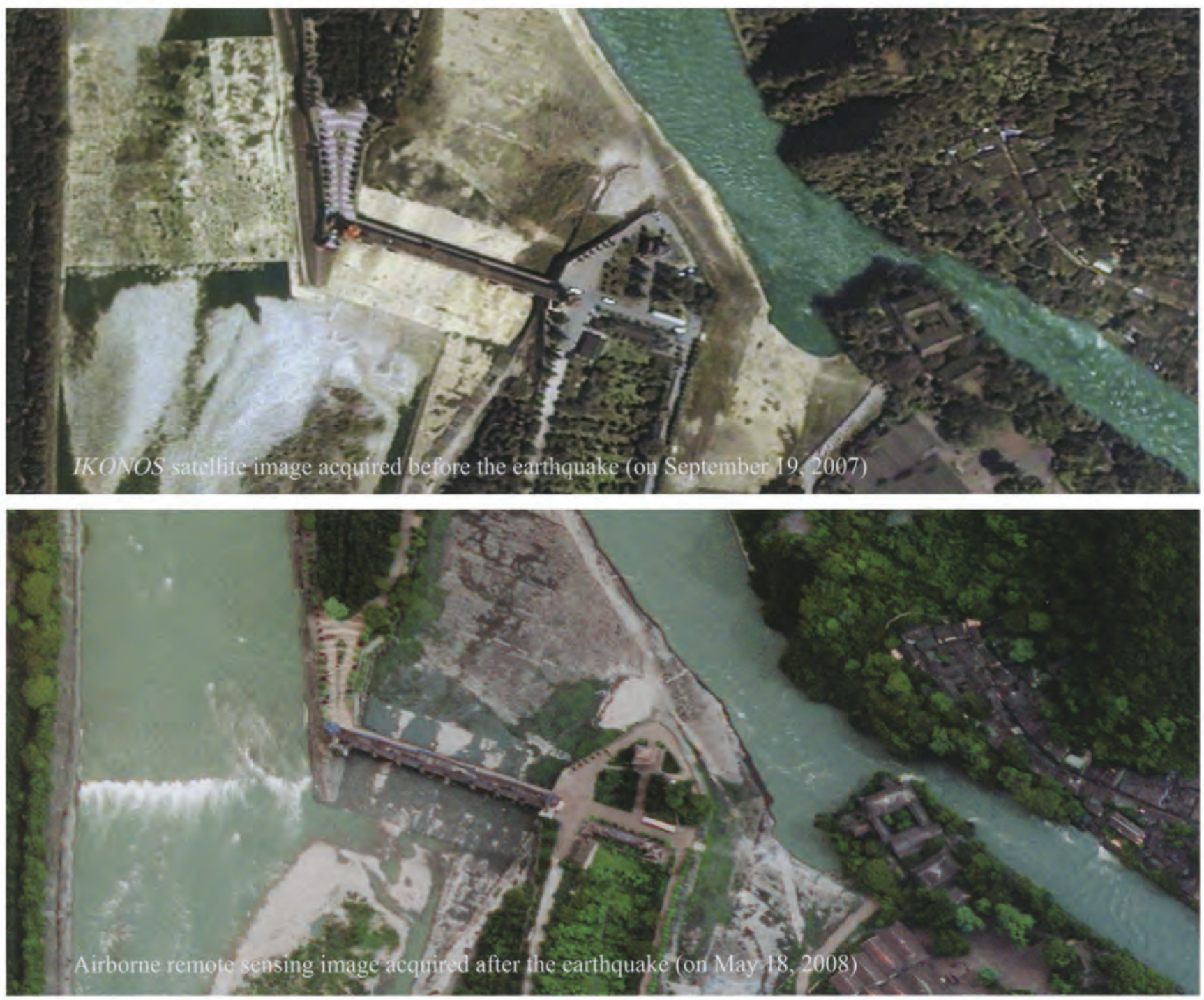

The Baopingkou Diversion Passage and the Feishayan Floodgate were unaffected 
The Dujiangyan Irrigation System is so astonishing not only because it is 2200 years old and continues to function properly, providing irrigation to the Chengdu Plain, but also because its importance to the valley increases as fresh water becomes a scarcer and more valuable resource. The Dujiangyan Irrigation System is also a unique architectural work, creating a model of harmonious coexistence between mankind and nature. It makes man, earth, and water a highly synchronous unity while making full use of rather than destroying natural resources, turning bane into boon, automatically dividing water, automatically removing silt, and automatically irrigating. The Dujiangyan Irrigation System represents a crystallization of ancient Chinese wisdom and an epoch-making masterpiece of Chinese civilization. It writes down a glorious page in the history of water conservancy in the world.
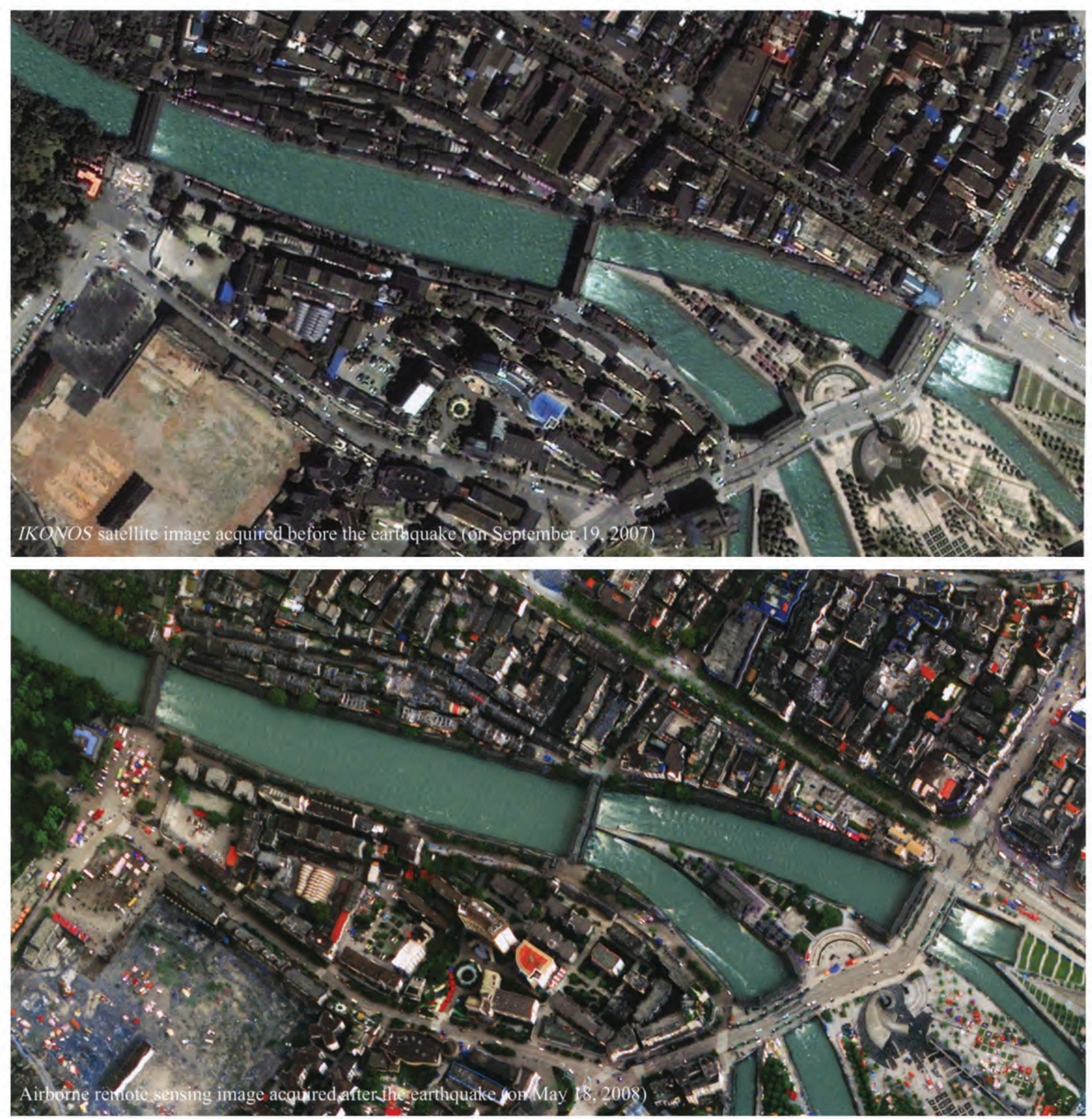

Nanqiao Bridge, Liutianwo Gate, Pubaiqiao Gate, and Zoujiang Gate all remain intact. 


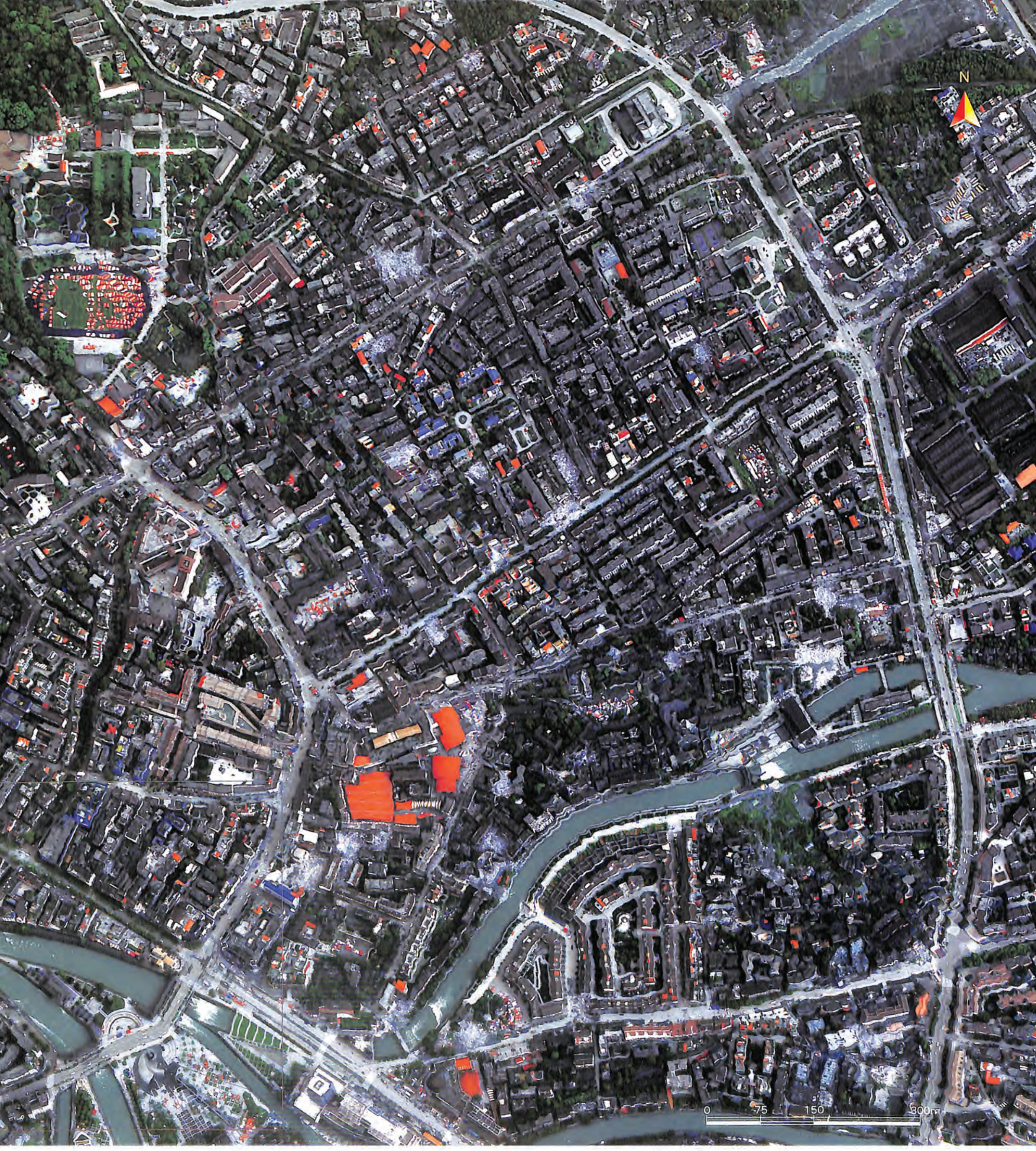




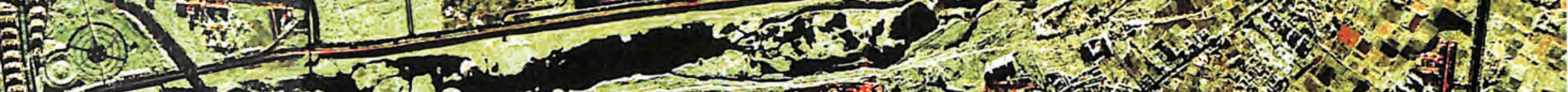

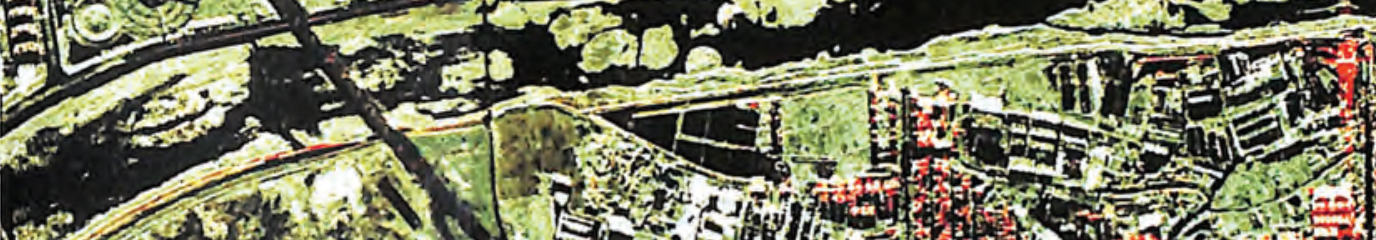

A

(1)

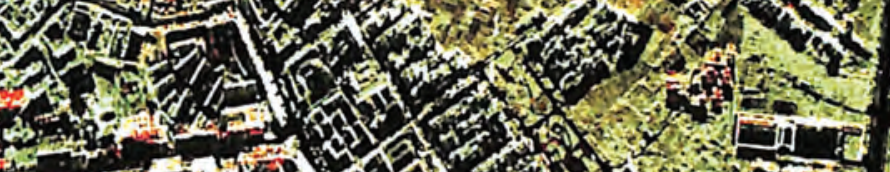

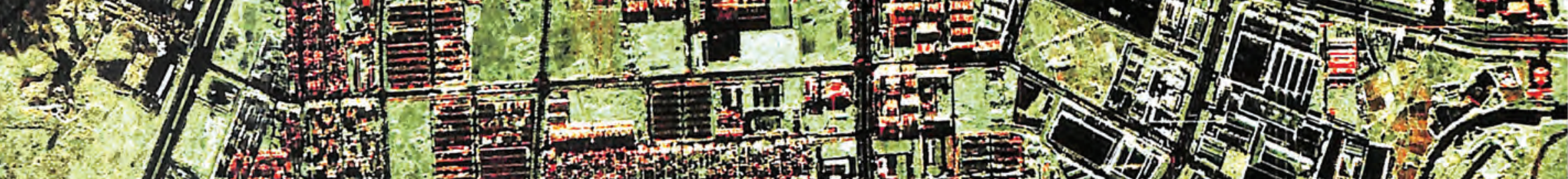

1.2. (3)

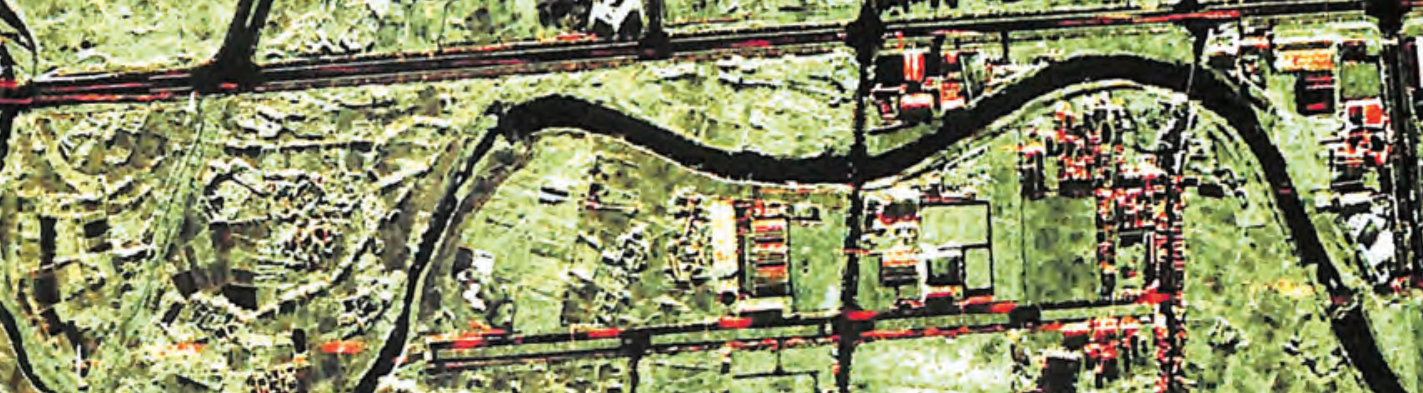

Q7.

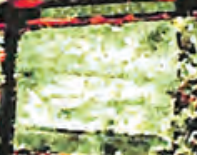

7.

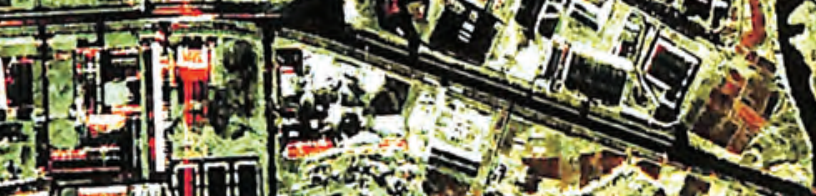

in

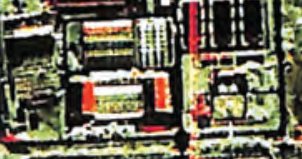

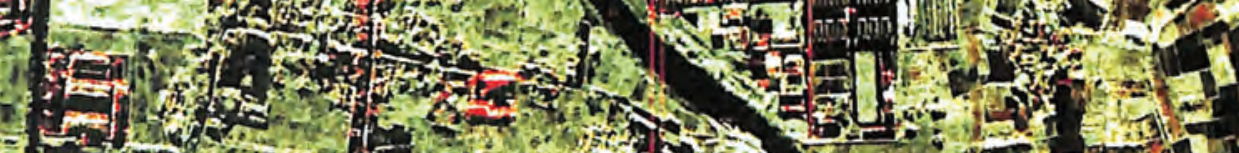

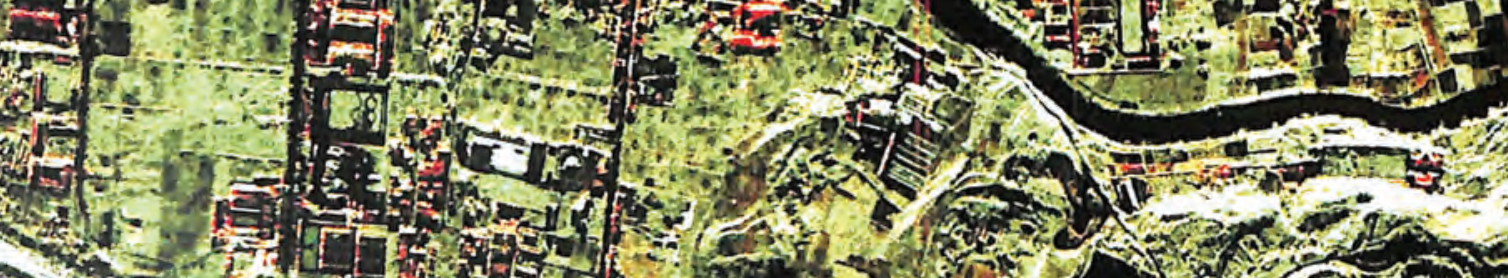

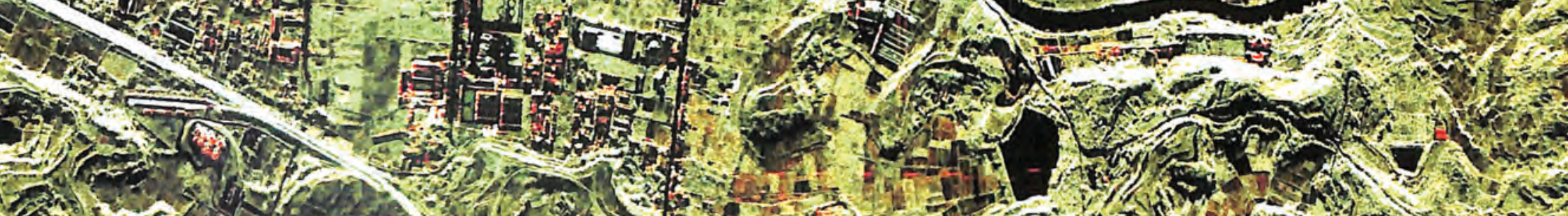
13. I

125

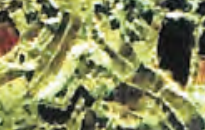

T.

$+0 .+2$

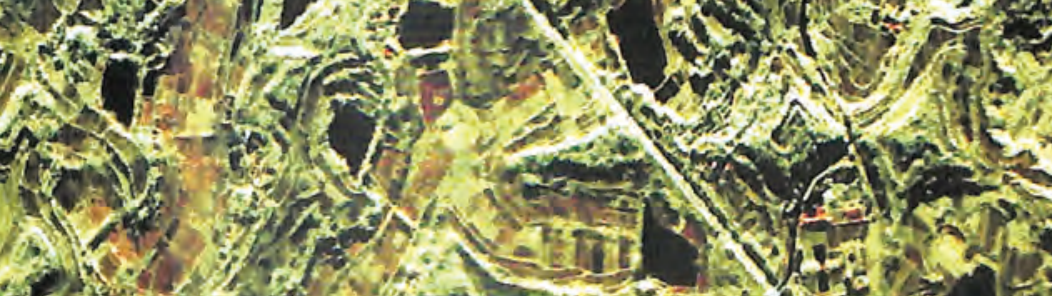
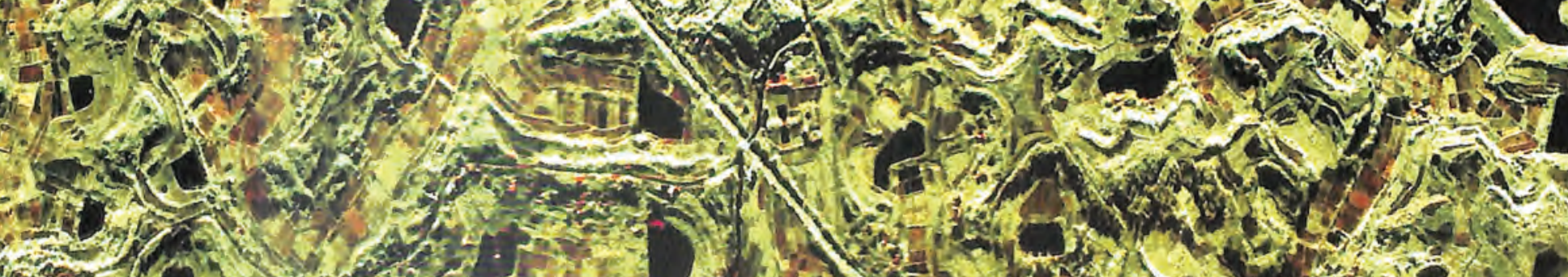


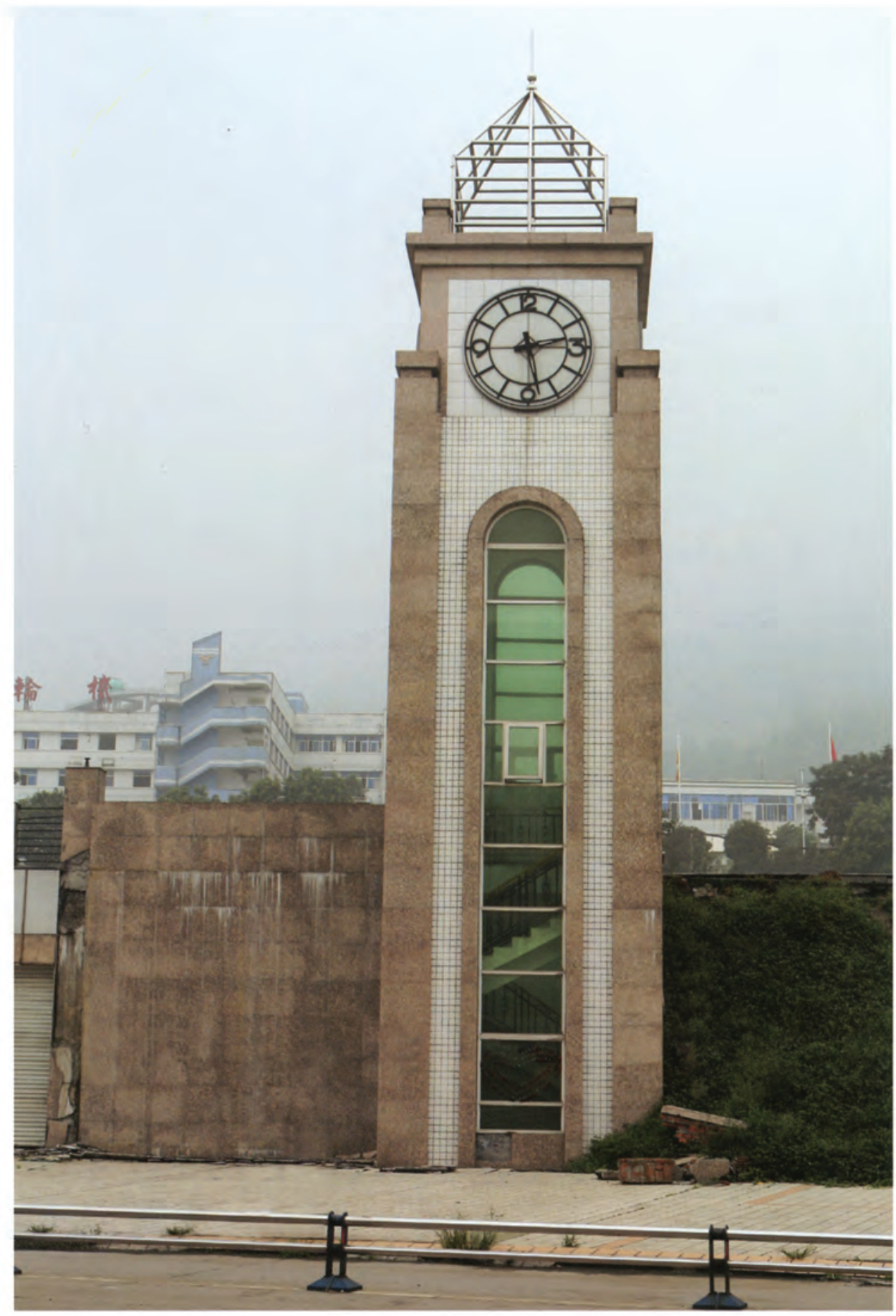

A bell tower in Hanwang town, Mianzhu city, Sichuan Province, and the time stopped permanently at 14:28 on May 12, 2008. 


\begin{tabular}{|c|c|c|c|}
\hline $\mathbf{A}$ & & G & \\
\hline Active fault & 29,30 & Ganhekou & 84 \\
\hline ALOS & $3,10,59$ & Ganxipu & 48 \\
\hline Anchang & 123 & Gaochuan & 59,122 \\
\hline Anxian & $59,90,93,110,114-116,119,120,122,123,125,127,184$ & Geological disaster & $20,50,78,157,164,172,173,184,196,198,203,207-209,211,212$ \\
\hline & & Giant panda & $94,196,210,211,228$ \\
\hline Б & & Guandili & $44-2$ \\
\hline Banpo & 218 & Guangii & 116,120 \\
\hline Banpocun power station & 212,218 & Guangyuan & $90,93,138$ \\
\hline Banzigou & 55 & Guanzhuang & 143 \\
\hline Barrier lake & $59,62,64-75,77-87,89,146,151,157,185,198,203,206,212,216$ & Guanzipu & 78 \\
\hline Bayi & 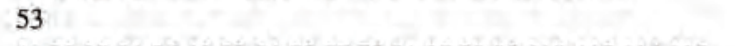 & Gujing & 59 \\
\hline Beichuan & $\begin{array}{l}11,23,30,31,36,43,53,64-73,77,78,81,87,90,93,110-112,114,116, \\
119,120,122,125,127,128,138,143,145,146,150-153,155,157-164, \\
167-170,188,196,199,206,212,216\end{array}$ & $\begin{array}{l}\text { Guozhupu } \\
\text { H }\end{array}$ & 170 \\
\hline Beichuan Middle School & 163 & Hanwang & $82,117,119,187,242$ \\
\hline Bingli & 177 & Hongbai & $112,212,223$ \\
\hline C & & Hongguang & 47,74 \\
\hline Caoba River & 164,172 & I & \\
\hline Caopo & $135,172,212,220$ & IKONOS & $3,8,47,50,62,89,90,105,146,193,235-238$ \\
\hline Changheba & 83 & Intensity & 141,144 \\
\hline Chaping & $65,122,127$ & & \\
\hline Chengdu & $4,99,128,229,231,237$ & J & \\
\hline Chenjiaba & $43,146,188$ & Jiangyou & $23,90,136,137,138,164,194$ \\
\hline County Road & $170,173,183,186$ & Jianjiang River & $20,24,25,30,70,72,73,80,81,164,167-170,190,196,207$ \\
\hline $\mathbf{D}$ & & Jintiaogou & 50 \\
\hline & & Jiyu & 109,184 \\
\hline $\begin{array}{l}\text { Dabao } \\
\text { Daojiaoli }\end{array}$ & III & Jiyu power station & 109 \\
\hline $\begin{array}{l}\text { Daojiaoli } \\
\text { Debris flood }\end{array}$ & 45 & Juyuan & 101 \\
\hline $\begin{array}{l}\text { Debris flood } \\
\text { Deyang }\end{array}$ & $\begin{array}{l}47,48 \\
148,149\end{array}$ & Juyuan High School & 101 \\
\hline $\begin{array}{l}\text { Deyang } \\
\text { Digital Elevation Model }\end{array}$ & 208 & $\mathbf{K}$ & \\
\hline $\begin{array}{l}\text { (DEM) } \\
\text { Donghekou }\end{array}$ & & Kuzhuba & $77,212,216$ \\
\hline $\begin{array}{l}\text { Donghekou } \\
\text { Dongjienao }\end{array}$ & 74,77 & Kuzhuba power station & 212,216 \\
\hline $\begin{array}{l}\text { Dongjienao } \\
\text { Dujiangyan }\end{array}$ & $\begin{array}{l}48 \\
9,10,16,90,99-101,103,164,191,212,225,227-234,236-238\end{array}$ & $\mathbf{L}$ & \\
\hline $\mathbf{E}$ & & Lamamiao & $37 \quad$ \\
\hline Earthquake intensity & & Landsat & $3,5,17,210,211,230,231$ \\
\hline $\begin{array}{l}\text { Earthquake intensity } \\
\text { Envisat }\end{array}$ & 144 & Landslide & $\begin{array}{l}20,25,27,43-45,47,48,50,59,62,65,66,70,72,74,77,78,81-83,85- \\
87,8908,\end{array}$ \\
\hline EROS-B & $\begin{array}{l}3,12,17 \\
3\end{array}$ & & $\begin{array}{l}87,89,98,100,104,108,109,111,123,128,135,136,146,155,157,159, \\
161,163,164,166,170,172,173,175,177,178,180-184,187-189,191\end{array}$ \\
\hline Erwang & 236 & & $-193,196,198,200,203,207,209,211,212,215,218,220,225,227$ \\
\hline F & & Laochang & 188 \\
\hline & & Leidashu & 205 \\
\hline Fengyi & 183,184 & Leigu & 152,153 \\
\hline Fotangbagou & 180 & Liangjiashan & 37 \\
\hline Fujiang River & $86,136,196,207$ & Lixian & $90,108,164,191$ \\
\hline Futangba & 212,218 & Long'an & 144 \\
\hline Futangba power station & 212,218 & Longfeng & 110 \\
\hline
\end{tabular}


SPOT

$3,6,17,62,73,90,106,107,200,203,208,209,211,215,232$

\section{$\mathbf{M}$}

Macaotan

Maliuwan

Maoxian

Miansi

Mianyang

Mianyuan River

Mianzhu

Minjiang River

Muyu

$\mathbf{N}$

Nanba

Namba Primary School

Nanxin

Nanxin power station

National Road

O

Optical lmage

\section{$\mathbf{P}$}

Pengzhou

Pingtong

Pingwu

Provincial Road

Q

Qianfo

Qingchuan

Qinghai-Tibet Platean

Qingjiang River

Qingxi

Qingyi

QuickBird

Qushan

$\mathbf{R}$

Radar image

Radarsat

Resouresat

S

Sandui

SAR

Seismic belt

Seismic intensity

Shaba

Shangheba

Shapai power station

Shiba

Shibangou

Shifang

Shigu

Shikan

Shuiguan

Songpan

SOS
84

$23,37,38,50,90,93,94,97,104-107,109,141,143,145.150,157,16$ $4,177,182-184,192,216$

212,218

$5,6,90,128,129,130,132,135,164,166$

166

$36,40,59,82,83,116,117,119,120,187,242$

20, 26-29.38.39.48.50,54-56,89,100,106,109,164,171,173-175, $177,179-184,186,187,191,196,207.209 .211,229.23$

141

$145,189,203$

145

$37,38,177,182,212,216$

212

$164,170,173,175,177,178,180-184,186$

$37,40.50,53,54,66-69,74,77,78,83,85,86,101,103,110-112,114,115$, $119,120,125,127,132,135,138,141,143,144,146,152,153,157,200$

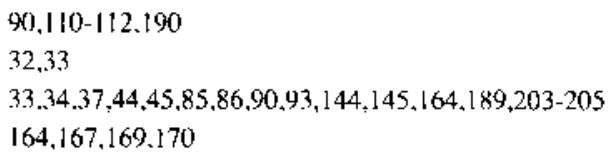

$90.110-112.190$

$32,3,3$

$33, .34 .37,44,45,85,86,90,93,144,145,164,189,203-205$ $164,167,169.170$

\section{2,184}

$47,53,59,74,77,78,90,93,141,143,157,164,195,199$ 104

77

143

132

$3,4,90,99$

$30,155,212,216$

$81,87,117,188-192$

$3,9,17,62,72,130.137 .148$

3

138

$2,9,11,13,14,16,62,82,84,90,101,106,129,164$

104,231

141

53

186

212,220

53

$47,74,77$

$84,90,112,114,115,212,22$

109

34,35

203

$135,150,151,169$
Synthetic aperture radar

T

Taipingyi power station $\quad 212,215$

Tajpingyi Reservoir $\quad 175$

Tangjiashan

Taoguancun

TerraSAR-X

Thrust fault

Tianchi

Tongkou Rjver

64.65

181

$3,11,62,81,100$

29

82,166

81,87

V

Village Road

177

W

Wenchuan

Wenjiaba

Wujia

$\mathbf{X}$

Xiaoba

Xiaojiagiao

Xiaomaoping

Xiaoyudong

Xiazhuang

Xiejummen

Xindian

Xinjian Elementray

School

Xinzao

Xiping

Xiushui

Xuankou High School

Xuanping

Xupingba

Y

Yan'eryan
Yangdian
Yanmen
Yanyangtan
Yinghua
Yingxiu

Yingxiu Primary School

Yinxing

Younian

Yuli

Yuni

$20,23,29,38,40,47,48,50,54-56,90,93,94,97,104,105,135,141.1$ $43,145,150,164,170,172,173,175,177,178,180,181,186,191-19$ $3,196,208,209.212 .215 .218,220$

85,86

135

122,12

$74,184,185$

54

190

220.221

166

54

100,101

132

138

125

07

$64,170,206$

201

183

56

177

78

114

$23,28,29,36,48,50-61,89,93,94,97,99.101,103,108.1101-112,11$ $4,116,119,120,122,127,138,143,145,146,150,152,164,178$

173.180 .208 .212 .215

40

$64,65,146,150,151,168-170$

115

Z

Zagunao 108

Zesang

55

170

178

168.169

Zhangilaping

Zhicheng

Zhongxing

Zipingpu Reservoir

Zundao
103

$192,212,224-227$

120 